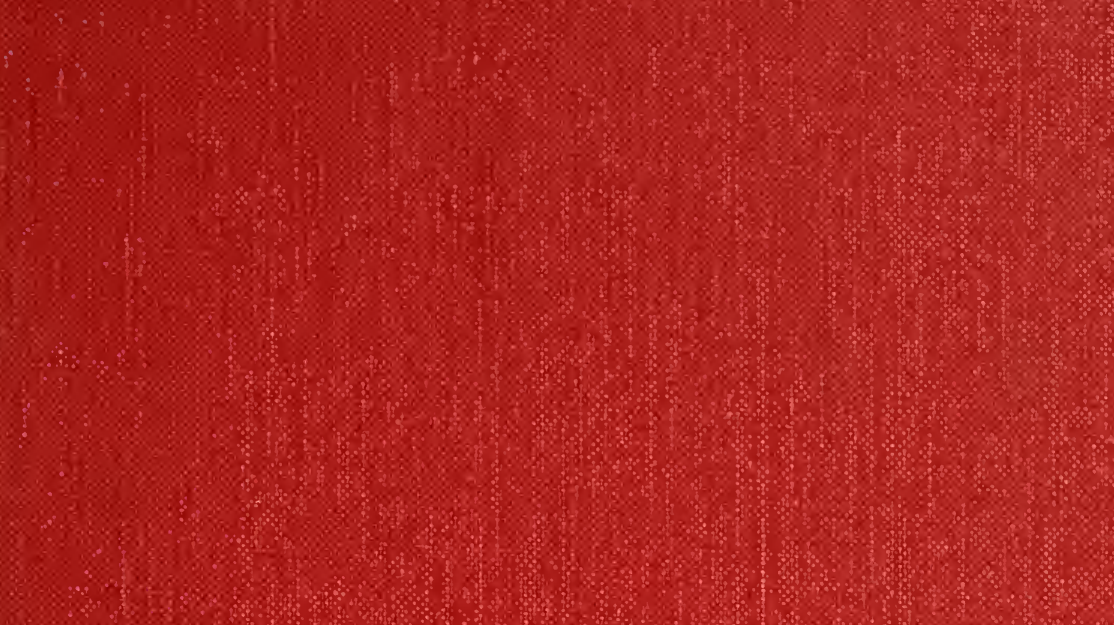
is $34 \%$ क 80 



\section{$2_{0} 20$}

$\triangle M \mathbb{I}$ 圆 I C $A \mathbb{N}$

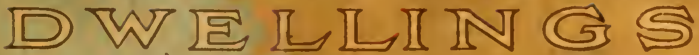
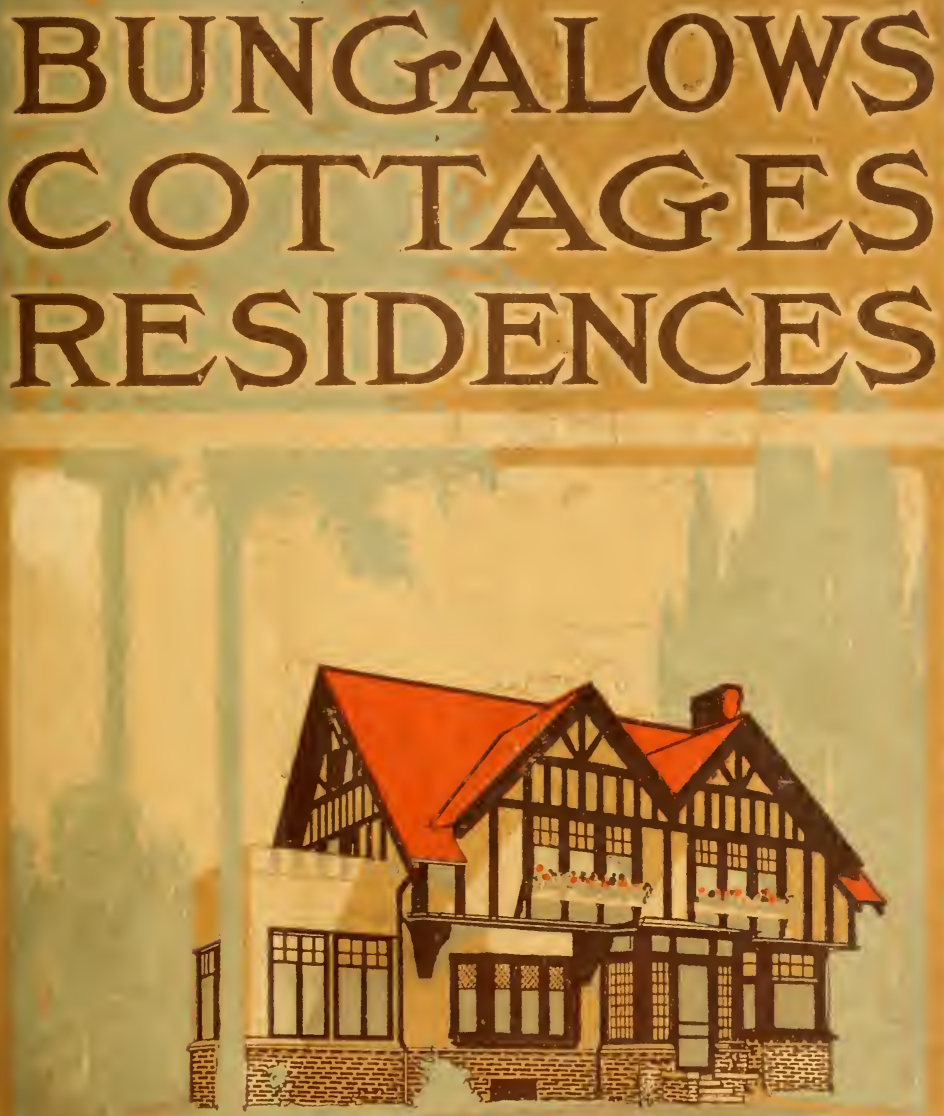

GLENN L. SAXTON ARCHITECT, MINNEAPOLIS. MINNESOTA. 



\title{
The Plan Book of American Dwellings
}

Being a Compilation of Original Home Designs

Showing Actual Photographic Exteriors

and Floor Plans of

Moderately Priced

Bungalows Cottages

Residences

BMITHSONIAN

APR 191988

LMBRARIES

\author{
Published by \\ GLENN L. SAXTON \\ ARCHITECT
}

Minneapolis, Minn. 
Copyright 1914 by GLENN L. SAXTON Minneapolis, Minn. 


\section{INTRODUCTORY}

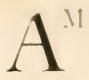

likIL: may well be proud of her large and beautiful lomes and wi the architects who designed them. The greater number of small lomes in all parts of the country, however, are with few exceptions. almu-t unifurmly lacking in any serinus attempt at convenience of arrangement ur heauty if design.

The reason for this is apparent: when a person decides to build a home of claborate proportions, he feels the need of a competent architect. He has the means to employ one, and he usually endeavors to engage the services if the best he can obtain.

(1) the wher hand, the man of moderate means, who can afford only: a nuchlum priced home, realizes that it is only through the most rigid ecunum that he can hope to build a home with the necessary rooms. finislierl in the simplest strle possible.

Prohably the majority of men in these circumstances determine at the unt-ct that they will build without the services of an architect. The architect- themselves are largely responsible for this state of affairs, too, for many of the prominent men in the profession avoid rather than seek commissions for building small houses.

This class of work, as a rule, does not rield a revenue commensurate with the work it involves. The labor in making drawings and specifications is ncarly as great on a small dwelling as on a large one, with the fee varying in juroportion to the cost. Therefore, the architects the country over. have established a sliding scale of charges which calls for a higher percentage on the smaller class of work.

Indoubtedly; howerer, the chief cause of the non-employment of an architect br the prospective small-home builder, and consequently the lack of real architectural merit which is so universally apparent in these small hriuses, is due to a misconception on the part of the man who is about to build.

Ife is mistaken in thinking that he will economize by planning the house himself, giving loose instructions to a contractor, or in attempting to build from cheap plans furnished by the contractor-carpenter himself.

In thinking that he can really secure the sort of home he wants, and save an architect's fee, he is committing a folly, that he will invariably realize, to his everlasting regret, when it is too late.

The man who purposely refrains from availing himself of competent technical skill in the designing of his home, is not only going to have a less convenient, less attractive, and less well-built house, hut he is also going tr) spend more money in getting it, than he can possibly save in a moderate charge for a well made set of working plans.

One may ask, what is the mission of such a book as this, if the personal taste and prejudice of the owner of the prospective house is to be shown in the home itself. The answer is, that it will help the owner to know nore definitely what he does want, what other people have foumd lesirable in a lome, and what, in a general way, constitutes a well halanced, economically constructed, livable house. 
The many plans in this book will give you a pretty definite impression of what your home should be.

If this book can suggest to the layman what the many possibilities are, for his future home, and he will order a set of my plans that best suits his requirements, I feel sure that he will ever after be numbered among the thousands of my already satisfied clients.

\section{Some General Remarks.}

My plans are carefully made and figured; drawn to $1 / 4$ in. scale and specifications fully written covering the building in every detail.

In selecting one of my plans do not let a minor detail, such as the change of a door or window from one location to another influence you not to use any particular plan that you otherwise like. These little changes are easily and quickly made and will cost you nothing.

My estimate of costs are based upon prices actually paid within the past 18 months for constructing the houses found in this book. I believe it is only fair to my prospective clients to treat this matter of cost honestly, and I advise him, (when comparing my estimate with others, many of whom estimate $50 \%$ too low) not to be misled in thinking that I have not given the matter of cost painstaking consideration. The prices found herein are always exclusive of heating and plumbing, as these items are liable to vary considerably.

The heating plant, for an eight room house, a hot air furnace for $\$ 165$, in my judgment, would be very satisfactory, but steam or hot water would cost from $\$ 250$ to $\$ 350$.

The plumbing for an average house could be put in economically for $\$ 250$ or any amount over that you wish to pay.

I wish to state that my plans are original and copyrighted and no one has a right to use one without my consent. If you see one of the plans contained in this book without my name you may know for a certainty that it is only a poor copy.

Place your confidence in me and order plans. I will make a special personal effort to see that every one of my clients gets just what he wants, and in just the way he wants it. I believe I can satisfy the most exacting tastes, if you will give me the opportunity.

\section{A Few Suggestions To My Patrons.}

There are many things to be said about planning and building a home; in fact, enough to more than fill this book without any illustrations, but the author will briefly mention a few of the really important points to be considered when building.

There has been in the past an almost universal disregard to points that are very helpful and useful to the builder of a home but if the reader will carefully study the following suggestions and be guided by them he will be more than repaid for his time. 


\section{Two Examples of Houses}

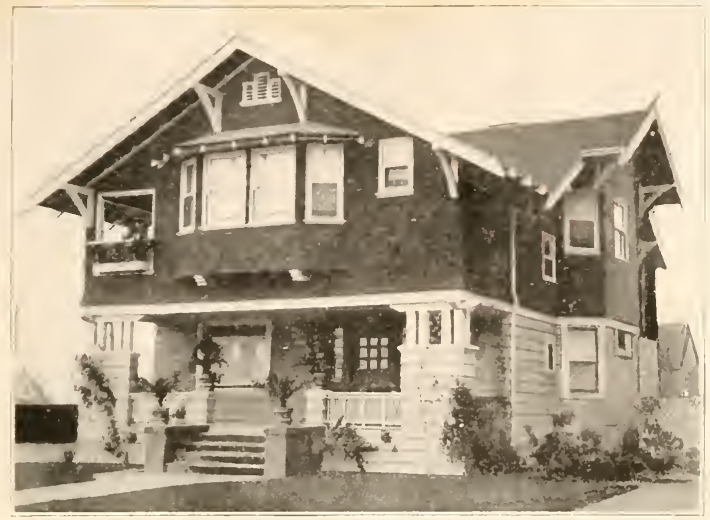

The Original Plan

First of all, never build a home without a complete set of plans and specifications. The two illustrations on this page will show at a glance what happened to the man who thought that his contractor was competent t(1) build his home without an architect's plans.

These two houses built in the same city are just one block apart. The first shows the house built according to one of my stock plans and specifications which cost the owner just $\$ 35$.

The second illustration shows the house built by a man who attempted to save the price of the architect's plans, and just compare the results! The imitation house is all out of proportion, the roof is too steep, and the brackets which support the cornice lowk like toothpicks. Compare the bays on the front gable in the 2 nd striry. ()n the imitation house the hay is all out of proportion and disfigures the looks of the house as much as a wart on the nose of a lecatiful woman. This may be a homely comparison but it is none tor) emphatic. The sleeping porch (n) the front corner of the imitation house, instead of being 7 or 8 feet wide as the original plans show it, is only 3 feet wide. It certainly is not ornamental and is of no practical use whatever and is merely a place for snow and ice to gather in the winter time. The house is the same

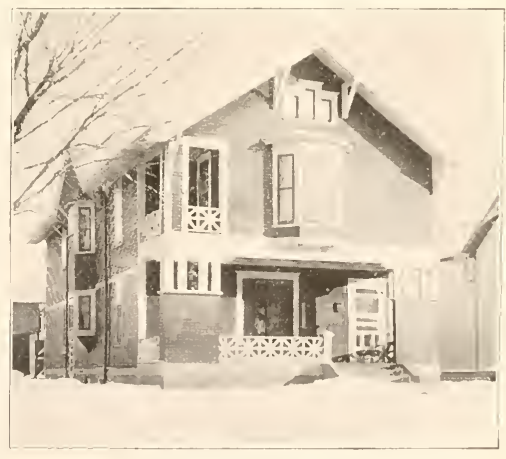

The Imitation Plan 
width but it looks to be only half as wide, for the reason that everything is out of proportion and was not properly planned before the contract was let to the builder.

This imitation house cost more money than the house correctly built, and owing to its hideous appearance, faulty planning and construction, its owner would have to take $\$ 1200$ to $\$ 1500$ less for it than would the owner of the first. This is certainly a striking illustration of a man being "penny wise and pound foolish." The man who purchased his plans is delighted with his home and has had numerous opportunities to sell at a good profit while the other man is dissatisfied, never has had an opportunity to sell and has even offered his home at a sacrifice. This is an experience, unfortunately, which thousands of home builders have had. It is for you to decide which class you wish to join.

\section{Free Plans.}

Never go to the man for plans who calls himself "Architect and Builder" or "Home Builders," who advertises to furnish you with FREE plans if you will allow him to build your home. There is a reason for his generosity. Did you ever really get anything for nothing?

It takes time to plan a home and make proper specification and socalled home building companies are not philanthropic enough to do this for you without lining their own pockets at the same time. When you stop to think of it, you can not expect them to, as the plans and specifications are worth something, depending of course, upon the size of the house. Their plans are invariably incomplete, specifications made wordy and ofttimes purposely confusing, frequently calling for the poorest grades of material. So don't you see, in this way they can take advantage of you by charging first class prices for work done with third and fourth class materials. This is the way you get your plans "for nothing." I know as an absolute fact that homebuilding institutions that furnish free plans make a profit of from $\$ 600$ to $\$ 1,000$ on every house they build. Would it not be a good idea for you to employ a competent architect to make your plans, and have the assurance that you were not paying an excessive profit for your home?

\section{Liens.}

If you have never done any building, you can hardly realize what it means to keep clear of liens. The lien laws are most unfair to the builder of a home in most states. Any firm who has furnished material, such as cement, plaster, lumber, mill work, etc., in fact any material which has gone into the construction, can file a lien on your property and compel you to pay for it a second time if your contractor has not settled his accounts for the material entering into the construction of your house, and unless you have taken the precaution to compel your contractor to furnish you with receipted bills for all this material from the concerns who have supplied it you are running a great risk. I have known of hundreds of people who, after having paid their contractor in full, for his contract, later discover that there were from $\$ 1,800$ to $\$ 2,000$ in liens filed against their homes which necessitated their paying for their homes practically twice.

By a little precaution you can overcome all of these difficulties and make the building of a home a pleasure instead of a hardship. 
Have a complete set of plans and specifications and insist upon the contractor following them absolutely:

Insist upon a Surety Bond from the contractor for protection against liens which will protect you in case the contractor fails to pay any of his bills. Do not make any changes in the plans after letting the contract, for that will invariably make a loop hole for the Bonding Company to crawl wut of, and finally do not let a contractor furnish you with "Free plans." If you do, you will certainly pay dearly for the plans you thought were free.

The architect has spent years of time and study and thousands of dollars for his experience and for the small price he asks for his plans you are receiving the benefits of all his experience. Now if you will only abide by these suggestions, your homebuilding will be safeguarded and a pleasure from start to finish. 


\section{A Few Illustrations and Suggestions In Home Planning.}

In selecting a plan always remember that every plan can be reversed for you without any extra charge. By reversing it, any plan can be made to fit an east, south, west or north exposure. Reversing the plan makes the position of the rooms exactly opposite from the way they are placed in the illustration shown in this book.

Any plan illustrated in this book can have the addition of a sun room or a sleeping porch added to it if desired, for the nominal additional cost of $\$ 5$, the same to be drawn on first or second story plan, with slip sheet attached to be placed in specifications.

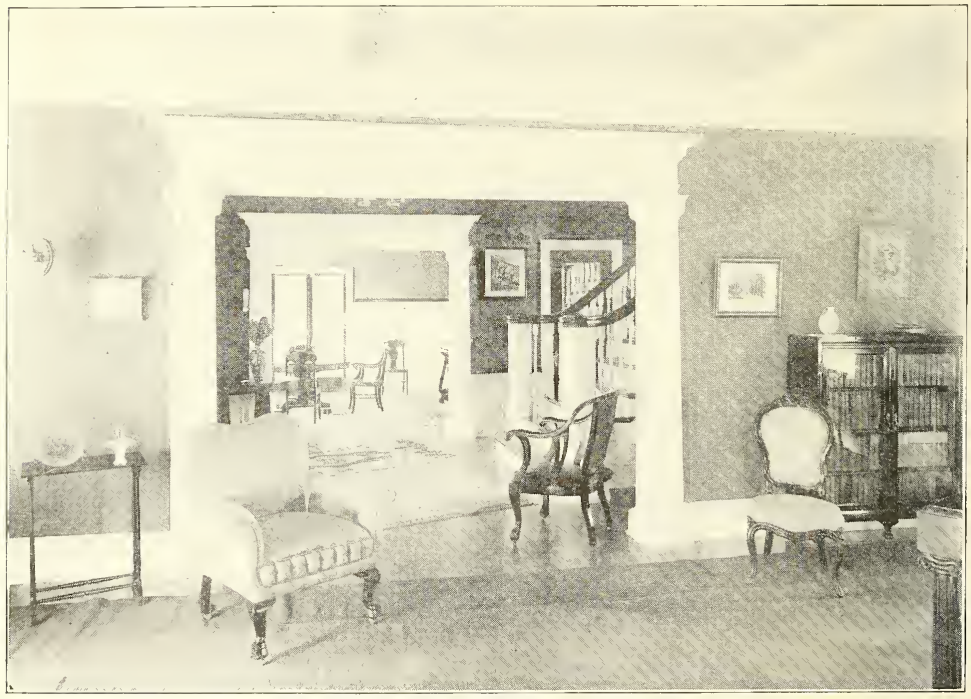

View from a living room looking through hallway opening into dining room beyond.

\section{Living Rooms.}

Our first illustrations of interiors are of living rooms. We always plan for an abundance of light and ventilation in the living room. We do not forget to leave wall space large enough for a piano or other large piece of furniture. Stairways are always carefully planned to have a wide approach, and care is taken to have ample headroom, wide treads and risers just the right height. If the living room has a fireplace, you may rest assured it is designed by an architect, who understands every essential of this important adjunct to the livable home. The fire place should have a separate flue, never less than $8 \times 12$ inches. Insist upon a damper with handle on the 


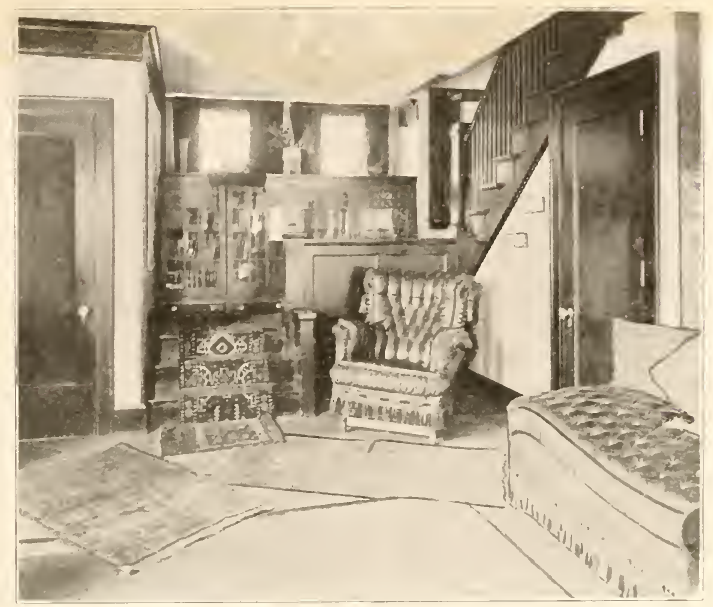

Living room showing stair case at one end.

face of tile or brick, to control the draft. The fireplace is the grandest thing that can be planned for a large living room, as it gives the best ventilation that a room can possible have, in addition to its rosy comfy glow in the winter evenings.

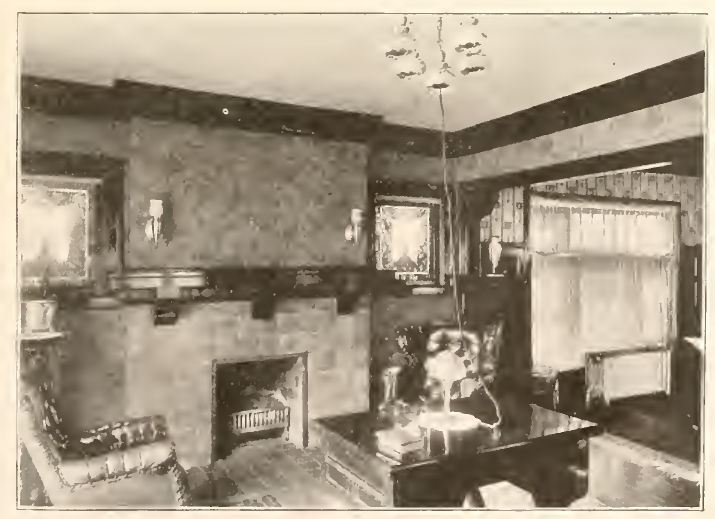

Living room showing an attractive fire place. 


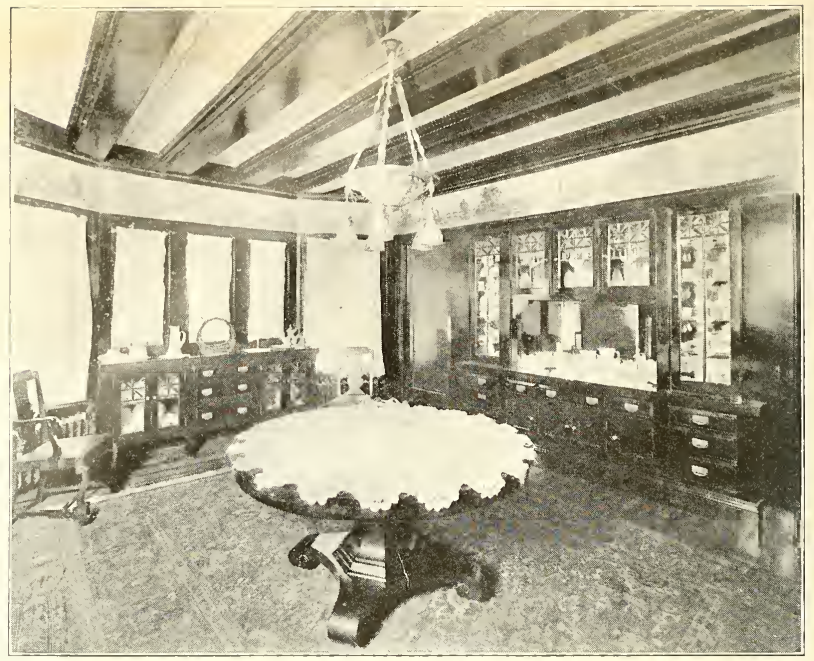

The Dining room, tasteful and handily arranged.

\section{Dining Room.}

A dining room should always be well lighted and ample wall space should be left for built-in or portable buffets, sideboards or china closets. Paneled wainscoting and beamed ceilings greatly enhance the beauty of this room. The illustration above shows a well proportioned dining room.

The illustration below shows a less pretentious dining room and is charming on account of its simplicity. The walls are paneled and lend themselves nicely to the decorator's art.

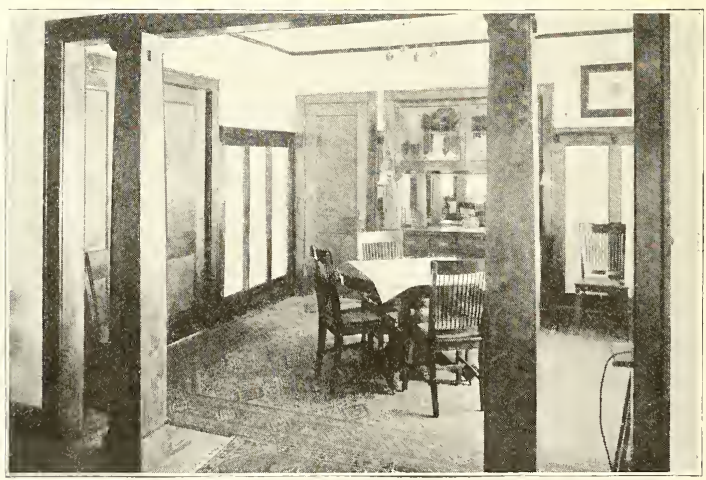

A well appointed little Dining room 
The stairway is really we of the most comspicuous features in a home. It can make or mar the most beautiful surroundings and consequently should be given special attention by the architect.

The properly constructed stairway must be worked out on some of the same principles as a problem in arithmetic. The building of the stairway therefore is an art as well as a science.

There are numerous well defined rules governing the buildof a stairway and if any of these rules are not observed, the result shows a lack of architectural skill at a glance.

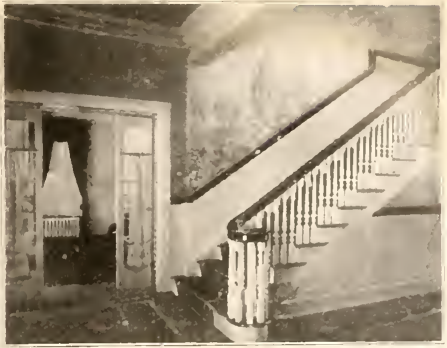

The Stairway is the principal thoroughfare in the home - it should be as attractive as possible.

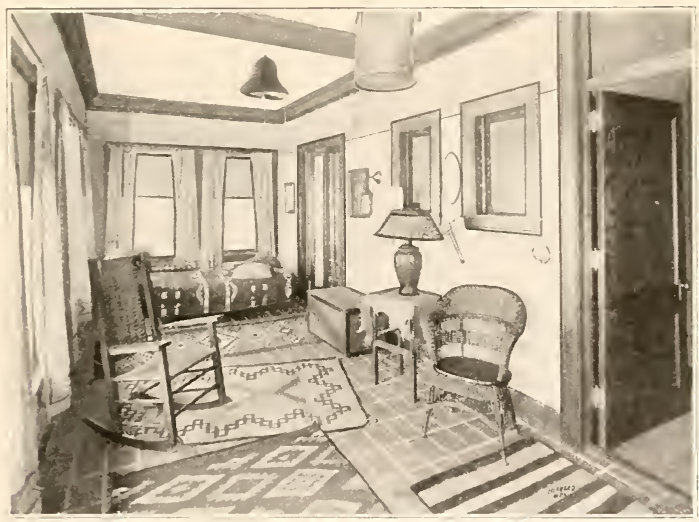

A Sun room which is delightful place the year round.

\section{Sun Room.}

The sunroom is a feature that has become very popular with the building public in the last four or five years and is adapted to most any style of house. It is really the most valuable asset of the entire home on account of its light, sunshine and fresh air. It is converted into a pleasant porch in the summer time and is the most delightful room throughout the winter. heing supplied with heat the same as the rest of the house. Having a sun room, one can dispense with a large piazza on one or two sides of the house which darken the rooms and shut out the sunshine. In northern climates these outside porches can only be used about three months out of the year while a sun room is a joy throughout the twelve months. 


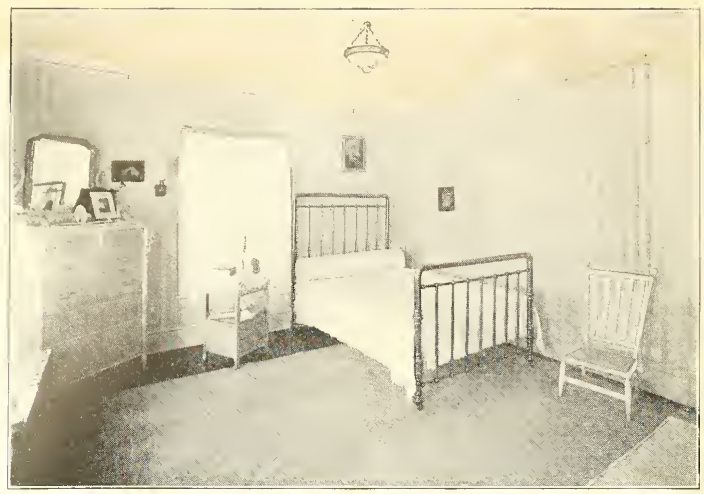

A Restful Chamber

The designing of a chamber should be carefully studied out." It should be the least pretentious and most harmonious room in the house. Simplicity should be its keynote.

The vital things to be considered are: windows on two sides of the chamber for ventilation, abundance of wall space for double or twin beds, dressers, dressing tables, etc. No chamber should be designed without ample space for the bed to be moved to at least two positions when desired.

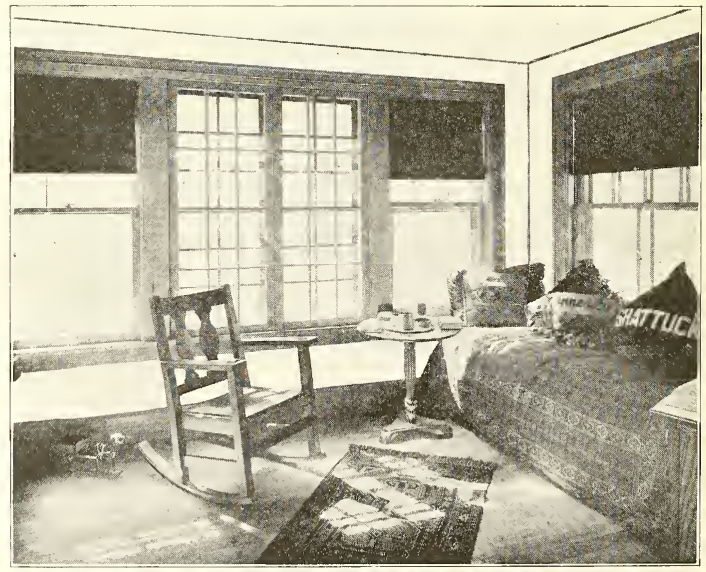

Here is a sleeping porch that any modest home can possess.

\section{Sleeping Porch.}

A well ventilated sleeping porch is the pet hobby of the author. The sleeping porch in our estimation, is one of the best investments that a 
homebuilder can make. It will discount the services of the best physician in the city even if he is employed by the year. The secret is that you breath the fresh pure air during your sleeping hours, which is worth more than any apothecary's pills in the world. A sleeping porch is one thing every house, little or big, should have.

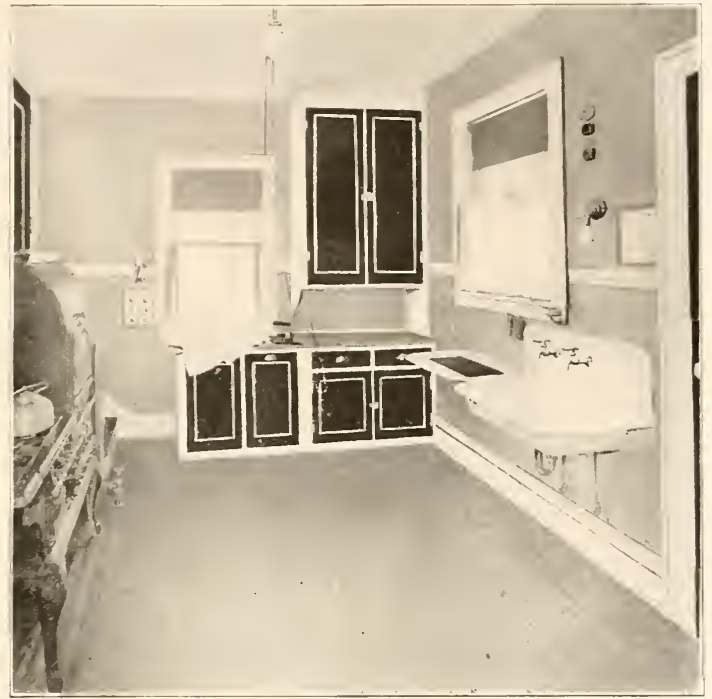

An ideal kitchen

The Kitchen.

An ideal kitchen is the one thing which every woman desires, and I regret to say, so few of them really possess. A modern housewife's idea of a kitchen has changed radically from the ideas of her mother's time. A few years ago the kitchen was the largest room in the house and compelled the housewife or maid to take thousands of unnecessary steps, to say nothing of the extra elbow grease necessarily used every week in scrubbing such a large expanse of floor.

The modern kitchen of today is small, compact, has a place for everything and everything in its place. The modern architect gives as much thought to the planning of the kitchen as to any other room in the house. He provides the most convenient place for the sink, usually under a window. with proper provision for the drain board. There is always sufficient space allowed for the range and, in fact, for every other fixture for this room, not forgetting the all-important refrigerator. Proper location for lights, outlets and receptacles for gas or electric iron. fans, etc., even to a wrought iron ventilating pipe for hood over the range to carry off the odors from the cooking, all receive his painstaking attention. 


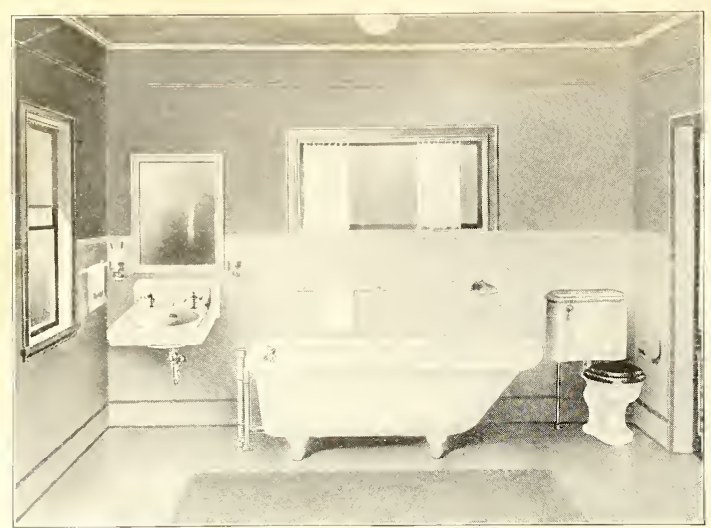

A simple, sanitary bathroom.

\section{Bathroom.}

A simple and sanitary bathroom is a luxury which is now within the reach of everyone, in this modern day of home planning. Ventilation and light are the most essential points to be considered in every bathroom, regardless of its size. I could write several chapters about the bathroom but space forbids. There is no part of the home where such wonderful strides have been

made in late years as in the equipment of the bathroom. It is gratifying to know that the desirable and beautiful fixtures which were once an unheard of extravagance are now within the reach of the modest homebuilder.

Beautiful enamel iron tubs, vitreous bowls, modern noiseless closets and sanitary metal wall cabinets with mirrored doors are luxuries fit for a potentate but these are found in every well constucted home today.

\section{Closet.}

A real modern closet is "Milady's" delight. Not the little stuffy affairs, jammed in just anywhere, but closets of ample size containing hat boxes, large drawers for gowns and skirts and everything conveniently arranged. A few years ago a good wife no doubt indulged in some very un-Christian like thoughts when she was forced to grope around in the dark closet for her favorite gown or slippers. Now when she wishes to select her gown, the electric light in the closet is automatically turned on when she opens the closet door, and automatically turned off when she closes it.

There are doubtless 1000 more home conveniences the writer could describe had he the space.

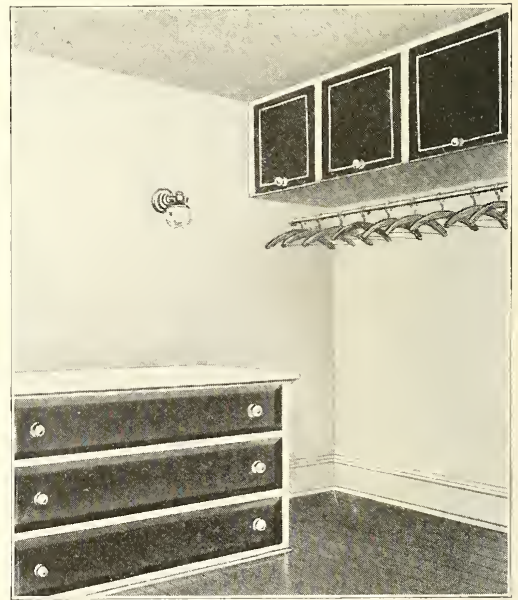

A perfectly equipped closet. 
Good closet space is invaluable. Must of the things mentioned, howerer. are within your reach and you can have then at a small cost if rou will employ an architect who makes a specialty of designing homes. These features described, plus many we have not mentioned are all incorporated in every set of our plans.

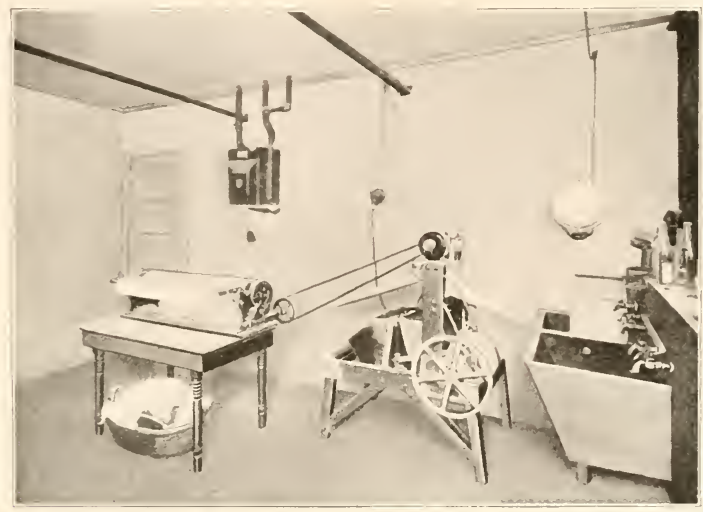

A Modern Laundry

Fifty years ago, Monday was always called "Blue Monday" on account of the confusion and gloom it generally cast over the entire household when the tubs and steaming boiler were brought into the kitchen for the week's washing.

Today, if you will allow us to design your new home, we will incorporate a laundry in the basement that will transform "Blue Monday," drudgery, into "Sunny Monday" a day of pleasure to which the housewife will look forward with as much anticipation as the Master of the house looks forward to Sunday. She will admit that wash day is a pleasure instead of a burden.

She may have a power washer, electric or steam dryer, gas or electric mangle for ironing the flat pieces and a gas or electric iron for the finest linens or lingerie and best of all, and electric iron to keep her cool and comfortable while doing this ironing. These features can all be incorporated in your new home if you let us plan it for you. 


\section{A Few Instructions To My Prospective Clients.}

When ordering plans, state correctly the number of the plan desired and as to whether it is to be as shown in the book, or "reversed." This means a transposition of the rooms from one side to the other. I will blue-print any set of plans "reversed" without extra charge.

All orders for plans must be accompanied by a certified check, P. O. or express money order. Orders that are not will be sent by express C. O. D., with the privilege of examination.

\section{Working Drawings.}

A full set of working plans comprises the floor plans of all stories drawn to one-quarter inch scale, with all necessary notes and figured dimensions plainly marked on same, four elevations and sections showing the method of construction, size of timbers, etc., as well as all necessary interior and exterior details worked out to scale and full size. "Also an original set of typewritten specifications, embracing all materials and labor required for the completion of building, masonry, carpenter work, painting, wiring, etc.

One full set of blue-prints and one copy of specifications will be understood to complete an order. Any additional copies will be charged for at the rate of five dollars for a full set of blue-prints and specifications.

\section{Alterations.}

Such minor alterations as changing the position of a door or window, or slight interior rearrangement not affecting the outside walls or outside door and window openings, will be made without additional charge. By inserting a slip-sheet in the specifications we can remove any possibility of there being a lot of bills of extras after the building is completed.

If you care to lay out your own idea of a floor plan, make a rough sketch of same and send it to me, together with the number of the design you like best, and I will make you a special price on original plans.

\section{Bill of Materials.}

Upon request I will furnish a bill of materials for any design in the book for $\$ 5$. But my plans and specifications are so prepared that estimates for lumber, mill work, etc., can be made directly from them, without going to the unnecessary expense of a bill of material. In my mind, the only person to make such a bill, is the contractor or builder who is going to put the material into the building. He can follow his own bill with far greater economy than one made by some one else.

Any person who has purchased a plan of me, may feel at perfect liberty to write or call upon me during the progress of his work, for information or advice pertaining to the construction of same. I make a special aim to have my clients so well pleased with my plans, that they will be willing to recommend me to their friends who contemplate the building of a home. I do not design houses exclusively, but plan buildings of all characters, and will be pleased to give you prices on such plans.

GLENN L. SAXTON, Architect. 


\section{SAXTON HOUSE PLANS GO TO ALL PARTS OF THE EARTH}

Below are reproduced envelopes which contained orders from people in foreign countries who were attracted by some of the designs in this book.

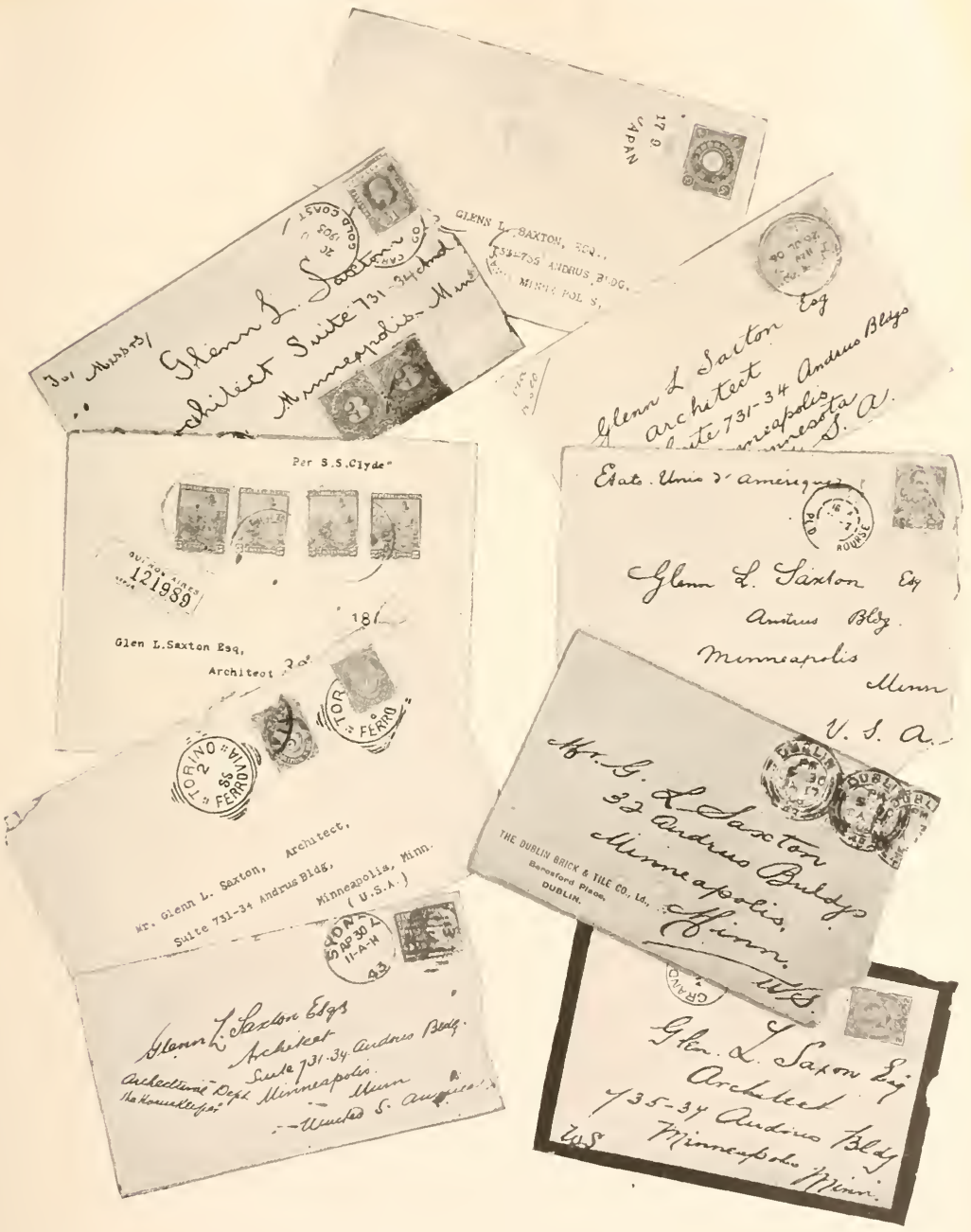




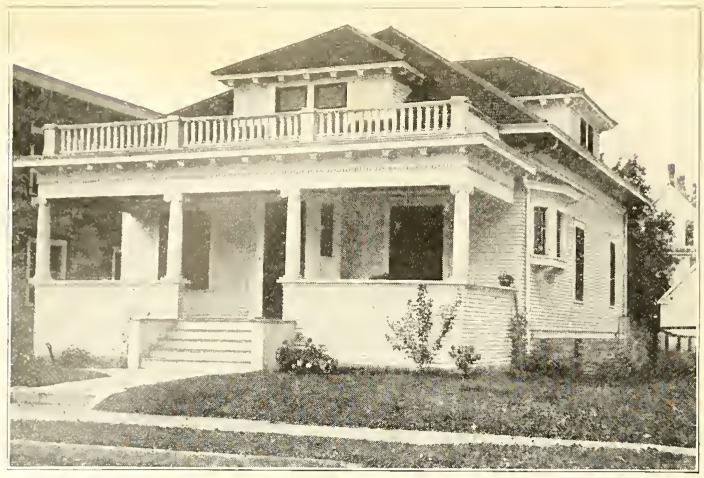

A Beautiful Bungalow-No. 988

The rooms of this bungalow open up together so as to make the house appear much larger than it really is. There are two bedrooms in the first story and two can be added in the second story. There are closets for each chamber and a good sized bath room. The living room and dining room are thrown together by a ligh, square columned archway. There is a bay in the dining room and built-in sideboard. Kitchen has built-in cupboards and table. The entry has a closet for mops and brooms, also for refrigerator.

Size, twenty-eight feet wide, thirty-six feet deep over main part. Birch floors throughout, Finish is gum or red oak in principal rooms and pine to paint in balance of house. Full basement under entire house. First story nine feet in the clear. Chambers in second story would finish eight feet. The estimated cost not including finishing second story, is $\$ 2,200$. Complete set of plans and specifications for $\$ 20.00$.

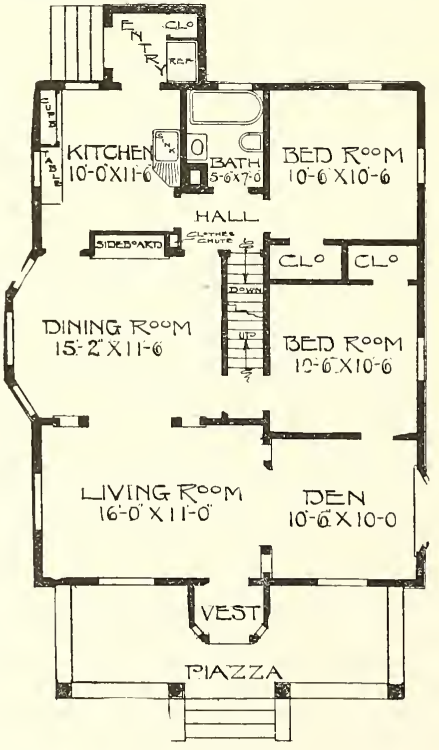

Complete plans and specifications for using Denison Load-Bearing Tile, licensed under Wilson-System Bearing W a 11 Construction for $\$ 40$. 


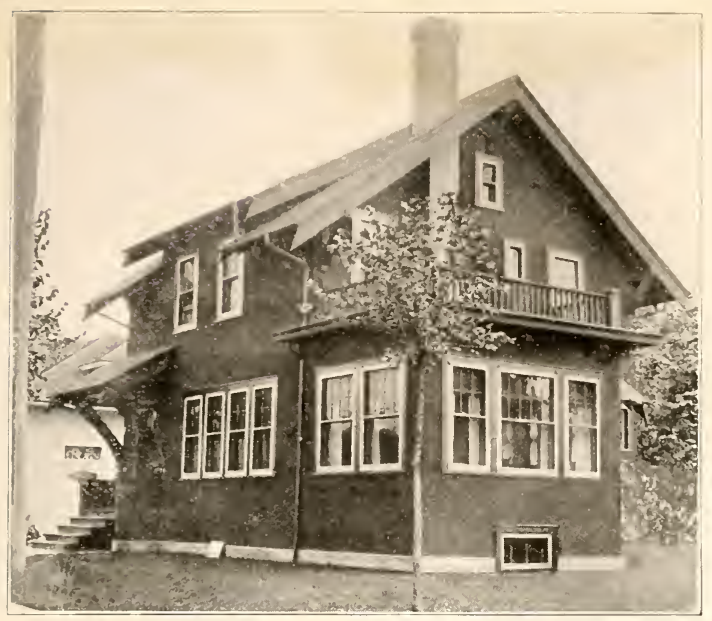

A design especial. 1y desirable to build on a short lot, or in fact it will look very pretty on any kind of a lot. Theri is a beautiful livins. room across the en. tire front with sur room at side. The sun room gives a liv. able piazza the year around.

The dining room with builtin side. board, at rear of liv ing room is thrown together with same by square columned arehway. There is also a grade door underneath the main stairs. In the second story there are three large chambers, good bath and splendid closet space. The balcony over sum parlor makes a splendid place to air
bedding and rugs. There is a full base. ment under $t \mathrm{his}$

\section{A Craftsman Design-No, 989}

lrome. First story 9 feet, throughout first story gum or red oak. Finish in second story pine to paint. Birch or maple floors throughout entire house. Size over main part 25 feet wide and 25 feet deep. Cost to build, $\$ 2,700$. Complete set of plans and specifications for $\$ 25$.

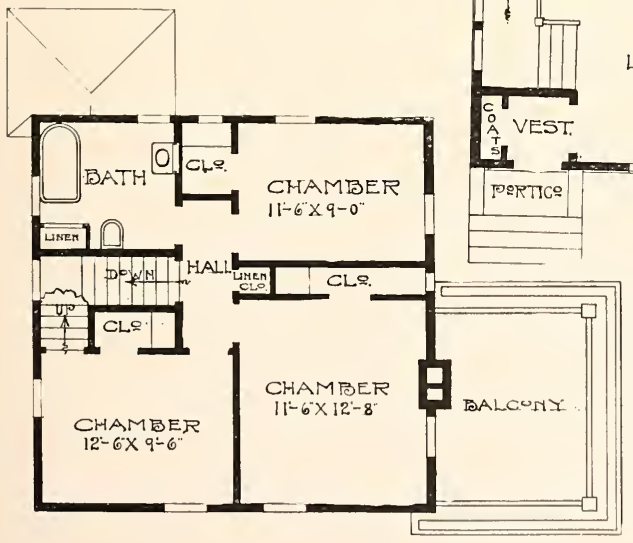

Complete plans and specifications for using Denison Loa'-Bearing Tile, licensed under Wilson-System Bearing IV a 11 Construction for $\$ 50$. 


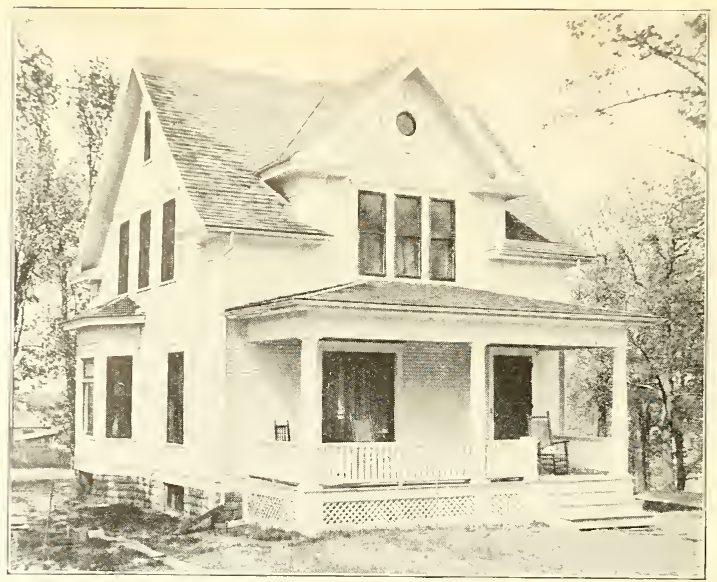

A Snug Home-No. 980

This home for an economical investment is as near complete as money can buy. Large living room. vestibule with coat closet off of same, good sized dining room, with a built-in sideboard, very pretty bay window across end of dining room, large pantry and a good sized kitchen, with entry, grade door and a very pretty staircase leading to the second story.

The second story has three chambers unusually well lighted, and abundance of eloset space, also a large bathroom and stairway to the third story.

There is a full basement under the entire house. First story 9 feet, second story 8 feet. Size 24 feet by 26 feet over main part. Cost to build, $\$ 2,150$. Birch or oak finish throughout first story, pine to paint second story. Hardwood floors throughout. Complete set of plans and specifications for $\$ 18$.
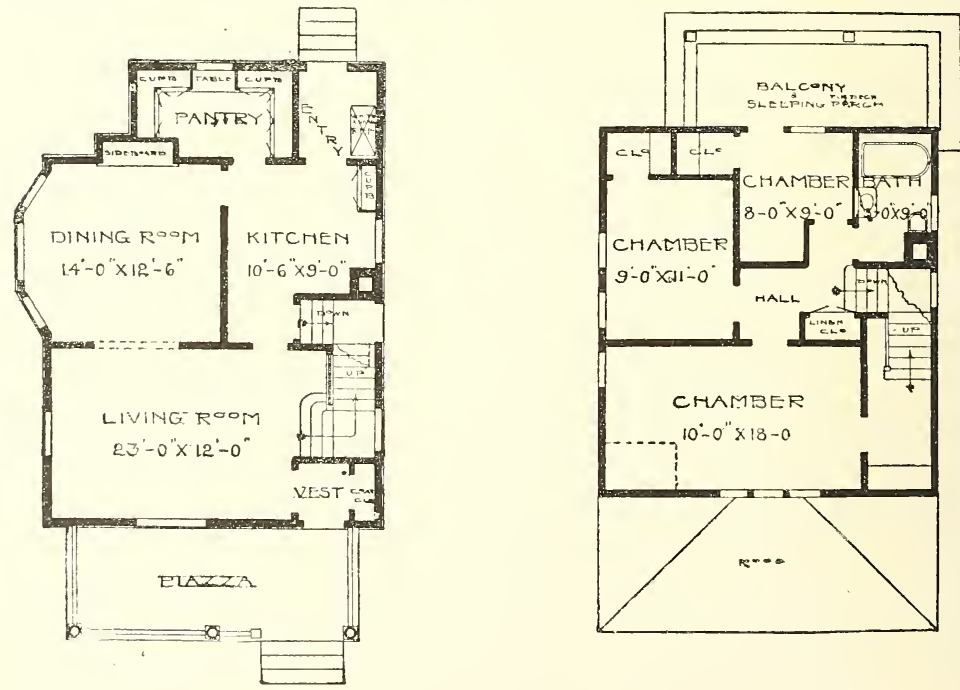

Complete plans and specifications for using Denison Load-Bearing Tile, licensed under Wilson-System Bearing Wa 11 Construction for $\$ 36$. 


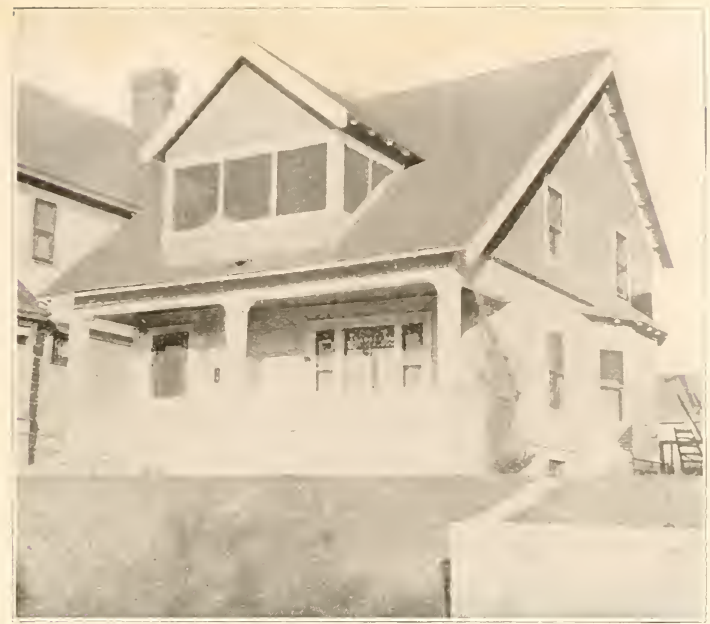

A Very Comfortable Cottage-No. 967

This plan has been built many times in some of the largest eities in the United States, and it is admired by every one. The size of the cottage is twenty-six feet wide and twenty-six feet dee over the main part. There is a full basement under the entire house. First story nine feet, second story eight feet. Cost, $\$ 1,900$.

We would suggest finishing this house in birch or gum. Second story is pine to paint. Complete set of plans and specifications for $\$ 18$.
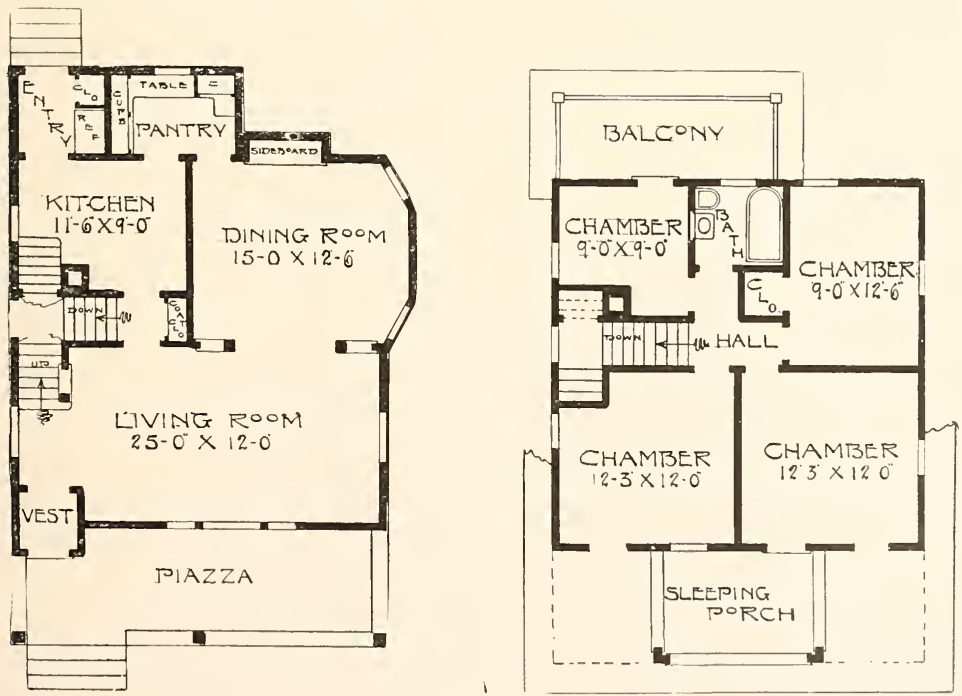

Complete plans and specifications for using Denison Load-Bearing Tile, licensed under Wilson-System Bearing IV a 11 Construction for $\$ 36$. 


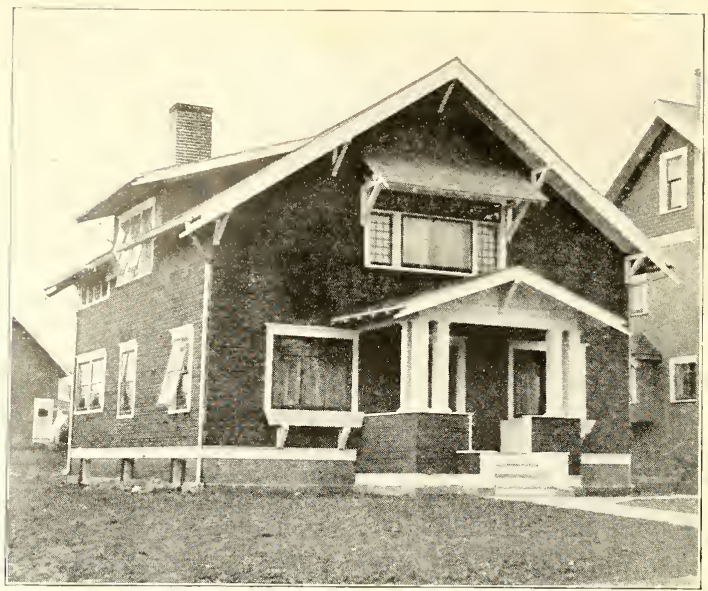

A Story And A Half Bungalow-No. 733

This bungalow has a central hall with living rooms on both sides. Dining room, kitchen and pantry on one side, living room and sun room on the other side. Stairs to second story in rear of hall, underneath which are stairs out through grade entrance or on down to basement.

$A$ beautiful fireplace, in living room. Back of this is sun room which takes the place of den or library making a splendid place to live in the sunshine.

The second story has three chambers, good closets, also sleeping porch all enclosed and very large bath. There is a full basement under entire building. Size 30 feet wide and 32 feet long over main part. Finish in first story is gum or birch, second story pine to paint.

Cost to build, $\$ 3,000$. Complete set of plans and specifications for $\$ 25$.
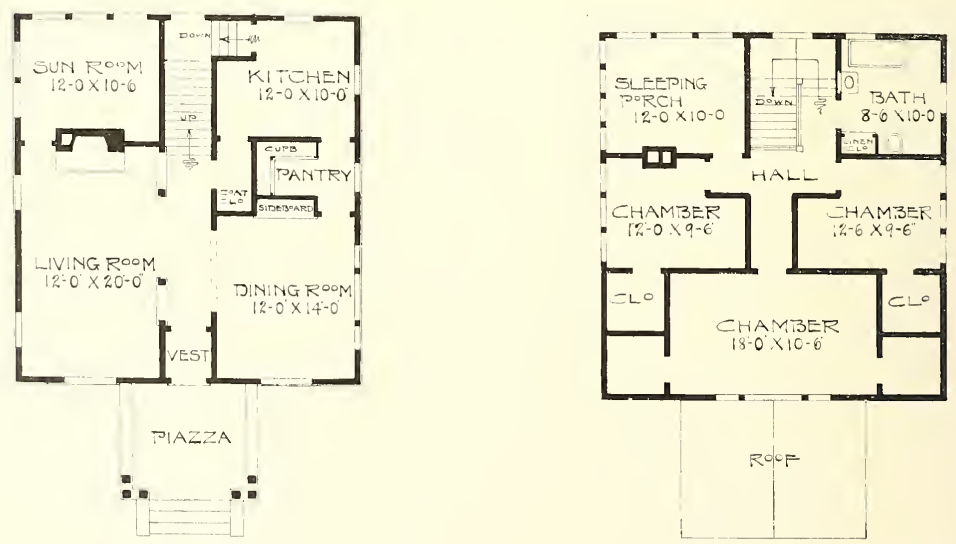

Complete plans and specifications for using Denison Load-Bearing Tile, licensed under Wilson-System Bearing W a 11 Construction for $\$ 50$. 


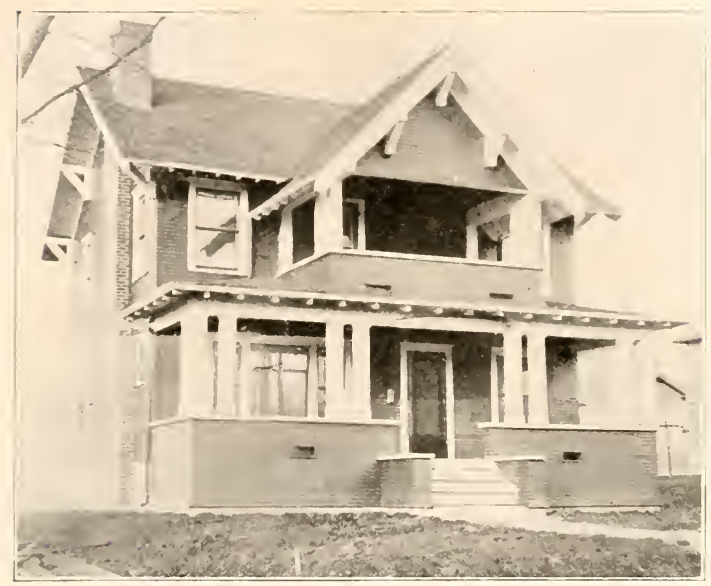

A Good Home-No. 865-B

This residence is a type of the bungalow home modified to a two-story residence. The house has considerable character and individuality, entirely different from any other house along the street, no matter where you might build, as this is an individual design. It is not only an attractive house from the exterior point of view, but it is also a practical house from an interior standpoint.

Size 30 feet wide and 26 feet deep, first story 9 feet, second 8 , full basement. Gum or oak finish in first story and pine to paint in second. Birch or maple floors throughout. Cost to build, $\$ 3,200$. Complete set of plans and specifications for $\$ 25$.
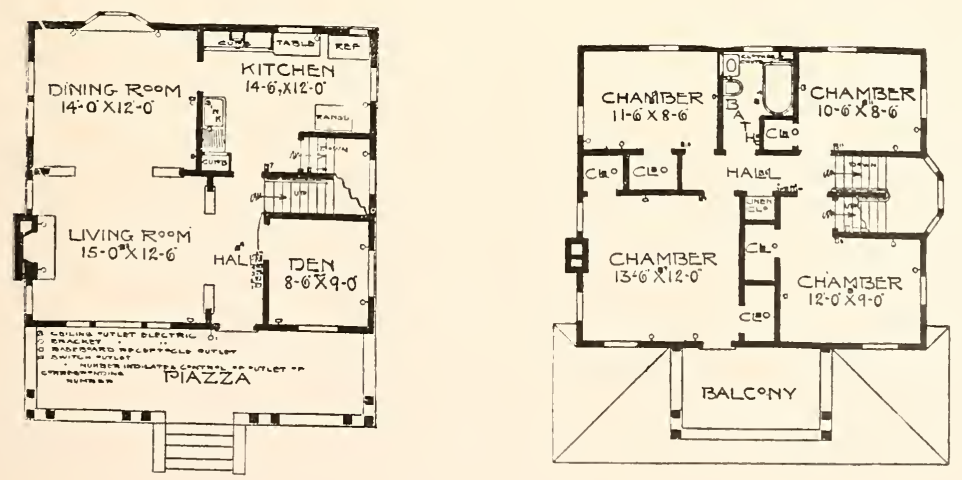

Complete plans and specifications for using Denison Joad-Bearing Tile: licensed under Wilson-System Bearing $\mathrm{W}$ a 11 Construction for $\$ 50$ 


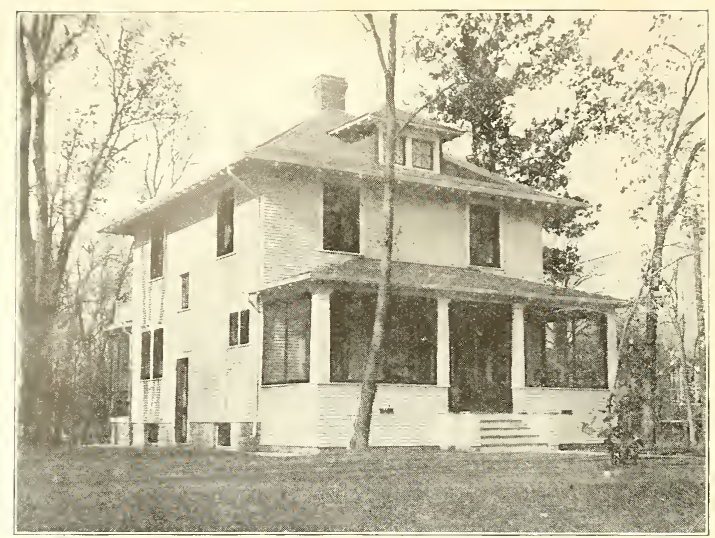

A Practical Square Home-No. 735

This makes a very complete plan and is within the reach of almost every home builder. There is a wide piazza across" entire front, which is sereened in, in summer and can be sashed in, in winter if desired. The living room has beautiful open fire-place. There is a very pretty dining room and well arranged kitehen.

The second story contains four good sized, well shaped rooms and there is ample closet space for each one of these chambers. There is large bath room with medicine cabinet, built in over lavatory with beveled plate mirror.

There is full basement under entire house. First story 9 feet second story 8 feet. Size 28 feet wide and 28 feet deep. Finish in first story is gum or red oak, with pine to paint in second story with birch or maple floors throughout both stories.

Cost to build, $\$ 3,100$. Complete set of plans and specifications for $\$ 25$.
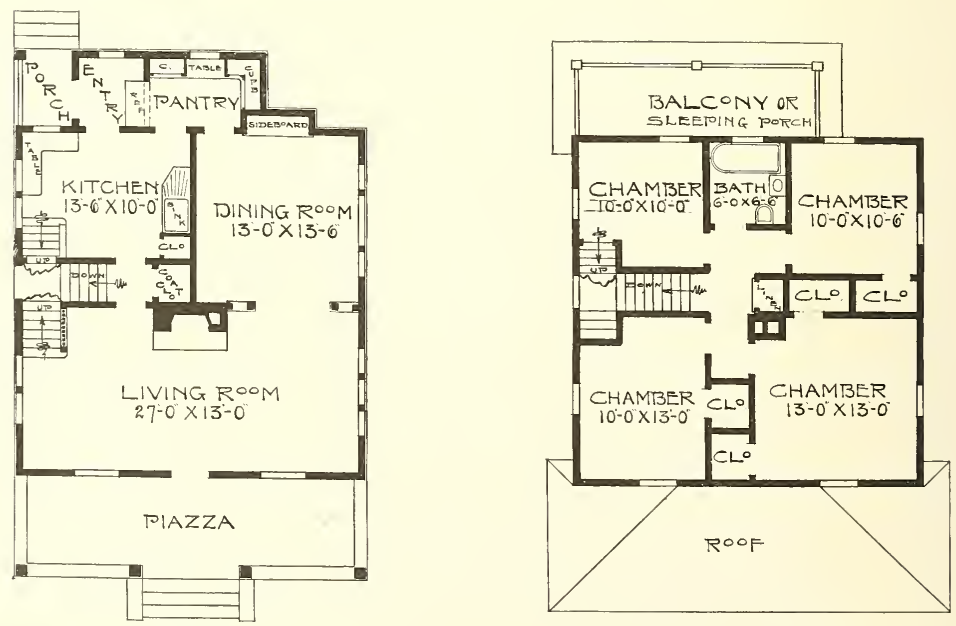

Complete plans and specifications for using Denison Load-Bearing Tile, licensed under Wilson-System Bearing $W$ a 11 Construction for $\$ 50$. 


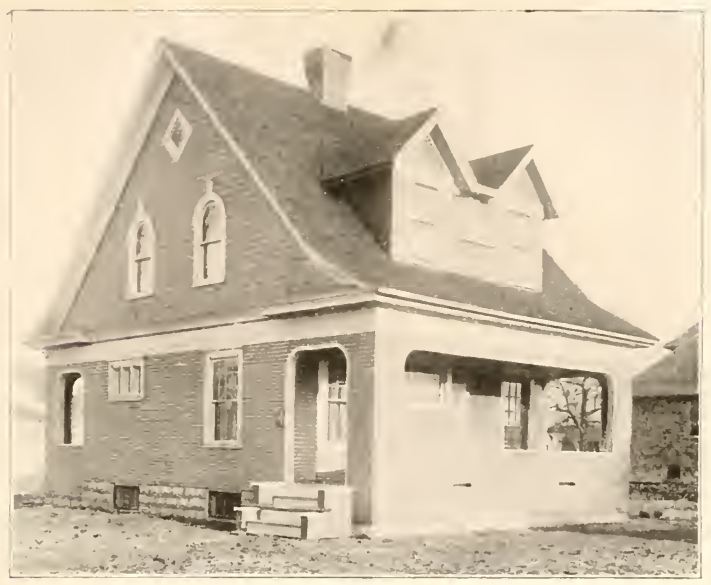

A Cozy Cottage Home-No. 393

This home makes one that is very complete in every respect. Large living room, with small reception hall. There is also a combination stairway leading to the second story, good sized front piazza, that can be screened in or shashed in, so that it can be used the year around; dining room

In the second story there are three chambers, all of which have windows on two sides. There a good sized bath. The closets are large, well arranged and with space for everything. There is a full basement under the entire house. First story 9 feet, second story 8 feet, finish throughout with birch, maple floors, oak or gum finish throughout the first story, and pine to paint in the second story.

Size 24 feet wide and 29 feet deep. Cost to build, $\$ 2,300$. Complete set of plans for $\$ 18$.
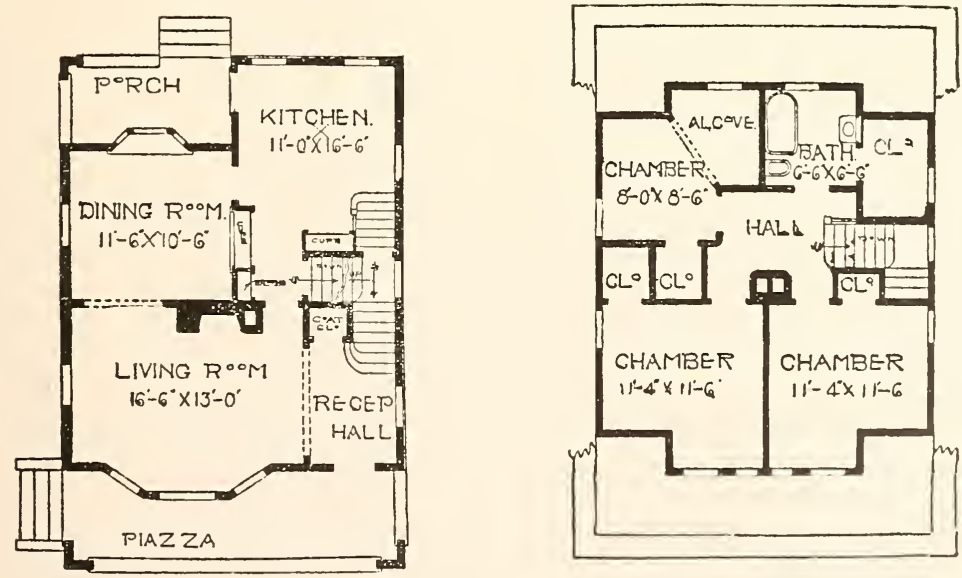

Complete plans and specifications for using Denison Load-Bearing Tile, licensed under Wilson-System Bearing $W$ all Construction for $\$ 36$. 


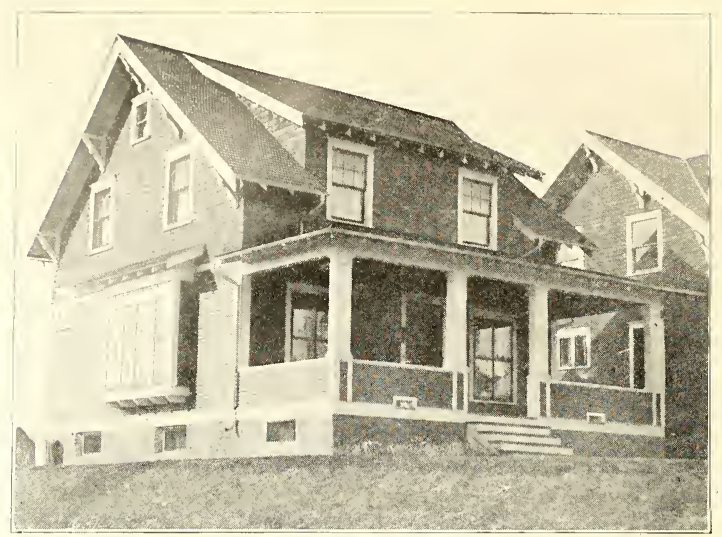

A Seven-Room Cottage-No. 725

The roof has wide projecting eaves, supported by large brackets, the whole design worked out on the Craftsman order

The first story has large living room across entire side with pretty bay window. There is a stairway to second story from rear of living room. The dining room has built-in sideboard, the kitchen is well supplied with cupboards and working table.

In the second story there are three chambers, all of which have windows on two sides. There is a large bath and medicine closet over lavatory. Good closets in each one of the chambers and sleeping porch in the rear.

The first story is 9 feet, second story 8 feet. Size of house 26 feet wide and 26 feet deep. Basement under entire house. Oak or gum finish in first story and pine to paint in second story.

Cost to build, $\$ 2,250$. Complete set of plans and specifications for $\$ 18$.
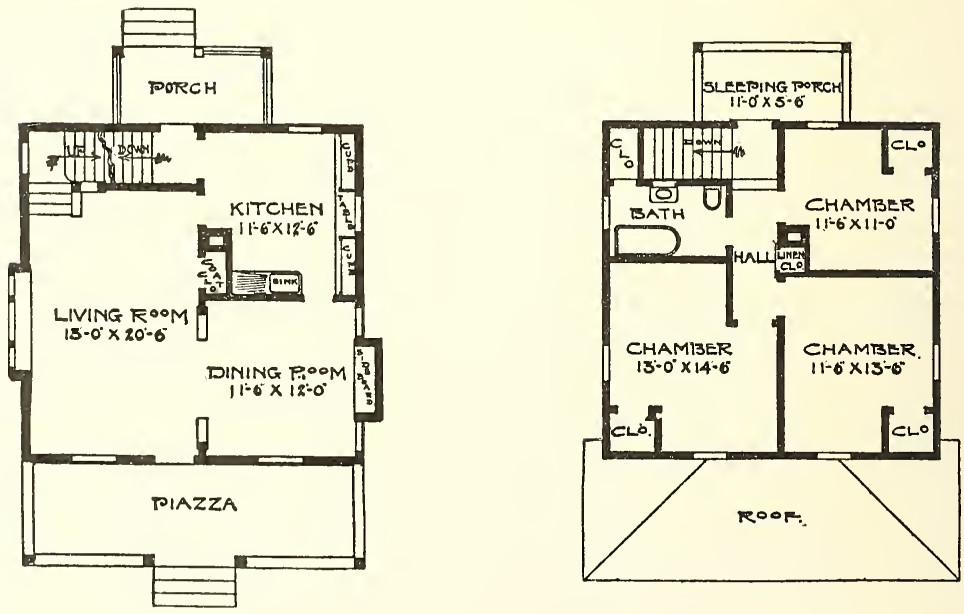

Complete plans and specifications for using Denison Load-Bearing Tile, licensed under Wilson-System Bearing Wa 11 Construction for $\$ 36$. 


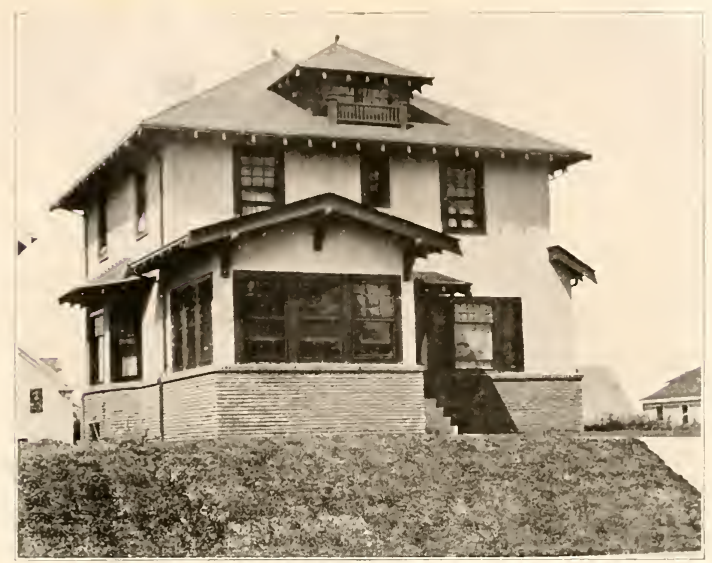

Rough Cast Residence-No, 775

$A$ very pleasing exterior for a rough east home with brick carried up to the height of the first story window sills, and the rough cast made pure white with cornice rafter ends, and window frames stained brown, and a moss green stain for the shingles on the roof, gives a very pleasing combination for this design.

There is a beautiful large living room across the entire side, and a pretty sun-room in front of same, elosed off with French doors. A very pretty dining room with built-in sideboard and china closet, also a conveniently arranged window.

Three nice chambers in second story, good closet space. Size $30 \mathrm{ft}$. wide and $26 \mathrm{ft}$. deep over the main part. Full basement. First story $9 \mathrm{ft}$, second story $8 \mathrm{ft}$. Finish red oak or gum throughout first story, birch second story. Birch or maple floors throughout. Cost to build, $\$ 3,000$ Complete set of plans and specifications for $\$ 25$.
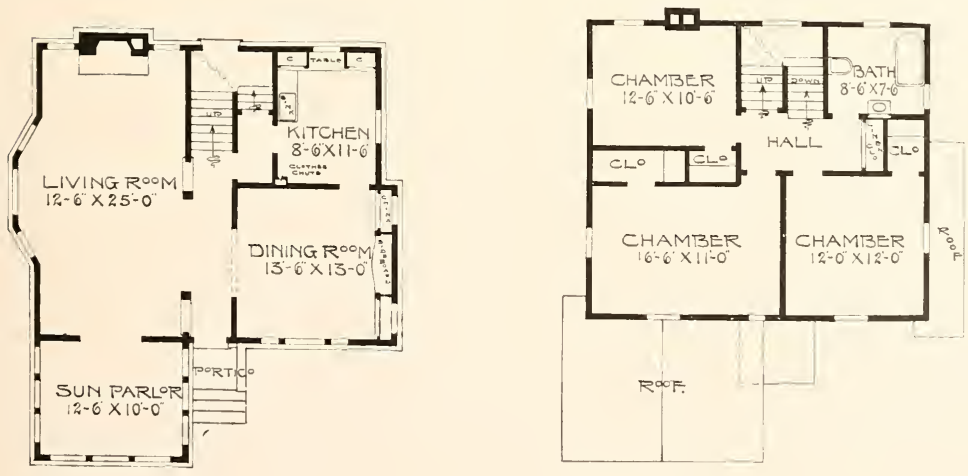

Complete plans and specifications for using Denison Load-Bearing Tile, licensed under Wilson-System Bearing $\mathrm{W}$ a 11 Construction for $\$ 50$. 


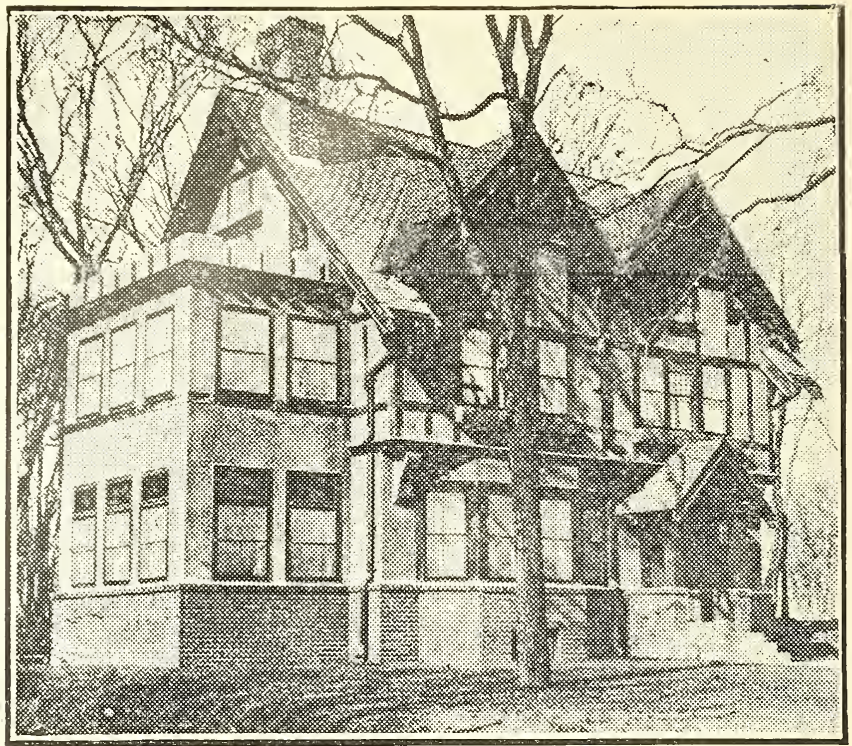

A Modern Half Timber Residence-No. 730

The house is, entered from a small portico into a good sized vestibule, with coat closet for guests. There is also a closet from reception hall for family use. The living room has built-in fireplace and French doors openiug to sun room. There is a dining room with built-in sideboard and beamed ceiling. Large pantry between dining room and kitchen, with well arranged cupboard space. A sleeping porch, which is sashed in, is entered from front chamber through French doors. There is a full basement under entire house. First story nine feet, second story eight feet, size $32 \mathrm{ft}$, wide and $30 \mathrm{ft}$ deep over main part. There is brick veneer carried up to height of first story window sills. Balance of first story is rough cast. Second story is English half timber and rough cast panels. The half timbers are painted or stained a dark brown. White oak or gum finish in first story and gum in second story, with birch or maple floors throughout. Cost to build, $\$ 5,500$. Complete set of plans and specifications for $\$ 35$.
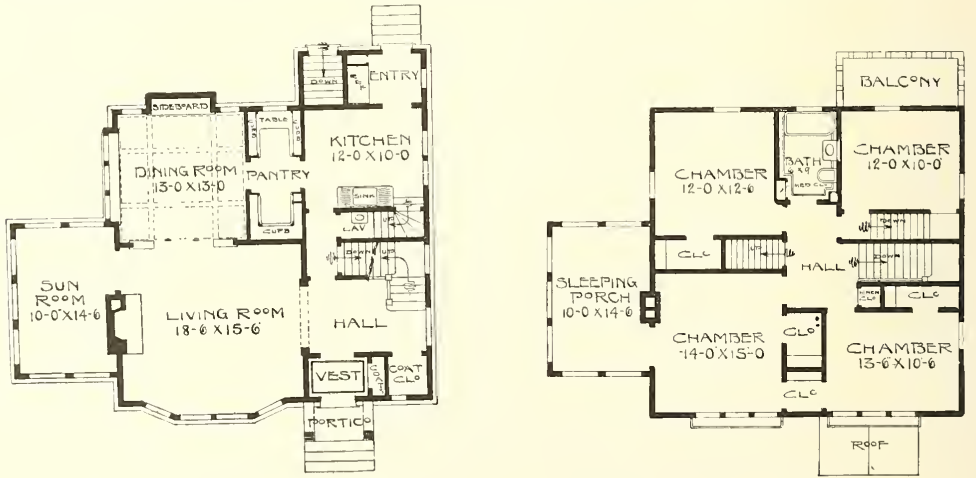

Complete plans and specifications for using Denison Load-Bearing Tile, licensed under Wilson-System Bearing $W$ a 11 Construction for $\$ 70$. 


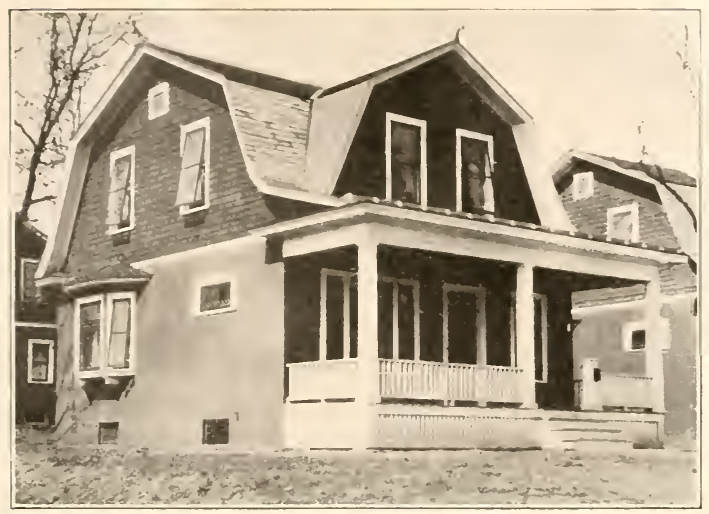

A Pretty Gable Roof Cottage-No. 753

This is a very practical little home to build; beautiful living room across the front, pretty dining room and well arranged kitchen with space provided for all of the kitchen furniture. There is a combination stairway to the second story in which there are three good sized chambers, also a large bath room, ample closet space.

There is a full basement under the entire house, size 24 feet wide and 26 feet deep. First story 9 feet, second story 8 feet.

Finish throughout first story gum or red oak. Finished in second story pine to paint. Birch or maple floors throughout both stories. Cost to build, $\$ 1,950$. Complete set of plans and specifications for $\$ 16.00$.
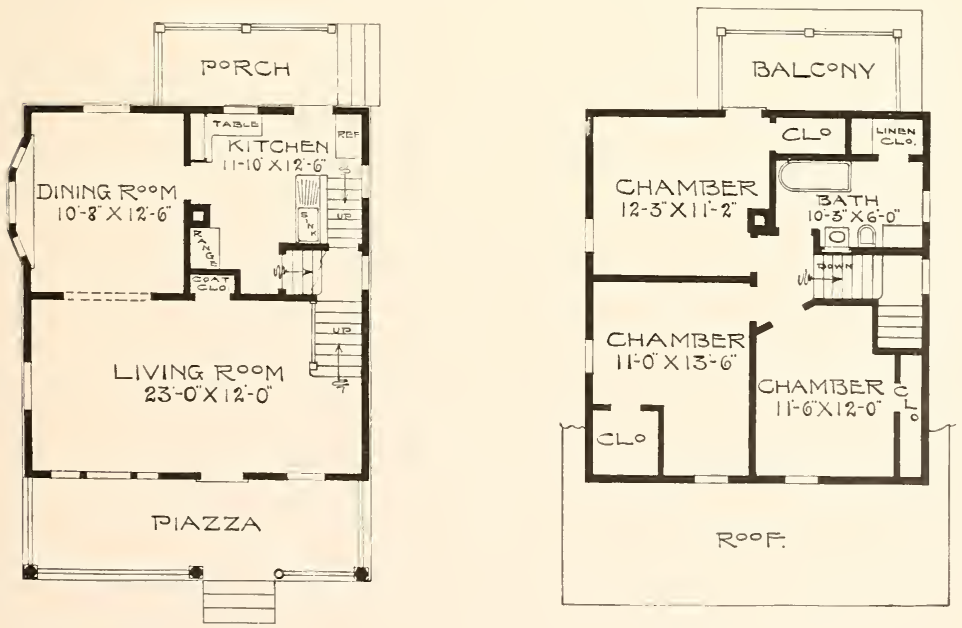

Complete plans and specifications for using Denison Load-Bearing Tile, licensed under Wilson-System Bearing IV a 11 Construction for $\$ 32$. 


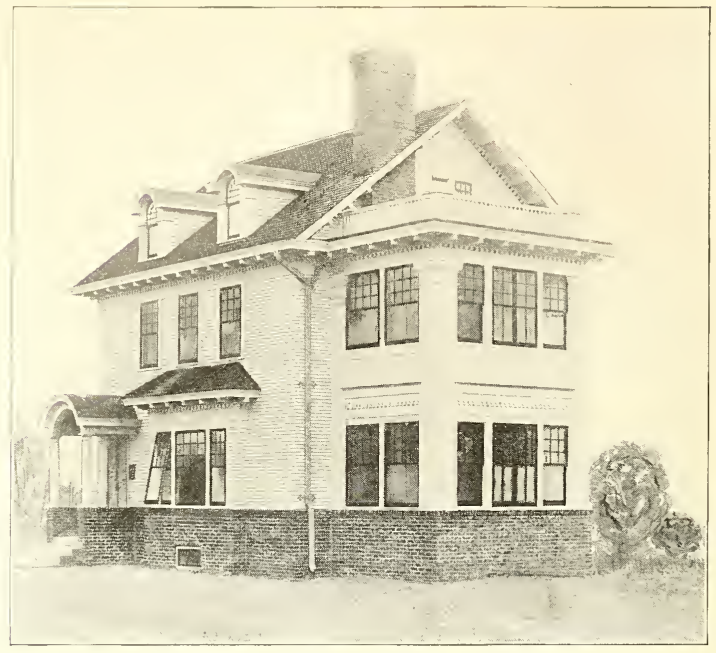

New England Colonial Design-No. 966

Cost to build, $\$ 3,800$.

This is from actual figures after this house has been duplicated in one of the largest cities in the United States four times. This plan is unique as it is the only plan designed up to the present time that can be adapted to five distinct styles of architecture without changing the doors or windows, or materially affecting the general plan in any way. We have this house made up as an old New England Colonial, Craftsman style, and English half-timber. The above three as shown. The size of the house is 26 feet wide and 28 feet deep over the main part. There is a sun room on the side which is 10 feet 6 inches wide, thus making a frontage of 36 feet 6 inches. a sun room on the side which is 10 feet 6 inches wide, thus making a frontage of 36 feet 6 inches.
Necessarily this calls for at least a 40 or 50 foot lot, or one wider still is even more appropriate for this home. This is such a good design that it is really unnecessary to write a word of description as the floor plans illustrated shows a home that is complete. There is not one wish that one thousand different home lovers have ever expressed but what are all included in this little home. The sun room and the sleeping poreh in ten years time are going to be the only kind of piazzas that will be put in homes, as in a cold climate a piazza around the front and sometimes around the entire sides keeps out the sunshine from all the rooms and is only hvable three months out of the twelve at the most. Now, with sun room and a sleeping porch which are all sashed in, in
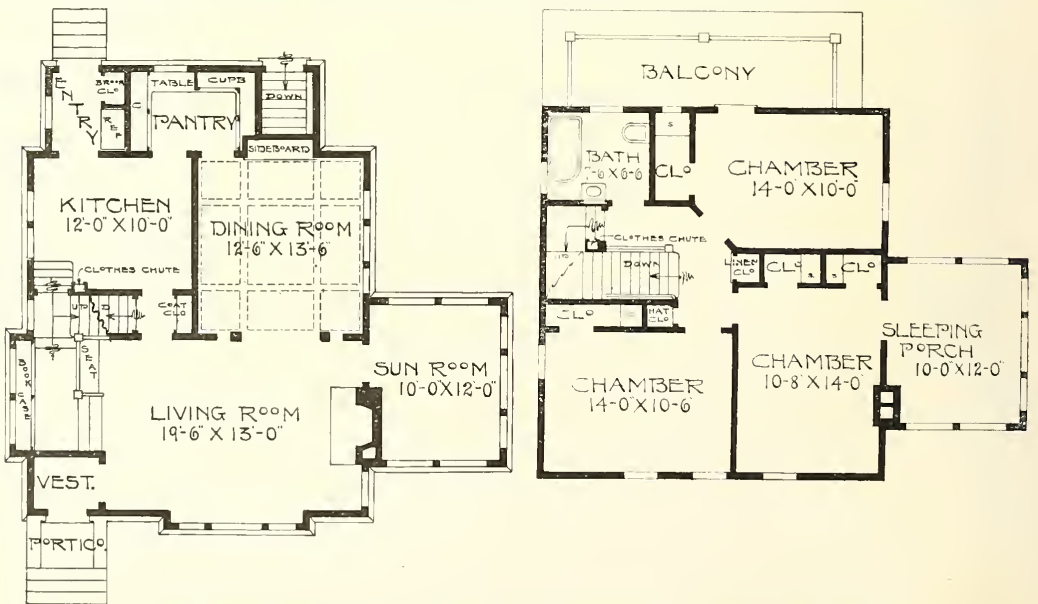

These floor plans can be reversed to fit Illustrations No. 966-A and 966-B. 


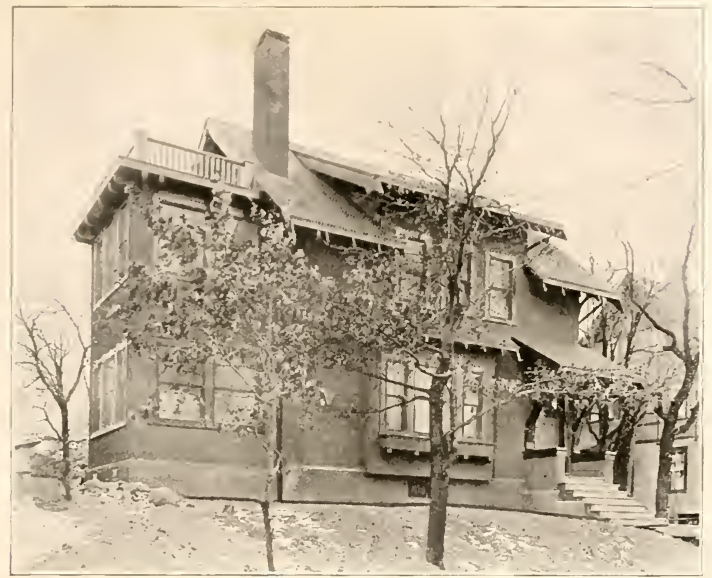

Craftsman Design-No. 966-A

case it gets too cool or starts to rain, you can put the windows down and raise the bottom one up and you can still sit on the piazza just the same, either in sunshine or rain, or snow. In your sun room we put in a radiator so that they are livable for 365 days in the year.

There is a full basement under this entire house. First story 9 feet, second story 8 feet. These heights are in the clear. First story is finished throughout in birch with bireh floors throughout both first and second stories. Red oak or gum could be used if one desired. The second story is finished in pine to paint, with birch doors to stain mahogany color to give the second story is finished in pine to paint, with birch doors to stain mahogany color to give the
old Colonial interior finish for the chambers. Complete set of plans and specifications for $\$ 35$ of any one of these three designs. Will blue print the plan either side up so as to fit the lot that you have.

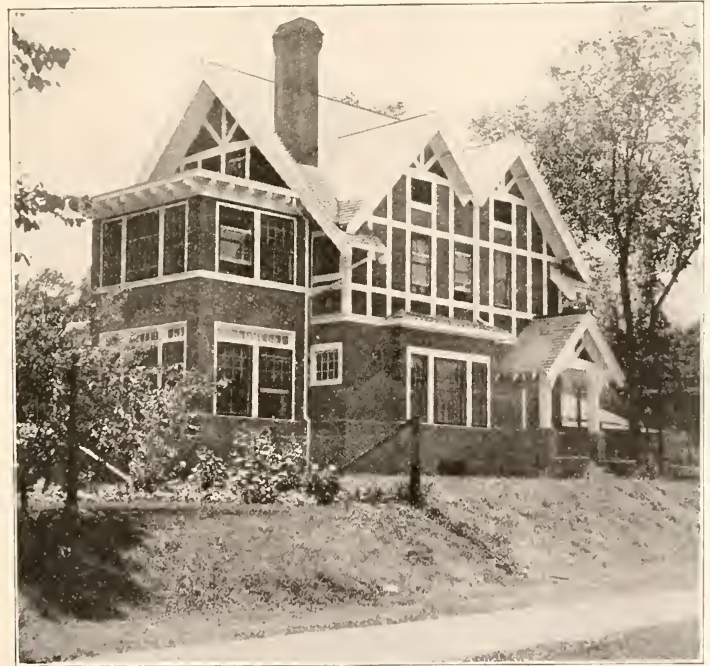

English Half Timber Design-No. 966-B

See the floor plans on opposite page that go with these two beautiful exteriors.

Complete plans and specifications for using Denison Load-Bearing Tile, licensed under Wilson-System Bearing Wall Construction for $\$ 70$. 


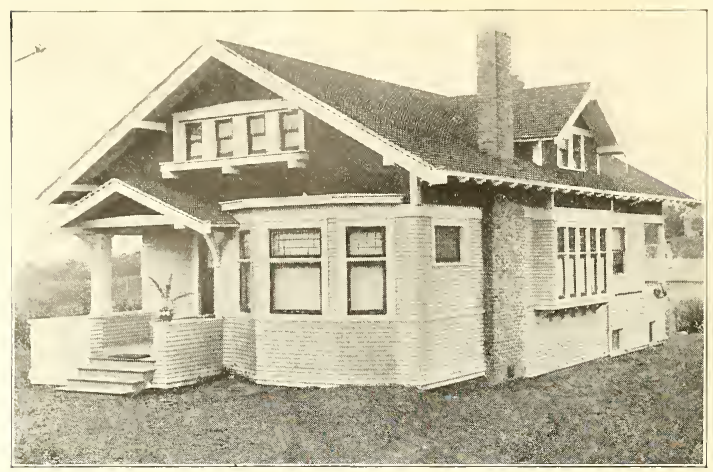

A Bungalow of Individuality-No. 744

This bungalow has a large living room, small hall, and a good sized coat closet across the front and a piazza that is 10 feet square, which can be screened in in the summer time and sashed in in the winter time if one desires. Two good chambers in first story, splendid eloset space, large linen closet and bath room. Dining room is made attractive by a group of five windows across end of same, built up on ledge shelf Kitchen is well arranged with built-in cupboard space. The refrigerator is planned to come flush on the kitchen side. Ice to be put in from closet opening on rear porch. There is a full basement under entire bungalow. First story 9 feet.

Three chambers can be finished in first story if one desires. Size 28 feet wide and 40 feet deep over the main part. Oak or gum finish throughout first story with bireh or maple floors throughout. Cost to build, $\$ 2,500$. Complete set of plans and specifications for $\$ 23$.

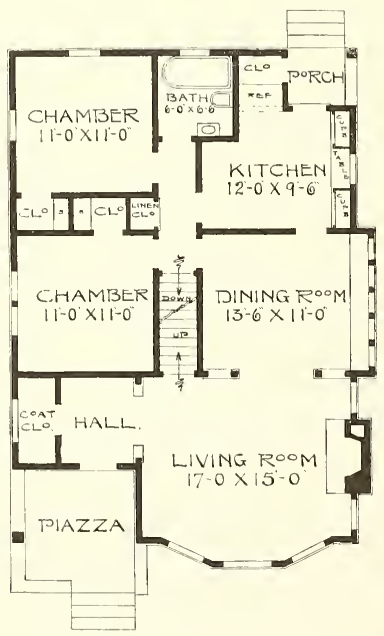

Complete plans and specifications for using Denison Load-Bearing Tile, licensed under Wilson-System Bearing $W$ a 11 Construction for $\$ 46$. 


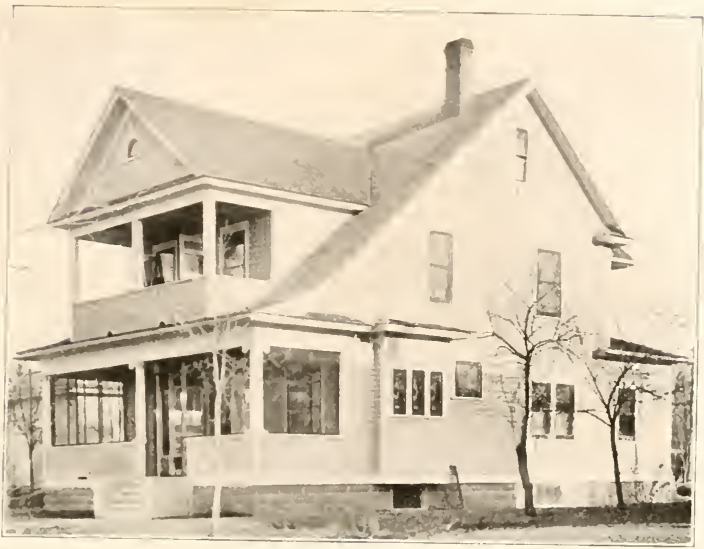

A Comfortable Home-No, 978

Four rooms in the first story besides a sewing room, or this room can be used for a den, or in case of emergeney for a bed room.

The living room is good sized, with a large reception room. These two rooms open together with columned archway, dining room in rear of living room with a very pretty built-in sideloard. kitchen has built-in cupboards, large entry, also a lavatory on this floor.

In the second story we have three splendid sleeping rooms, large bath, and sleeping porch over the rear one-story part, giving the capacity of four chambers. This sleeping porch can be sashed-in in the winter time, and used for a permanent room if one desires.

Size 26 feet by 38 feet deep. This is over the entire house including the one-story part in the rear. There is a full basement under the entire louse. First story 9 feet, second story 8 feet.

Finish throughout first story gum or oak. Floors either maple or red oak. Second story pine to paint. Cost to build, $\$ 2,900$. Complete set of plans and specifications for $\$ 25$.
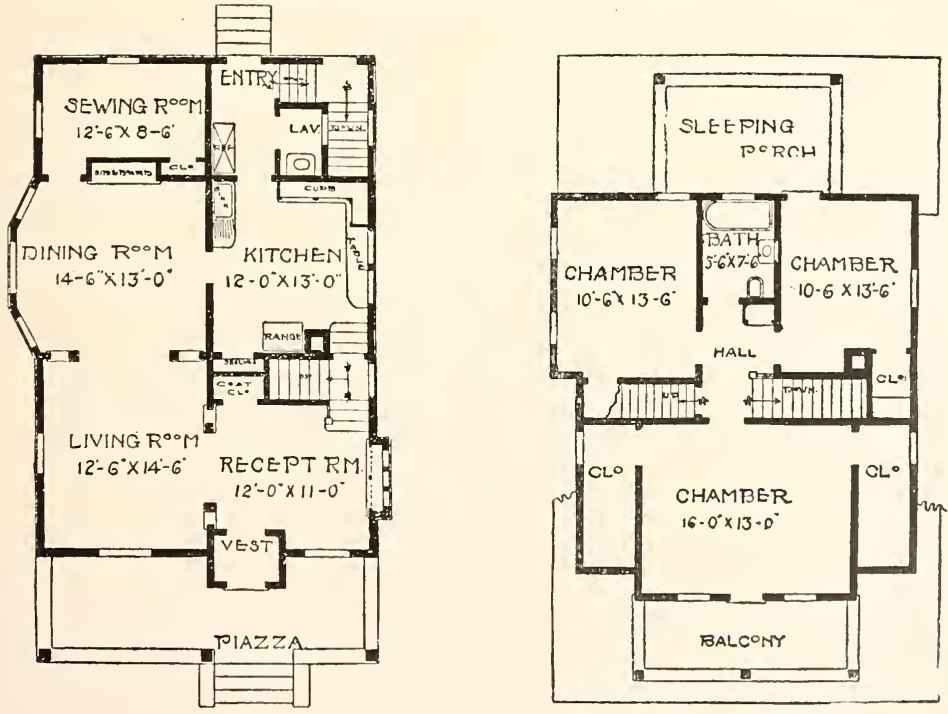

Complete plans and specifications for using Denison Load-Bearing Tile, licensed under Wilson-System Bearing IV a 11 Construction for $\$ 50$. 


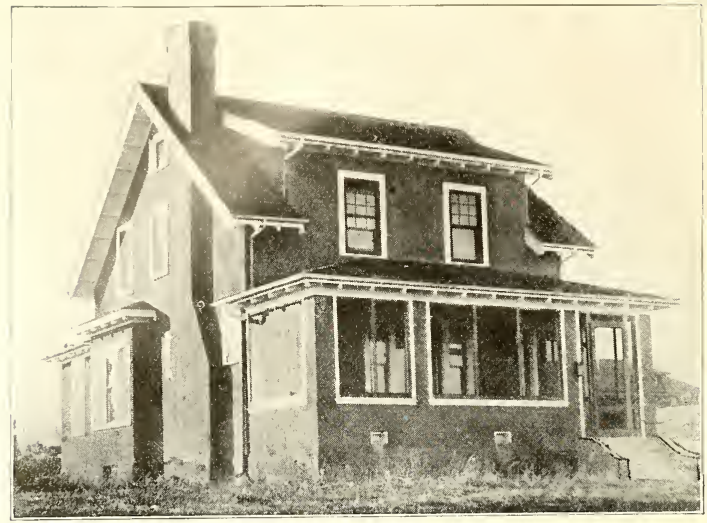

A Study in Plaster-No. 958

Here is a pretty little style of a modest home that has all the requirements of a much larger house, and anyone who is interested in a home that will cost $\$ 3,000$ cannot fail to be impressed with this design.

By carefully studying the floor plans, you will realize what a comfortable and convenient layout this little home is. The size is 26 feet wide and 26 feet deep over the main part. There is a basement under the entire house. First story 9 feet, second story 8 feet.

The finish for the first story is in red oak, or gum. Finish of the second story is pine to paint. The floors throughout either red oak birch or maple. We believe that this is one of the best little desions, and one of the most complete layouts for a model lome that was ever put out. Would advise you to study the plan very carefully. In this little home, there is a place for everything, and everything is in its place.

Cost to build, $\$ 3,000$. Complete set of plaus and specifications for this home for $\$ 25$.
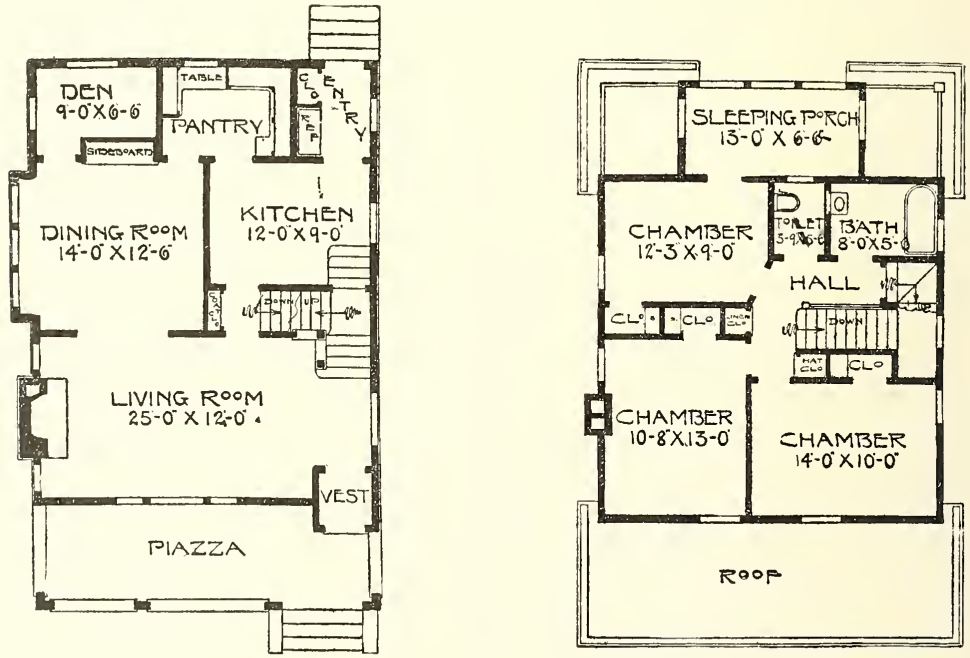

Complete plans and specifications for using Denison Load-Bearing Tile, iicensed under Wilson-System Bearing W a 11 Construction for $\$ 5 \mathrm{C}$. 


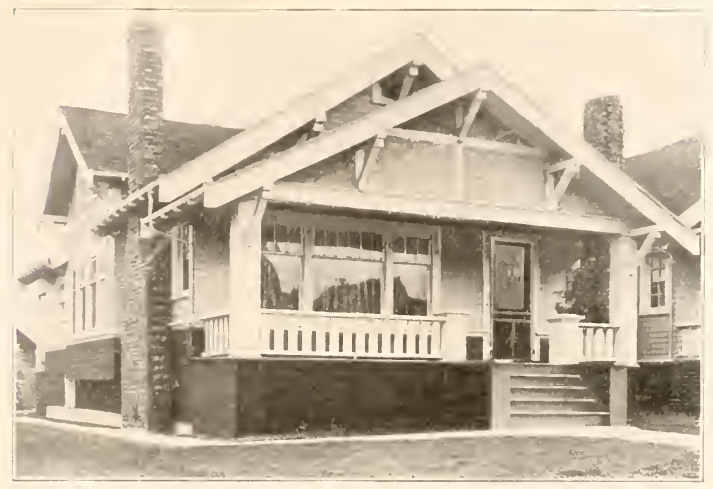

A Pleasant Bungalow Home-No. 743

This bungalow is planned with two bed rooms and bath in the first story, saving the house wife many steps each day in not having to climb up and down the stairs to reach the sleeping romms. This bungalow is planned with a beautiful large living room, which covers the entire front with a large open fireplace across the end. Dining room is opened up with the living room by a high pedestaled archway, Very pretty sideboard built in the dining room on the rear wall. Every detail for the kitchen is planned out very carefully. Abundance of eupboard space and space for all of the kitchen furniture.

Two or three chambers can be finished in the second story if one desires. Full basement. First story 9 feet. Size 28 feet by 38 feet. Birch or maple floors throughout first story; finish to t.e red oak or yum throughout. Cost to build, $\$ 2,400$. Complete set of plans and specifications for $\$ 23$.

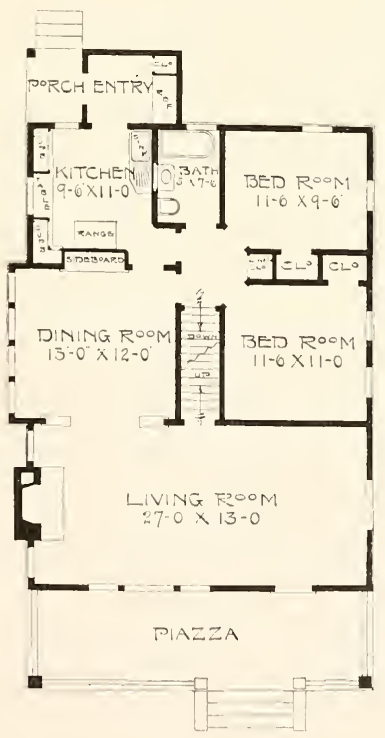

Complete plans and specifications for using Denison Load-Bearing Tile, licensed under Wilson-System Bearing W a 11 Construction for $\$ 46$. 


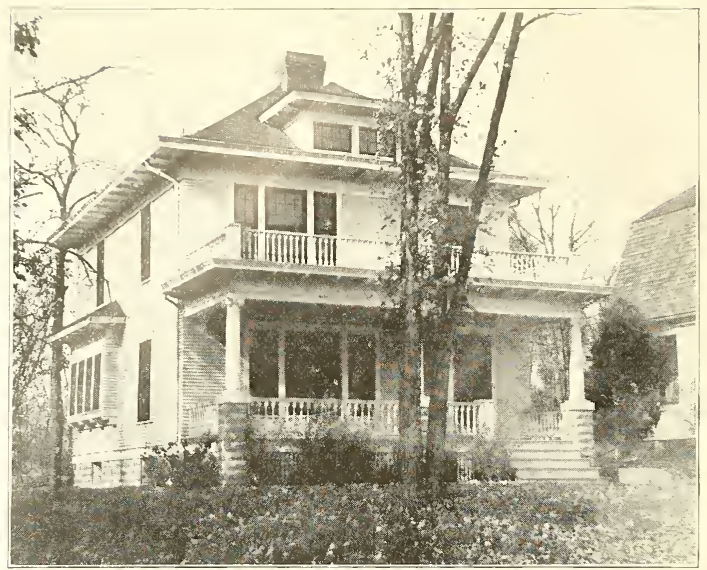

An Imposing Colonial Home-No. 729

Here is a colonial design which is inexpensive to build and has all the features and details that are put into the more expensive plans. Laro open fireplace at the rear of living room, with an open stairway at one side and high pedestaled arehway opening into the dining room at the other side. The stairway is a combination from living room and kitchen. The kitchen has built-in cupboards and rear entry porch for refrigerator. The arrangement of the ehambers is unusual, a rest room or living room connecting with the front chamber. Linen closet from hall and two smaller sleeping rooms and bathroom. Size, twenty-four feet wide and twenty-eight feet deep. Full basement under entire building. First story nine feet second story eirgt feet Birch or maple floors throughout first and second stories. Red oak or gum finish in first story and pine to paint in second story. Cost to build, $\$ 2,800$. Complete set of plans and specifications for $\$ 25.00$.
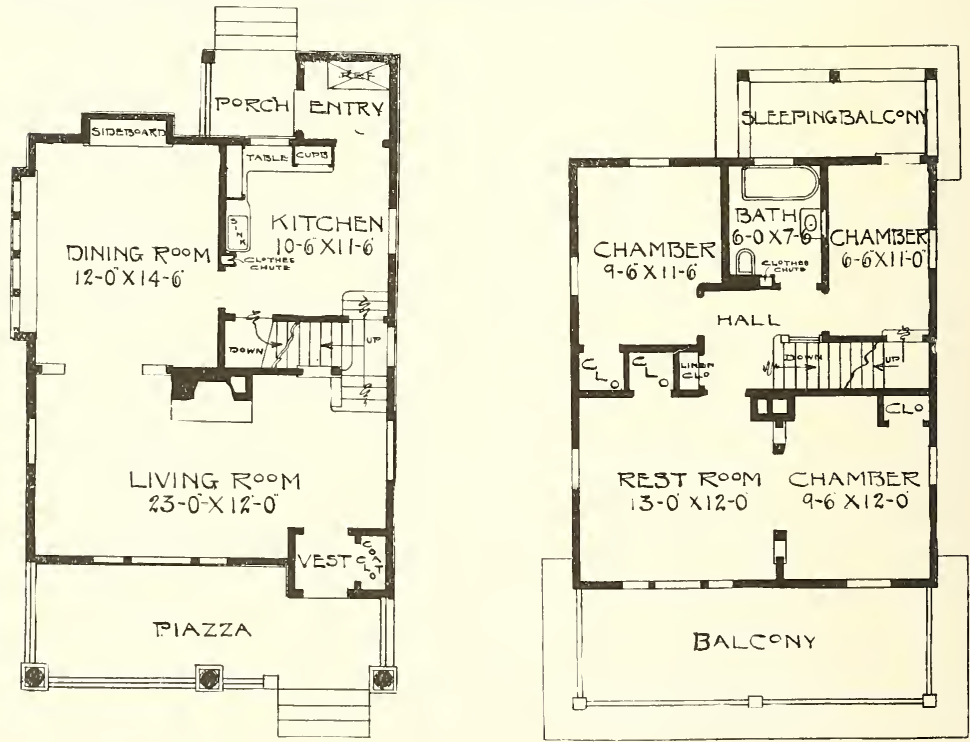

Complete plans and specifications for using Denison Load-Bearing Tile, licensed under Wilson-System Bearing Wa 11 Construction for $\$ 50$. 


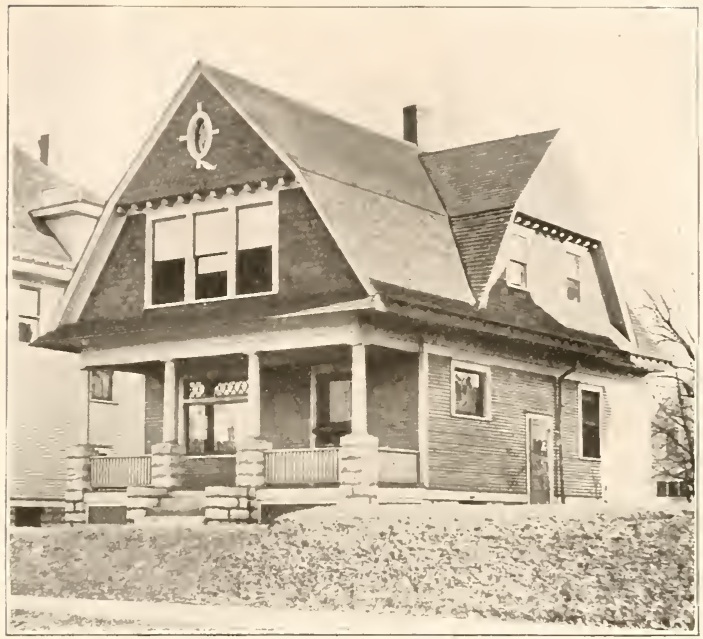

A Good Sensible Home To Build-No. B78

This little cottage is 22 feet wide and 27 feet deep. There is a good sized living room and nice dining room and kitehen. Combination stairway with grade door. This is a practical home and has been built many times. There is a full basement under the entire house.

First story 9 feet, second story 8 feet. The chambers in second story are good sized, large closet space, and good bath room.

Georgia pine or gum finish in the first story, pine to paint in second story. Birch or maple floors throughout first and second story. Cost to build, $\$ 1,800$. Complete set of plans and speci. fications for $\$ 16$.
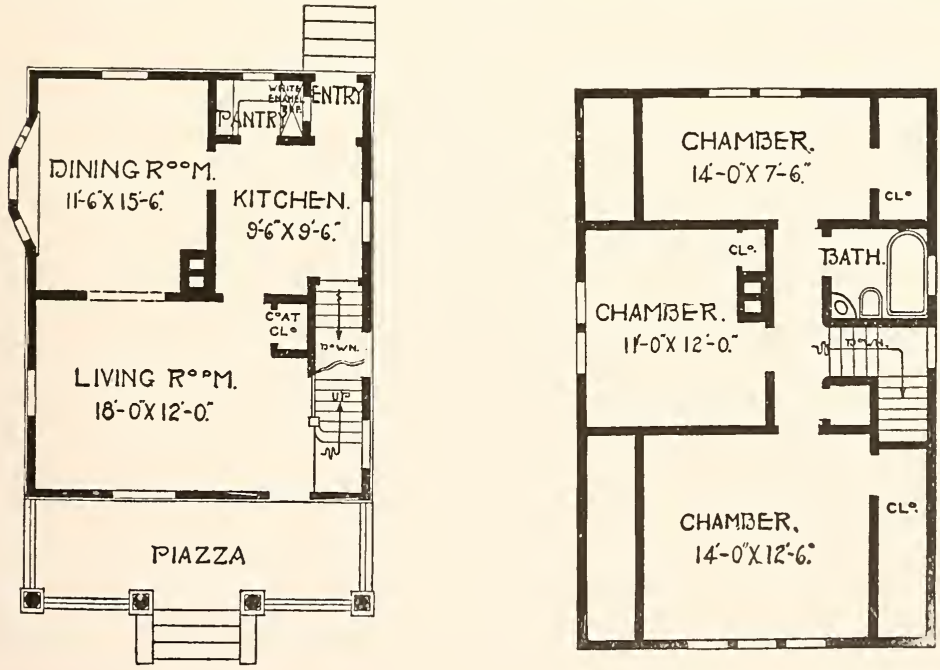

Complete plans and specifications for using Denison Load-Bearing 'Tile, licensed under Wilson-System Bearing IV a 11 Construction for $\$ 32$. 


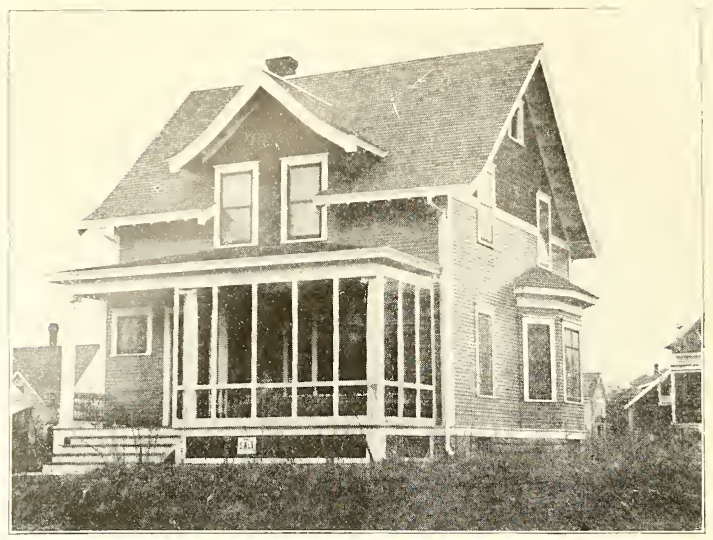

A Suburban Cottage-No. 734

This makes a very pretty country, suburban, or even city cottage. There is a wide piazza across the front, large vestibule and good sized coat closet with built-in seat in same. There is a small reception room connectmo with living room by cased opening. There is a very pretty dining room with bay window, large pantry back of dining room and kitchen. Also entry in rear and space for refrigerator.

The second story of this plan has three chambers, large closets and very good sized bath. There is also nice sleeping poreh out over rear one-story part. Size 24 feet wide and 26 feet deep over main part. Full basement. First story finished in hardwood, gum. Second story pine to paint.

Cost to build, $\$ 2,250$. Complete set of plans and specifications for $\$ 18$.
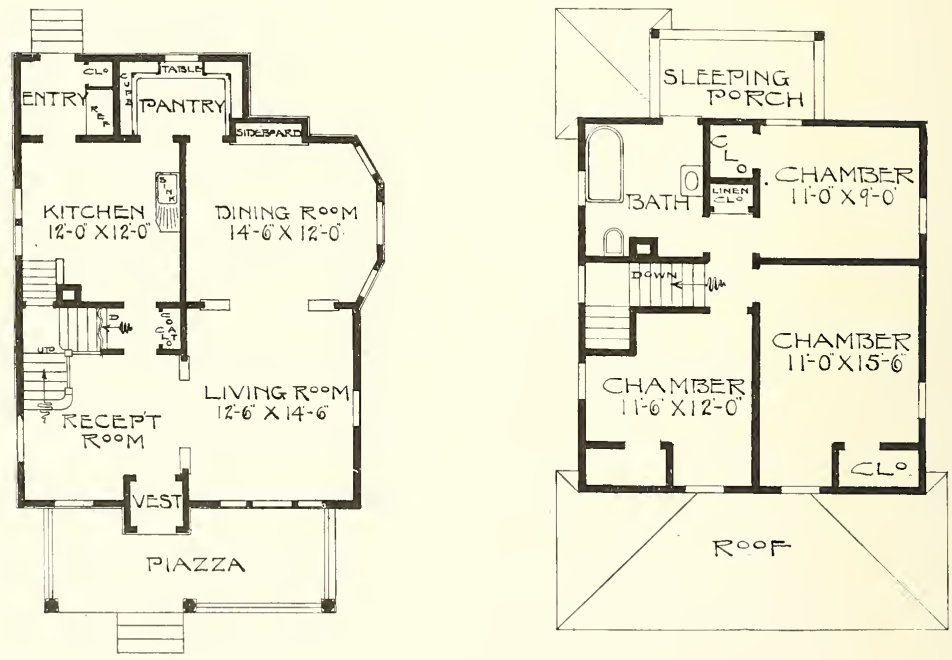

Complete plans and specifications for using Denison Load-Bearing Tile, licensed under Wilson-System Bearing $\mathrm{W}$ a 11 Construction for $\$ 36$. 


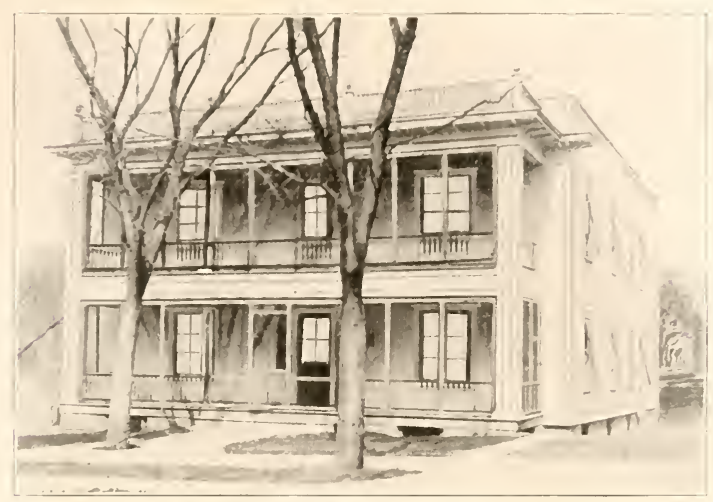

A Four Family Frame Apartment-No. 721

Here is a splendid investment for any man who has a good lot in either the city or a small town. It will bring him in from 12 to $20 \%$ on his money. Especially would it be a splendid invest. ment for a small town as there would always be at least four families who would desire a small apartment of this kind to live in. We only show, the first floor plan and the second is just the apare os the first civin eacl family large lixing room, two hed rooms dining room and kitchen and bath room, which is termed a five room apartment. There is a full basement under entire building. Each story is 9 feet. Size of house 40 feet wide and 50 feet deep.

Finish throughout red oak or gum and birch or white maple floors throughont first and second story.

iost to luild. $\$ 5,000$. Complete set of plans and specifications for $\$ 40$.

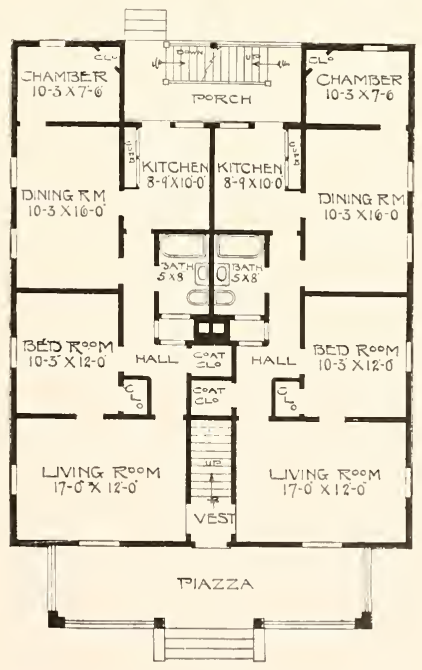

Complete plans and specifications for using Denison I oad-Bearing Tile, licensed under Wilson-System Pearing $\|$ a 11 Construction for $\$ 80$. 


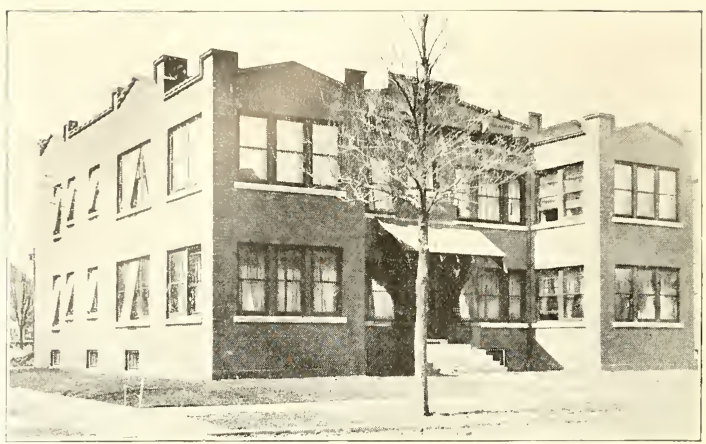

A Four Flat Building, A Good Investment-No. 750

A four family flat building is a good investment for a man either in a small village or in a large city as by building four living apartments all under one roof on the same foundation you get a more economical investment than you would to build four detached cottages. The arrangement of the floor plans is very complete. Each flat has a private sleeping porch and sun room combined, making a fine feature for a flat building. By carefully examining the floor plan one can see what an exceptionally fine floor plan we have for the rooms.

There is a full basement, first and second story, each 9 feet in the clear. Size of building 52 feet wide and 40 feet deep over the main part. Birch or red oak finish throughout. Maple floors throughout both stories.

This building is also planned with briek up to the first story window sills and rough east above cost of same would be alout $\$ 7,800$.

Cost to build, $\$ 8,600$. Complete set of plans and specifications for $\$ 50$.

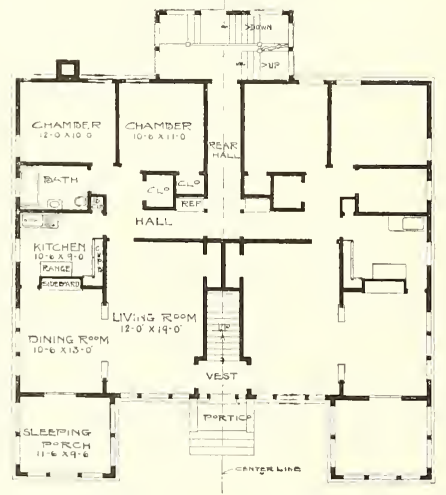

Complete plans and specifications for using Denison Load-Bearing Tile, licensed under Wilson-System Bearing W a 11 Construction for $\$ 100$. 


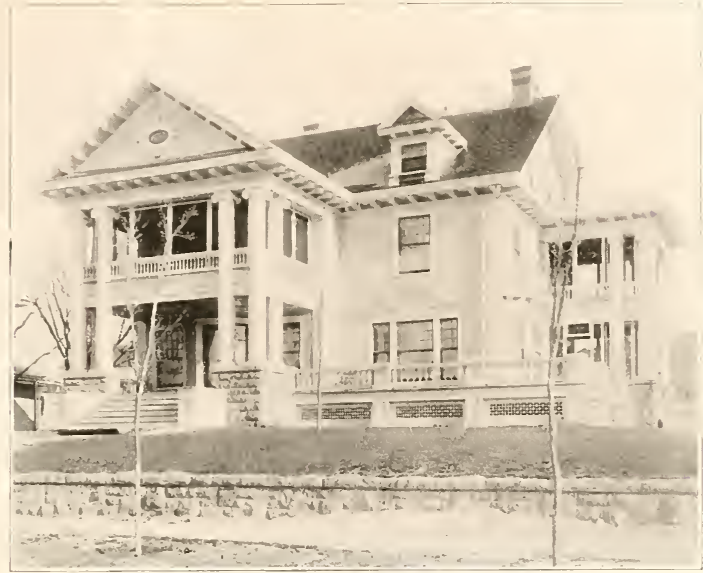

A Beautiful Georgian Colonial-No. 976

There is no style of architecture in the world that is as commanding as the beautiful Old Colonial which is an adaptation of the classie orders.

A beautiful large living room. This connects with the library, which can be used as a music room, drawing room. or any purpose that one desires. Dining room ean be reached by passing through the nook from the living room. Across the rear wall of the dining room is a built-in sideboard, with china elosets on either side, butler's pantry conneeting kitehen with dining room, lavatory, good sized pantry opening out of kitchen, also entry and place for refrigerator, clothes clute, and all kinds of cabinets for the housekeeper to keep her utensils in.

Second story has four splendid rooms. Front right chamber has dressing room supplied with toilet and lavatory. The chambers are all well lighted. There is abundance of good closet space. Birch or maple floors throughout. Finish is gum or red oak first story and pine to paint in second.

Size 38 feet wide and 32 feet deep over main part. Full basement under the entire house. First story 9 feet six inches, second story 8 feet 6 inches. Cost to build, $\$ 8,000$. Complete set of plans and specifications for $\$ 50$.
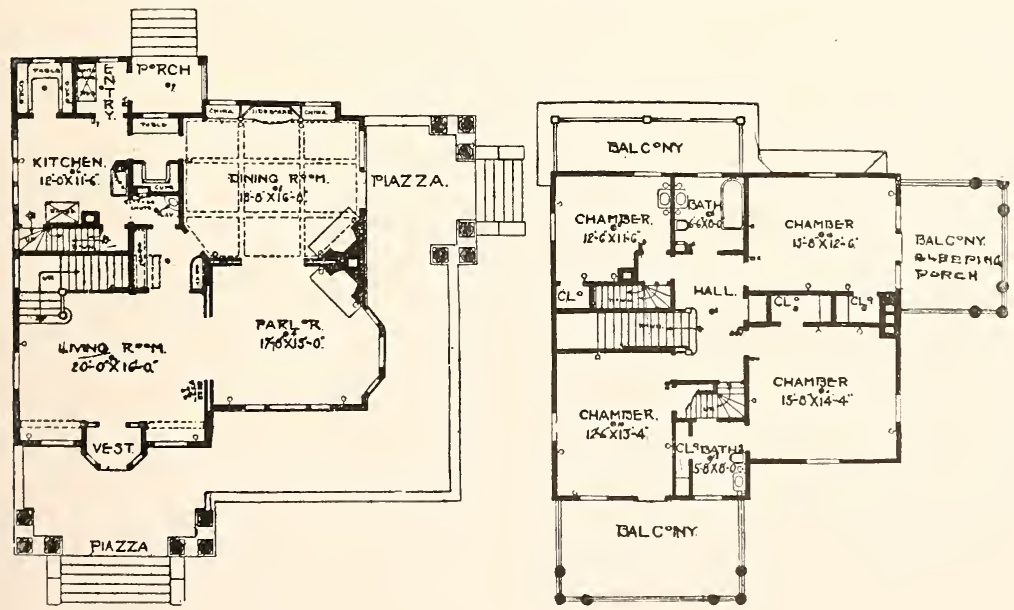

Complete plans and specifications for using Denison Load-Bearing Tile, licensed under Wilson-System Bearing IV a 11 Construction for $\$ 100$. 


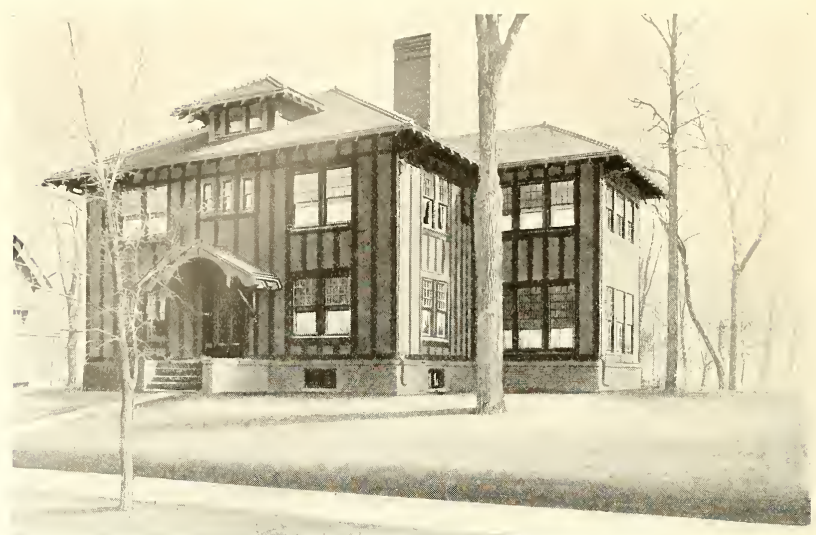

A Beautiful Half Timber Residence-No. 972

If any of our readers are interested in a better type or more expensive home, occasionally we are going to give you one to study.

The exterior of this residence is beautiful. The half-timber effect is made of slashed grained Washington fir, running from the water table to the frieze of the cornice. The cement in between these half-timbers is colored a cream color and the half timbers are stained with a brown stain, thus making a very beautiful contrast, the light cream cement in the paneis and a beautiful rich brown for all the half-timber work.

From the den you pass on into the beautiful sun room at the side. This sun room is livable the year around. You can not only enjoy the pleasure of this space in the summer time but you can use it every day in the year, as there is a radiator piped to same, thus making it the most livable room in the whole house.

The culinary department is well arranged. There are two stairways one from the kitchen and one from the front hall, also a grade door.

In the second story we have four rooms besides the sleeping porch. The room that is used as a sewing room can be used as a bedroom, if desired. There are two bath rooms. Size 36 feet by 32 feet, finished in hardwood throughout.

Cost to build, $\$ 10,000$
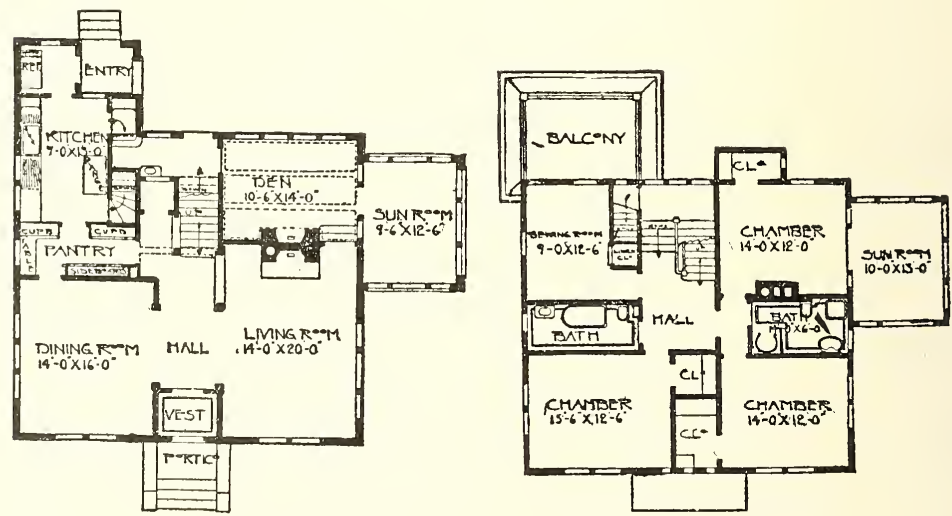


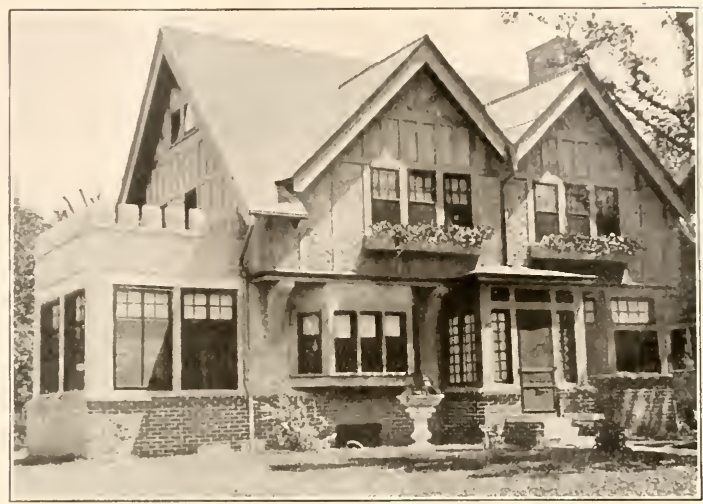

\section{A Splendid Example of the English Half Timber With Rough Cast Exterior-No. 959}

The size of the house is 35 feet wide, exclusive of the sun room, and 26 feet deep over the main part. The house is arranged with a central hall stairwar leading to serond story and rear, with stairway to basement underneath, with combination grade door in rear. The living room covers the entire side of the house, with a large open fire place in the center of same.

On the seconil floor there are four large light and roomy chambers and good sized bath. Large closets. Also linen closet and stairway leading to good sized attic. Basement unler entire building, first story 9 feet, second story s feet. Red gum or oak finish through first story, pine to paint, in second story. This beautiful home can be huilt for $\$+, 500$. ('omplete set of plans and speeifications for this home for $\$ 3.5$.

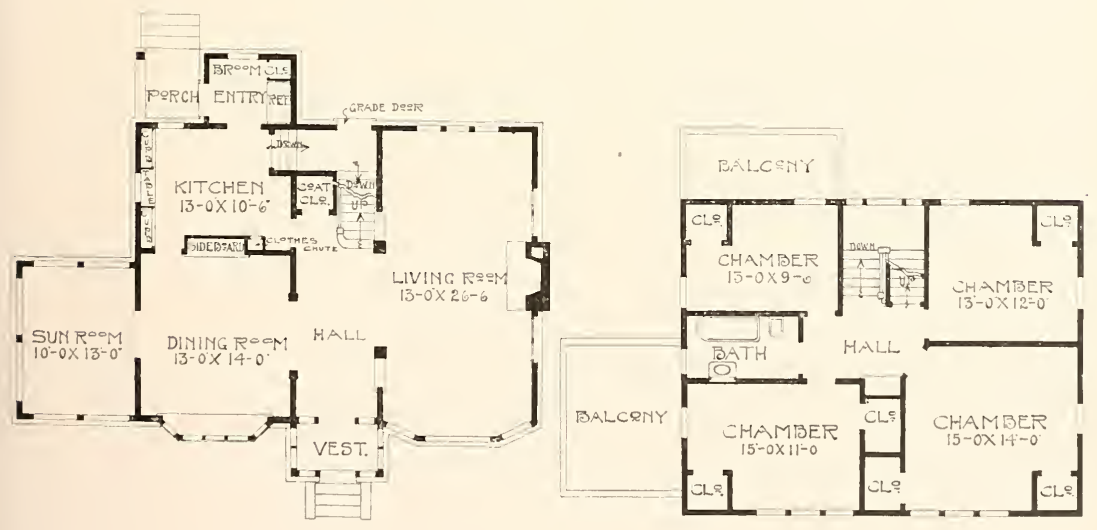

Complete plans and specifications for using Denison Load-Bearing Tile, licensed under Wilson-System Bearing il a 1.1 Construction for $\$ 70$. 


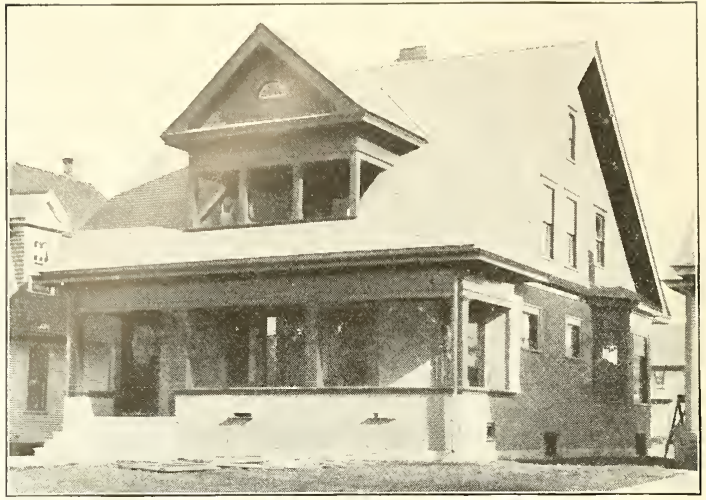

A Complete Cottage Home--No. 958

This makes a beautiful home, a splendid living room and built-in fire place, a combination stairway, also a grade door. In the dining room there is a built-in china closet and the sideboard making a beautiful view from the living room. In the second story we have three splendid chambers and closet space that is unexcelled. A full basement under the entire house, first story 9 feet, second story 8 feet, size 27 feet wide and 32 feet deep over the main part. Finish throughout first story, oak or gum; second story, pine to paint. Cost to build, $\$ 3,100$. Complete set of plans and specifications of this cottage for $\$ 20$.
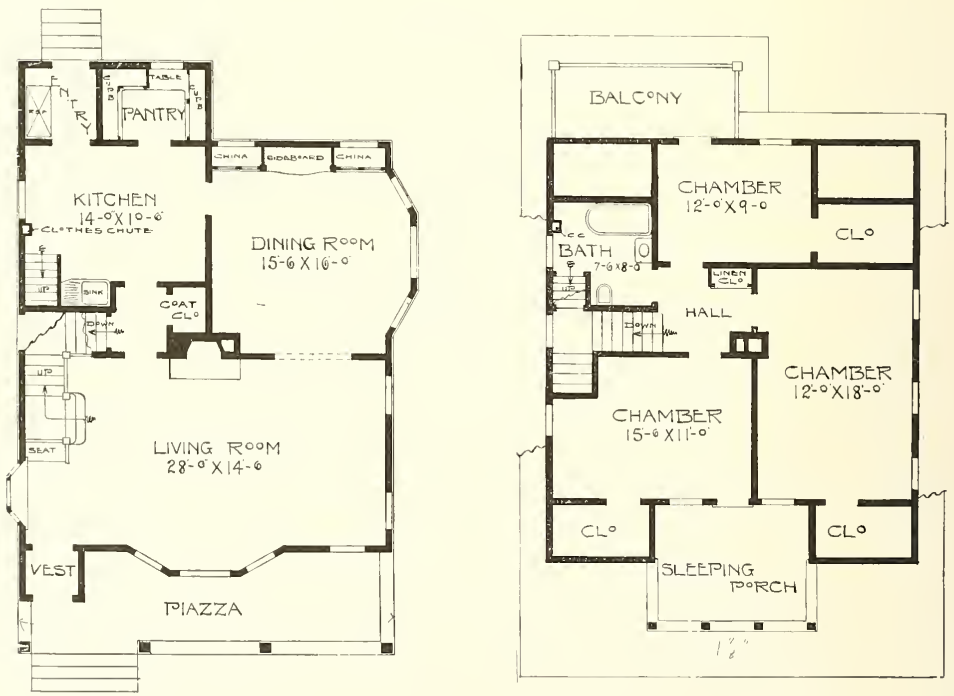

Complete plans and specifications for using Denison Load-Bearing Tile, licensed under Wilson-System Bearing $W$ a 11 Construction for $\$ 40$. 


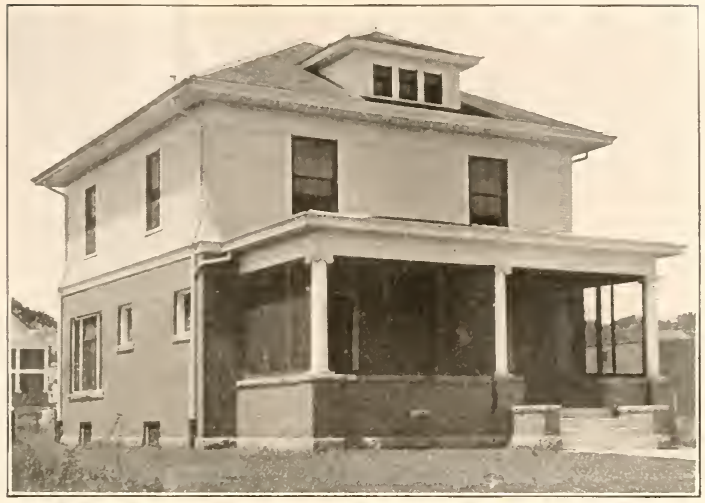

A Square Colonial Home-No. 949

A beautiful living room across the entire front, a combination stairway with grade door underneath, built-in sideboard, three splendid chambers in second story, and a bath that is the pride of any housewife, being unusually large, equipped with a bath, closet, merlicine eloset, etc. There is also abundance of closet space, full basement, first story 9 feet, second story o feet. Size $2 \mathrm{~s}$ feet by $2 \mathrm{~s}$ feet over the main part. Finish throughout first story, birch or gum; second story, pine to paint; oak or maple floors in first story and maple floors throughout the second story. The first story is briek veneered up to the belt course, with narrow siding above. $\$ 25$.

This plan will cost to build, $\$ 3,200$. Complete set of plans and specifications for
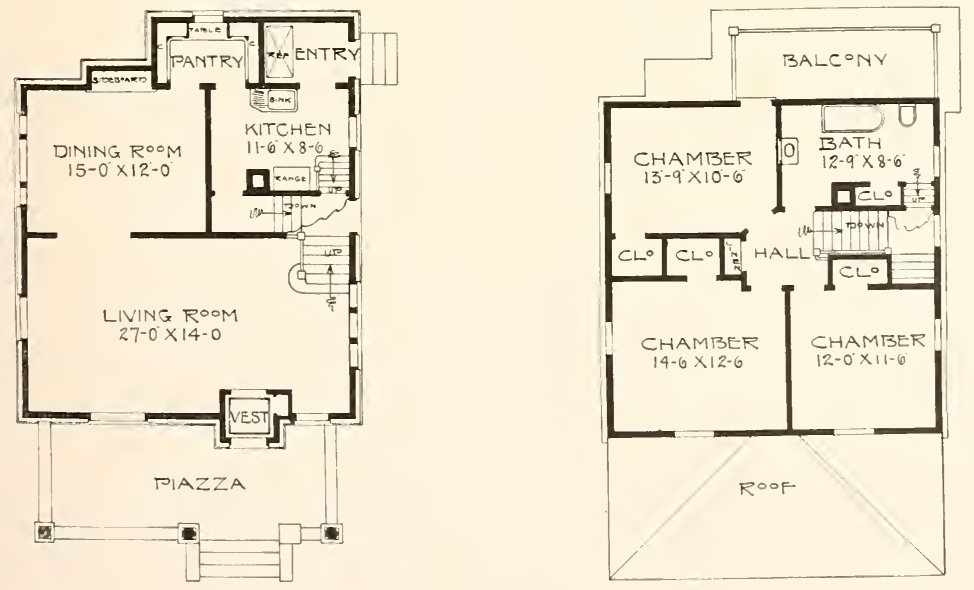

Complete plans and specifications for using Denison Load-Bearing Tile, licensed under Wilson-System Bearing IV a 11 Construction for $\$ 50$. 


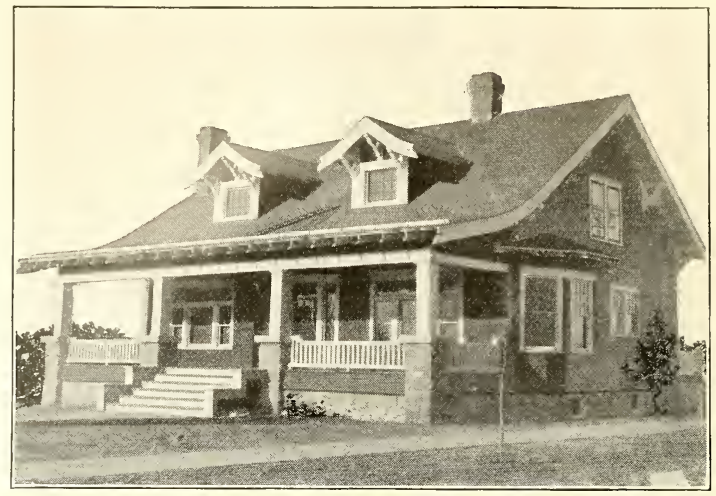

A Homelike Bungalow-No. 956

The bungalow would grace any of the avenues of California. The gable roof, rumning parallel with the street extends out over the hroad piazza, and is broken by two small dormers. The wide cornice is supported by heary sawed brackets. The exterior has a massive and substantial appearance and yet suggests comfort. Width 40 feet, depth 32 feet. Lumberman's home at Pierre, S. D.

The arrangement of the room is homelike. The large open fire-place suggests a hearty welcome to the visitor. The kitchen is not large, but makes up for lack of room in the many conveniences provided. The grade door and cellarway are at the rear. There are two bed rooms and a bath in the first story, with two large bedrooms in the second story. The living and dining rooms can be prettily finished in gum and the balance of the first story in natural birch, and the second story in white enamel pine. Birch floors are preferable. In all, this plan possesses a great deal of merit and excels in home comforts and conveniences. Cost to build, $\$ 3,500$. Complete set of plans and specifications for $\$ 25$.
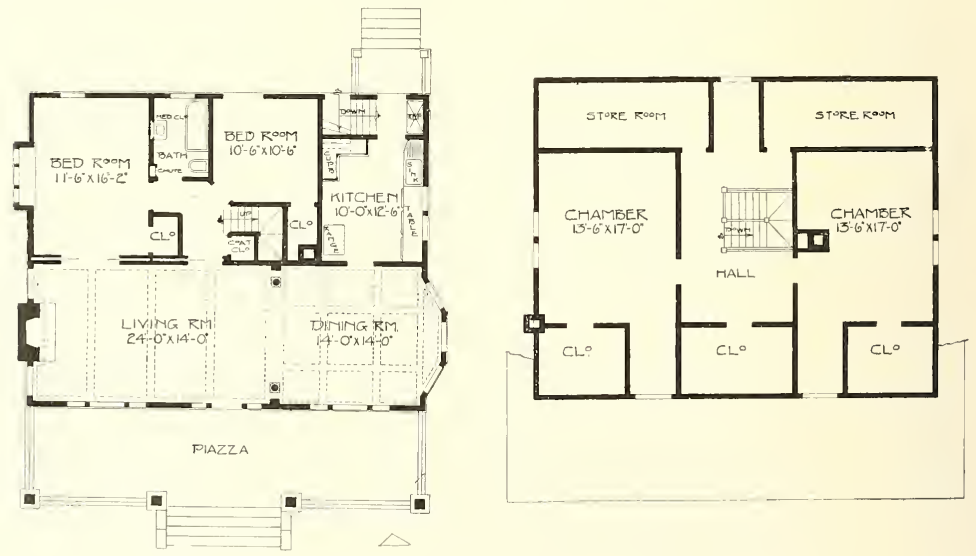

Complete plans and specifications for using Denison Load-Bearing Tile, licensed under Wilson-System Bearing Wal1 Construction for $\$ 50$. 


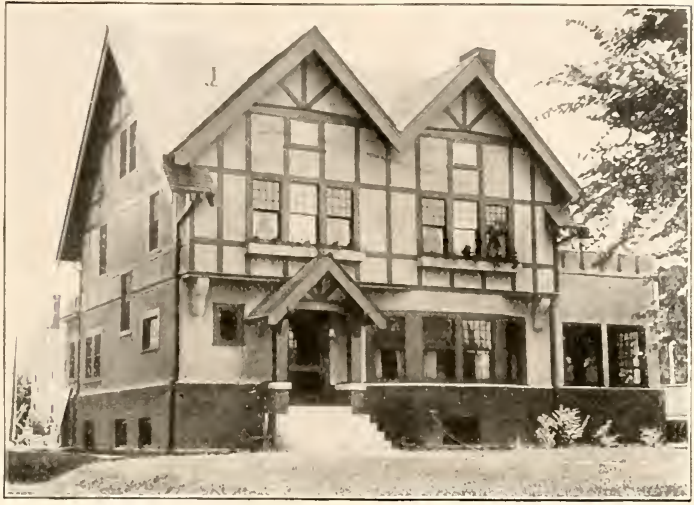

An English Half Timber Residence-No. 953

Any one can appreciate what a beautiful home this plan makes. The sun room is a special feature in this house and it could be built with a sleeping porch above if desired. The living room is unusually large and opening together with the sun room through French doors gives an unlimited amount of space to the first floor plan. The suu room makes a livable piazza the year around. There is a full basement, first story 9 feet, second story $\mathrm{S}$ feet. This house is finished in red oak throughout the first story, with gum wood or birch to enamel in the second story, oak floors, in first story and birch floors throughout second story. Size 32 feet wide and 30 feet deep over the main part. This house can be contracted for $\$ 5,400$. Complete set of plans and specifications for $\$ 35$.
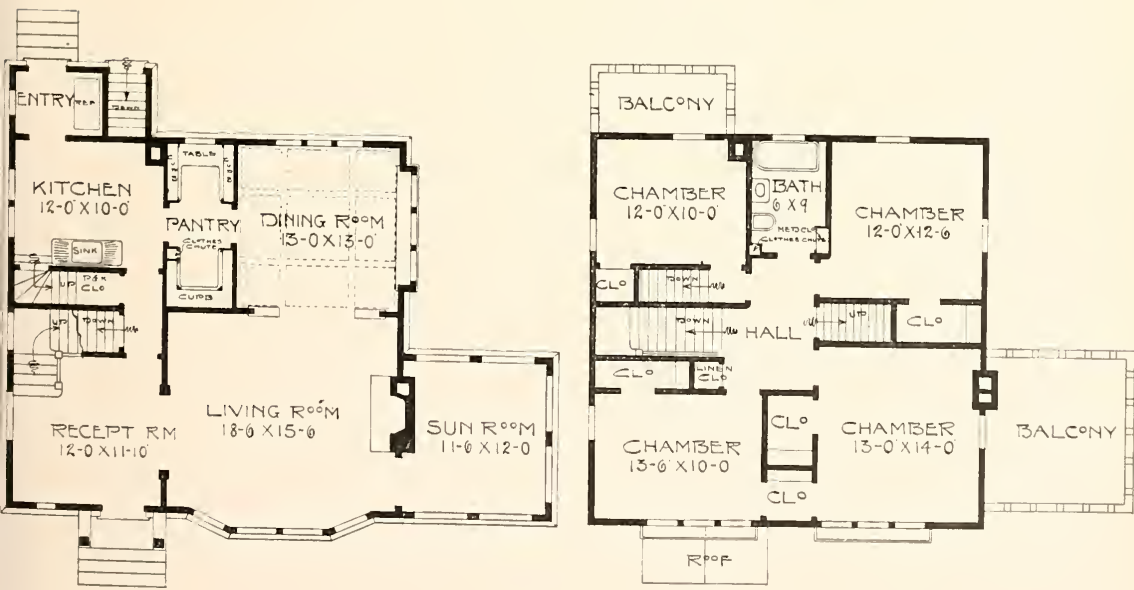

Complete plans and specifications for using Denison Load-Bearing Tile, licensed under Wilson-System Bearing IV a 11 Construction for $\$ 70$. 


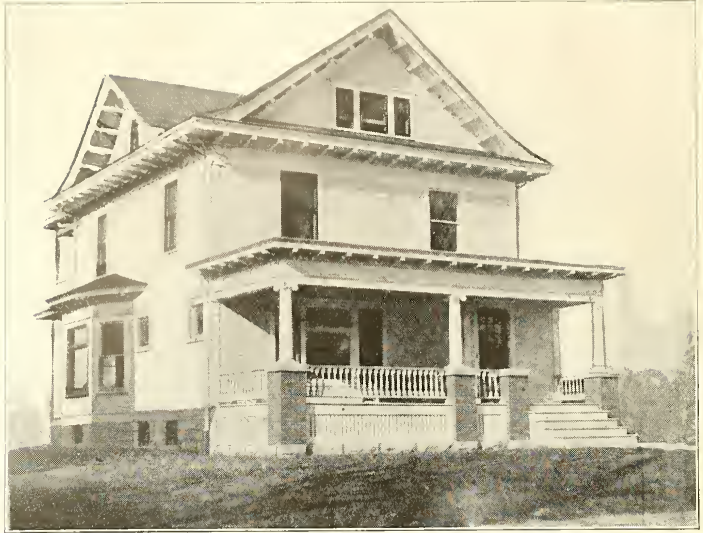

A Good Colonial Design-No. 957

This design has many attractive features: A 10 -foot piazza, a large living room across the entire front, combination stairway, a beautiful dining room, splendid closet space and a sleeping porch in the rear in the second story. Size over the main part is 26 feet wide and 28 feet deep, full basement, first story 9 feet, second story 8 feet. Floors throughout of birch or maple or red oak in first story and birch throughout second story. Finish in first story birch or gum wood throughout; second story, pine to paint. Cost to build, $\$ 3,200$. Complete set of plans and specifications of this colonial house for $\$ 25$.
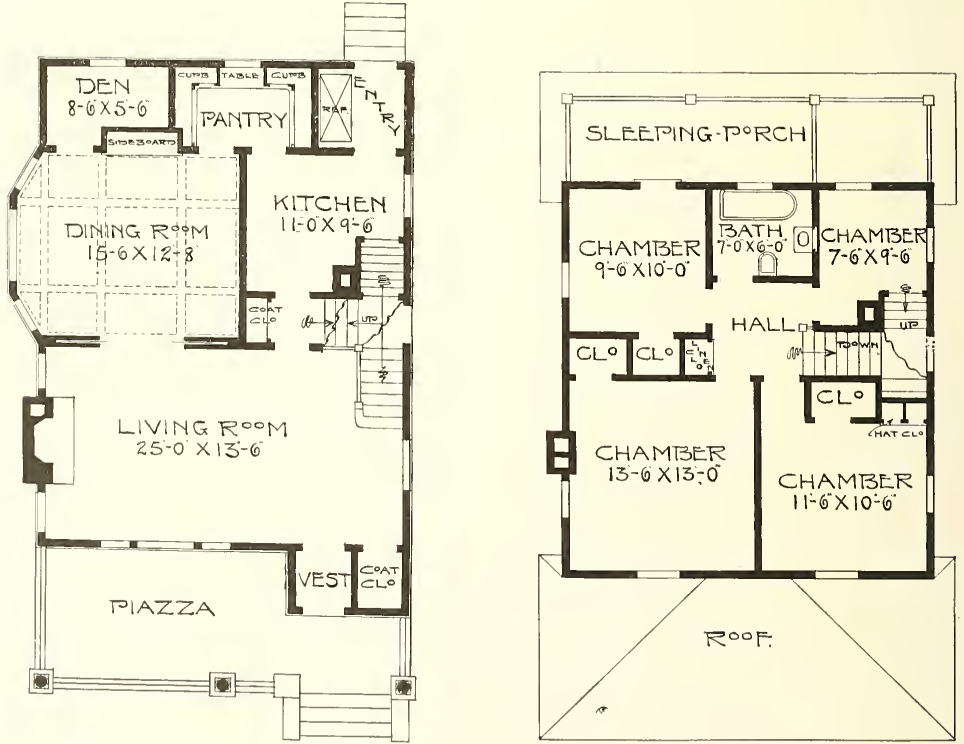

Complete plans and specifications for using Denison Load-Bearing Tile, licensed under Wilson-System Bearing $W$ a 11 Construction for $\$ 50$. 


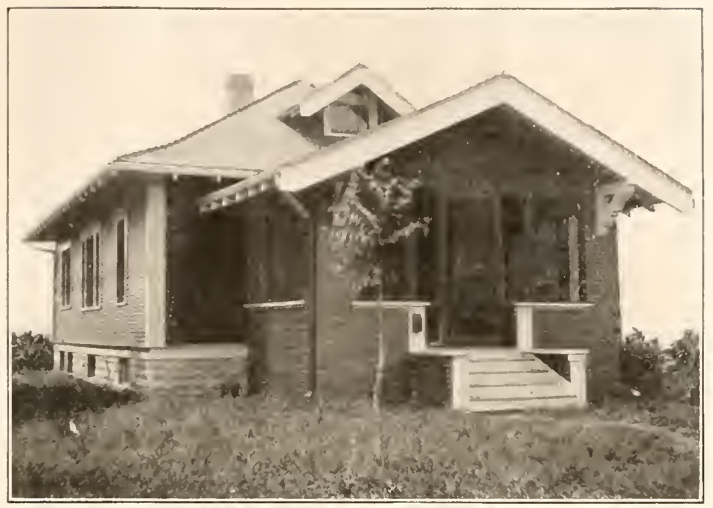

A Modest Bungalow-No. 955

This design and its floor plan are exceedingly interesting and will bear considerable study.

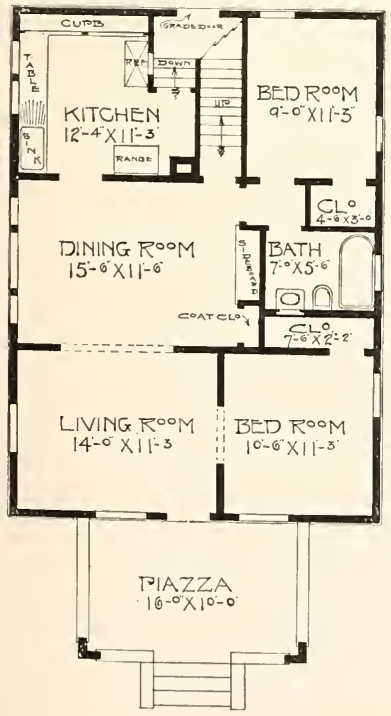

The living room, dining room and kitchen are conveniently arranged on one side of the house and the two bed rooms, with closets and bath between, on the opposite side, making a house that can be taken care of with the least amount of labor.

The dining room has a built-in sideboard and a coat closet. The kitchen makes up what it lacks in size in its practical arrangement and the many conveniences offered: The range and sink and nearness to the dining room and the drain board and moulding table under the windows. The refrigerator is so located that it is easily accessible from the dining room and yet can he iced without having the ife man enter the kitehen. There is a combination cellar stairway and outside entrance.

A full basement unter the entire house is seven feet high and the first story is nine feet. The floors throughout are of birch and the finish either gum wood or oak. Cost to build for $\$ 1,900$. Complete set of plans and specifications for $\$ 16$.

Complete plans and specifications for using Denison Load-Bearing Tile, licensed under IVilson-System Bearing $\mid V$ a 11 Construction for $\$ 32$. 


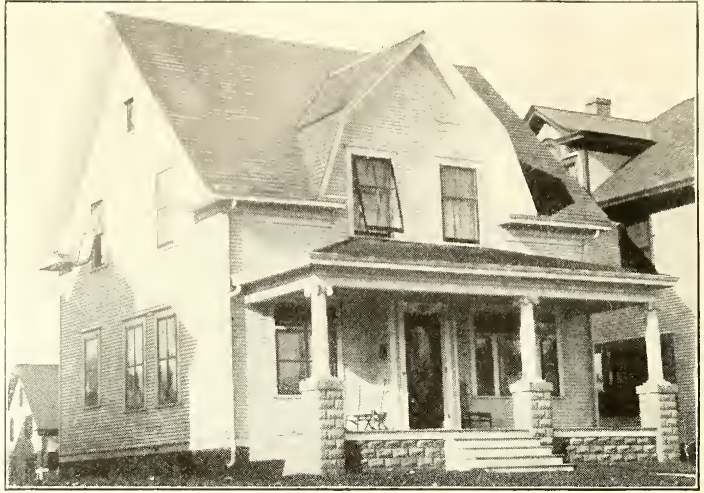

A Gambrel Roof Cottage-No. 962

This design makes a splendid city or country house. The living room and dining room are opened together by high perlestal opening, the dining room has a projecting bay window and a very pretty built-in sideboard; pantry between the kitchen and dining room. The refrigerator is located so that the ice can be put in from the rear porch without coming into the house. In this cottage we have a very pretty stairway paneled up with pedestal and square columns. Back of the living room is a small room that can be utilized for a den, sewing room, or can be used as a chamber if desired. The second story has three fine chambers, nice closet space, a big bath, and linen closet; there is also a balcony over the rear one-story part. This house has a full basement, first story 9 feet, second story 8 feet. Size 24 feet wide and 26 feet deep over the main part. Hardwood floors throughout, gum woor or oak finish or Washington fir in the first floor, pine to paint, in the second story.

Cost to build, $\$ 2,150$. Complete set of plans and specifications of this cottage for $\$ 18$.
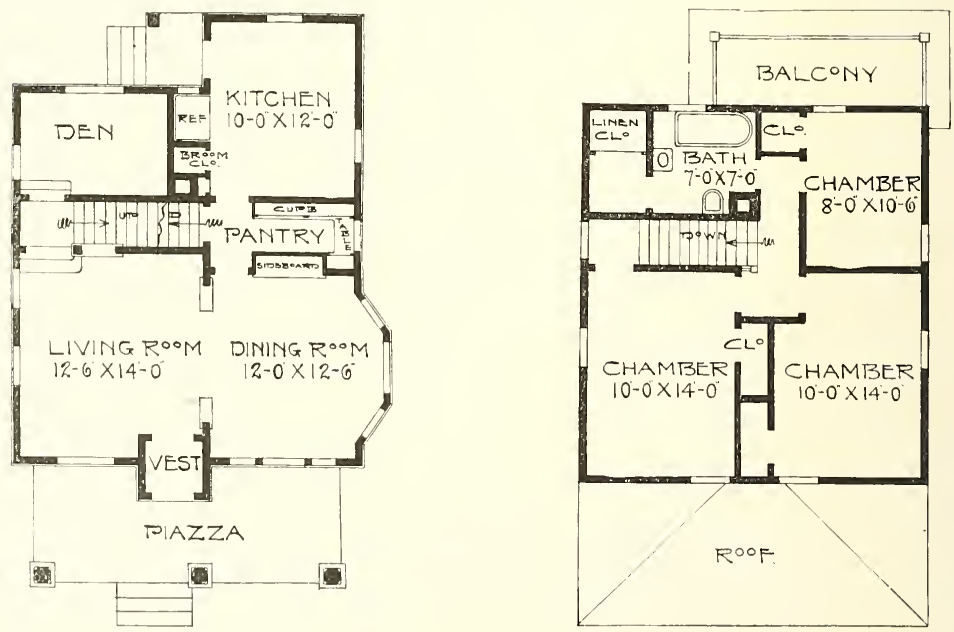

Complete plans and specifications for using Denison Load-Bearing Tile, licensed under IVilson-System Bearing IV a 11 Construction for $\$ 36$. 


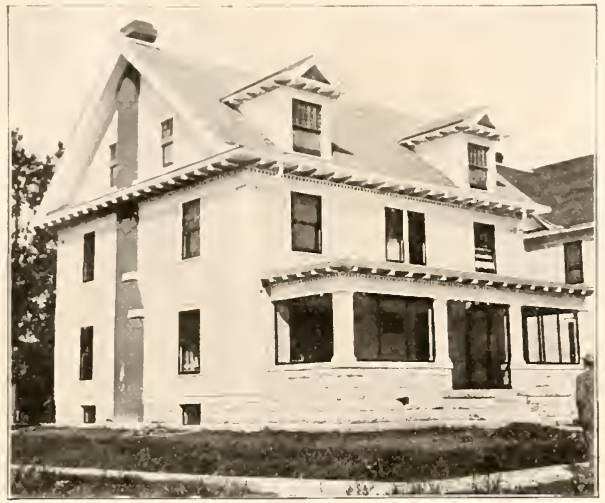

A Complete Colonial Home-No. 960

This is one of my most practical and complete colonial homes, well arlapted to a goorl sizerl family, either for a city or suburban or country home. The size of the house is :36 feet wide by 34 teet deep. In the secomb story there are five well-arranged and gool sized chambers, all of which have good closet space. There are two selarate stairways leading to the second story, one from the rear entry, and the beautitul open stairway lealling from the hall from the center of the house. The first story is finisherl in gum woor or red oak throughout, second story is finished in pine, enameled any color that owner desires, with gum or birch doors or pine doors stained and varnished to represent mahogany, earrying out the old New England Colonial idea for the treatment of the same. There is a full basement uncler the entire house, the floor of the piazza is marle of reinfored conerete; first story is 9 feet, second story is s feet.

Cost to build, $\$ 5,200$. Complete set of plans and sperifications of this residence for +30 .
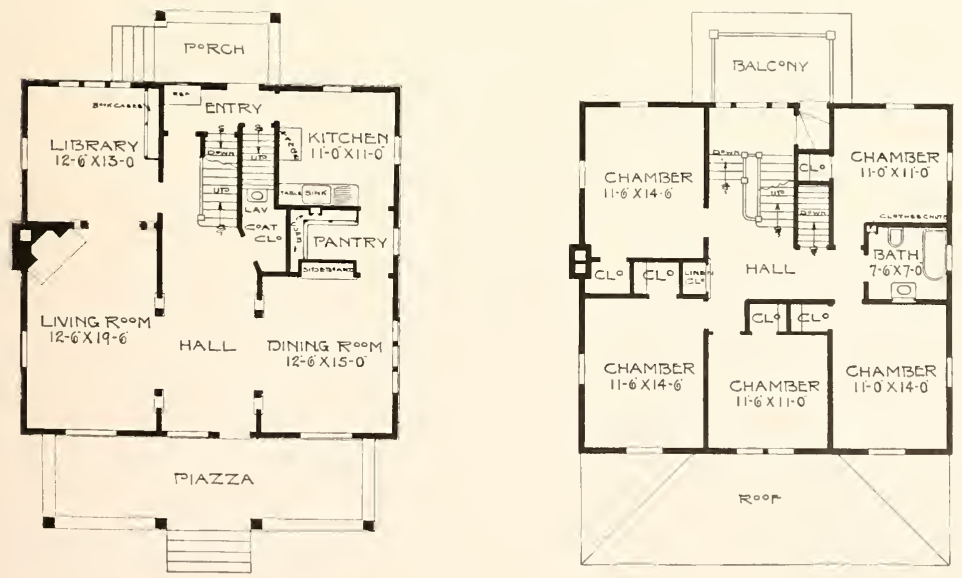

Complete plans and specifications for using Denison Load-Bearing Tile, licensed under Wilson-System Bearing 11 a 11 construction for $\$ 60$. 


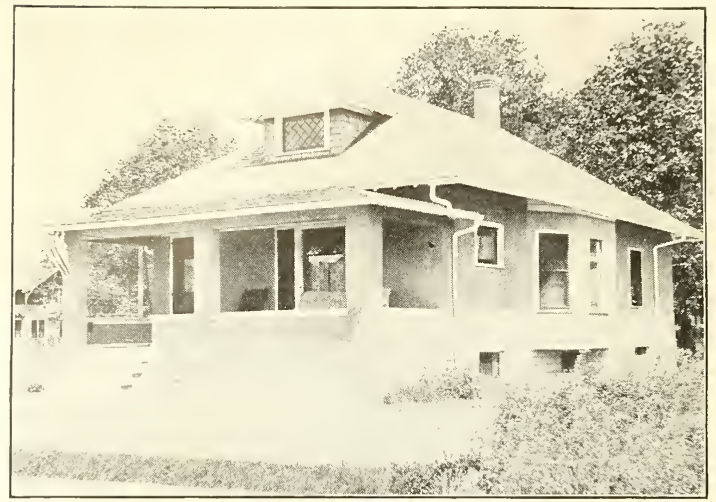

A Rough-Cast Bungalow-No. 951

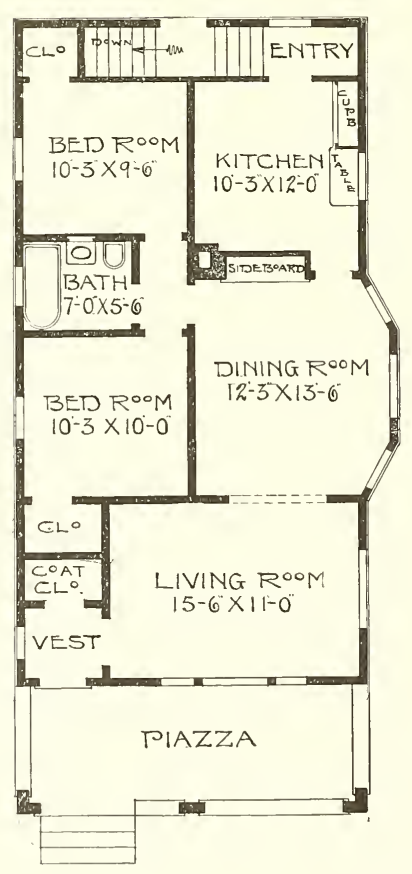

People who have lived in flat buildings will appreciate the convenience of this plan of having all the rooms on one floor. This plan has been built a number of times and has proven a very popular home, being well arranged and economical to build, full basement under entire house, first story feet. There could be one room finished in the attic by putting in a stairway from the closet in the rear of the back bed room running up over the stairs going to the basement. Finished throughout in red oak or gum wood with maple floors. Size 22 feet by 42 feet. This little bungalow ean be built for $\$ 2,050$. Complete set of plans and specifications for $\$ 15$.

Complete plans and specifications for using Denison Load-Bearing Tile, licensed under Wilson-System Bearing $\mathrm{W}$ a 11 Construction for $\$ 30$. 
Just a Substantial Colonial Residence-No. 963

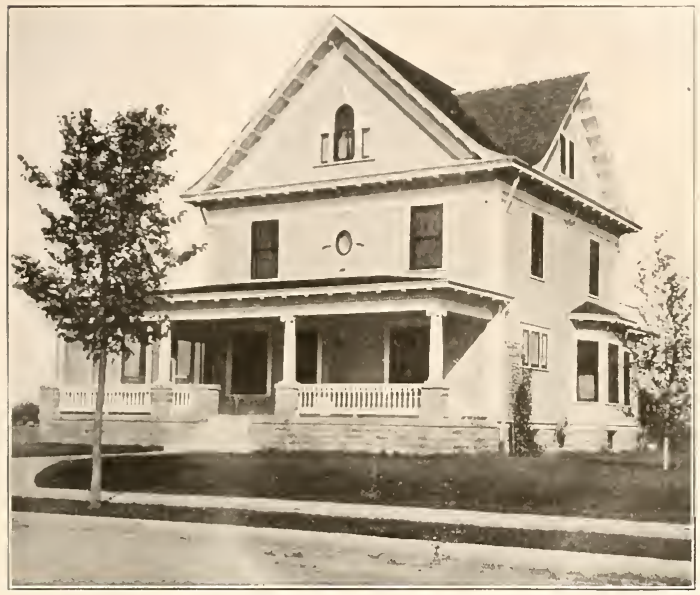

In this house the living room and par. lor are dirided witl: a wille colummet opening. If desirerl. this space call all the marle into ous large living-roon ant the restibule ran lie left out entirely or ran be built on the piazza, thus learing the living room with regular lines inside. This house has a grant piazza covering the entire front and part of one sicle, which is 10 feet wide, and if resired a sleeping porch or sun room can be built across the entire rear over the one. story part. The seeond story has four gooil chambers and an unlimiter amount of closet space, large bath, and a very jretty hall. A full basement. The finish in first story is planned for oak or gum wood, throughout, with oak floors; second story, pine, to paint, or Washington fir. First story is 9 feet high, second story, 8 feet; and there is also splendid space in the attic. One could finish 2 rooms in same if lesired. The size of the house is 26 feet by 30 feet.

Cost to build, $\$+100$. Complete set of plans and specifications of this residence for $\$ 30$.
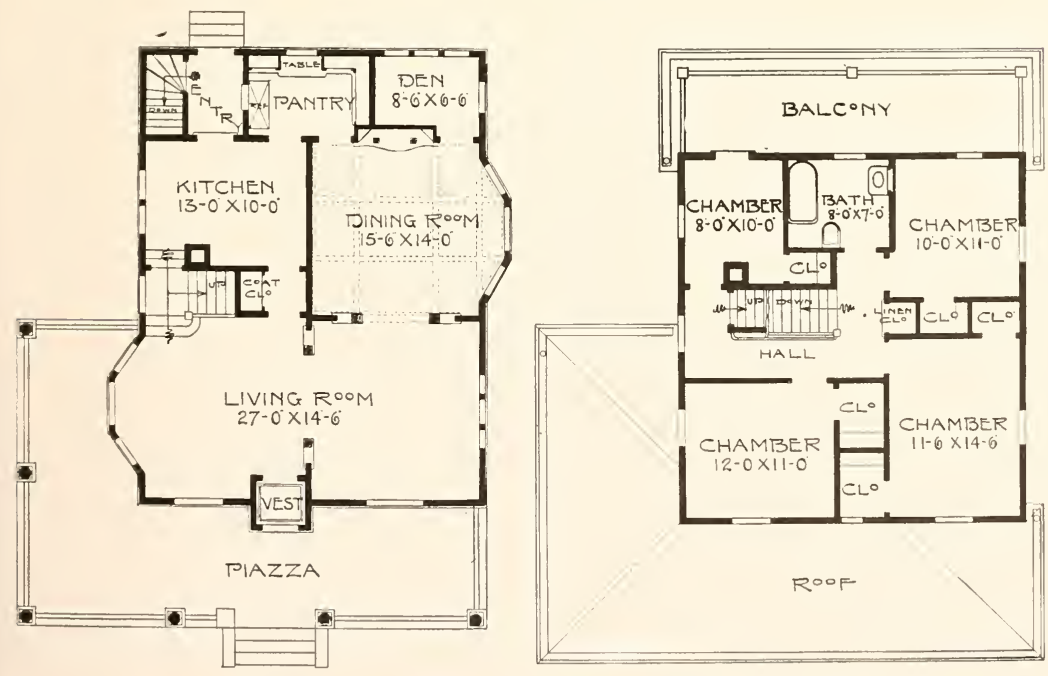

Complete plans and specifications for using Denison Load-Bearing Tile, licensed under Wilson-System Bearing IV a 11 Construction for $\$ 60$. 

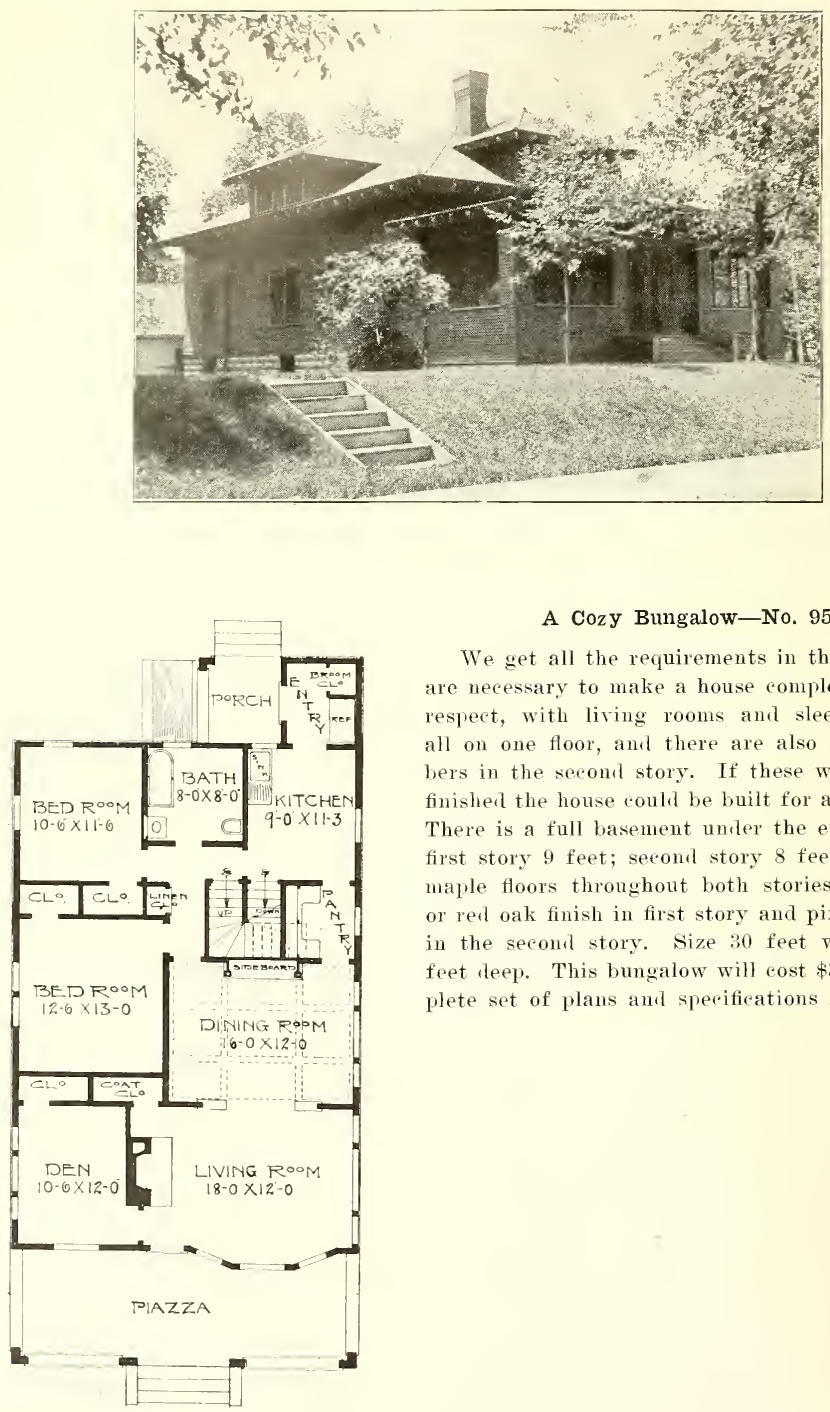

A Cozy Bungalow-No. 954

We get all the requirements in this plan that are necessary to make a house complete in every respect, with living rooms and sleeping rooms all on one floor, and there are also three chambers in the second story. If these were left unfinisher the house could be built for about $\$ 3,200$. There is a full basement under the entire house; first story 9 feet; second story 8 feet. Birch or maple floors throughout both stories, with gum or red oak finish in first story and pine, to paint, in the second story. Size 30 feet wide and 44 feet leep. This bungalow will cost $\$ 3,500$. Complete set of plans and specifications for $\$ 25$.

Complete plans and specifications for using Denison Load-Bearing Tile, licensed under Wilson-System Bearing W a 11 Construction for $\$ 50$. 


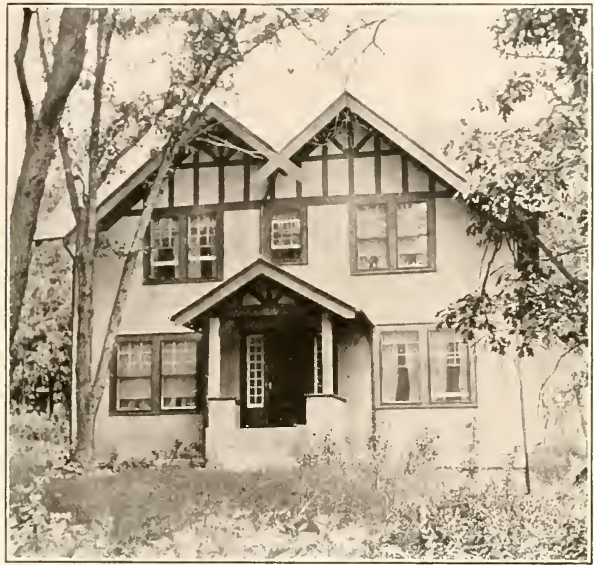

A Rough-Cast Residence-No. 952

Here we have a house that has many attractive features. The loouse is entered through a central hall, with open stairway leading to second story; the living room on one sirle and dining-room on opposite side. The living-room is unusually large with large screened-in piazza in rear of same, which can be sashed in and used for a sun roon in the wister time if desired. The piazza can be built at the side of livingroom if dwired by awlier. There are three goorl chambers in the second story besides the sleeping forch. A full hasement, first story 9 feet, second story 8 feet. Finisherl in red oak or gum in first story; pine, to paint, in second story, and hardwood floors throughout. size 33 feet wide and 22 feet deep over the main part.

This artistie residence can be built for $\$ 3,000$. Complete set of plans and specifications for $\$ 20$.
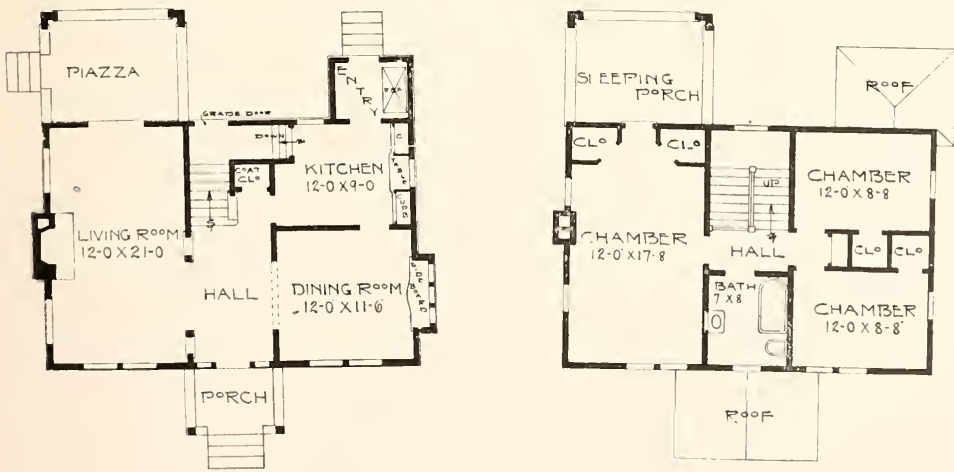

Complete plans and specifications for using Denison Load-Bearing Tile, licensed under Wilson-System Bearing $\mid V$ a 11 Construction for $\$ 40$. 


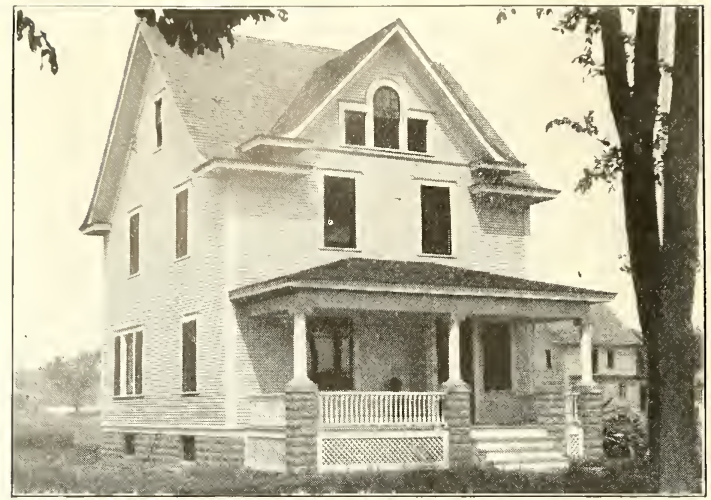

A Good Home With 16 Feet Studding-No. 961

One of these big living rooms across the entire front, opening up with the dining room by pedestal archway, with built-in cupboards in each one, which can have leater glass in panels, thus making book cases on each side-opening in the living room. We have a combination stairway with grade door under the same. This house contains all of the features that are desired by the housewife-broom closet in the entry, refrigerator trapped into laundry in basement, ete. In the second story there are three large chambers, good closets, linen closets and an unusually large bath room, with sleeping porch in the rear. The size of this louse is 24 feet by 26 feet, full basement, first story 9 feet, second story 8 feet. Birch or maple floors throughout. Bireh or gum; secoud story, pine, to paint.

Cost to build, $\$ 2,250$. Complete set of plans and specifications of this cottage for $\$ 18$.
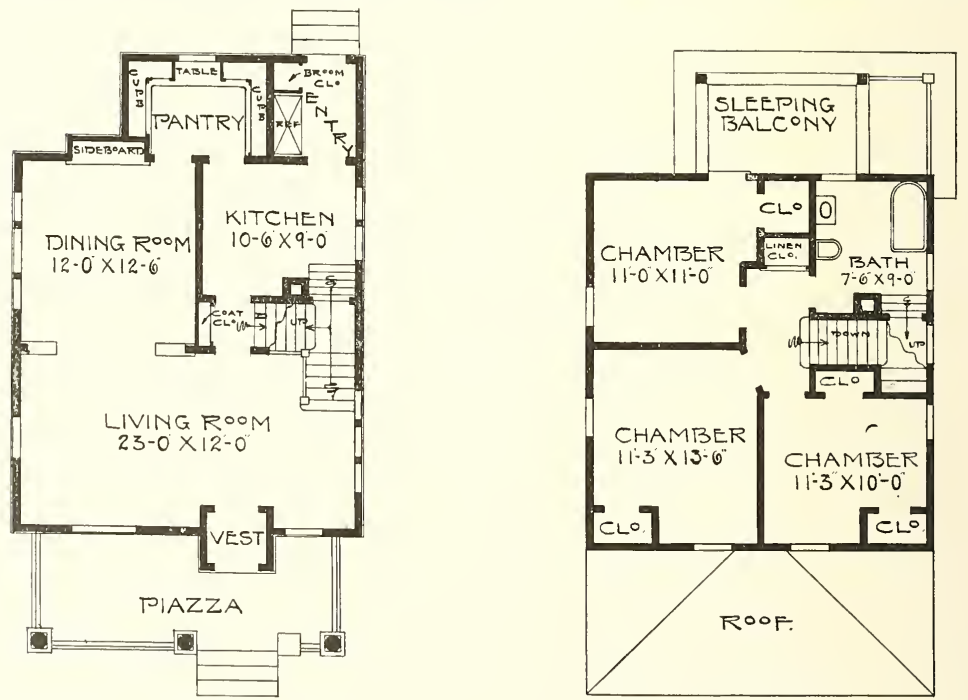

Complete plans and specifications for using Denison Load-Bearing Tile, licensed under Wilson-System Bearing Wall Construction for $\$ 36$. 


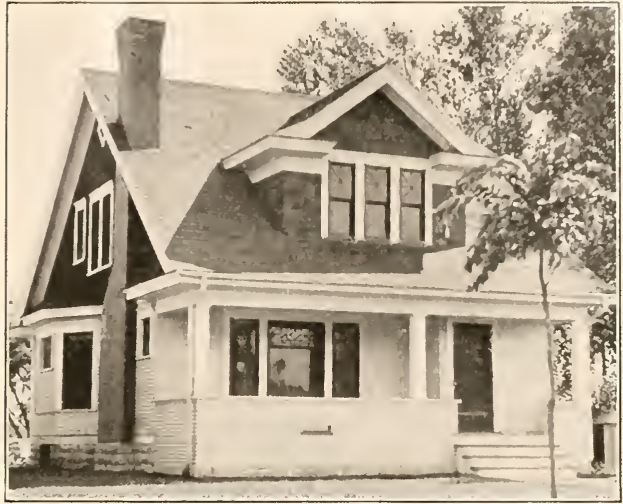

Just a Cottage Home-No. 950

There is a beautiful living room across the entire front with spacious diniug room in rear of same, a small den or sewing room in rear opening into the dining room. A combination stairway with grade door uuderneath. Three good chambers in second story and abundance of closet space, large bath room, linen closet aud a sleepiug porch connecting with the rear chamber, full basemeut, first story 9 feet, second story 8 feet, all the chambers iu second story fiuished full height. Birch or maple floors throughout with red oak or gum in first story and pine to paint in seeond story. Size 26 feet by 28 feet over main part. This interesting cottage can be built for $\$ 2,850$, and includes the beamed ceiling in living room and dining room and panel wainscotting. Complete set of plans aud specifications for $\$ 18$.
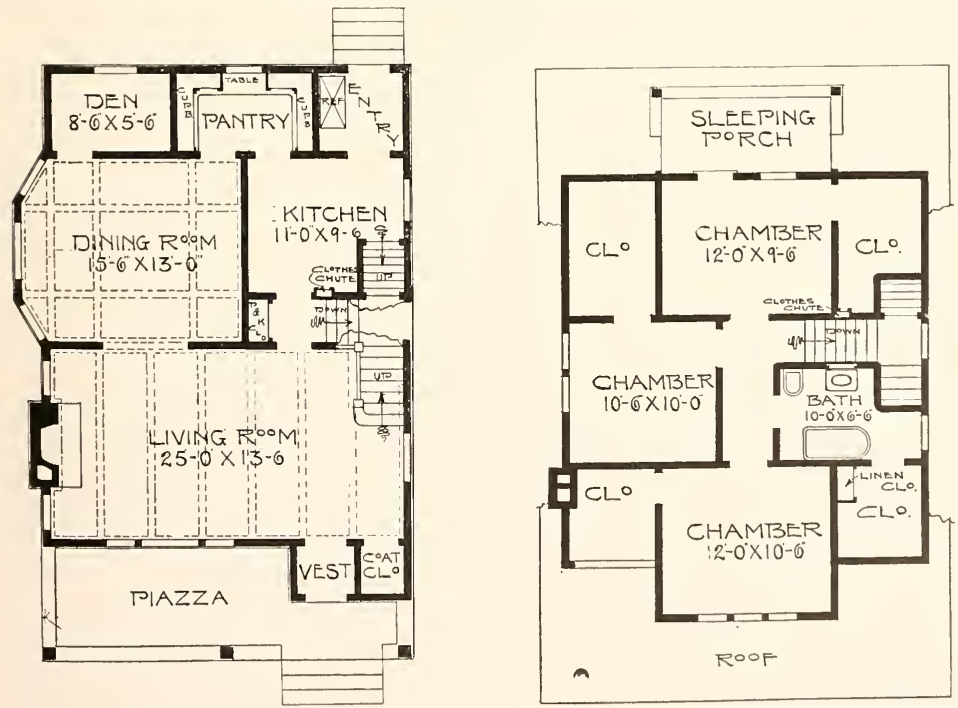

Complete plans and specifications for using Denison Load-Bearing Tile, licensed under Wilson-System Bearing IV a 11 Construction for $\$ 36$. 


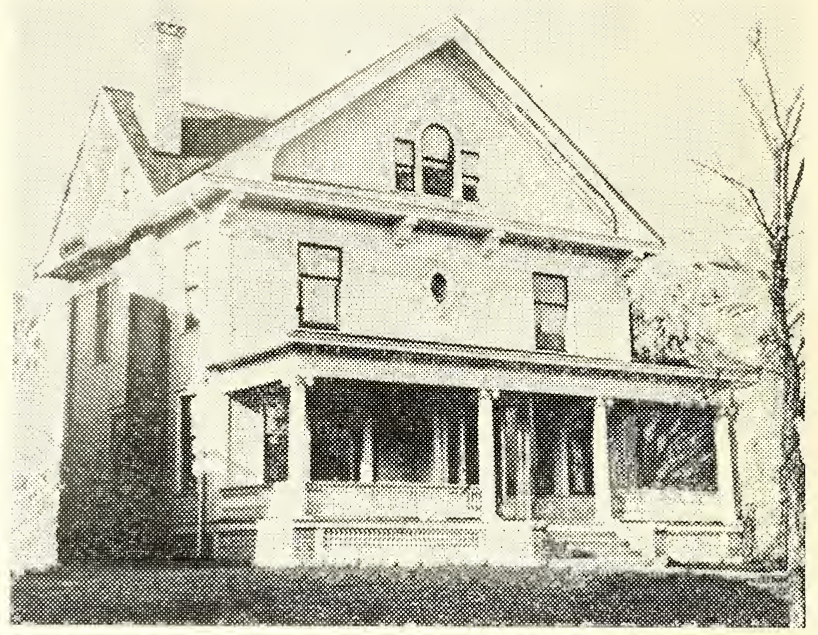

A Modern Colonial Residence-No. 822

Full basement, first story 9 feet 6 inches, second story 9 feet. Size of house is 32 feet wide and 27 feet 6 inches deep over the main part. First story finished in birch or gum throughout, second story pine to paint, birch or maple floors in both stories. Cost to build, $\$ 4,250$. Complete set of plans and specifications for $\$ 30$.
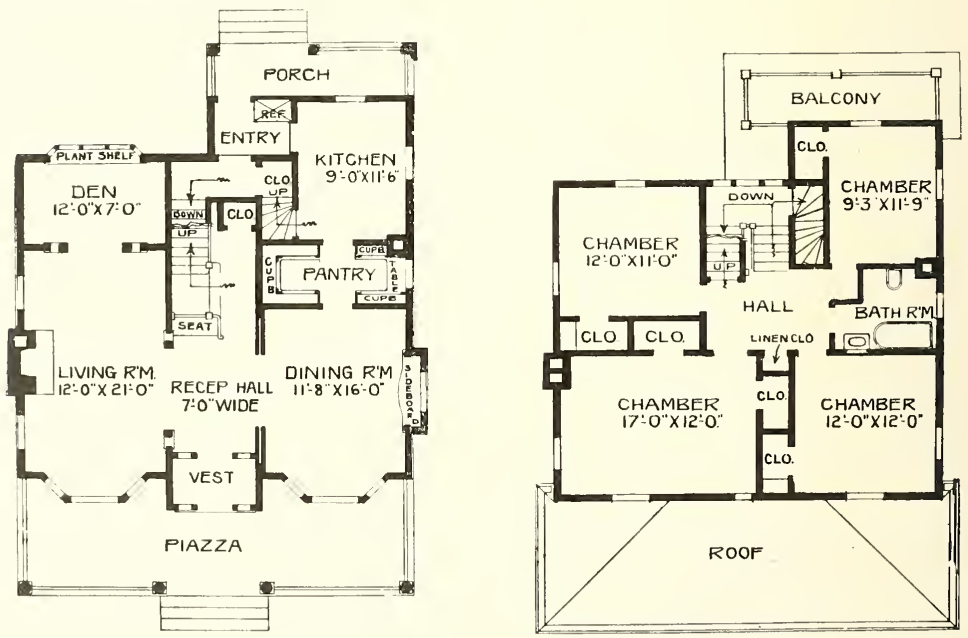

Complete plans and specifications for using Denison Load-Bearing Tile, jicensed under Wilson-System Bearing W a 11 Construction for $\$ 60$. 

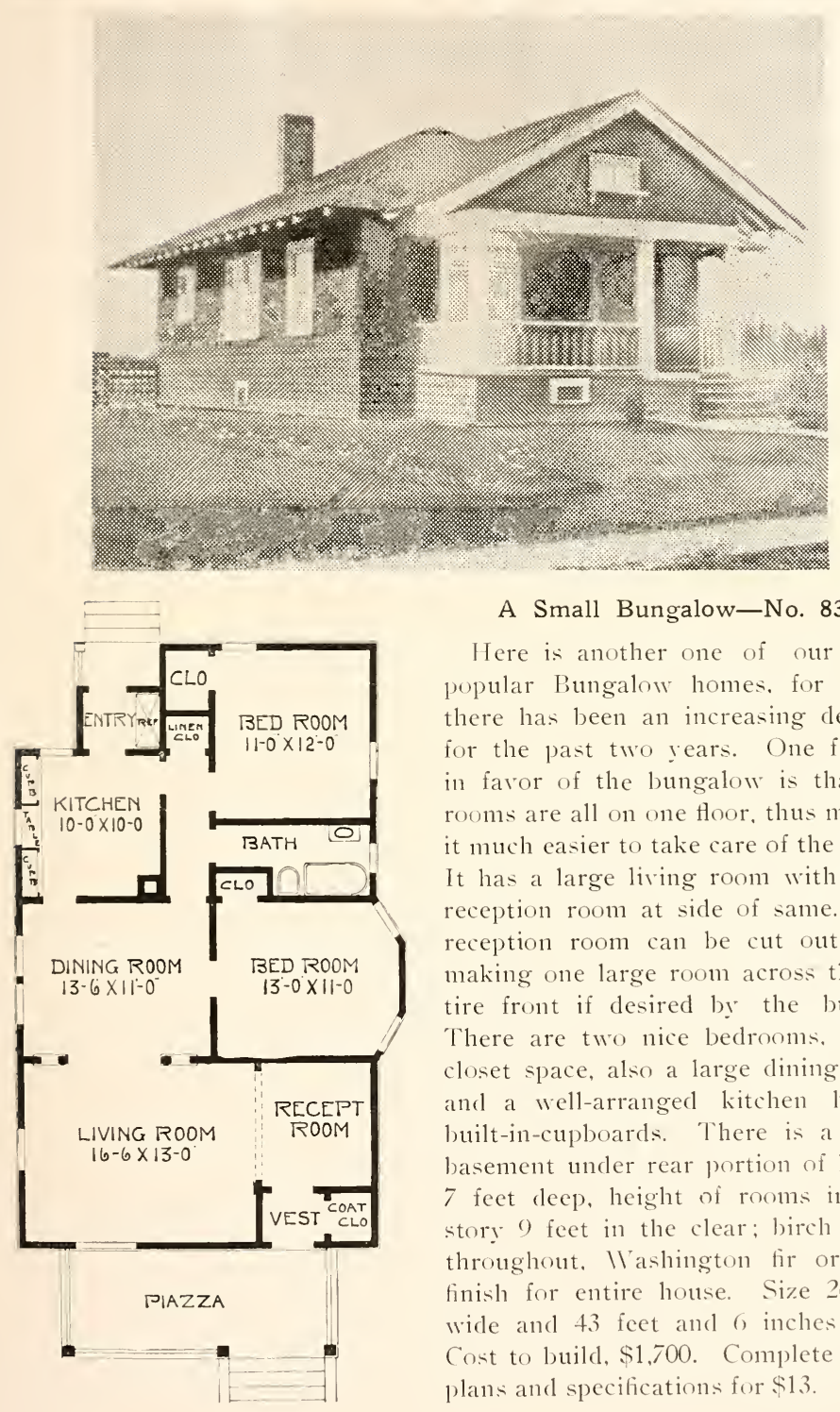

A Small Bungalow-No. 836

Here is another one of our very popular Bungalow homes, for which there has been an increasing demand for the past two years. One feature in faror of the bungalow is that the rooms are all on one floor, thus making it much easier to take care of the home. It has a large living room with small reception room at side of same. The reception room can be cut out, thus making one large room across the entire front if desired by the builder. There are two nice bedrooms. ample closet space, also a large dining room and a well-arranged kitchen having built-in-cupboards. There is a small basement under rear portion of house. 7 feet deep, height of rooms in first story 9 feet in the clear; birch floors throughout. Washington fir or gum finish for entire house. Size 26 feet wide and 43 feet and 6 inches deep. Cost to build, $\$ 1,700$. Complete set of plans and specifications for $\$ 13$.

Complete plans and specifications for using Denison Load-Bearing Tile, licensed under Wilson-System Bearing IV a 11 Construction for $\$ 26$. 


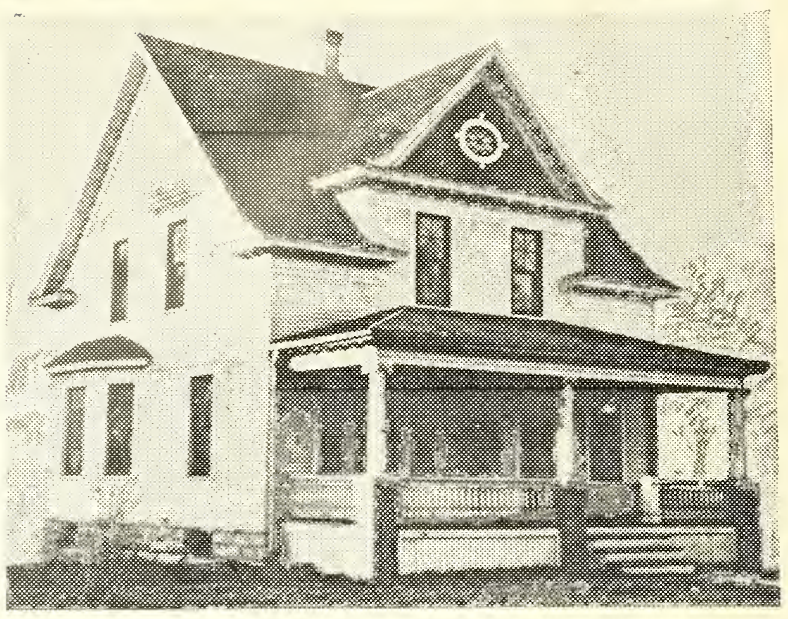

A Comfortable Cottage Home-No. 821

The size of this cottage is 24 feet by 26 feet, with full basement. First story 9 feet and second story $\&$ feet. Birch floors throughout; birch or gum finish throughout first story and pine to paint in second story. If one desires the cottage could be built 26 to 28 feet, keeping the rooms in the same proportions for about $\$ 350$ additional to the present cost. Cost to build, $\$ 2,200$. Complete set of plans and specifications for $\$ 15$.
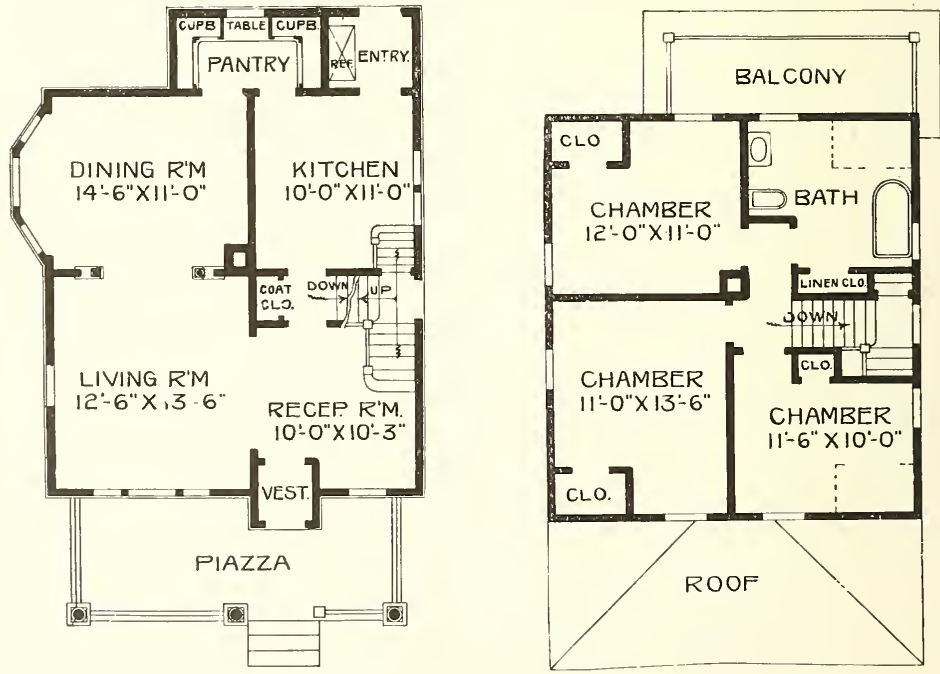

Complete plans and specifications for using Denison Load-Bearing Tile, licensed under Wilson-System Bearing Wall Construction for $\$ 30$. 

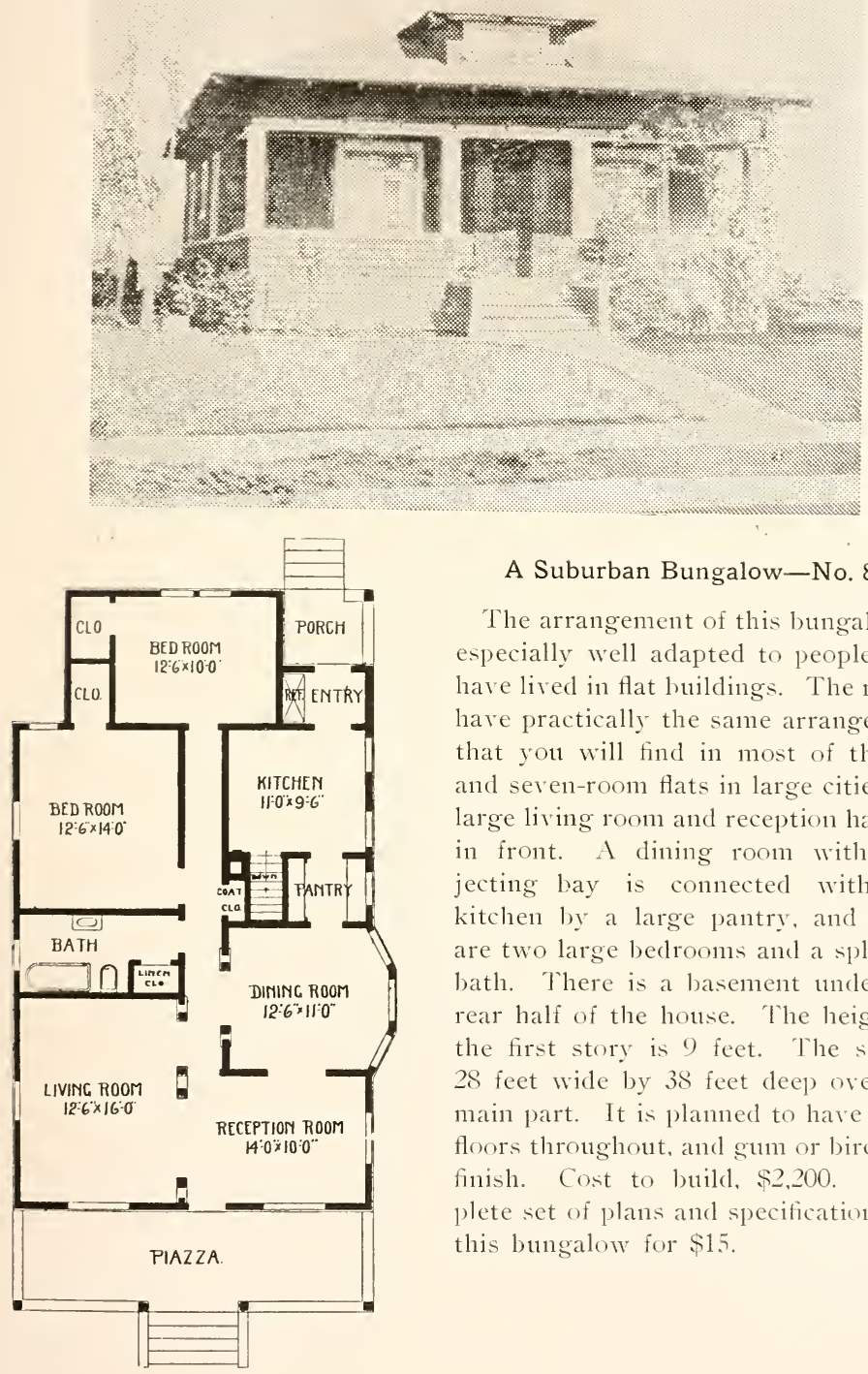

A Suburban Bungalow-No. 824

The arrangement of this bungalow is especially well adapted to people who have lived in flat buildings. The rooms have practically the same arrangement that you will find in most of the six and seven-room flats in large cities. A large living room and reception hall are in front. A dining room with projecting bay is connected with the kitchen by a large pantry, and there are two large bedrooms and a splendid bath. There is a basement under the rear half of the house. The height of the first story is 9 feet. The size is 28 feet wide by 38 feet deep over the main part. It is planned to have birch floors throughout, and gum or birch for finish. Cost to build, $\$ 2,200$. Complete set of plans and specifications for this bungalow for $\$ 15$.

Complete plans and specifications for using Denison Load-Bearing Tilc, licensed under Wilson-System Bearing IV a 11 Construction for $\$ 30$. 


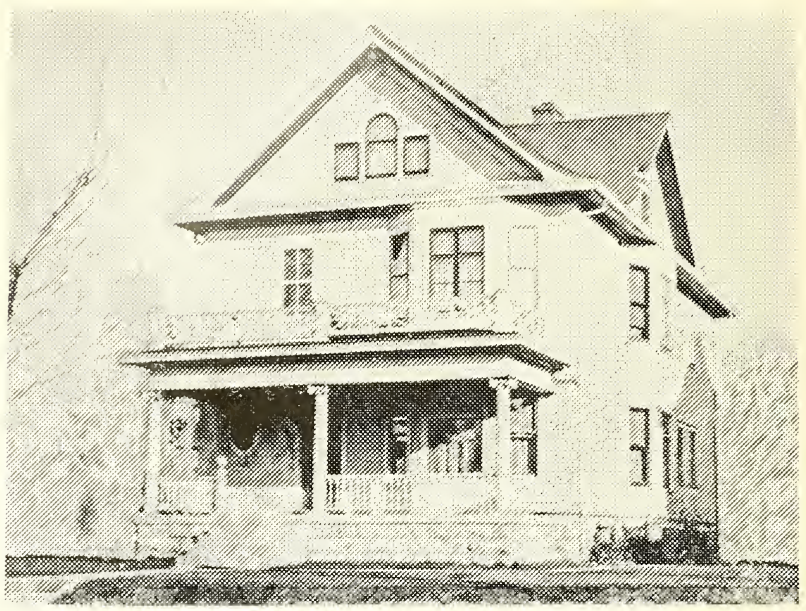

A Compact Duplex-No. 823

Anyone who is interested in building a duplex cannot fail to be interested in this plan. This has the one unusual feature in a duplex of this size, that is, three bedrooms in each flat. As a general rule there are only two, but this gives us three good-sized and well arranged bedrooms. Large living room and dining room. Dining room has built-in sideboard. The size is 26 feet wide and 50 feet deep : each story 9 feet, basement 7 feet 6 inches. Finished with birch floors and gum or birch trim. A duplex of this character is one of the best paying investments that can be had in the way of a building.

Cost to build, $\$ 5,000$. One complete set of plans and specifications for $\$ 30$. 

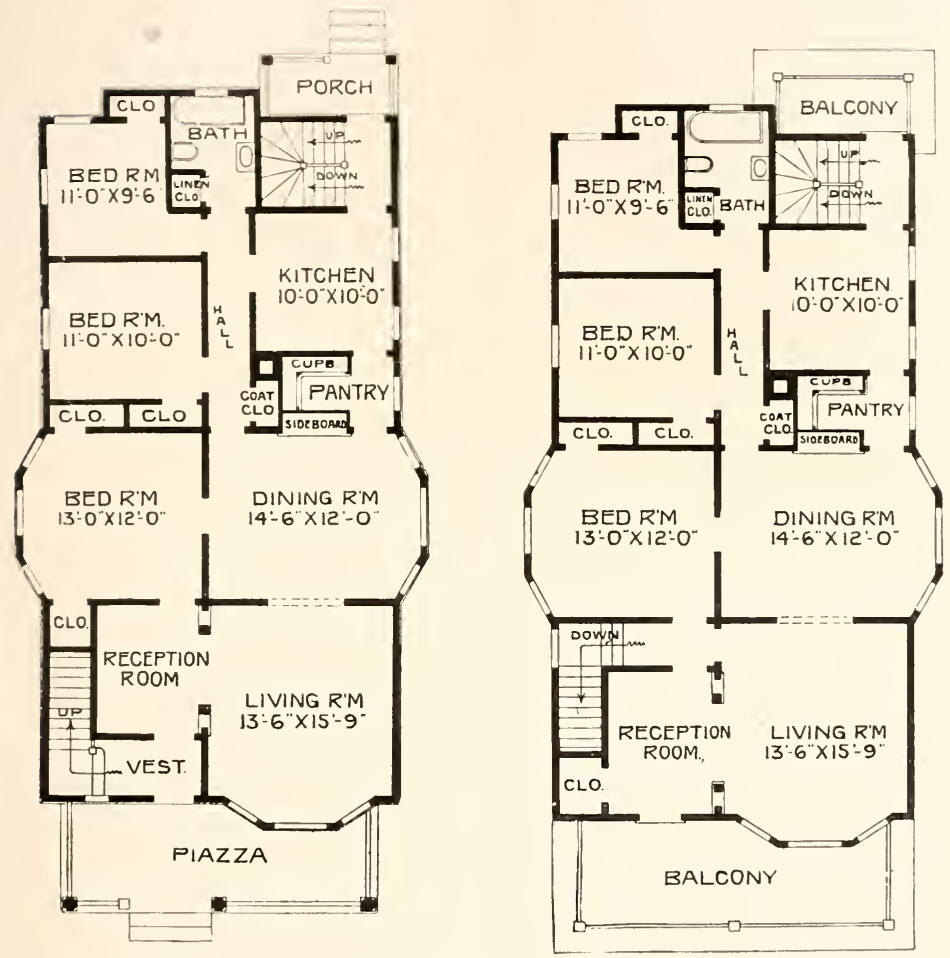

Complete plans and specifications for using Denison Load-Bearing Tile, licensed under Wilson-System Bearing II a 11 Construction for $\$ 60$. 


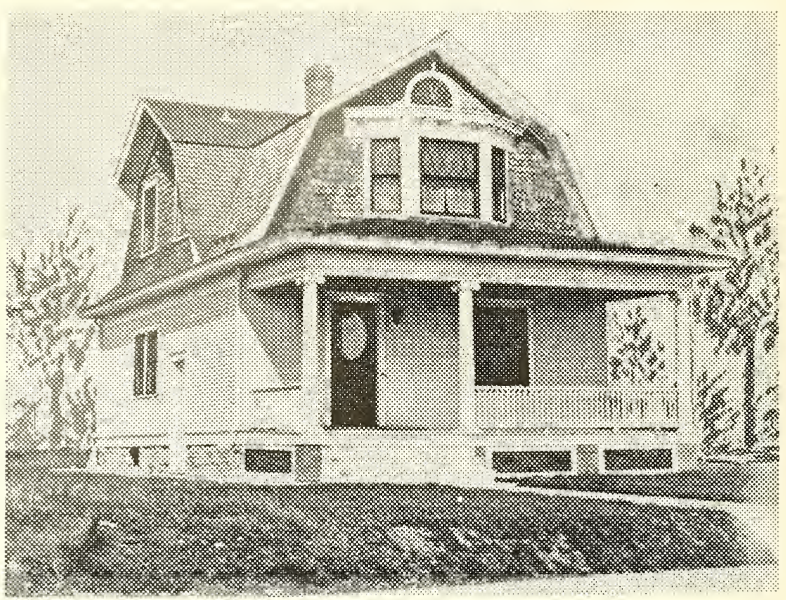

A Good Cottage Home-No. 835

Size, 24 feet wide by 30 feet deep; basement under entire house; first story 9 feet, second story 8 feet. Birch floors throughout; first story finished in gum or birch, second story in pine to paint. Cost to build, $\$ 2,050$. Complete set of plans and specifications for $\$ 16$.
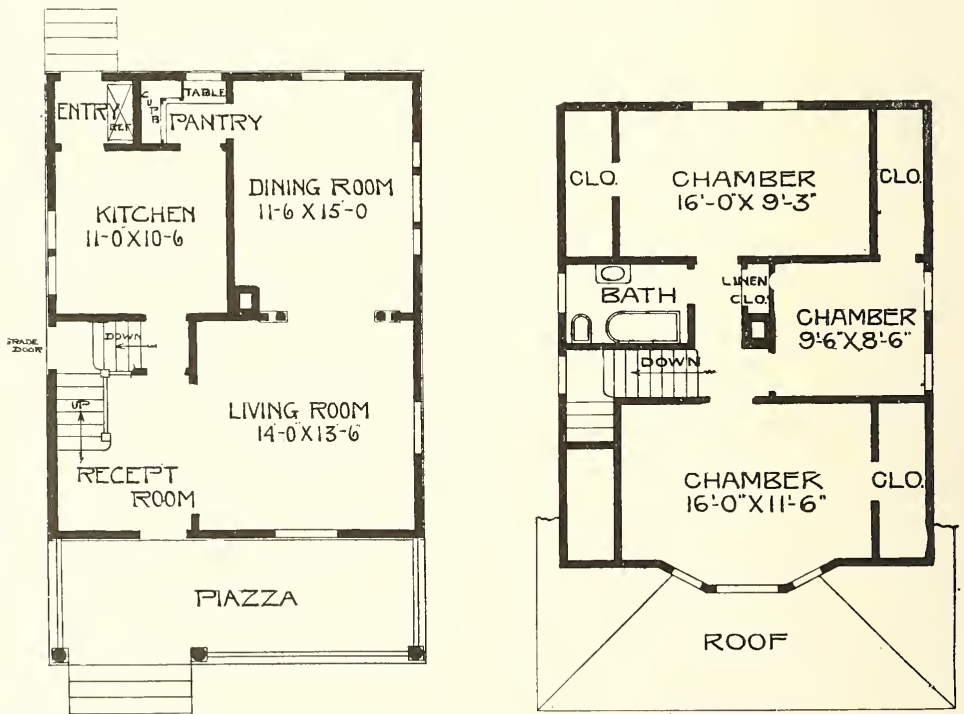

Complete plans and specifications for using Denison Load-Bearing Tile, licensed under Wilson-System Bearing $W$ a 11 Construction for $\$ 32$. 


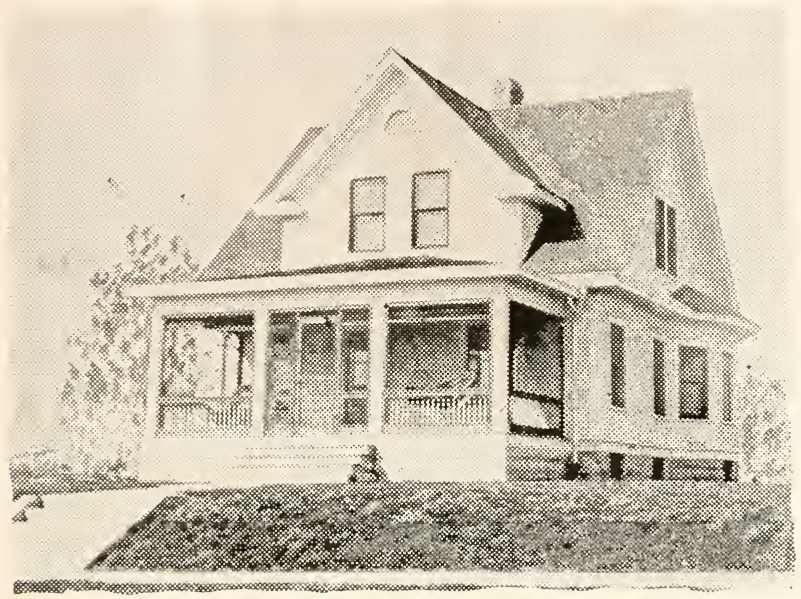

A Convenient Cottage Home-No. 832

Size, 26 feet wide and 28 feet deep, full basement; first story 9 feet, second story 8 feet; hardwood finish in first story to be gum or birch with hardwood floors throughout, pine to paint in second story. Cost to build, $\$ 2,200$. Complete set of plans and specifications for $\$ 15$.
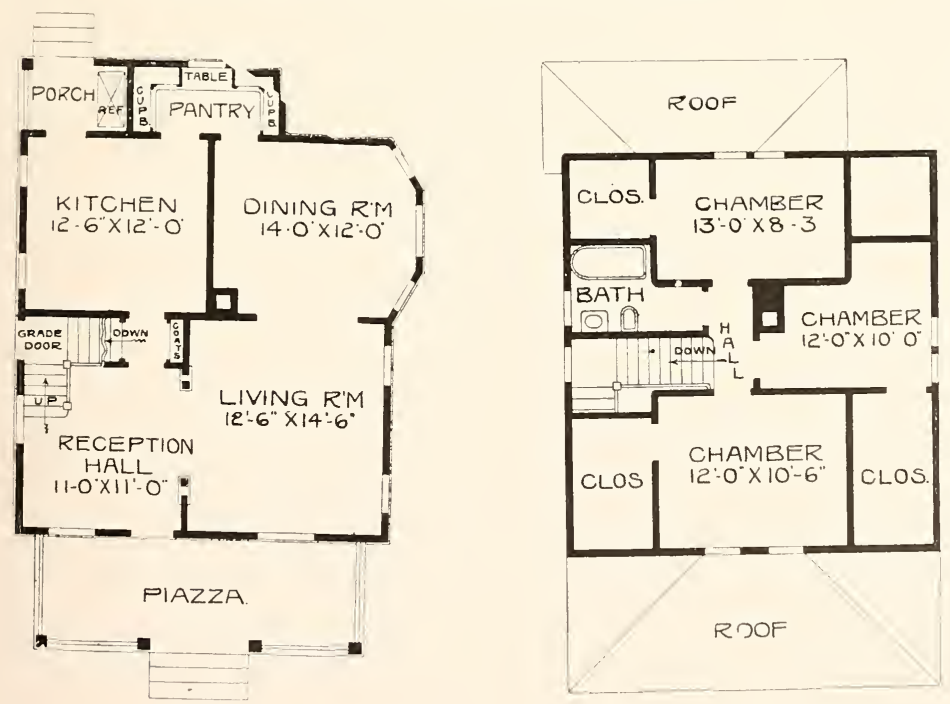

Complete plans and specifications for using Denison Load-Bearing Tile, licensed under Wilson-System Bearing W a 11 Construction for $\$ 30$. 

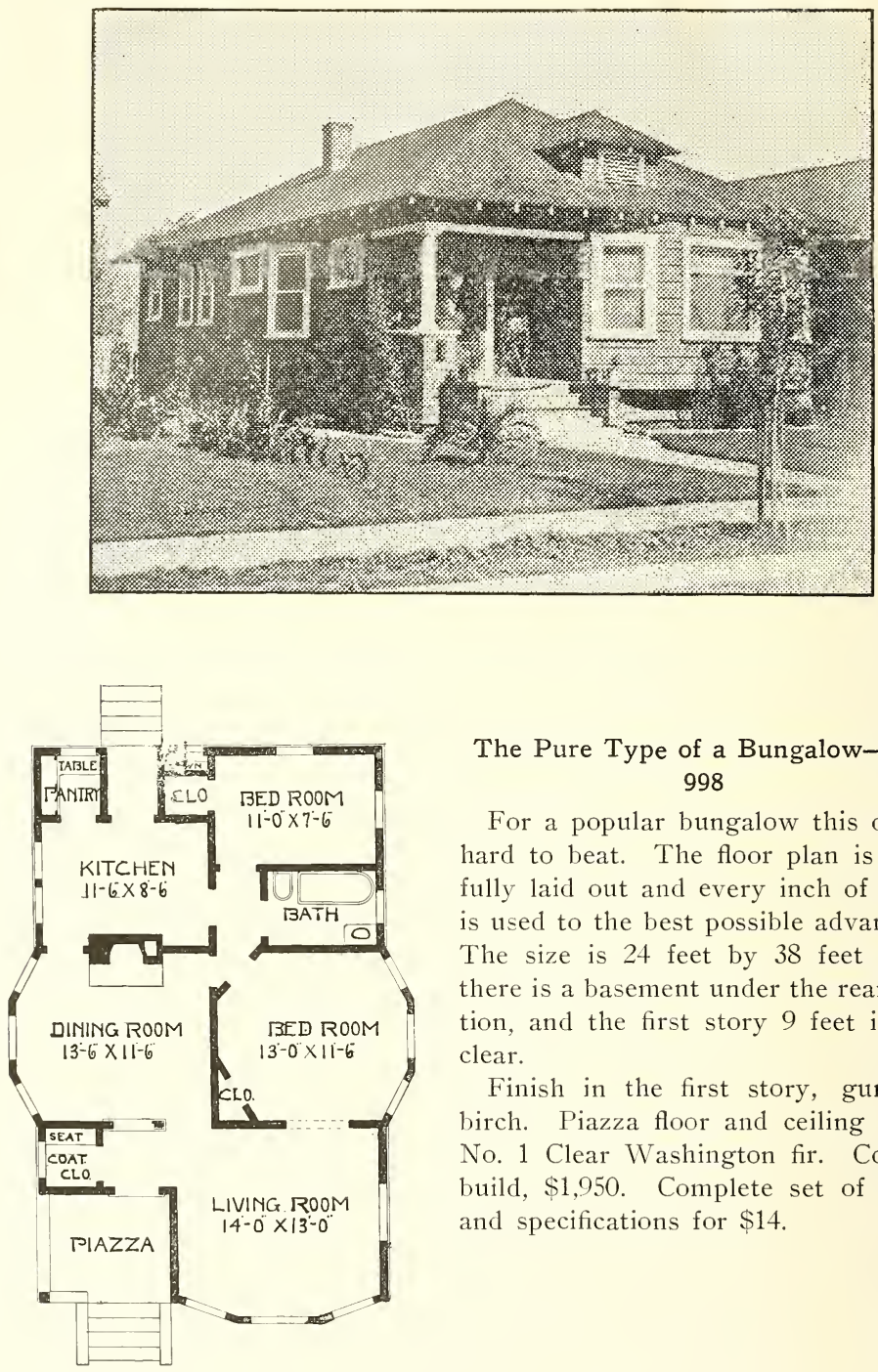

The Pure Type of a Bungalow-No. 998

For a popular bungalow this one is hard to beat. The floor plan is carefully laid out and every inch of space is used to the best possible advantage. The size is 24 feet by 38 feet deep; there is a basement under the rear portion, and the first story 9 feet in the clear.

Finish in the first story, gum or birch. Piazza floor and ceiling to be No. 1 Clear Washington fir. Cost to build, $\$ 1,950$. Complete set of plans and specifications for $\$ 14$.

Complete plans and specifications for using Denison Load-Bearing Tile, licensed under Wilson-System Bearing Wal1 Construction for $\$ 28$. 


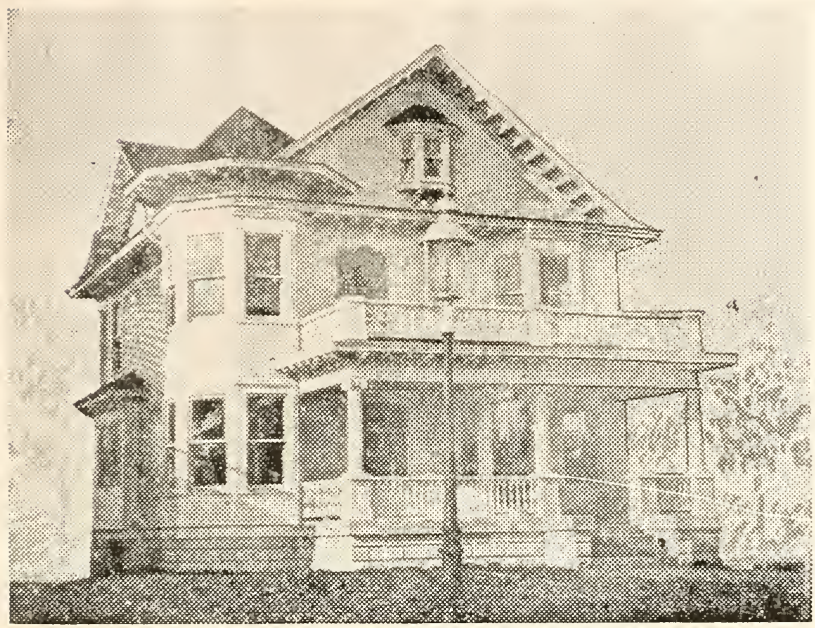

A Desirable Colonial Home-No. 825

The house is 28 feet wide and 30 feet deep over the main part; full basement; first story 9 feet, second story 8 feet: birch floors throughout, with birch or gum finish in first story, pine to paint in second. Cost to build, $\$ 3,500$. Complete set of plans and specifications for $\$ 25$.
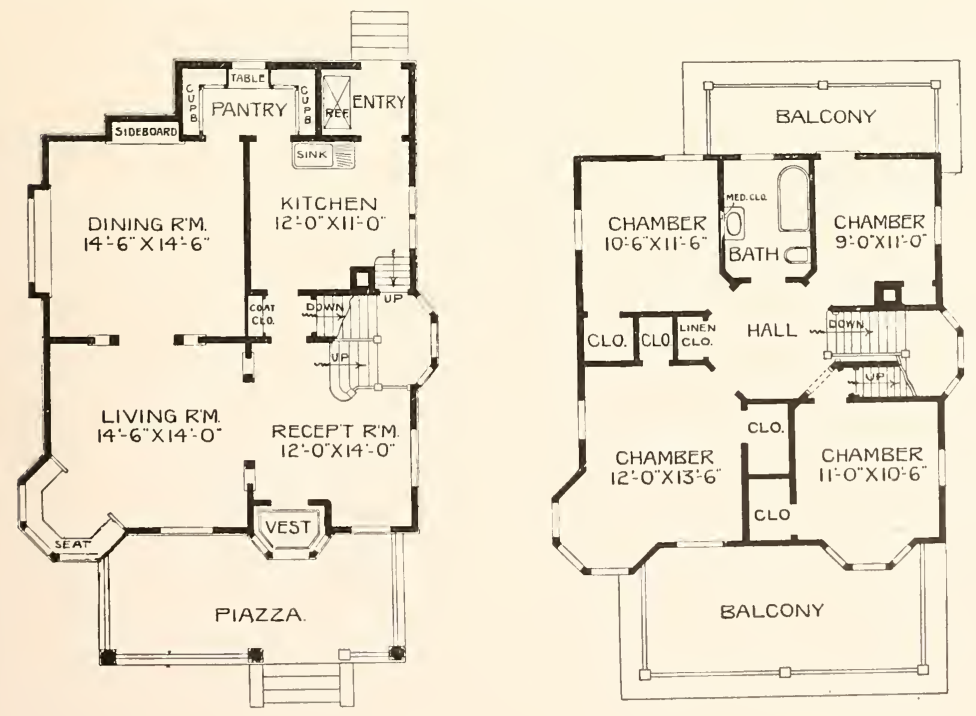

Complete plans and specifications for using Denison Load-Bearing Tile, licensed under Wilson-System Bearing $W$ a 11 Construction for $\$ 50$. 


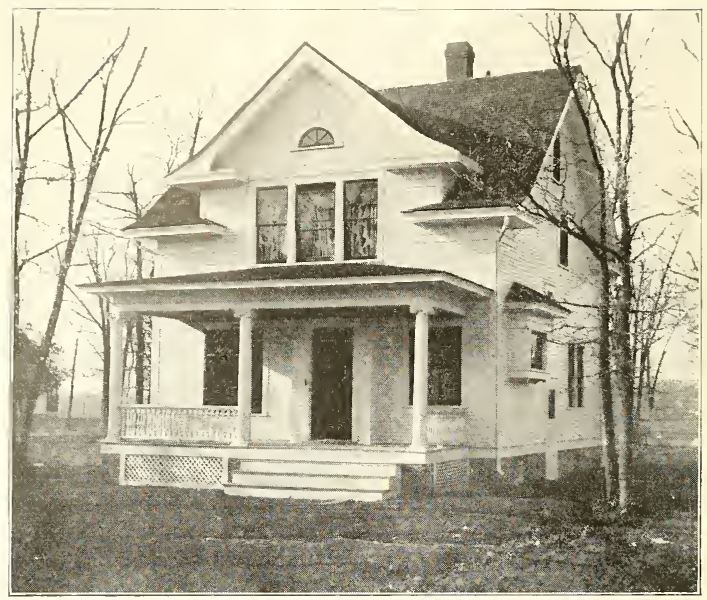

A Suburban Home-No. 838

Size of this cottage is $24 \mathrm{ft} .6$ ins. wide and $30 \mathrm{ft}$. 6 ins. deep over all, hardwood floors throughout, gum or birch finish in first story and pine to paint in second story. Full basement, first story 9 feet, second story 8 feet. Cost to build, $\$ 2,300$. Complete set of plans and specifications for $\$ 16$.
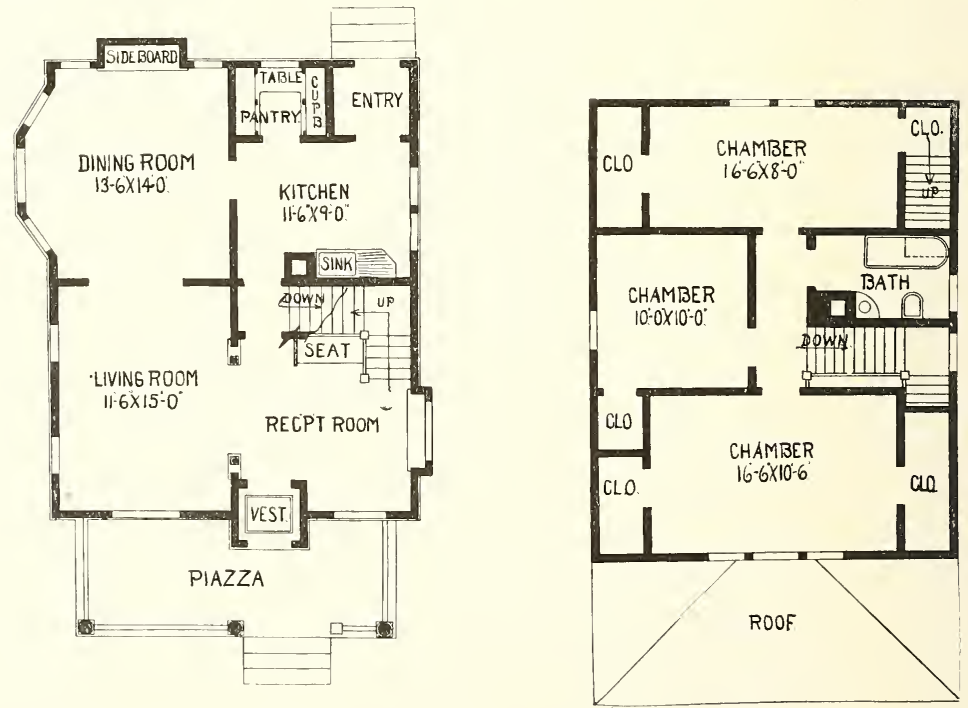

Complete plans and specifications for using Denison Load-Bearing Tile, licensed under Wilson-System Bearing Wal1 Construction for $\$ 32$. 


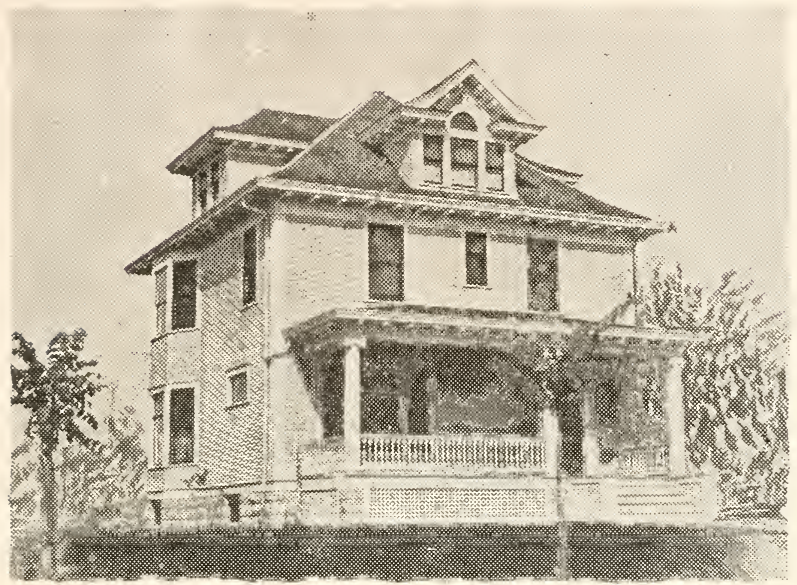

A Well Arranged Colonial Home-No 834

Size, 28 feet wide by 30 feet deep over the main part. There is a full basement 7 feet deep; first story 9 feet, second story 8 feet; birch floors throughout; first story finish in gum or birch, second story pine to paint. Cost to build, $\$ 3,200$. Complete set of plans and specifications for $\$ 25$.
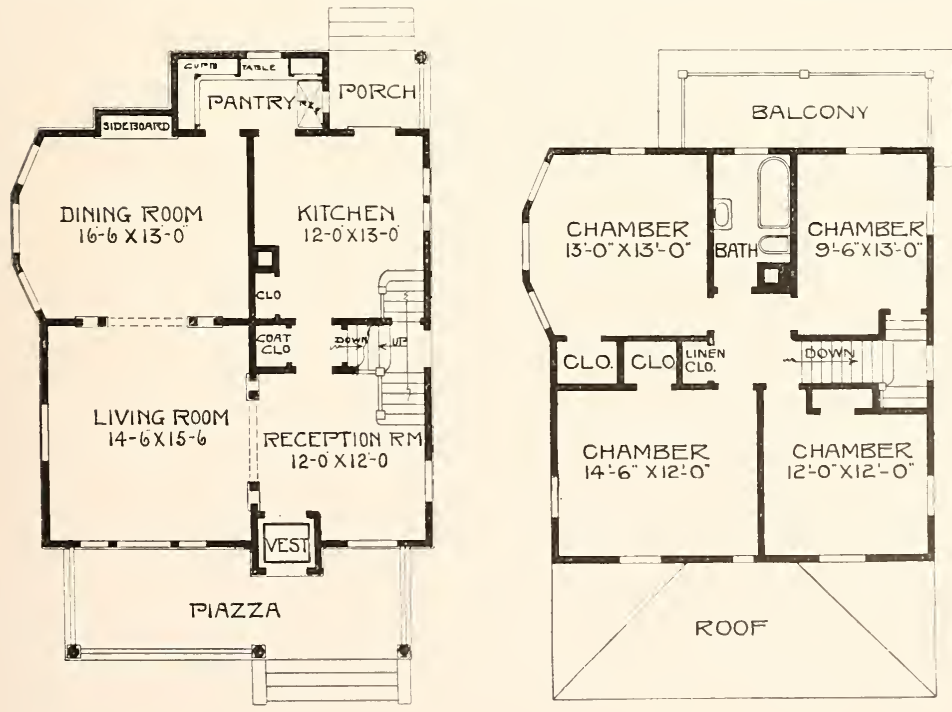

Complete plans and specifications for using Denison Load-Bearing Tile, licensed under Wilson-System Bearing II all Construction for $\$ 50$. 


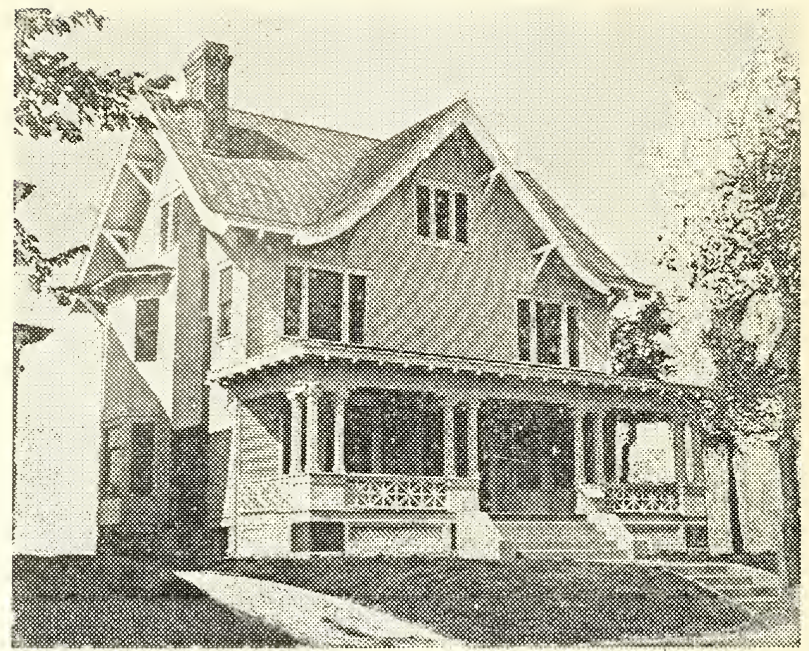

A Beautiful Residence-No. 831

There is full basement under the entire house. Birch floors throughout, 9 feet 6 inches; second story 9 feet. Cost to build, $\$ 4,750$. Complete set first story finished in gum or birch, second story finished in pine to paint. Size, 35 feet wide and 27 feet 6 inches deep over the main part. First story of plans and specifications for $\$ 30$.

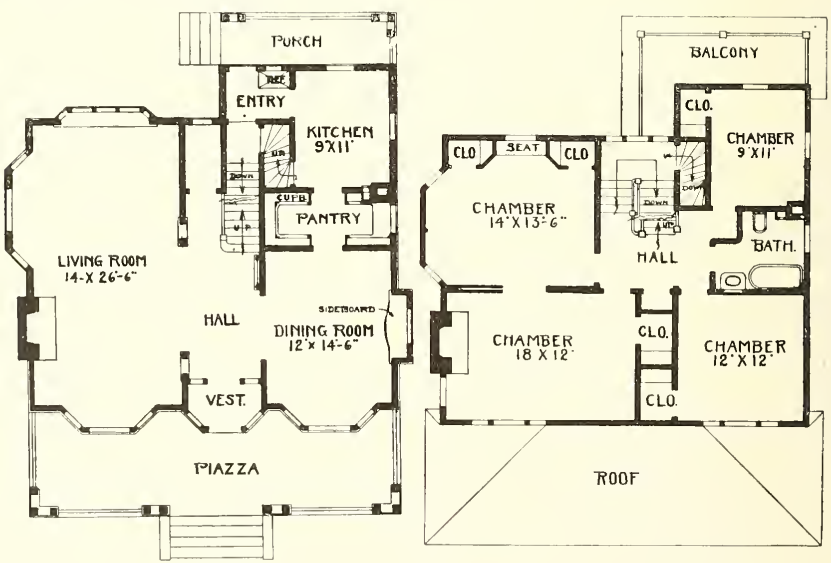

Complete plans and specifications for using Denison Load-Bearing Tile, licensed under Wilson-System Bearing Wa 11 Construction for $\$ 60$. 


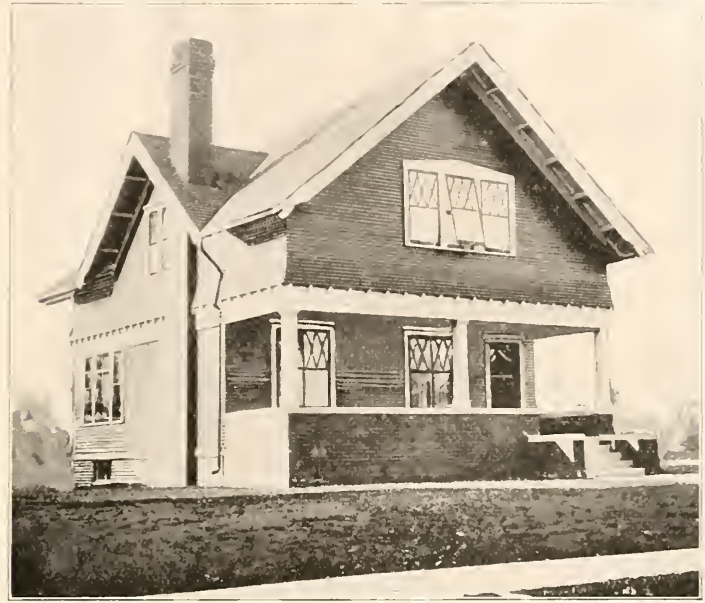

The Home Beautiful-No. 820

Size 26 feet wide by 28 feet deep over the main part. There is full basement; first story 9 feet; second story 8 feet. Birch floors throughout, "gum or birch finish in first story, pine to paint in second. Cost to build, $\$ 2,650$. Complete set of plans and specifications for $\$ 20$.
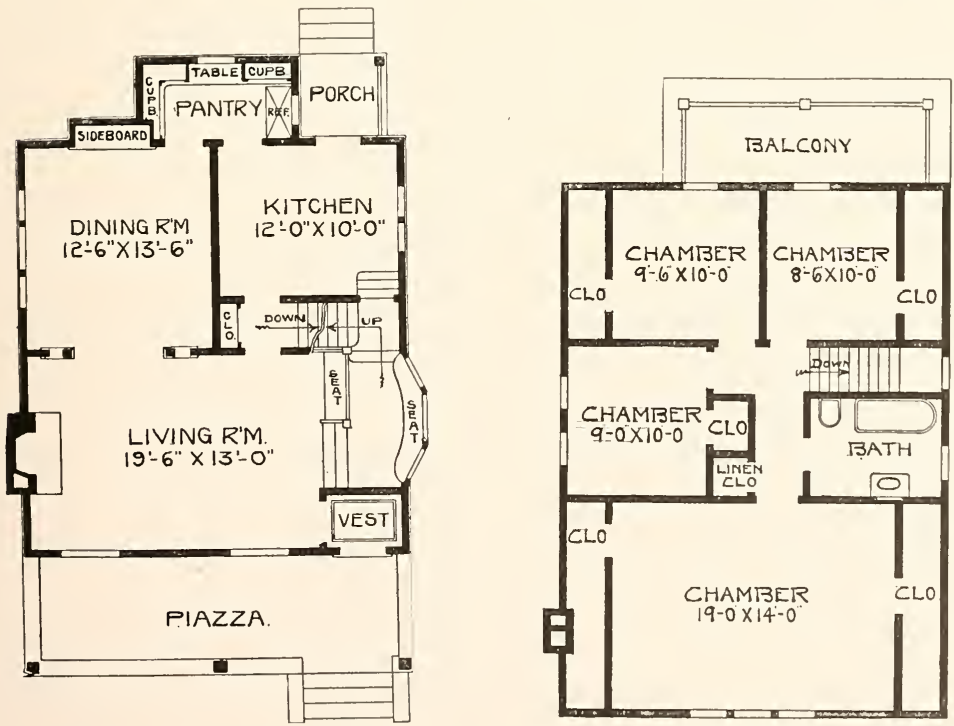

Complete plans and specifications for using Denison Load-Bearing Tile, licensed under Wilson-System Bearing $\mathrm{W}$ a 11 Construction for $\$ 40$. 


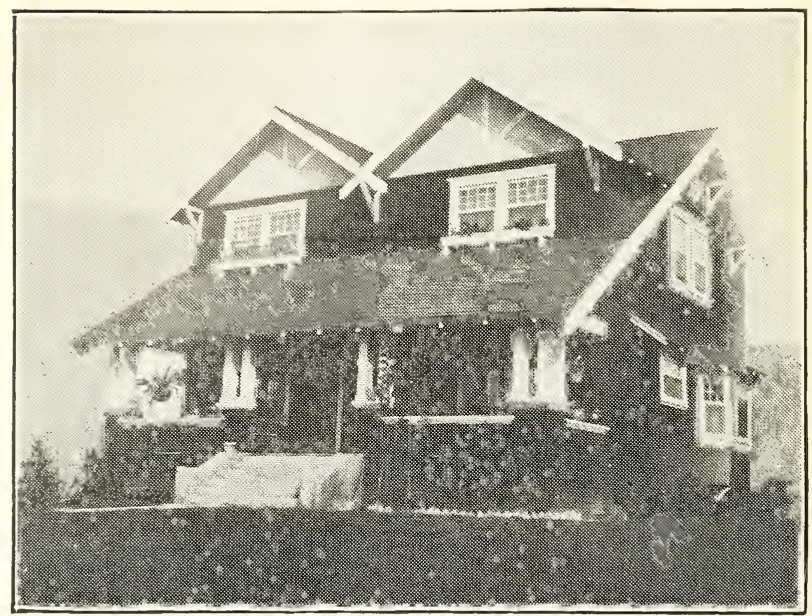

An Artistic Dwelling-No. 840

The size of the house is 32 leet 6 inches wide and 28 feet deep over the main part. There is a full basement, the first story is 9 feet, and the second story is 8 feet in the clear. Birch floors throughout with gum or birch finish in the first story and pine to paint in the second. Cost to build $\$ 3,125$. Complete set of plans and specifications for $\$ 25$.
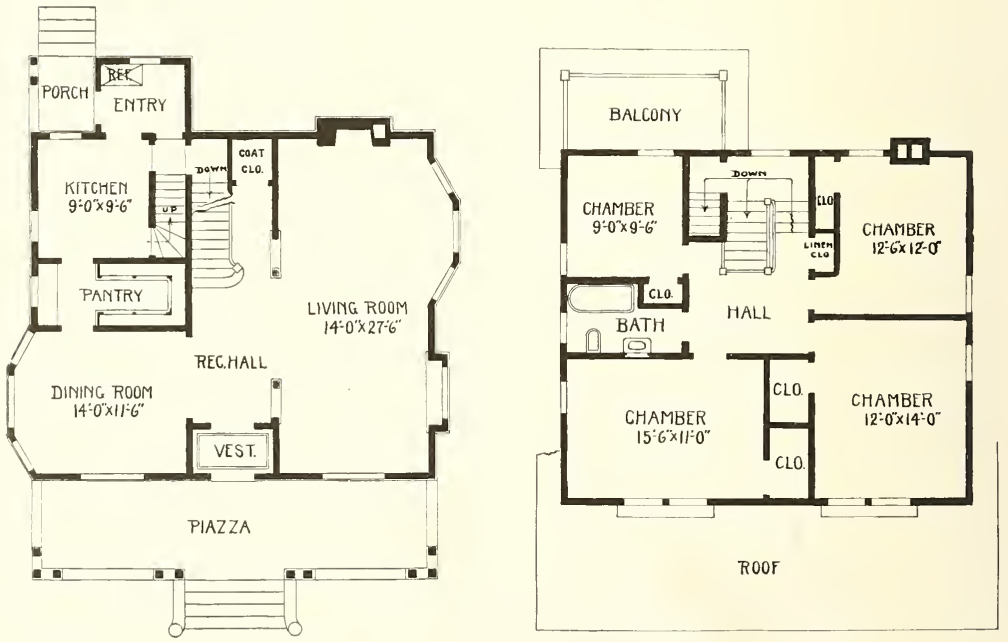

Complete plans and specifications for using Denison Load-Bearing Tile, licensed under Wilson-System Bearing Wa 11 Construction for $\$ 50$. 


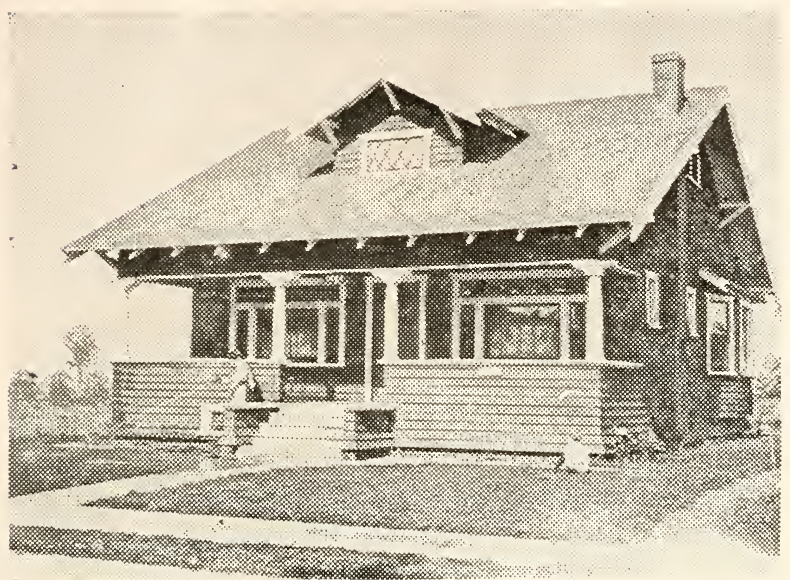

Your New Home--No. 857.

The house is 34 feet wide and 25 feet 6 inches deep over the main part. There is a basement under the living room side. A whole basement can be made if one desires. The first story is 9 feet and the second 8 feet. Gum or birch finish is used in the first story and pine to paint in the second, with birch floors throughout. Cost to build, $\$ 2,200$. Complete set of plans and specifications for this beautiful bungalow for $\$ 18$.
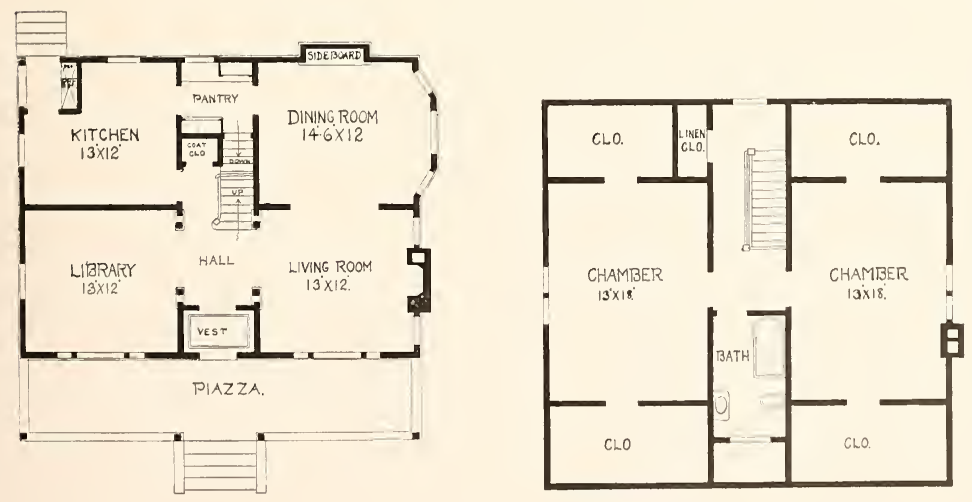

Complete plans and specifications for using Denison Load-Bearing Tile, licensed under Wilson-System Bearing IV a 11 Construction for $\$ 36$. 


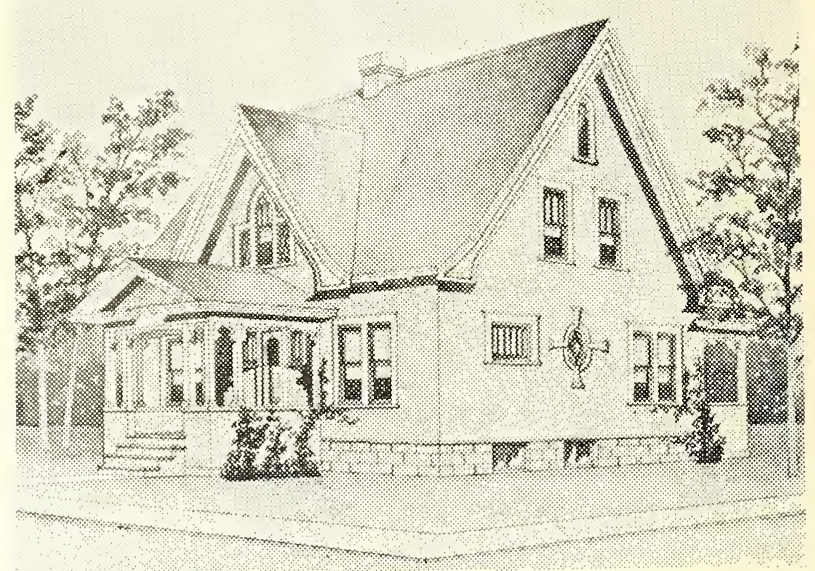

Beautiful Inexpensive Cottage Home-No. 994

First story is 9 feet, second story 8 feet. Size of house, $33 \times 27$ feet 6 inches over the main part. Birch or maple floors in first story; finish in first story to be gum and pine to paint in second. Piazza floors and ceilings to be No. 1 Clear Washington fir. Cost to build, $\$ 2,850$. Complete set of plans and specifications for $\$ 20$.

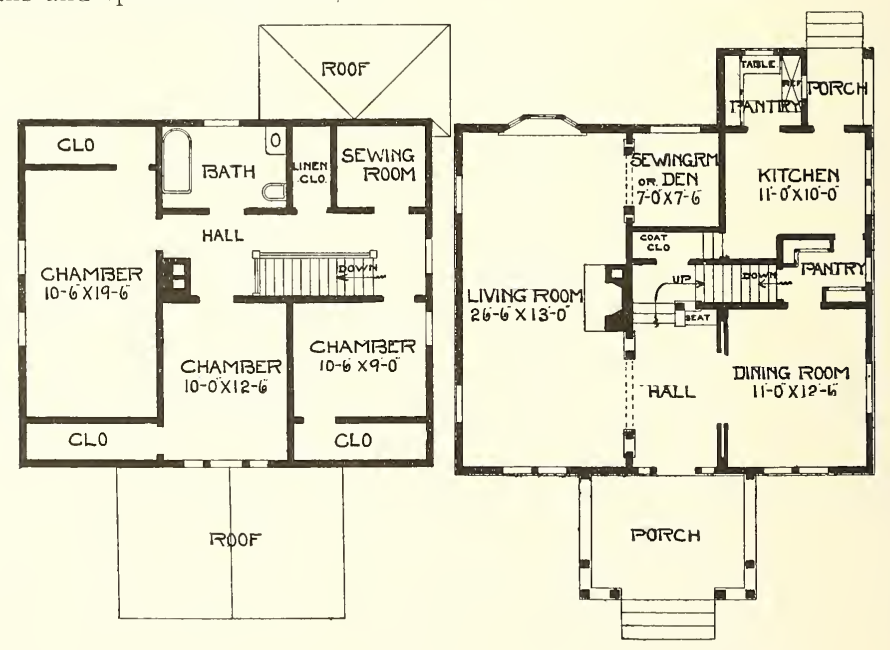

Complete plans and specifications for using Denison Load-Bearing Tile, licensed under Wilson-System Bearing W a 11 Construction for $\$ 40$. 


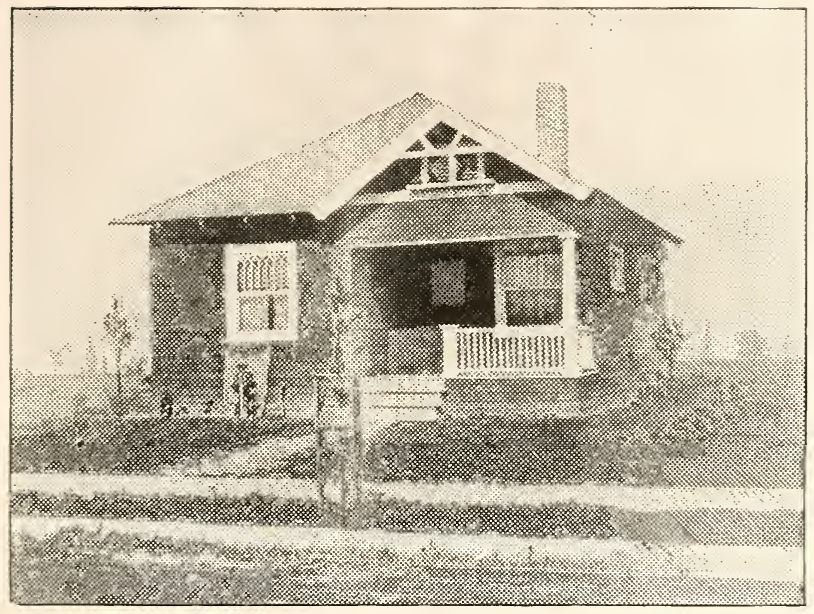

A Modest Bungalow-No. 854

A very good plan for a small family. It has one large bedroom, and it can be arranged to have one room in the attic if desired. In this plan the dining room is brought forward, making an arrangement such as we put in very expensive homes. A small cellar under kitchen and bedroom portion. Size, 26 feet wide by 34 feet long. Rooms 9 feet high in the clear; birch floors throughout, gum or birch finish. Cost to build, $\$ 1,000$. Complete set of plans and specifications for $\$ 10$.

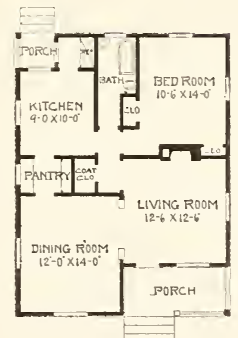

Complete plans and specifications for using Denison Load-Bearing Tile, licensel under Wilson-System Bearing $\mathrm{W}$ a 11 Construction for $\$ 20$. 


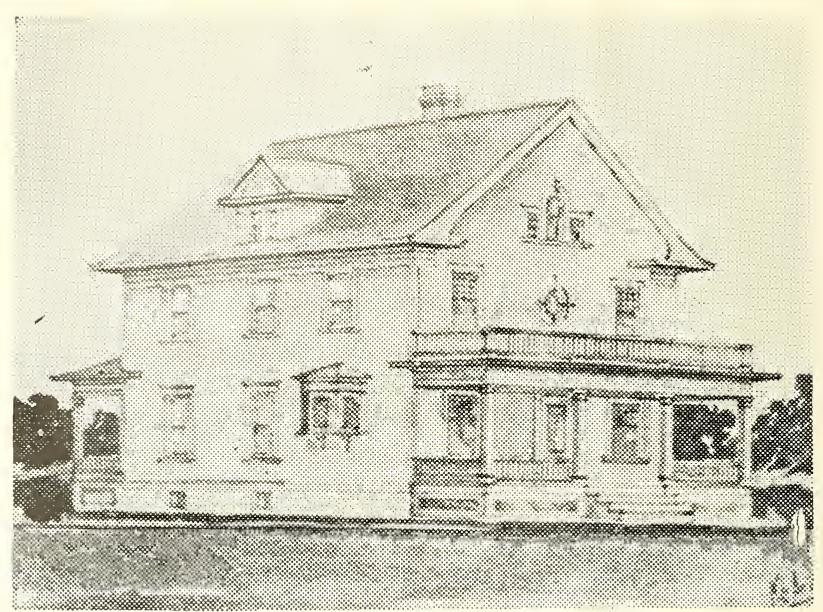

A Plain Colonial Home-No. 883

The size is 33 feet wide and 34 feet 6 inches deep. There is a full basement under the entire house. The first story is finished throughout in gum or birch, second story is planned for pine to paint. There are birch floors throughout. The first story 9 feet, second 8 feet, and basement 7 feet in the clear. Piazza floors and ceilings to be No. 1 Clear Washington fir. Cost to build, $\$ 3,850$. Complete set of plans and specifications for $\$ 30$.

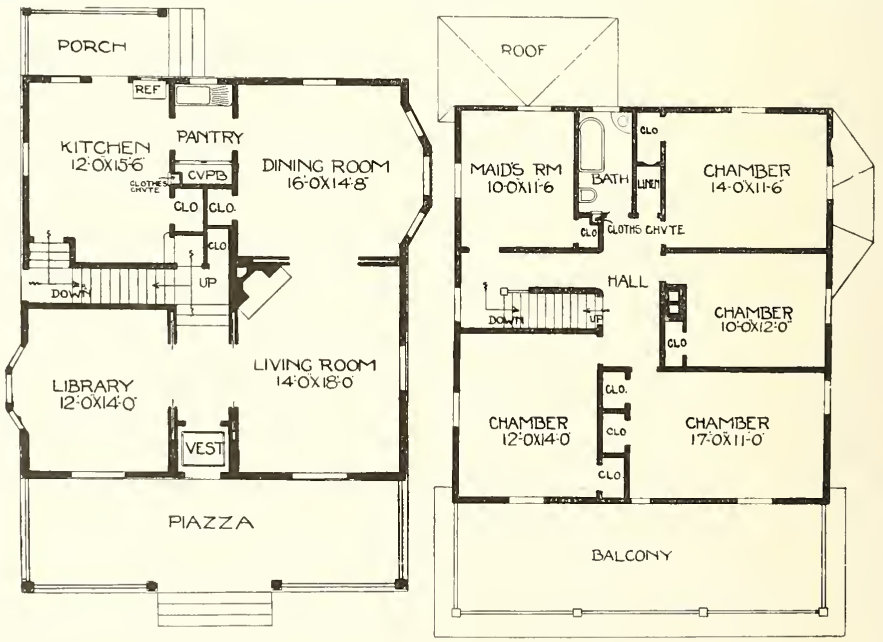

Complete plans and specifications for using Denison Load-Bearing Tile, licensed under Wilson-System Bearing iV a 11 Construction for $\$ 60$. 


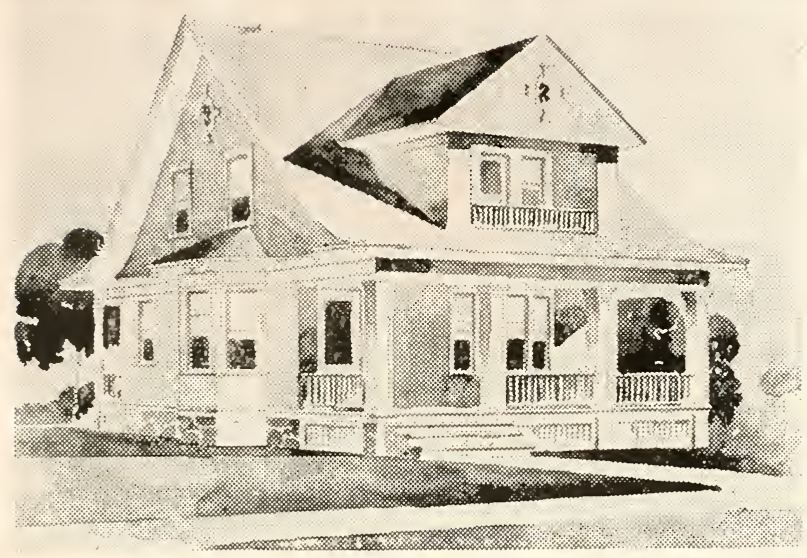

An Up-to-Date Home-No. 877

The rooms as shown on the plans, are extra large, well laid out, and well arranged. The house is provided with a full basement, and could have stairs going to a small attic, if desired. Size of house, 26 feet by 27 feet. 9 feet, and second floor 8 feet in height. Size of house, 26 feet by 27 feet. The exterior of the first floor is sided, while the second floor and roof are of shingles. First story finish is of gum or birch; second, pine to paint. Piazza floors and ceiling are of No. 1 Washington fir. Cost to build, $\$ 2,500$. Complete set of plans and specifications, $\$ 15$.

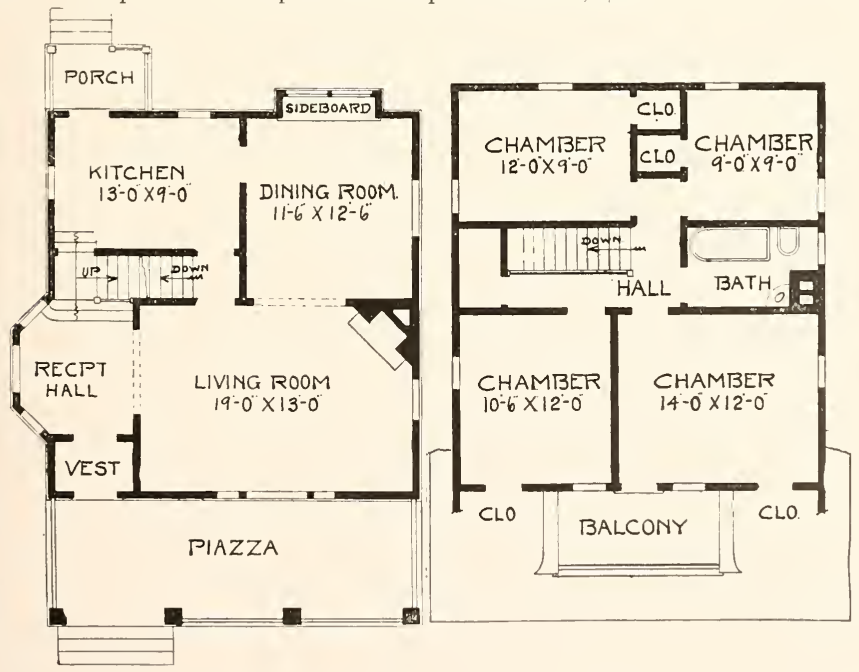

Complete plans and specifications for using Denison Load-Bearing Tile, licensed under Wilson-System Bearing W a 11 Construction for $\$ 30$. 


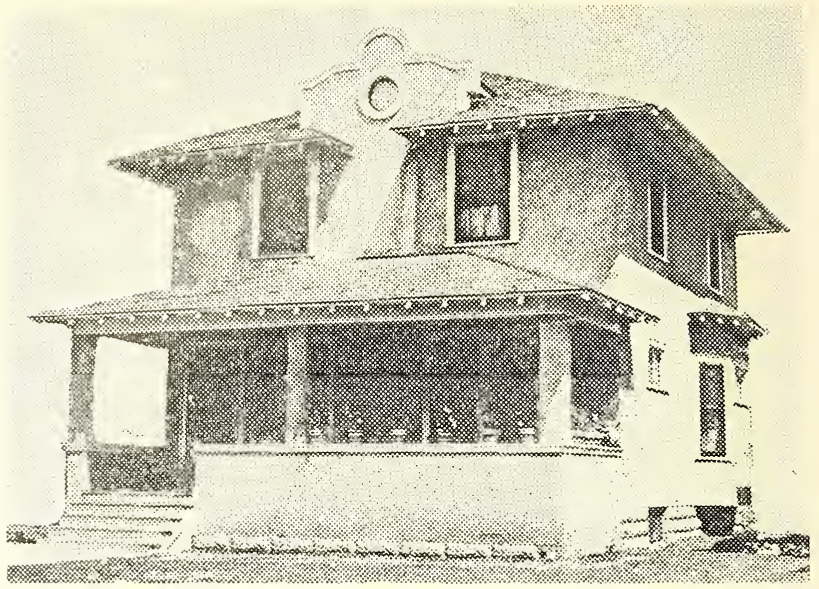

A Small Rough Cast Cottage-No. 981

This house is covered with rough cast on the exterior and the finish inside is red oak or gum

first story and pine to paint in second.
For a practical house that is only twenty-four feet wide and twenty-six feet deep, with well arranged space, here is a plan that would be hard to equal. First story, nine feet; second story, eight feet. Cost to build, $\$ 2,300$. Complete set of plans and specifications for $\$ 20$.
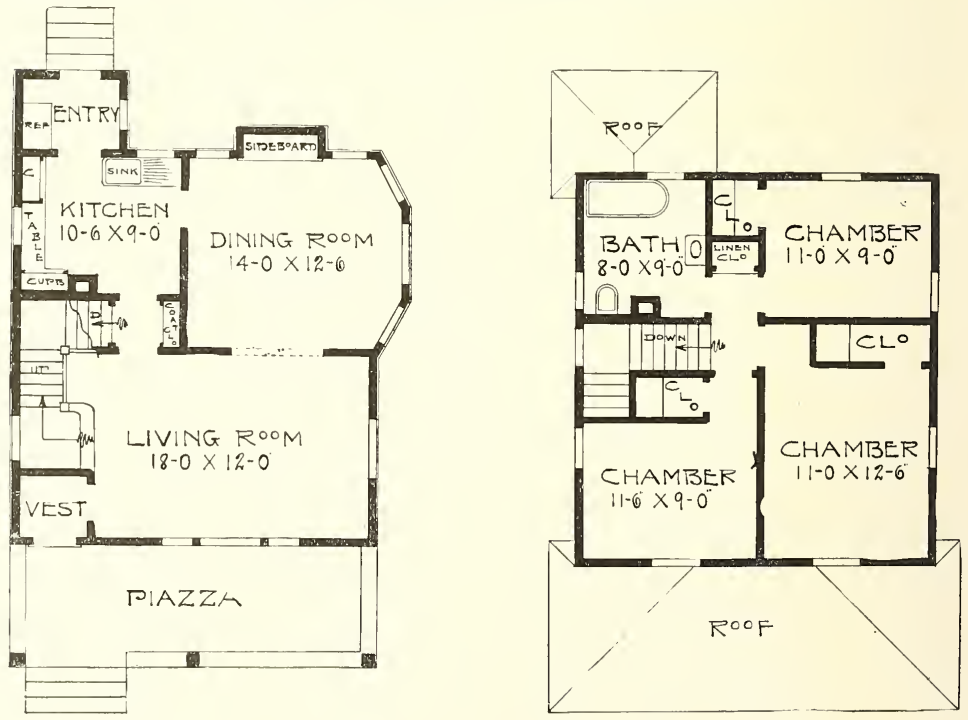

Complete plans and specifications for using Denison Load-Bearing Tile, licensed under Wilson-System Bearing Wa 11 Construction for $\$ 40$. 


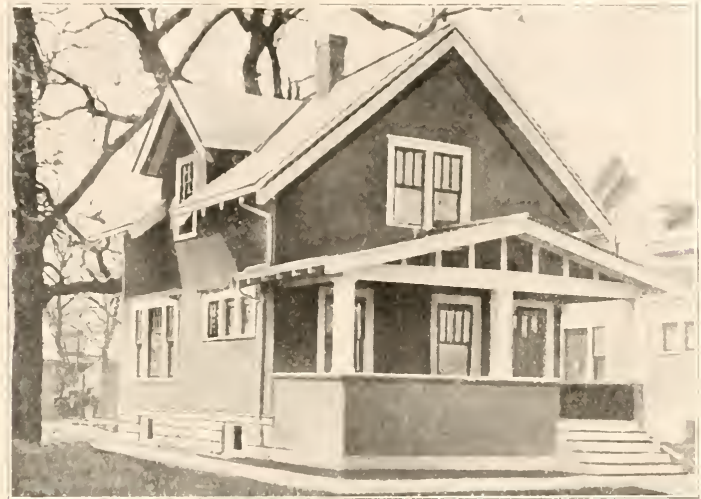

A Splendid Cottage at Low Cost-No, 752

For a small cottage home this is very practical plan. There is a beautiful living room across the front, vestibule and open stairway at one end of this room, and a high pedestaled arehway leading into the dining room. The kitehen has built-in cupboards, also table and ample space for the balance of the kitchen furniture. The chimney is so located that the house can be heated with store heat or a heating plant in basement.

Three chambers in the second story, very large elosets, good bath and a balcony out over one-story rear part. Full basement, first story 9 feet, second story 8 feet. All of the ehambers in seeond story finished full height. Gum or red oak finish throughout first story. Pine to paint in second story, white maple floors throughout both stories, size 22 feet wide and 26 feet deep over the main part. Cost to build, $\$ 1,950$. Complete set of plans and specifications for $\$ 18$.
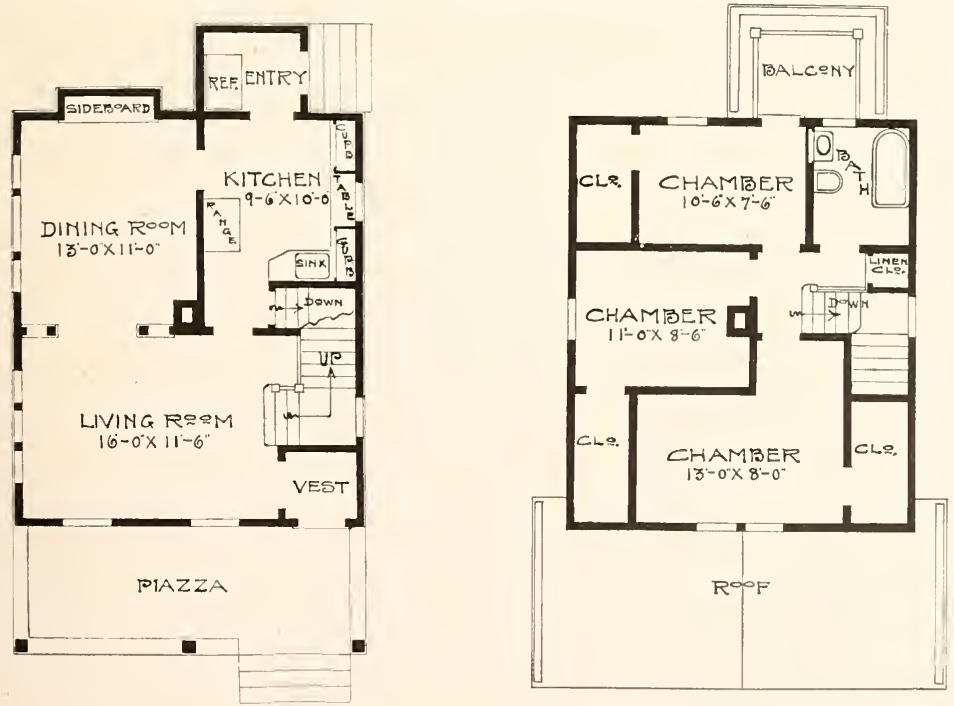

Complete plans and specifications for using Denison Load-Bearing Tile, licensed under Wilson-System Bearing $\mathrm{W}$ a 11 Construction for $\$ 36$. 


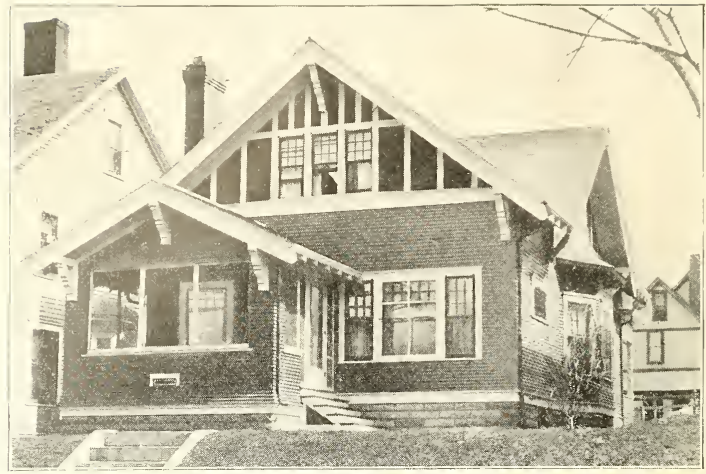

An Ideal Bungalow Home- -No. 751

Any one interested in a bungalow for their own home will find this a very interesting plan to study. This plan has a den and living room across the front. There is also a bed room and bath in the first story of this plan with a small room connected with this bed room, that can be used for a dressing room or sewing room as owner desires.

Second story has three large chambers and abundance of eloset space. Full basement under entire house, first story 9 feet, second story 8 feet. Size 26 feet wide and 40 feet deep over the main part. Finish in first story red oak or gum throughout. Pine to paint in second story. Birch or maple floors in each story. Cost to build, $\$ 3.500$. Complete set of plans and specifications for $\$ 26$.

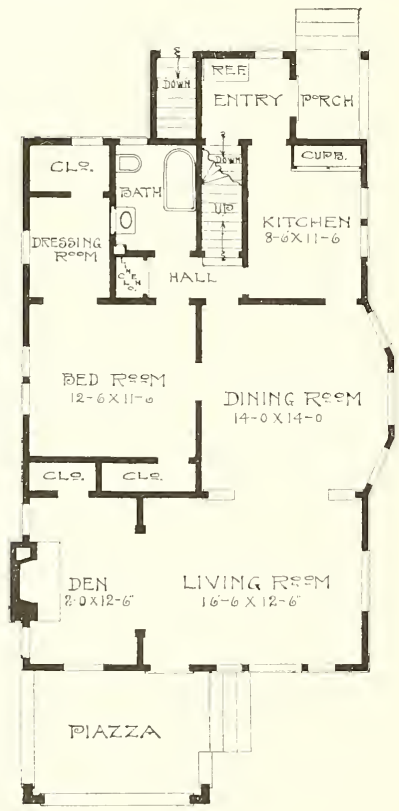

BALCENY
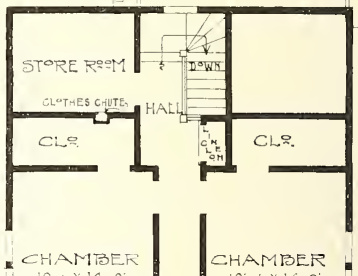

$10-6 \times 14-0$

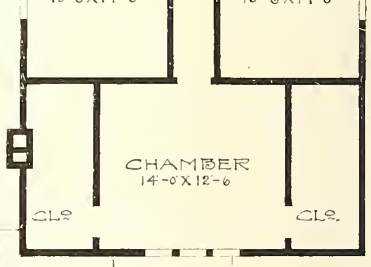

Complete plans and specifications for using Denison Load-Bearing Tile, licensed under Wilson-System Bearing $W$ a 11 Construction for $\$ 52$. 


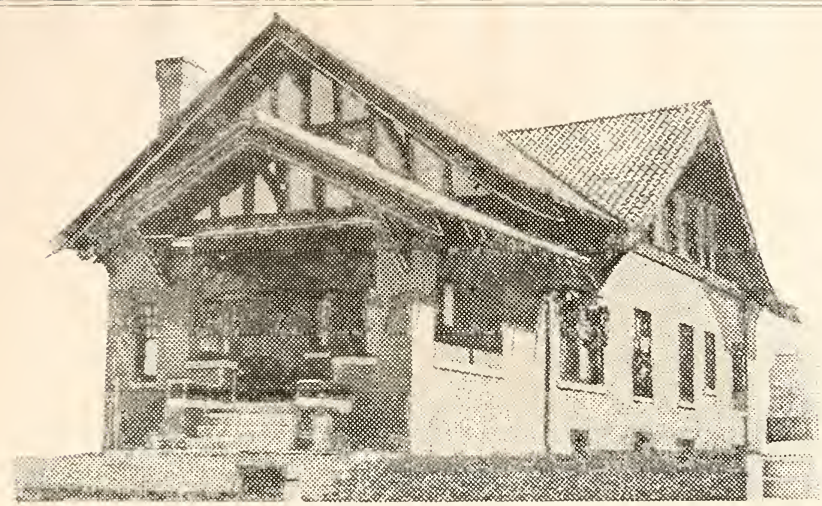

A Bungalow Adapted to any Climate-No. 977

This bungalow can be built in Southern California, Salt Lake, Denver, in Canada, or any loca. tion on the Atlantic coast. This is one of the most complete bungalows that has ever been produced. First story ten feet, second story eight feet in the clear. Size thirty-two feet wide and forty-eight feet deep, first story finished in red oak or gum, second story pine to paint. The sun room is also finished in Washington fir. Cost to build, $\$ 7,500$. Complete set of plans and specifica. tions for $\$ 35$.
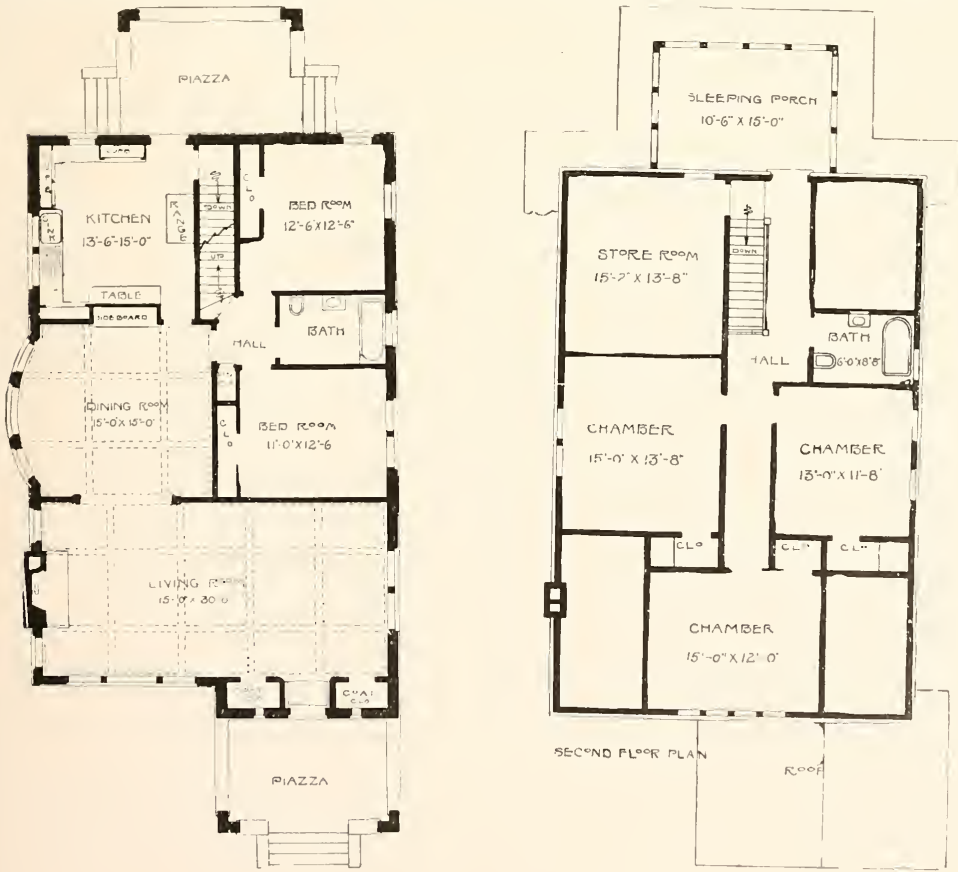

Complete plans and specifications for using Denison Load-Bearing Tile, licensed under Wilson-System Bearing $\mathrm{W}$ a 11 Construction for $\$ 70$. 


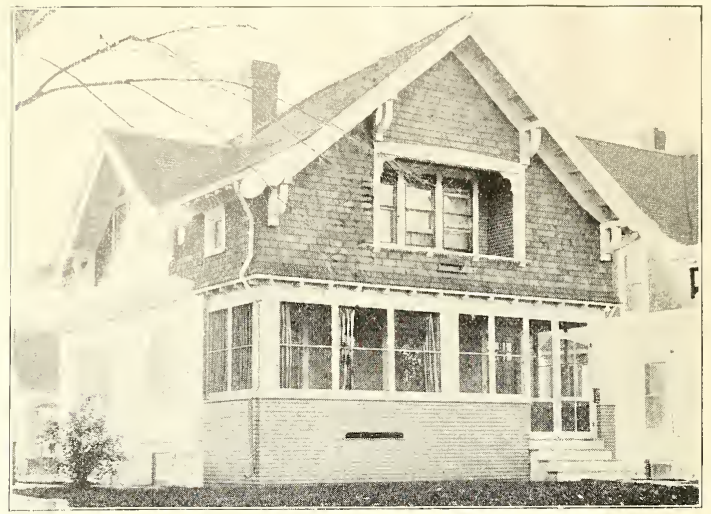

A Bungalow of Sunshine-No. 965

Here is a corking good bungalow to build, either in a eity, a suburb, a lot in a country town or a small village.

This little bungalow has a beautiful living room across the front, a dining room in the rear of same, good pantry and large kitchen, combination stairway, and a splendid piazza across the entire front of the house. This piazza can be sashed in in the winter and make a sun room of same if one desires.

The second story is well laid out and carefully planned and we are sure that it will meet with the approval of every housewife. There is a full basement under the entire house. First story, 9 feet, second story 8 feet. The rooms are all finished up to full height.

First story is finished in gum, red oak or Washington fir of clear quality. Second story is pine to paint, or southern pine or Washington fir could be used for the second story if one desires. Size 26 feet wide and 28 feet deep.

Cost to build, $\$ 2,850$. Complete set of plans and specifications for this home for $\$ 18$.
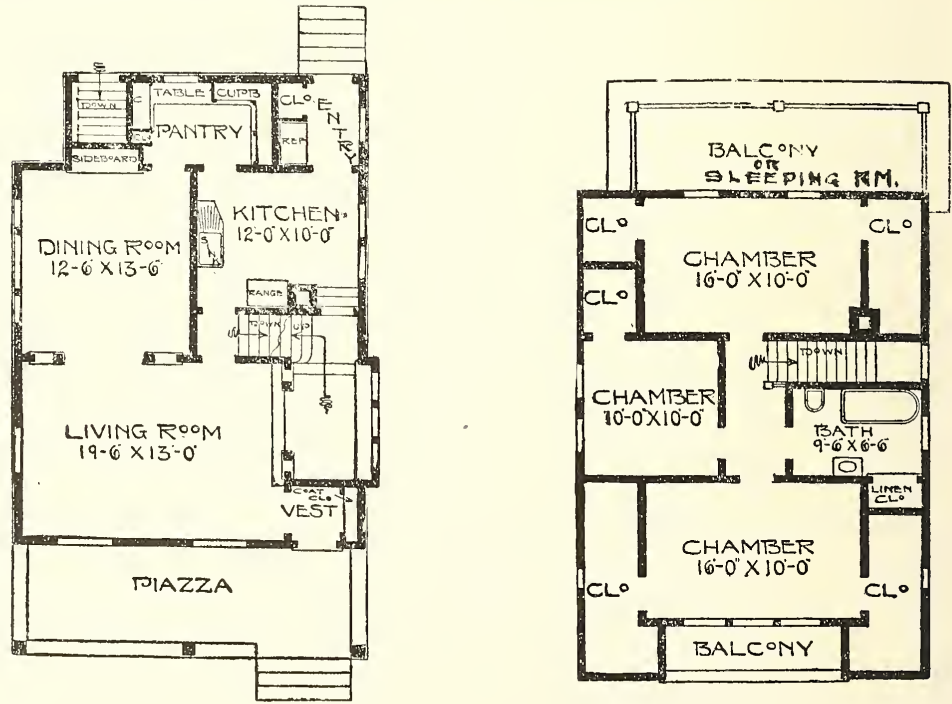

Complete plans and specifications for using Denison Load-Bearing Tile, licensed under Wilson-System Bearing $W$ a 11 Construction for $\$ 36$. 


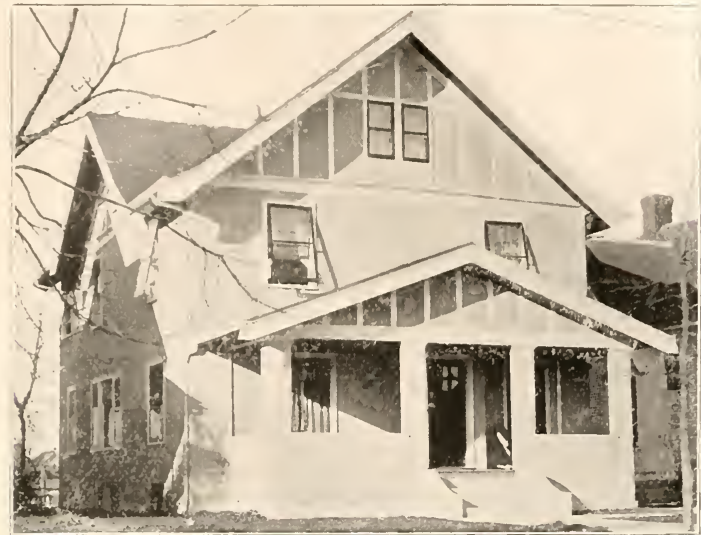

A Rough Cast Residence-No. 754

From this you pass through the vestibule into the reception room opening together with living room by columned archway. This plan has a combination stairway from the reception room, also from the kitchen with a grade door and stairway to basement underneatl same. Pretty dining room well lighted, with a handsome sideboard built in. Den in rear of same. There is a large pantry and good sized kitchen. Entry has space for refrigerator with large closet.

In the second story we have four chambers, sleeping porch and a balcony besides large closets, good sized bath room and linen closet. Full basement. First story 9 feet, second story 8 feet. Size 28 feet wide and 37 feet 6 inches deep over the entire first story exclusive of piazza rear porch. Finish in first story red oak or gum. Finish in second story pine to paint, maple or birch floors throughout both stories. Cost to build, $\$ 3,900$. Complete set of plans and specifications for $\$ 25.00$

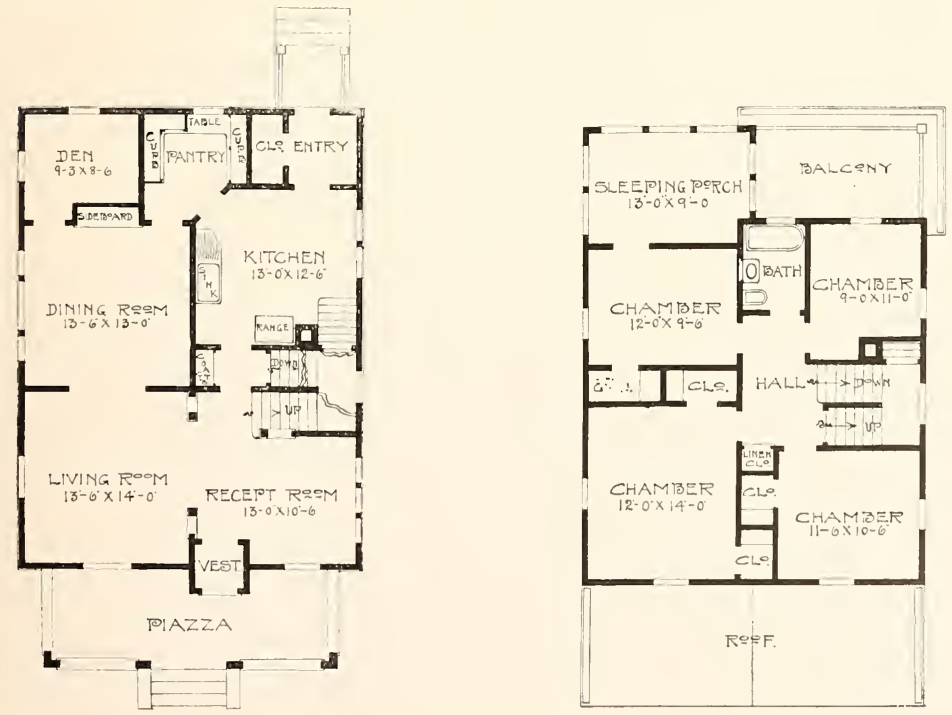

Complete plans and specifications for using Denison Load-Bearing Tile, licensed under Wilson-System Bearing $\mathrm{W}$ a 11 Construction for $\$ 50$. 


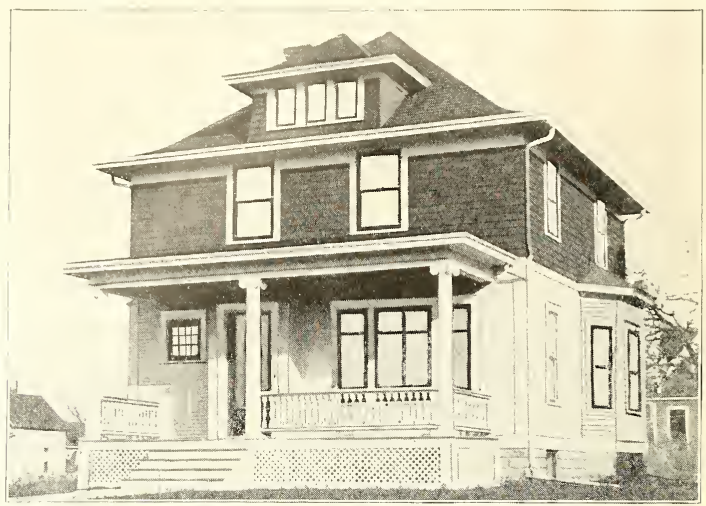

Two-Story Shingle and Clapboard Design-No. 726

This is a very practical two-story house with eight rooms and is very economical as there are very few corners and angles to be turned, for expense in building always comes in making projections on a building, as it doubles the expense each time.

The first floor plan is well arranged and contains reception room, living room, dining room and kitchen which is desired by a great many people. The reception room is connected with living room by large pedestaled opening, thus throwing these two rooms together and giving the appearance of practically one large room still making a division of same.

The second story of this house contains four chambers, large bath room and closet for each chamber besides linen closet.

There is a large sleeping room across rear in second story. Size of house is 26 feet wide and 28 feet deep. Full basement. First story 9 feet, second story 8 feet. Finish in first story gum or red oak, finish in second story pine to paint. Cost to build, $\$ 2,900$. Complete set of plans and specifications for $\$ 25$.
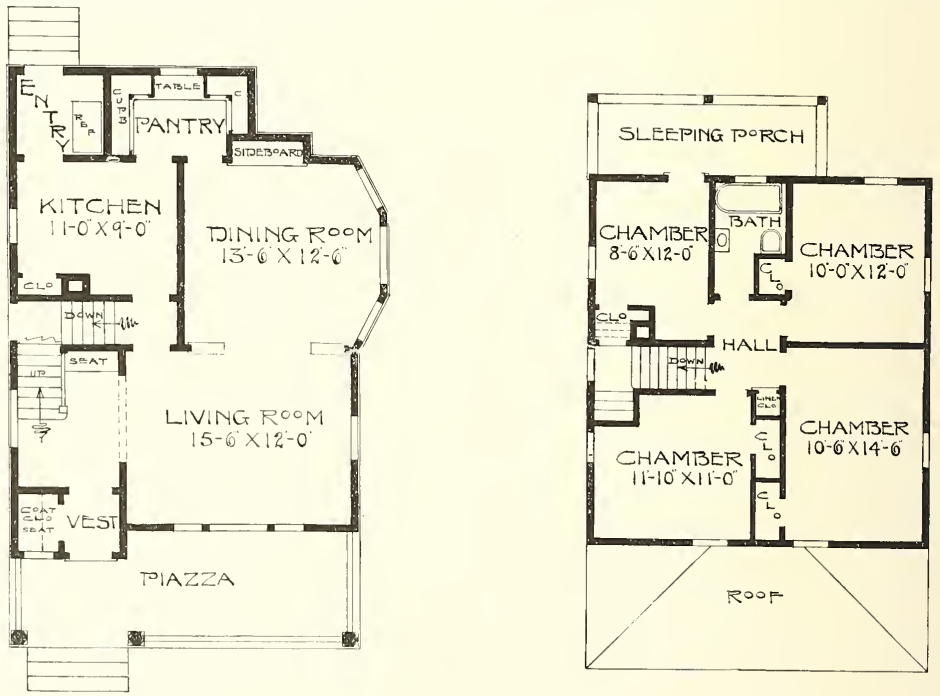

Complete plans and specifications for using Denison Load-Bearing Tile, licensed under Wilson-System Bearing $W$ a 11 Construction for $\$ 50$. 


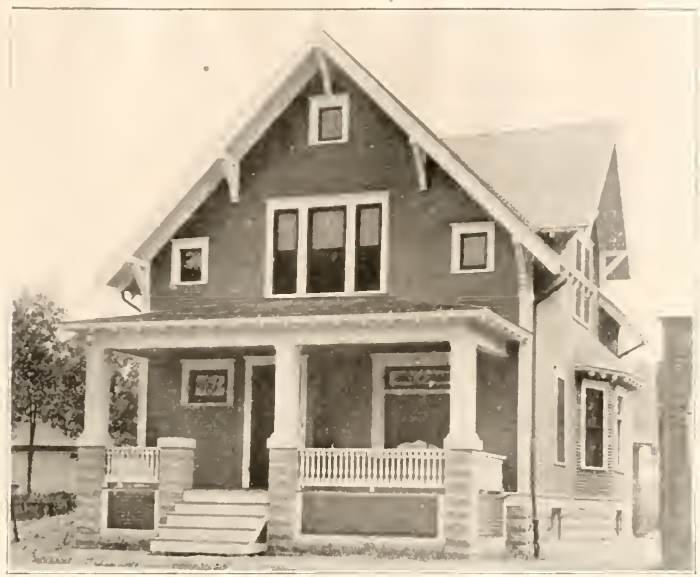

A Very Popular and Attractive Little Home-No. 723

Here is offered a plan that meets the popular demand for a large piazza in front, with a reception room and living room across the entire front, making practically one large room. The reception room has combination stairway, grade door underneath; coat closet between this room and kitchen. The kitchen is connected with dining room through large pantry with built-in cupboards. Kitchen has rear entry, with mop and broom closet and space for refrigerator.

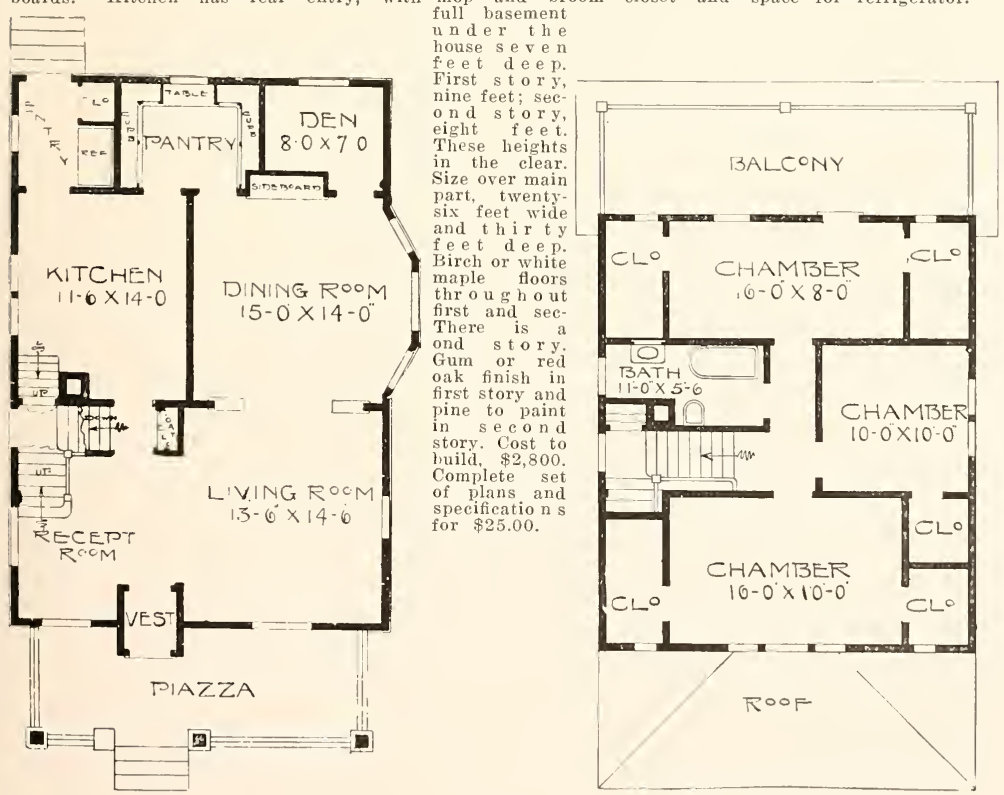

Complete plans and specifications for using Denison Load-Bearing Tile, licensed under WVilson-System Bearing $\mathrm{W}$ a 11 Construction for $\$ 50$. 


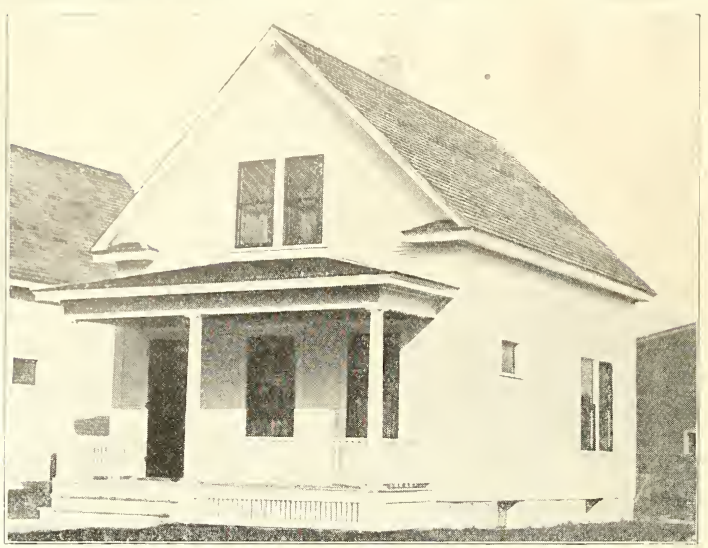

A Modest Cottage Home-No. 724

This is a very compact cottage home that is within the limits of any salaried man, makes a very comfortable home and has all the features that are contained in homes that cost many times the amount of this one.

In the first story of this cottage we have a large living room, pretty open stairway, also coat closet and vestibule. There is a good sized dining room and kitchen with rear entry. In the second story are two good sized chambers, good closet space and good sized bath room. If one does not desire to have the house modern, the bath room can be used as a small sleeping room. In this way we get the capacity of three chambers in the second story.

Size of house is 22 feet wide and 24 feet deep. Maple floors in first and second story. Hardwood finish in first story, gum to paint in second story. Full basement. First story, $81 / 2$ feet, second story 8 feet. Cost to build, $\$ 1,000$. Complete set of plans and specifications of this house for $\$ 10$.
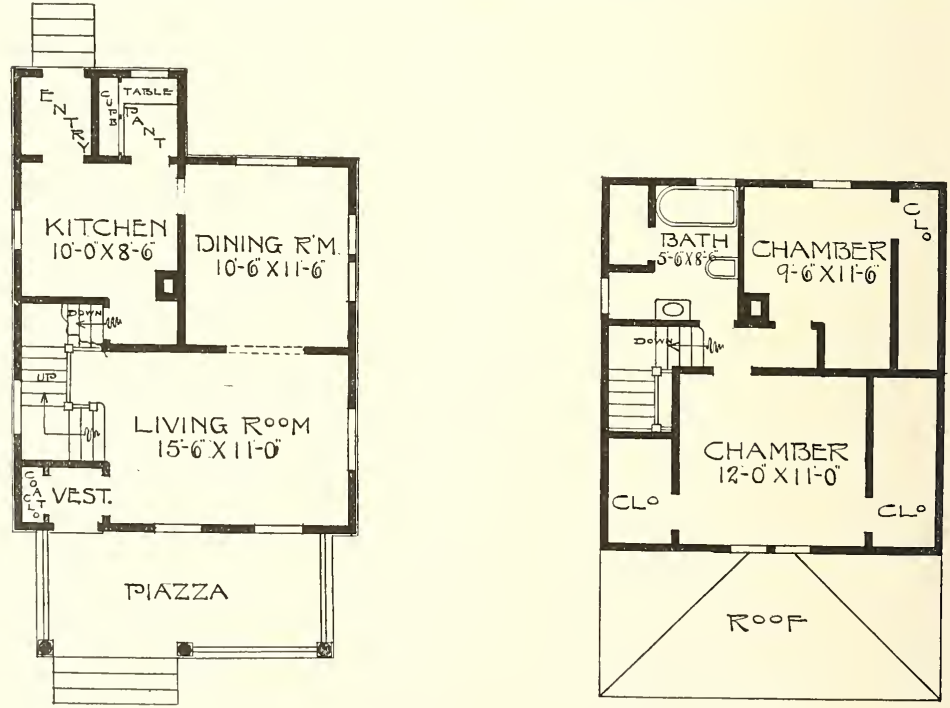

Complete plans and specifications for using Denison Load-Bearing Tile, licensed under Wilson-System Bearing W W 11 Construction for $\$ 20$. 


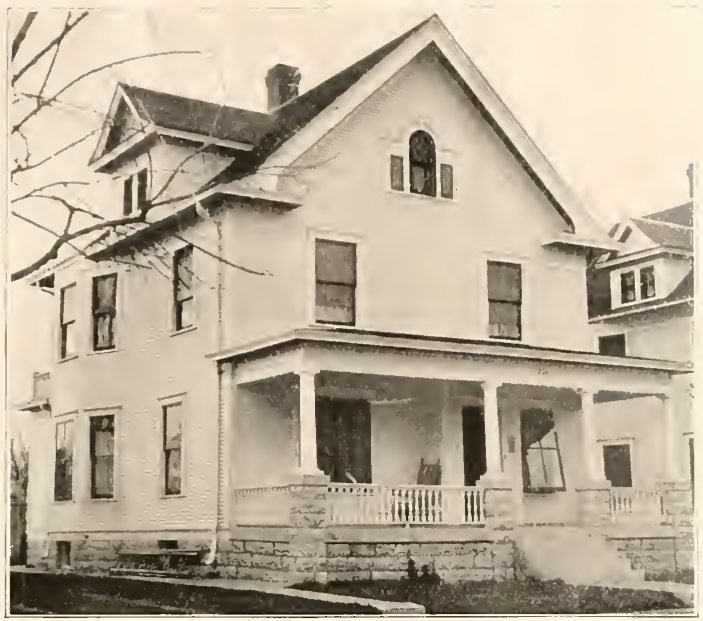

A Good Colonial Design-No. 732

This colonial design is adapted as either a city or suburban home. There are a reception room, living room and dining room and kitchen; also good sized pantry, entry and large closet from dining room which could be used for a small sewing room. Combination stairs from reception room and kitchen to second story, with grade stairs underneath. There is a balcony across the second story rear, and a sleeping porch with roof can be built here instead of open balcony. Full basement. Size, twenty-six feet wide and twenty-eight feet deep. First story finished in birch or gum, second story pine to paint, with birch or maple floors throughout both stories. Cost to build, $\$ 3,000$. Complete set of plans and specifications for $\$ 25$.
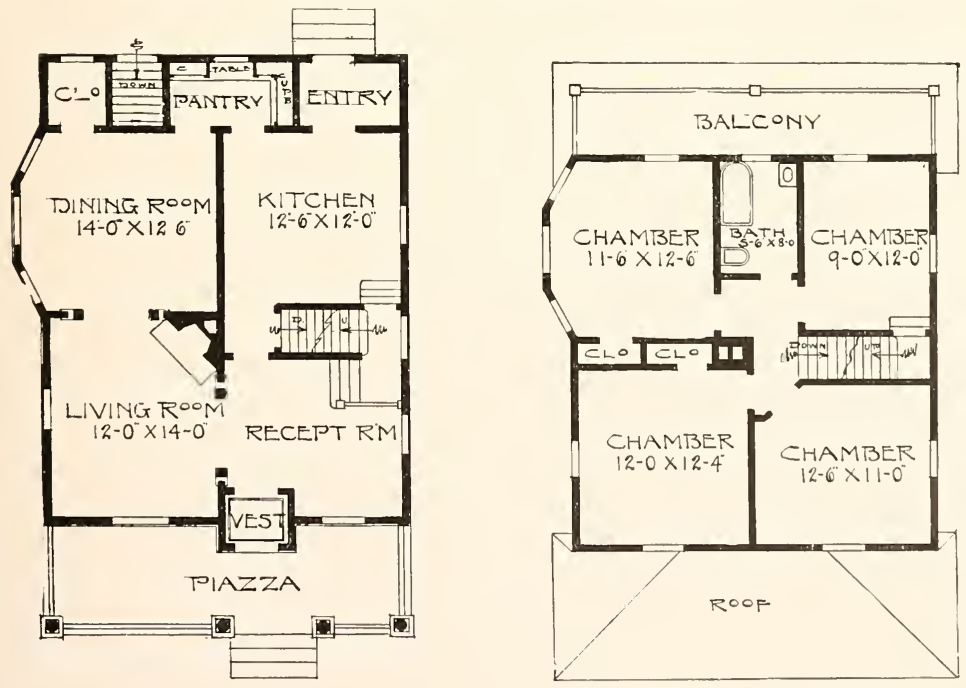

Complete plans and specifications for using Denison Load-Bearing Tile, licensed under Wilson-System Bearing IV a 11 Construction for $\$ 50$. 


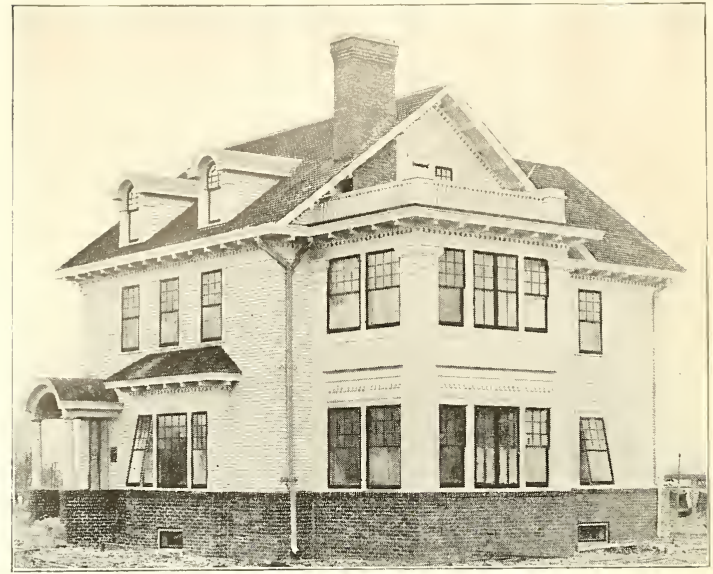

A Real Duplex-No. 973

Built in a city of over 8 or 10 thousand inhabitants will pay a revenue of from 15 to 18 per cent on your investment. We have also made an especial effort to make this residence look like an individual home.

The living room opens nicely with sun room with a French door onto the same. These sun rooms are combined and make liberal porches, both day and night. They are sashed and screened in and a wall bed is installed in each one, thus giving the capacity in each one of the apartments of two good chambers.

The dining room is in the rear of the living room and has a beautiful built-in sideboard. The kitchen has built-in cupboards, working table and everything that goes to make a small living apartment complete. The front stairway is 4 feet and the rear stairway is 3 feet 8 inches wide in the clear. The contract price of this includes two splendid chambers finished in the third story, one for each apartment. Finish gum throughout both stories with birch floors throughout.

Size 26 feet wide and 38 feet deep over the main part. The sun room is 10 feet 6 inches wide by 13 feet 10 inches long.

Cost to build, $\$ 4,400$. Complete set of plans and specifications for $\$ 35$.
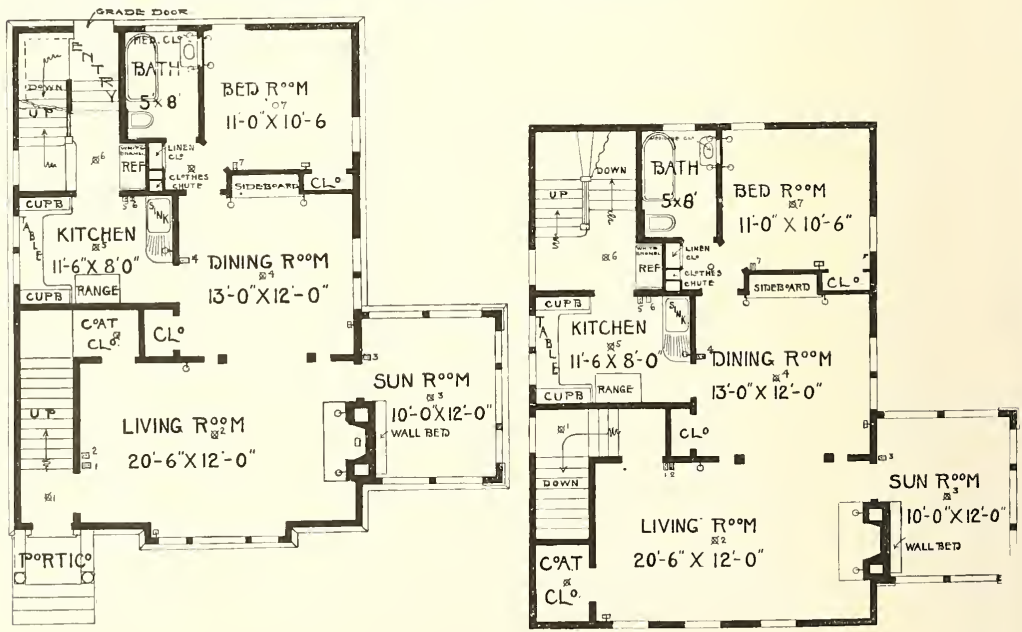

Complete plans and specifications for using Denison Load-Bearing Tile, licensed under Wilson-System Bearing $W$ a 11 Construction for $\$ 70$. 


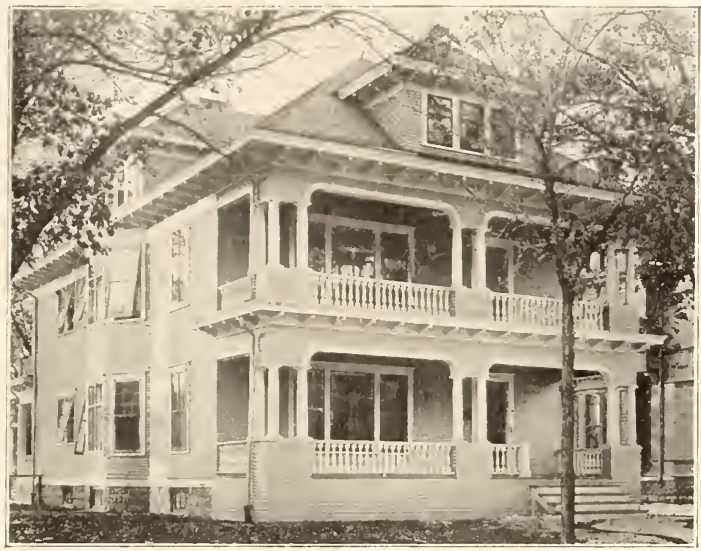

A Practical Home For Two Families-No, 974

The duplex has this advantage, that every room throughout the entire building has outside exposure, thus making it more sanitary, pleasanter to lise in and last but not least, that all of your rooms are on one floor, thus overcoming the necessity of having to climb up stairs from the main rooms to the chambers or bath room.

This duplex has all of the most modern features incorporated in same, that of large living room, beautiful dining room with beam ceiling. There are two large chambers, well lighted and
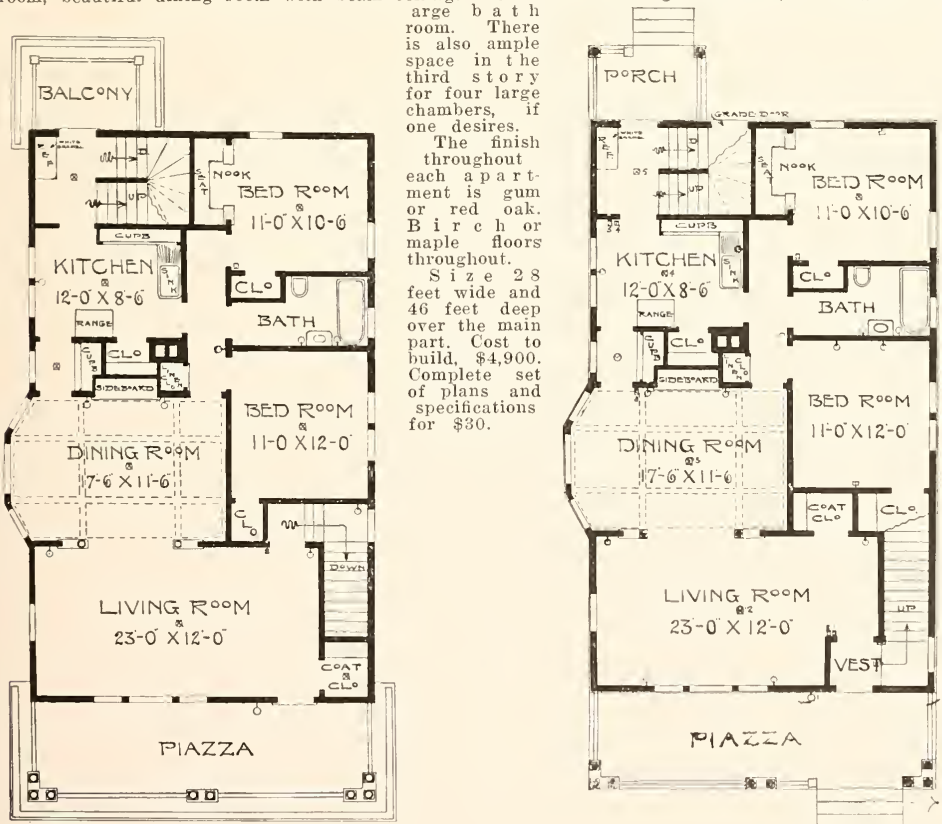

Complete plans and specifications for using Denison Load-Bearing Tile, licensed under Wilson-System Bearing IV a 11 Construction for $\$ 60$. 


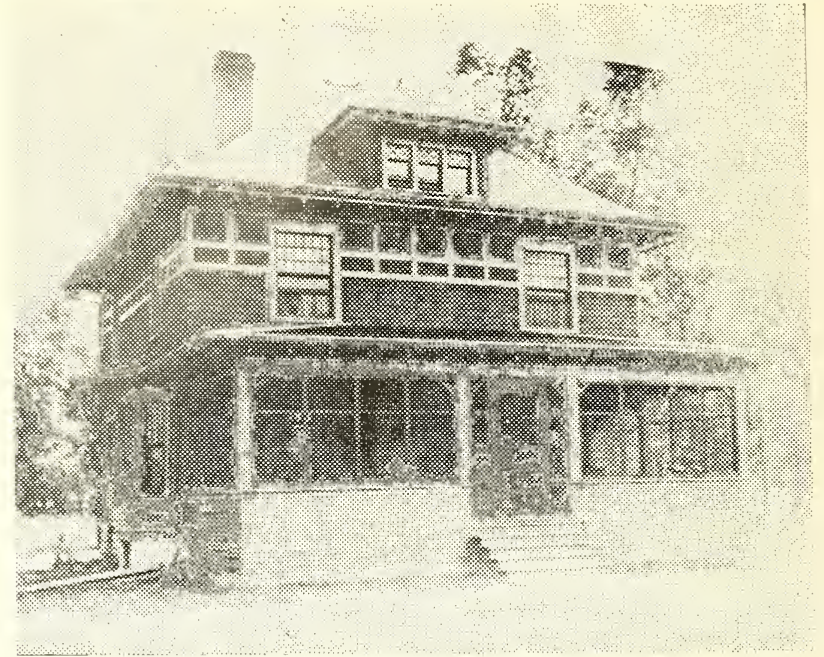

Attractive Design in Shingle and Siding Effect-No. 889

It is designed to have gum or birch finish in the first story, and pine to paint in second, with hardwood floors throughout. A full basement 7 feet 6 inches high; first story 9 feet, second story 8 feet 6 inches. Dimensions, 30x28 feet. Piazza floors and ceilings No. 1 Clear Washington fir. Cost to build, $\$ 3,250$. Complete set of plans and specifications for $\$ 25$.
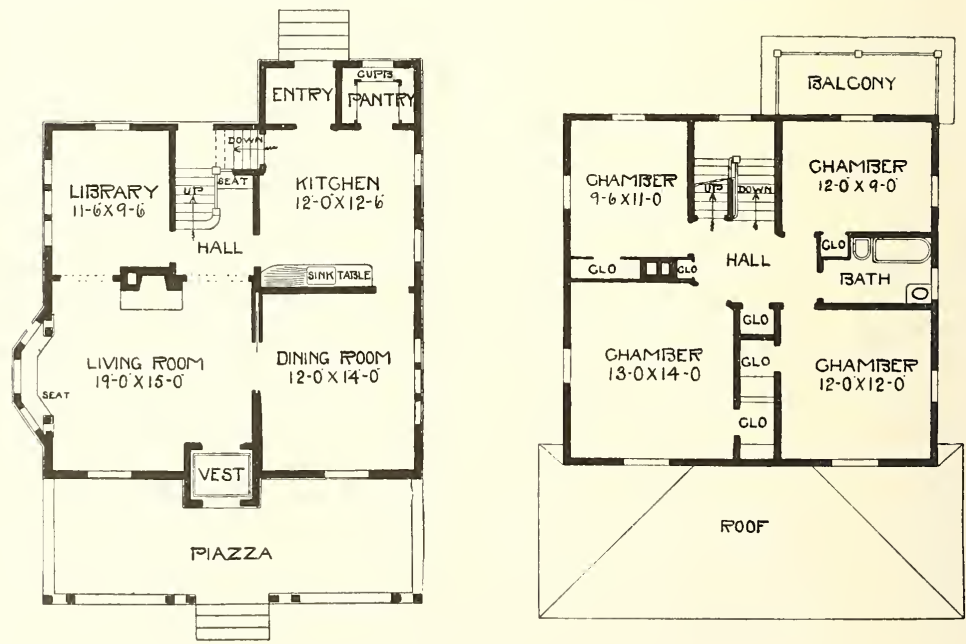

Complete plans and specifications for using Denison Load-Bearing Tile, licensed under Wilson-System Bearing Wal1 Construction for $\$ 50$. 


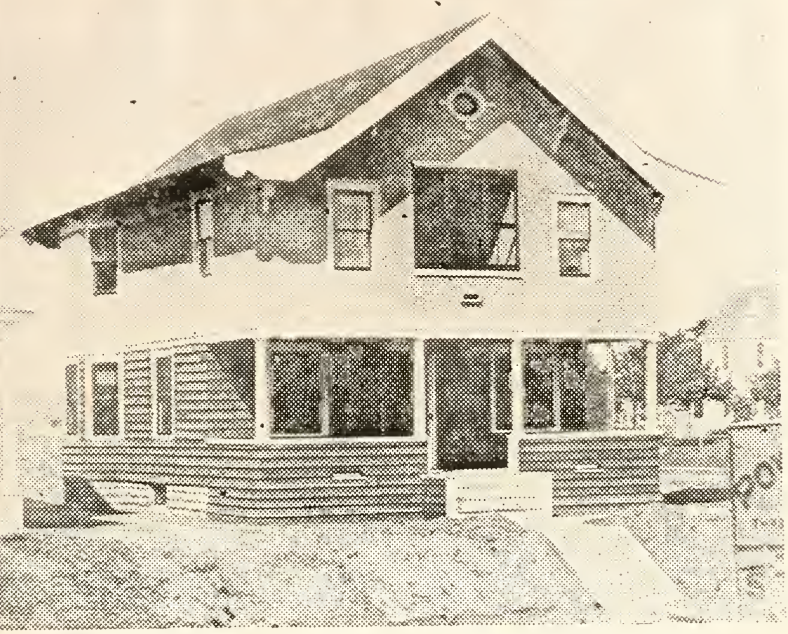

An Odd Design in Frame and Cement-No. 993

The size is 26 feet by 26 feet; full basement, 7 feet high, first story 9 feet, second story 8 feet. Finished in gum or birch in first story, pine to paint in the second; hardwood floors. Piazza floors and ceiling to be No. 1 Washington fir. Cost to build, $\$ 2,400$. Plans and specifications for $\$ 18$.

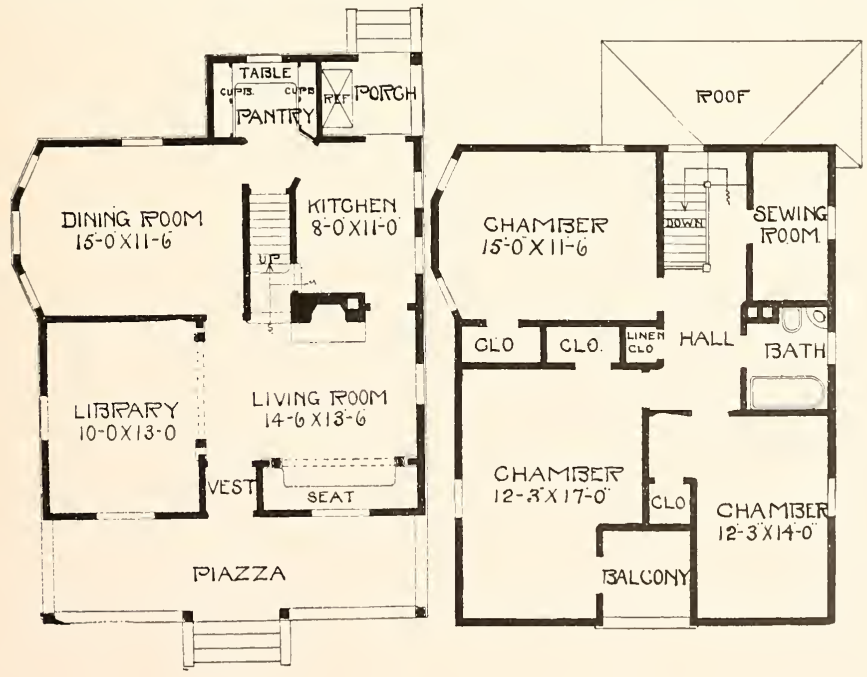

Complete plans and specifications for using Denison Load-Bearing Tile, licensed under Wilson-System Bearing $W$ a 11 Construction for $\$ 36$. 


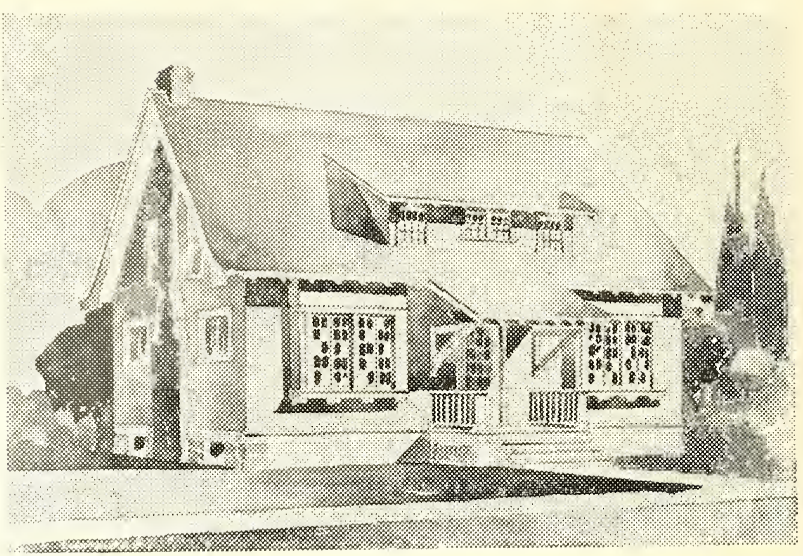

An Attractive and Practical Home-No. 874

This is a neat and well laid out little home, as well as being up-to-date. Anyone desiring to build a home of this size could not do better than to study this well. It is provided with a full basement, while on the first floor is a very generous living room, nice, well lighted hall and good sized dining room and kitchen. On the second floor are two extra large bedrooms and bath, with large closets. The exterior can be either rough cast cement, shingle or siding, as individual taste may require.

The size over all is $33 \times 22$ feet, with 9-foot ceilings on first floor and 8 -foot ceilings on second floor. The first story is finished in gum or birch. Piazza floors and ceilings to be No. 1 Clear Washington fir. Cost to build, $\$ 2,300$. Complete set of plans and specifications for $\$ 10$.

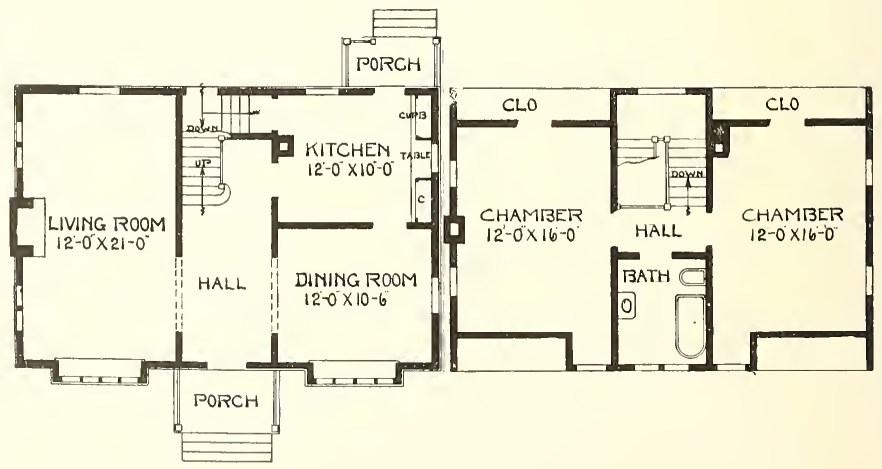

Complete plans and specifications for using Denison Load-Bearing Tile, licensed under Wilson-System Bearing W a 11 Construction for $\$ 20$. 


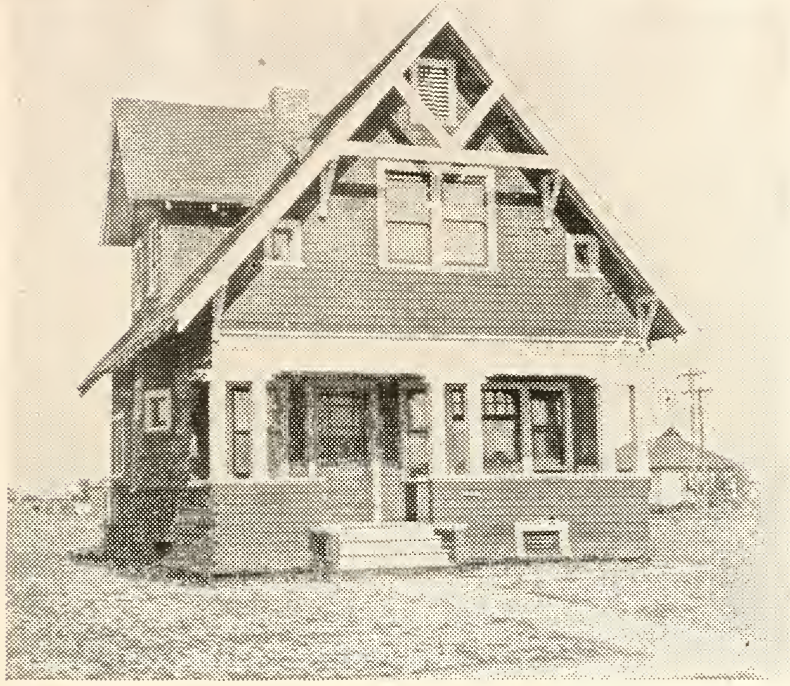

A Practical Economical Cottage-No. 867

The size over all is $25 \times 28$ feet 6 inches, and a full basement 7 feet in height is called for. The first floor is 9 feet, second 8 feet. First story finished in gum or birch. Piazza floors and ceilings to be No. 1 Washington fir. Cost to build, $\$ 2,000$. Complete set of plans and specifications for $\$ 15$.

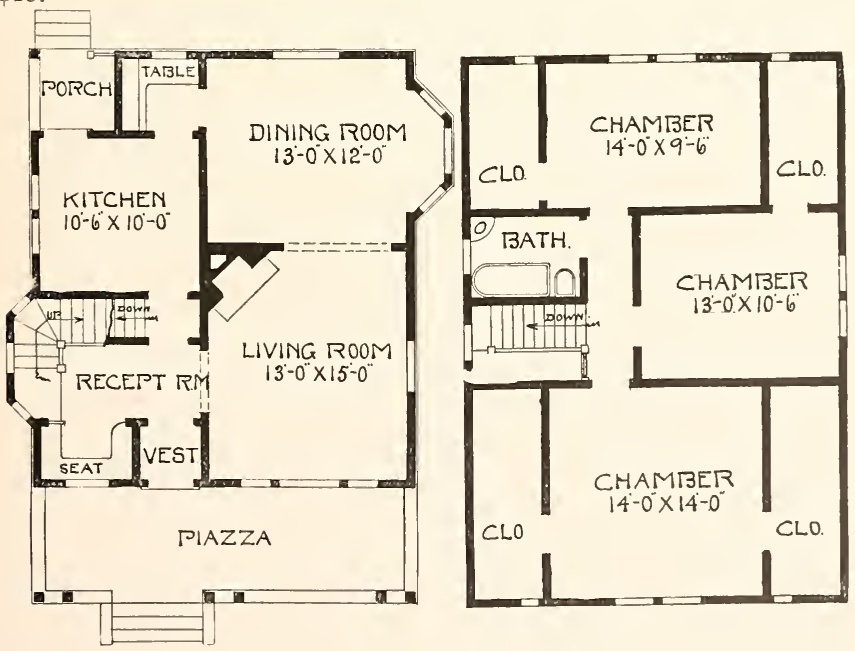

Complete plans and specifications for using Denison Load-Bearing Tile, licensed under Wilson-System Bearing $W$ all Construction for $\$ 30$. 


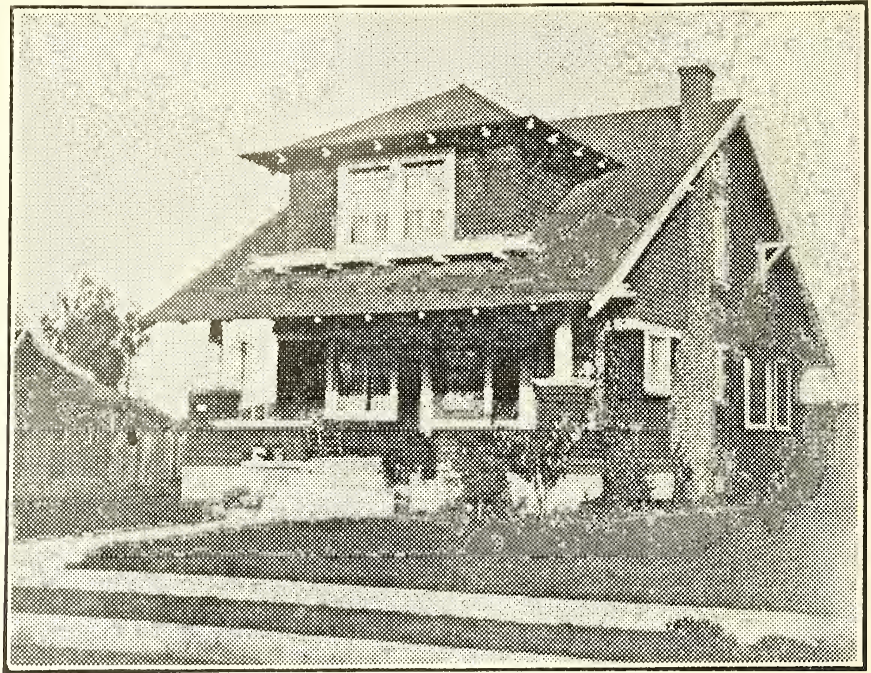

A Cottage by the Sea-No. 999

There is a full basement, 7 feet deep; first story 9 feet, second 8 feet. Width 25 feet over the main part, and depth 28 feet. Finish to be gum or birch in first story, pine to paint in second. Piazza floors and ceiling to be No. 1 Clear Washington fir. Cost to build, \$2,600. A complete set of plans and specifications for this beautiful cottage for $\$ 16$.

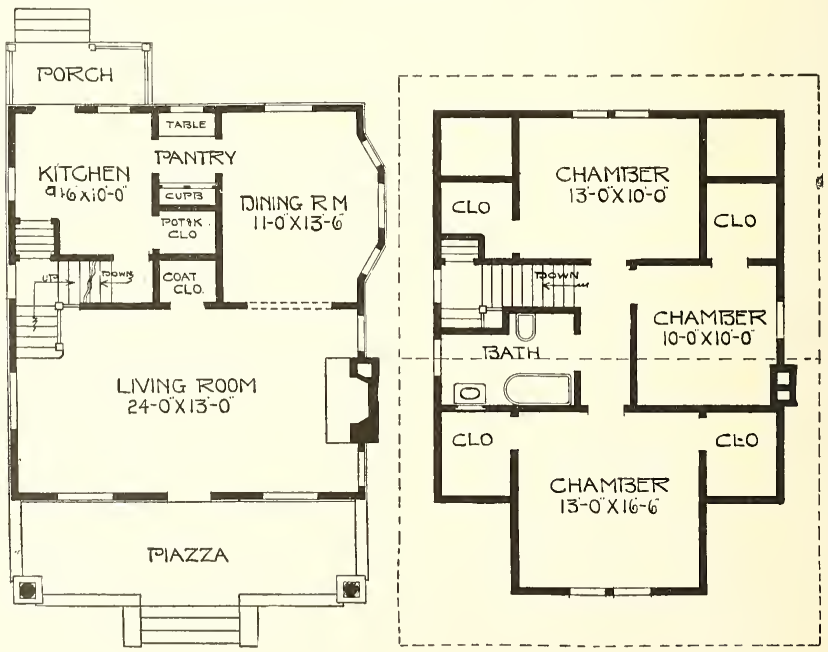

Complete plans and specifications for using Denison Load-Bearing Tile, licensed under Wilson-System Bearing $\mathrm{W}$ al1 Construction for $\$ 32$. 

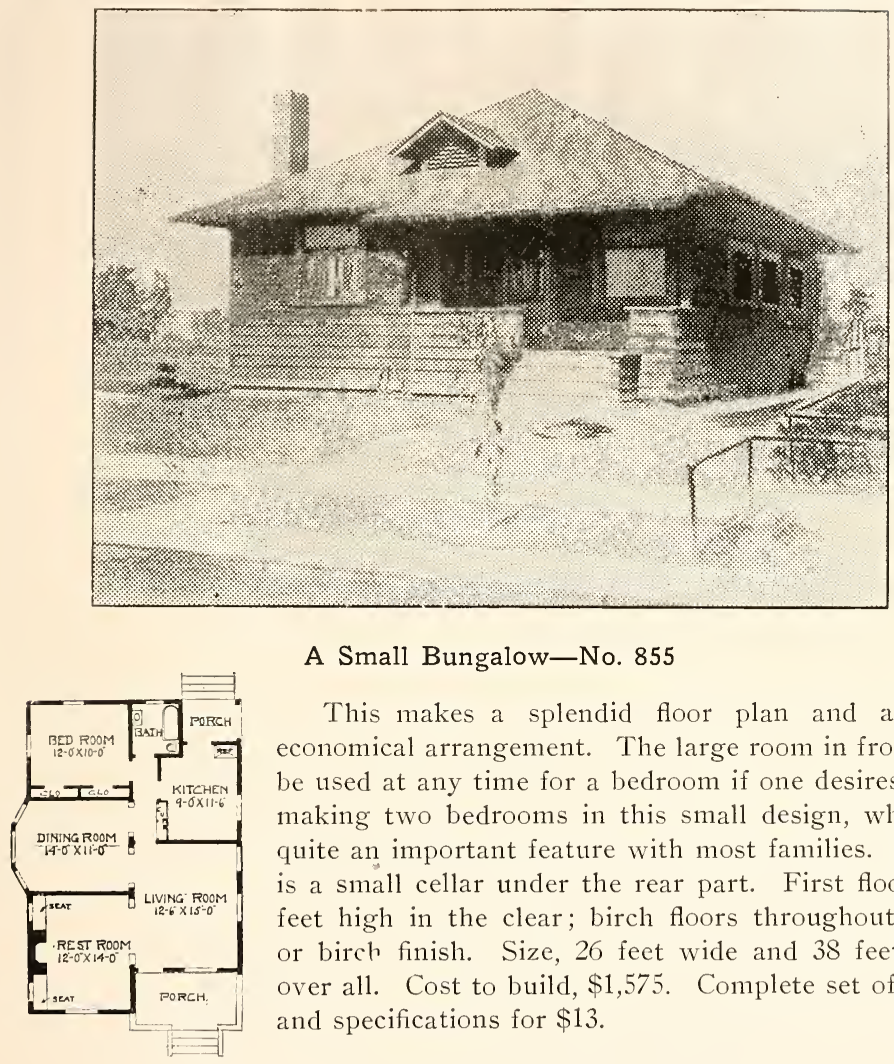

A Small Bungalow-No. 855

This makes a splendid floor plan and a very economical arrangement. The large room in front can be used at any time for a bedroom if one desires, thus making two bedrooms in this small design, which is quite an important feature with most families. There is a small cellar under the rear part. First floor is 9 feet high in the clear; birch floors throughout, gum or birch finish. Size, 26 feet wide and 38 feet deep over all. Cost to build, $\$ 1,575$. Complete set of plans and specifications for $\$ 13$. 


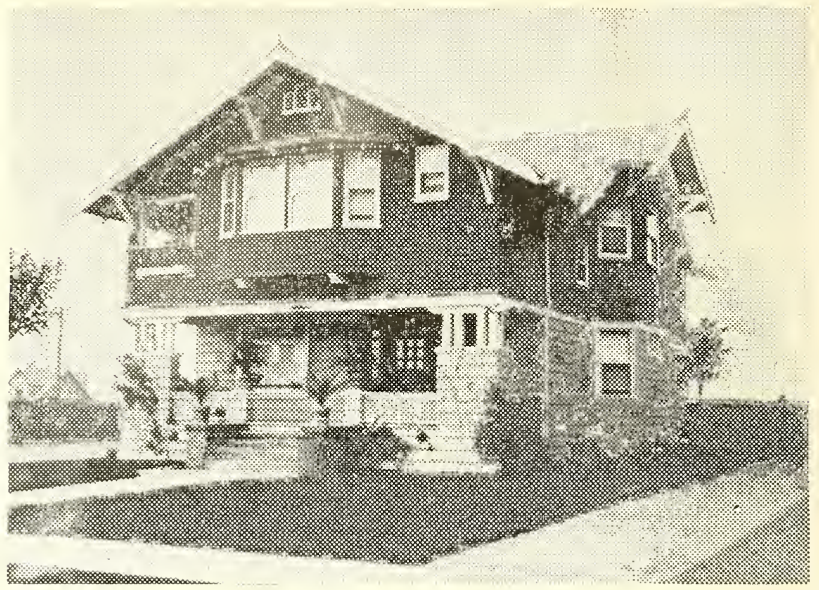

An Artistic Residence. Built in 1908-No. 864

Size, 28 feet wide and 30 feet deep over main part. First story 9 feet, second 8 feet. These heights are in the clear. Full basement under entire house. First story finished in gum or birch; second story pine to paint. Cost to build, $\$ 3,250$. Complete set of plans and specifications for $\$ 30$.

This is the house used in the introductory-showing the house built by the man who purchased an architect's plans.

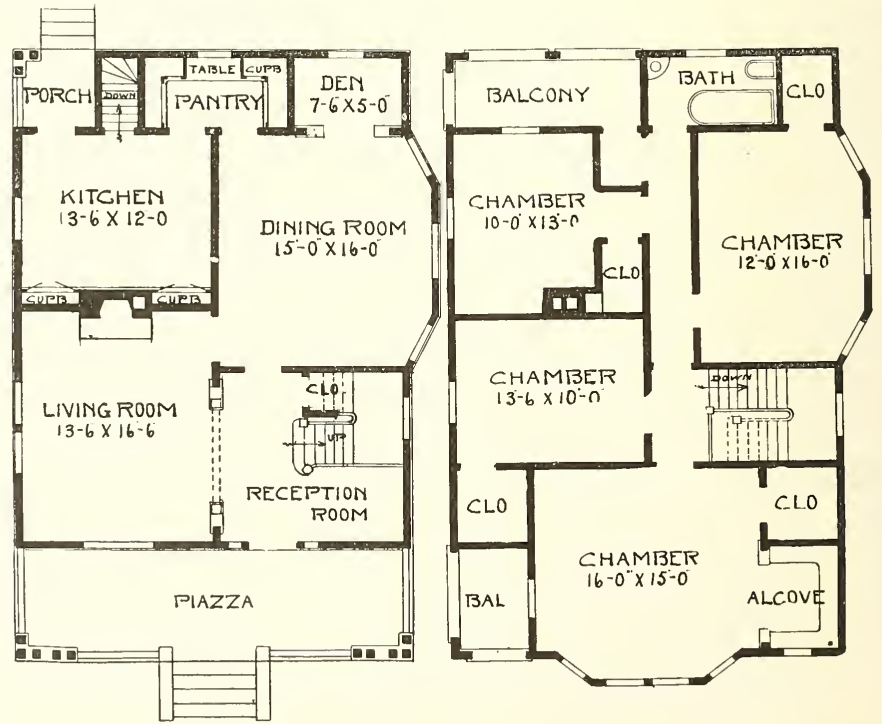

Complete plans and specifications for using Denison Load-Bearing Tile, licensed under Wilson-System Bearing Wal1 Construction for $\$ 60$. 


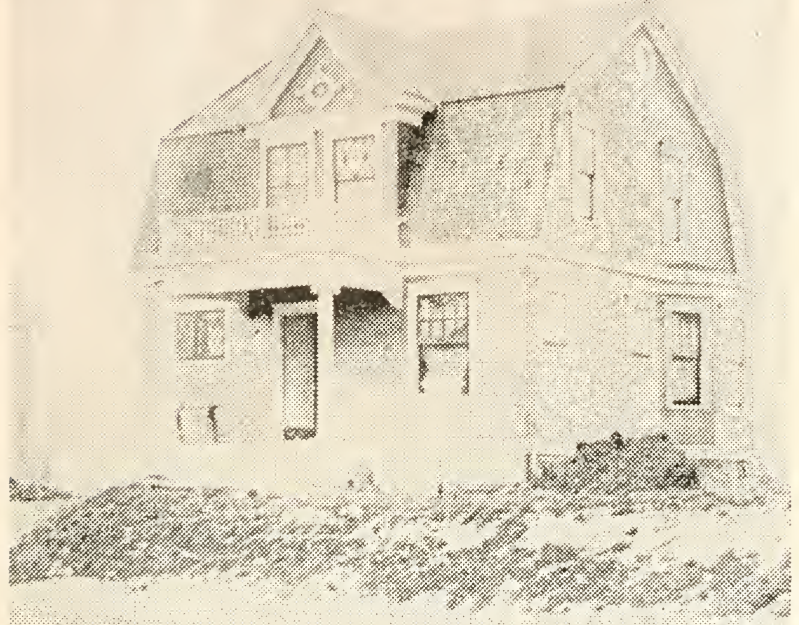

Gable Roof Cottage-No. 882

The front of house is made into one large living room. First story finished in gum or birch, second pine to paint. Piazza floors and ceiling $\mathrm{No}$. 1 Washington fir. Size, 26x22 feet orer main part, full basement; first story 9) feet, second 8 feet, birch floors throughout. Built in 1907, for \$2.200. Complete plans and specifications for $\$ 15$.
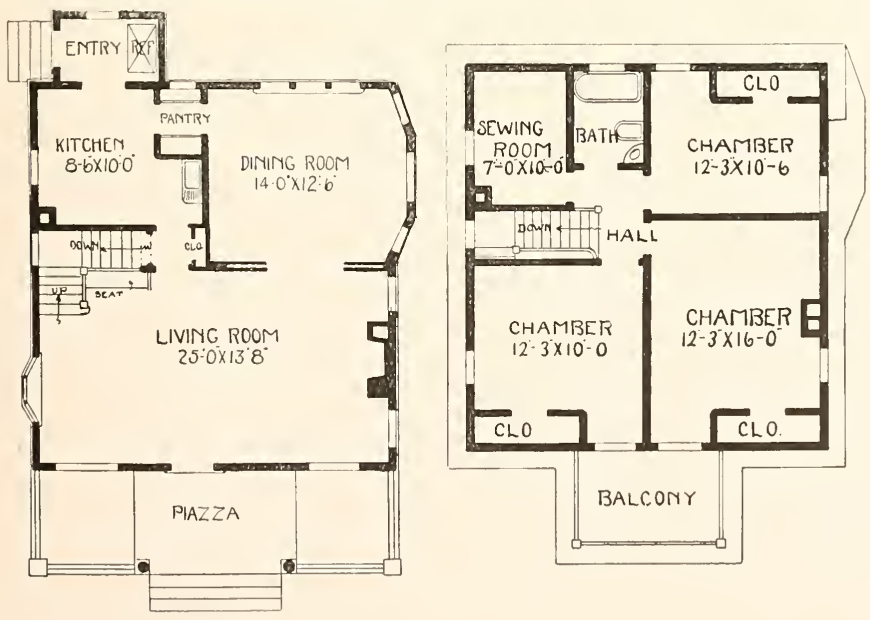

Complete plans and specifications for using Denison Load-Bearing Tile, licensed under Wilson-System Bearing $\mathrm{W}$ a 11 Construction for $\$ 30$. 


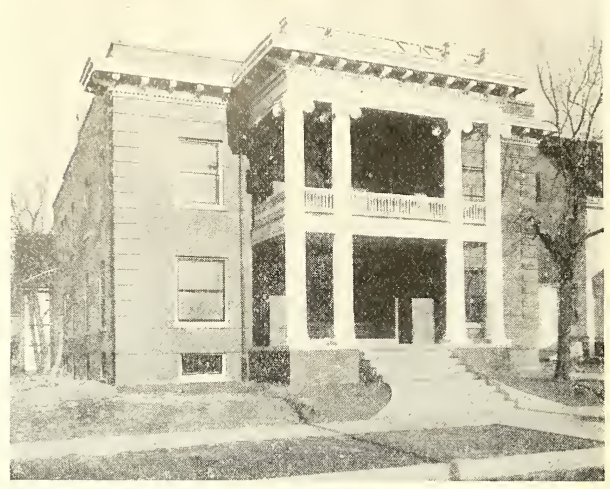

A Practical Four Flat Building-No. 850

The building is finished in red oak or gum, excepting kitchens and pantries, and all given a golden oak stain. The floors are white maple throughout. The exterior has an impressing appearance, being that of a sturdy colonial style of architecture, which will look the same twenty years from now that it does the day of the completion of the building. Size, $44 \times 62$ feet over the building proper. The cost to build complete, including four hot water heating plants, open plumbing, besides the laundry in basement, $\$ 11,500$. This building is paying as an investment 14 per cent. Two compete sets of plans and specifications for $\$ 100$.
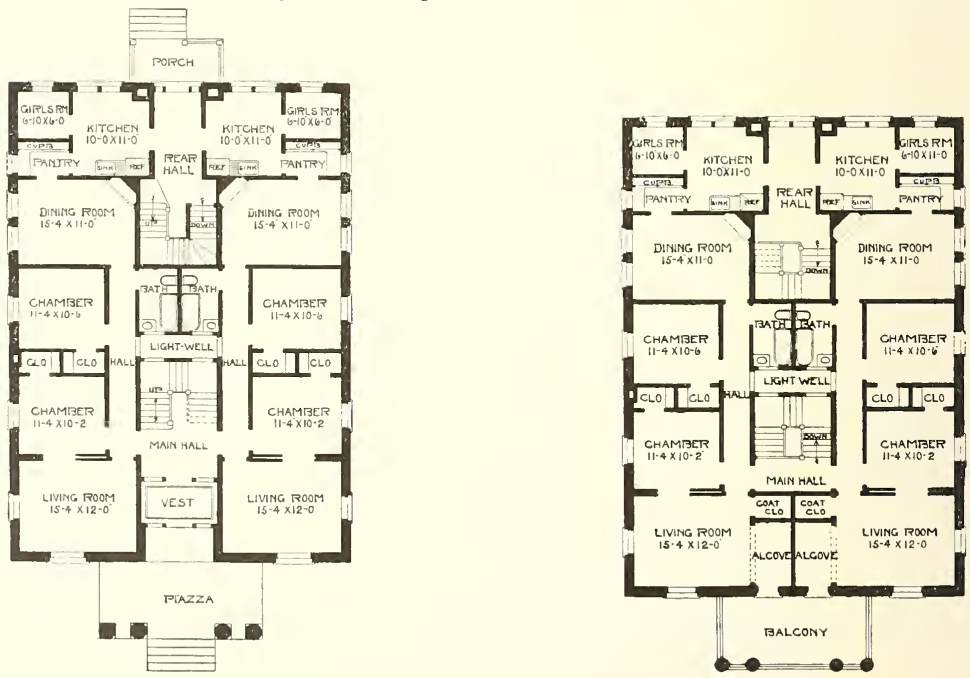

Complete plans and specifications for using Denison Load-Bearing Tile, licensed under Wilson-System Bearing Wa 11 Construction for $\$ 200$. 


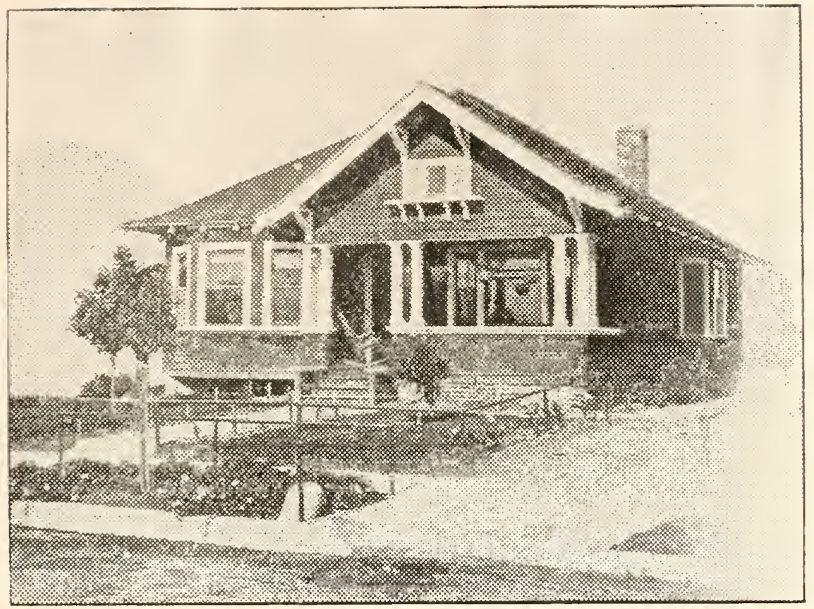

\section{A Comfortable Bungalow Home-No. 852}

I bungalow in this section of the country, that is, its name, seems to lose its significance. In the Southwestern section of the country where the bungalow originated, the term refers to a one story house only. A house that is a story and a half or two stories is never spoken of as a bungalow. I Te, in this section, have been educated to live in flat buildings; naturally the bungalow will appeal to us more than a two story or a story and a half building, and I dare say that within the next five or six years this type of

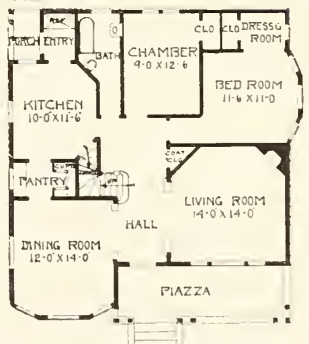
building is going to predominate over the whole United States. There is a basement under front of house. Ample room for laundry and heating room. First story is 9 feet in the clear. There is an abundance of store rooms in the attic, and if you choose you can finish two rooms in this space, but it is not intended to be finished at this price. Hardwood floors throughout. Birch or gum finish in all rooms except the two bedrooms, which are to be pine to paint. Size, 34 feet wide and 36 feet deep, including the piazza. Cost to build, $\$ 2,100$. Complete set of plans and specifications for this design for $\$ 15$.

Complete plans and specifications for using Denison Load-Bearing Tile, licensed under Wilson-System Bearing $W$ a 11 Construction for $\$ 30$. 


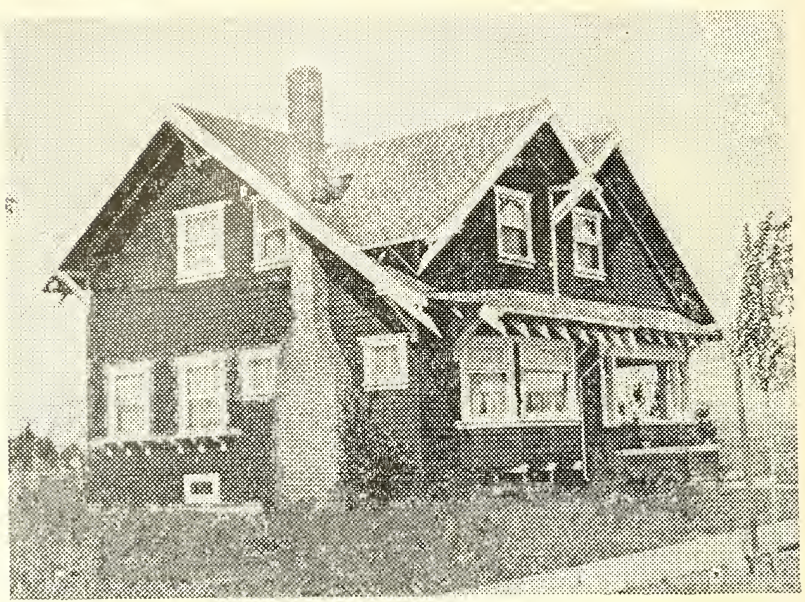

\section{A Snappy Home-No. 853}

The house is 37 feet wide and 26 feet deep. There is a full basement 7 feet high. The first story is 9 feet and the second 8 feet; these heights all in the clear. Birch floors are used throughout, with gum or birch finish in the first story and pine to paint in the second. Cost to build, $\$ 3,000$. Complete set of plans and specifications for this beautiful house for $\$ 25$.
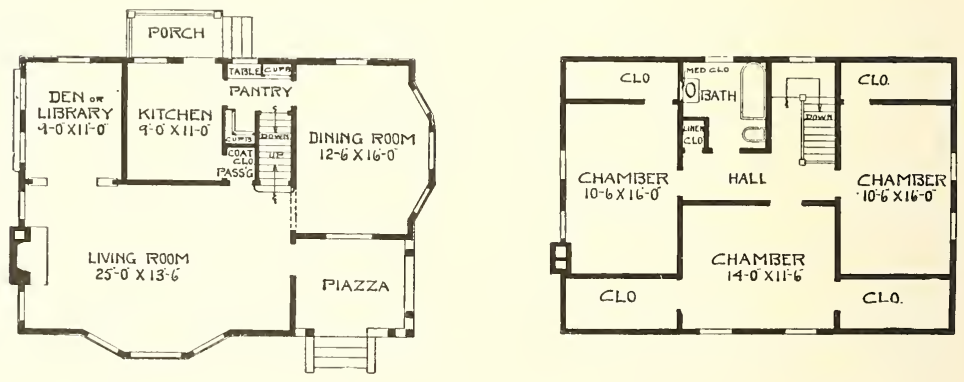

Complete plans and specifications for using Denison Load-Bearing Tile, licensed under Wilson-System Bearing $W$ a 11 Construction for $\$ 50$. 


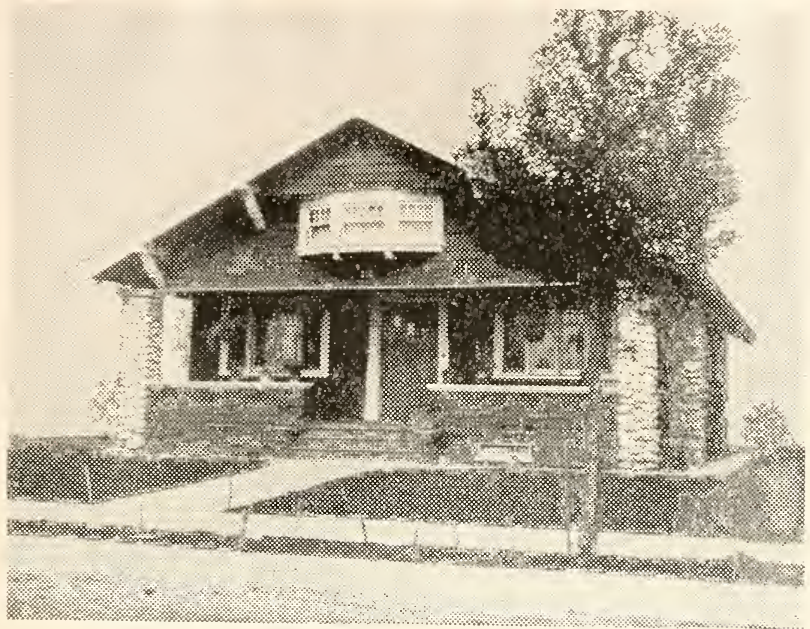

A Bungalow of Sunshine-No. 863

The size of the house is 28 feet square over the main part. There is a full basement 7 feet deep. The first story is 9 feet in the clear, second story 8 feet. This bungalow is planned to be finished in gum throughout first story, and pine to paint in the second, with birch floors throughout. Cost to build, $\$ 2,210$. Complete set of plans and specifications of this bungalow for $\$ 16$.

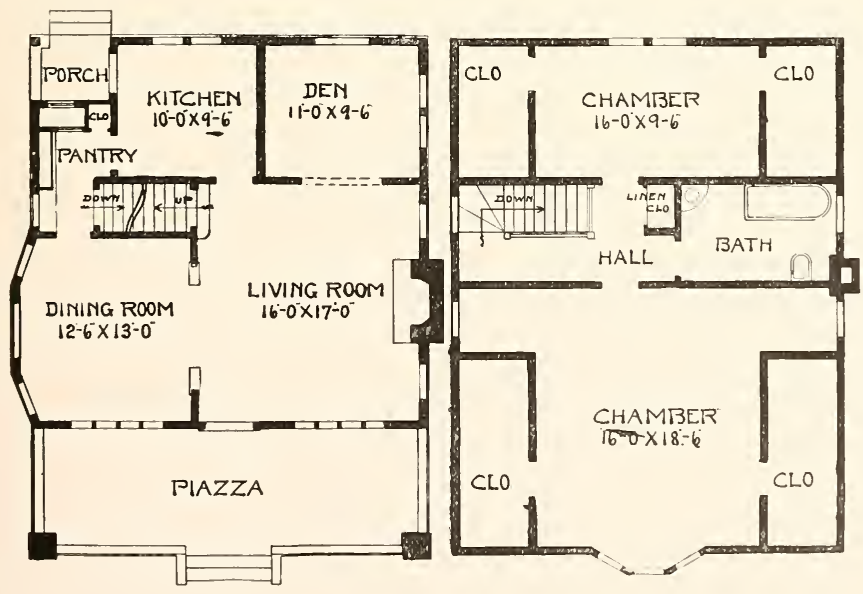

Complete plans and specifications for using Denison Load-Bearing Tile, licensed under IVilson-System Bearing IV a 11 Construction for $\$ 32$. 


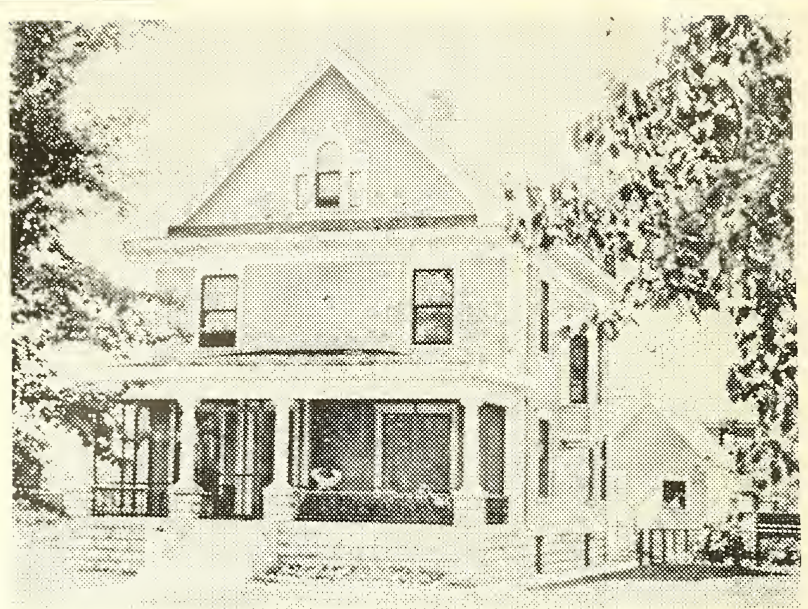

An Attractive Colonial Design-No. 888

First story finished in gum, second pine to paint, birch floors throughout, full basement 7 feet high, first story 9 feet, second 8 feet 6 inches. Size $28 \times 32$ feet. Cost to build, $\$ 4,100$. One complete set of plans and specifications for $\$ 25$.

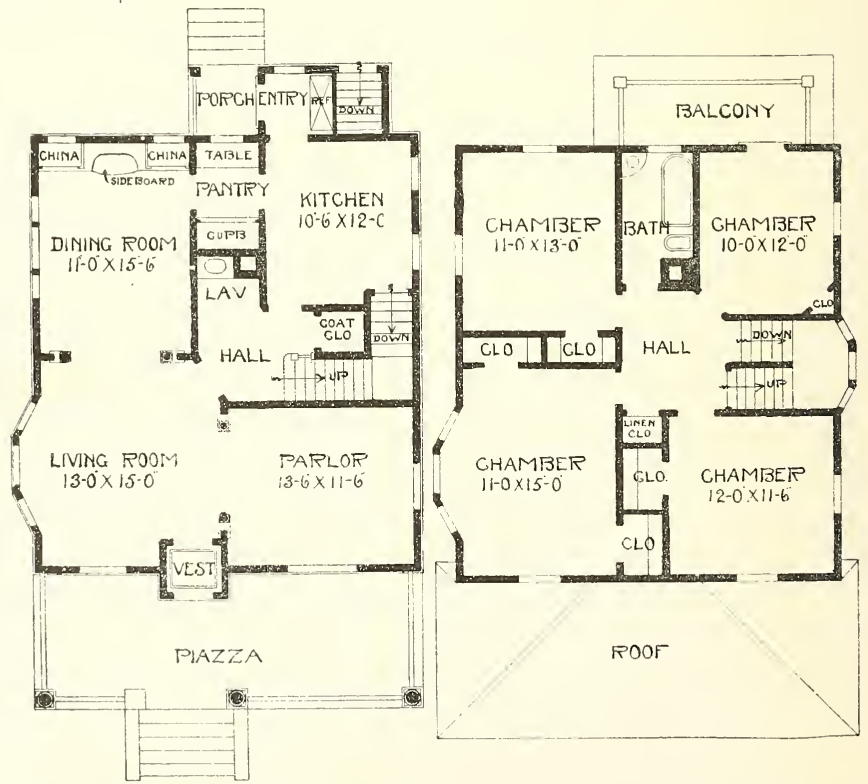

Complete plans and specifications for using Denison Load-Bearing Tile, licensed under Wilson-System Bearing W a 11 Construction for $\$ 50$. 


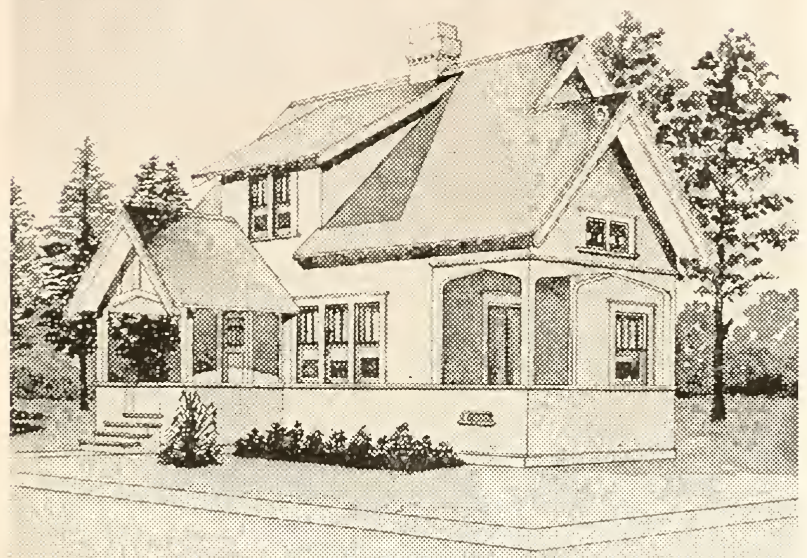

A Home That Has Character-No. 884

The house is 28 feet wide and 26 feet deep over the main part. The first story is 9 feet, second story 8 feet. The chambers in the second story finish up full height and are very desirable rooms. The entire house is finished in gum or red oak. Piazza floors and ceilings to be No. 1 Washington fir. Cost to build, $\$ 2,250$. One complete set of plans and specifications, $\$ 17$.

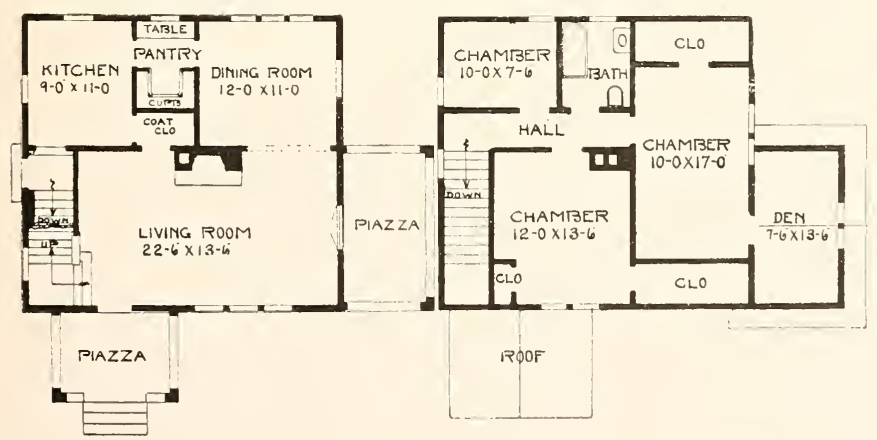

Complete plans and specifications for using Denison Load-Bearing Tile, licensed under Wilson-System Bearing IV a 11 Construction for $\$ 34$. 


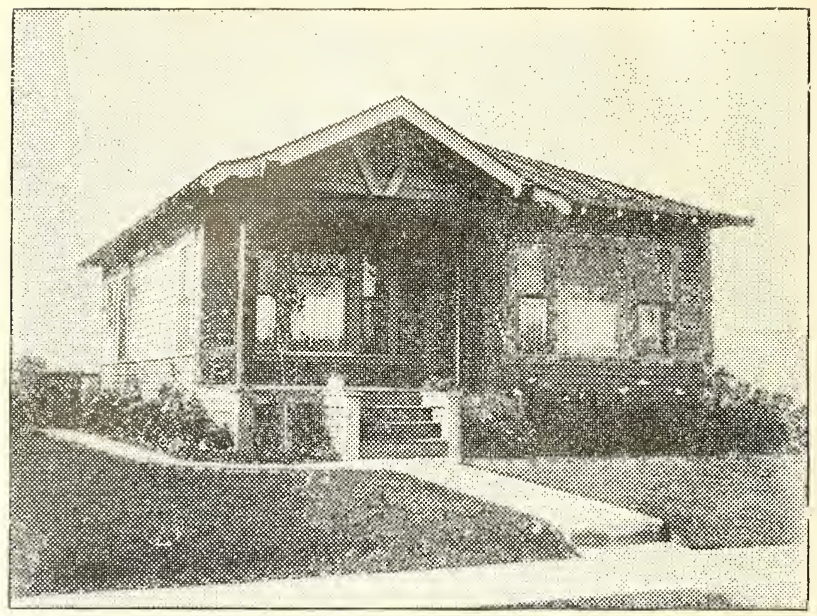

A Little Home For Two-No. 856

Here is a little bungalow with just enough space for two. There is a beautiful large living room, nice dining room, built-in sideboard, coat closet, bedroom, bathroom and everything to make a home complete. If you are looking for a bungalow for a small family, here is one that has the world beat.

The first story is 9 feet in height in the clear. Birch floors throughout. Finish is gum. The size is 24 feet

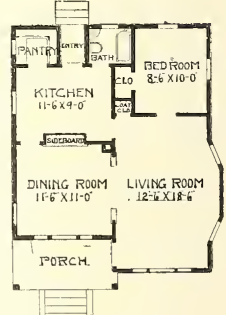
wide and 30 feet deep over all. Cost to build, $\$ 1,355$. Complete set of plans and specifications for $\$ 13$.

Complete plans and specifications for using Denison Load-Bearing Tile, licensed under Wilson-System Bearing $W$ a 11 Construction for $\$ 26$. 


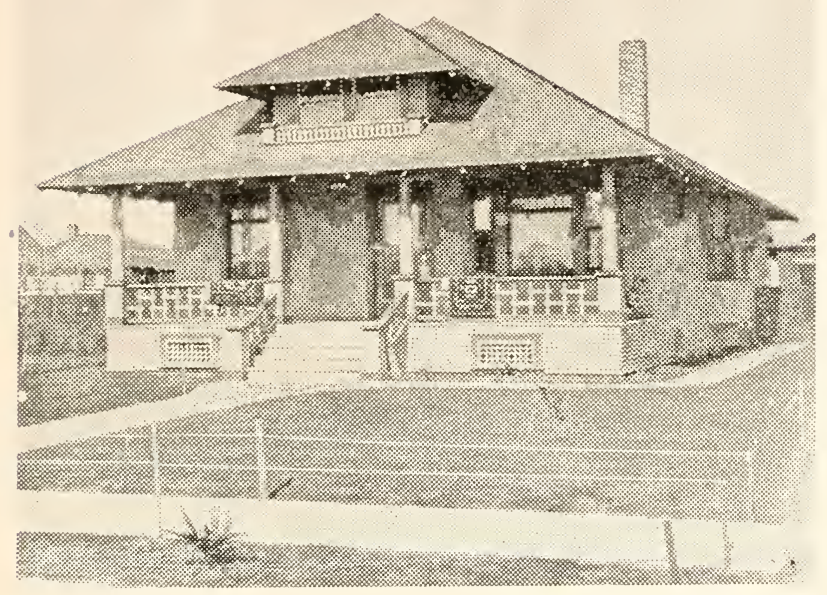

A Homelike Cottage-No. 868

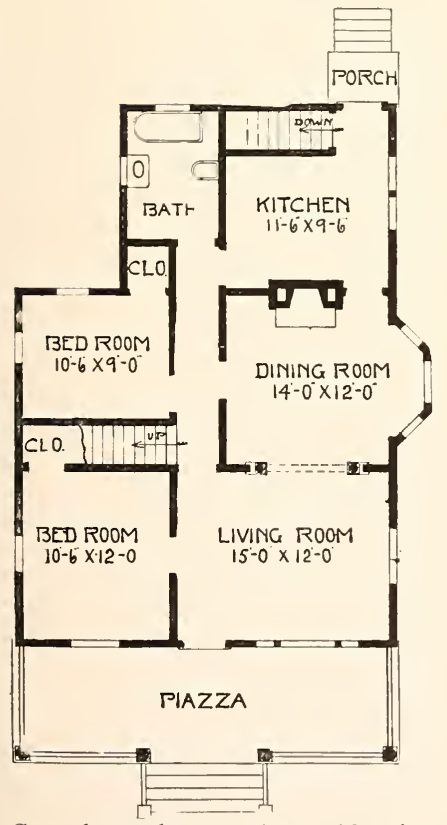

In this design I present something which is in great favor on the coast, and though only the first floor is finished, there is ample room on the second floor for a couple of small rooms. Because of its simplicity it should also prove to be an economical house to build. The rooms are all of generous size. The size over all is 27 feet by 38 feet. The basement is 7 feet high and the first floor is 9 feet. Either a large or small basement can be had at the option of the builder.

The exterior is sided though either shingles or plaster would look well.

Cost to build, $\$ 2,000$. One complete set of plans and specifications for $\$ 12$.

Complete plans and specifications for using Denison Load-Pearing Tile, licensed under IVilson-System Bearing IV a 11 Construction for $\$ 2 t$. 


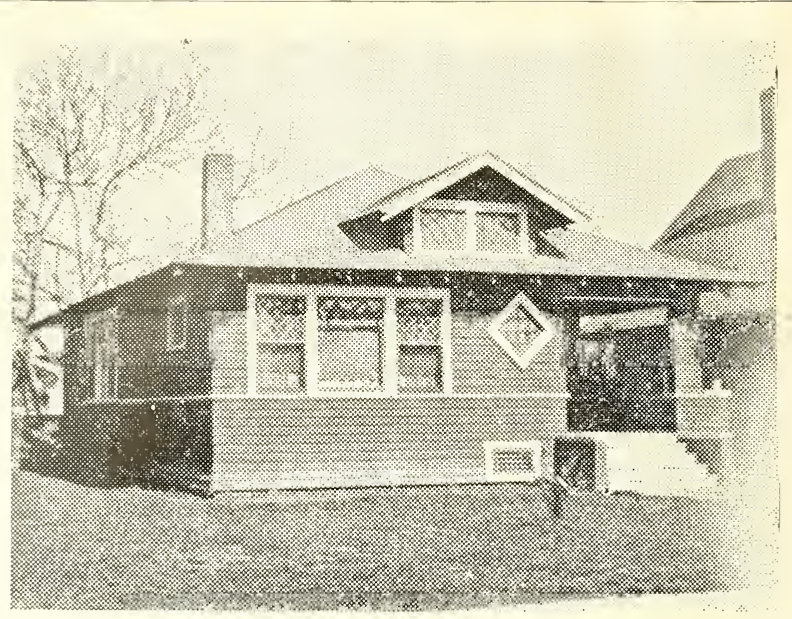

An Attractive Bungalow-No. 876

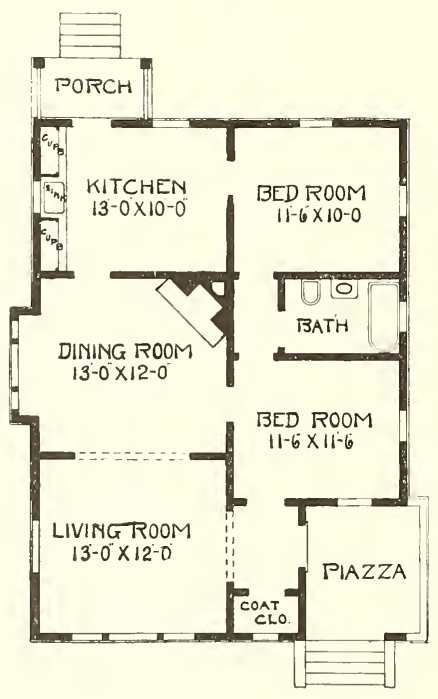

Anyone wishing to build a bungalow, or a home where all the rooms are on one floor, could not well find a more attractive design than this.

A small cellar is provided beneath the kitchen, but a full basement could be had if desired.

The rooms are 9 feet in height, the bungalow is planned for hardwood floors throughout. The finish is gum. Size of the bungalow is 26 feet wide by 36 feet deep. The exterior can be sided or shingled. Piazza floors and ceilings to be No. 1 Clear Washington fir.

Cost to build, $\$ 1,800$. One complete set of plans and specifications for $\$ 12$. 


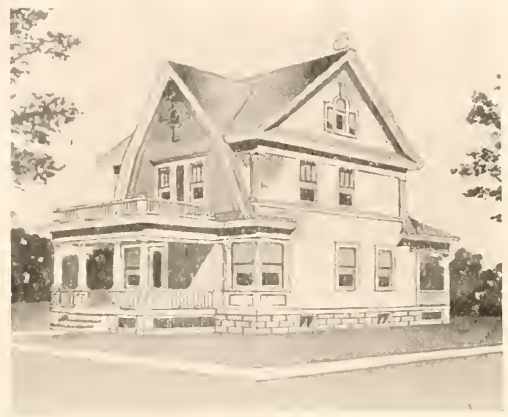

\section{Design-No. 851}

The residence design is that of a much more pretentious building being a full two story house which you will discover by examining the exterior and floor plans carefully, but the double pitched gable in front really gives the effect of a cottage exterior. There is also an unusually large attic which can be used for amusement or a billiard room.

27 feet wide and 28 feet deep over the dining room side. The rooms are nicely arranged there being a library in front, which can be used as a music room, den, or even a bedroom, if one desires, by closing it off with a sliding door. There could be a door cut through from this room into the hall, so as to be able to go into the second story without going through the living room. The stairs lead to the attic from the hall, and in the first story there is a combination so that you can go from the kitchen as well as from the front way. First story finished in gum or red oak, second story pine to paint. This house will cost $\$ 3,200$ to build. Complete set of plans and specifications for the sum of $\$ 25$.
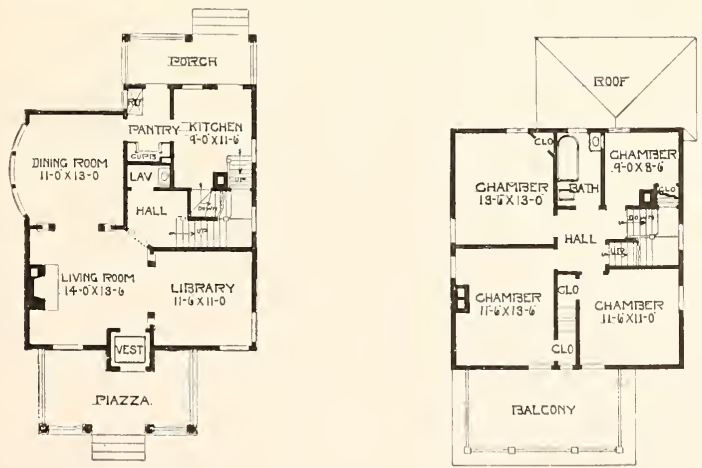

Complete plans and specifications for using Denison Load-Bearing Tile, licensed under Wilson-System Bearing W a 11 Construction for $\$ 50$. 


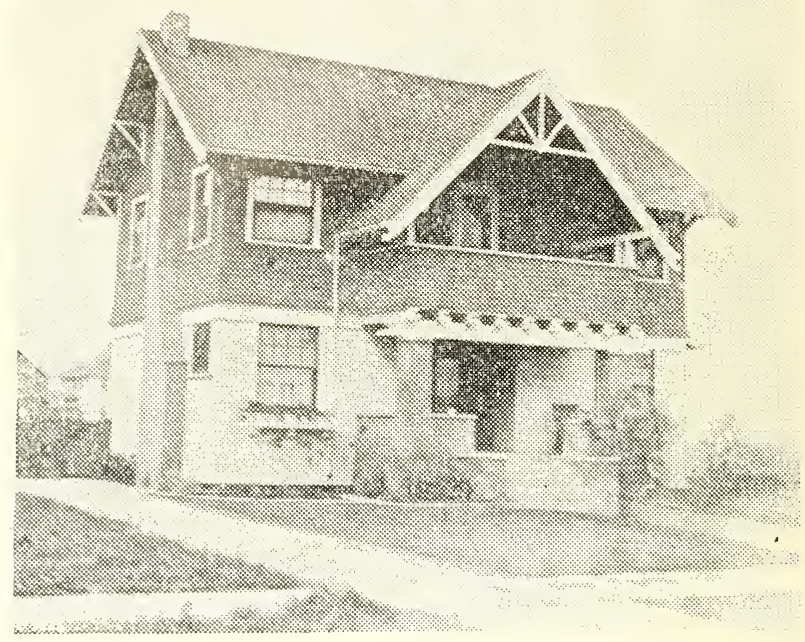

A Model Home-No. 865

The first story is finished in red oak or gum, second story in pine to paint. Size is 33 feet 6 inches wide by 25 feet 6 inches deep over main part. It has a full basement. First story is 9 feet, second 8 feet in the clear. First story sided, second story shingled on outside. Cost to build, $\$ 2,500$. Complete set of plans and specifications of this design for $\$ 25$.

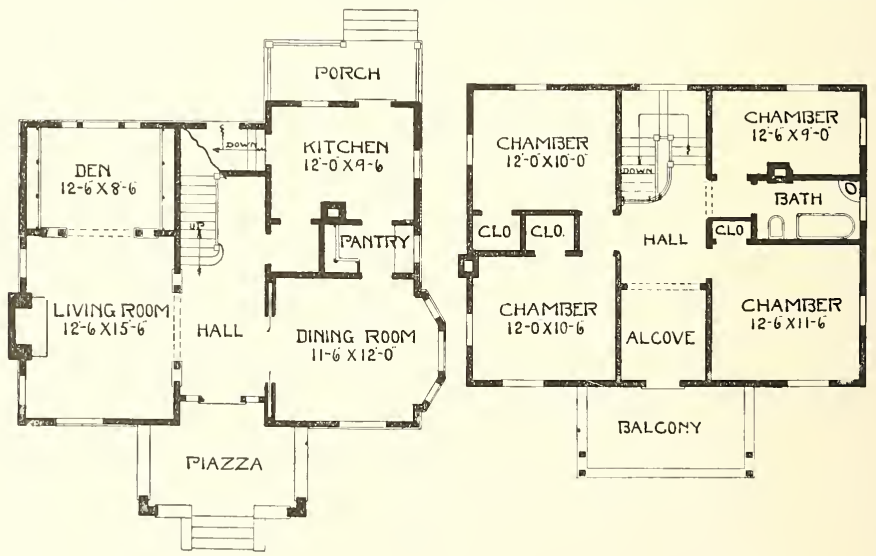

Complete plans and specifications for using Denison Load-Bearing Tilc, licensed under Wilson-System Bearing W W 11 Construction for $\$ 50$. 


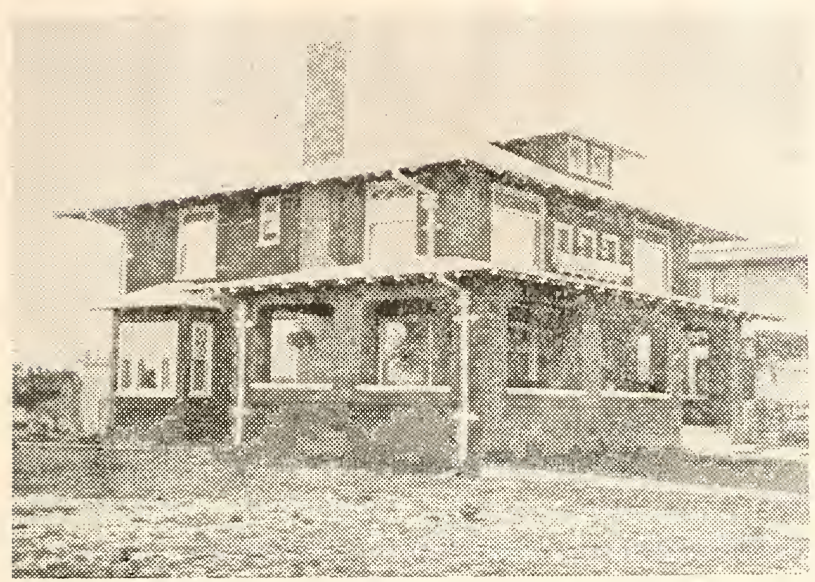

A Beautiful Modern Home-No. 869

In this home we have a somewhat more expensive house than usual, but anyone desiring to build a home of this style and size could not do better than to examine this carefully, then pay us a visit. The floors throughout are of hardwood. Finish in first story gum or birch, while the finish of the second story is white enamel. Full basement 7 feet high, the first story 9 feet, second 8 feet 6 inches in the clear. The exterior is of shingles, though rough cast cement would look well. The size over the main body is $34 \times 30$ feet, and all the rooms are of ample size, as may be seen by the drawings. Cost to build, $\$ 4,800$. Complete set of plans and specifications for $\$ 30$.
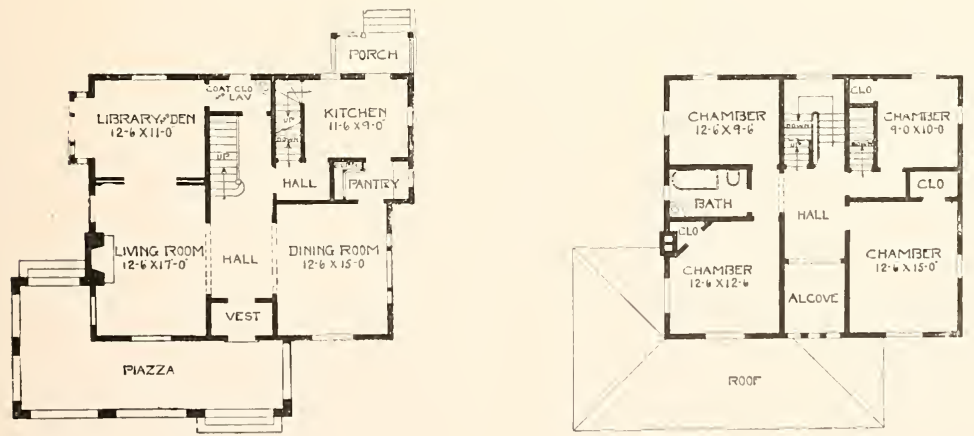

Complete plans and specifications for using Denison Load-Bearing Tile, licensed under Wilson-System Bearing W a 11 Construction for $\$ 60$. 


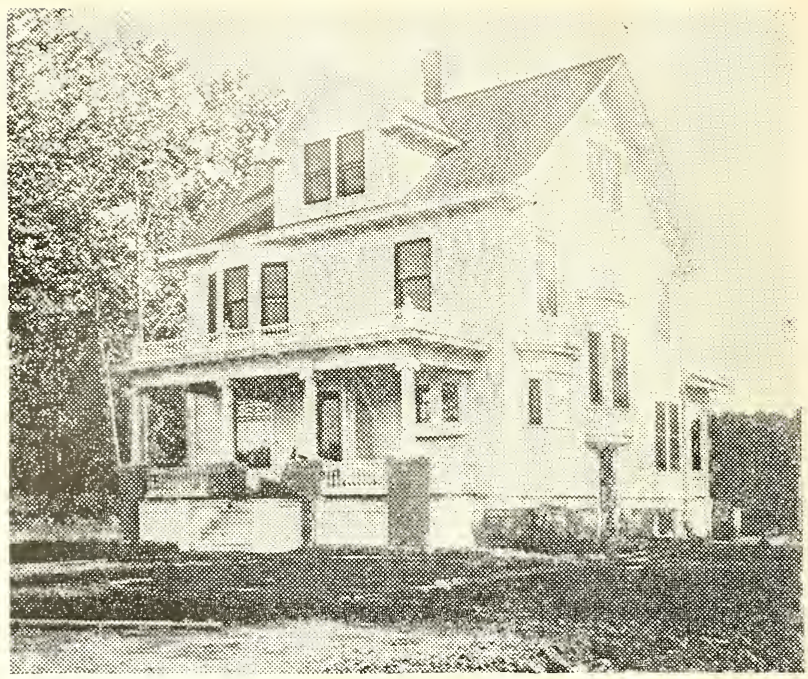

A Popular Colonial Home-No. 886

The first story is finished in gum or birch, birch floors in first and second story, finish pine to paint in second story. Size, 30 feet wide by 28 feet deep. First story is 9 feet, second story 8 feet.

Cost to build, $\$ 4,100$. Complete plans and specifications for $\$ 25$.

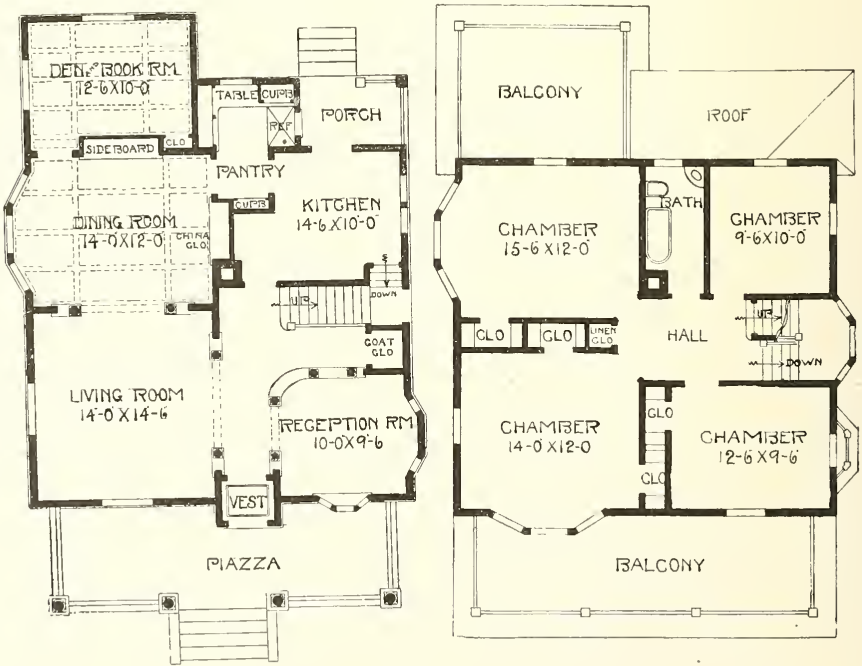

Complete plans and specifications for using Denison Load-Bearing Tile, licensed under Wilson-System Bearing $\mathrm{W}$ a 11 Construction for $\$ 50$. 


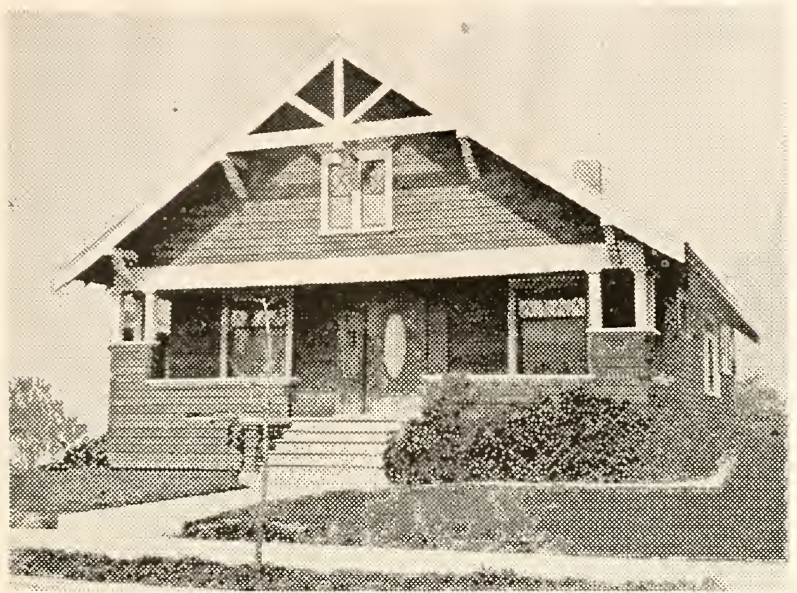

A Bungalow With All Comforts-No. 862

Here is a beautiful living room that is 27 feet wide and 14 feet deep. size of house is $2 s$ feet wide and 36 feet over main part. The first story is 9 feet, second $s$ feet. There is a basement under the rear portion that comes up on a line with the rear wall of living room, which gives ample spare for a heating plant, fuel room, also regetable cellar and laundry. The first story is finished in birch or gum, second in pine to paint with birch floors throughout. Cost to build, $\$ 2,300$. Complete set of plans and specifications of this design for $\$ 20$.
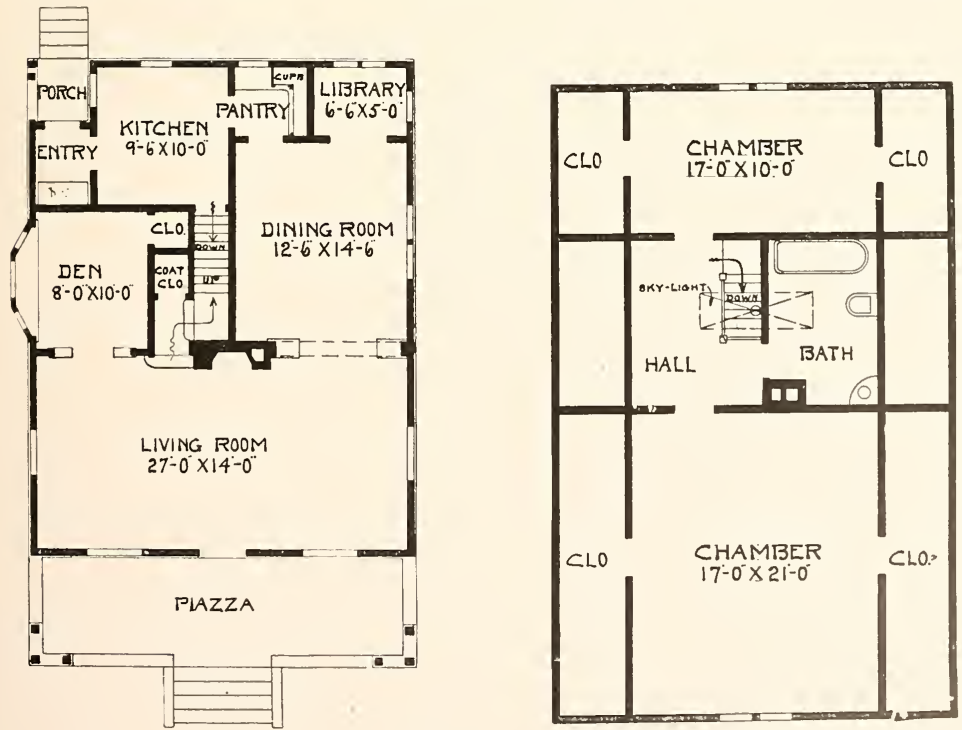

Complete plans and specifications for using Denison Load-Bearing Tile, licensed under Wilson-System Bearing IV a 11 Construction for $\$ 40$. 


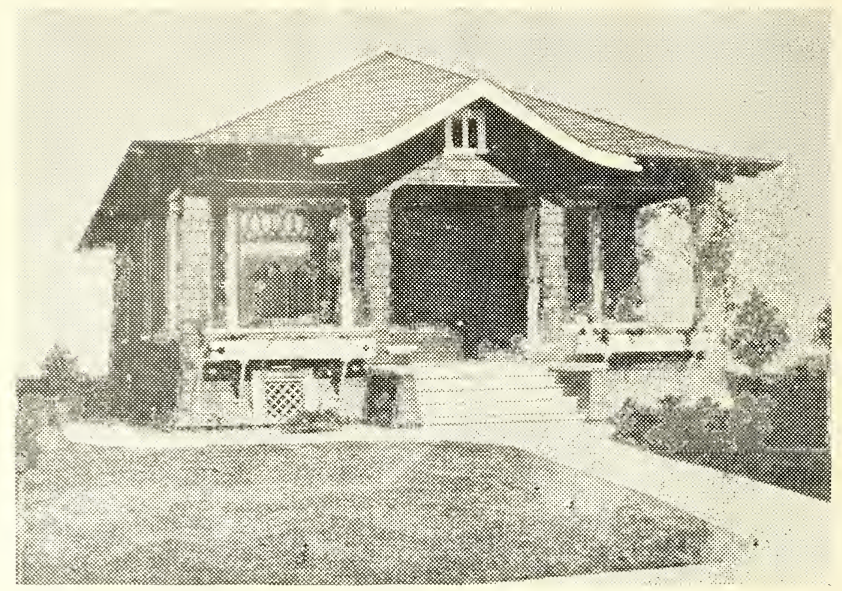

A Simple Bungalow-No. 861

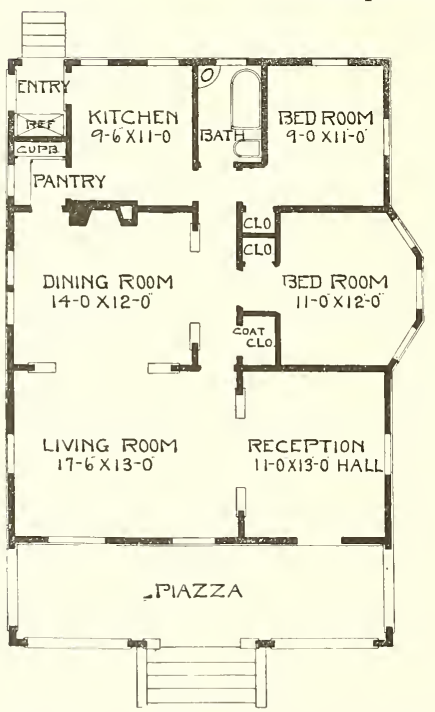

If readers are looking for something in the bungalow line, this is a little gem to study. This is what is called the six-room bungalow. The rooms are thrown together, making practically one large room, 29 feet wide. There is a little hall from the back of the bungalow which allows one to pass from the front to the rear of the house without entering or passing through any of the rooms, in each of which there is a hall entrance. This is as near a perfect floor plan as can be got up for a bungalow of this size. There is a small basement under the kitchen and bedroom across the rear.

The size of the house is $30 \times 38$ feet over the main part. The first story is 9 feet in the clear, finished with hardwood floors throughout and gum or birch finish in each room. Cost to build, $\$ 1,950$. Complete set of plans and specifications of this design for $\$ 15$.

Complete plans and specifications for using Denison Load-Bearing Tile, licensed under Wilson-System Bearing $\mathrm{W}$ a 11 Construction for $\$ 30$. 


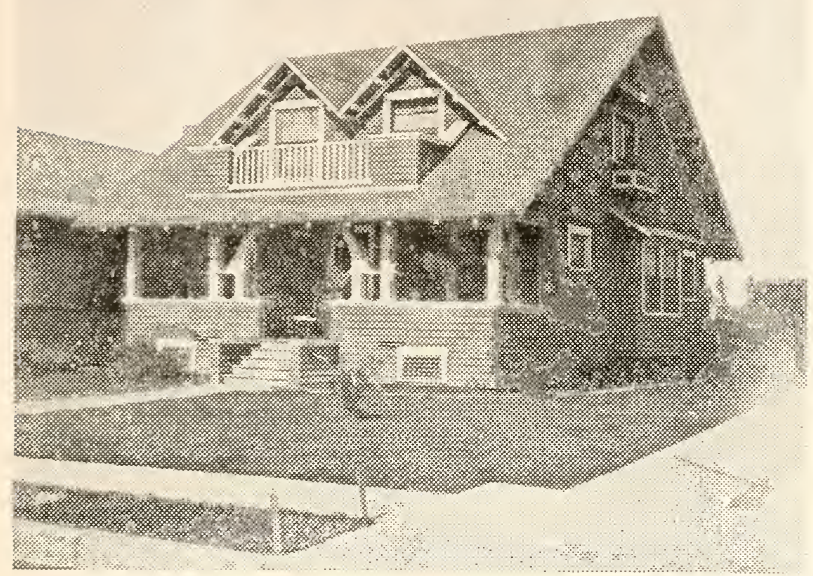

A Beautiful Home-No. 878

Size, 27 feet wide and 31 feet 6 inches deep. First story 9 feet, second story $\&$ feet. Full basement. First story birch or gum, second story pine to paint. Piazza floors and ceilings No. 1 Clear Washington fir. Cost to build, $\$ 2,850$. One set of plans and specifications, $\$ 21$.

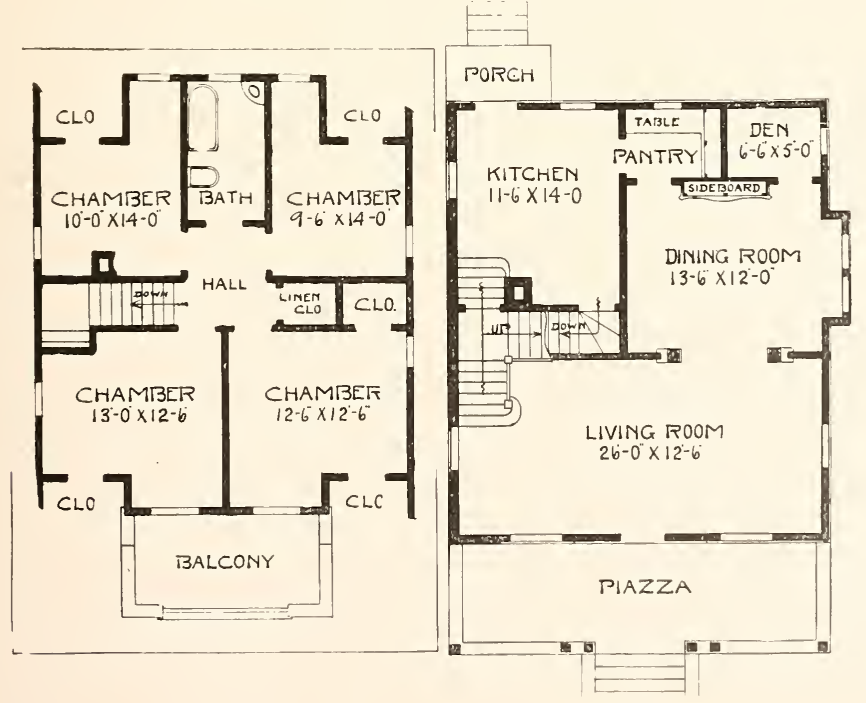

Complete plans and specifications for using Denison Load-Bearing Tile, licensed under Wilson-System Bearing $W$ a 11 Construction for $\$ 42$. 


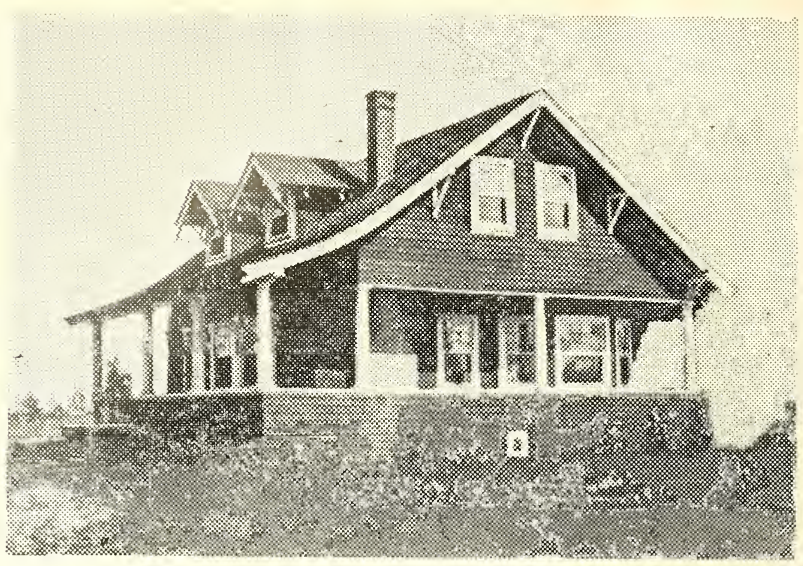

A Cottage Home-No. 845

There is a beautiful large living room running across the front, 27 feet long. Dining room and kitchen are back of the living room. The combination gives an opportunity to go out from the front room or from the kitchen. A pantry built in the rear connects the dining room and the kitchen. The size is 28 feet wide over the main part and 26 feet deep; basement under the full house. First story 9 feet and second story 8 feet. First story is planned to be finished in gum or birch throughout; second story in pine to paint. Cost to build, $\$ 2,300$. Complete set of plans and specifications, $\$ 17$.

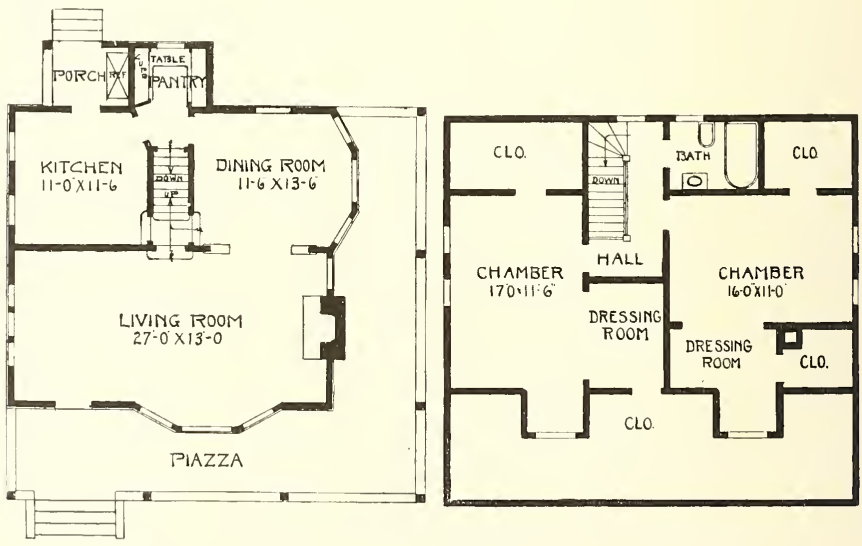

Complete plans and specifications for using Denison Load-Bearing Tile, licensed under Wilson-System Bearing $W$ a 11 Construction for $\$ 34$. 


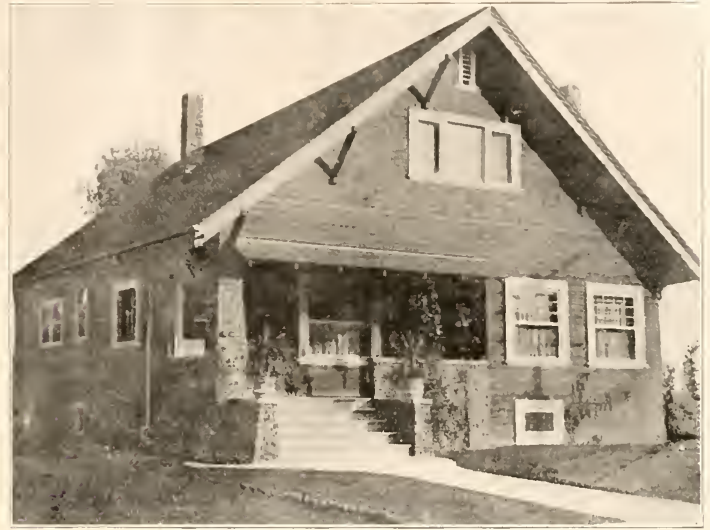

An Economical Comfortable Home-No. 846

The house is finished throughout the first story in red oak or gum and in the second story with pine to paint. Birch floors are used throughout. The size of the house is 28 feet wide by 41 feet 6 inches deep over all. The first story is 9 feet and the second 8 . There is a large basement under one-half the house, located in the front part. Complete set of plans and specifications for this house for $\$ 20$.
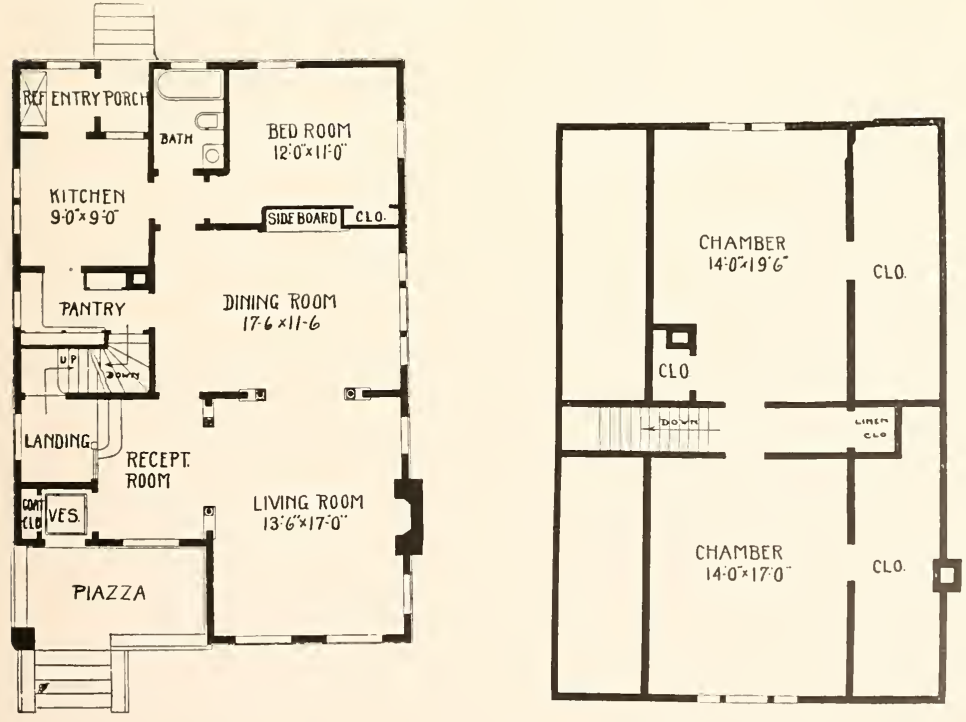

Complete plans and specifications for using Denison Load-Bearing Tile, licensed under Wilson-System Bearing Wa 11 Construction for $\$ 40$. 


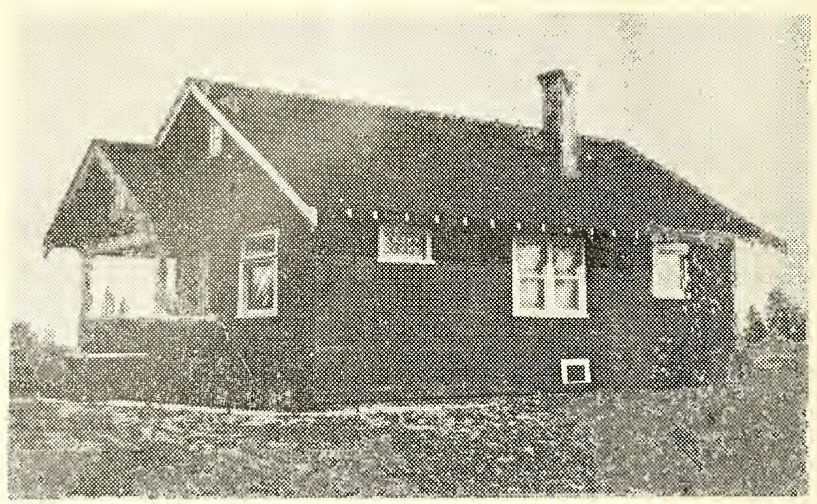

A Small Bungalow-No. 843

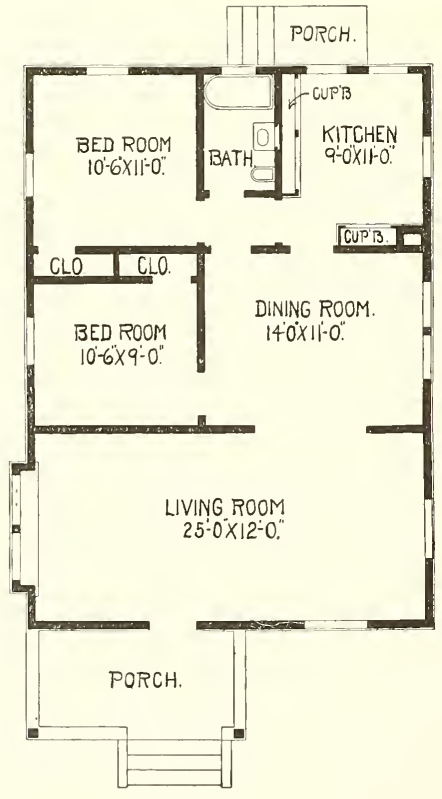

This small bungalow is one of my most economical designs to build, making a very good looking cottage, although the design is as plain and simple as it can possibly be made. There is a good sized porch in front, a beattiful living room across the entire house, dining room and kitchen and built-in kitchen cupboard, also two bedrooms with good sized closet space. It is designed to have a small cellar under the rear kitchen and bedroom portion with a trap door to go down from the kitchen. Gum finish and birch floors.

If you are looking for something that is practical, all on one floor and economical to build, here is one that will please you.

The size is 26 feet wide and 36 feet deep over all. Cost to build, $\$ 1,500$. Complete set of plans and specifications for $\$ 10$.

Complete plans and specifications for using Denison Load-Bearing Tile, licensed under Wilson-System Bearing $W$ a 11 Construction for $\$ 20$. 


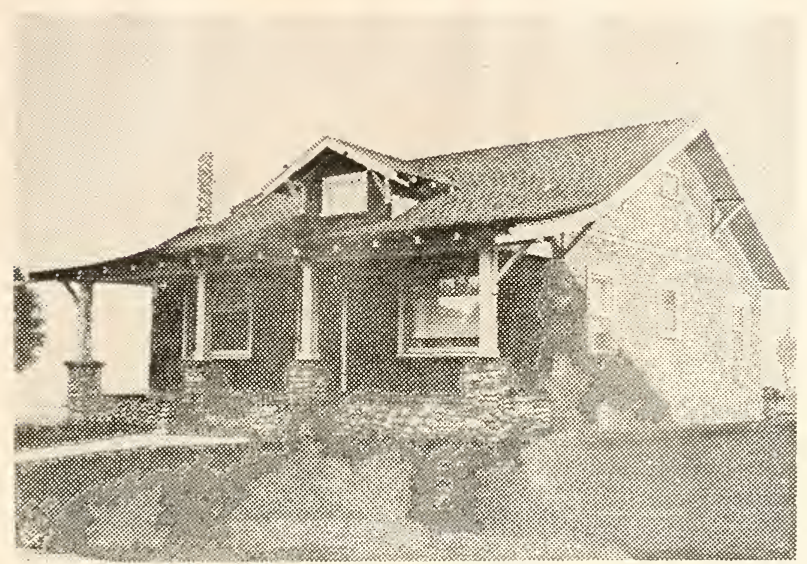

Bungalow-No. 842

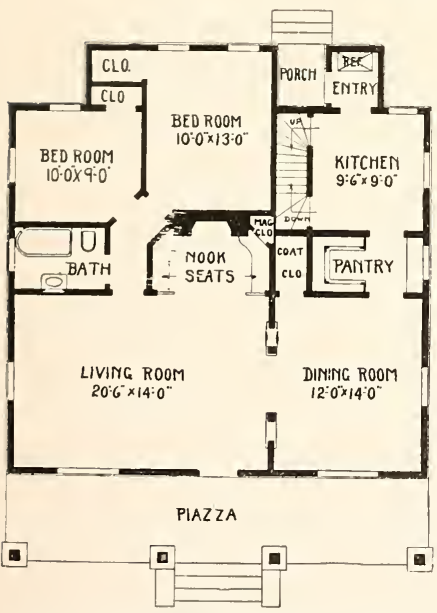

The bungalow is growing more and more in popularity. WV make a special effort to give you something good in the way of up-to-date bungalow plans. The features in the one for this illustration are the large living room with nook, open fireplace and seats at each side.

In this bungalow we have two good sized bedrooms in the first story and there is space to put in one or two rooms in the second story, although this is not figured in at the price of building this plan and if one desires a real bungalow home I would not make any space in the second story except for storage.

There is a good sized basement under one-half of the house, the size is 34 feet wide and 30 feet deep, the story 9 feet in the rlear. Birch floors throughout; gum or birch finish. Cost to build, $\$ 1,875$. Complete plans and specifications for $\$ 15$.

Complete plans and specifications for using Denison Load-Bearing Tile, licensed under Wilson-System Bearing W a 11 Construction for $\$ 30$. 


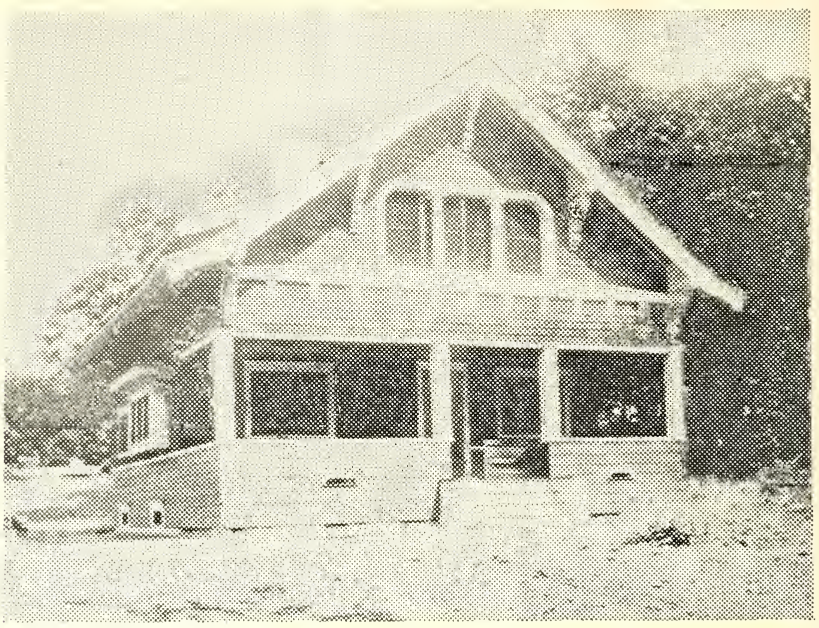

An Ideal Bungalow-No. 887

There are four liberal sized rooms in the first story, two chambers, closet room and bath in second story. Finished in gum, birch or red oak, with birch floors in first story, with pine to paint in second. Size is $26 \times 26$ feet. First story is 9 feet, second story 8 feet. Cost to build, $\$ 2,100$. Complete set of plans and specifications for $\$ 15$.

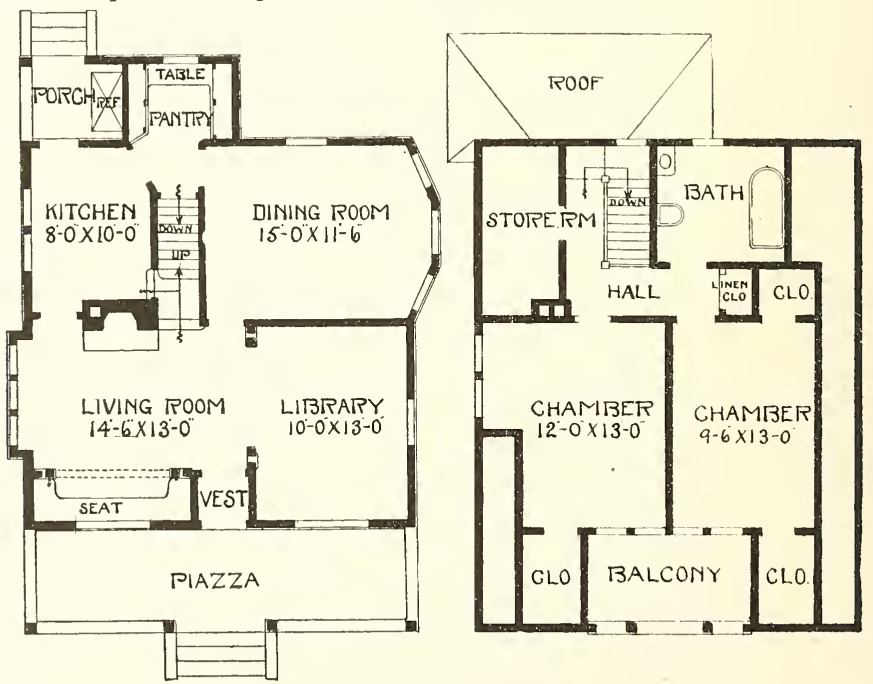

Complete plans and specifications for using Denison Load-Bearing Tile, licensed under Wilson-System Bearing $\mathrm{W}$ a 11 Construction for $\$ 30$. 


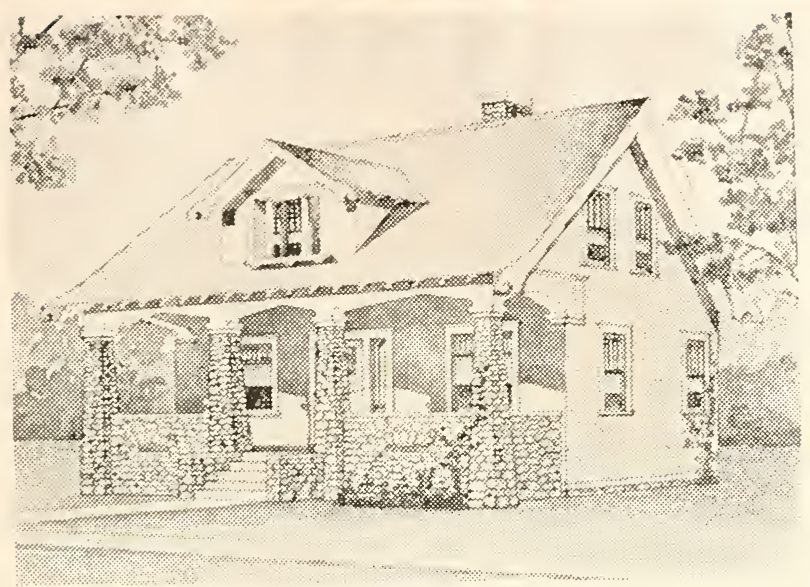

\section{An Up-to-Date Bungalow-No. 879}

This artistic cottage has all the attractive features of a mansion that would cost three times the price of this house. Note the beautiful living room running from front to rear of the entire house, 23 feet long. The basement is 7 feet deep, first story 9 feet, second 8 feet. First story finished in gum or birch, second story, pine to paint. Birch or maple floors are used throughout. Size is 35 feet wide and 24 feet deep over the main part. Cost to build, $\$ 2,795$. Complete set of plans and specifications for $\$ 25$.

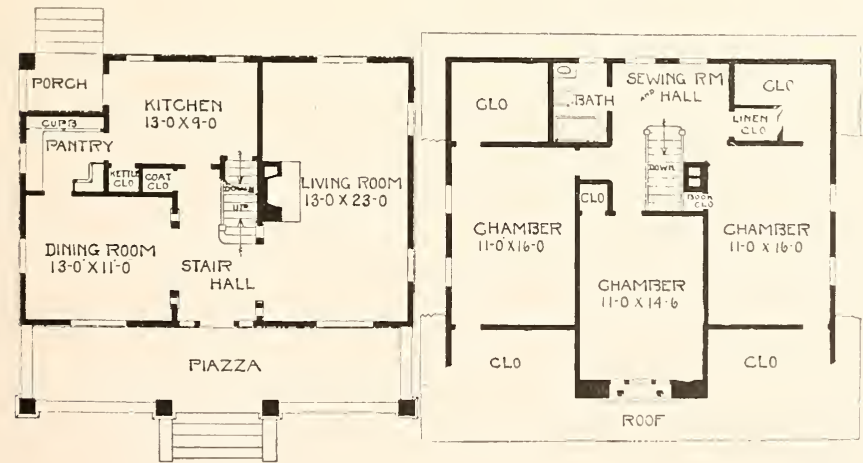

Complete plans and specifications for using Denison Load-Bearing Tile, licensed under Wilson-System Bearing IV al1 Construction for $\$ 50$. 


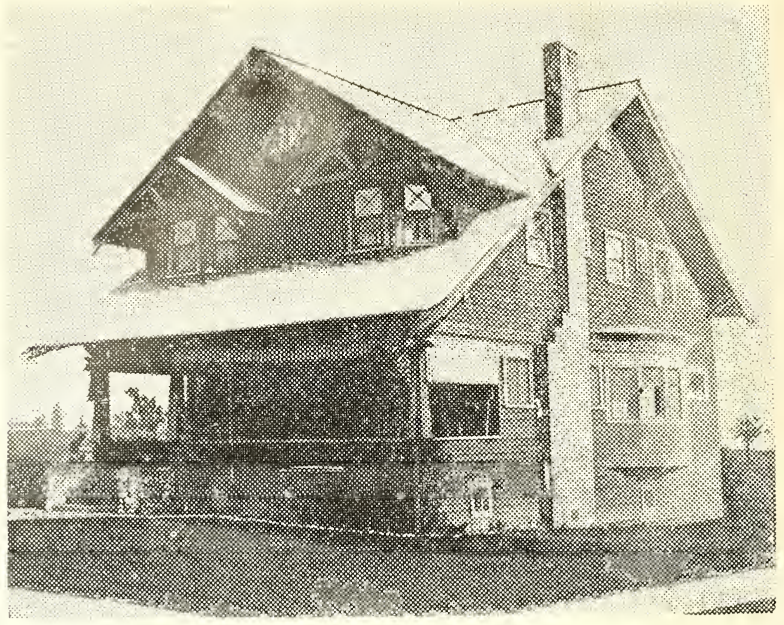

A Unique Home-No. 847

The house is 28 feet wide and 32 feet deep over all; a full basement; first story is 9 feet, second story 8 feet in the clear; first story finished in gum, birch or oak, second story pine to paint. Cost to build, $\$ 3,300$. Complete set of plans and specifications for $\$ 25$.
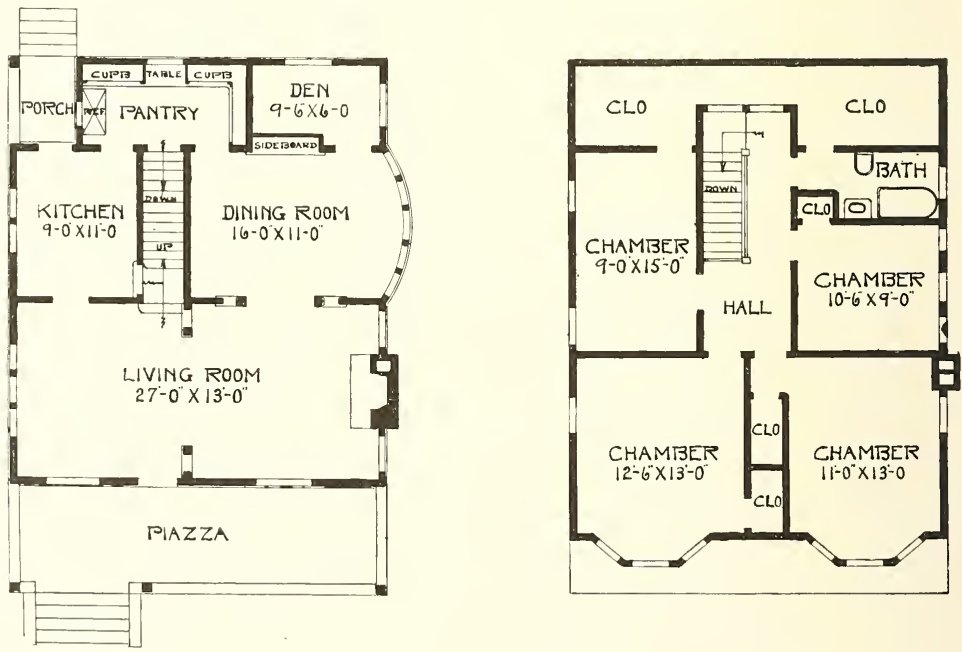

Complete plans and specifications for using Denison Load-Bearing Tile, licensed under Wilson-System Bearing W a 11 Construction for $\$ 50$. 


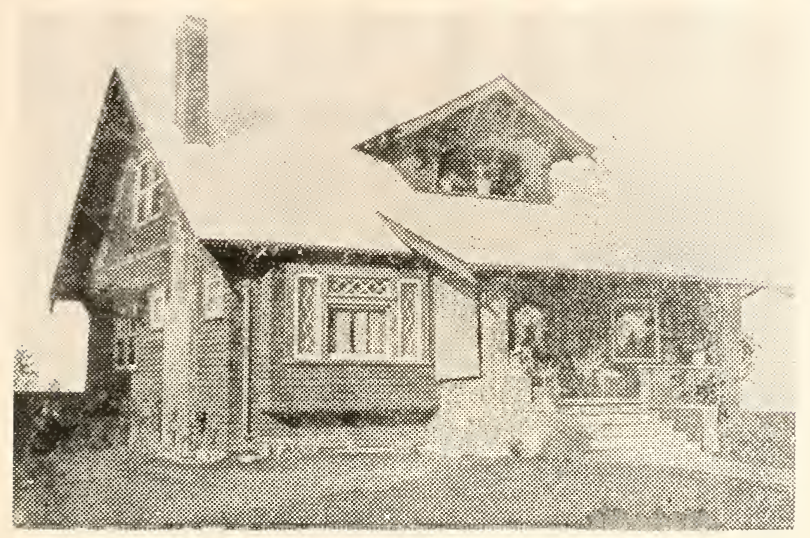

\section{A Cottage Home-No. 848}

The size of the house is 32 feet wide and $2+$ feet deep over the main part, full basement 7 feet deep; first story 9 feet, second story 8 feet. The heights are in the clear when finished. Birch floors are used throughout: birch or gum finish in the first story, and pine to paint in the second. Cost to build, $\$ 2,375$. Complete set of plans and specifications for $\$ 16$.
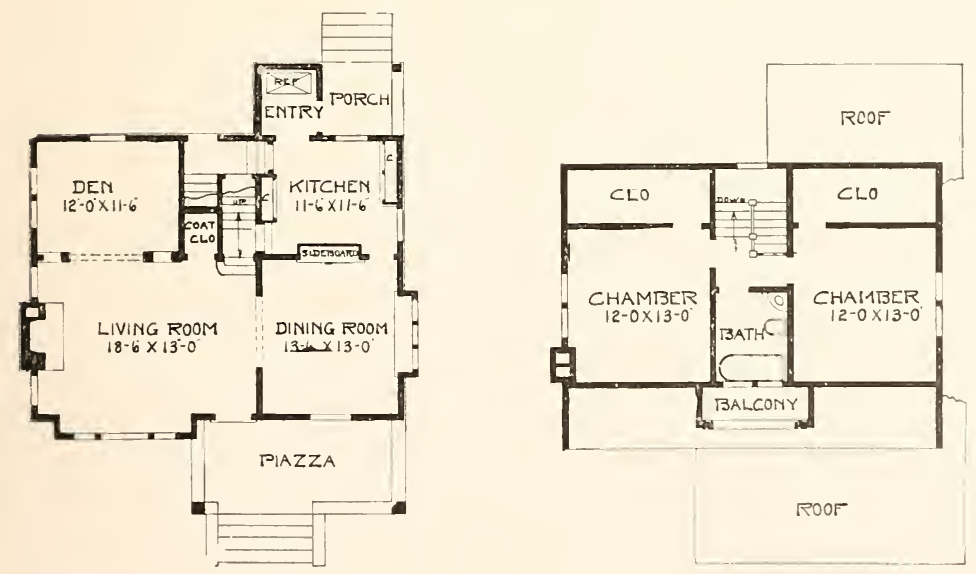

Complete plans and specifications for using Denison Load-Bearing Tile, licensed under Wilson-System Bearing IV a 11 Construction for $\$ 32$. 


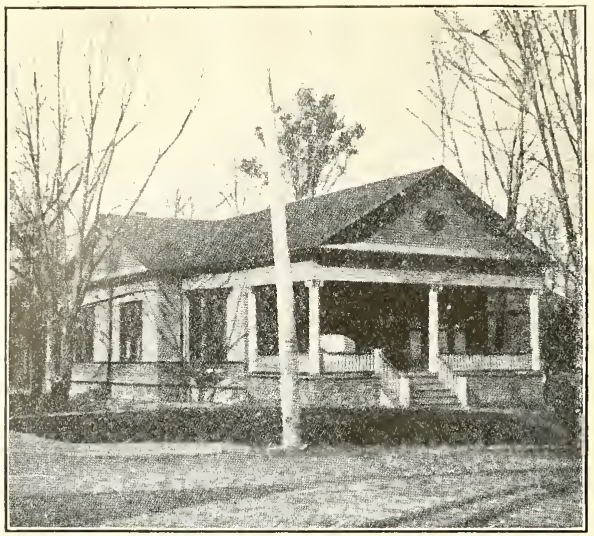

Bungalow-No. 401

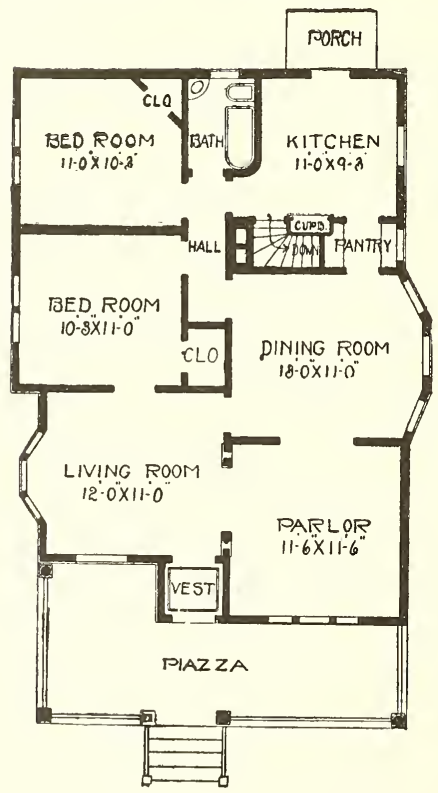

This design is for a one story colonial house of five rooms. The size is 25 feet wide by 38 feet deep. The main floor of house is set up well from the grade and the story is 9 feet in height.

The floors are of hardwood and the three principal rooms finished in red oak or gum. The finish in the remaining portion of the house is painted. The entrance is central with a vestibule opening into a nice living room, and thence to the right, into the parlor and dining room, with kitchen and pantry back of dining room, and the rear hall through which the two bedrooms are reached and the bath room. There is a nice cellar under the rear part of the house.

This house can be built for $\$ 2,100$. Complete plans and specifications for $\$ 10$. 


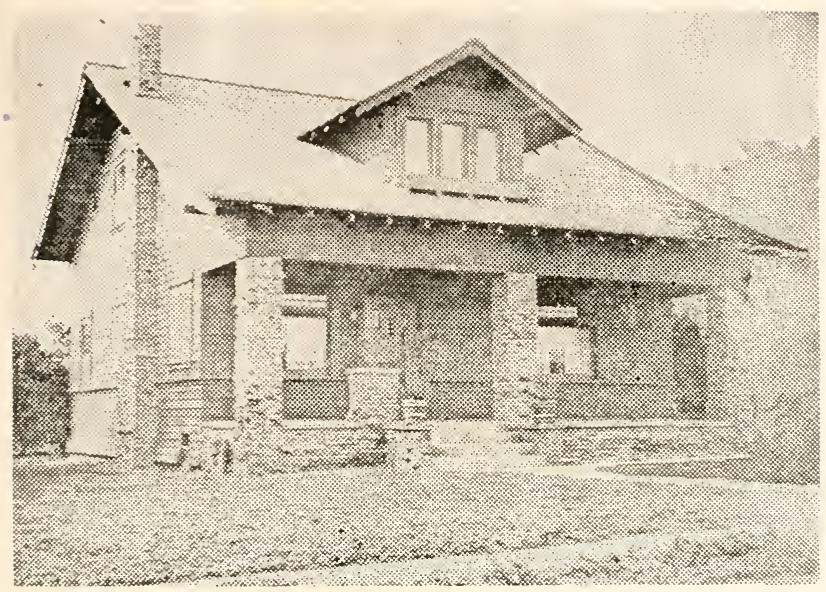

A Beautiful Bungalow Home-No. 891

Width 34 feet, and depth 28 feet, over the main part. This exterior is rery simple, but yet how beautiful. The piazza is built of brick, laid hitand-miss, instead of having the regulation round columns and turned balusters. The walls are shingled and stained a soft brown. The arrangement of interior is ideal and affords five splendid sleeping rooms, if so many are desired. However, the estimated cost does not include the finishing up of the second story, and it could be left unfinished until more chambers were needed. First story finish red oak or gum, birch or maple floors. Birch floors throughout. Cost to build, $\$ 2,650$. Price of plans and specifications, $\$ 20$.

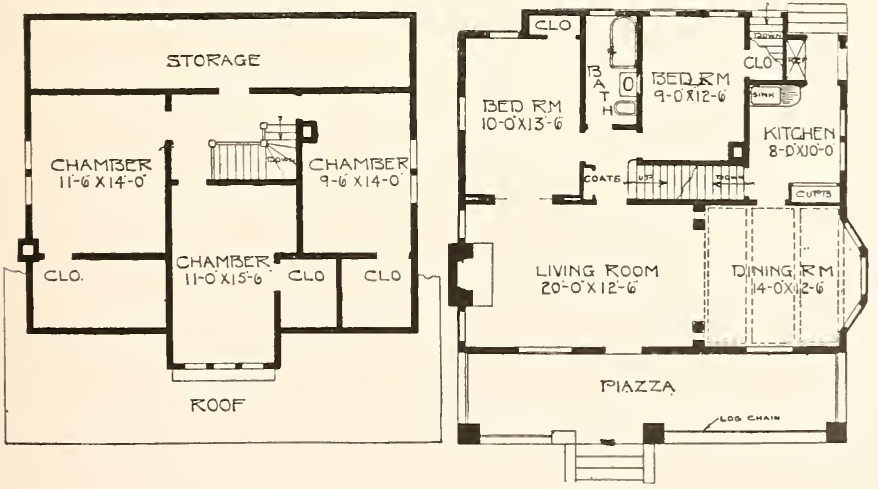

Complete plans and specifications for using Denison Load-Bearing Tile, licensed under Wilson-System Bearing $\mathrm{W}$ a 11 Construction for $\$+0$. 


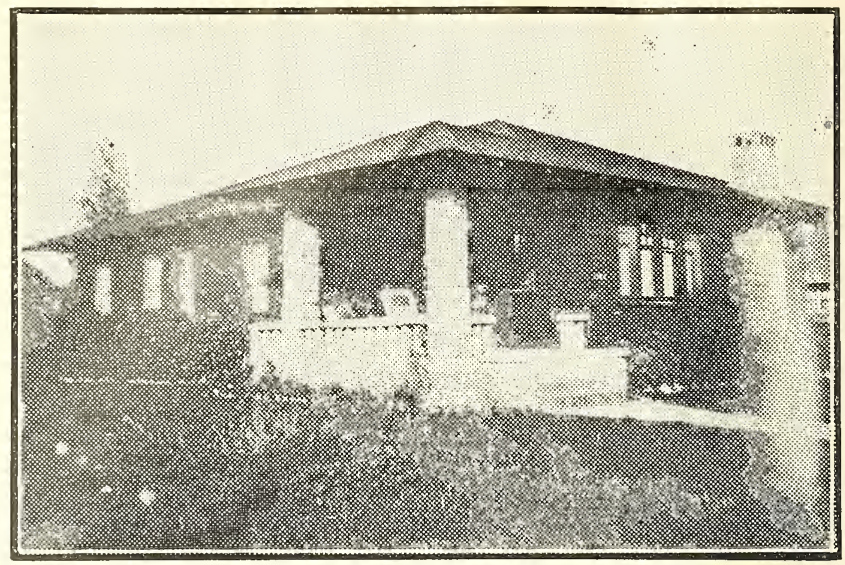

Simplicity in Bungalow Architecture-No. 894

With 26 feet, depth 46 feet. Simplicity is the key-note of this charming bungalow. Just the stone piazza, placed to one side and the wide projecting eaves are required to give it the charm and homelike air. The fireplace in living room is placed directly in front of the opening into dining room, which has a tendency to make that room cheerful during meals. At the rear of kitchen is a combination grade entrance and inside stairway to cellar. Birch or gum finish and maple floors. Cost to build, \$2,600. Price of plans and specifications, complete, $\$ 16$.

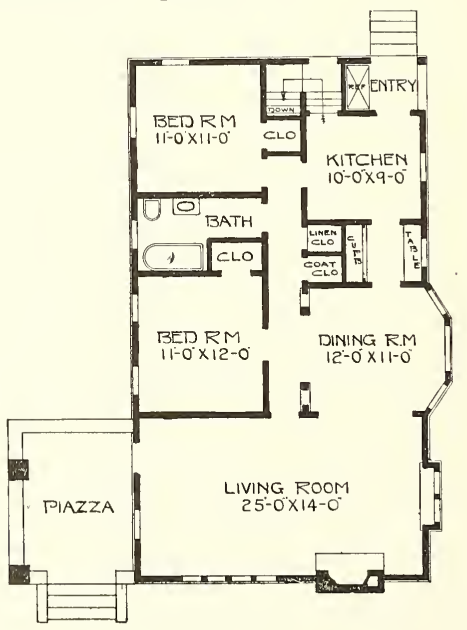

Complete plans and specifications for using Denison Load-Bearing Tile, licensed under Wilson-System Bearing Wall Construction for $\$ 32$. 


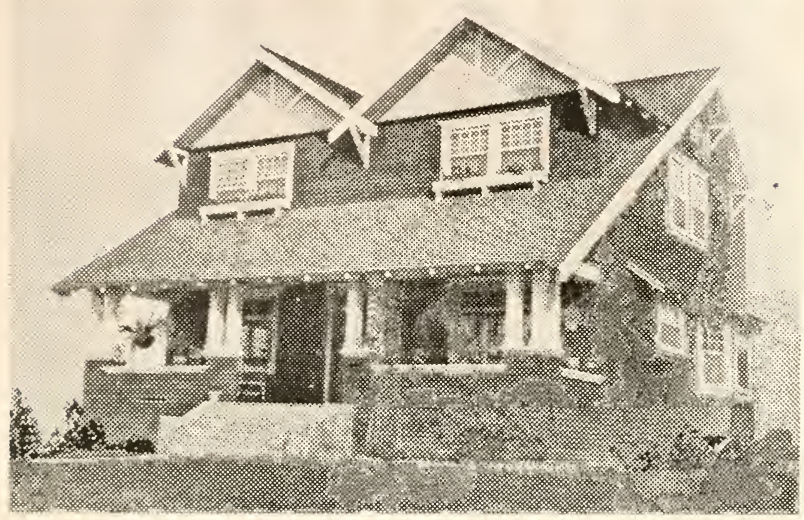

A Practical and Artistic Home-No. 920

Width 32 feet 6 inches and depth 30 feet. This house has the appearance of a cottage of the bungalow type; but in reality is a full two-story house. A full 7 -foot basement; the first story is 9 feet and the second 8 feet. A new and popular feature is the position of the dining room at the front of the house. As we live a great deal of the time in the dining room, it is fitting that it be placed, where it can afford a view of the street. Finish red oak or gum, birch or maple floors throughout. Cost to build, $\$ 3,800$. One set of plans and specifications will be furnished for $\$ 30$.
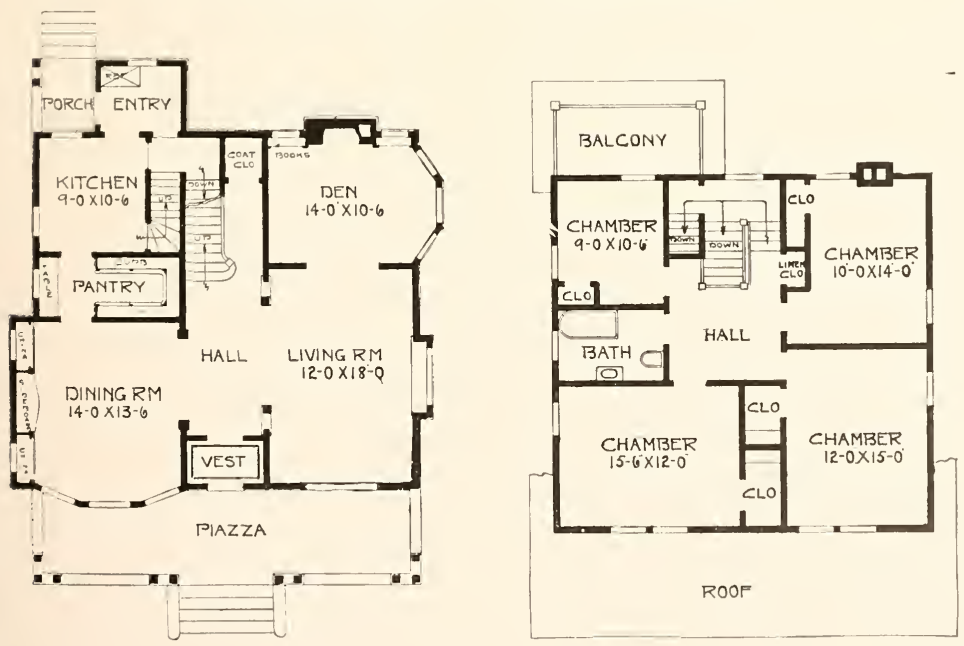

Complete plans and specifications for using Denison Load-Bearing Tile, licensed under Wilson-System Bearing iV a 11 Construction for $\$ 60$. 


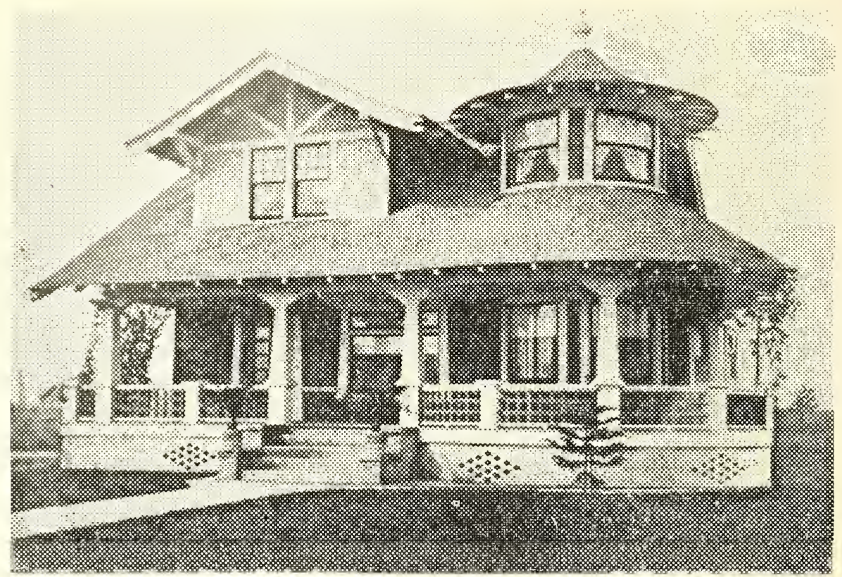

\section{A Beautiful Home-No. 895}

Width 30 feet, depth 27 feet over the main part. A splendid piazza across the entire front and around the circular bay makes an abundance of piazza space. The well arranged living room has a circular bay at one corner and a fire-place and nook with seats at the opposite corner. In the dining room is a ledge shelf window with buffet underneath. The principal rooms are thrown together by archways with square columns, set on high paneled bases. First story finished in red oak, birch or gum, second story in pine to paint, with birch floors throughout. Cost to build, $\$ 4,100$. Price of plans and specifications, $\$ 30$.

Complete plans and specifications for using Denison Load-Bearing Tile, licensed under Wilson-System Bearing $W$ a 11 Construction for $\$ 60$. 
No. 895

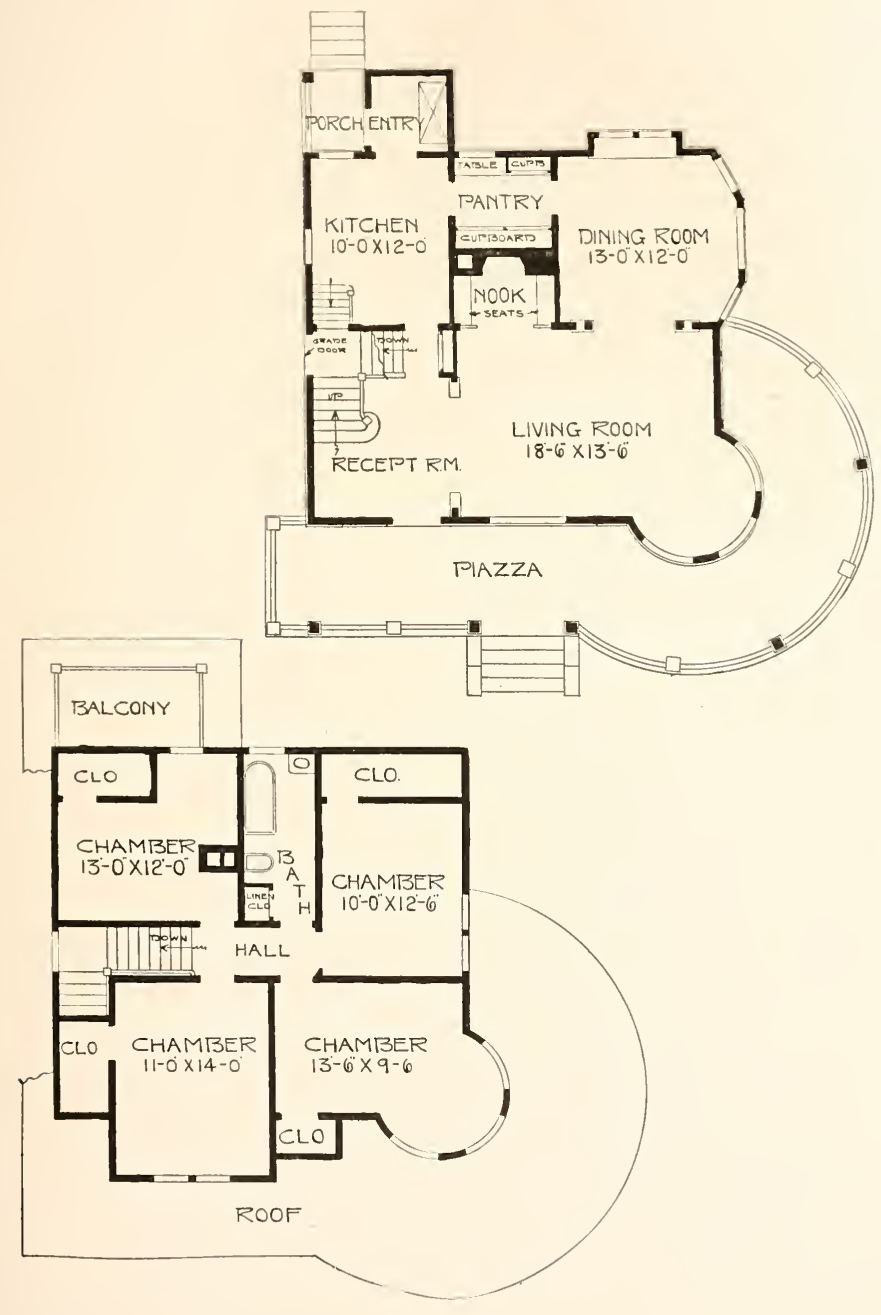




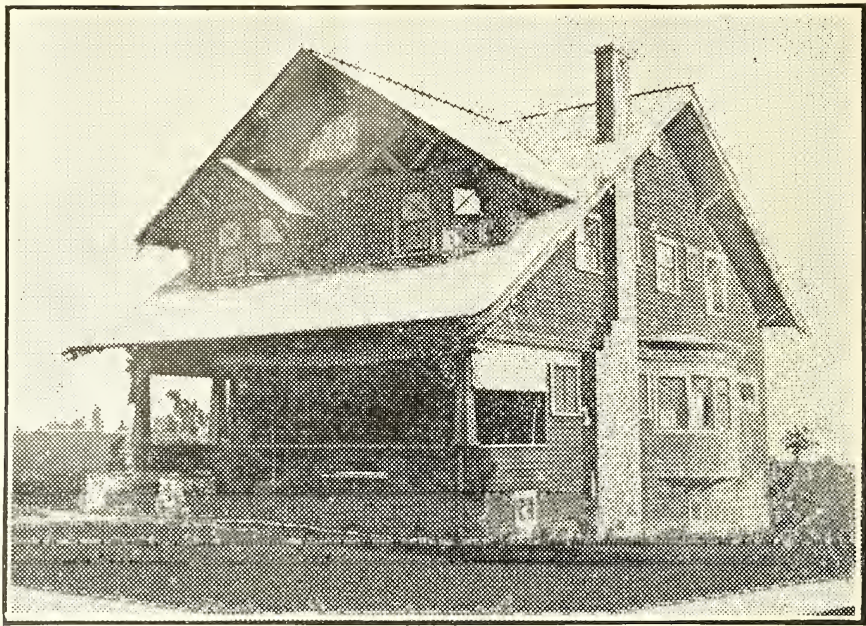

A Popular Residence Plan-No. 930

Width 28 feet, depth 32 feet. This residence has the bungalow style of architecture carried out in a harmonious way for the entire exterior. The stairway is a combination from the reception hall and kitchen. Birch or gum finish in first story, pine to paint in second, birch floors throughout. Cost to build, $\$ 3,200$. Price of plans and specifications, $\$ 25$.
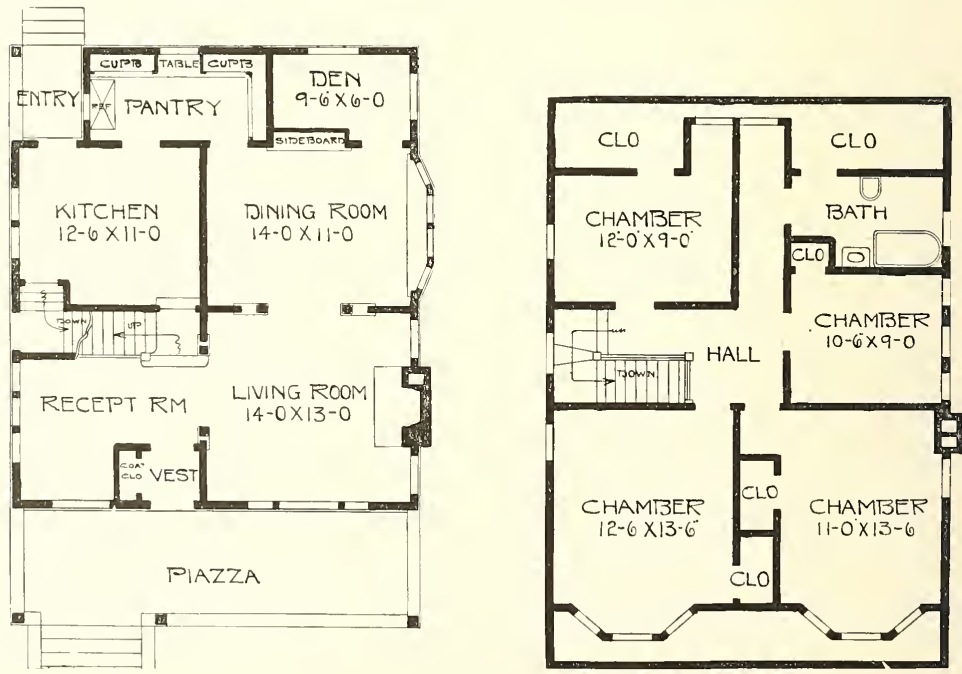

Complete plans and specifications for using Denison Load-Bearing Tile, licensed under Wilson-System Bearing $W$ a 11 Construction for $\$ 50$. 


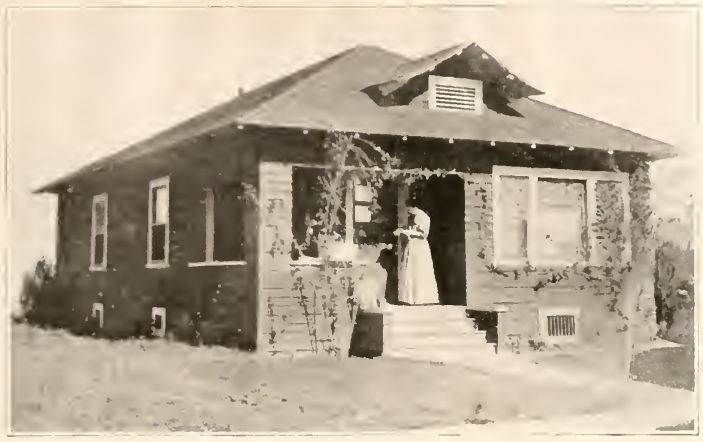

A Bungalow Home-No. 896

Width 26 feet, depth 38 feet, over the main part. The purpose of building a bungalow is to get all the living and sleeping rooms on the first floor, and this design shows what can be done along that line for the least amount of money. Finish gum or birch with maple or birch floors. The arrangement of rooms is compact and complete, as can be seen by floor plans. The exterior is beautiful though simple. Cost to build, $\$ 2,000$. Set of plans and specifications, complete, $\$ 15$.

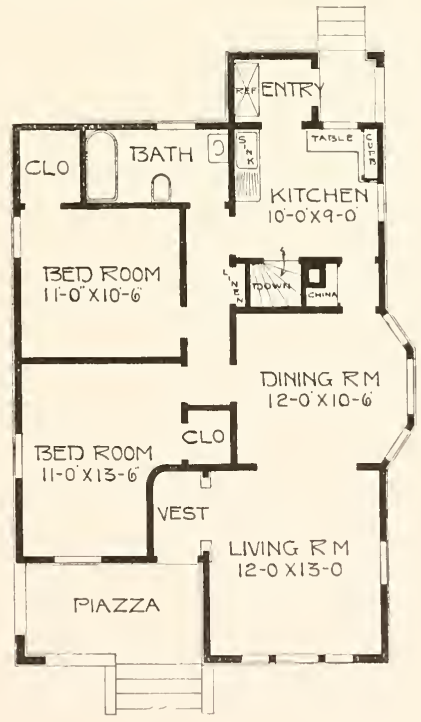

Complete plans and specifications for using Denison Load-Bearing Tile, licensed under Wilson-System Bearing $\mathrm{W}$ a 11 Construction for $\$ 30$. 


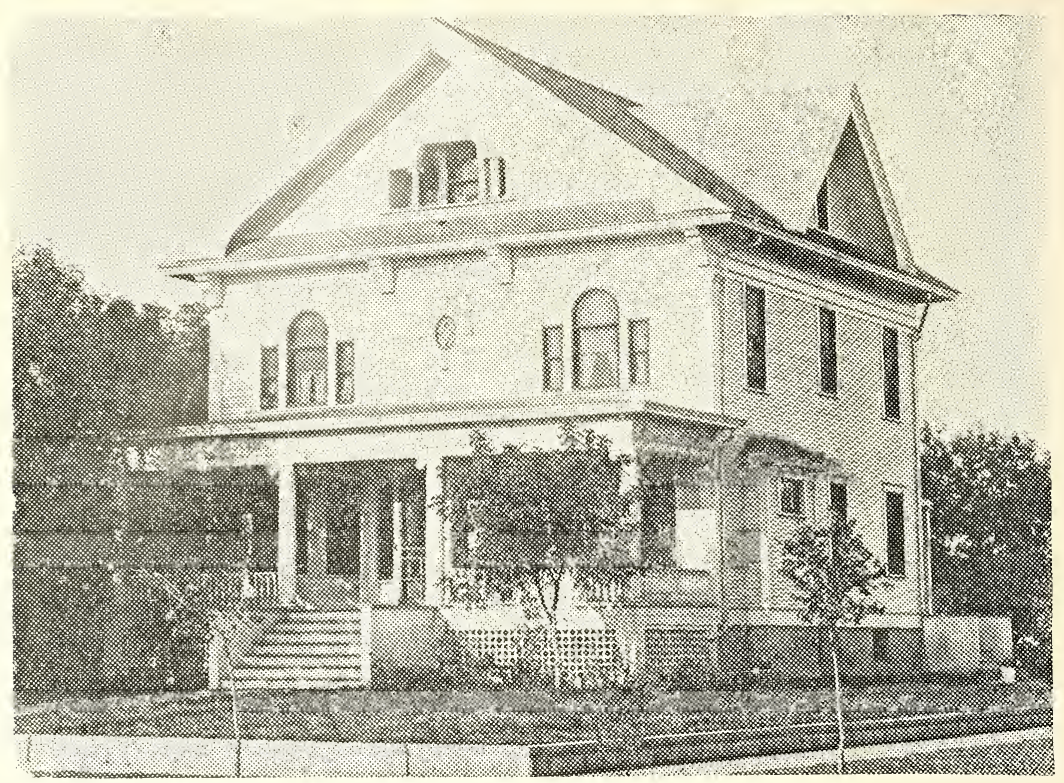

A Modern Colonial Home-No. 926

Width 33 feet, depth 27 feet 6 inches over main part. A reproduction of a beautiful colonial home, as built in Armour, South Dakota. It has also been built in seven other states, its popularity being due to the fact that it is one of the most practical of medium priced residences. The first story is finished in plain red oak, birch or gum, with birch floors. The second story has pine to paint for finish and birch floors. Note the large chambers and splendid closet space in second story. Cost to build, $\$ 4,500$. Price of one complete set of plans and specifications, $\$ 30$.

Complete plans and specifications for using Denison Load-Bearing Tile, licensed under Wilson-System Bearing Wa 11 Construction for $\$ 60$. 


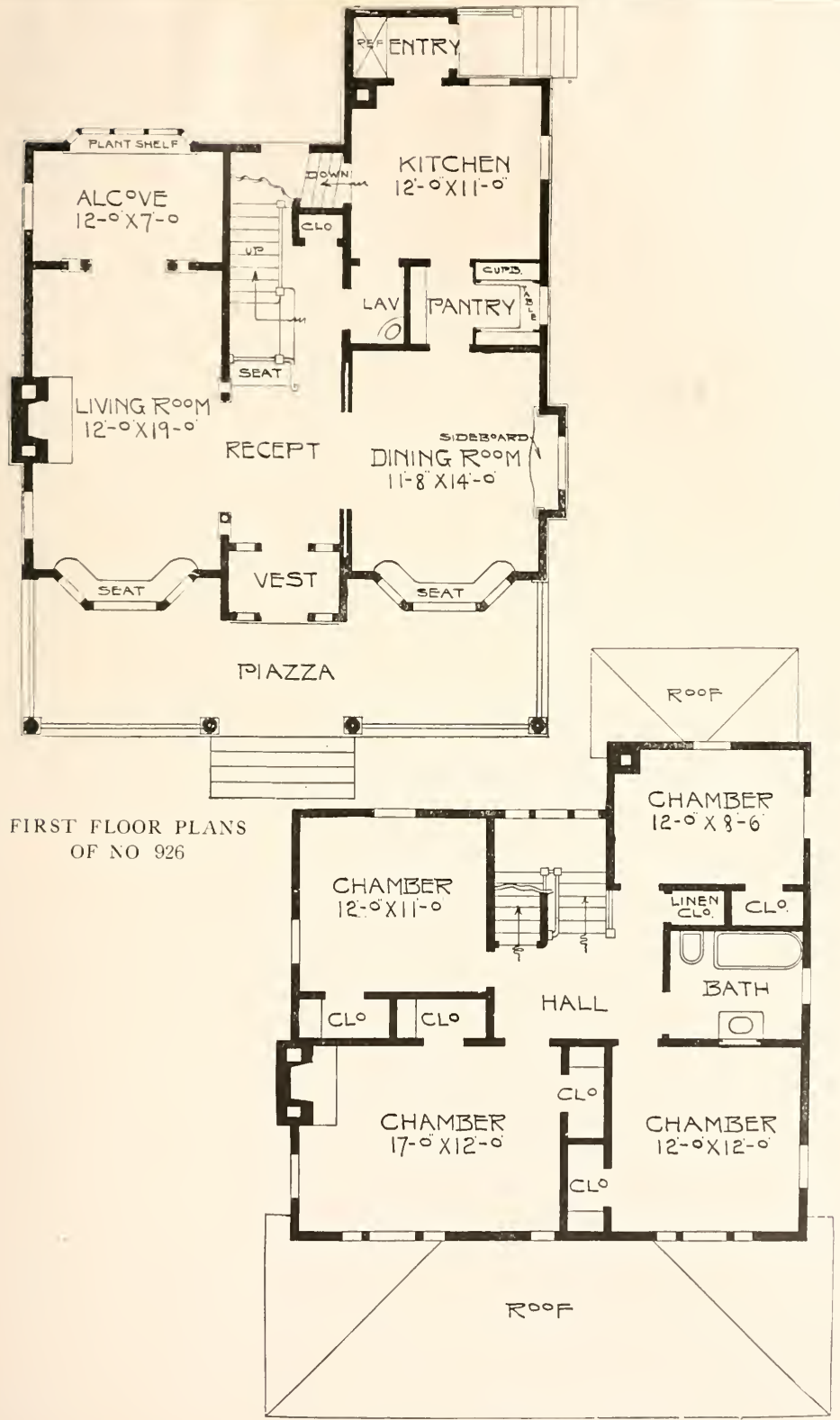




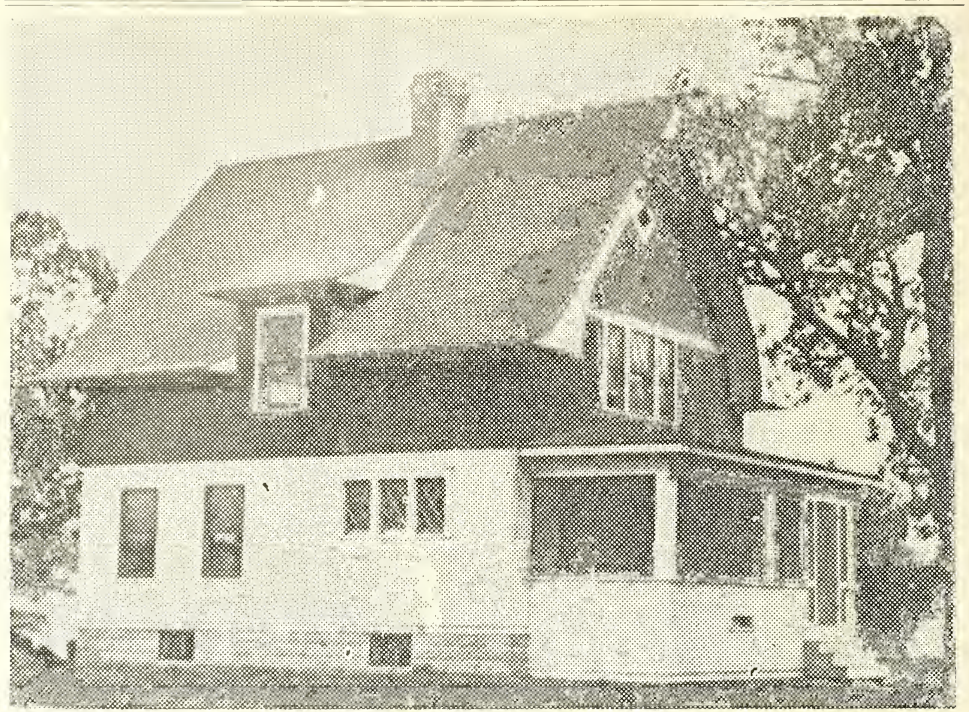

\section{A Charming Cottage-No. 938}

Width 26 feet; depth 28 feet. A cottage well adapted to the needs of a small family, comprising six rooms, so arranged as to be most easily taken care of. The living room is as large as is found in homes of much larger size, and so also is the dining room. Both rooms are finished in red oak or gum, stained a rich brown. The dining room has a built-in sideboard with high stained glass windows at each side. In the second story there are three splendid chambers, closets, a bath and a large linen closet. These rooms are finished in white enamel. There are birch floors throughout. First story 9 feet, second story 8 feet high. Cost to build, $\$ 2,200$. One complete set of plans and specifications, $\$ 18$.
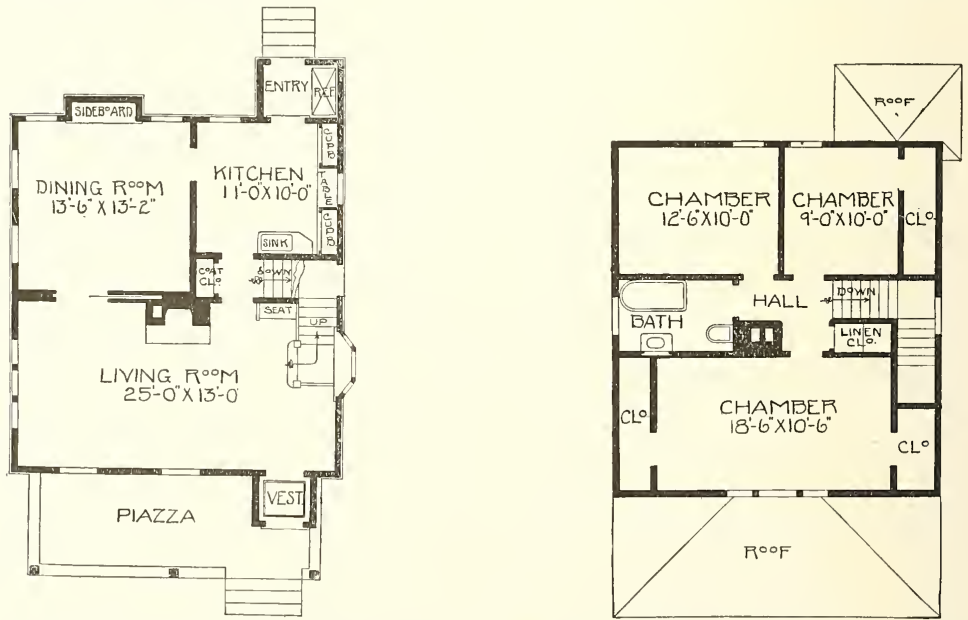

Complete plans and specifications for using Denison Load-Bearing Tile, licensed under Wilson-System Bearing $W$ a 11 Construction for $\$ 36$. 


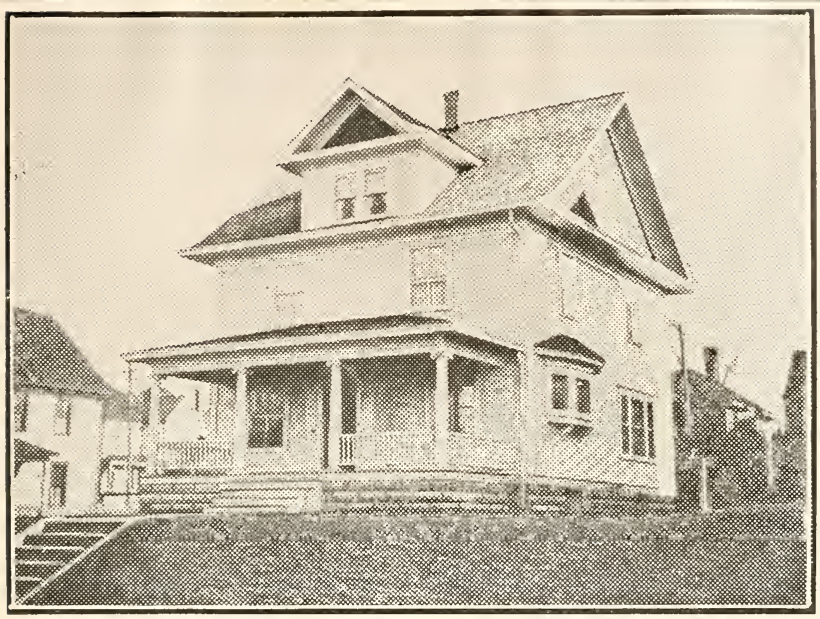

A Modern Residence-No. 931

Width 32 feet, depth 28 feet, over main part. A rery good example of the modern square house, which though the most economical kind of a house to build, has often many commendable features. The exterior is plain but does not lack character, and will look the same for years to come. The feature of the central hall is seldom incorporated in inexpensive houses. Another good feature is the combination grade door and kitchen entrance to cellar. First story finished in clear birch or gum and second story in pine to paint, with birch floors throughout. Cost to build, \$2.900. Complete set of plans and specifications for $\$ 25$.

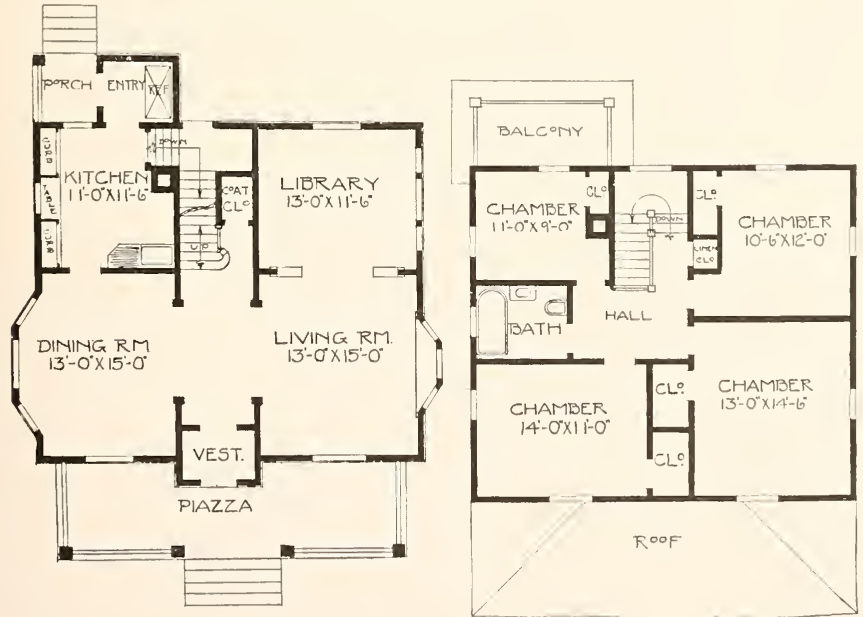

Complete plans and specifications for using Denison Load-Bearing Tile, licensed under Wilson-System Bearing iW a 11 Construction for $\$ 50$. 


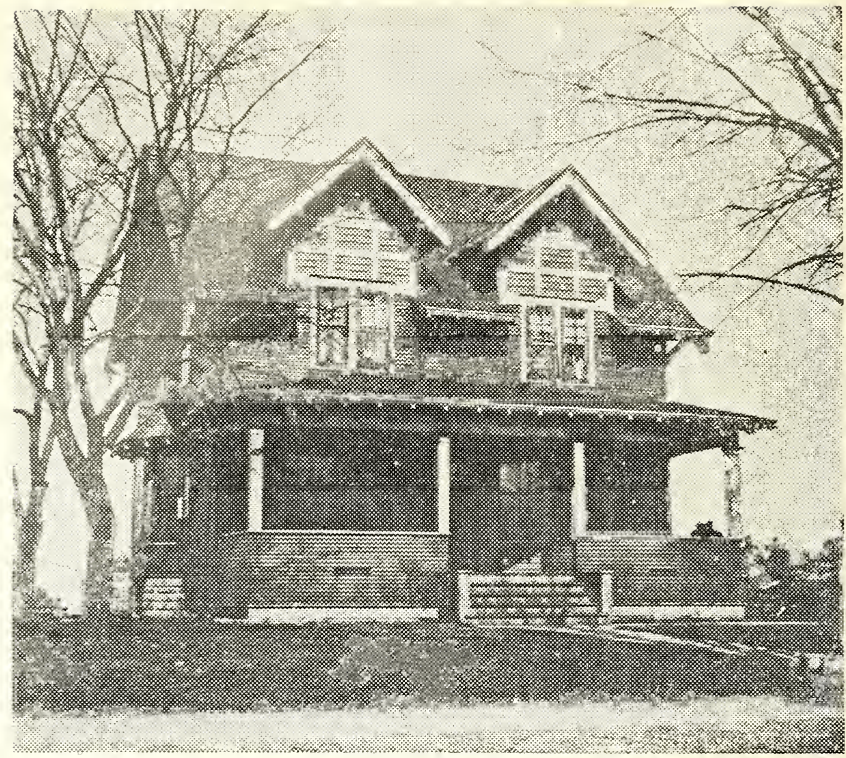

An English Cottage-No. 935

Width 30 feet, depth 26 feet, over main part. The English half-timber, when adapted to our American ideas and arrangements makes a very attractive home. Here is an effective treatment of exterior in clapboards and shingles, shingles in gables and dormers, where rough-cast cement would be even more effective. First story 9 feet high and second story 8 feet. Red oak or gum finish in first story and pine to enamel in second, with birch doors, stained to match the finish of the first story. Birch floors in both stories. Cost to build, $\$ 3,100$. One set of plans and specifications for $\$ 25$.
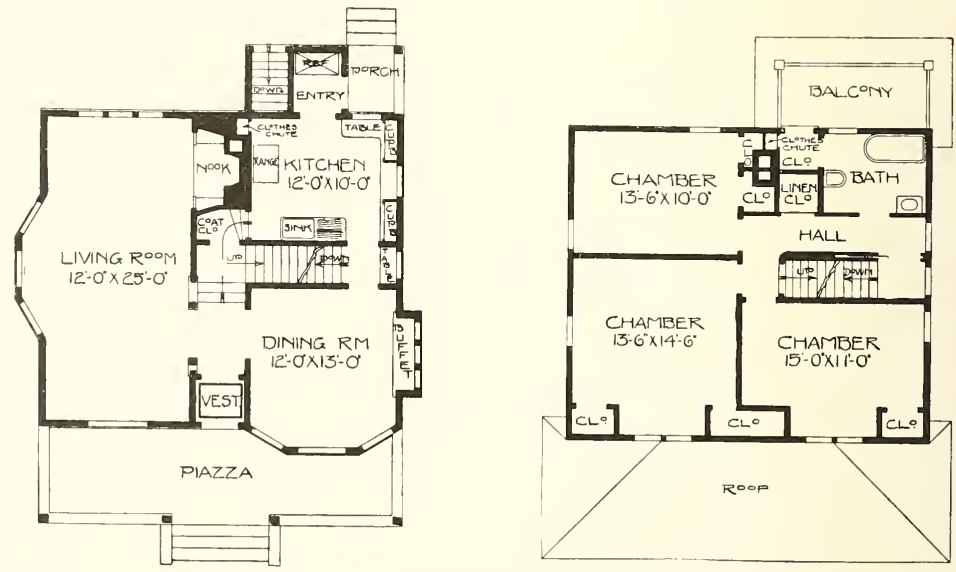

Complete plans and specifications for using Denison Load-Bearing Tile, licensed under Wilson-System Bearing $\mathrm{V}$ a 11 Construction for $\$ 50$. 


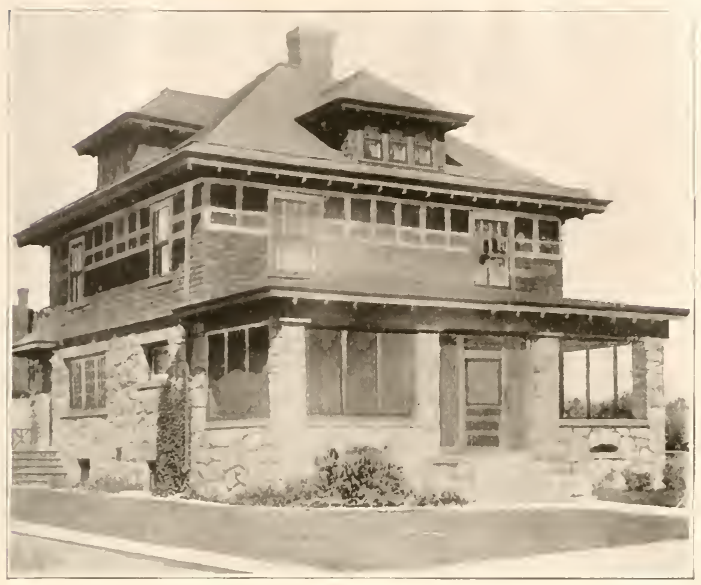

A Doctor's Residence-No. 939

A house especially suited to meet the needs of a physician or dentist who requires a small office at his home. The arrangement of each floor is practical and convenient and the house is one easily taken care of. The exterior of the first story is built of split-face boukders. Size 30×30 over the main part. First story finished in a choice of red oak or gum, with birch floors. Second story finished in white enamel with two panel birch doors, stained to represent mahogany, with floors of bireh. First story 9 feet, second story $\&$ feet. Cost to build, $\$ \pm, 000$. Price of one set of plans and specifications, $\$ 30$.
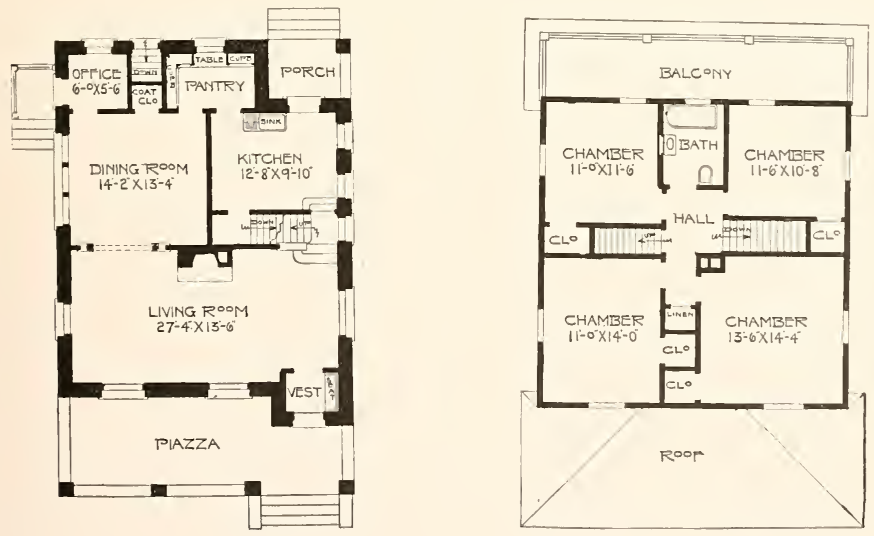

Complete plans and specifications for using Denison Load-Bearing Tile, licensed under Wilson-System Bearing II a 11 Construction for $\$ 60$. 


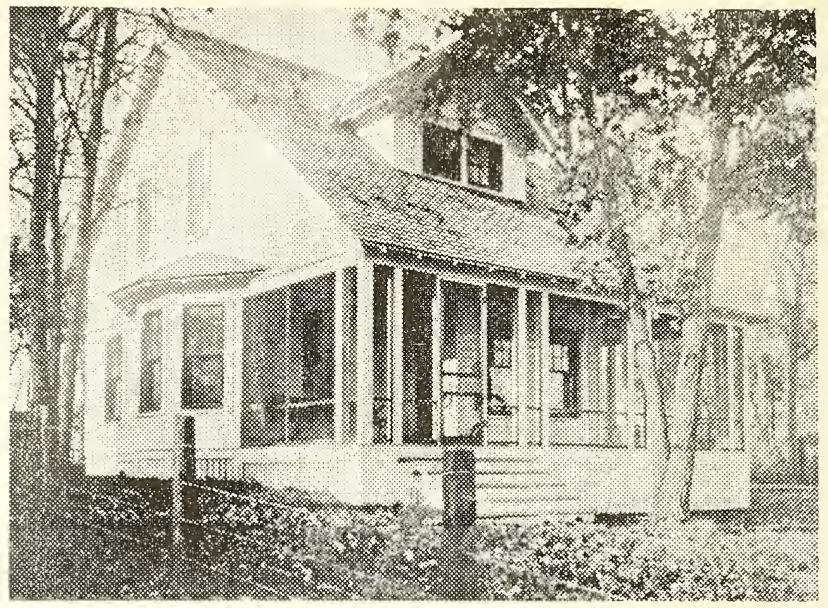

A Burr Oak Retreat-No. 89

Cost to build as a lake cottage $\$ 800$. As finished home $\$ 1,300$ at present prices. Here is an investment for anyone who desires either a city home or lake cottage. I would advise for a lake cottage, where there is no basement required, that the living room be a trifle shorter, and the bathroom be put under the stairs to the second story. The second story can be finished into four chambers if desired which would be ample large for chambers in a lake cottage. The house has the appearance of one that would cost $\$ 2,500$. First story 8 feet 6 inches, second story 8 feet, the price includes a full basement. First story finished in gum or birch, second pine to paint. Birch or maple floors throughout. One complete set of plans and specifications for $\$ 10$.

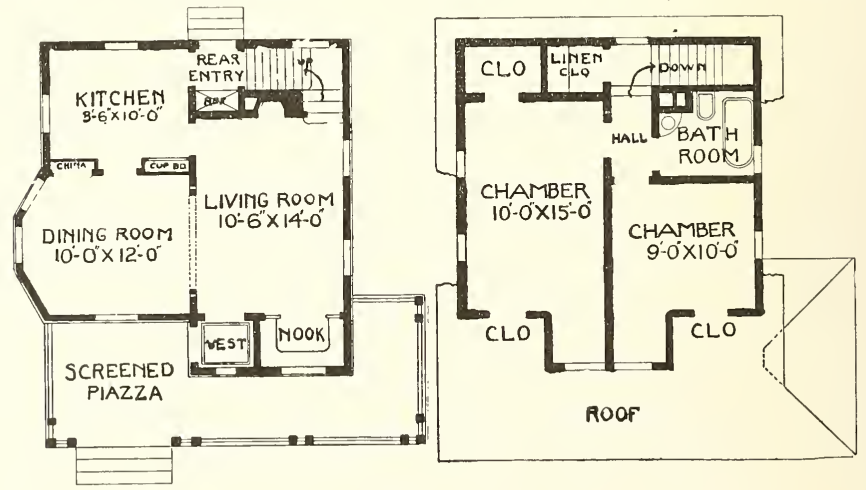

Complete plans and specifications for using Denison Load-Bearing Tile, licensed under Wilson-System Bearing $W$ a 11 Construction for $\$ 20$. 


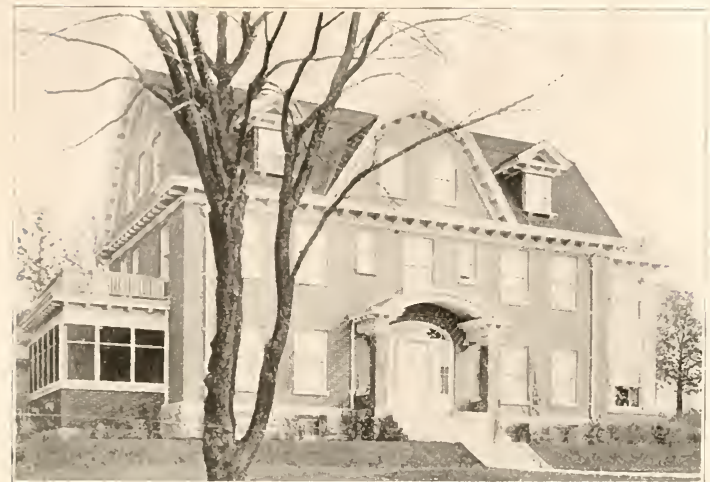

A Beautiful Colonial Residence-No. 693

This beautiful brick reneer residence would be a splendid home to build in any locality. It is the pure old New England Colonial carried out in every detail. In the first story we have the central hall with beautiful columned stairway. The living room is on one side of the hall connecting with the sun room, on the other side of the hall we have the dining room, pantry and kitchen with piazza on this side for a summer dining room.

In the second story there are five splendid chambers, besides a sleeping porch. There is a full basement under entire house. Size 50 feet wide and 32 feet deep over main part, exclusive of sun room and piazza. First story 9 feet 6 inches, second story 8 feet 6 inches, finish throughout first story witl gum or red oak, finish in second story paint to enamel. Cost to build, $\$ 12,000$ to $\$ 15,000$, depending on materials that are used.

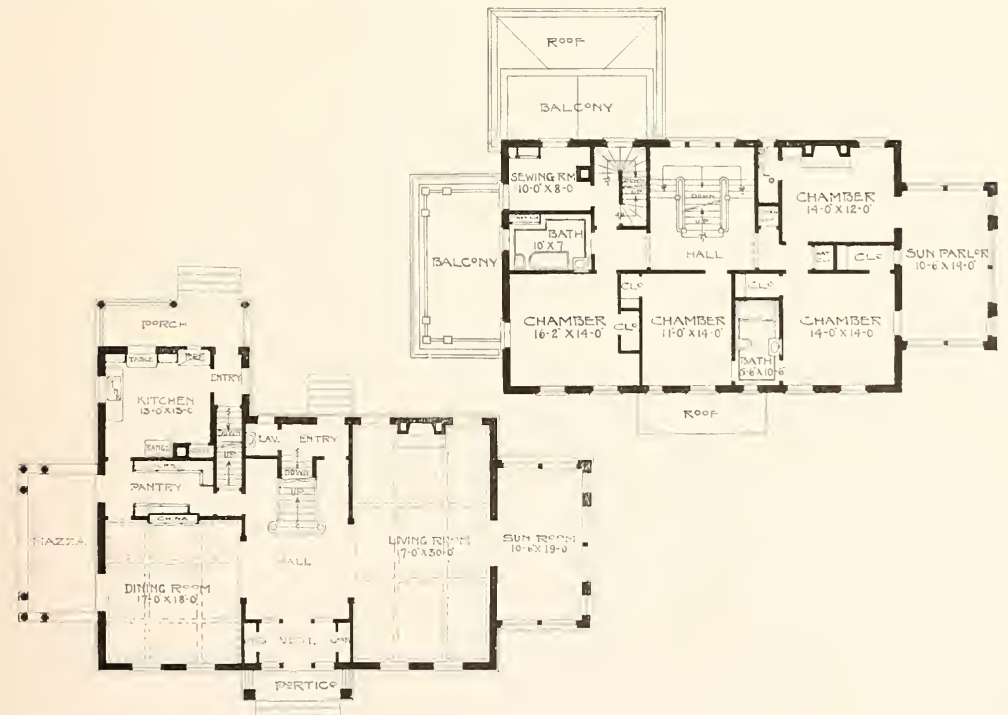




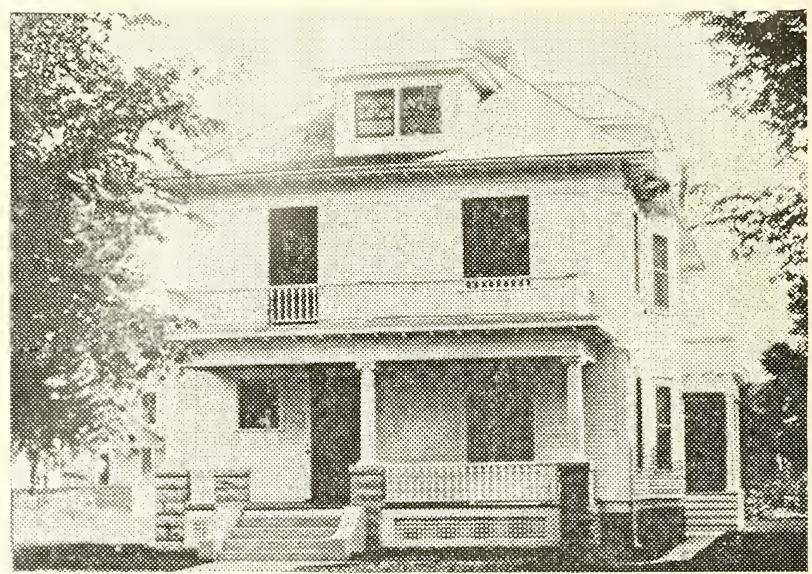

A Roomy Colonial Residence--No. 839

The size of this house is $30 \mathrm{ft}$. wide, $48 \mathrm{ft}$. deep, exclusive of porches. Full basement under entire house $7 \mathrm{ft} .6$ ins. deep; first story $9 \mathrm{ft}$., second story $8 \mathrm{ft}$., first story finished in birch or gum; second story pine to paint. Birch floors in both first and second stories. Cost to build, $\$ 4,500$. One complete set of plans and specifications for $\$ 30$.
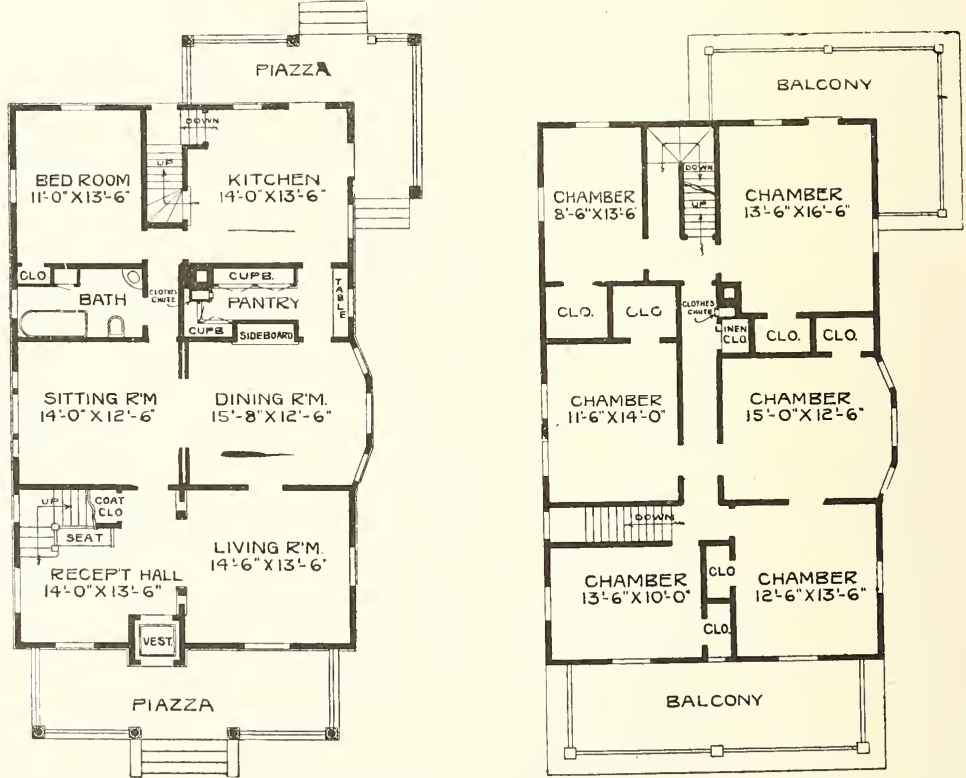

Complete plans and specifications for using Denison Load-Bearing Tile, licensed under Wilson-System Bearing W a 11 Construction for $\$ 60$. 


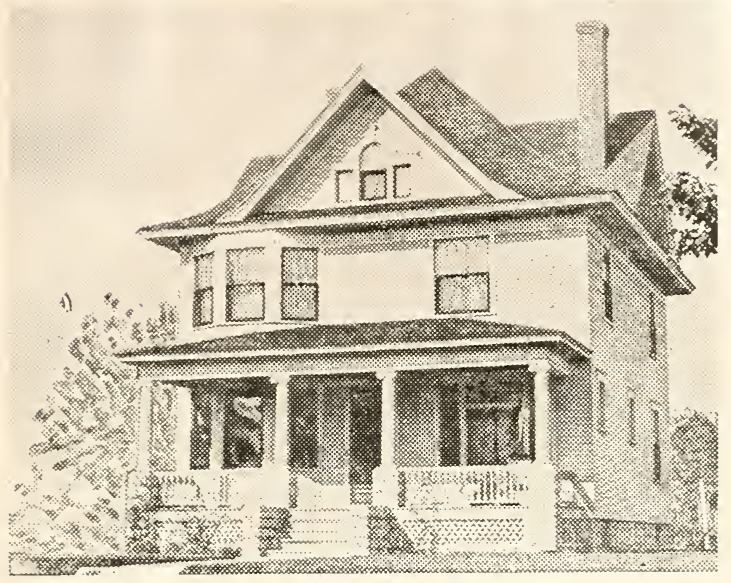

A Colonial Home-No. 833

Size, 28 feet wide by 30 feet deep, full basement. First story 9 feet; second story 8 feet. Birch floors throughout, gum or birch in first story and pine to paint in the second story. Cost to build, $\$ 3,100$. Complete set of plans and specifications for $\$ 25$.
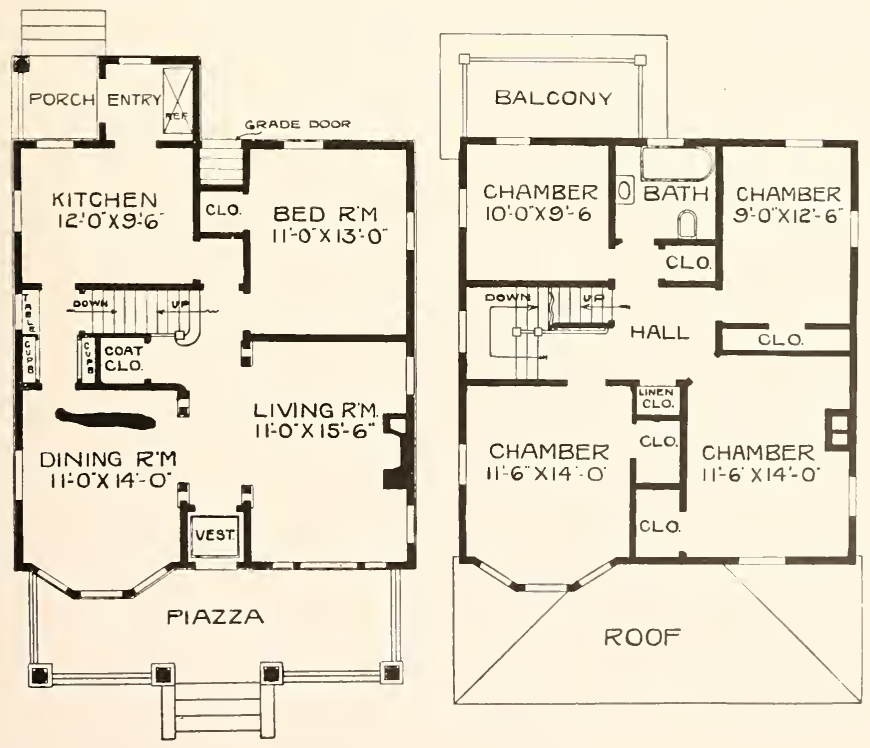

Complete plans and specifications for using Denison Load-Bearing Tile, licensed under Wilson-System Bearing IV a 11 Construction for $\$ 50$. 


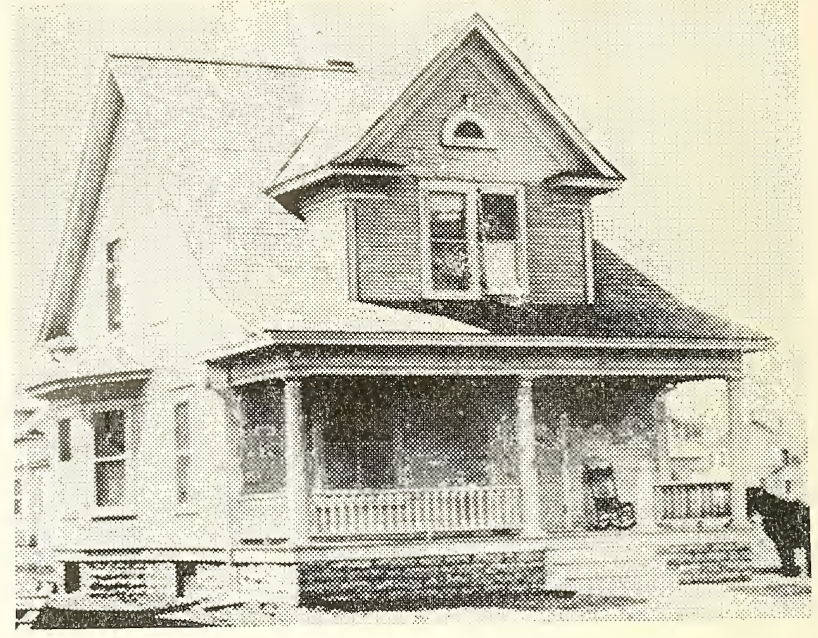

A Splendid Cottage Home-No. 990

Size, 24 feet wide and 26 feet deep. First story 9 feet, second 8 feet. first story finished in gum or birch, second pine to paint, birch floors throughout. Piazza floors and ceiling to be No. 1 Clear Washington fir. Cost to build, $\$ 2,000$. Complete set of plans and specifications for $\$ 15$.

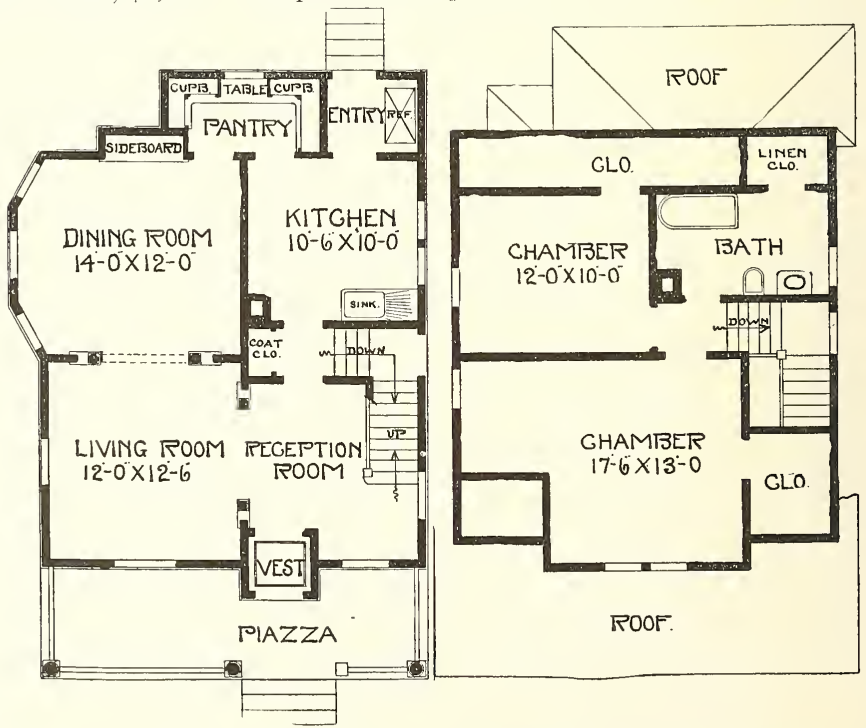

Complete plans and specifications for using Denison Load-Bearing Tile, licensed under Wilson-System Bearing Wall Construction for $\$ 30$. 


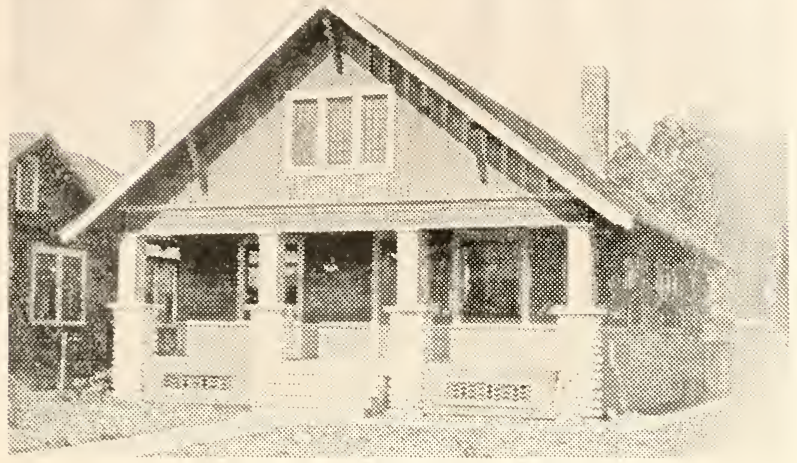

A Lake Dwelling-No. 871

Size, 27 feet by 36 feet. Height of cellar, 7 feet ; first floor, 9 feet, and second is 8 feet. Gum or birch for finish in first story, and pine to paint in second. Piazza floors and ceilings to be No. 1 Clear Washington fir. Cost to build, $\$ 2,450$. Complete plans and specifications for $\$ 15$.
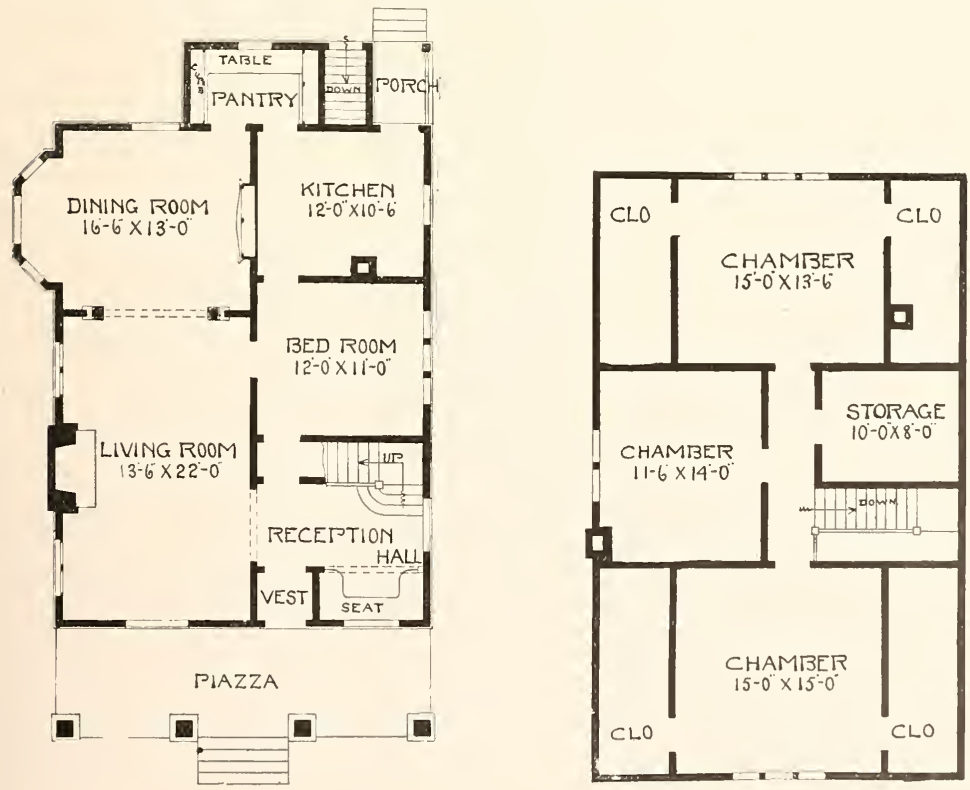

Complete plans and specifications for using Denison Load-Bearing Tile, licensed under Wilson-System Bearing $\mathrm{W}$ a 11 Construction for $\$ 30$. 


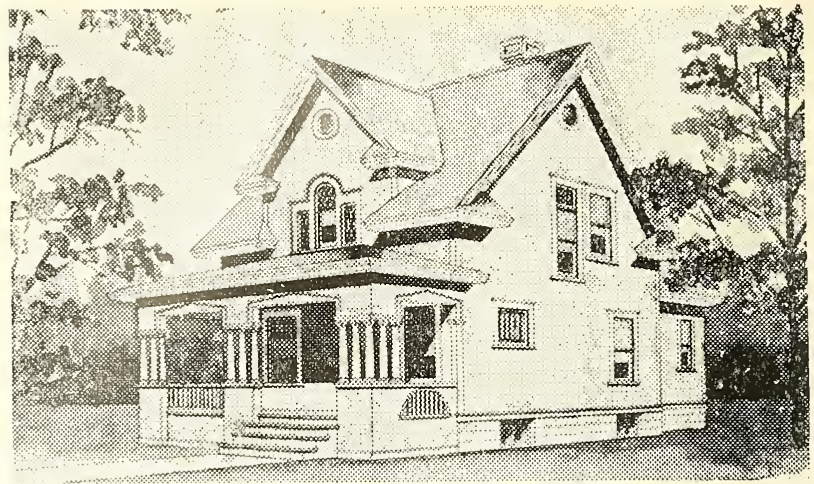

A Modern Cottage Home-No. 866

The basement is 7 feet 6 inches. The first story is 9 feet, second 8 feet 6 inches. The house is planned for birch or maple floors throughout. First story finished in gum or birch, second in pine to paint. Size of house is $26 \times 28$ feet, over the main part. Cost to build, $\$ 2,950$. Complete plans and specifications for $\$ 20$.

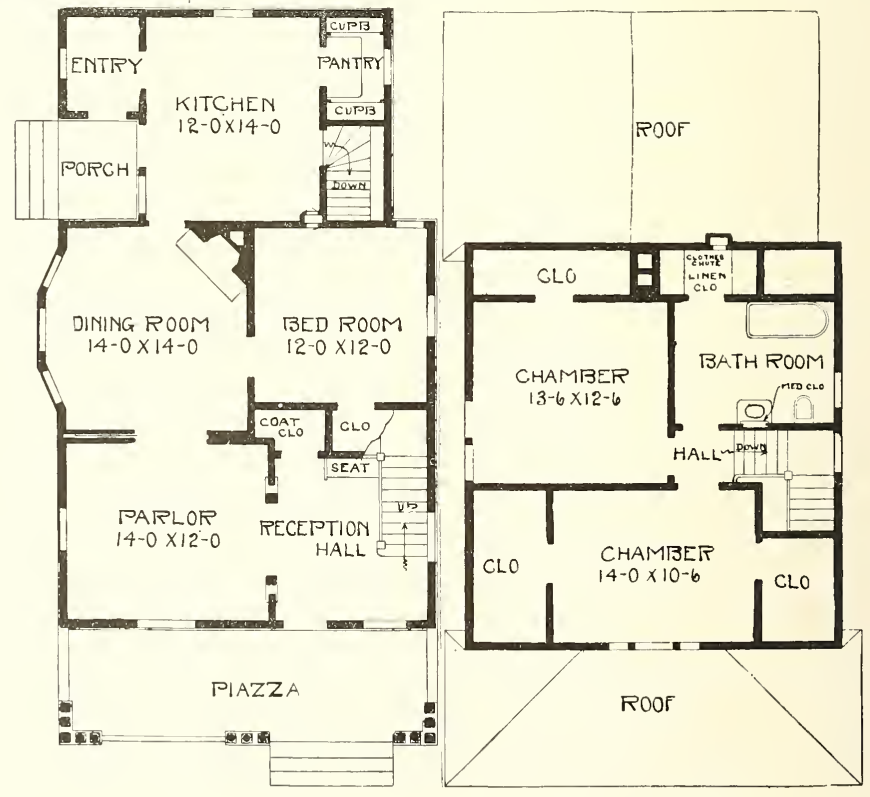

Complete plans and specifications for using Denison Load-Bearing Tile, licensed under Wilson-System Bearing $\mathrm{W}$ a 11 Construction for $\$ 40$. 


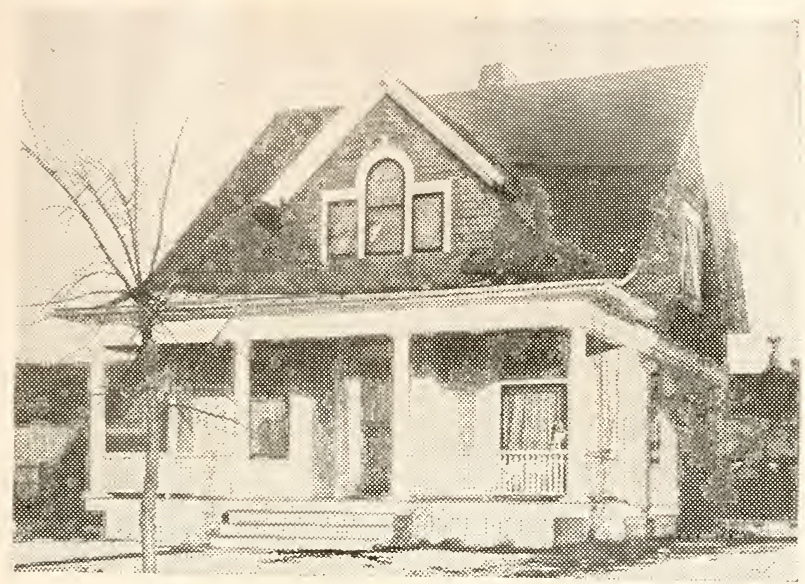

A Model Home-No. 872

Size of house, 26 feet by 28 feet. A light and airy basement under the whole of the house, 7 feet 6 inches in height, is provided. First story 9 feet, second story 8 feet. Finish in first story to be gum or birch, second story pine to paint. Piazza floors and ceiling to be No. 1 Washington fir. Cost to build, $\$ 2,200$. Complete set of plans and specifications, $\$ 15$.

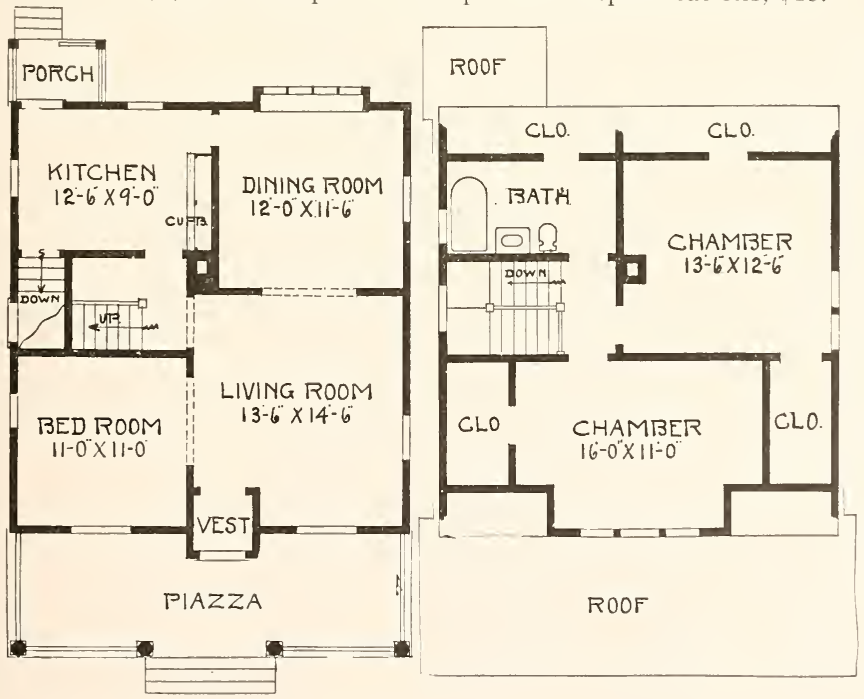

Complete plans and specifications for using Denison Load-Bearing Tile. licensed under Wilson-System Bearing IV a 11 Construction for $\$ 30$. 


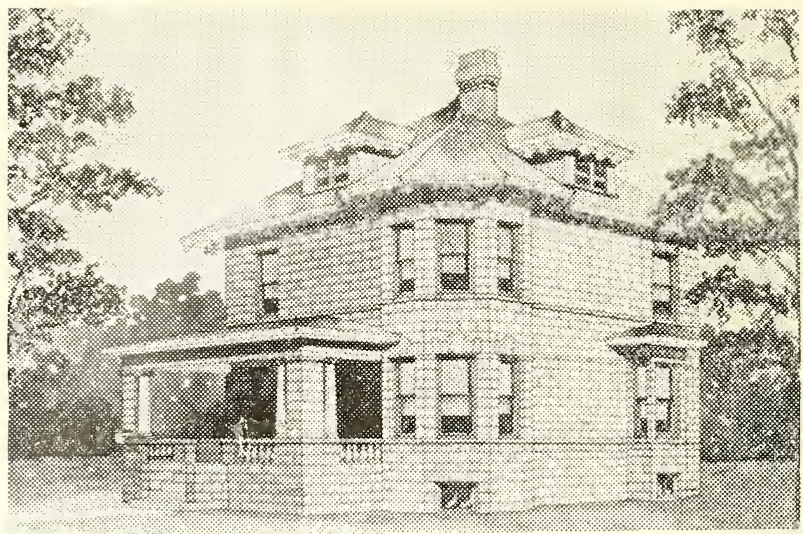

A Cement Stone House-No. 992

If you are contemplating building a cement block house or any kind of a building treated with cement blocks, or cement exterior, communicate with me.

There is a full basement under the entire house, 7 feet 6 inches. First story is 9 feet high and the second 8 feet.

Size of house is 28 feet wide and 30 feet deep over the main part. Birch floors throughout. Gum or birch finish in first story, and pine to paint in the second. Cost to build, $\$ 5,000$. Complete set of plans and specifications for $\$ 30$.

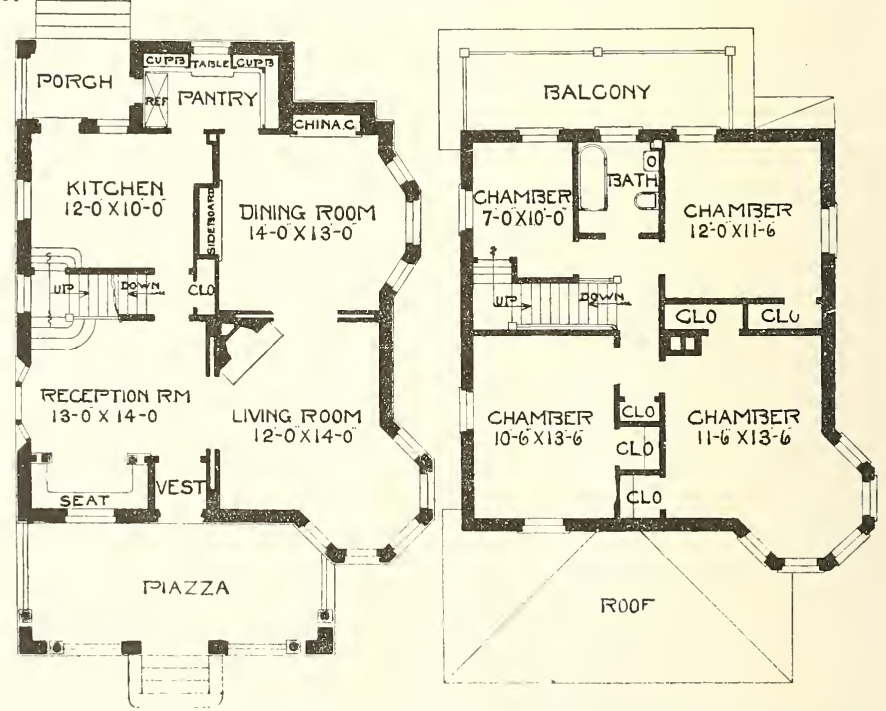

Complete plans and specifications for using Denison Load-Bearing Tile, licensed under Wilson-System Bearing W a 11 Construction for $\$ 60$. 


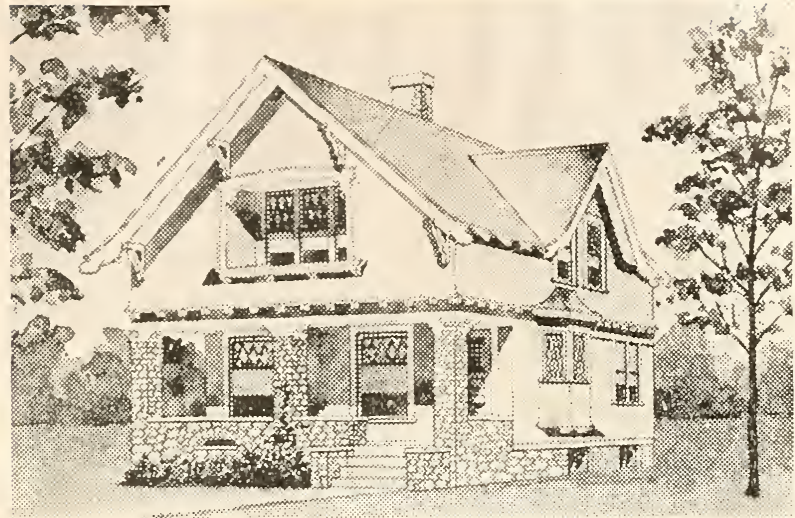

A Beautiful Cottage-No. 873

There is a 7 -foot basement under the entire house; first story 9 feet, second story 8 feet. Size, 26 feet wide by 28 feet deep. Gum or birch finish in first story, pine to paint in second. Piazza floors and ceiling to be No. 1 Washington fir. Birch floors throughout. Cost to build, $\$ 2,850$. Complete plans and specifications for $\$ 20$.

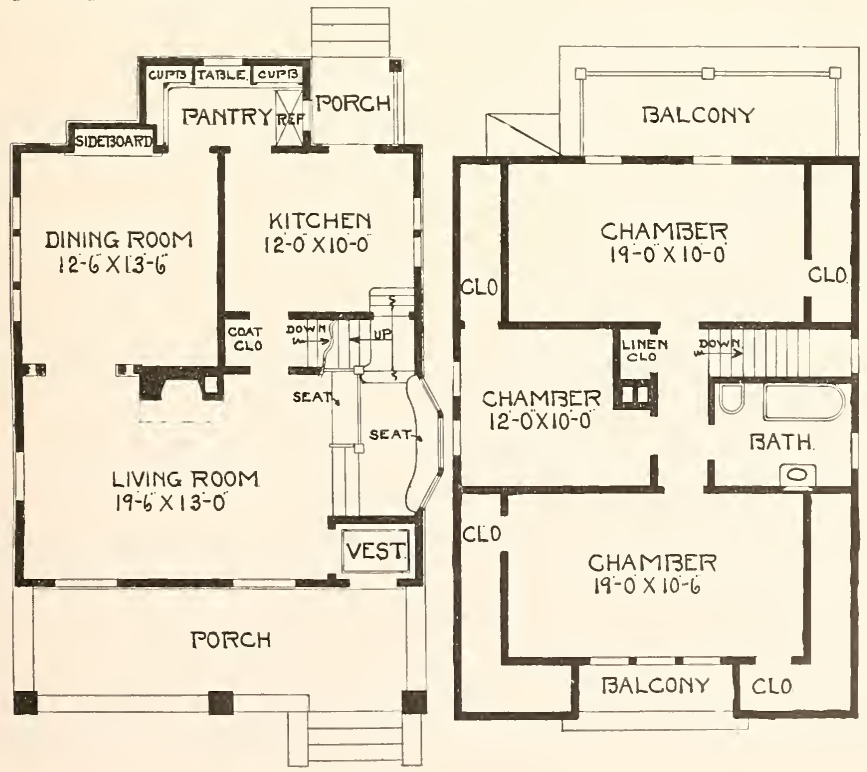

Complete plans and specifications for using Denison Load-Bearing Tile, licensed under Wilson-System Bearing iV a 11 Construction for $\$ 40$. 


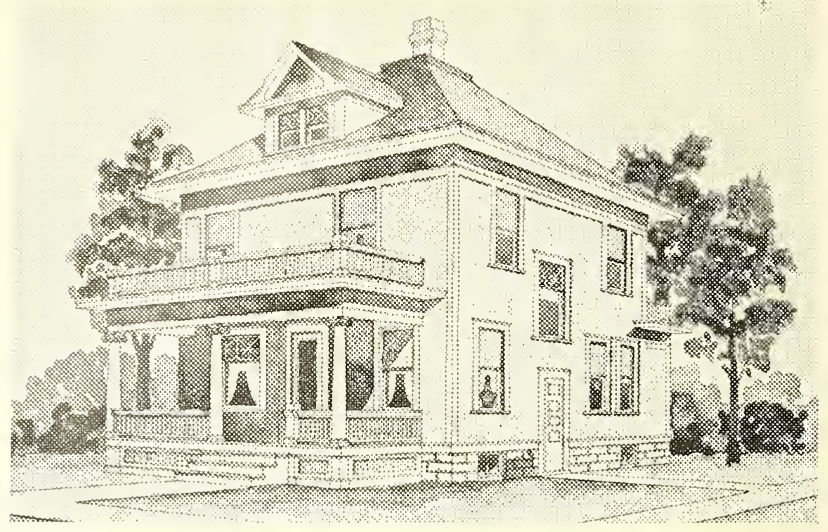

A Comfortable Home-No. 996

Here is a splendid arrangement for an eight-room house, and one of the most popular designs. The rooms are all large and well lighted. There is a full stone basement; first story is 9 feet high; second, 8 feet 6 inches. Size, 26 feet by 28 feet deep. Birch floors throughout. Gum or birch in first story, and pine to paint in second story. Piazza floors and ceilings to be No. 1 Washington fir. Cost to build, $\$ 2,850$. Complete set of plans and specifications, $\$ 20$.

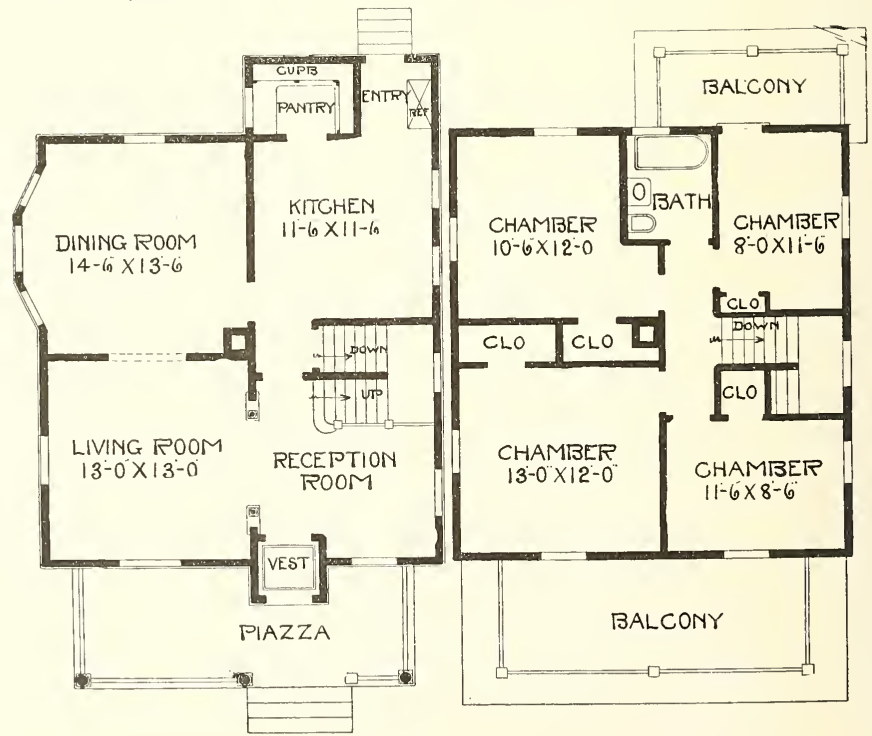

Complete plans and specifications for using Denison Load-Bearing Tile, licensed under Wilson-System Bearing Wa 11 Construction for $\$ 40$. 


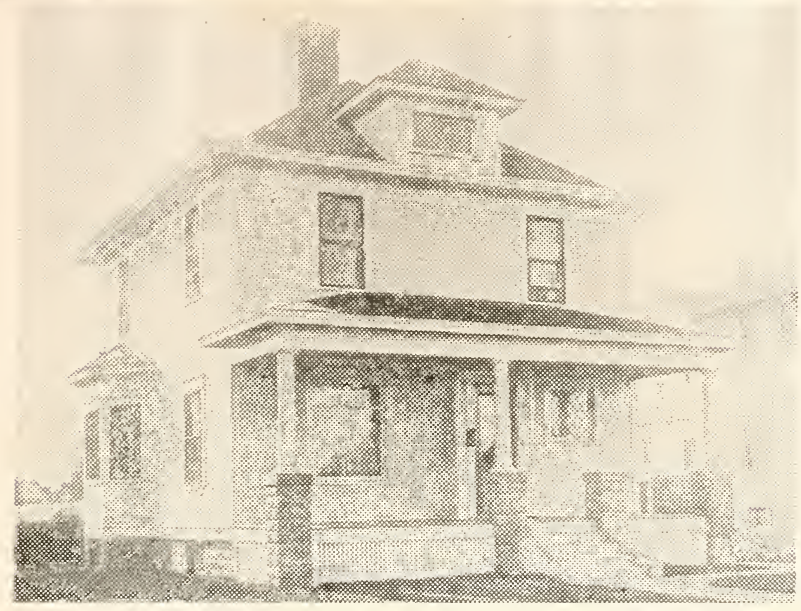

An Economical Home-No. 997

Here is a splendid investment in an eight room colonial house. The size is 26 feet wide and 28 feet deep. There is a full basement under the entire building. 7 feet deep. The first story is 9 feet, second story 8 feet in the clear. There is also good space in the attic. Birch floors are used throughout. Finish in first story, gum or birch; second story. pine to paint. Piazza floors and ceiling to be No. 1 Washington fir. Cost to build, $\$ 3,000$. Complete set of plans and specifications, $\$ 20$

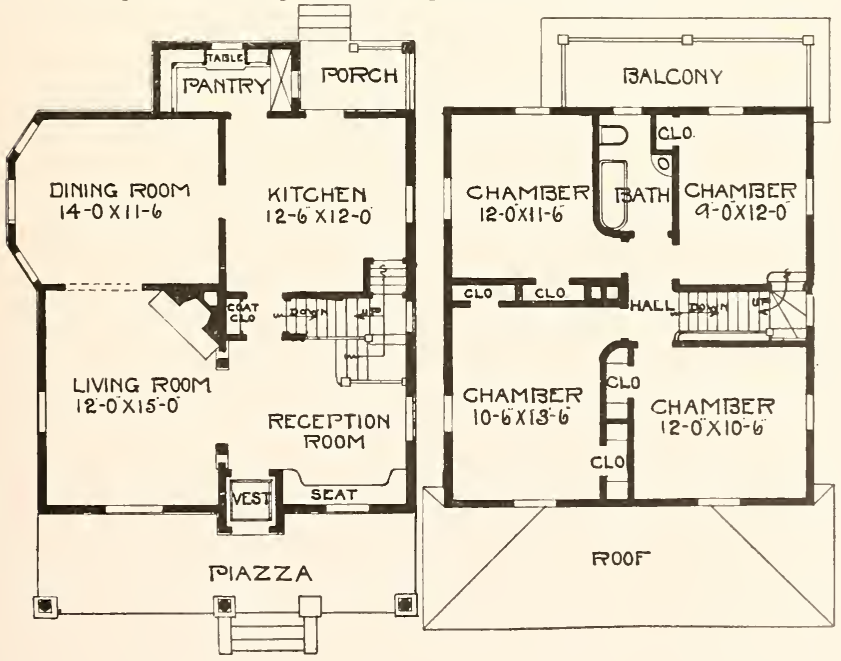

Complete plans and specifications for using Denison Load-Bearing Tile, licensed under Wilson-System Bearing IV a 11 Construction for $\$ 40$. 


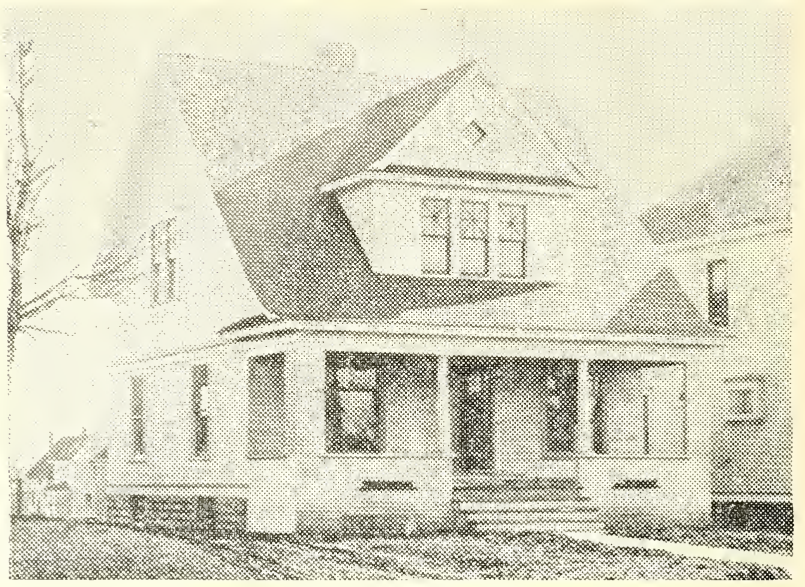

A Home to be Proud of-No. 875

The first story is 9 feet, second 8 feet. Gum or birch finish in first story and pine to paint in second. Birch or maple floors throughout. Piazza floors and ceiling to be No. 1 Clear Washington fir. Size of house, 26x26 feet. Cost to build, $\$ 2,200$. Complete plans and specifications for $\$ 15$.

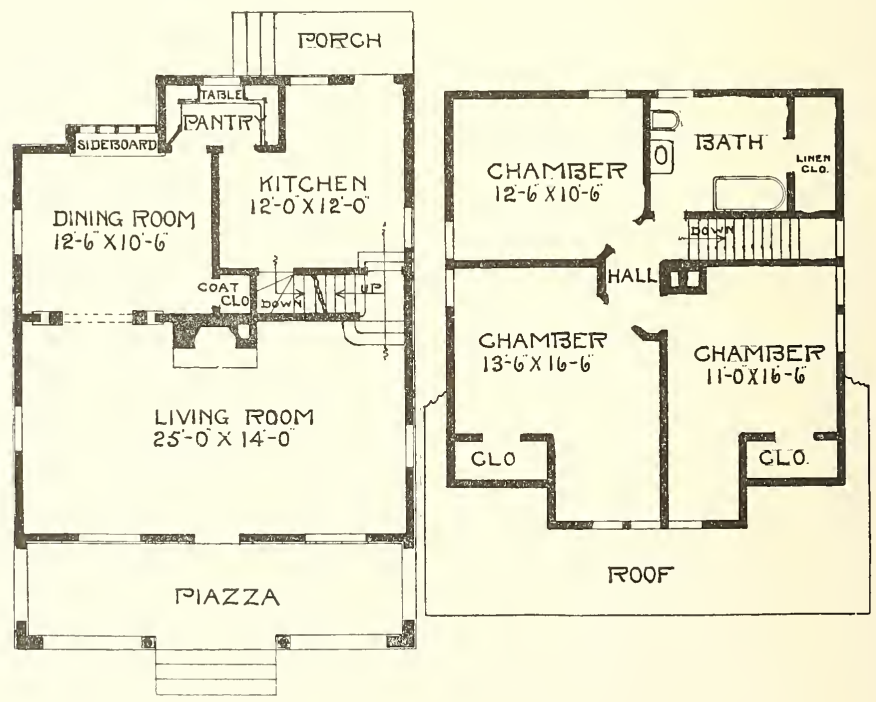

Complete plans and specifications for using Denison Load-Bearing Tile, licensed under Wilson-System Bearing $W$ a 11 Construction for $\$ 30$. 


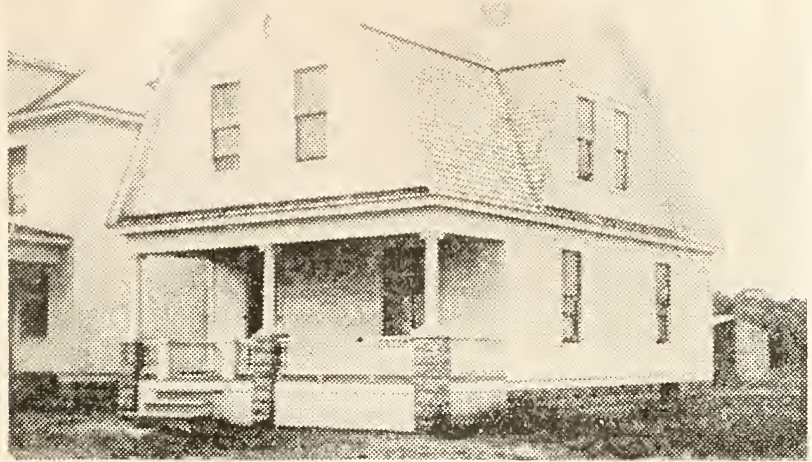

A Splendid Cottage Home-No. 885

Size, $23 \times 28$ feet 6 inches. Height of first story 9 feet, seeond story 8 feet. Finished in gum first story, pine to paint in seeond story. Cost to build, $\$ 2,250$. Complete plans and specifications for $\$ 15$.

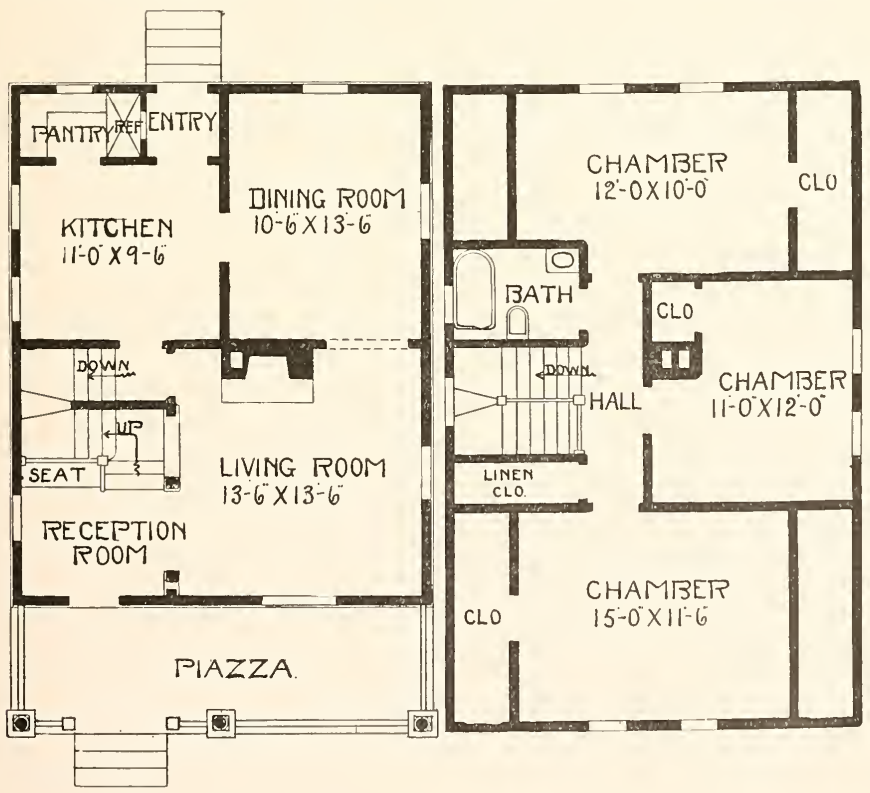

Complete plans and specifications for using Denison Load-Bearing Tile, licensed under Wilson-System Bearing iV a 11 Construction for $\$ 30$. 


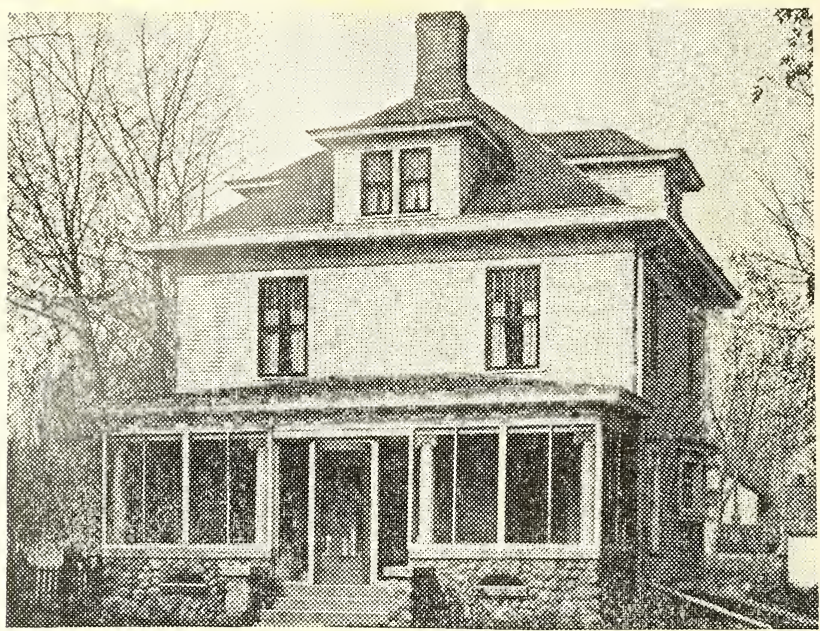

A Practical and Economical Residence-No. 899

Size of house is $26 \times 28$ over the main part. The dining room has a built-in sideboard, beamed ceiling and Dutch window, all features combining to make a beautiful home. In the second story there are three large chambers, good closets, linen closet, bath room and sewing room. There is ample space in the third story for one or two rooms, if desired. Birch floors throughout with birch or gum finish in first story and pine to paint in the second story. Cost to build $\$ 2,925$. Price of plans and specifications, $\$ 25$.
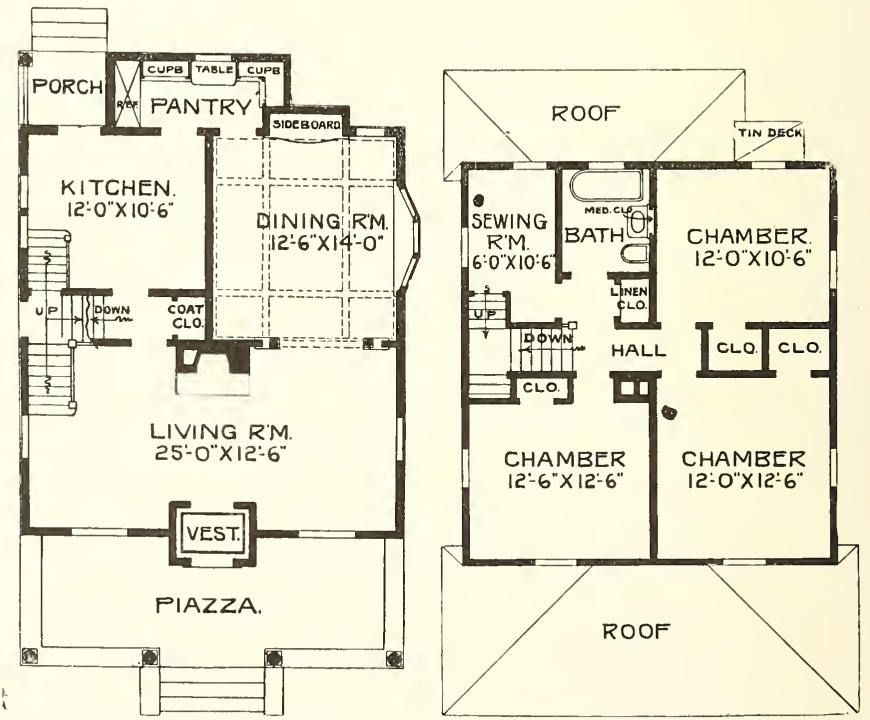

Complete plans and specifications for using Denison Load-Bearing Tile, licensed under Wilson-System Bearing W a 11 Construction for $\$ 50$. 


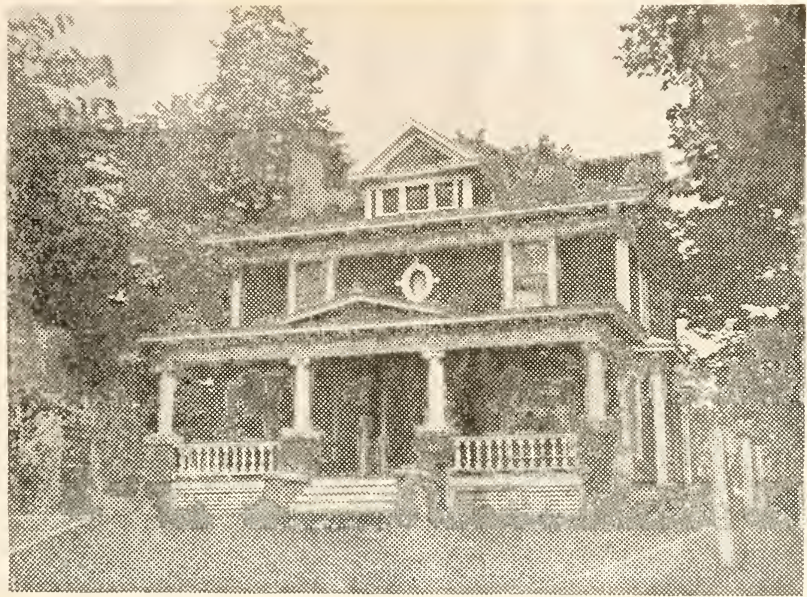

A Modern Colonial Residence-No. 893

Width 30 feet, depth 28 feet over the main part. A large living room and dining room occupy the front half of the first story and are connected with a columned archway. The columns are square and extend from the floor to the top of opening. Through the archway the fire-place can be seen from the dining room. In second story are four chambers. All features combine to make an exceptionally complete home. The first story may be finished in red oak or birch, with birch floors throughout. Cost to build, $\$ 4,800$. Price of plans and specifications, $\$ 30$.

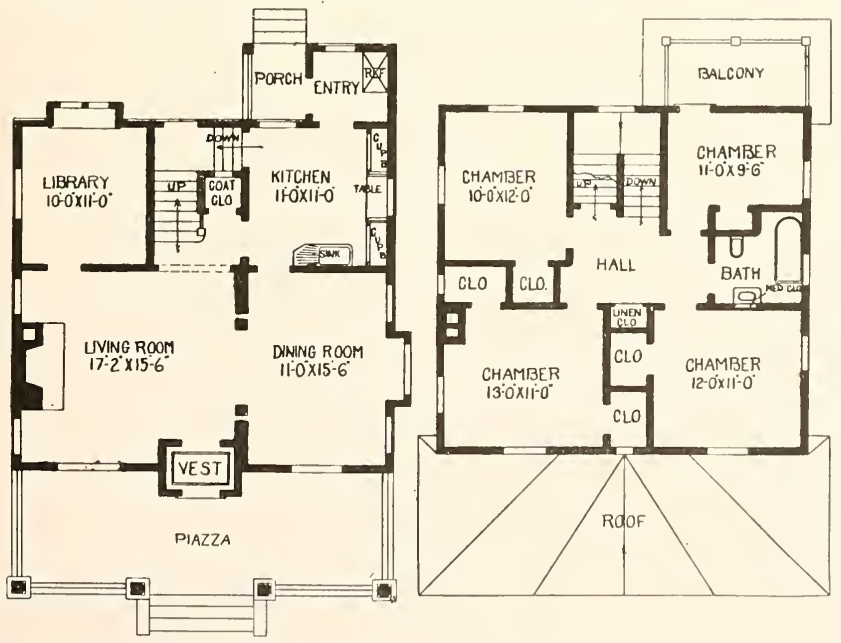

Complete plans and specifications for using Denison Load-Bearing Tile, licensed under Wilson-System Bearing IV a 11 Construction for $\$ 60$. 


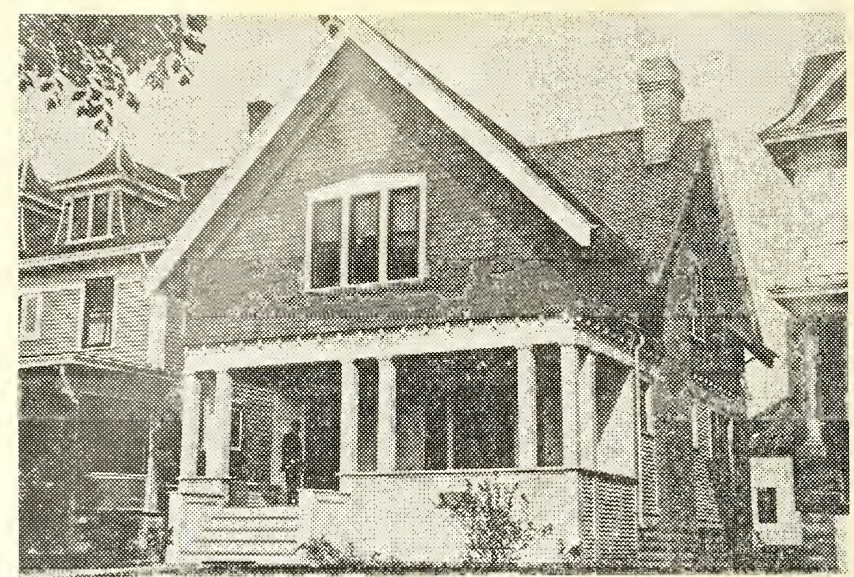

Just a Small Home-No. 892

Width 24 feet, depth 28 feet over main part. An attractive little home, which is really not so small. There are six rooms, all large and roomy. The living room has a fire-place at one end and a well arranged stairway and built-in seat at other end. There are three splendid chambers, ample closets and bath in second story. First story finished in birch or fir and second story in white enameled pine. Cost to build, $\$ 2,600$. Price of plans and specifications, $\$ 20$.
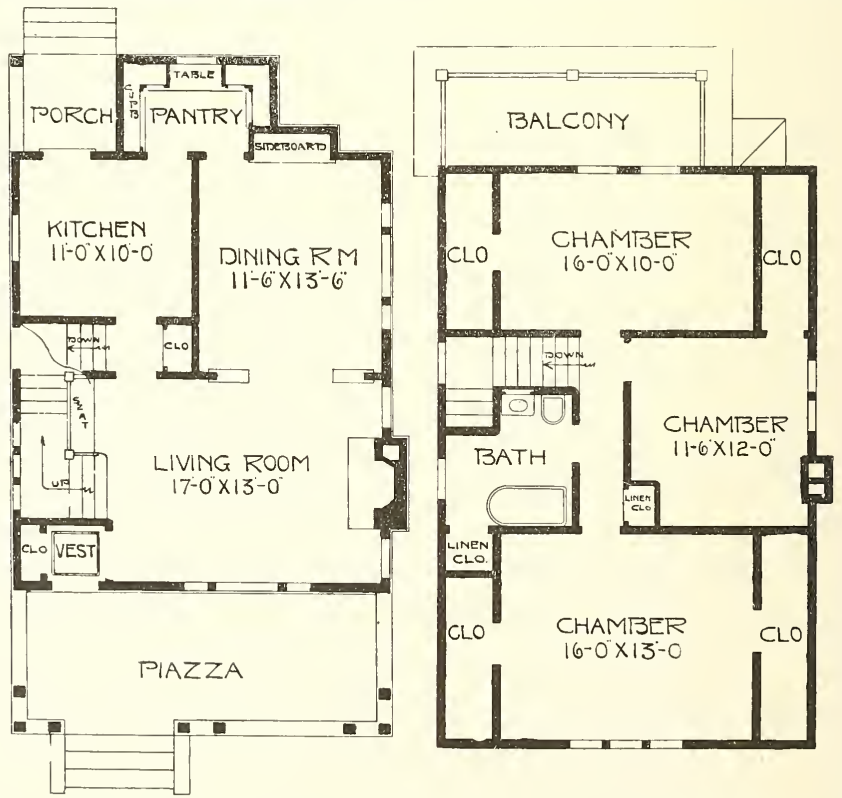

Complete plans and specifications for using Denison Load-Bearing Tile, licensed under Wilson-System Bearing Wa 11 Construction for $\$ 40$. 


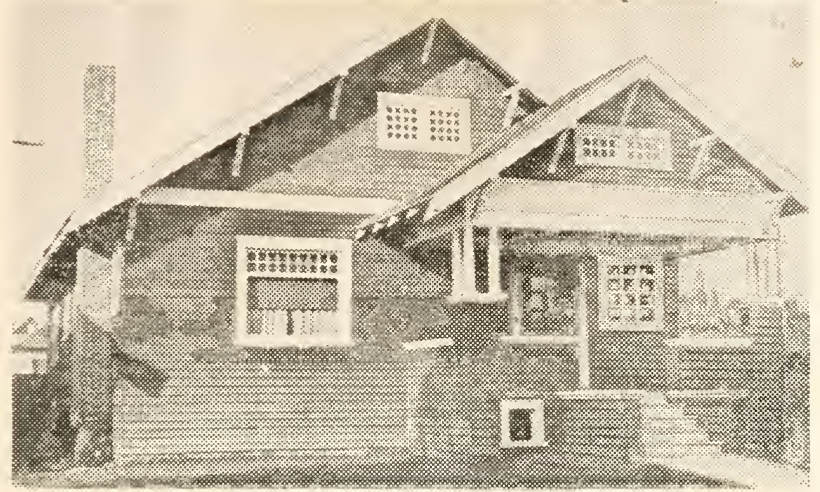

A Practical Bungalow-No. 860

Width 28 feet, depth 38 feet, over the main part. A charming little home with a very practical interior, comprising six rooms. A beautiful living room, with an open fire-place opens upon an equally beautiful dining room. by means of sliding doors. Red oak or gum finish and maple or birch floors. There are two splendid chambers, and stairways to both the basement and second stories. Cost to build, $\$ 2,100$. Price of one complete set of plans, $\$ 16$.

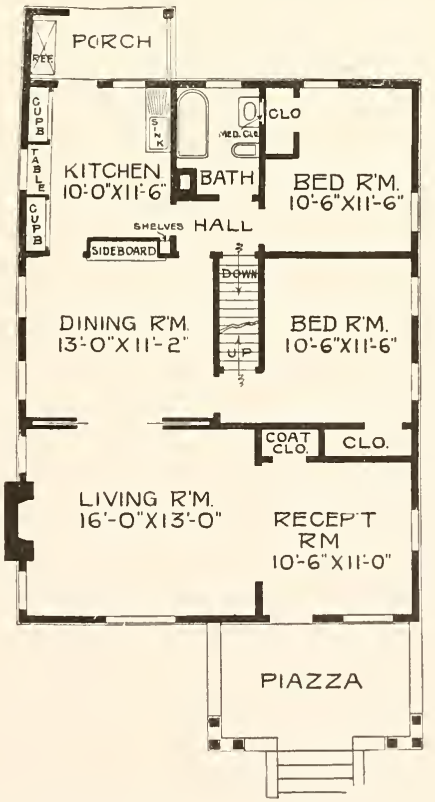

Complete plans and specifications for using Denison Load-Bearing Tile, licensed under Wilson-System Bearing $\mathrm{W}$ a 11 Construction for $\$ 32$. 


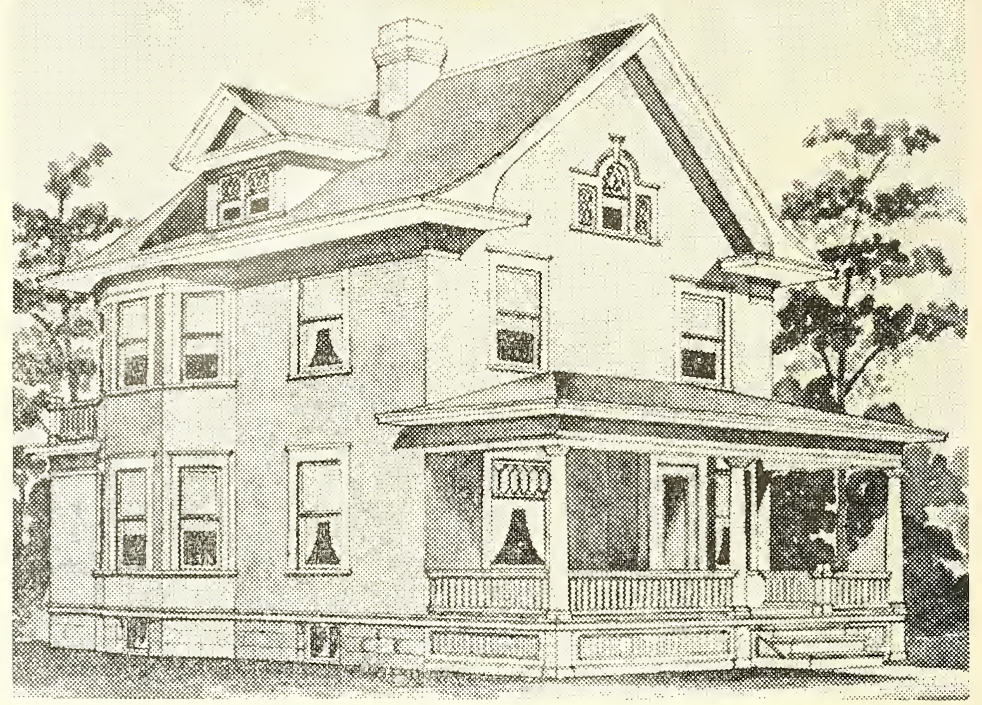

A Popular Colonial Home-No. 86

Built 70 times.

This house is $24 \times 26$ feet over the main portion, and contains eight splendid rooms. First story 9 feet, second story 8 feet, and full basement 7 feet high. Cost to build,

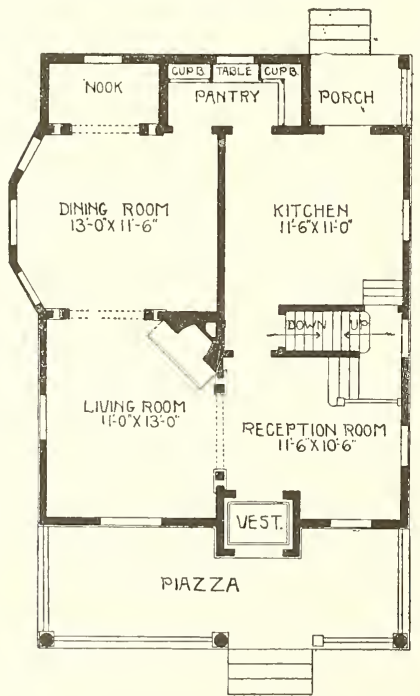
$\$ 2,500$. Complete plans and speeifications for $\$ 20$. We can also furnish this beautiful home $26 \times 28$ also $26 \times 30$ feet with the same arran $g$ ement of rooms for $\$ 25$.

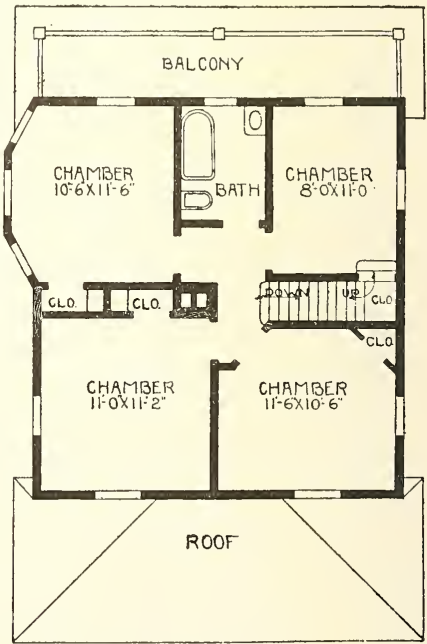

Complete plans and specifications for using Denison Load-Bearing Tile, licensed under Wilson-System Bearing Wa 11 Construction for $\$ 50$. 


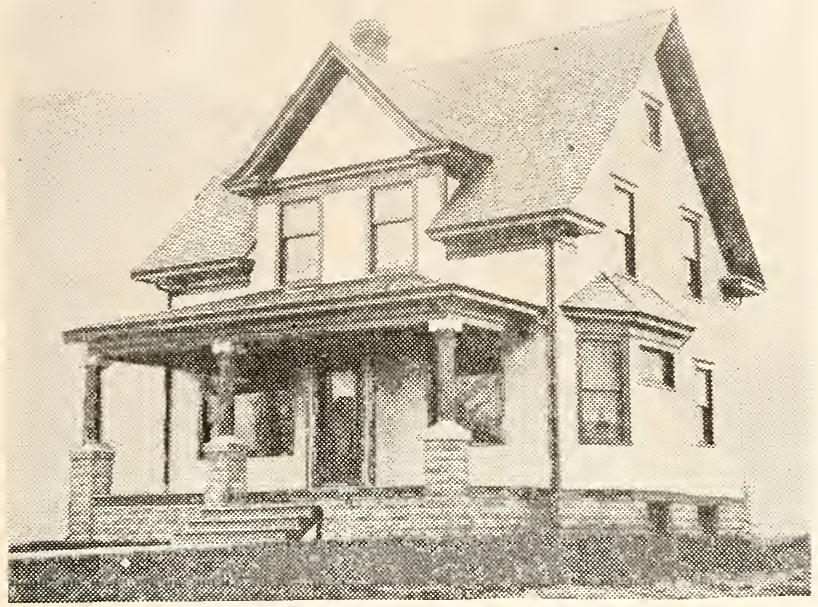

A Splendid Cottage Home-No. 827

Size of house 28 feet wide and 26 feet deep. This design ean be appreciated by those who are seeking an artistic and practical home. The dining room is brought forward to the front of house, a feature growing more and more in favor. There are built-in cupboards in the kitchen, and that great convenience, a clothes chute. Small panel doors open into the chute from both the kitchen and bathroom. The first story may be finished in red oak, birch, or gum and the second story in a mixed quality of birch or pine to paint. Cost to build, $\$ 2,250$. Price of plans, $\$ 15$.

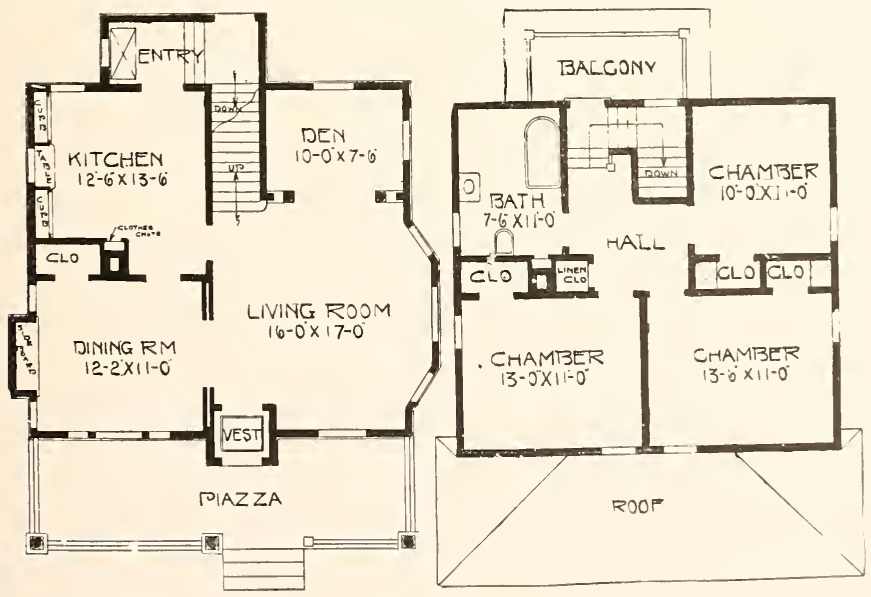

Complete plans and specifications for using Denison Load-Bearing Tile. licensed under Wilson-System Bearing iv a 11 Construction for $\$ 30$. 


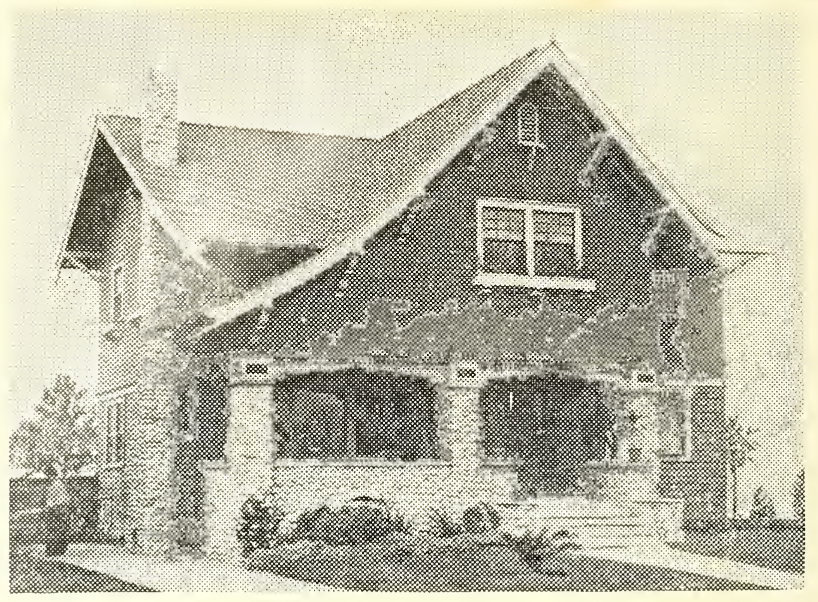

An Original Residence Design-No. 826

Size of house is 34 feet wide and 26 feet deep over the main part, with a full basement. Here is a plan somewhat out of the ordinary. A comfortable cobble-stone piazza extends across two-thirds of the front. Above it are a large chamber and closets, the projection affording a unique treatment of the roof, a front gable and sweep with wide eaves, supported on heavy brackets. The chimney and fire-place are of cobblestone. Birch floors throughout; birch or gum finish in first story and pine to paint in second story. Cost to build, $\$ 3,550$. One set of plans and specifications for $\$ 30$.

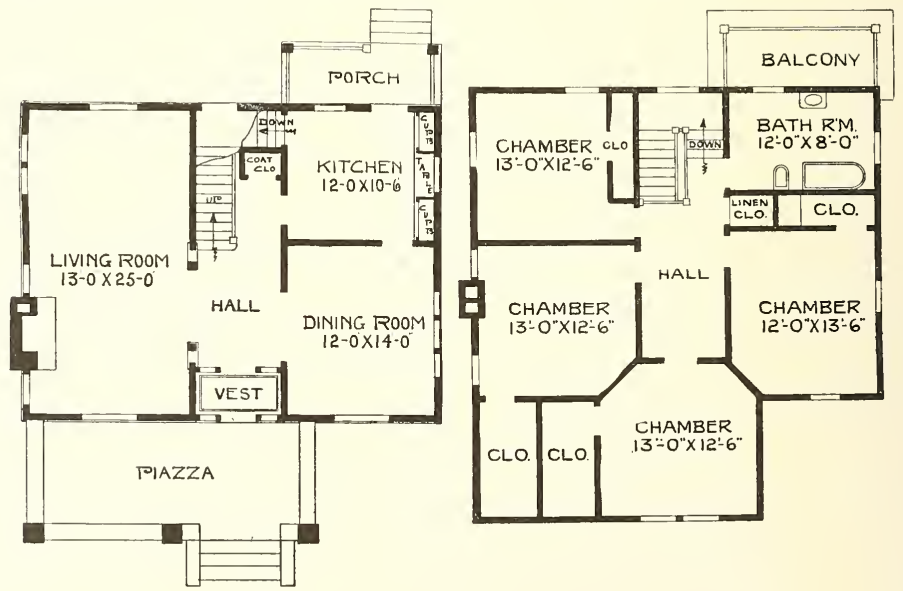

Complete plans and specifications for using Denison Load-Bearing Tile, licensed under Wilson-System Bearing Wa 11 Construction for $\$ 60$. 


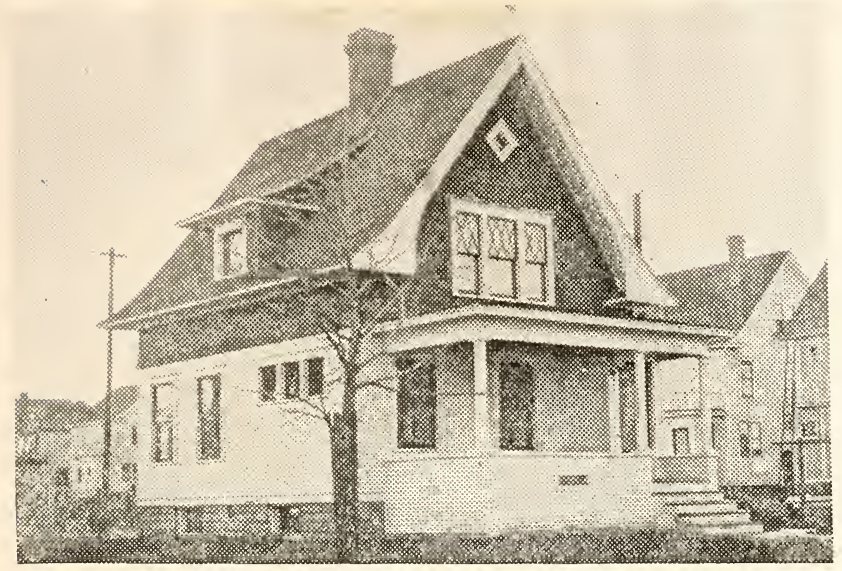

A Popular Cottage Home-No. 837

Size, 22 feet wide, 24 feet 6 inches deep, full basement; first story 8 feet, second story 8 feet. Birch floors throughout; birch or gum finish in first story, and pine to paint in second story. Cost to build, $\$ 1,900$. Complete set of plans and specifications for this cottage for $\$ 13$.
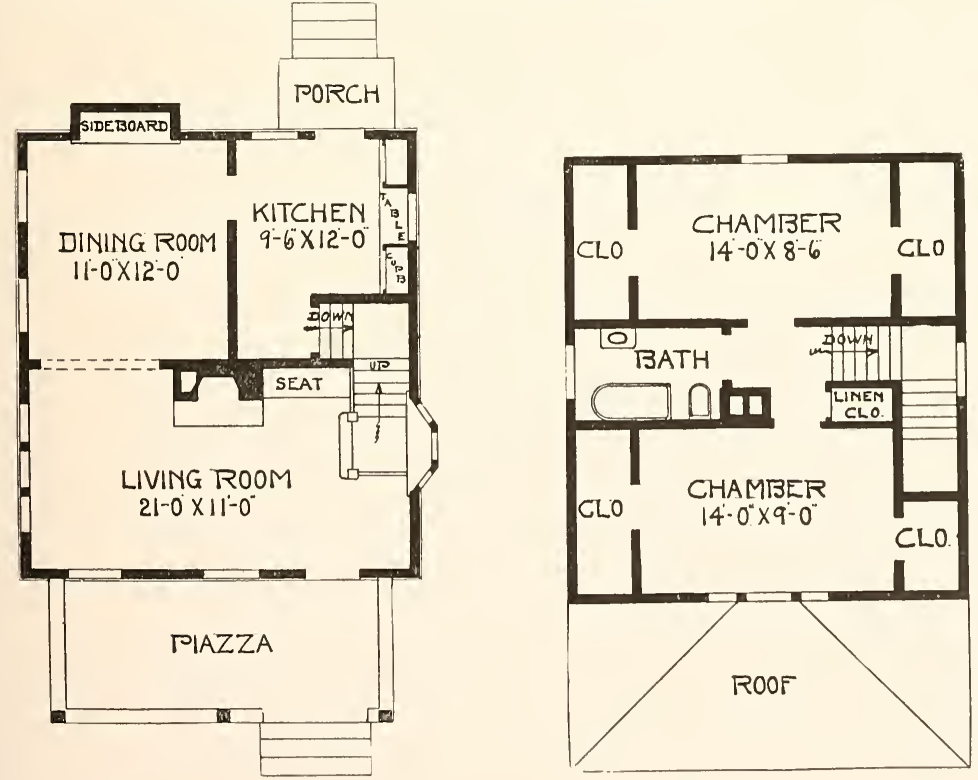

Complete plans and specifications for using Denison Load-Bearing Tile, licensed under Wilson-System Bearing $\mathrm{W}$ a 11 Construction for $\$ 26$. 


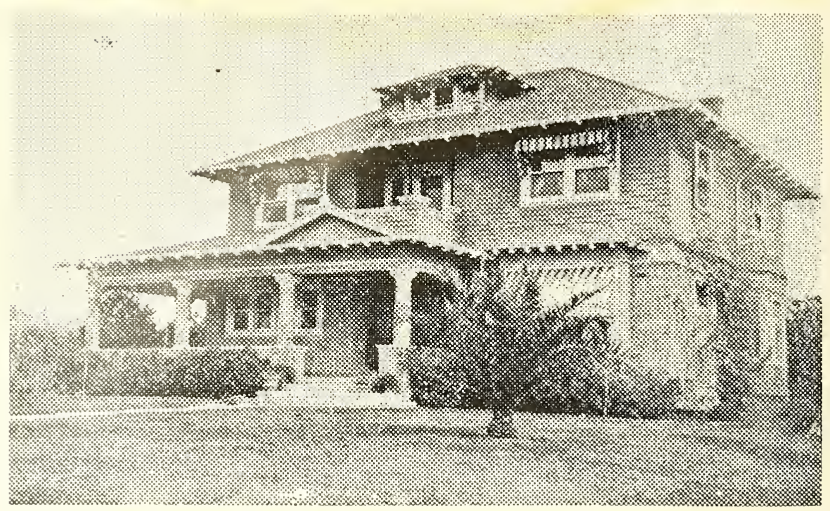

A Typical California Home Adapted to Northern Climate-No. 933

Width 32 feet, depth 28 feet over the main part. This is an example of the type of houses which are being built so extensively in California, the land of beautiful homes. Its popularity is undoubtedly due to its beautiful exterior. The roof has an open cornice supported by sawed and dressed rafter ends, and a single low dormer. The arrangement of the rooms is ideal. An economical feature is the position of the chimney which provides a flue for the fire-place, one for the heating plant and kitchen range, a combination which eliminates an extra chimney and saves probably $\$ 120$. The first story is 9 feet high and the second $8 \mathrm{~T} / 2$ feet. Birch floors. First story is finished in gum or red oak and second in white enameled pine with birch doors. Cost to build, $\$ 3,250$. Complete set of plans and specifications for $\$ 30$.
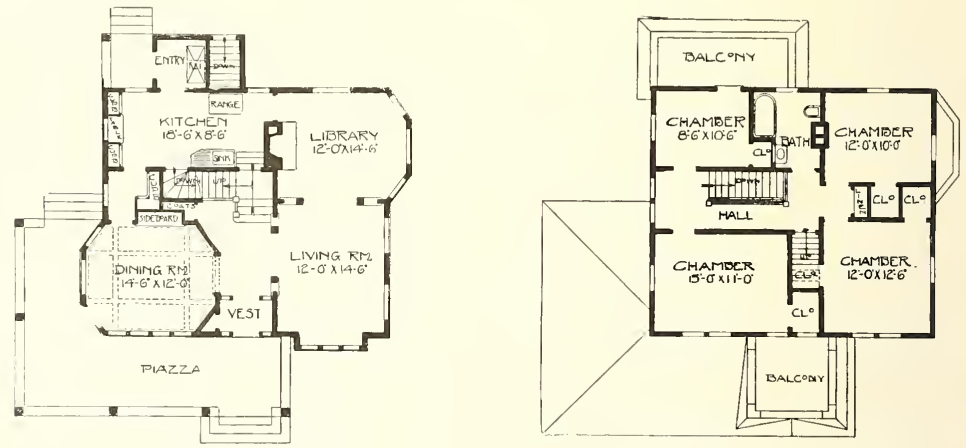

Complete plans and specifications for using Denison Load-Bearing Tile, licensed under Wilson-System Bearing W a 11 Construction for $\$ 60$. 


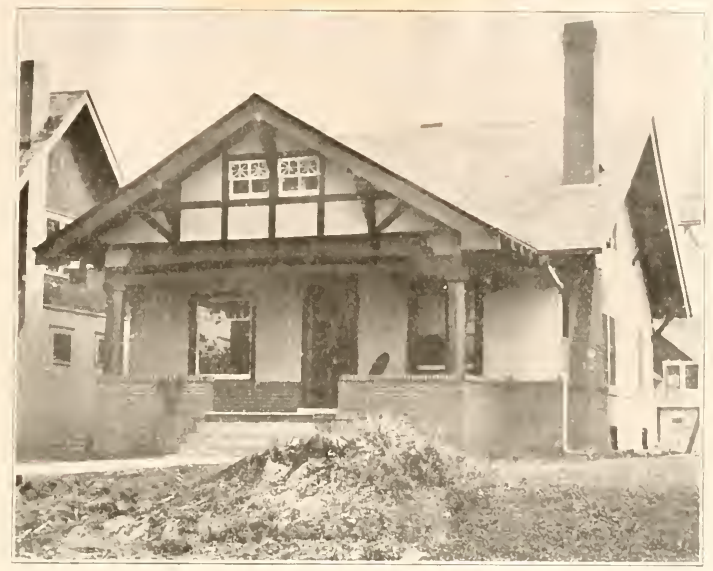

A Brick and Rough Cast Bungalow-No. 720

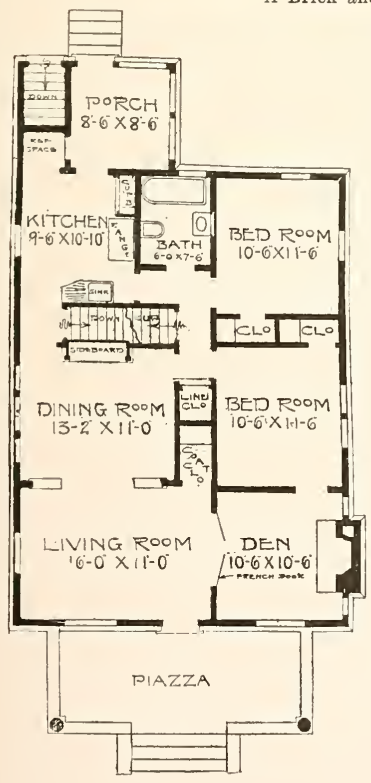

This bungalow has all the features that could be desired in a home. The living rooms well arranged are on one side of the house, and the den and bed rooms on the other. Both the chambers, bath, and kitchen can be reached from the hall in the center, without passing through the other rooms.

We have a very pretty den built in this bungalow with French doors opening into the living room. The dining room is very prettr, lighted with three large windows at side. Kitchen has built-in cupboards and is well arranged for the sink, range, etc. Also built-in space for refrigerator where the ice can be put in from the rear porch. This porch is sereened in and sashed in and ean be used as a dining room in summer if you desire. There is a grade entrance at the side of this poreh in rear, anil two good sized chambers can be finished in second story if it is so desired, giving the capacity of four sleeping rooms.

Size of this bungalow 25 feet wide and $3 \mathrm{~s}$ feet deep over main part. Front piazza is ? feet wide and 22 feet long. Full basement under entire house. First story 9 feet, secomel story 8 feet, that is, that would be the height of the two chambers if finished. Maple or birch lloors thronghout first story. Finish throughout first story red oak or gim. Cost to build, $\$ 2,600$. Complete set of plans and specifieations for $\$ 25$.

Complete plans and specifications for using Denison Load-Bearing Tile, licensed under Wilson-System Bearing IV a 11 Construction for $\$ 50$. 

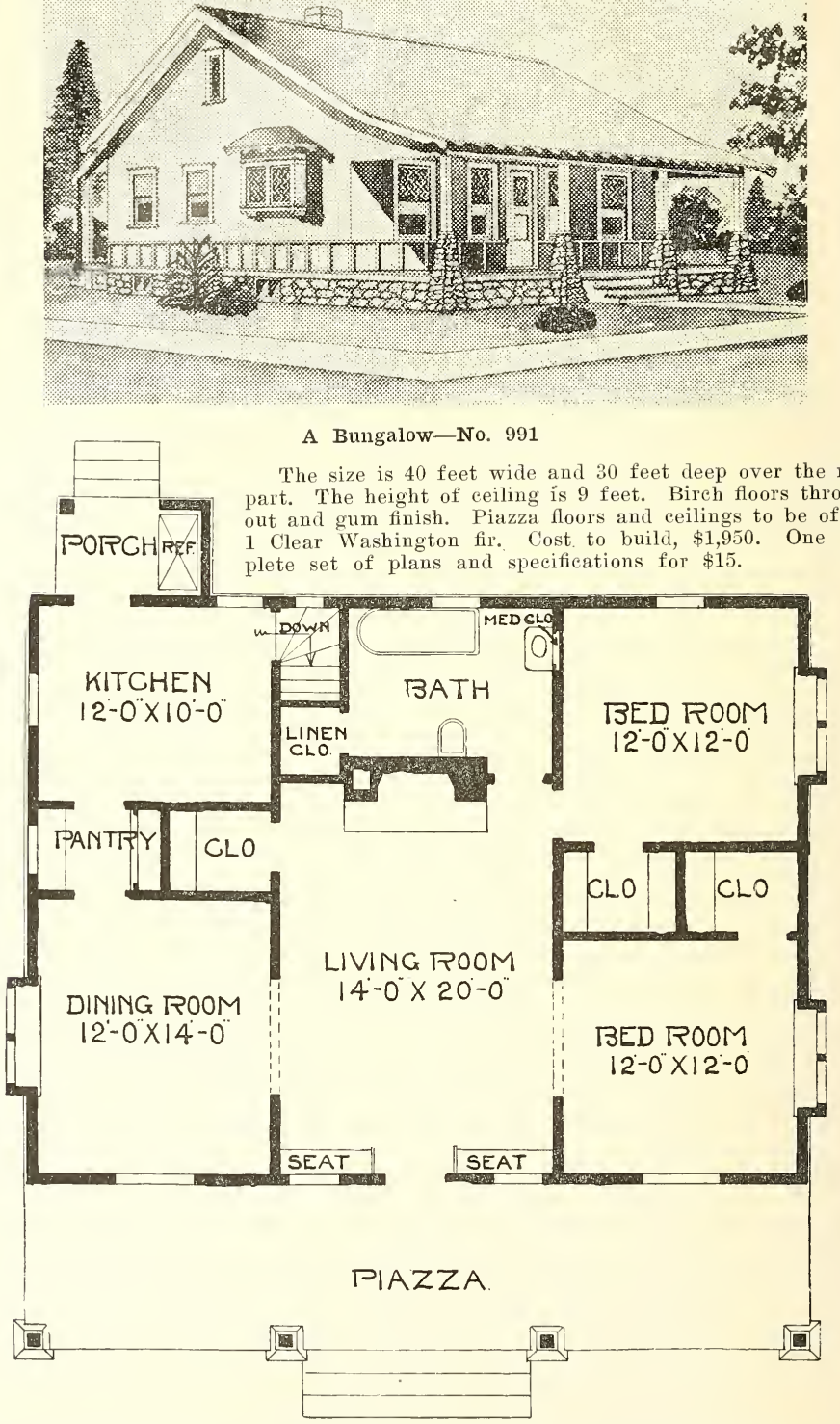

Complete plans and specifications for using Denison Load-Bearing Tile, licensed under Wilson-System Bearing $W$ a 11 Construction for $\$ 30$. 


\section{Your House Can Have Fire Proof Walls}

\section{At About the Cost of Wood if You Build of}
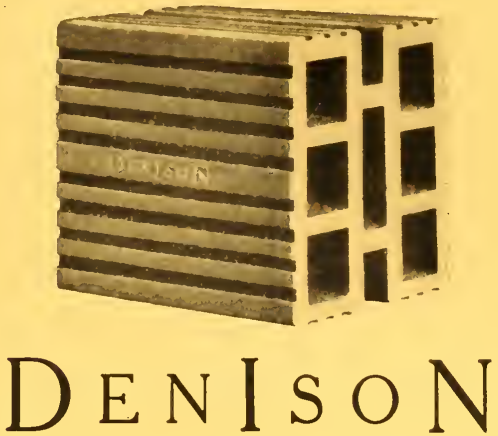

Load Bearing Tile

(Licensed under the Wilson System Bearing Wall Construction, United States and foreign patents pending and allowed.)

Fire resisting construction has proved beyond a doubt that it pays even when it costs more. If you build any house in this book of DENISON LOAD BEARING TILE, you will get fire-proof walls at just about the cost of ordinary first-class wood construction; sometimes a trifle more, and sometimes even less. A wooden house covered with metal lath and stucco costs the same or more than a house built with DENISON LOAD BEARING TILE walls.

Built of DENISON LOAD BEARING TILE a house would be warmer in winter and cooler in summer, and your insurance would be less - besides an added safety from fire, which no amount of insurance can give you. Your house would be absolutely moisture proof and absolutely rat and vermin proof.

The department of Buildings of the city of Minneapolis has proved by actual test that DENISON LOAD BEARING TILE will withstand a pressure of over one hundred and forty thousand $(140,000)$ pounds per square foot of bearing surface. That means that a DENISON TILE wall is stronger than a brick wall, yet costs practically the same as wood. Tests showing the same results have also been made by State Testing Laboratories of lowa, Wisconsin and other states, but of course the best proof of all is the satisfactory use of the tile in hundreds of buildings, great and small.

DENISON LOAD BEARING TILE walls may be faced with stucco (or brick veneer if desired) without furring and lathing, or other treatment of any sort. When used for barns, outbuildings, factories, etc., the tiles are made with smooth outside faces, and need not be finished in any way.

We have said enough to make a wise homebuilder want to know more. Take our advice and write us NOW-before you go any further with your building plans. You'll be surprised to see what can be done with DENISON TILE.

\section{Denison Fire Proofing Co. Mason City, lowa}

Please mention this book when you write 


\section{HOTEL RADISSON}

Minneapolis, Minnesota

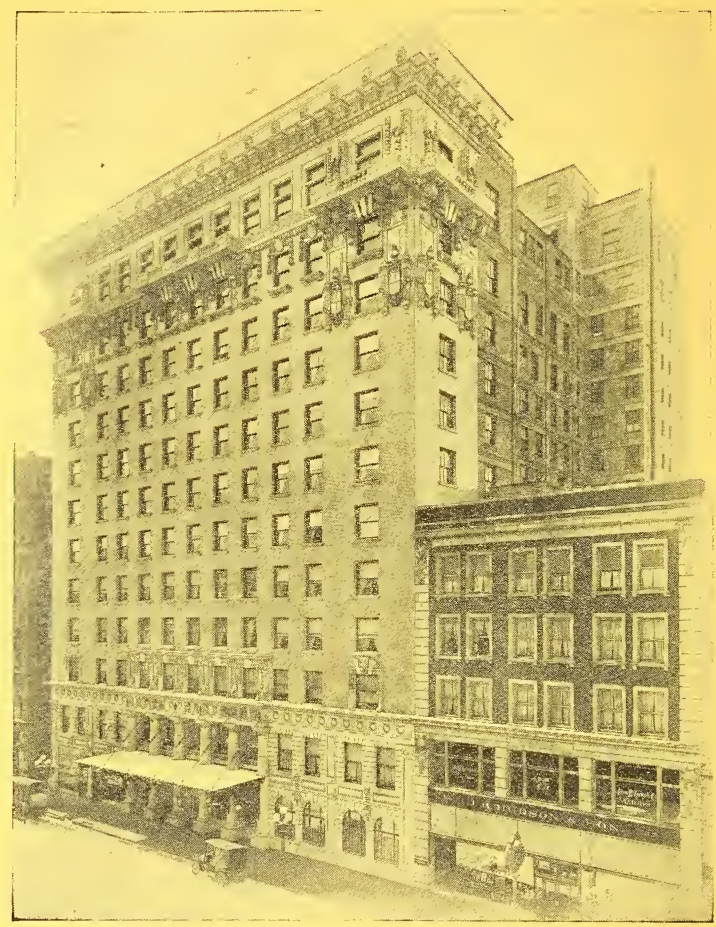

Largest Twin City Hotel

New and Fire Proof

Popular Prices

Center of Theatrical

and Shopping Districts

Cuisine Unexcelled
The Ladies' Hotel

Ladies' Shop

Official Hostess

Private Library

Afternoon Teas

"A Hotel of Character and Comfort"

Hotel World 


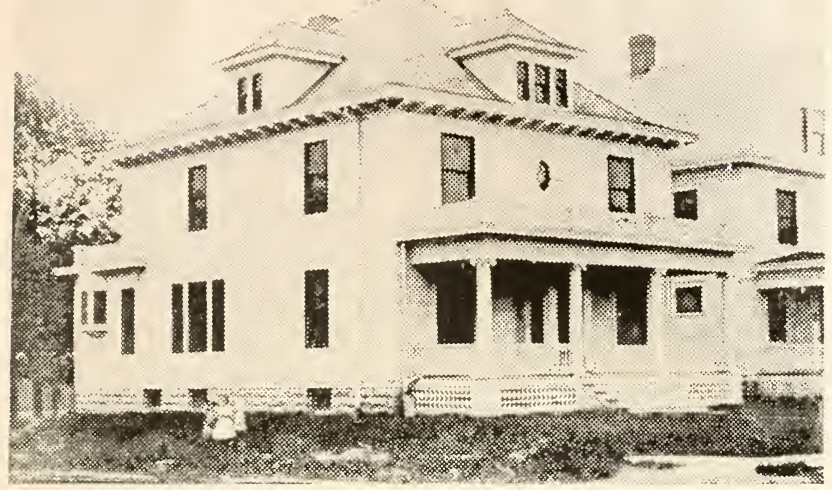

An Attractive Home-No. 83

This illustration shows an exceptionally good arrangement, both first and second stories. The size of this house is 31 feet wide and 36 feet deep. The first story is designed to be finished in gum or red oak, with maple floors, second story in pine to paint. Cost to build, $\$ 4,200$. Complete set of plans and specifications for $\$ 35$.
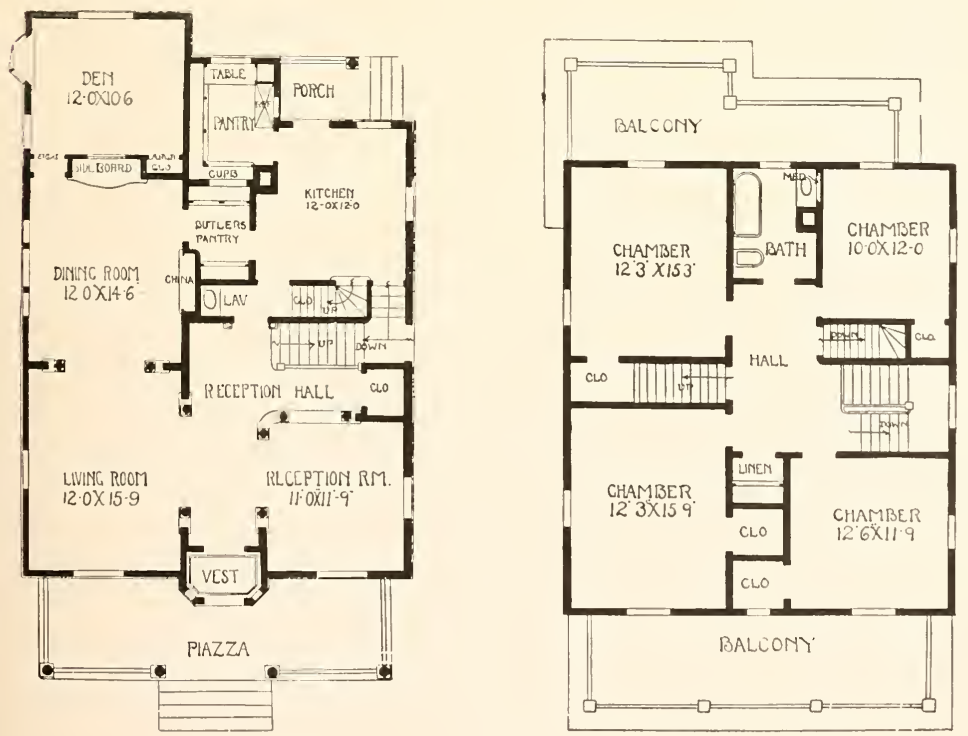

Complete plans and specifications for using Denison Load-Bearing Tile, licensed under Wilson-System Bearing IV a 11 Construction for $\$ 70$. 


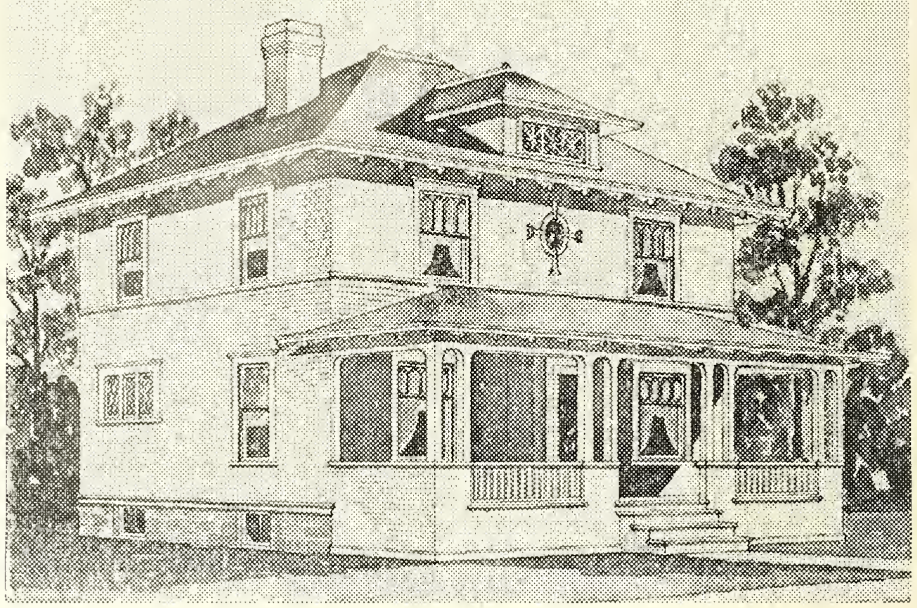

An Artistic Design-No. 94

The popularity of the square house is erer increasing. There are four large rooms in the first story, all opening up together in a most pleasing manner. Size, 30 feet wide and 26 feet deep, with full basement. The first story is 9 feet high, and the second story 8 feet 6 inches. Downstairs is finished in gum or birch and the second story in pine to paint. Cost to build, $\$ 2,800$. Complete set of plans and specifications for $\$ 25$.
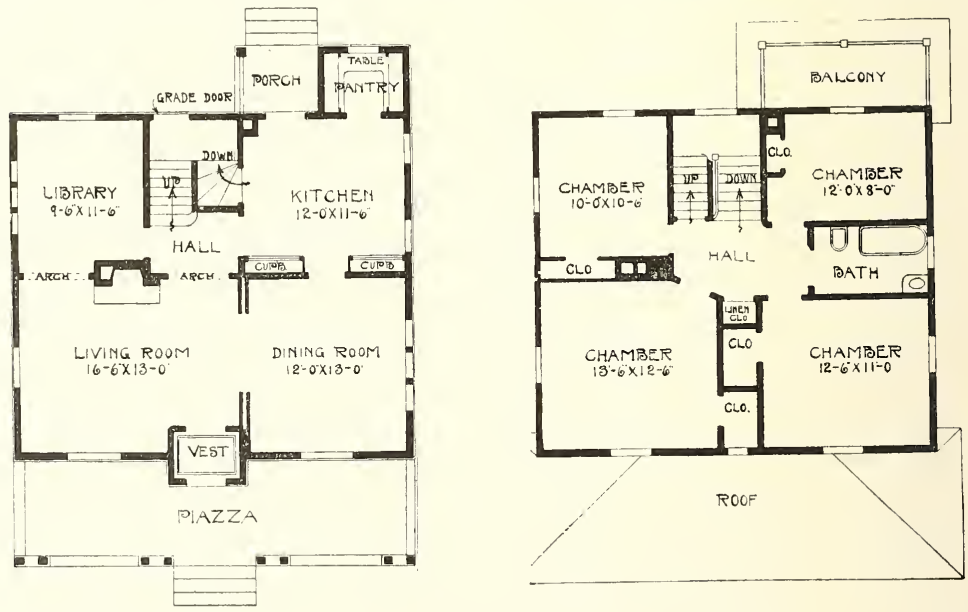

Complete plans and specifications for using Denison Load-Bearing Tile, licensed under Wilson-System Bearing Wa 11 Construction for $\$ 50$. 


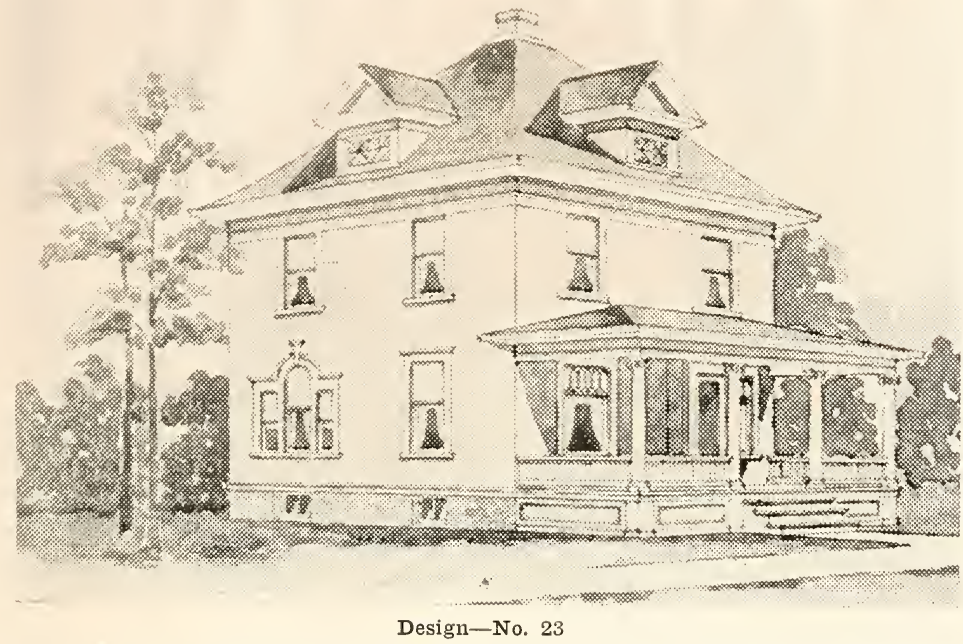

Size 25x2s ft. Finish birch or gum in first story and pine to paint in second, maple floors throughout, first story $9 \mathrm{ft}$., second story $\mathrm{s} \mathrm{ft}$. 6 inches in the clear when finished, full basement $\tau \mathrm{ft}$. high. Cost to builh, $\$ 3,050$. Complete set of plans and specifications for $\$ 25$.
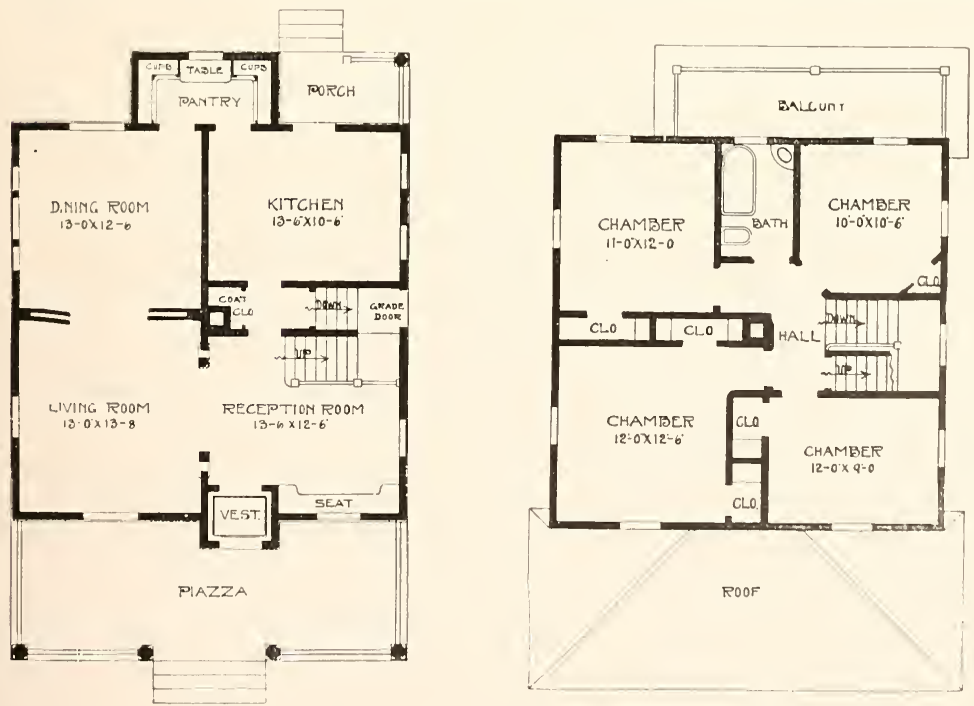

Complete plans and specifications for using Denison Load-Bearing Tile, licensed under Wilson-System Bearing IV a 11 Construction for $\$ 50$. 


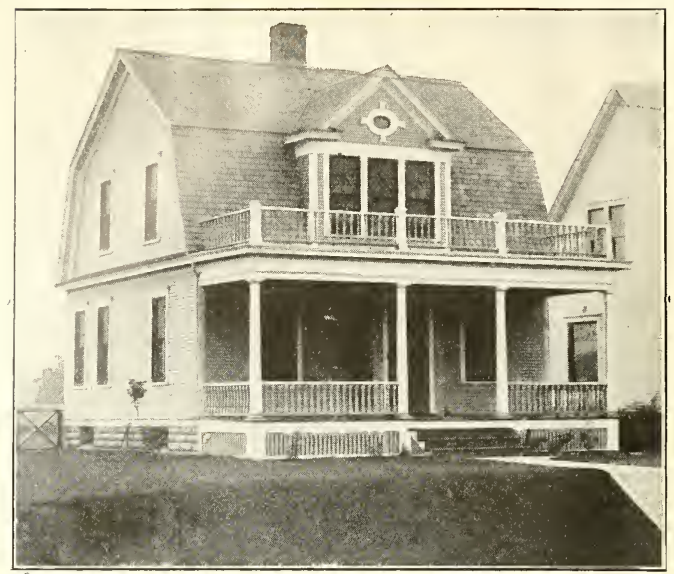

Design-No. 95

This little floor plan will speak for itself. I would advise you to study the plan carefully. There are three rooms in the first story, combination stairway and everything that makes a house complete. Gum or birch finish, birch floors. In the second story you find two rooms and bath. Cost to build, $\$ 1,840$. Complete plans and specifications for the sum of $\$ 10$.
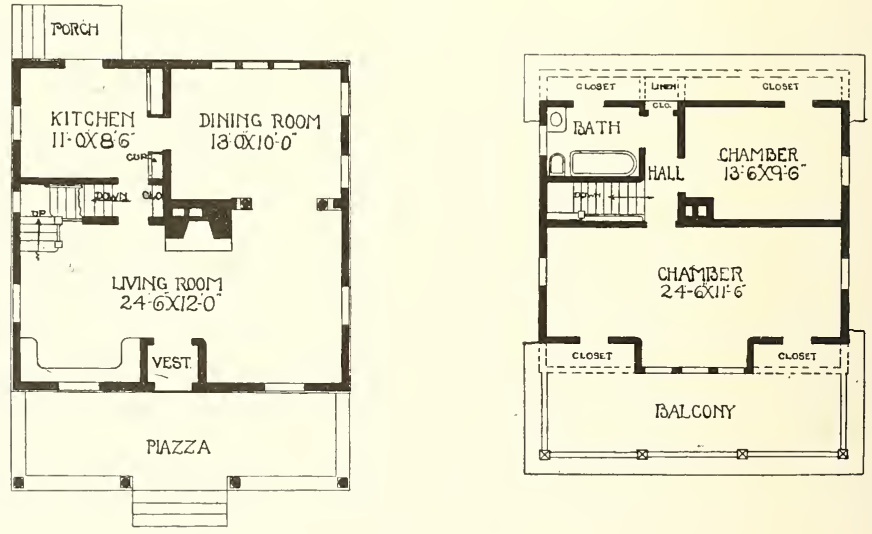

Complete plans and specifications for using Denison Load-Bearing Tile, licensed under Wilson-System Bearing Wa 11 Construction for $\$ 20$. 


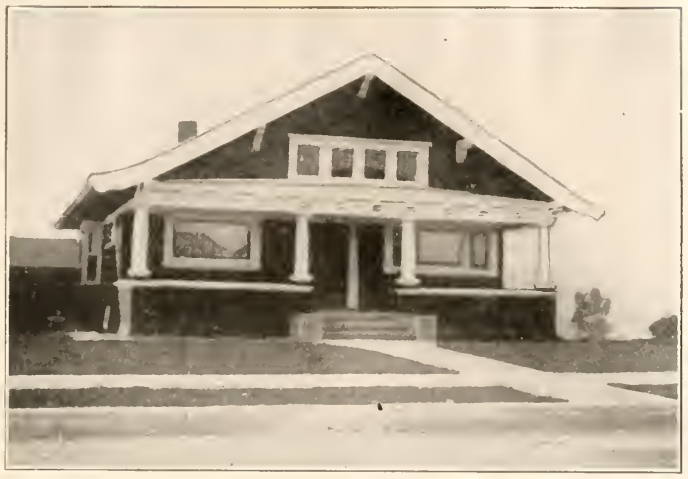

A California Bungalow-No. 110

This is just the little cottage you have been looking for and I trust you will admit that for this style of a home it is a model one. The floor plans are all one could desire, with beautiful living room, fire-place and combination stairway from kitchen and living room; large dining room with extended bay window. Two splendid chambers and bath with ample closet space in second story. Size is $26 \times 26$ feet, basement under rear part. First story 9 feet, second story 8 feet; these heights in the clear when finished. First story finished in birch or gum, with birch floors. Pine to paint in the second story. Cost to build, $\$ 1,850$. Complete set of plans and specifications for the small sum of $\$ 13$.
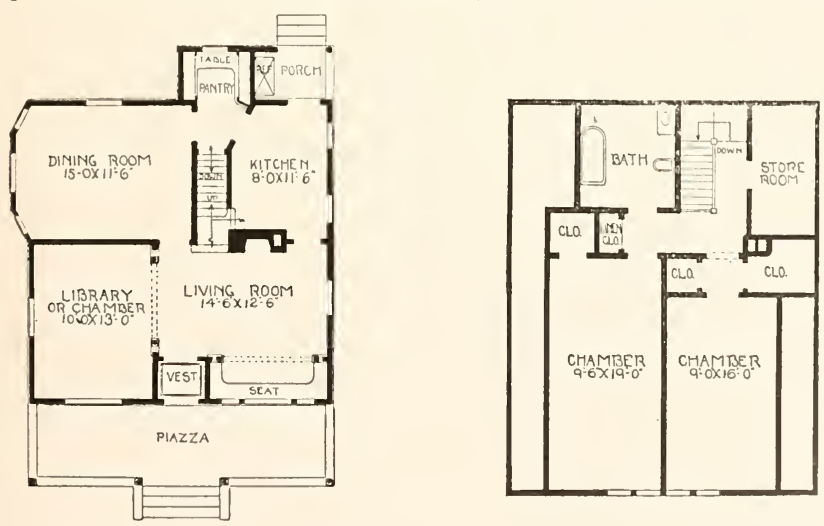

Complete plans and specifications for using Denison Load-Bearing Tile, licensed under Wilson-System Bearing IV a 11 Construction for \$26. 


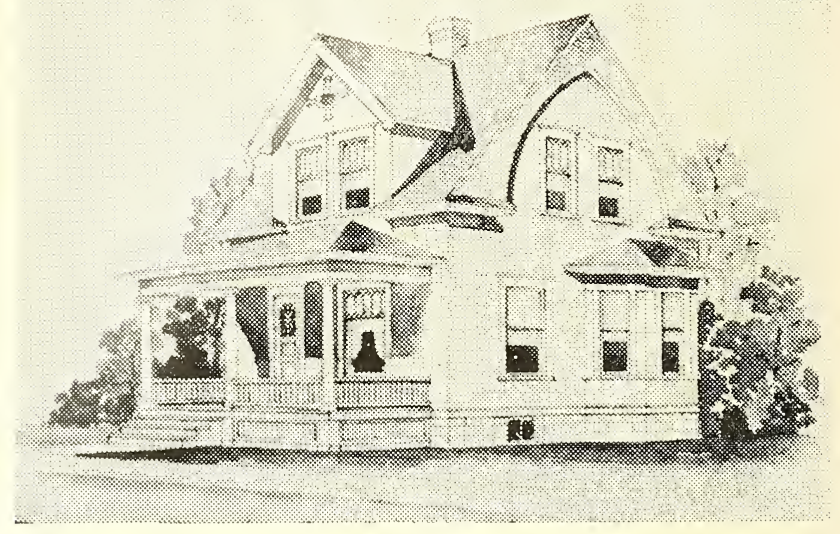

Design-No. 52

A charming one and one-half story cottage. The size is $22 \times 24$ feet. The first story ceiling 9 feet, second story ceiling 8 feet. There is a basement under the living room. First story should be in birch or gum, and the second story in pine to paint with birch floors throughout. Cost to build, $\$ 1,975$. Complete set of plans and specifications for $\$ 15$.
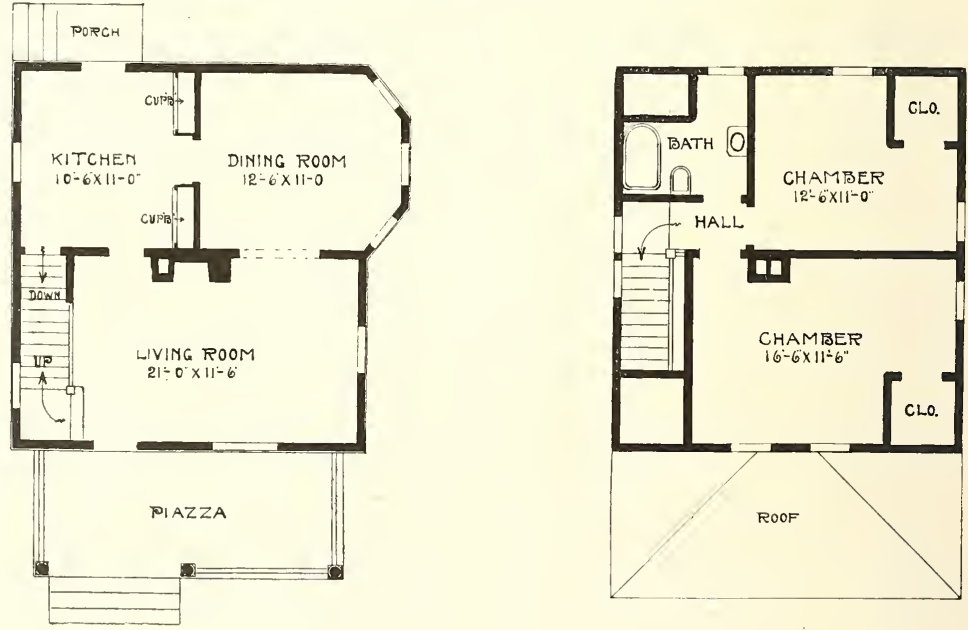

Complete plans and specifications for using Denison Load-Bearing Tile, licensed under Wilson-System Bearing W a 11 Construction for $\$ 30$. 


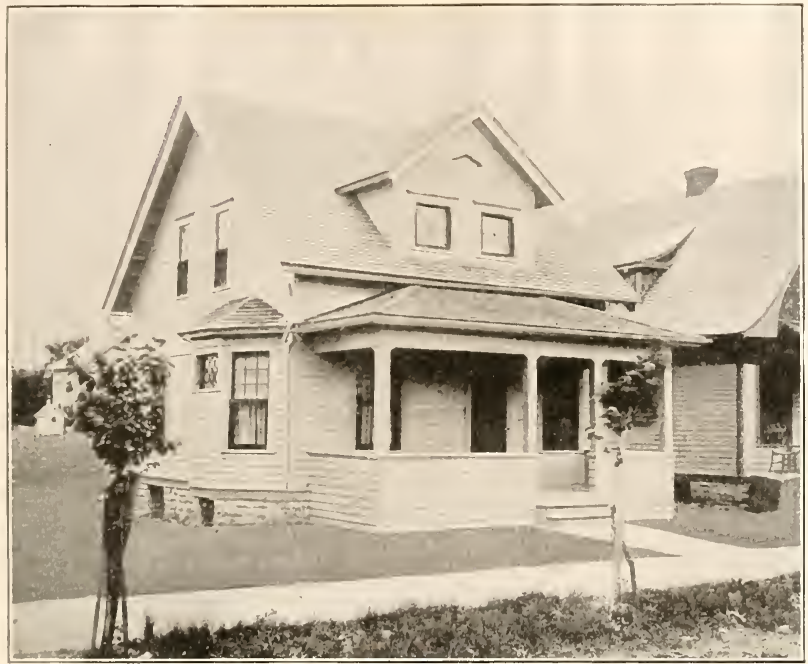

The Bride's Cottage-No. 76

It is one of my prize designs. There is a nice broad piazza across the entire front, and a beautiful living room. The living room and dining ronm are thrown together by archway, while the kitchen is a model of conrenience. Birch floors throughout, with birch or gum finish in first story and pine to paint in second. Full basement, first story 8 feet 6 inches. second story 8 feet in the clear when finished. Cost to build, $\$ 1,475$. Complete set of plans and specifications for $\$ 10$.
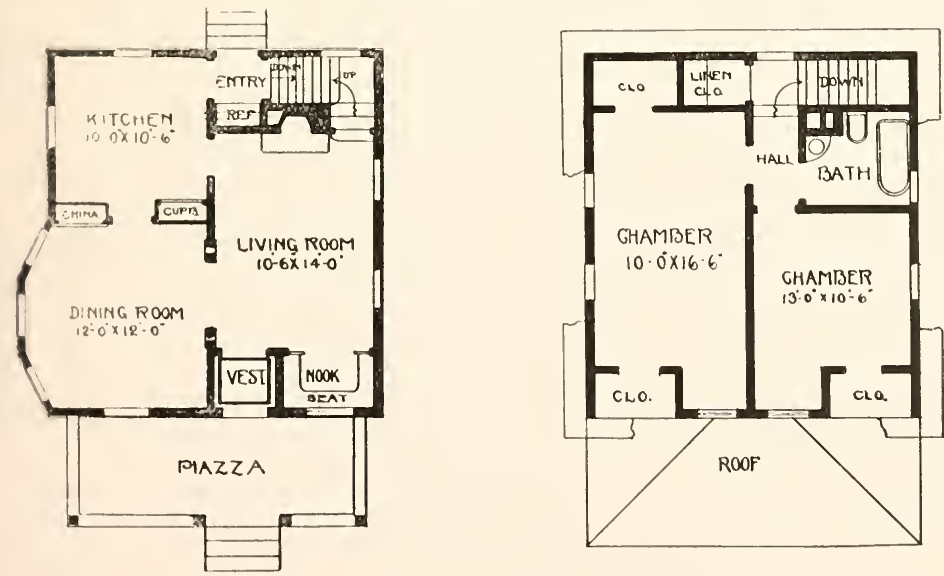

Complete plans and specifications for using Denison Load-Bearing Tile, licensed under Wilson-System Bearing $\mid \mathrm{V}$ all Construction for $\$ 20$. 


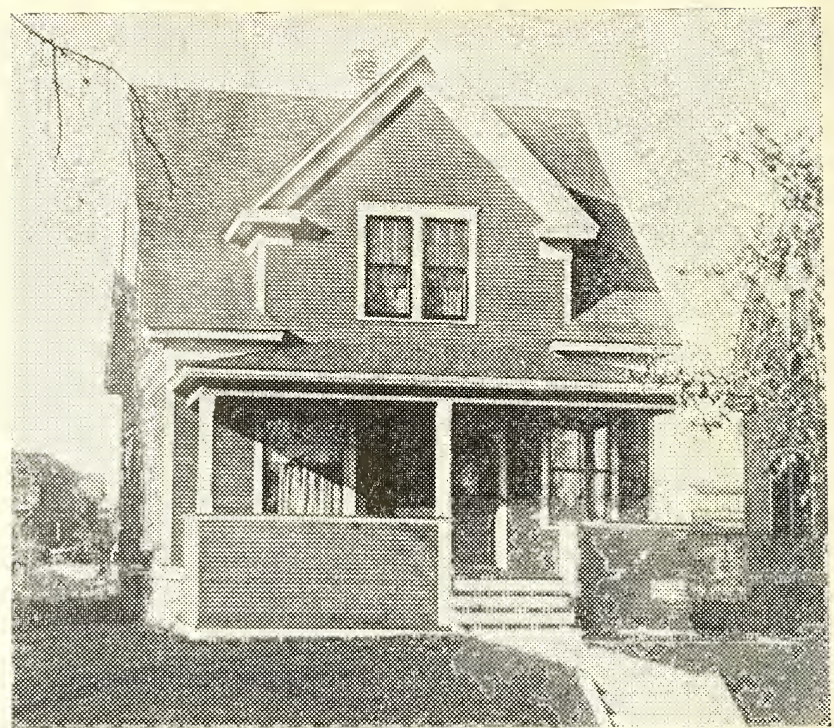

Design-No. 113

The first story is $9 \mathrm{ft}$., with birch floors and birch or gum finish in the three principal rooms; the second story is $8 \mathrm{ft}$. high, with pine floors and pine finish, to paint. Size, $24 \mathrm{ft}$. by $26 \mathrm{ft}$. deep. Built at cost of $\$ 2,000$. Complete set of plans and specifications for $\$ 15$.
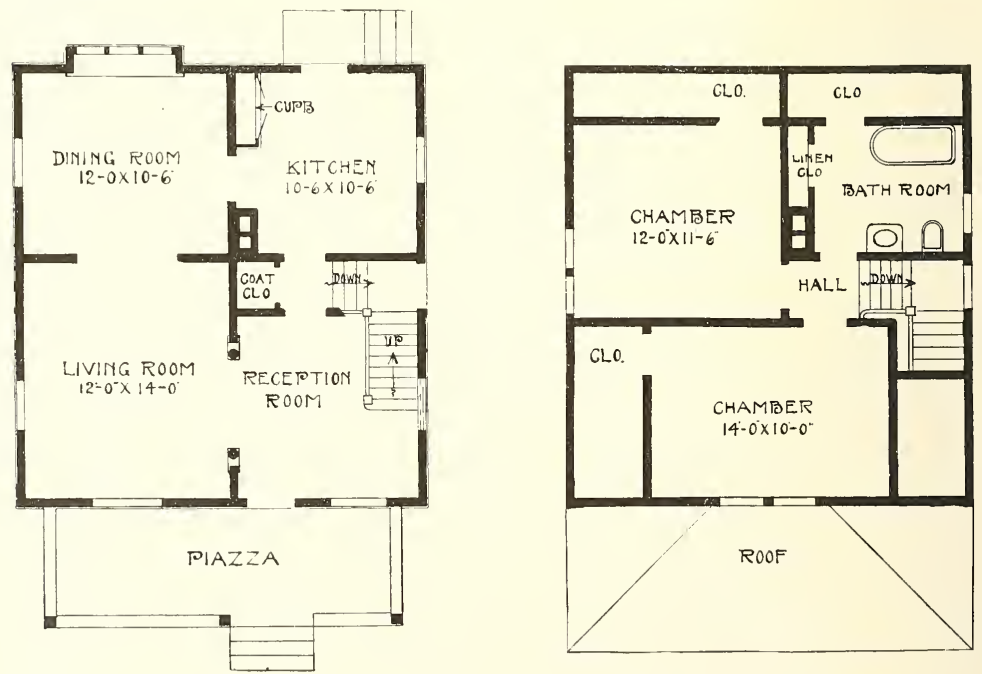

Complete plans and specifications for using Denison Load-Bearing Tile, licensed under Wilson-System Bearing IV a 11 Construction for $\$ 30$. 


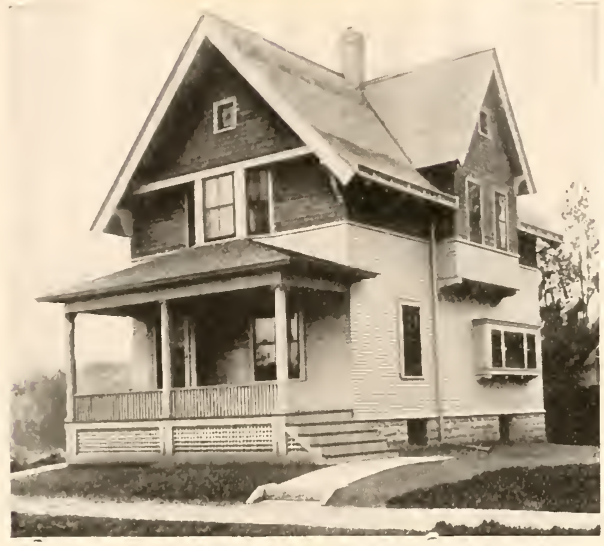

A Little Gem-No. 78

The plan was designed to have the approach from the front, but you will notice that the photograph shows a side entrance which was desired by owner for narrow lot. Size, 22x30 feet. Cost to build, \$2,100. Complete set of plans and specifications for $\$ 15$.
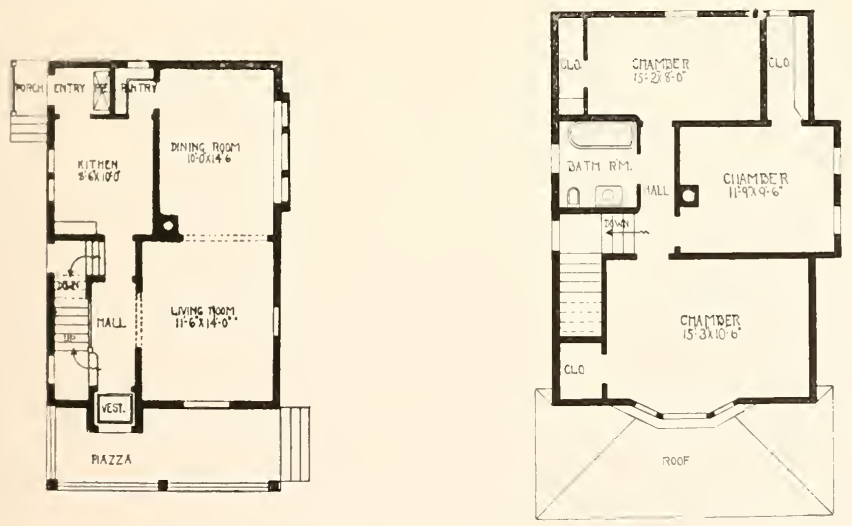

Complete plans and specifications for using Denison Load-Bearing Tile, licensed under Wilson-System Bearing IV a 11 Construction for $\$ 30$. 

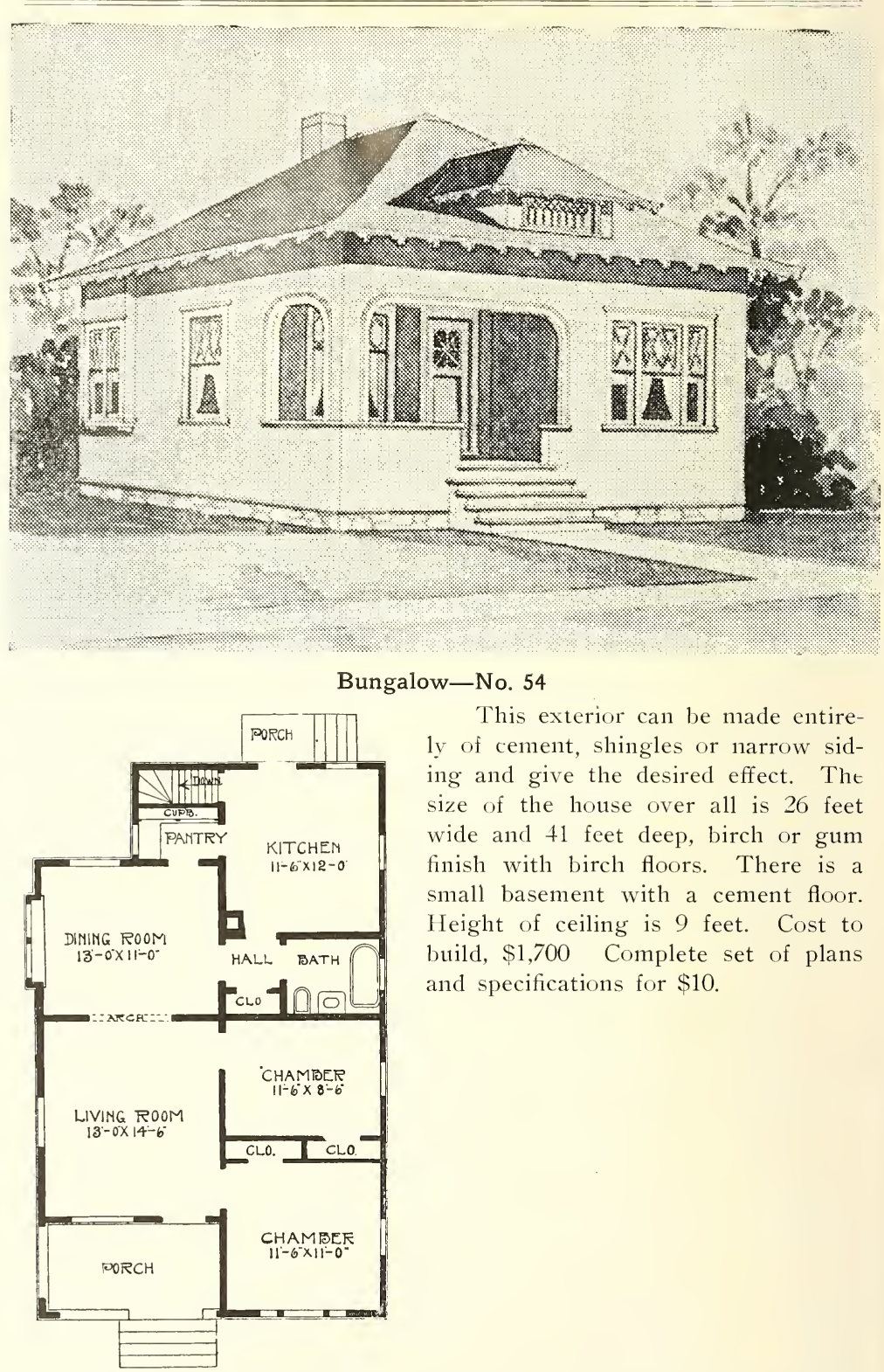

This exterior can be made entire$1 \mathrm{y}$ of cement, shingles or narrow siding and give the desired effect. The size of the house over all is 26 feet wide and 41 feet deep, birch or gum finish with birch floors. There is a small basement with a cement floor. Height of ceiling is 9 feet. Cost to build, $\$ 1,700$ Complete set of plans and specifications for $\$ 10$.

Complete plans and specifications for using Denison Load-Bearing Tile, licensed under Wilson-System Bearing $W$ al1 Construction for $\$ 20$. 


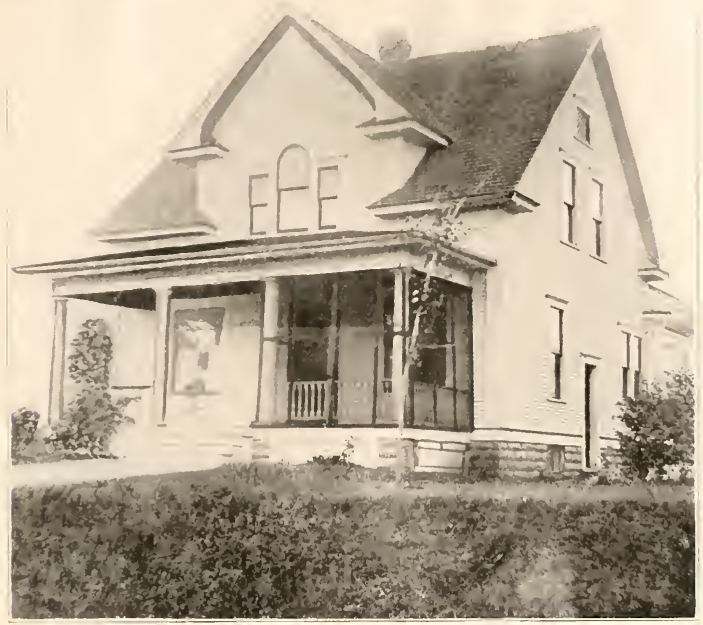

A Home of Sunshine-No. 22

There are six rooms of convenient size, and also a small sewing room. The size is 26 feet wide and 27 feet deep. The first story is 9 feet high and the second story 8 feet high. The first story is finished throughout in Georgia pine or gum with birch floors. The second story is finished in

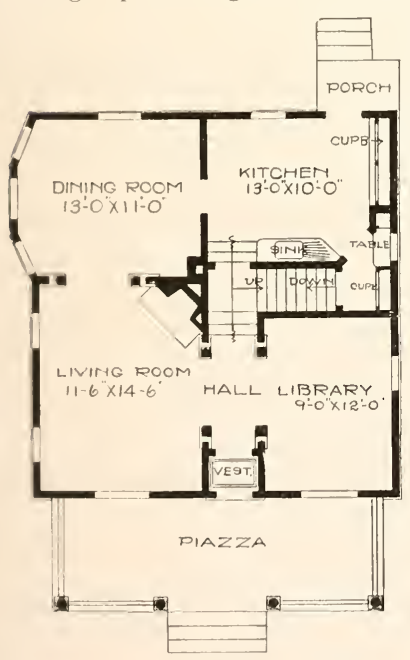
pine to paint and with pine floors. Cost to build, $\$ 2$,250. Pl a n s and specifications for $\$ 15$.

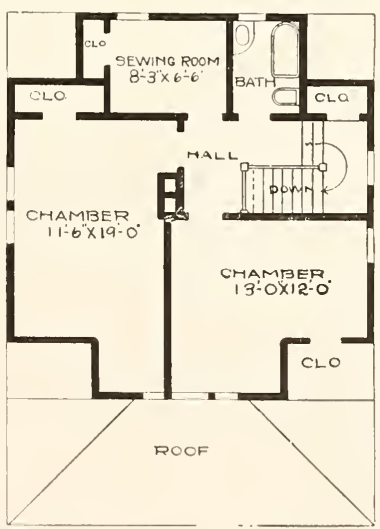

Complete plans and specifications for using Denison Load-Bearing Tile, licensed under Wilson-System Bearing IV a 11 Construction for $\$ 30$. 


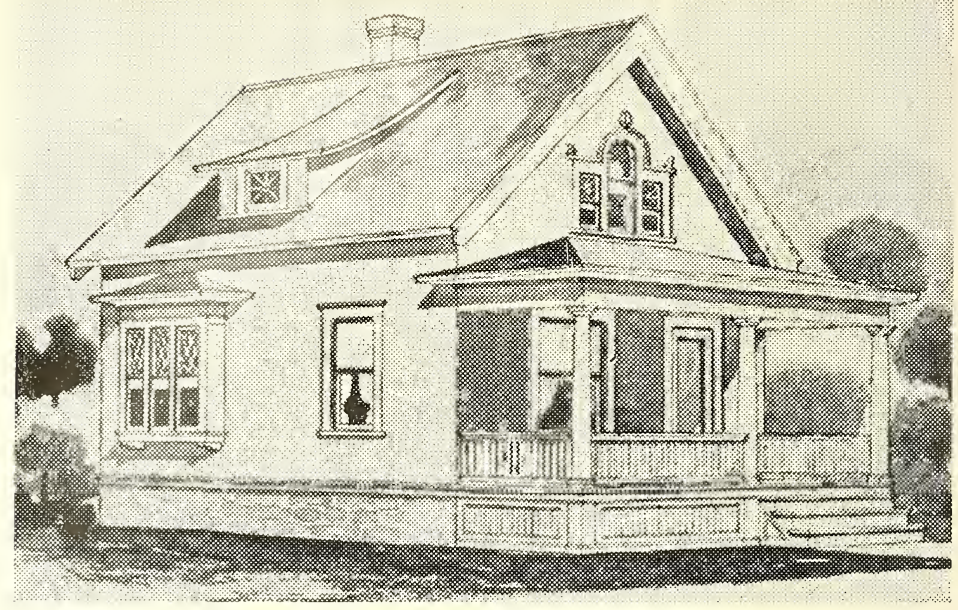

The Small Cottage Home-No. 82

It is 20x24 ft. exclusive of the piazza, which is $7 \mathrm{ft}$. wide. First story, $8 \mathrm{ft} .6 \mathrm{in}$., second story $8 \mathrm{ft}$. heights in the clear. This cottage will cost $\$ 1,450$ to build complete, plastered and finished. This will include hardwood floors for the first story, and Georgia pine in second story. Finish birch or gum. Complete set of plans and specifications for $\$ 10$.
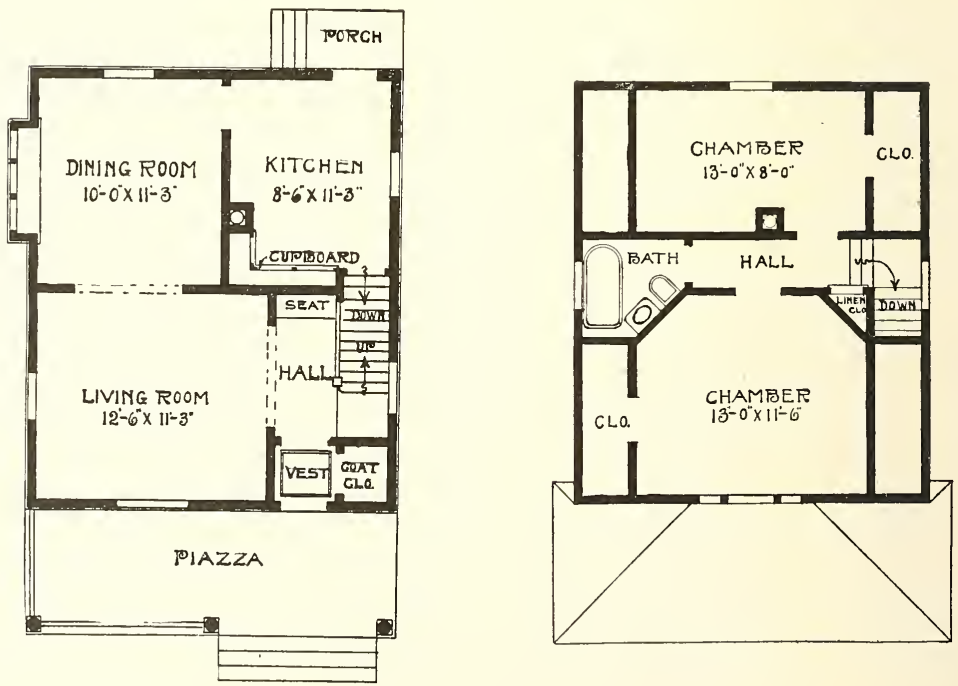

Complete plans and specifications for using Denison Load-Bearing Tile, licensed under Wilson-System Bearing $W$ a 11 Construction for $\$ 20$. 


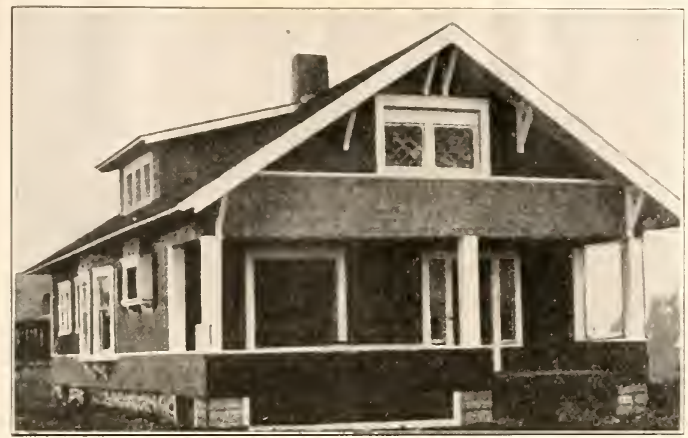

A Little Gem of a Bungalow-No. 106

You will agree with us that this is not only on artistic but well arranged floor plan. Would make an ideal lake home or residence in the city. There can also be three of four rooms finished in the second story if one desires, but this is not figured in this estimate. Beautiful large

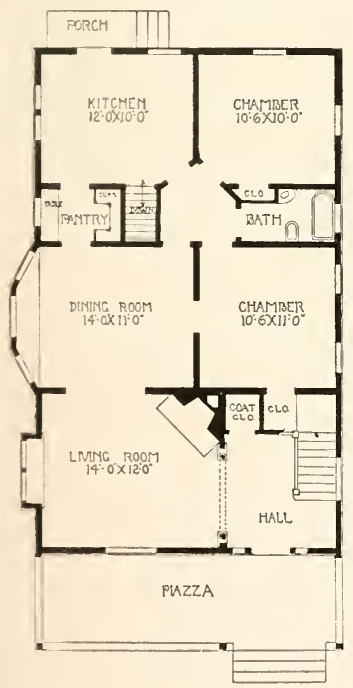
living room with an open fire-place and Dutch window, all the features which make the room attractive. This is one of my best arranged plans where the rooms are all on one floor. There is a full basement in rear part coming to front wall of the dining room. The height of same being 7 feet. The first story is 9 feet in the clear. Birch or gum finish throughout with hardwood floors. The size is $2+$ feet wide and 39 feet 6 inches deep. Cost to build, $\$ 1,825$. Complete set of plans and specifications for $\$ 13$.

Complete plans and specifications for using Denison Load-Bearing Tile, licensed under Wilson-System Bearing IV a 11 Construction for \$26. 


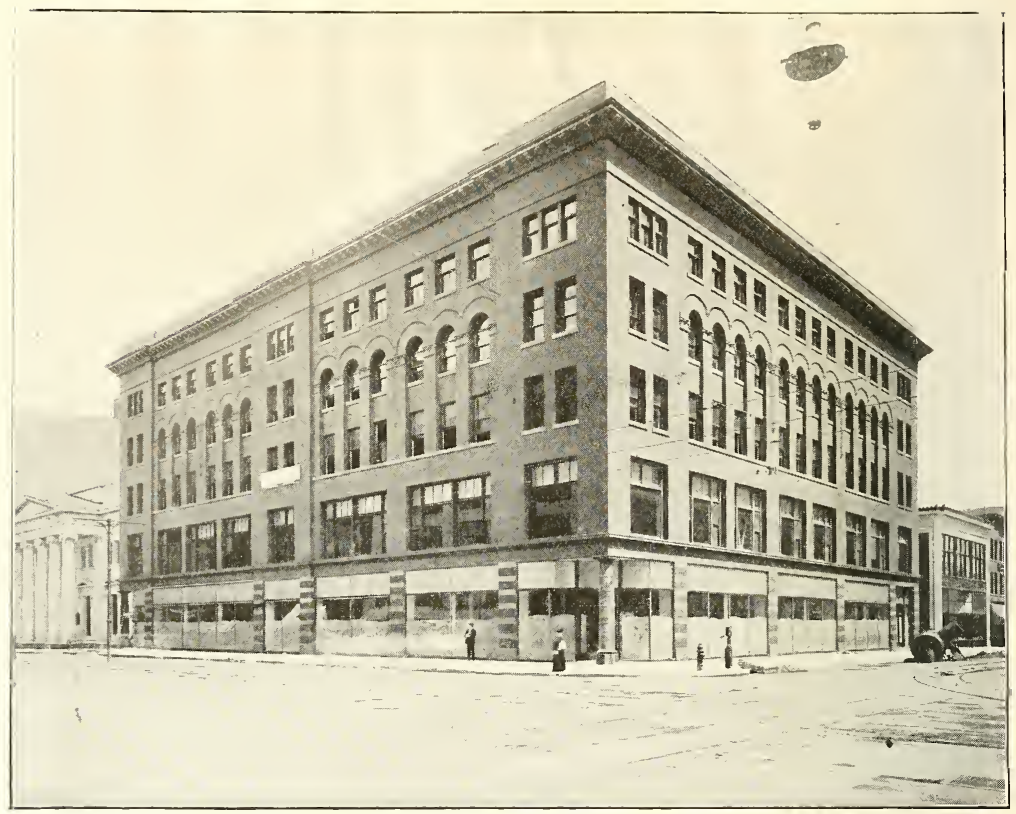

We Specialize on Reinforced Concrete Buildings

The Home of Boutell Brothers, Minneapolis

We furnish plans for any kind of a building.

Anyone who may be interested in a building of this character will save money by letting us make their plans and specifications. We will send the complete plans of this building on approval for $\$ 50$, this amount to be returned in case these plans or any others are not used in the erection of a new building. We simply require this amount to show your intention of going ahead with the plans for building. 


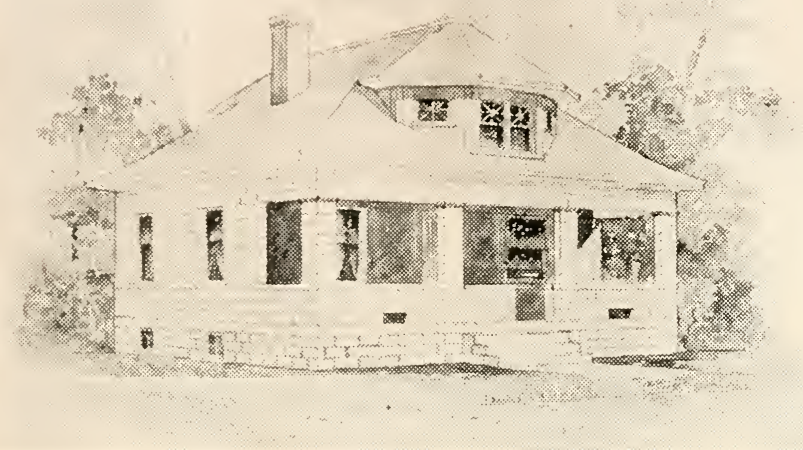

A Cement Block House-No. 96

There is a full basement, first story 9 feet, second story 8 feet, 30 feet wide and 30 feet deep. The three principal rooms are finished in birch, the balance in pine to paint. Cost to build, $\$ 2,400$. Complete plans and specifications for $\$ 20$.
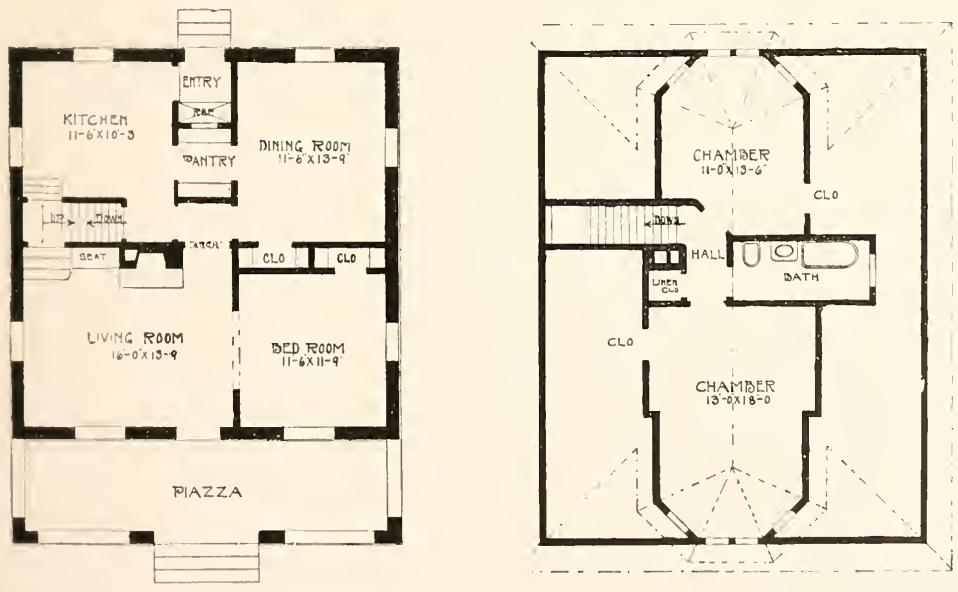

Complete plans and specifications for using Denison Load-Bearing Tile, licensed under Wilson-System Bearing $\mathrm{W}$ a 11 Construction for $\$ 40$. 


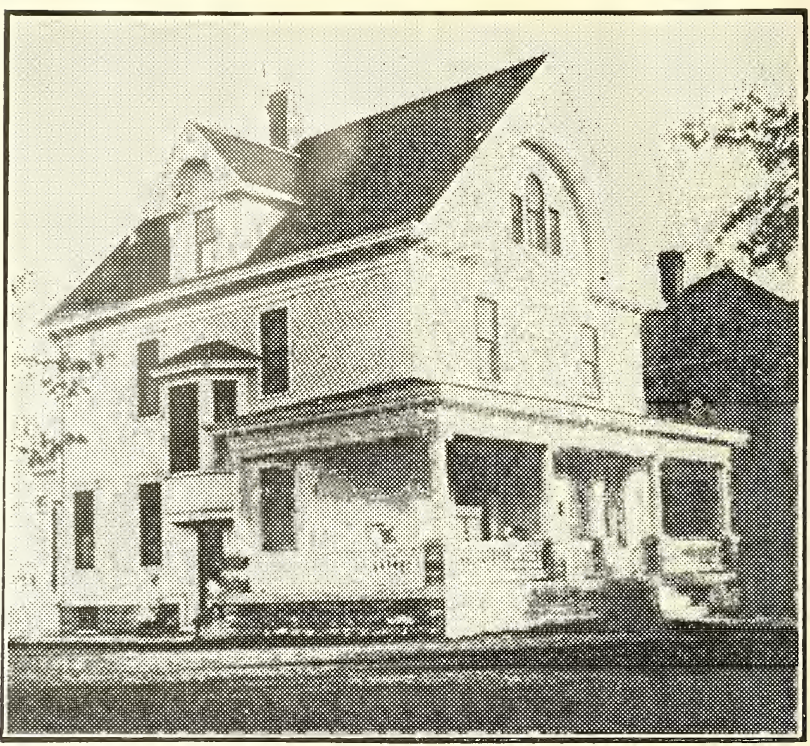

A Popular Design-No. 94-B

The house is $28 \times 38$ feet. A large piazza stretches across the entire front and around the corner. There is a full basement under the entire house. First story 10 feet, second story 9 feet and there is a large space in the attic. Cost to build, $\$ 3,680$. Complete set of plans and specifications for $\$ 25$.

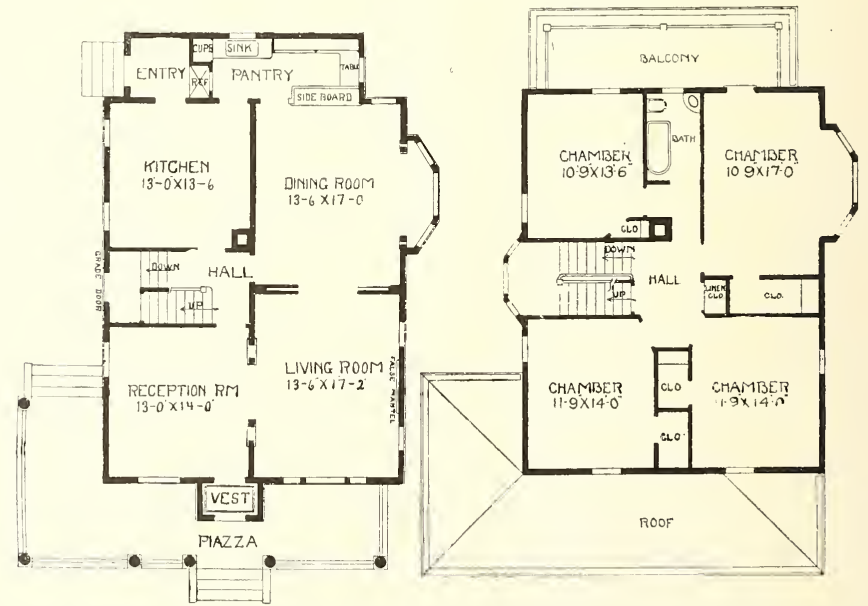

Complete plans and specifications for using Denison Load-Bearing Tile, licensed under Wilson-System Bearing Wal1 Construction for $\$ 50$. 


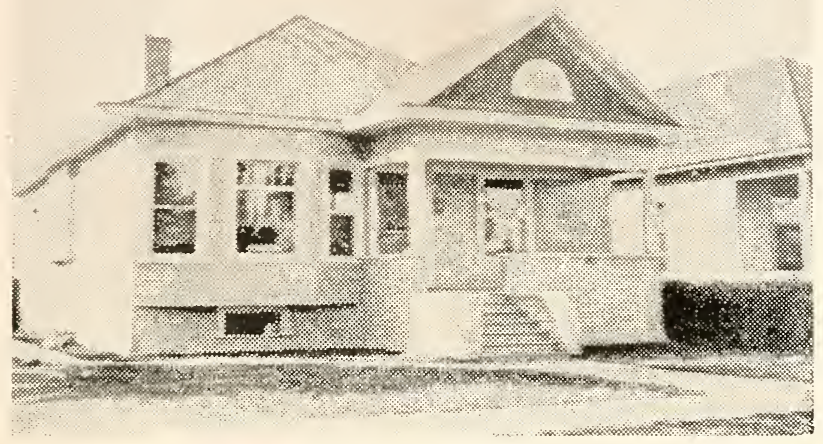

A Bungalow Just For Two-No. 98

A cozy one-story cottage. This design would make a splendid lake cottage or city home. It is well arranged for an elderly couple, all the rooms being on one floor. The arrangement of the rooms is remarkably good, all opening together in nice shape, of good size and well lighted. The special feature of this cottage home is the large living-room with open fire-place. The size of the house is 26 feet wide and 30 feet deep, the rooms being 9 feet in the clear in height. There is a small basement under the rear portion. Birch floor throughout. Living and dining room finished

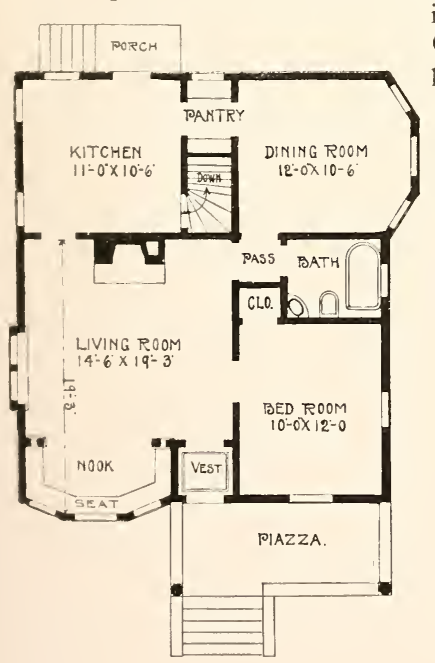
in gum wood, balance in pine to paint. Cost to build, $\$ 1,550$. Complete set of plans and specifications for $\$ 15$.

Complete plans and specifications for using Denison Load-Bearing Tile, licensed under Wilson-System Bearing $\mathrm{W}$ all Construction for $\$ 30$. 


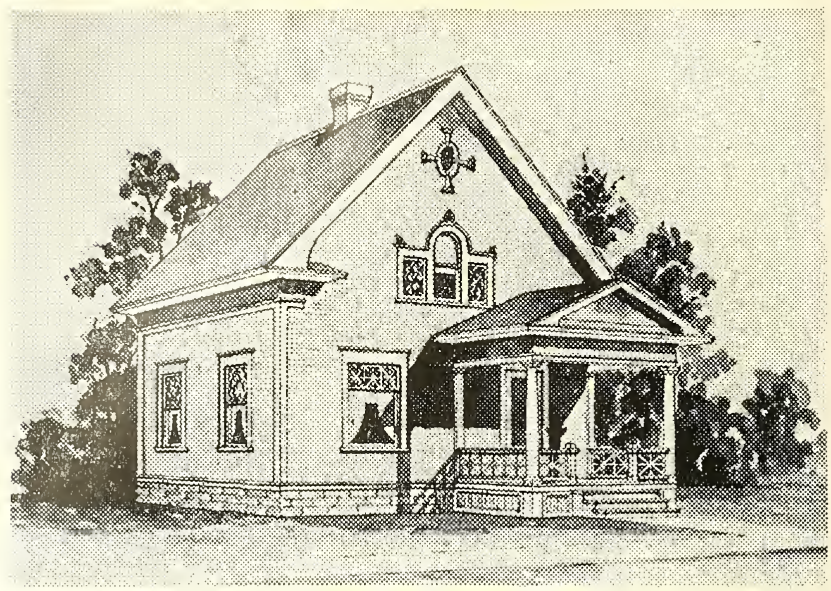

A Small Cottage Home-No. 90

There are six well arranged rooms. Those in the first story are 8 feet 6 inches high and planned to be finished in birch. The second story is 8 feet high and finished in pine to paint. Size of cottage is 24 feet wide and 22 feet deep, with small cellar. Cost to build, $\$ 1,250$. Complete set of plans and specifications for $\$ 10$.
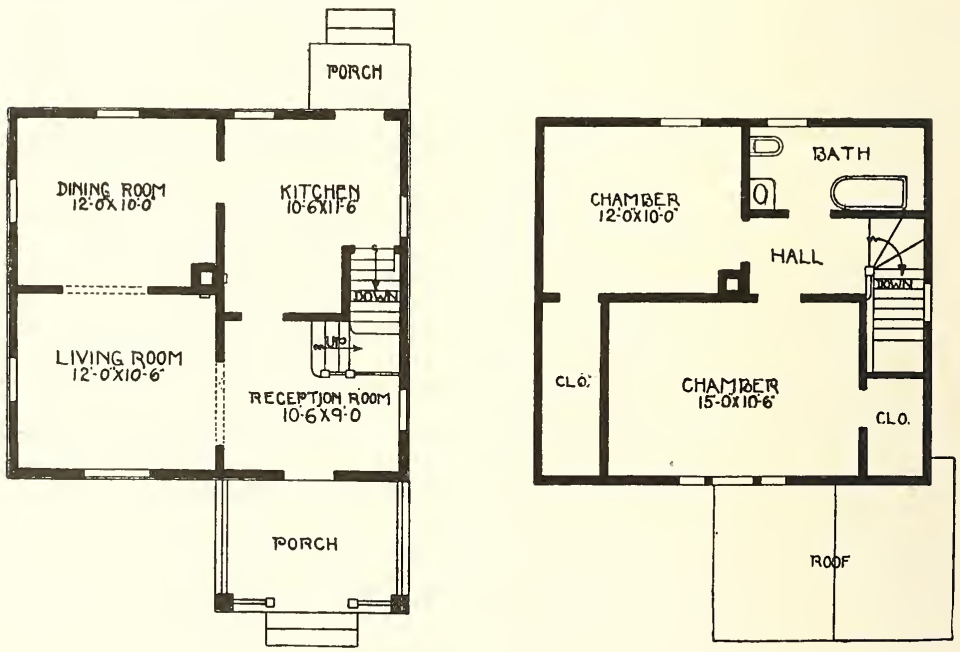

Complete plans and specifications for using Denison Load-Bearing Tile, licensed under Wilson-System Bearing $W$ a 11 Construction for $\$ 20$. 


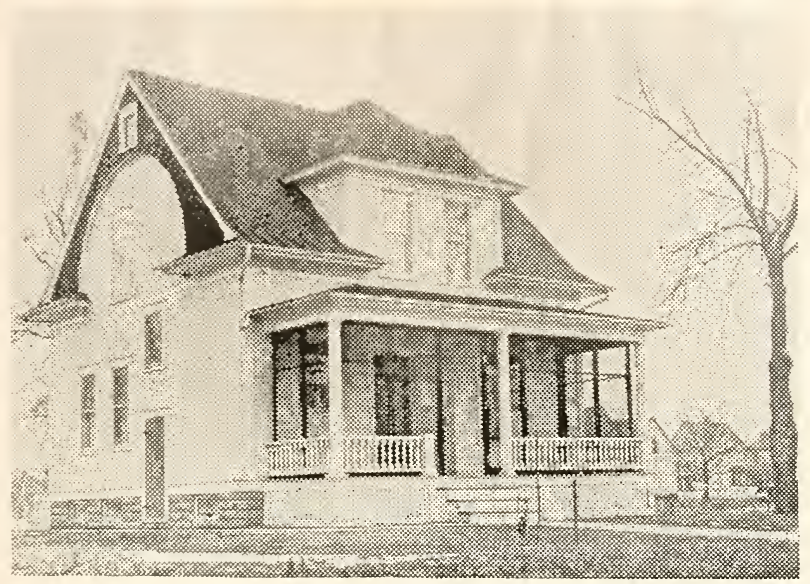

A Cozy Home For Two-No. 7

This house is intended to be finished with hardwood floors throughout, full basement, first story finished in gum or birch, second story pine to paint. Cost to build, $\$ 2,100$. Complete plans and specifications for this beautiful cottage, $\$ 15$.

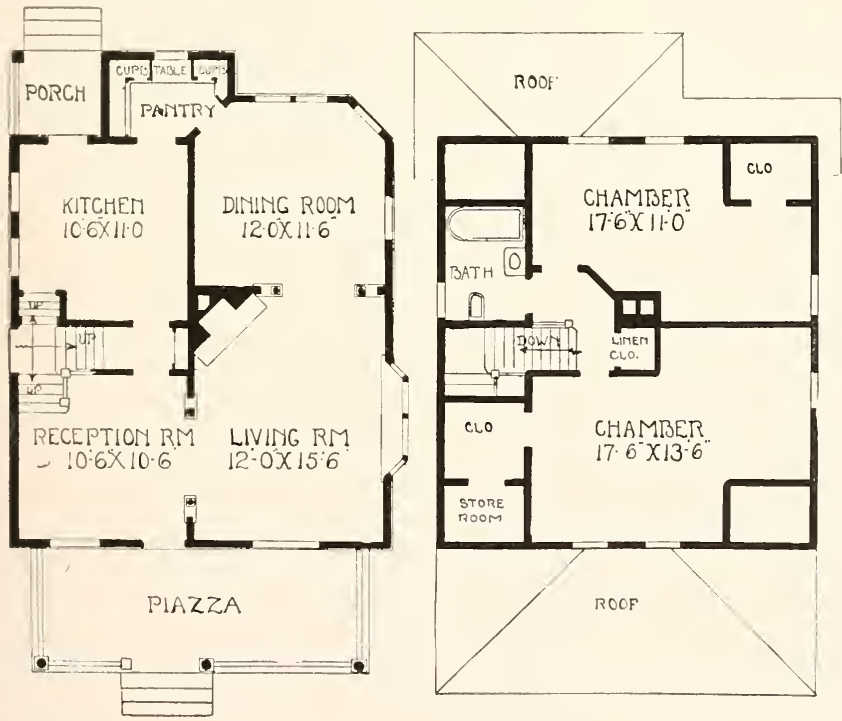

Complete plans and specifications for using Denison Load-Bearing Tile, licensed under Wilson-System Bearing $\mathrm{W}$ a 11 Construction for $\$ 30$. 


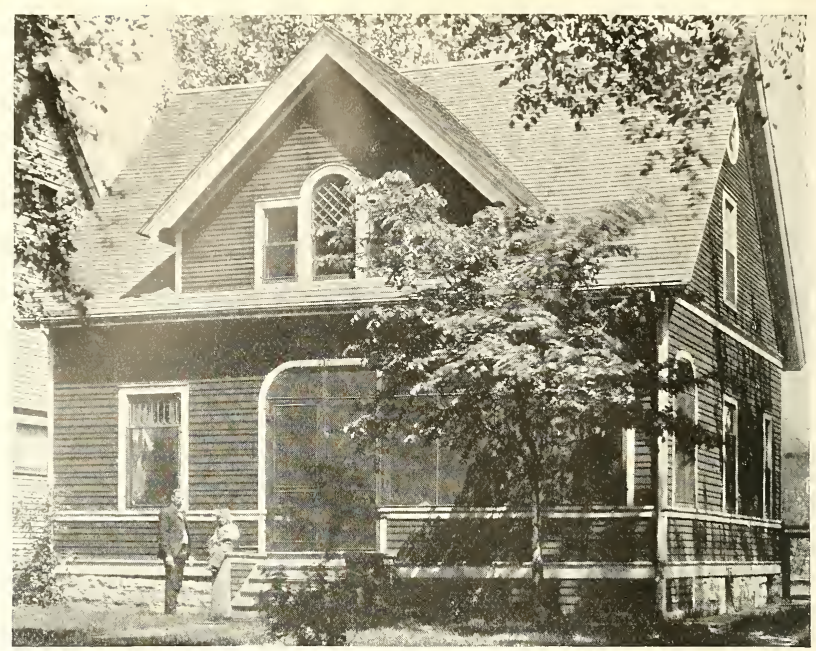

\section{Cottage Design-No. 406}

This beautiful cottage has been built over 225 times for about $\$ 2,300$, this being the cost of building in Minneapolis and vicinity. There are four good sized rooms in first story and three chambers in second story with bath room and convenient closets. There is one main chimney with fireplace in the sitting room. There is a full basement. The first story is finished in gum or birch stained, birch floors throughout first story. Second story pine painted and pine floors. Complete plans and specifications for this cottage home for $\$ 15$.
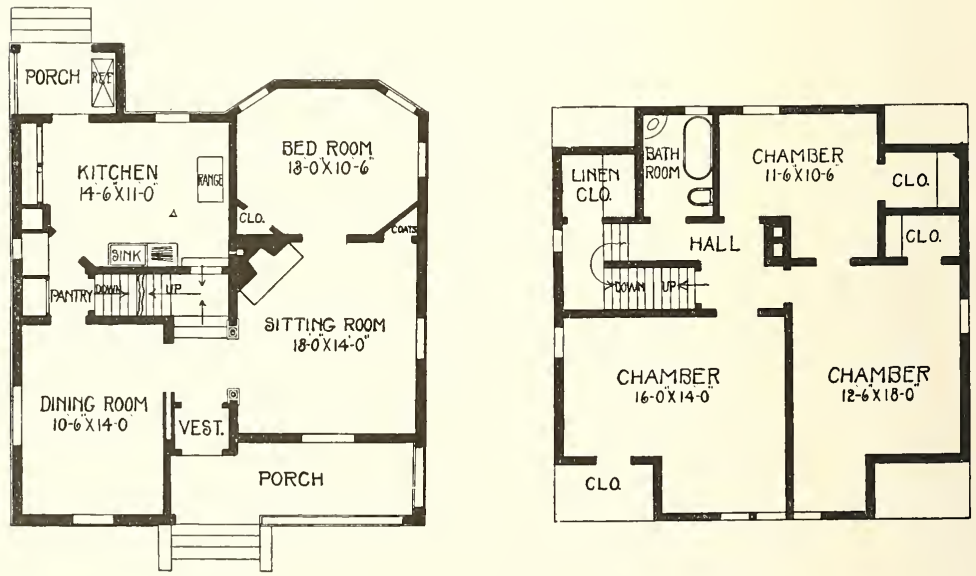

Complete plans and specifications for using Denison Load-Bearing Tile, licensed under Wilson-System Bearing $W$ al1 Construction for $\$ 30$. 


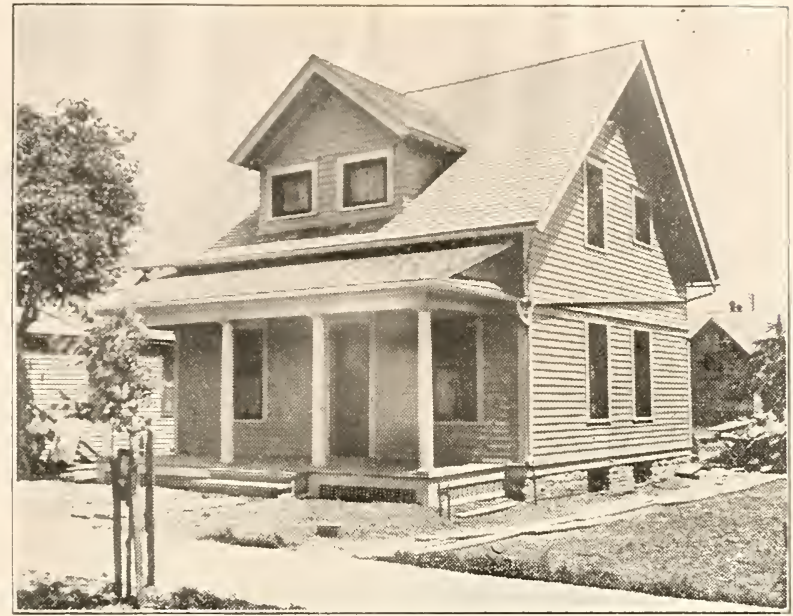

A Little Paradise for Two-No. 80

The size is 22 feet wide and 24 feet deep. Hardwood floors are given throughout, first story is finished in birch, second story in pine to paint. Full basement. Height of first story is 9 feet, second story 8 feet in the rear. Cost to build, $\$ 1,300$. Complete set of plans and specifications for $\$ 10$.
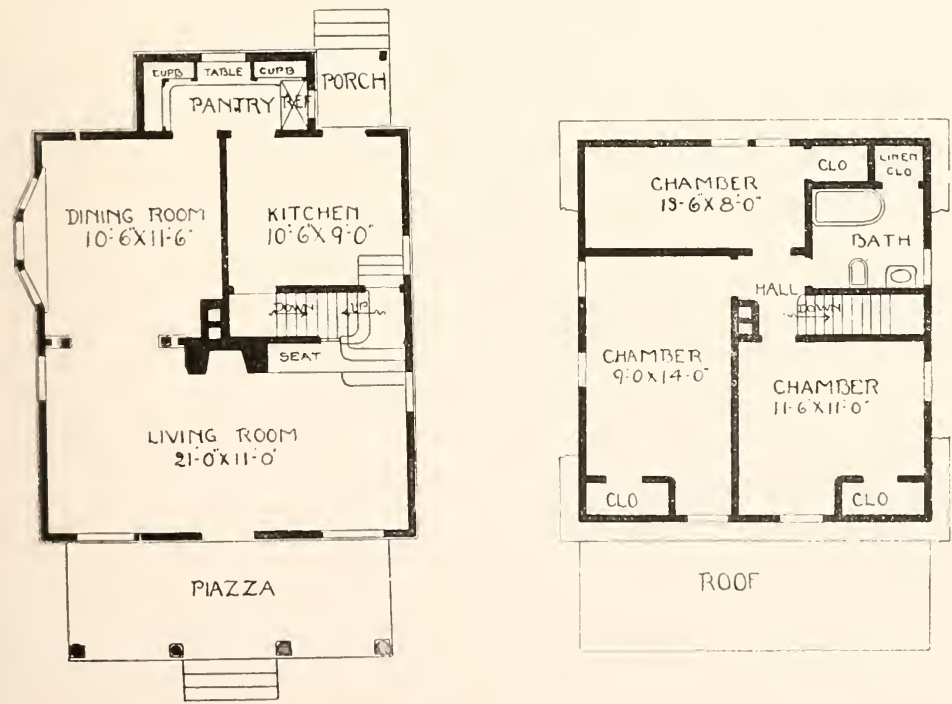

Complete plans and specifications for using Denison Load-Bearing Tile, licensed under WVilson-System Bearing $\mathrm{W}$ a 11 Construction for $\$ 20$. 


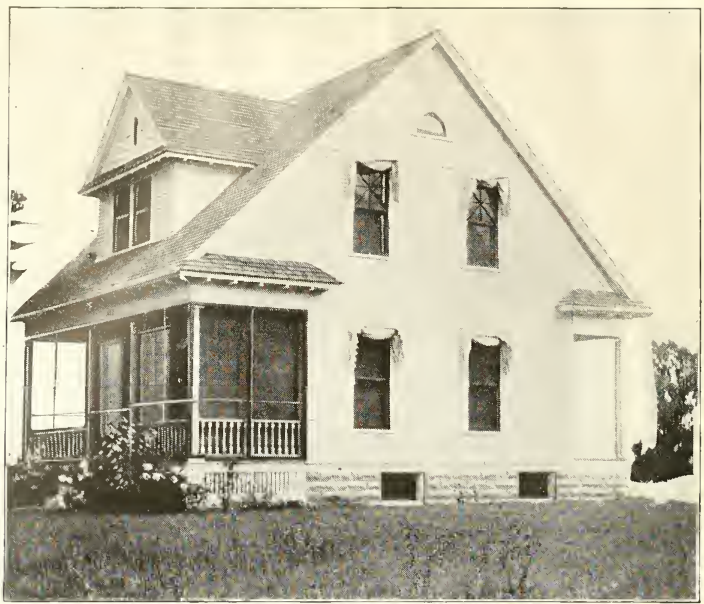

A Little Gem of a Five Room Cottage-No. 100

This cottage is $24 \times 24$ feet, exclusive of piazza, contains five large rooms and bath, also good storage space. There is a cellar under half of house. Height of first story 9 feet, second story 8 feet, hardwood floors and finish in first story, gum or birch, pine to paint in second. Cost to build, $\$ 1,575$. Complete set of plans and specifications for $\$ 10$.
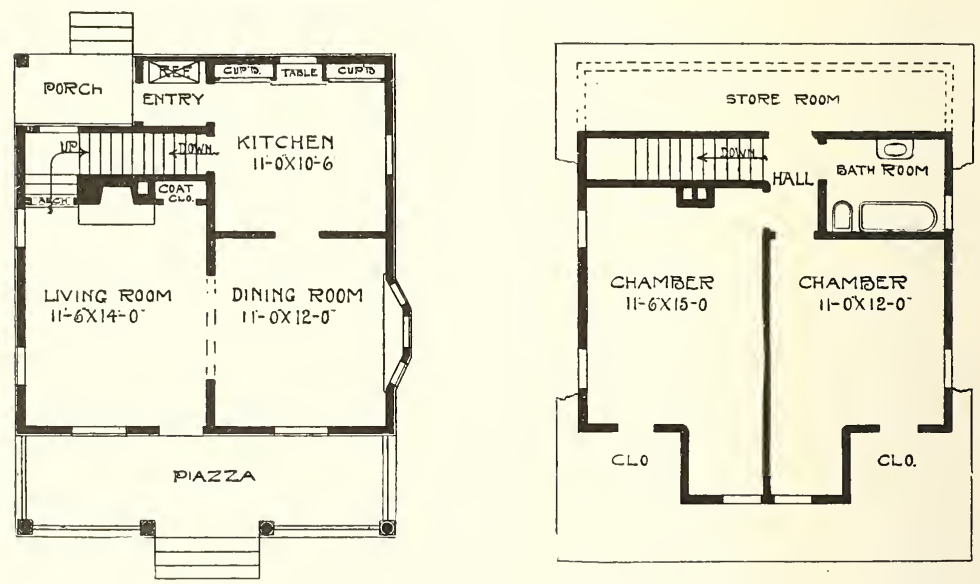

Complete plans and specifications for using Denison Load-Bearing Tile, licensed under Wilson-System Bearing W a 11 Construction for $\$ 20$. 


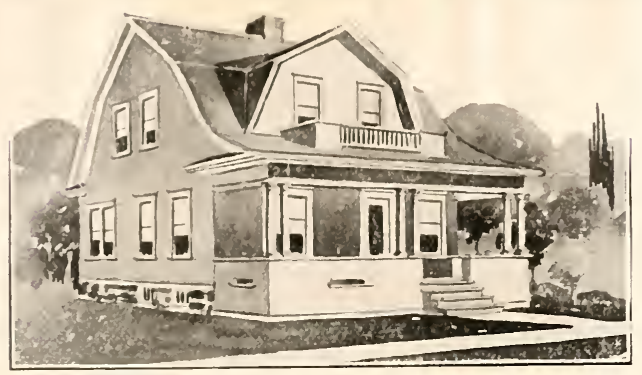

Gable Roof Cottage Design-No. 210

This colonial residence has been built in the northern part of Minnesota. First story 9 feet, second story 8 feet 6 inches. Also has been built as a cement house, the first story being made of cement blocks, the second story frame. Also made with the cobblestone exterior for the first story. To build this house of cement blocks or cobblestone it would cost in the neighborhood of $\$ 3,500$, built as a frame residence it would cost to build, $\$ 2,800$. This includes the entire first story finished in hardwood with hardwood floors throughout. This is one of our most popular designs. Complete plans and specifications for $\$ 20$.
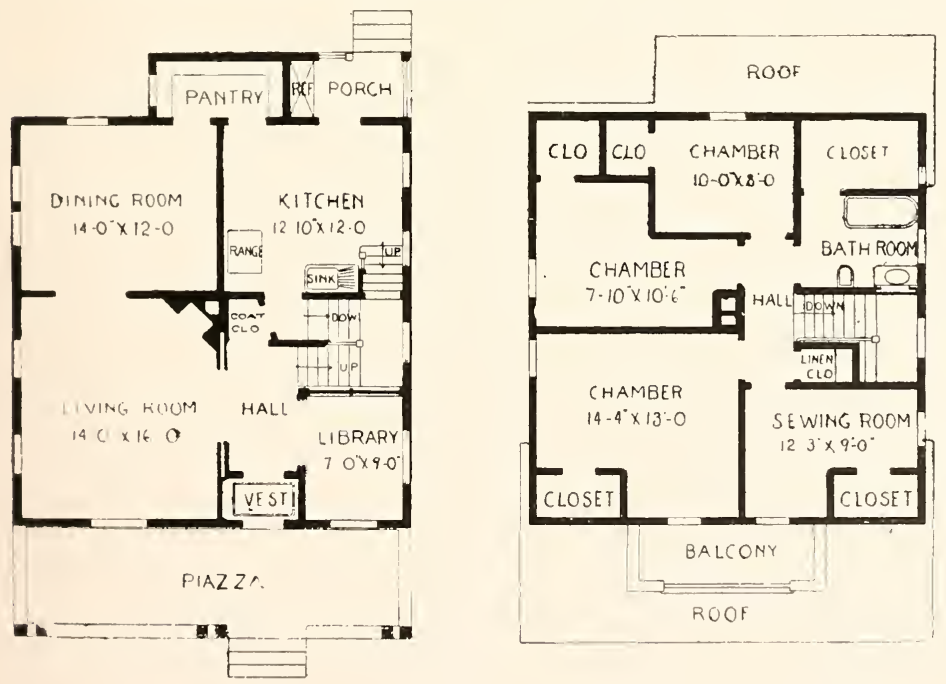

Complete plans and specifications for using Denison Load-Bearing Tile, licensed under Wilson-System Bearing IV a 11 Construction for $\$ 40$. 


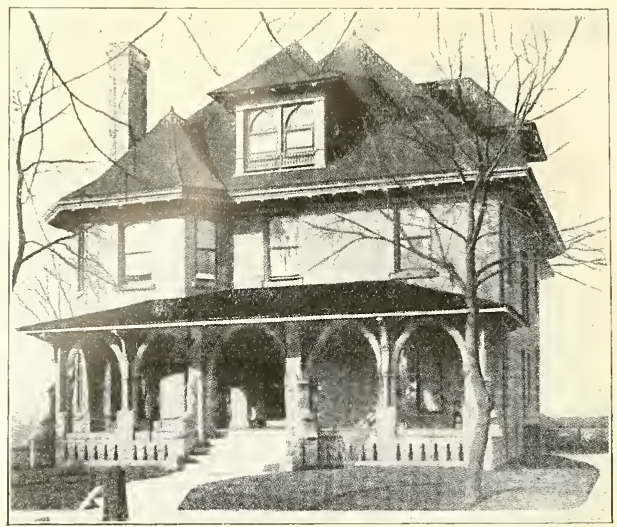

Brick Design-No. 256

This house contains 8 nice rooms, besides bath, reception hall, closet space, etc., and is nearly square. Height of the stories are, first story 9 feet, second story 8 feet 6 inches. Can be built of frame for the sum of $\$ 4,500$, or can be built of brick veneer, using a nice red sand mould brick, laid up in flemish bond for the sum of $\$ 5,200$. Complete plans and specifications for the house for $\$ 35$.
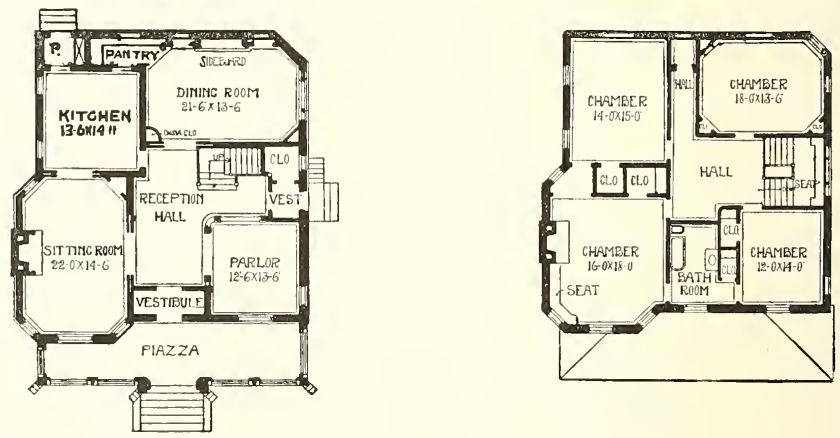

Complete plans and specifications for using Denison Load-Bearing Tile, licensed under Wilson-System Bearing $W$ a 11 Construction for $\$ 70$. 


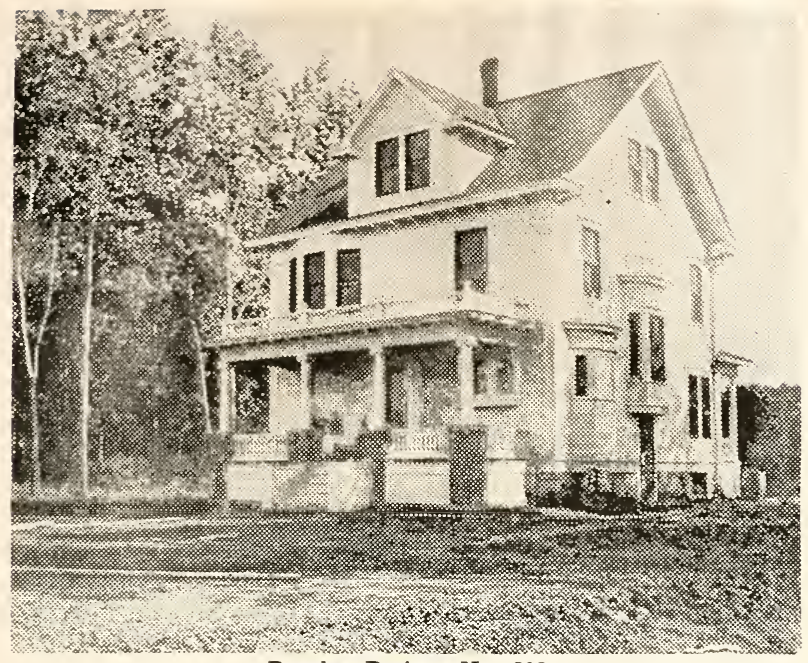

Popular Design-No. 302

A beautiful S room colonial house duplicated many times, contains $S$ liberal sized rooms, four rooms besides pantry, vestibule, combination stairway and good sized hall in first story. Second story has four high airy good shaped chambers besides bath and good sized closet space. This house can be built complete for $\$ 3,100$, this is finishing the house in birch or gum, in the three principal rooms and hall in first story, balance finished in pine to paint. First story $9 \mathrm{ft.}$, second $8 \mathrm{ft}$., basement $7 \mathrm{ft}$. I furnish complete plans and specifications for this popular house for $\$ 20$. You will note that the floor plans are reversed.

Any plan in the book can be blue printed reverse if desired.
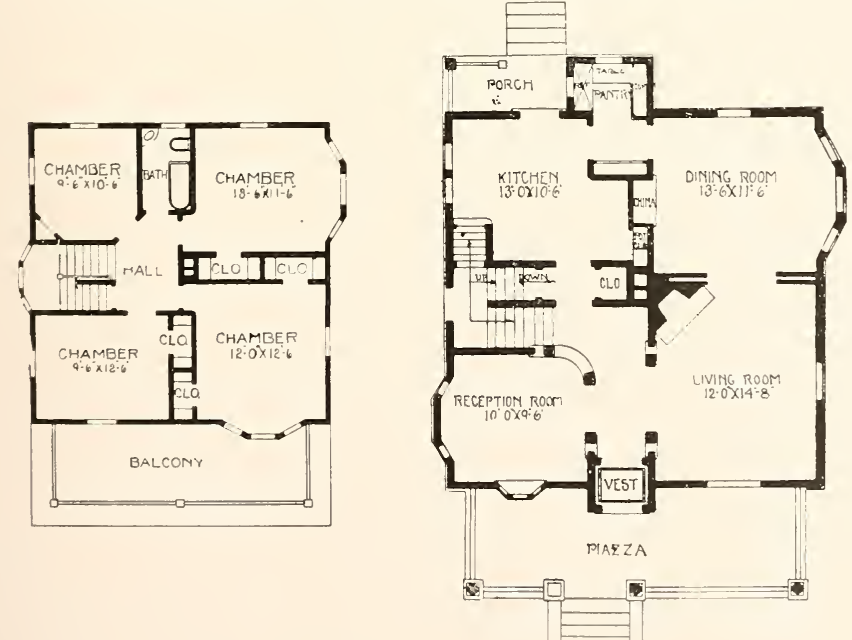

Complete plans and specifications for using Denison Load-Bearing Tile, licensed under Wilson-System Bearing IV a 11 Construction for $\$ 40$. 


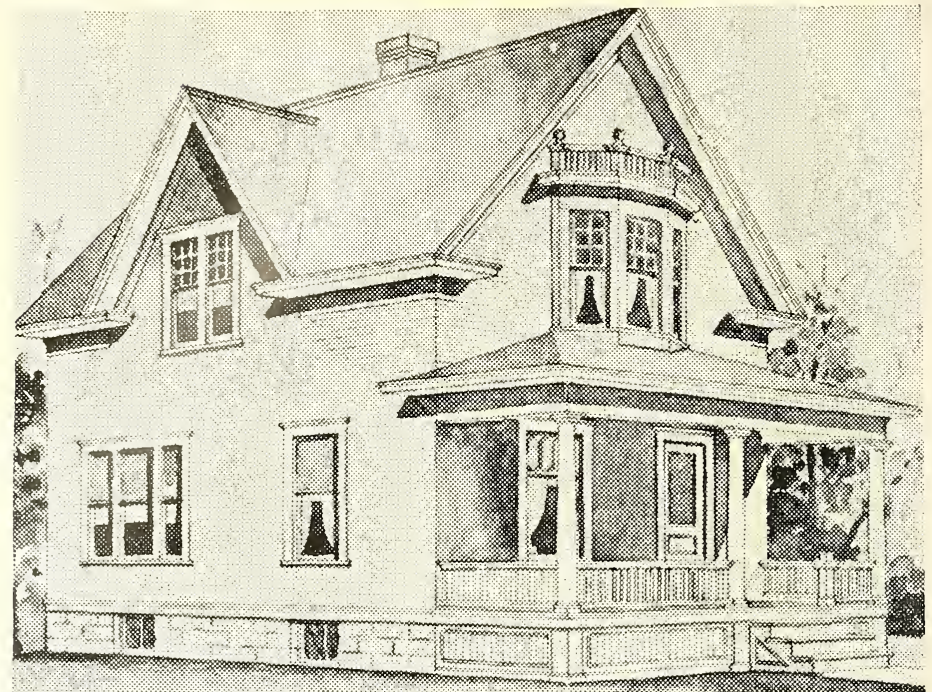

A Model Cottage-No. 202

This plan is $23 \times 28$. Full basement under entire house. The first story is 9 feet, the second story 8 feet. First story finished in gum or birch. Second story in pine to paint. Cost to build, $\$ 2,100$. Complete plans and specifications for $\$ 15$.
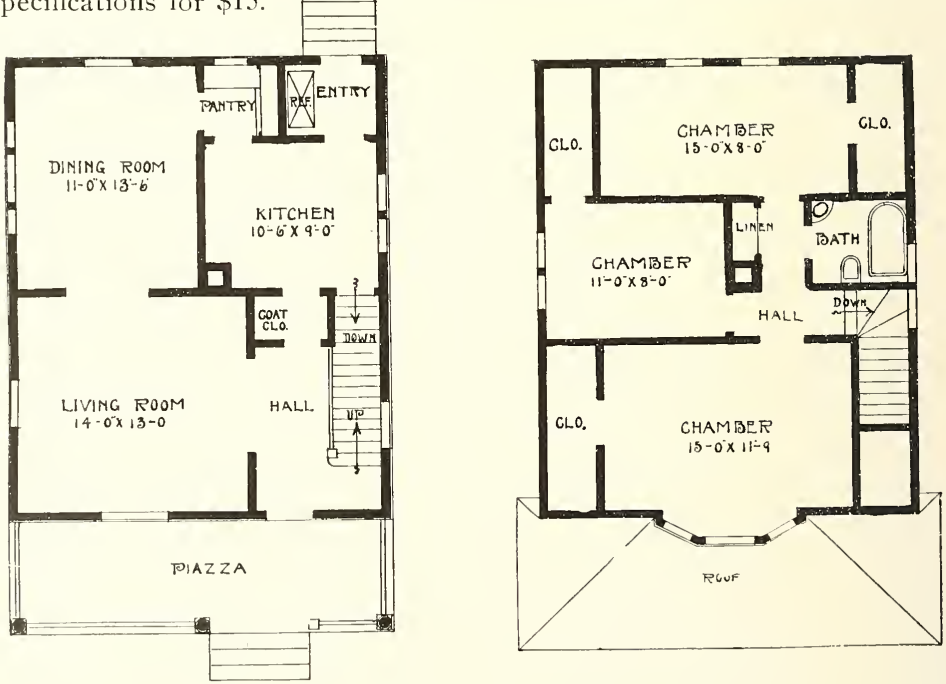

Complete plans and specifications for using Denison Load-Bearing Tile, licensed under Wilson-System Bearing $W$ a 11 Construction for $\$ 30$. 


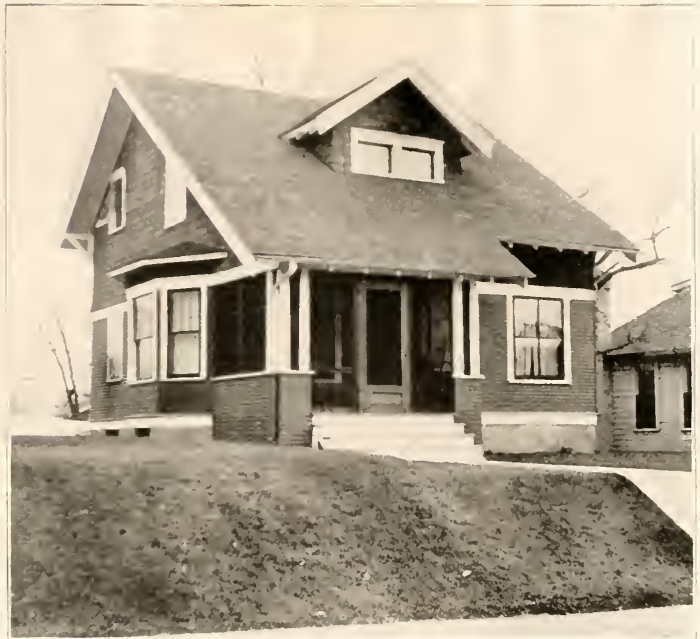

Another Popular Cottage-No. 206

Size 22x24. An elegant big living room 10 feet 6 inches $\times 18$ feet, a nook with a seat around the same across the front, looking directly into the big open fire-place at the rear end. In the second story are two elegant large chambers, besides large bath room, closets and a large linen closet. Height of first story 9 feet, second story 8 feet, and basement under living room part 7 feet high. Gum or birch finish in first story, pine to paint in second. Birch or maple floors throughout. This cottage can be built as a bungalow for $\$ 850$, built for a winter cottage, plastered and back plastered, for the sum of $\$ 1,400$. Complete plans and specifications for $\$ 10$.

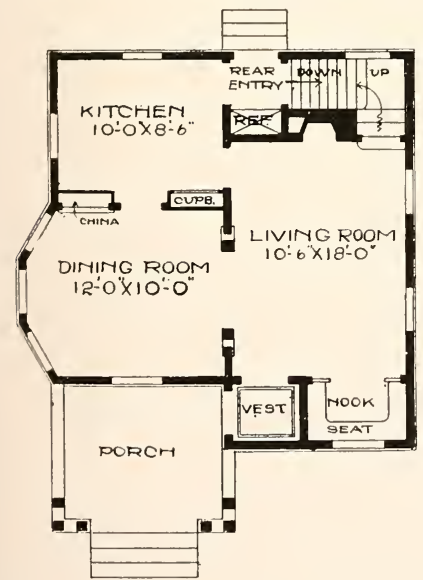

Built 25 times.

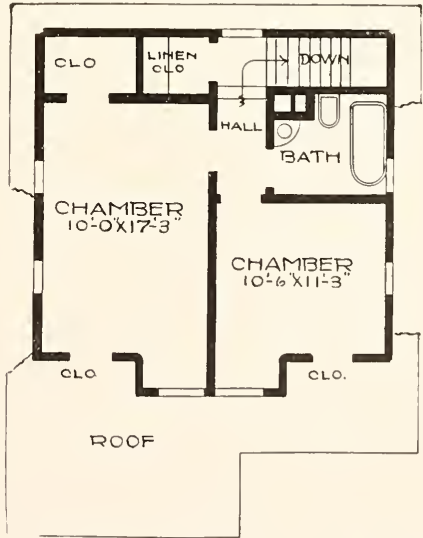

Complete plans and specifications for using Denison Load-Bearing Tile, licensed under Wilson-System Bearing W a 11 Construction for $\$ 20$. 


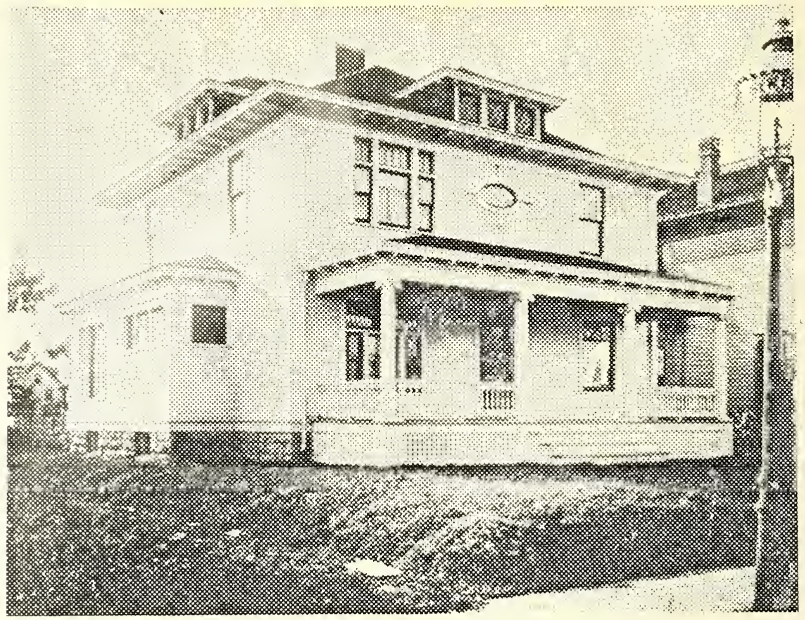

An Ideal Floor Plan-No. 220

Built 10 times.

This beautiful colonial residence will speak for itself. The arrangement is ideal. A broad piazza with Ionic columns across the front. Pantry between this large dining room and kitchen. In the second story there are four elegant chambers, besides bath, linen closet and a high roomy hall. Full basement 7 feet deep, first story 9 feet 2 inches, second story 8 feet. This house will bear considerable study, and is one not to be given a casual glance. Gum or birch in first story, pine to paint in second. Birch or maple floors throughout. Cost to build, $\$ 3,200$. Size 30 feet by 30 feet, exclusive of alcove and porches. Complete plans and specifications for $\$ 25$.

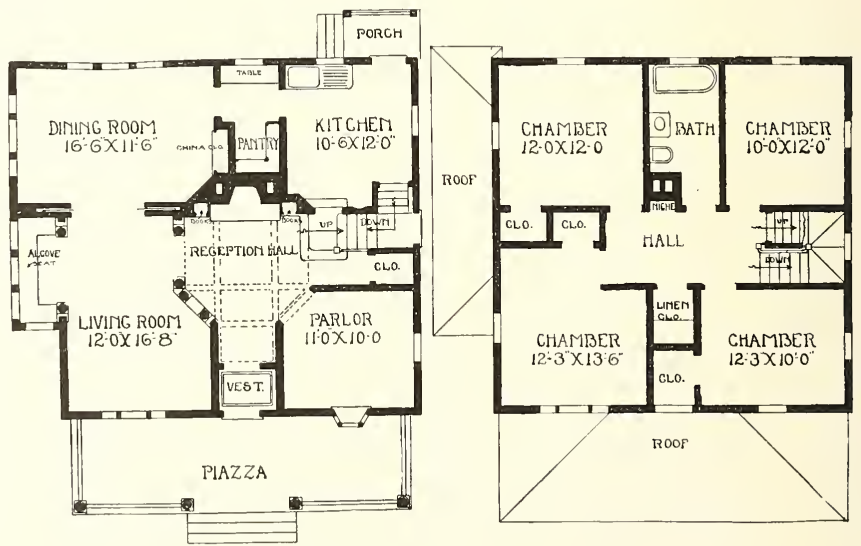

Complete plans and specifications for using Denison Load-Bearing Tile, licensed under Wilson-System Bearing $\mathrm{W}$ a 11 Construction for $\$ 50$. 


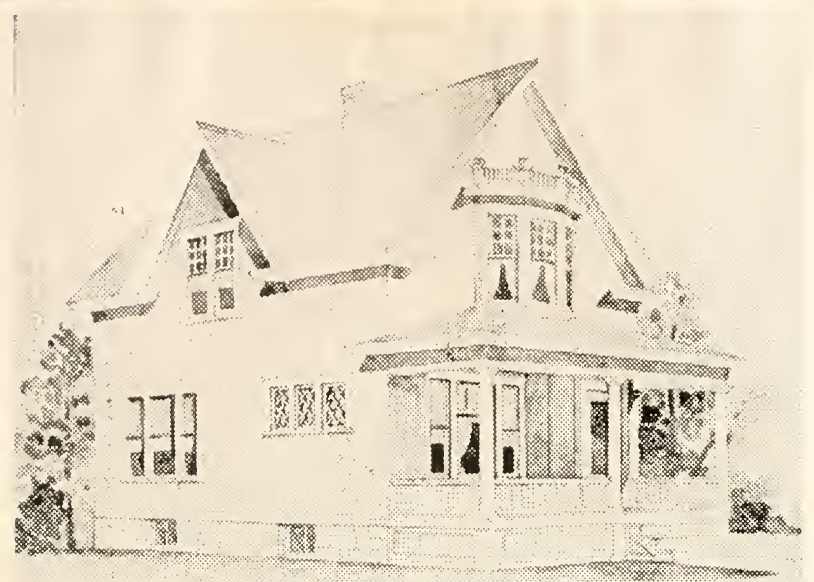

\section{Design No. 3}

A Good Colonial Design. This house would look pretty with a green roof and the body of the house painted ivory white. There is a full basement, size $26 \times 30$ feet. First story 9 feet, second 8 feet. The principal rooms in first story are finished in birch or gum, second story pine to paint. birch floors throughout. Cost to build, $\$ 2,600$. Complete set of plans and specifications for $\$ 20$.
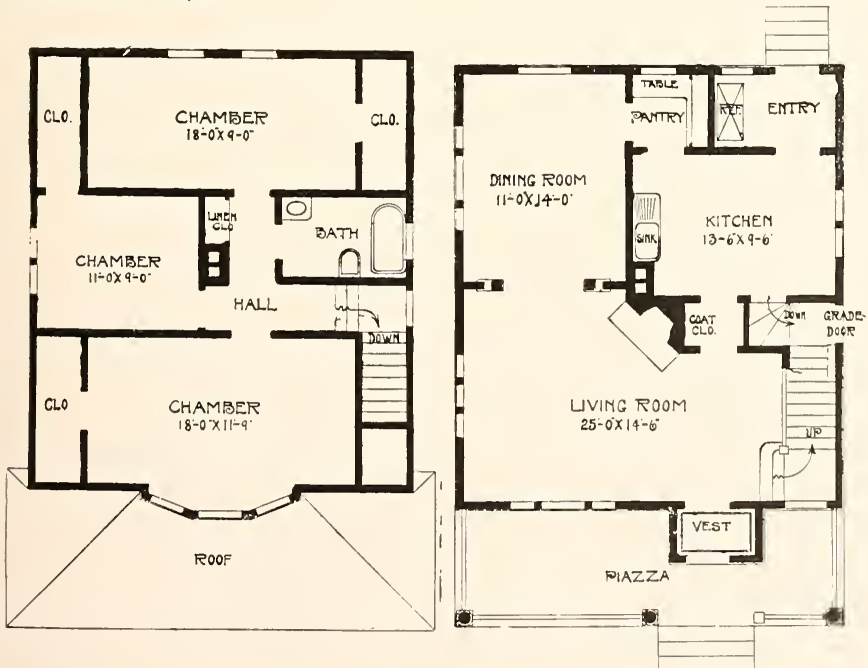

Complete plans and specifications for using Denison Load-Bearing Tile, licensed under Wilson-System Bearing IV a 11 Construction for $\$ 40$. 


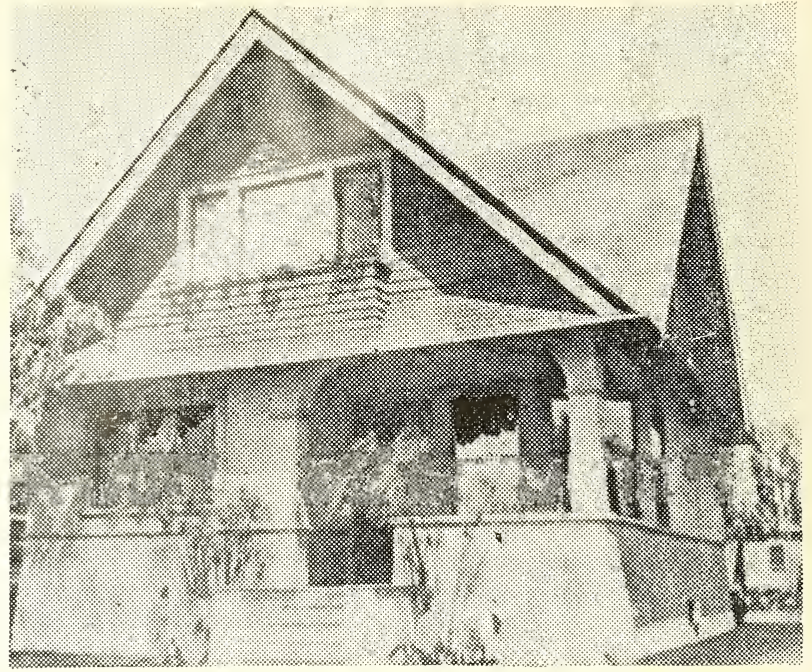

A Cement or Clapboard Design-No. 84

A Cement Cottage, or it can be clapboarded if one desires. This cottage is 26x26 feet over all; the first story 9 feet in height, the second 8 feet, and a full basement. Hardwood floors and finish are provided in first story with pine to paint in the second. Cost to build, $\$ 2,075$. Complete plans and specifications in cement for $\$ 20$. In frame for $\$ 15$.
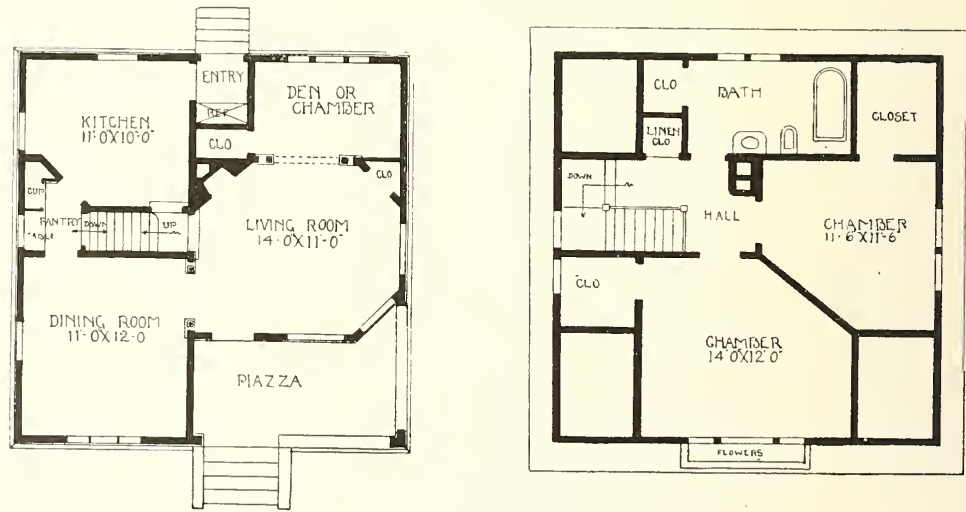

Complete plans and specifications for using Denison Load-Bearing Tile, licensed under Wilson-System Bearing Wal1 Construction for $\$ 30$. 


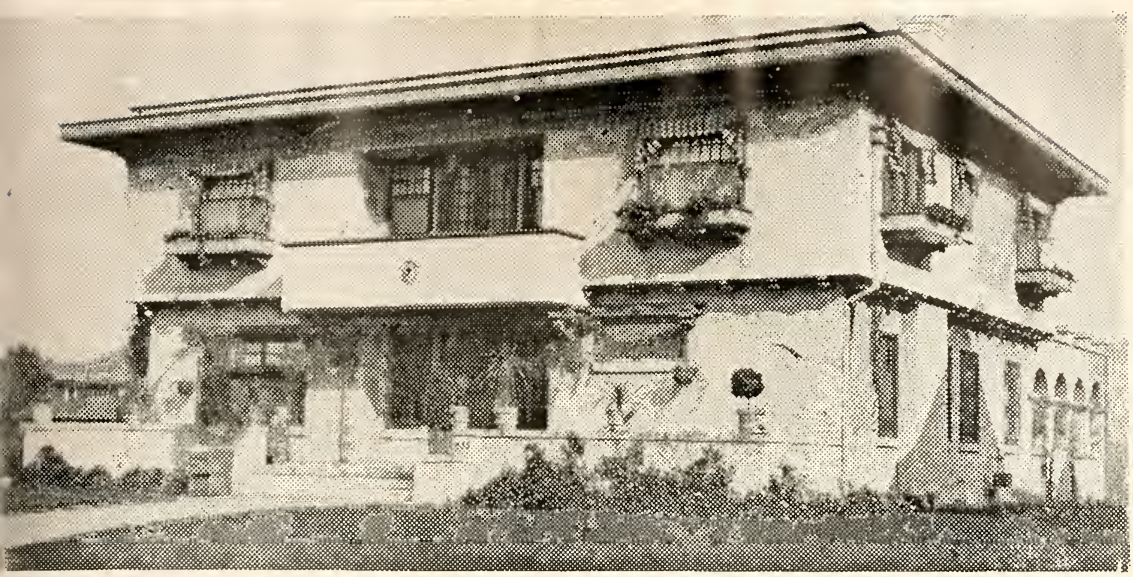

A Study in Plaster-No. 941

Width 46 feet, depth 30 feet over the main part. An effective treatment of exterior in rough cast cement. This dwelling has all the important features found in homes that cost many times more. One of the special features is the sun piazza adjoining the long living room, which for winter use is enclosed with glazed windows, that can be dropped into pockets during the summer, and sereened in for summer use. Other attractive features are the open fire-place, the beautiful symmetrical central hall, and the built-in sideboard in the dining room. In the second story there are four large chambers, a bath and another room which ean be utilized as a guest room, den or nursery. Height of the first story $9 \frac{1}{2}$ feet, second story $81 / 2$ feet. Cost to build, $\$ 9,000$.
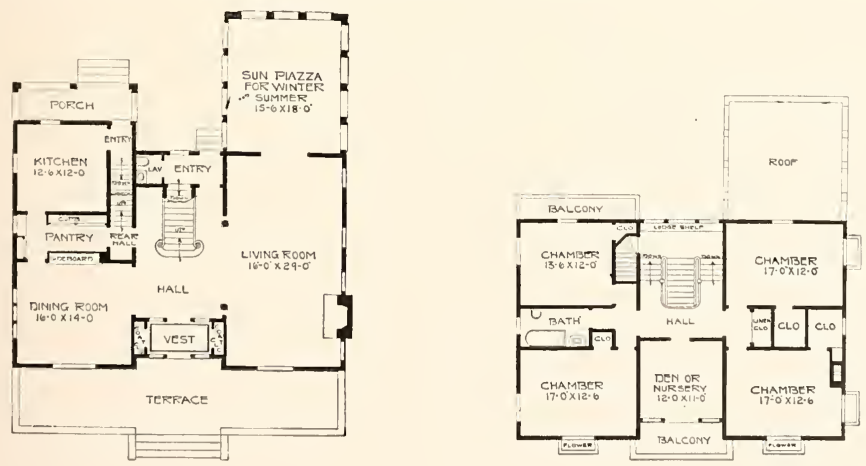


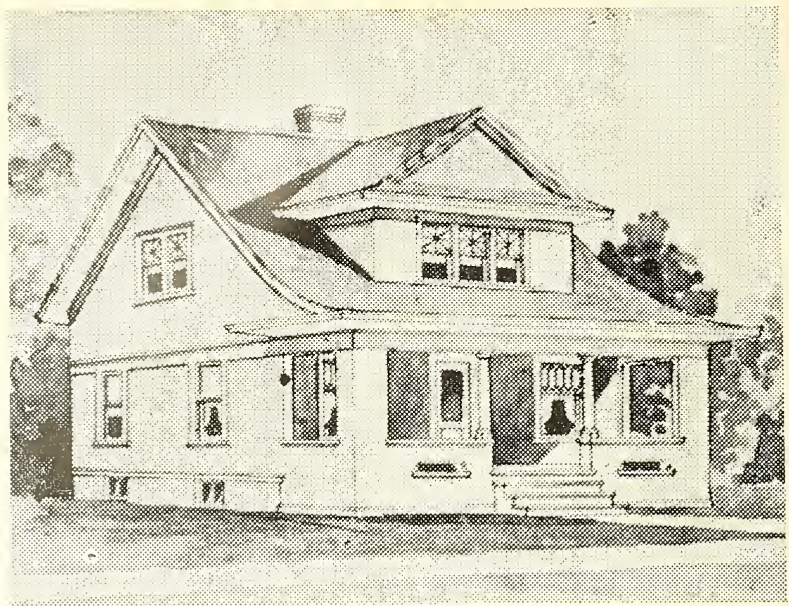

Colonial Cottage-No. 214

A colonial cottage of pure and simple type. Size 26 feet $\times 26$ feet, exclusive of large piazza across entire front, which is 7 feet wide. First story 9 feet, finished in gum or birch, second story 8 feet, finish pine to paint. Birch or maple floors throughout. Basement under rear portion. This is a good economical house to build. Contains four nice chambers, hall and pantry. Has a combination stairway to the second story, three liberal sized chambers in the second story, besides large closet space, linen closet and bath room. Cost to build, $\$ 2,200$. Complete plans and specifications for $\$ 15$.

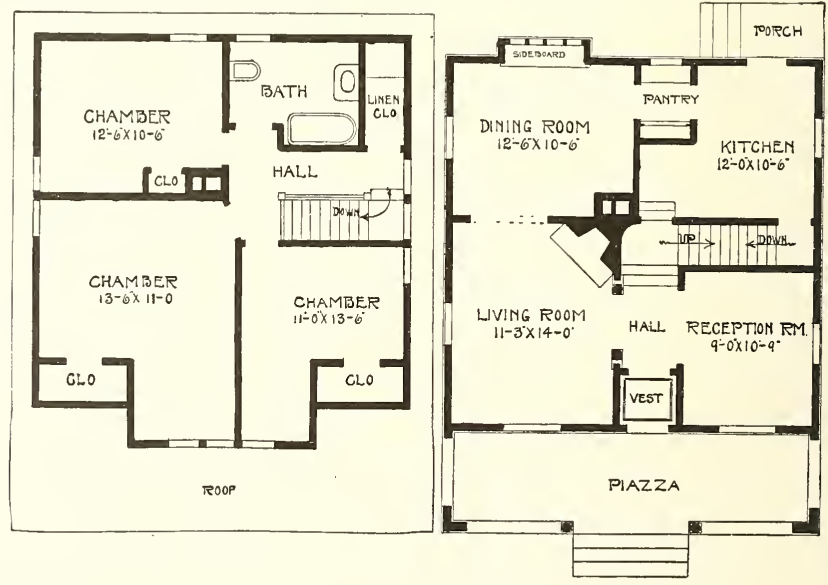

Complete plans and specifications for using Denison Load-Bearing Tile, licensed under Wilson-System Bearing $\mathrm{W}$ a 11 Construction for $\$ 30$. 


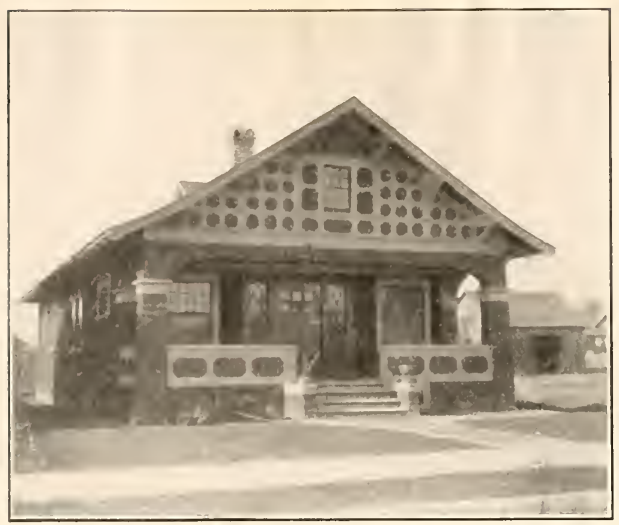

A Beautiful Bungalow-No. 9

Cost to build, $\$ 2200$. The price includes finishing two rooms in the second story. Size over all 28 feet wide, by 38 feet deep. Basement under rear part. First story 9 feet, finished in gum or birch, second story 8 feet, finish: pine to paint. Birch or maple floors throughout. If you are looking for a beautiful bungalow home, study this design. Complete plans and specifications for $\$ 15$.

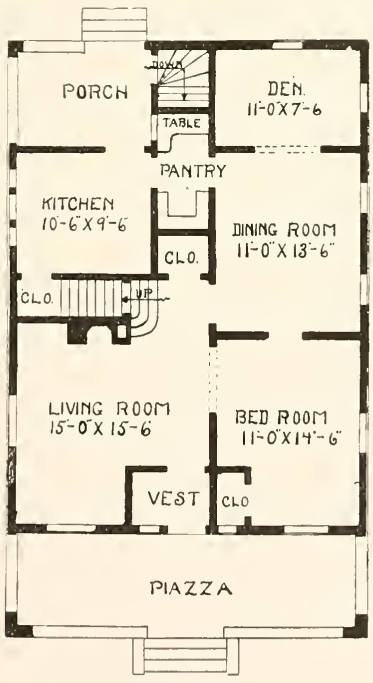

Complete plans and specifications for using Denison Load-Bearing Tile, licensed under Wilson-System Bearing W a 11 Construction for $\$ 30$. 


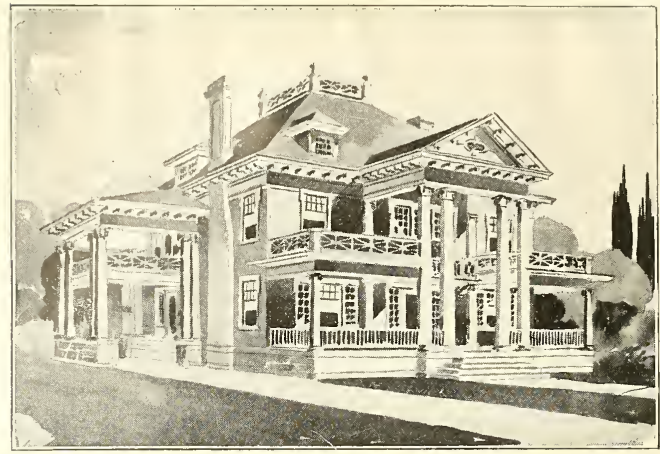

A Georgian Colonial Home-No. 280

Birch floors are used throughout both stories. The first story can be finished in either oak, gum or birch and the second in pine, enameled white, with birch doors mahogany stained. Height of first story 11 feet, second story 9 feet. There is a full basement 7 feet 6 inches high. Cost, if built of frame, $\$ 11,000$, if veneered with brick, $\$ 12,500$. If you are interested in a building of this character, you can save money in building by corresponding with us in regard to plans and specifications.

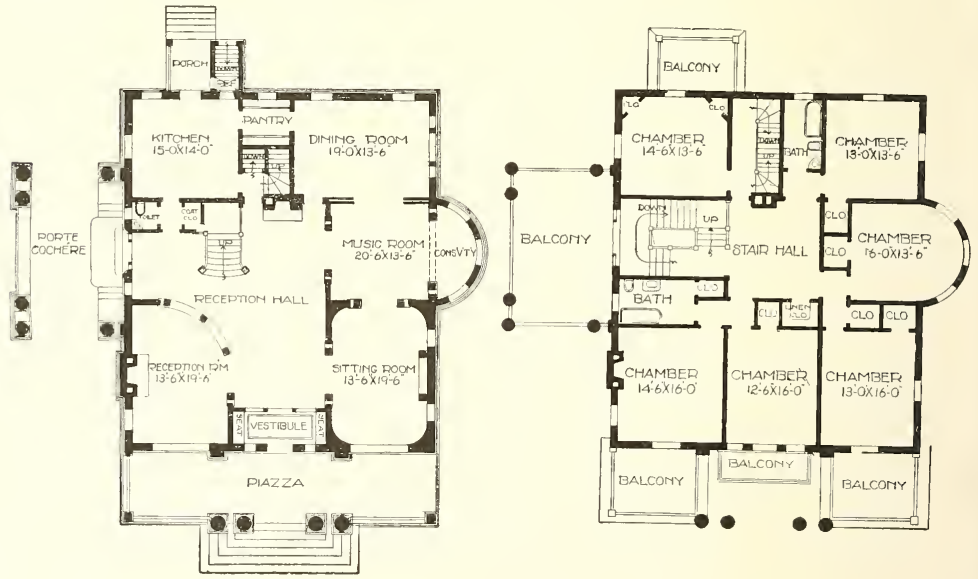




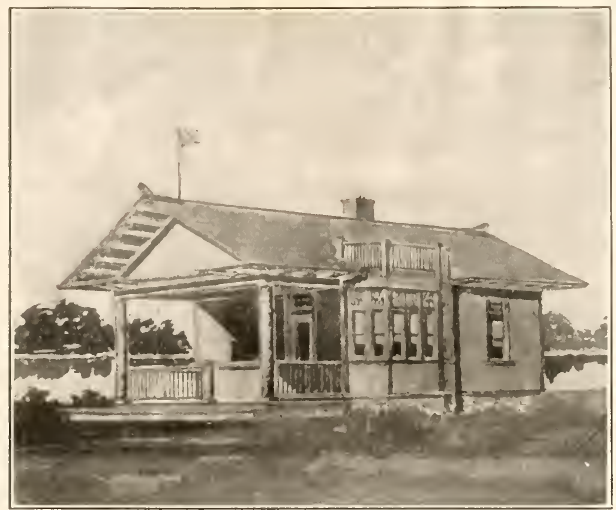

A Cottage in the Woods-"A Bungalow"-No. 343

A beauty for the money. The cottage is boarded and shingled on the outside, the dressed timbers showing on the inside and the outside painted or stained in colors. The roof is double boarded and battened. Can be finished up for a cottage to live in the year around, shingled roof, plastered throughout the inside for about $\$ 750$. There is a fireplace constructed of field boulders, adding to the attractiveness of the interior. The main roof extends out over the porch and is supported with two rustic log columns left with the natural bark on. Size 26 feet 6 inches $x 19$ feet 6 inches. Cost to build, $\$ 350$. Complete set of plans and specifications for $\$ 8$.

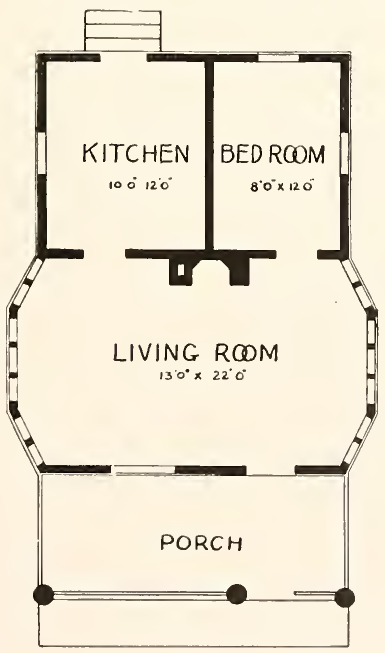

Complete plans and specifications for using Denison Load-Bearing Tile, licensed under Wilson-System Bearing IV a 11 Construction for $\$ 16$ 


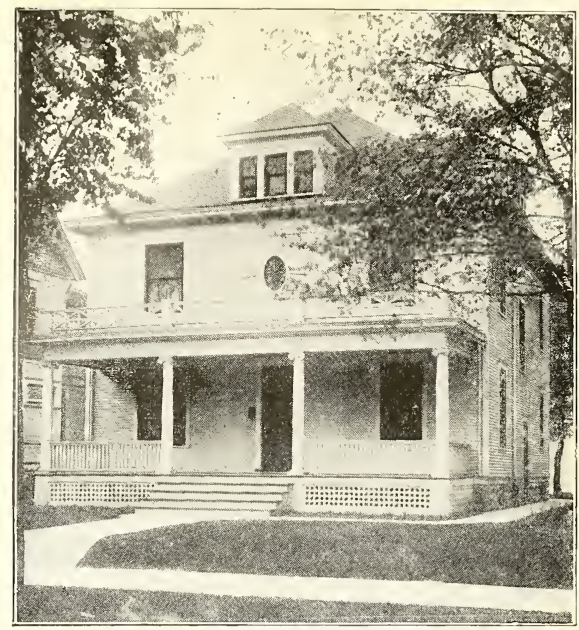

A Beautiful Colonial Design--No. 357

The house is finished throughout, first story with white oak, birch or gum, second story pine, painted. Birch or maple floors throughout. The two interiors shown on the opposite page are interiors taken from the sitting room, one looking into the dining room, and the other looking into the reception hall back to the front stairs and into the reception room. Cost, $\$ 4,000$. Complete plans and specifications for $\$ 25$.
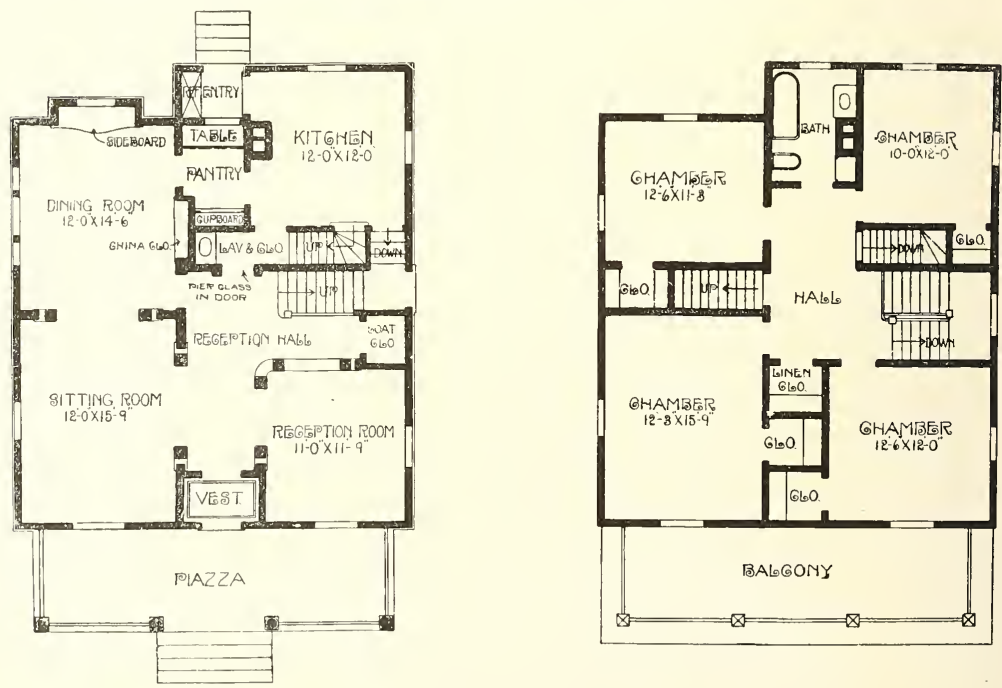

Complete plans and specifications for using Denison Load-Bearing Tile, licensed under Wilson-System Bearing $\mathrm{W}$ a 11 Construction for $\$ 50$. 


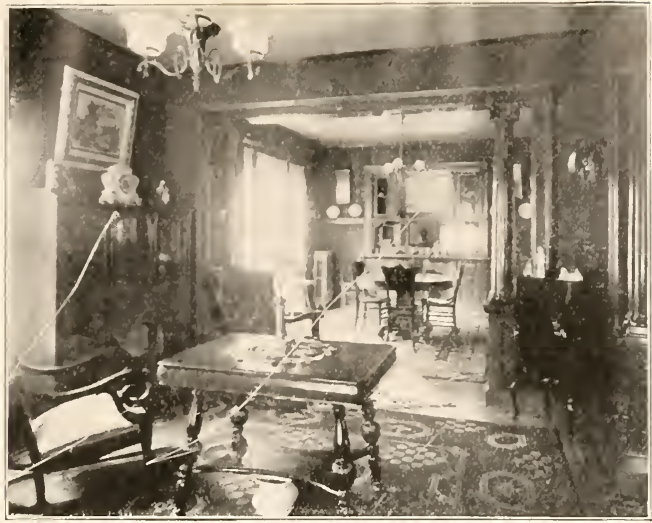

No. 357

Interiors-No. 357

Here is a study of colonial interiors. The finish is gum wood. In my judgment this is one of my best efforts of interiors, taken from a house that only cost $\$ 4,000$. These are from one of the most modern low-cost houses in the city of Minneapolis, which has a population of over 300,000 .

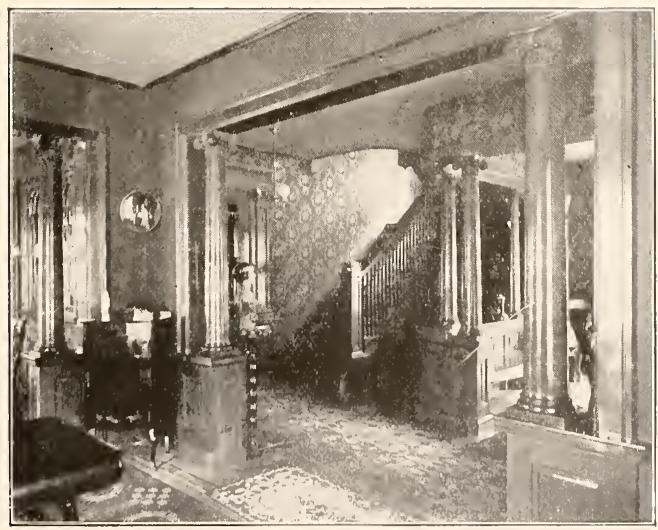

No. 357 


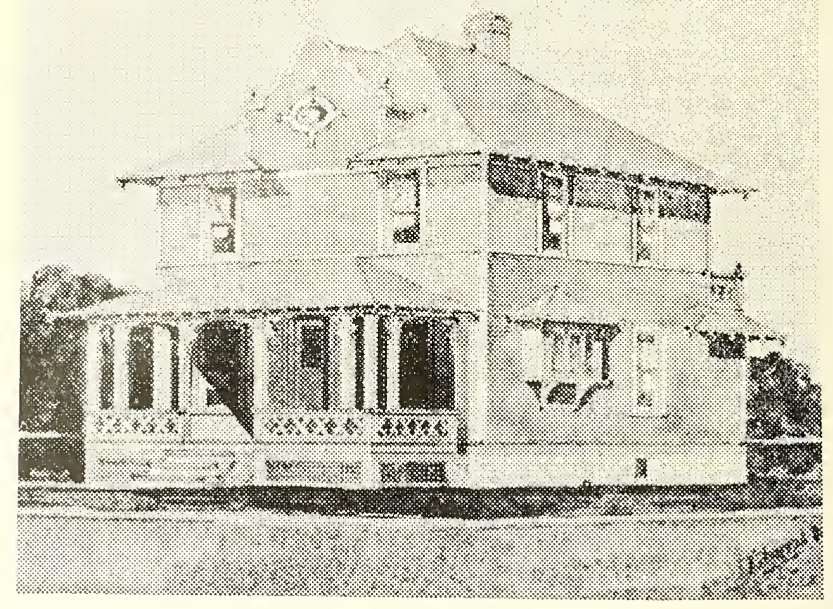

A Beautiful City or Lake Home-No. 141

First story 9 feet, second story 8 feet. First story finished in gum or birch, second story pine to paint. Birch or maple floors throughout. Size 26 feet wide by 24 feet deep over main part. Cost to build, $\$ 2,500$. Complete plans and specifications for $\$ 20$.
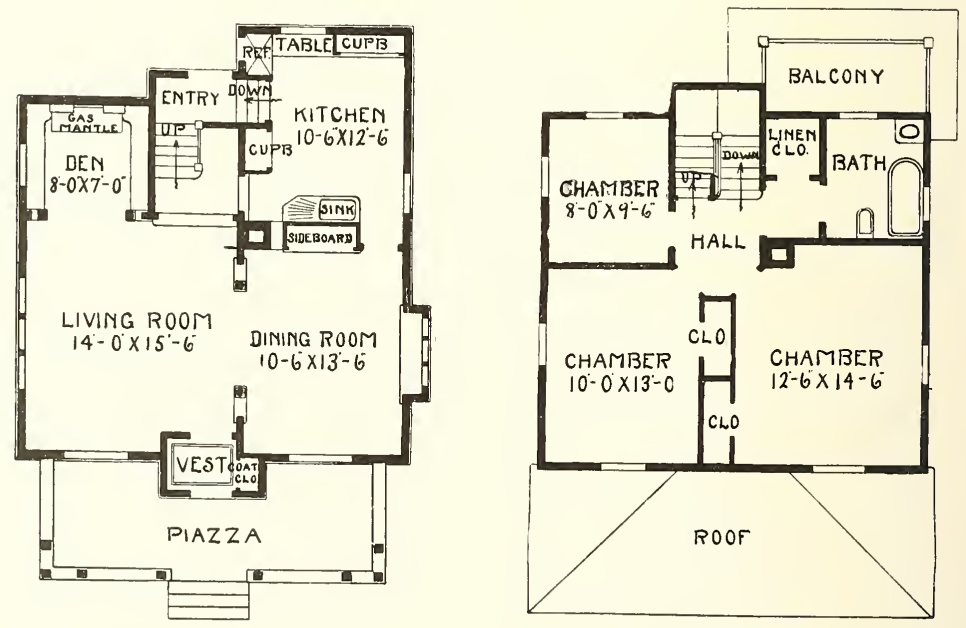

Complete plans and specifications for using Denison Load-Bearing Tile, licensed under Wilson-System Bearing $\mathrm{W}$ al 1 Construction for $\$ 40$. 


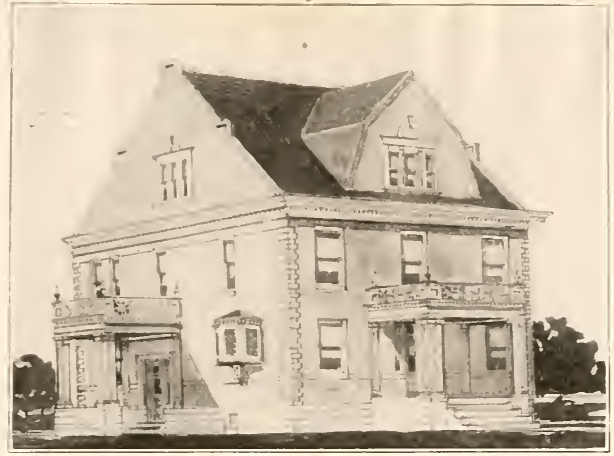

A House With All The Home Comforts-No. 133

This beatiful colonial residence contains all the features essential to make an ideal home. The house is reneered with pressed brick, of a dark shade, to cost about $\$ 32$ or $\$ 33$ per thousand. The first story has beamed ceiling in the den, living room and dining room. Finish in first story birch or gum, second story pine to paint. Birch or maple floors throughout. The house is 34 feet wide by 42 feet deep, the first story is 9 feet, second story $\&$ feet. There is a full basement under the entire house 7 feet deep. Cost to build, $\$ 7,300$. Complete set of plans and specifications for this beautiful brick veneered residence for $\$ \$ 0$.
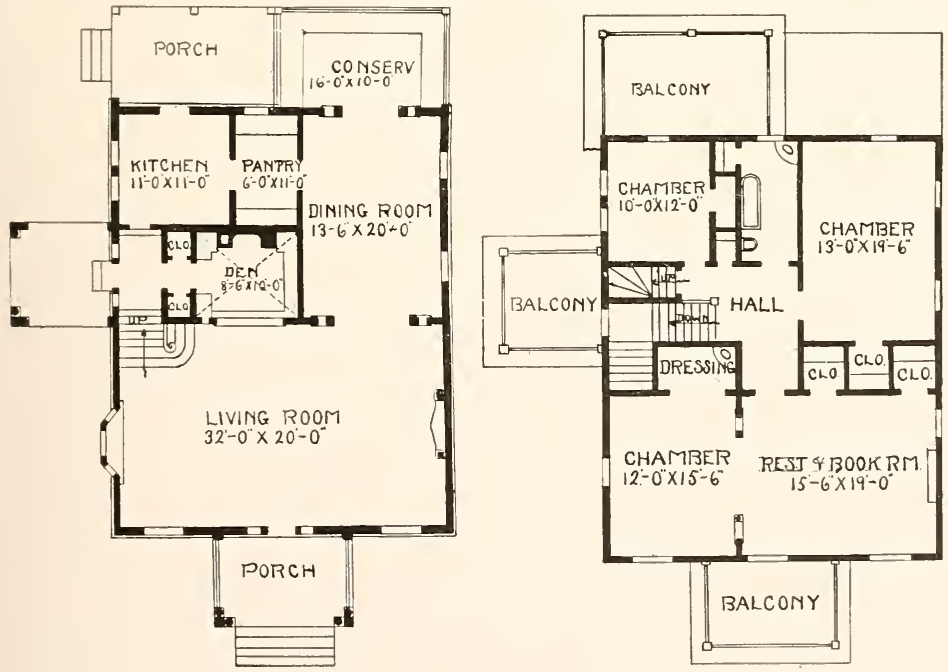

Complete plans and specifications for using Denison Load-Bearing Tile, licensed under Wilson-System Bearing Wa 11 Construction for $\$ 160$. 


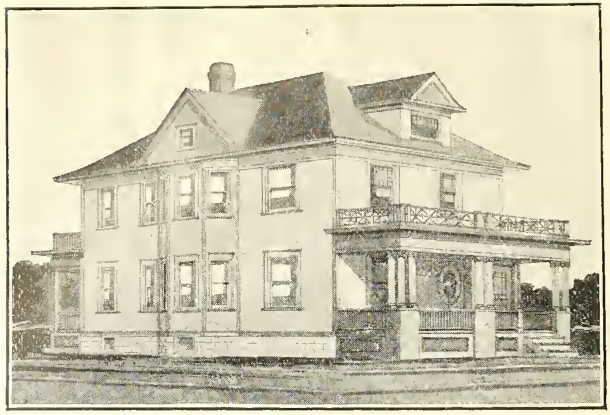

An Economical Duplex-No. 143

There having been considerable demand for duplex houses we are now giving you another ideal floor plan which we consider unusually well arranged. Size $28 \times 42$ feet. Full basement. First story 9 feet, second story 8 feet, 9 inches. There is also space to finish two or three servants' rooms in third story. Can go from second or third floor to basement without interfering with first floor tenant. Floors throughout are narrow birch or maple. Finish in first, white oak, gum or birch, in second, pine to paint Cost to build, $\$ 5,000$. Complete plans for $\$ 25$.
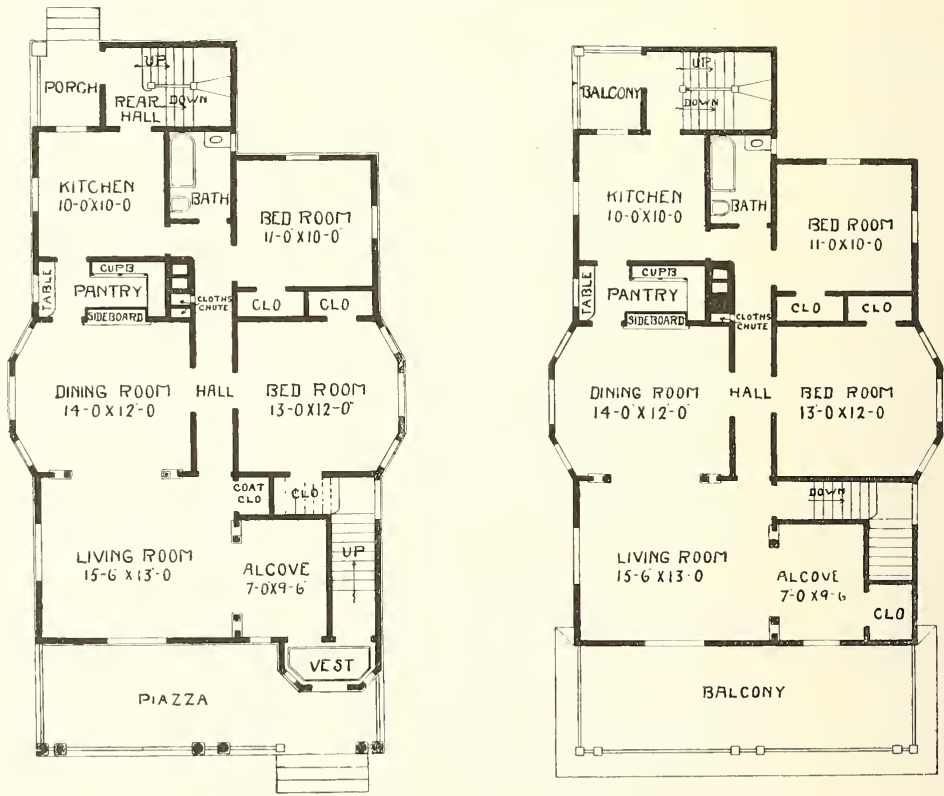

Complete plans and specifications for using Denison Load-Bearing Tile, licensed under Wilson-System Bearing W a 11 Construction for $\$ 50$. 


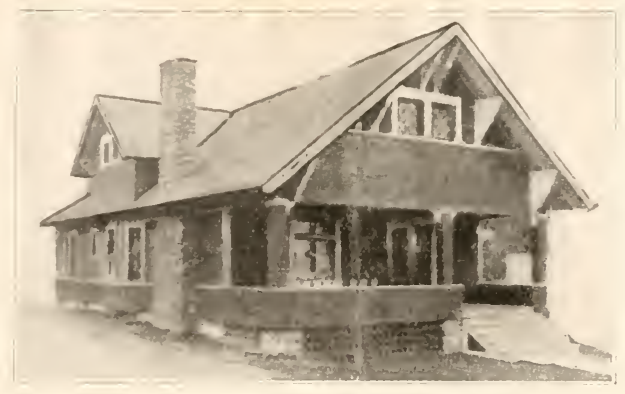

A Charming Bungalow-No. 215

There are five nice rooms on the first floor well arranged for conrenience. First story 9 feet, finished in gum or birch, second story 8 feet in the clear, pine to paint. Birch or maple boors throughout. Cost to build, $\$ 2,000$. Second story is unfinished. Add $\$ 450$ to finish the second story. Complete set of plans and specfications for $\$ 15$.

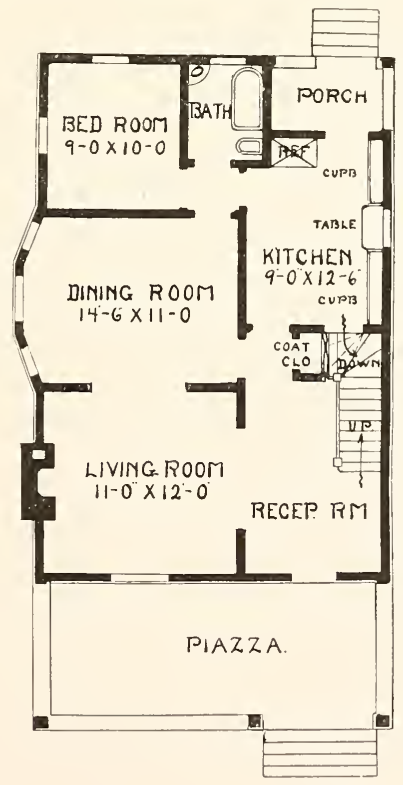

Complete plans and specifications for using Denison Load-Bearing Tile, licensed under Wilson-System Bearing IV a 11 Construction for $\$ 30$. 


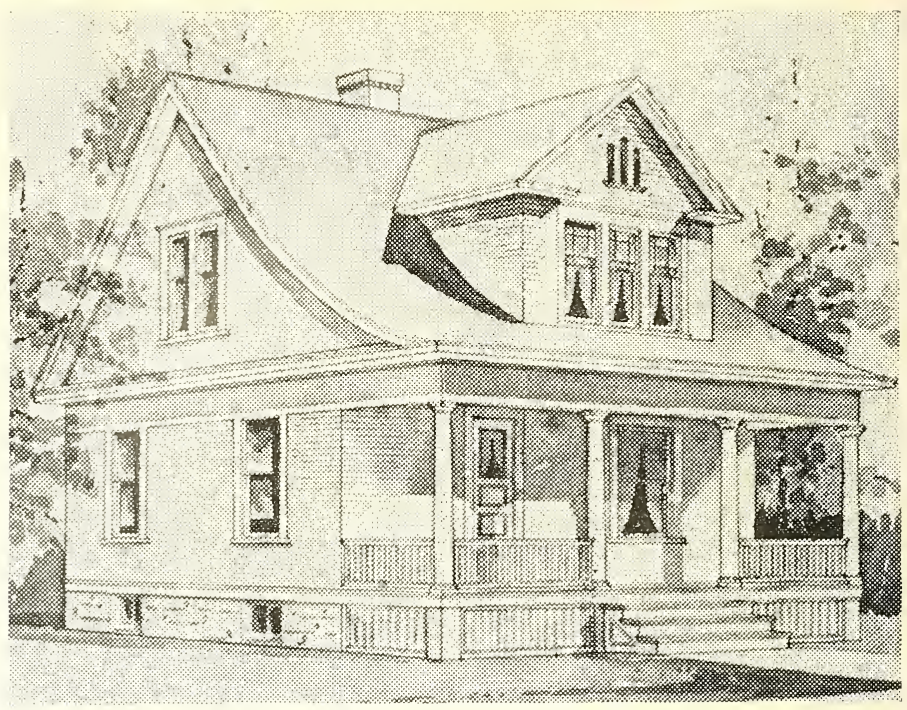

Design No. 389

The inside finish can be of gum or birch in first story, varnished and pine to paint in second. Floors of birch or maple. We recommend to paint the woodwork in second story in some of the light enamels, three coats would make a good finish. Size of the house is $26 \times 24$ feet, the ceilings are 8 feet 6 inches high in first story and 8 feet high in second story, with angles in ceiling of chambers slightly cut by the roof. Estimated cost $\$ 1,400$. Plans and specifications, $\$ 10$.
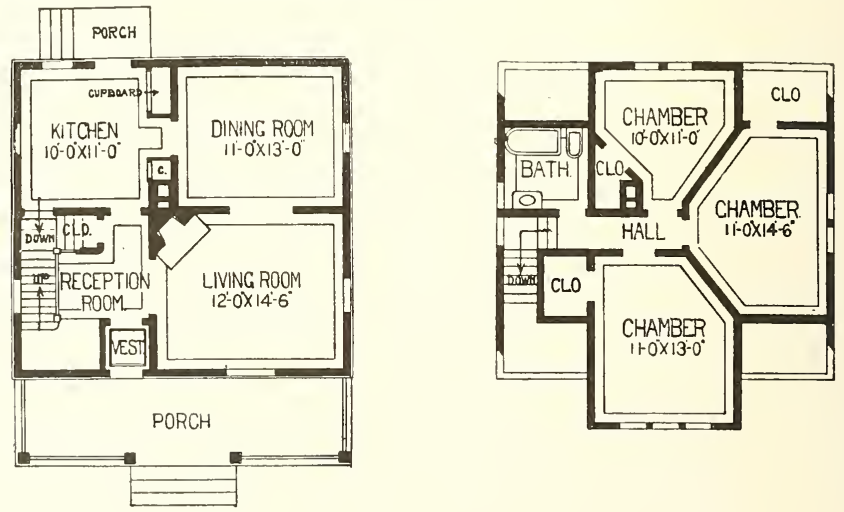

Complete plans and specifications for using Denison Load-Bearing Tile, licensed under Wilson-System Bearing Wa 11 Construction for $\$ 20$. 


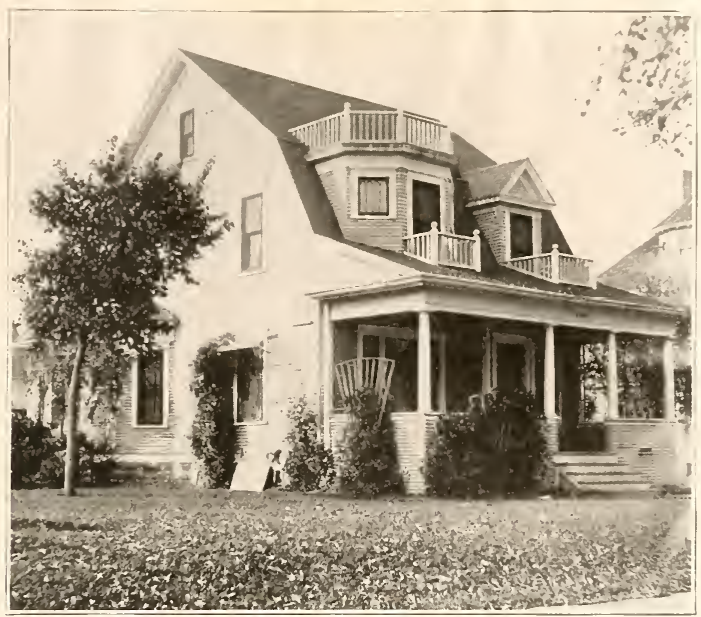

For City or Country-No. 254

Built as a lake cottage, also as a winter home. First story 9 feet, second story 8 feet, basement under kitchen portion. Finish in first story gum or birch, pine to paint in second. Birch or maple floors throughout. Cost to build, $\$ 2,150$. Complete plans and specifications for $\$ 15$.
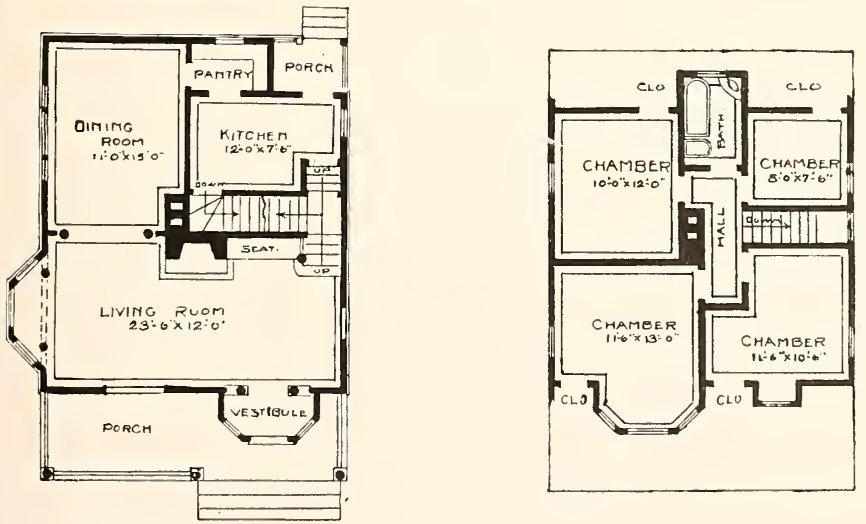

Complete plans and specifications for using Denison Load-Bearing Tile, licensed under Wilson-System Bearing $\mathrm{W}$ a 11 Construction for $\$ 30$. 


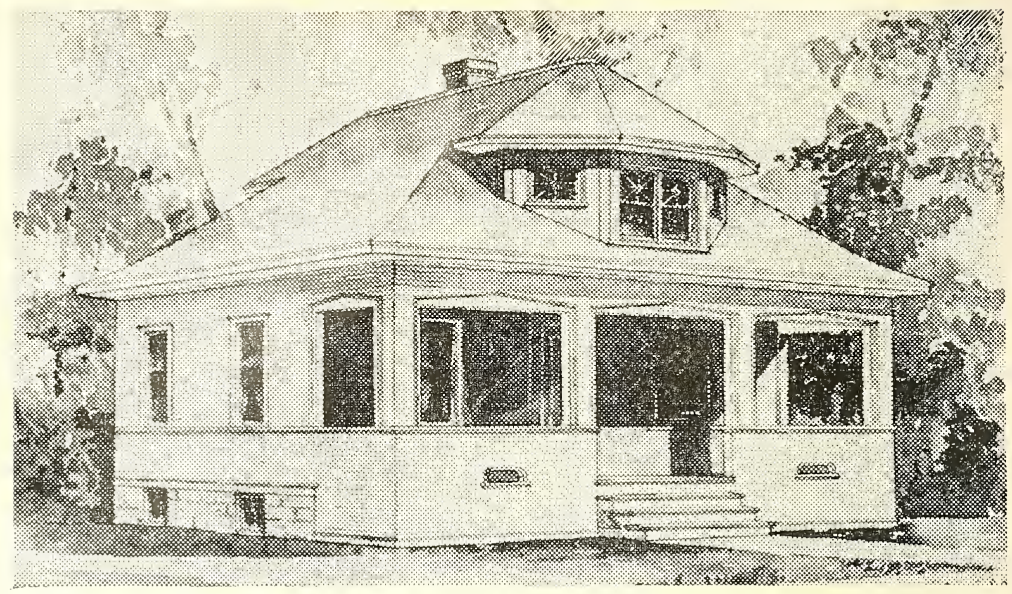

\section{All The Comforts of Home-No. 387}

The size of the house is 26 feet square. It should be set up from the ground about 3 feet and have a nice little cellar under the kitchen portion. First story, 8 feet high; second story, 8 feet high in the center. This house can be constructed for $\$ 1,600$. Gum or birch finish in first story, pine to paint in second. Birch or maple floors throughout. Complete plans and specifications for this little house for $\$ 10$.
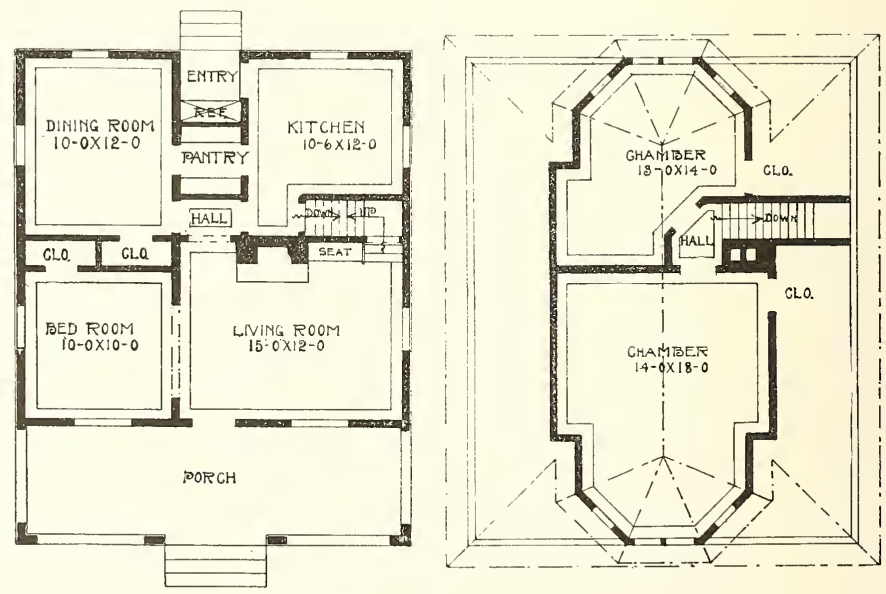

Complete plans and specifications for using Denison Load-Bearing Tile, licensed under Wilson-System Bearing W a 11 Construction for $\$ 20$. 


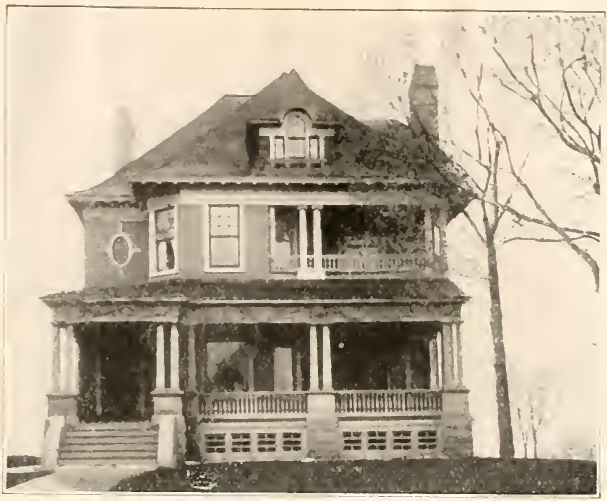

Another Colonial-No. 21

The interior in this colonial house is artistically arranged, with handsome reception hall and staircase, seats, fireplaces, etc. The rooms are medium size. The large open fireplace in the sitting room is designed to be of ornamental brick, built with a wide opening to burn wood. The first story is finished in birch or gum in the front portion, and yellow pine in the rear. The second story in pine to paint. The floors are polished birch or maple. A large two-story piazza is the feature of the front, with handsome Ionic columns, standing on pressed brick piers with cut stone caps and cut stone steps. This house costs to build $\$ 4,200$. Size 34 feet wide by 45 feet 6 inches deep over all. Complete set of plans and specifications for $\$ 30$.
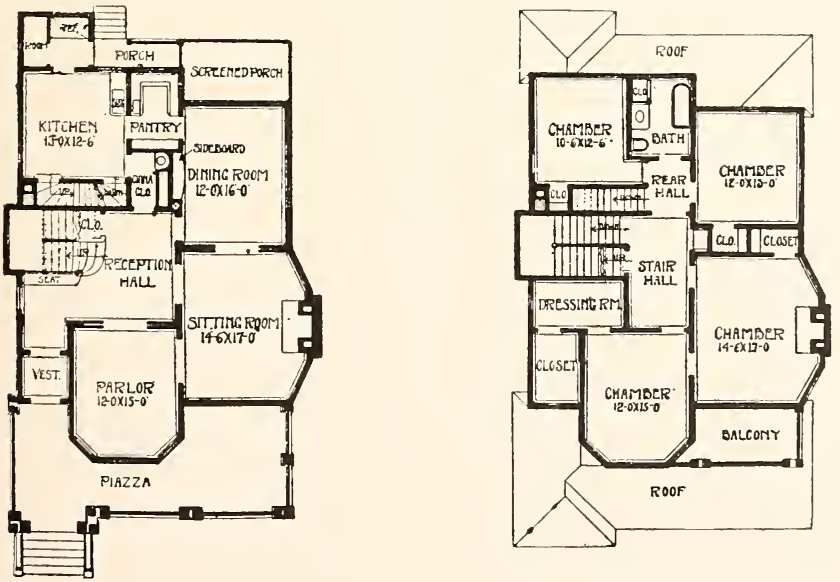

Complete plans and specifications for using Denison Load-Bearing Tile, licensed under Wilson-System Bearing $W$ a 11 Construction for $\$ 60$. 


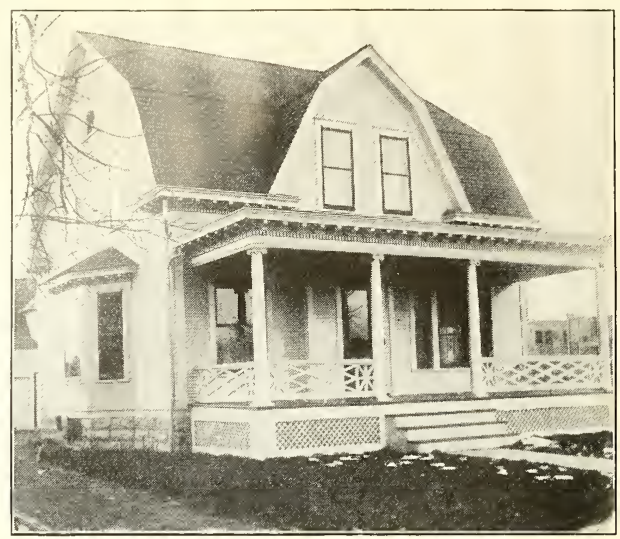

A Gambrel Roofed Home-No. 75

It is finished with birch floors throughout, finished in birch or gum in first story and pine to paint in second. House 28 feet square. Cost to build, $\$ 2,800$. Complete plans and specifications for this fine residence for $\$ 20$.
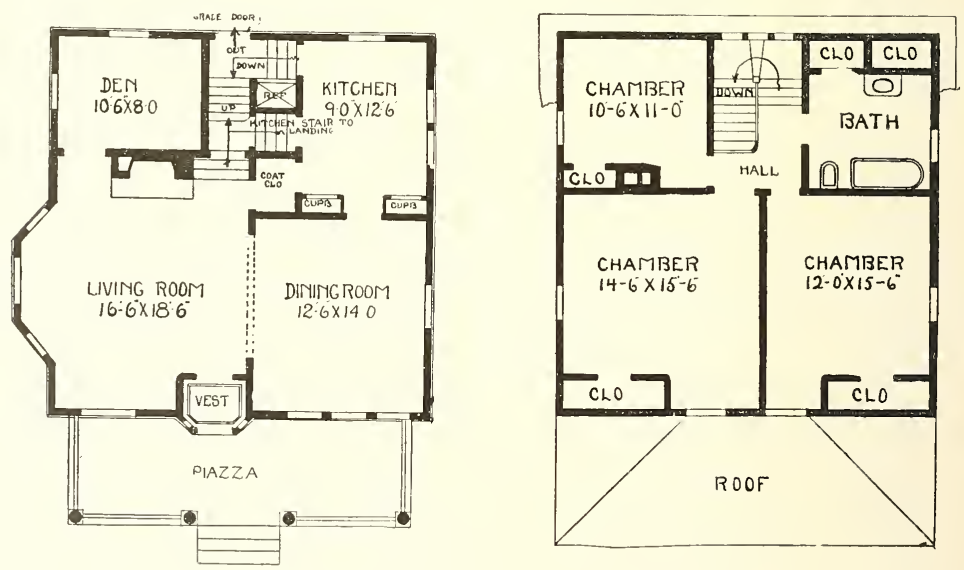

Complete plans and specifications for using Denison Load-Bearing Tile, licensed under Wilson-System Bearing Wa 11 Construction for $\$ 40$. 


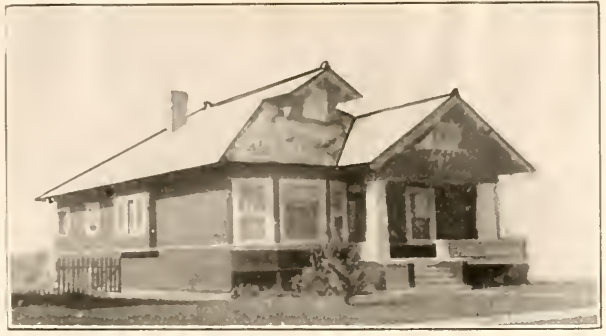

\section{A Bungalow of Sunshine-No. 85}

Size of this Bungalow is 30 feet wide and 38 feet deep, and contains 6 nice rooms. Can be finished as a lake home, just sided up on the uutside, for the sum of $\$ 1,200$, or can be built as a city home or winter home for $\$ 1,900$. This price includes back plastering and finished up all complete with hardwood, gum or birch throughout principal rooms. Pine to paint in bed rooms, birch or maple floors throughout. Height of ceilings 9 feet. We consider this one of our best bungalow plans. Complete plans and specifications for $\$ 15$.

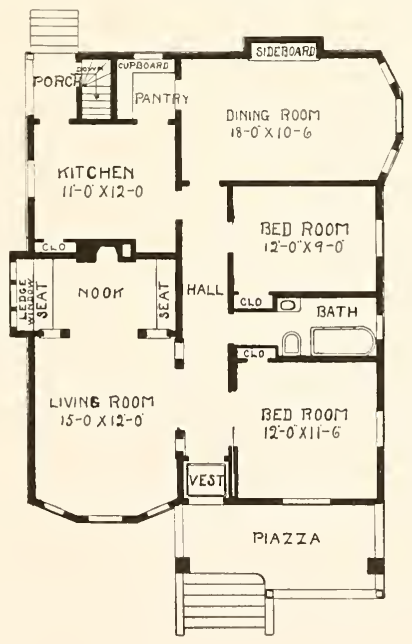

Complete plans and specifications for using Denison Load-Bearing Tile, licensed under Wilson-System Bearing IV a 11 Construction for $\$ 30$. 


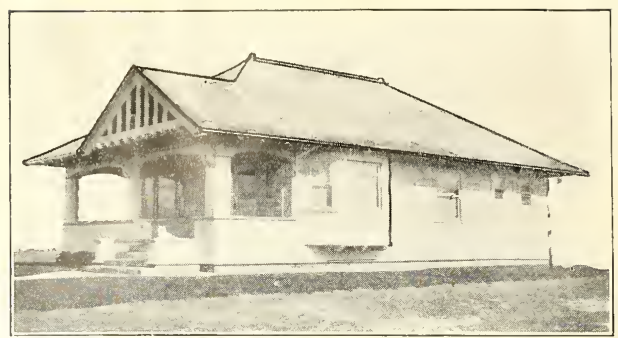

A Summer or Winter Bungalow-No. 87

Can be built as summer cottage or lake home for $\$ 800$. Size $26 \times 28$ feet over the main part. This is what we call a five room bungalow. The beautiful porch across the front makes it especially desirable for a lake cottage. Ceilings 9 feet throughout, gum or birch finish and hardwood floors throughout. Cost to build, as winter home, $\$ 1,400$. Complete plans and specifications for $\$ 12$.

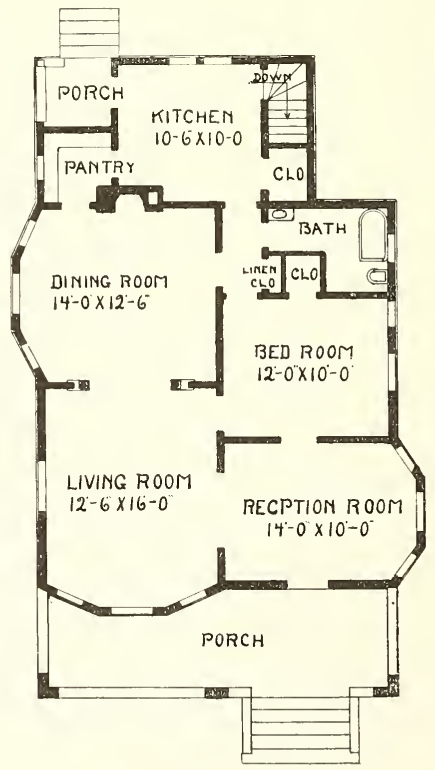

Complete plans and specifications for using Denison Load-Bearing Tile, licensed under Wilson-System Bearing Wa 11 Construction for $\$ 24$. 


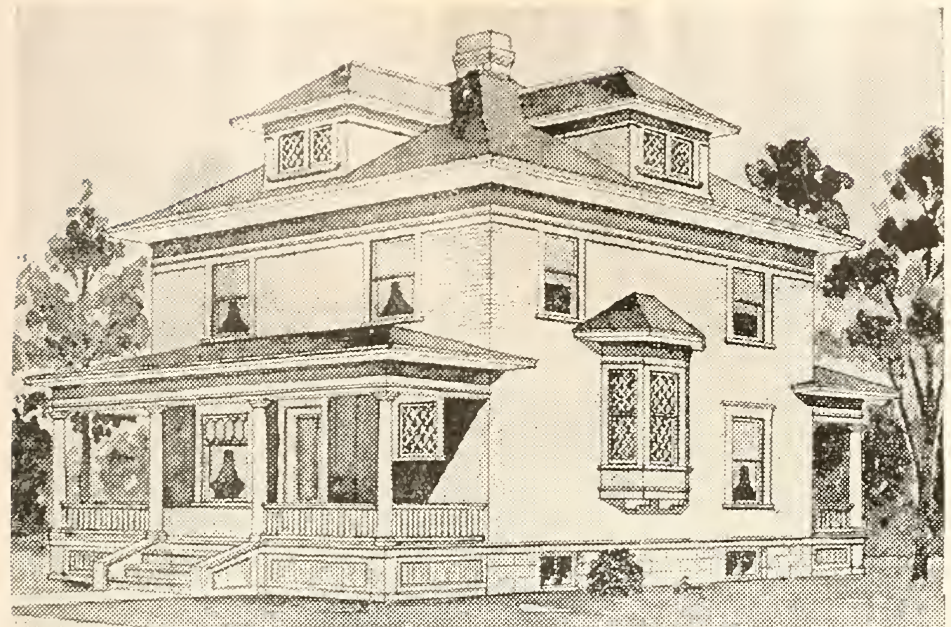

A Comfortable Home-No. 20

This house is 28 feet wide and 30 feet deep over the main part. Full i)asement 7 feet in the clear. First story 9 feet 2 inches and second story 3 feet 4 inches. The first story is finished in birch or gum with maple or birch floors throughout. Second story finished in pine to paint.

Complete plans and specifications for this house for $\$ 25$.
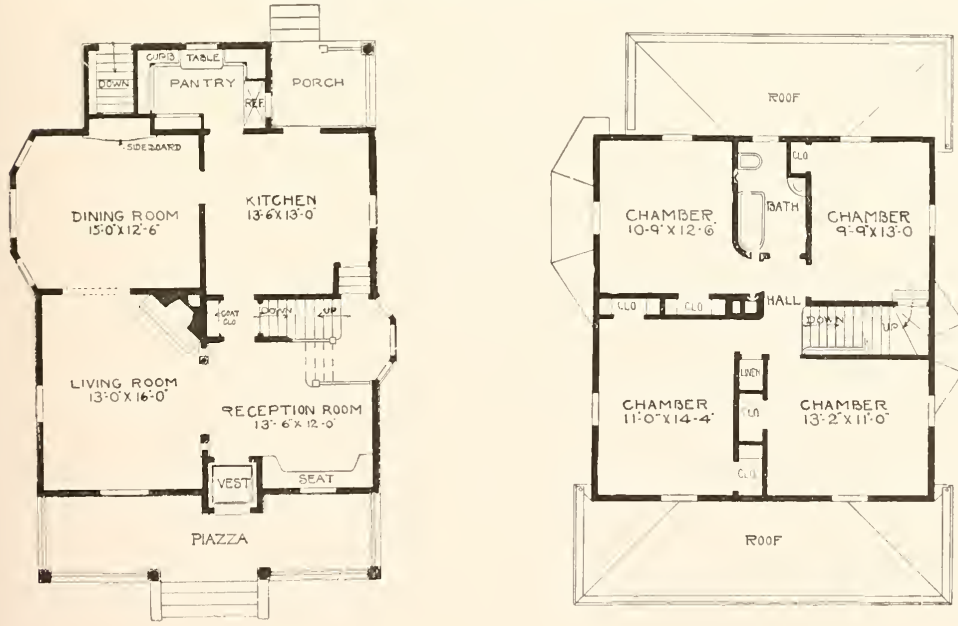

Complete plans and specifications for using Denison Load-Bearing Tile, licensed under Wilson-System Bearing $\mathrm{W}$ a 11 Construction for $\$ 50$. 


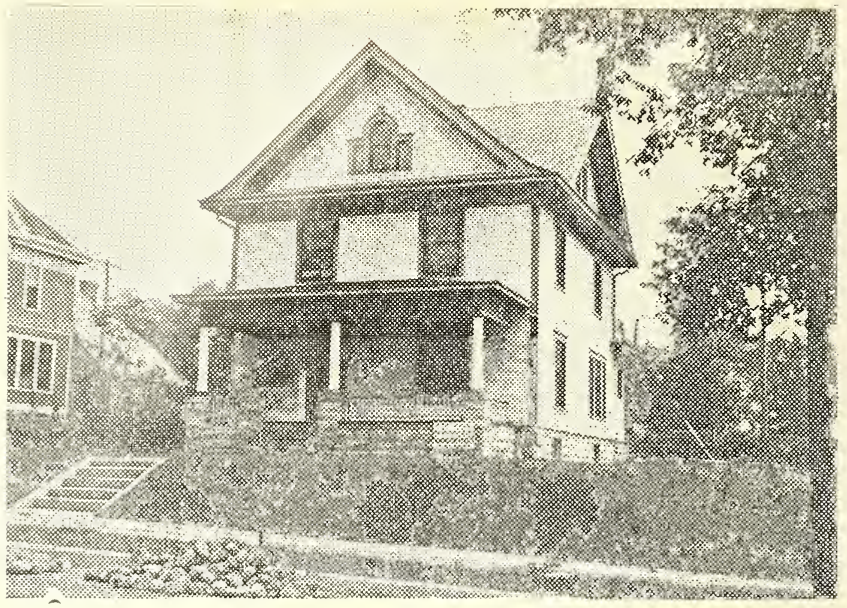

A Substantial Home-No. 947

Width, $26 \mathrm{ft.}$; depth $30 \mathrm{ft}$., over the main part. A good practical and economical plan for an eight-room house. The rooms are well arranged and open up nicely together. If one desires, the living and reception rooms can be made one large room by leaving out the partition between them. First story $9 \mathrm{ft}$, second story $8 \mathrm{ft}$. Birch floors throughout. Birch, red oak, or gum finish in first story and pine to enamel in second story. Cost to build, $\$ 3,400$. One set of plans and specifications for $\$ 25.00$.
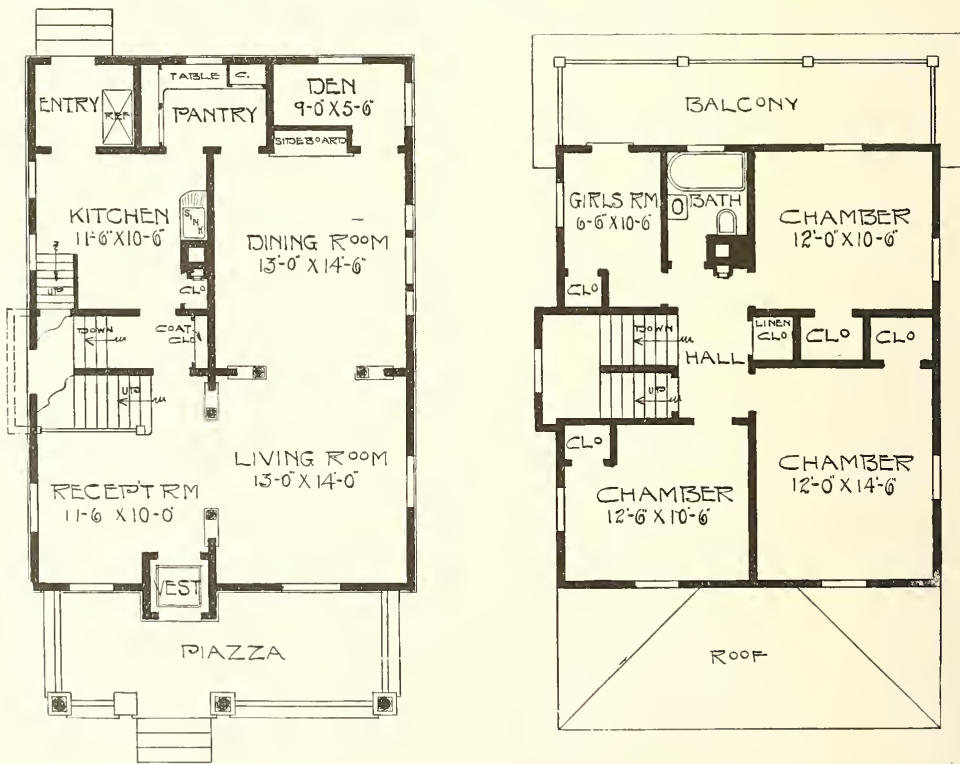

Complete plans and specifications for using Denison Load-Bearing Tile, licensed under Wilson-System Bearing $W$ a 11 Construction for $\$ 50$. 


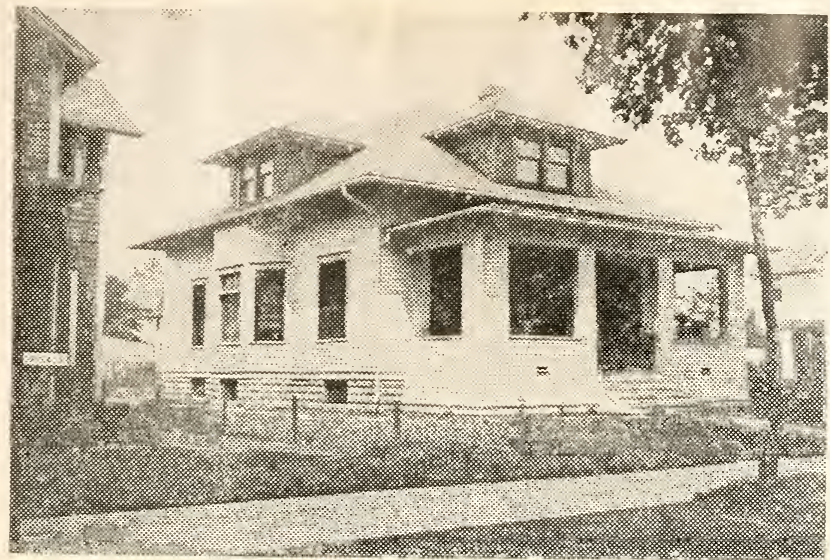

A Bungalow Home-No. 948

Built 40 times in the U. S. A. Width, $28 \mathrm{ft}$; depth, $36 \mathrm{ft}$. A complete bungalow home, having all the requirements and conveniences that are found in a two-story house, all arranged on one floor so that the housework is reduced to a minimum. There is room in the second story for two or three fair sized rooms. The estimated cost does not include the finishing up of the second story. First story finished in gum, birch or red oak, birch or maple floors throughout first floor. A full basement, $7 \mathrm{ft}$. deep. First story $9 \mathrm{ft}$. Cost to build, $\$ 2,000$. One set of plans and specifications for $\$ 16$.

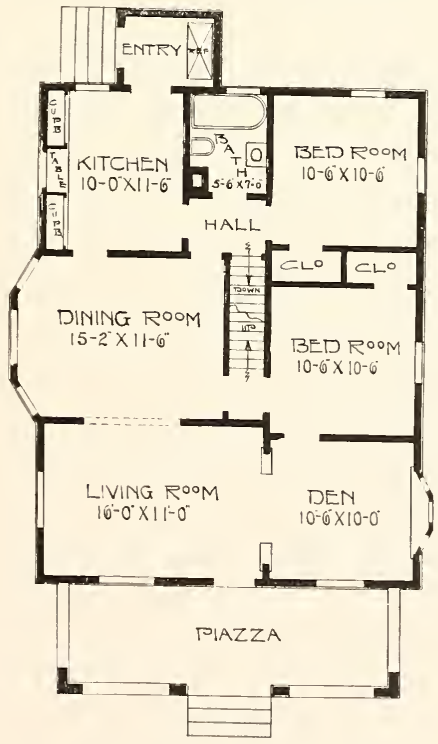

Complete plans and specifications for using Denison Load-Bearing Tile, licensed under Wilson-System Bearing IV a 11 Construction for $\$ 32$. 


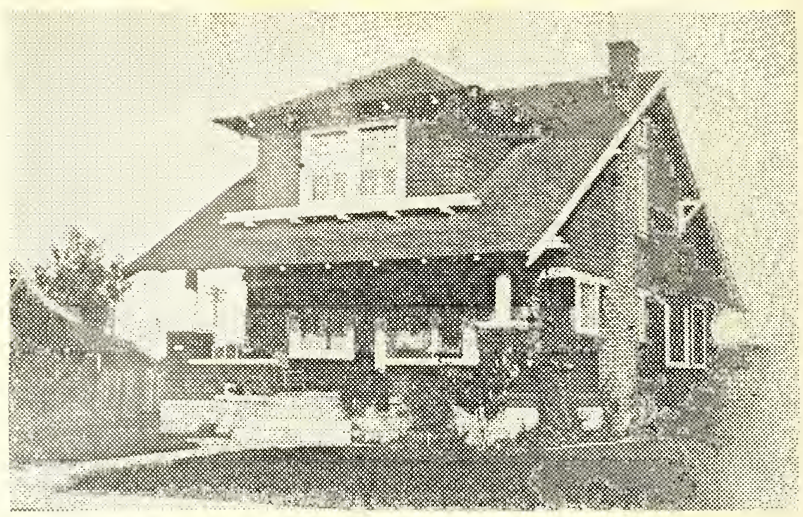

A Home-No. 937

Width 26 feet, depth 28 feet over the main part. Another of the bungalow type of story-and-a-half cottage, all of whose rooms are full height, first story 9 feet and second story 8 feet. The dining room has a beamed ceiling and paneled wainscoting. Gum or red oak finish in the first story and pine to paint in second. Cost to build, $\$ 3,200$. Complete set of plans and specifications for $\$ 25$.
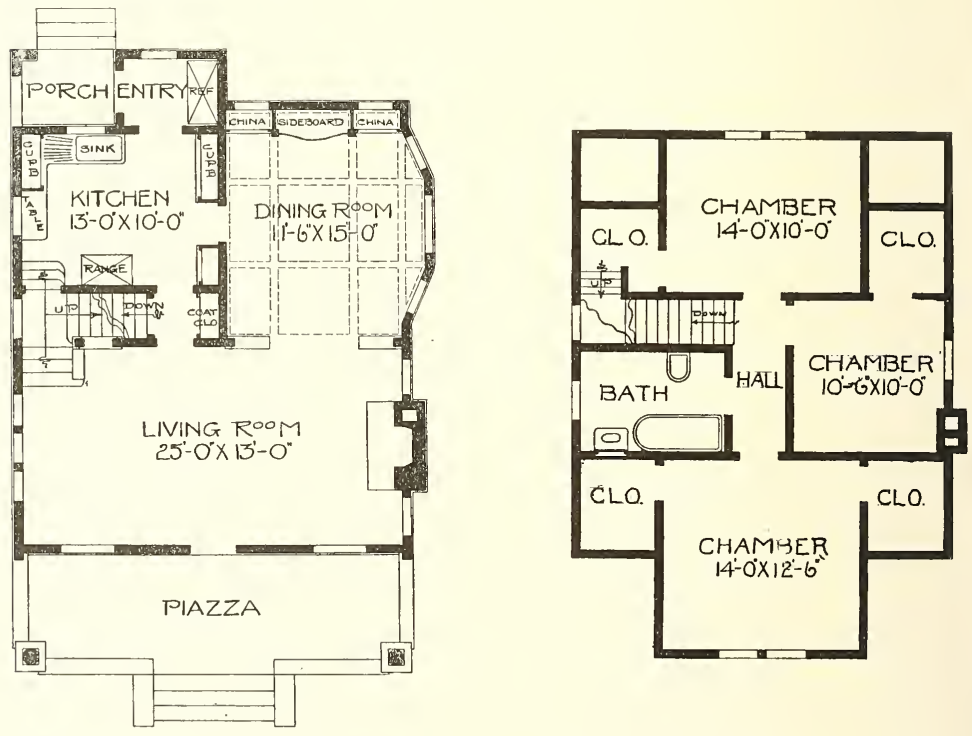

Complete plans and specifications for using Denison Load-Bearing Tile, licensed under Wilson-System Bearing Wa 11 Construction for $\$ 50$. 


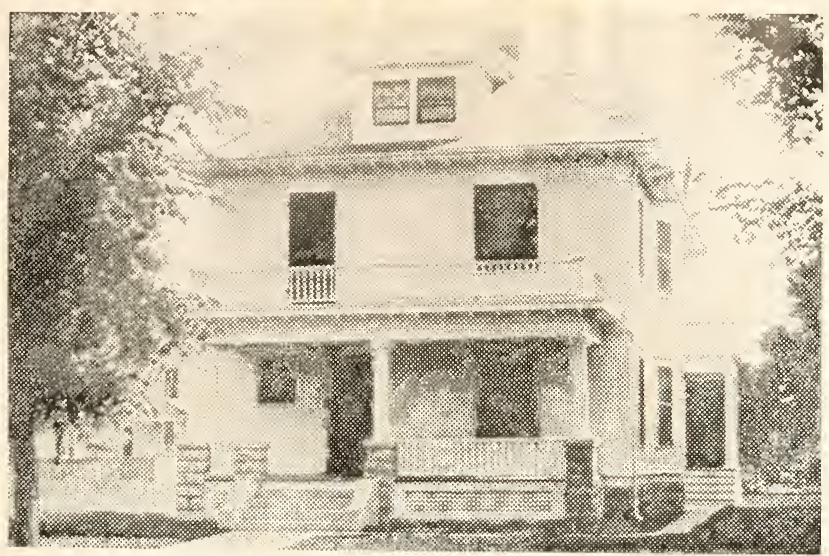

A Practical Duplex-No. $\$ 95$

I believe this duplex has been built in a number of states, even as far south as Miami, Fla, If you want a good practical plan and a $15 \%$ investment, here is just the plan you want. Birch or maple floors throughout, finish in each duplex, gumwood, birch or southern cypress. Size 26 feet wide, 48 feet deep. Cost to build, $\$ 4,600$. Complete set of plans and specifications, $\$ 25$.

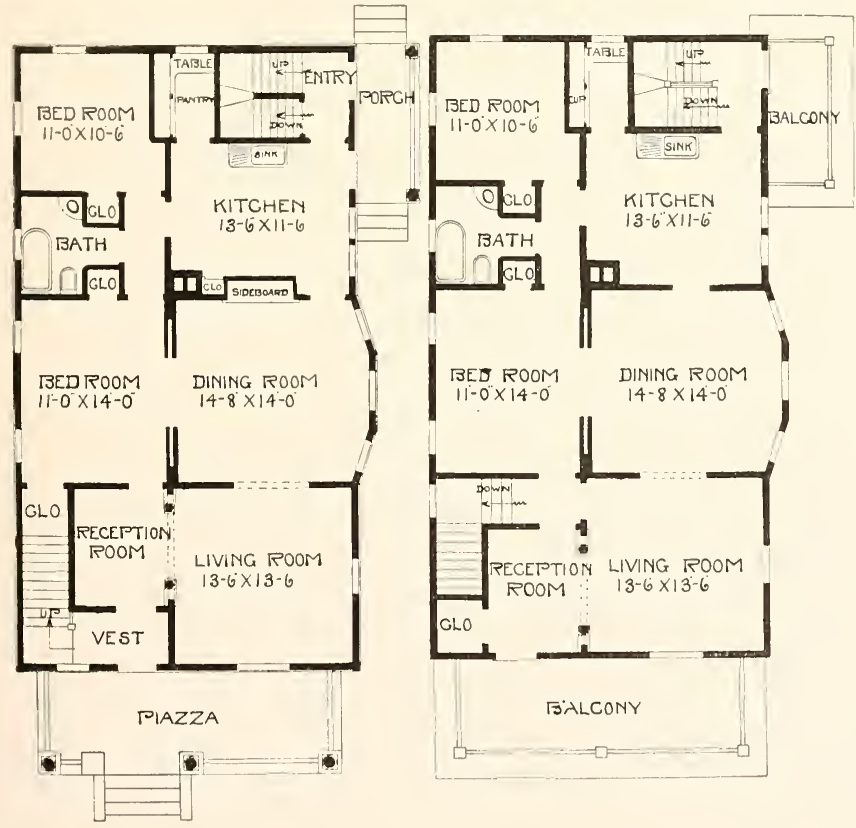

Complete plans and specifications for using Denison Load-Bearing Tile, licensed under Wilson-System Bearing $\mathrm{W}$ a 11 Construction for $\$ 50$. 


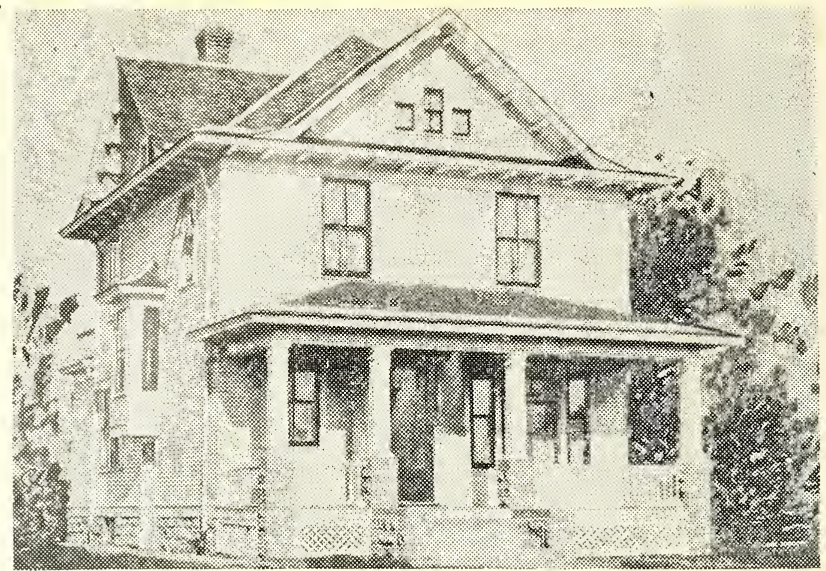

A Practical and Sensible Home-No. 932

Width 26 feet, depth 30 feet, over the main part. A feature found in many good homes is the large living rooms across the front of the house, one large livable room. It increases the beauty and apparent size of the whole interior. The first story is finished in red oak, gum, or birch if desired, and the second story in pine to enamel with birch floors on both. There is a full 7 -foot basement. The first story is 9 feet high, and the second 8 feet. Cost to build, $\$ 3,050$. Plans and specifications, $\$ 25$.

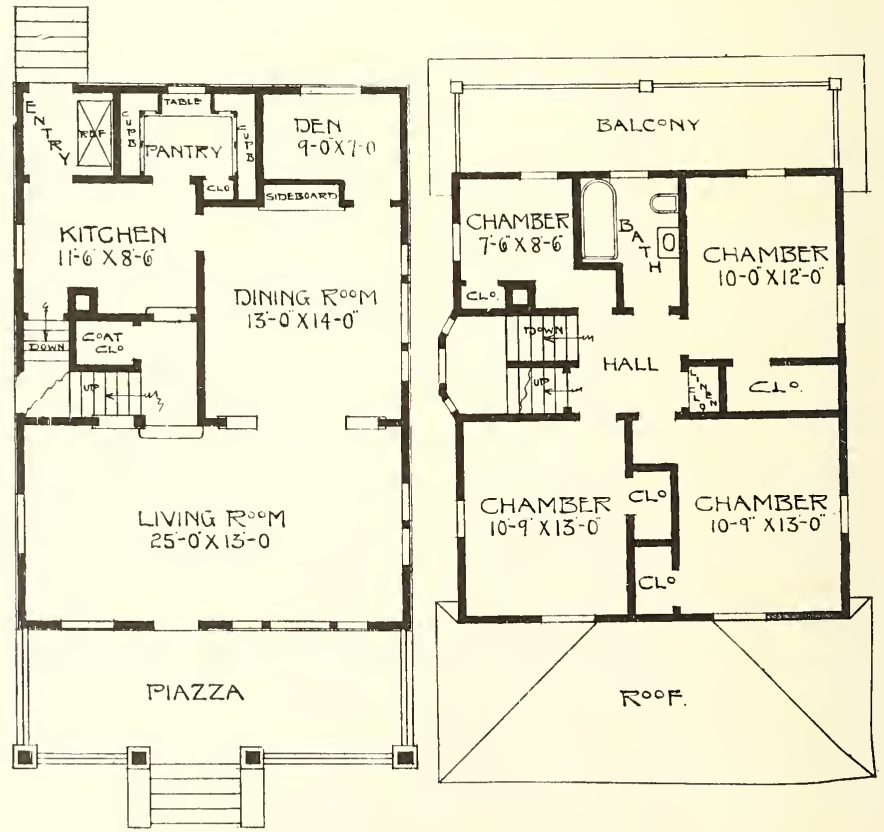

Complete plans and specifications for using Denison Load-Bearing Tile, licensed under Wilson-System Bearing W a 11 Construction for $\$ 50$. 


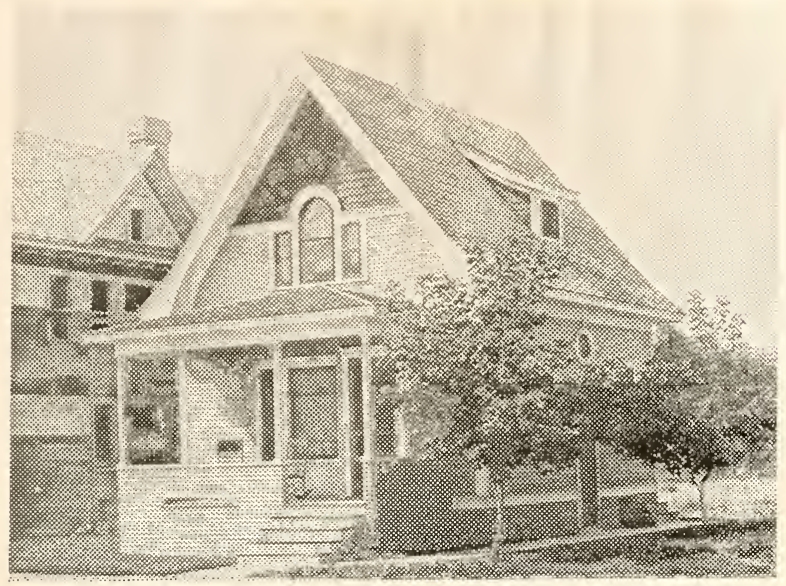

A Cozy Home-No. 870

The rooms, though not numerous, are of ample size and conveniently laid out. Size is 20 feet 6 inches by $2+$ feet 6 inches. Finished in gum or birch. Cost to build, $\$ 1,350$. Complete plans and specifications for $\$ 10$.

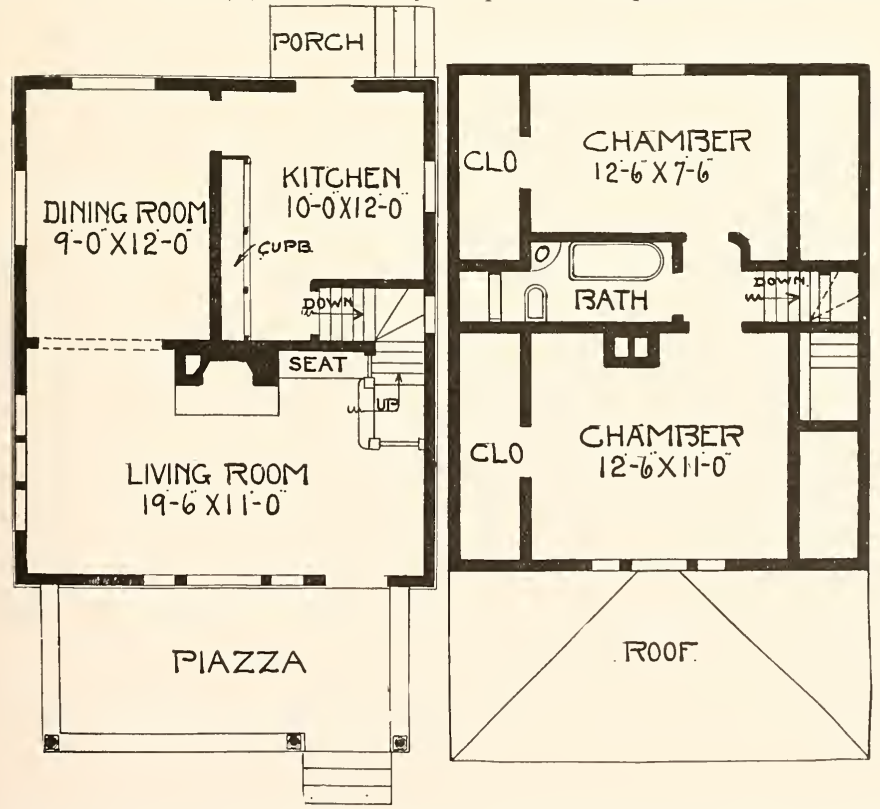

Complete plans and specifications for using Denison Load-Bearing Tile, licensel under Wilson-System Bearing Wall Construction for $\$ 20$. 


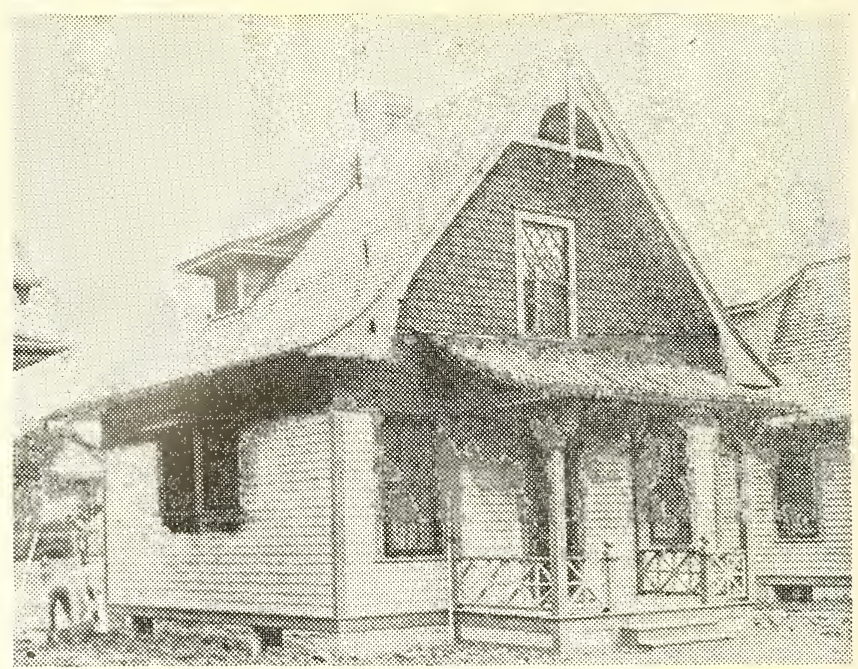

Just a Shack-No. 13

It is designed to have hardwood finish and floors down stairs with pine to paint in the second story. Height of ceiling in first story, $8 \mathrm{ft} .8 \mathrm{in}$, second story $8 \mathrm{ft}$. Size $20 \mathrm{ft} .6 \mathrm{in}$. by $24 \mathrm{ft}$., basement under one-half of house. Cost to build, $\$ 1,475$. Complete

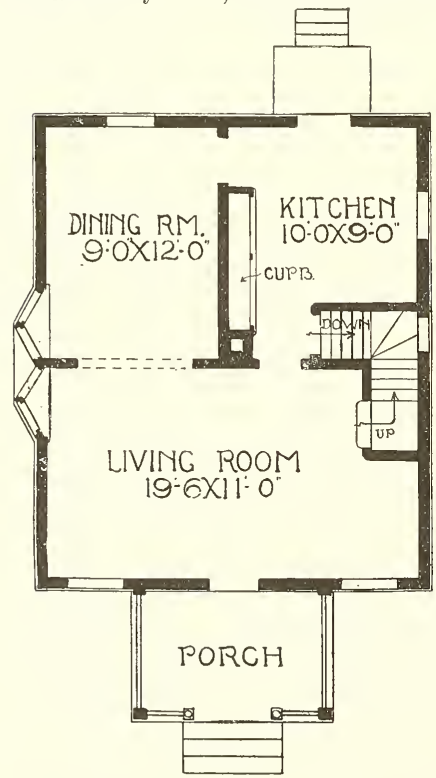
set of plans and specifications for $\$ 10$.

Built 50 times.

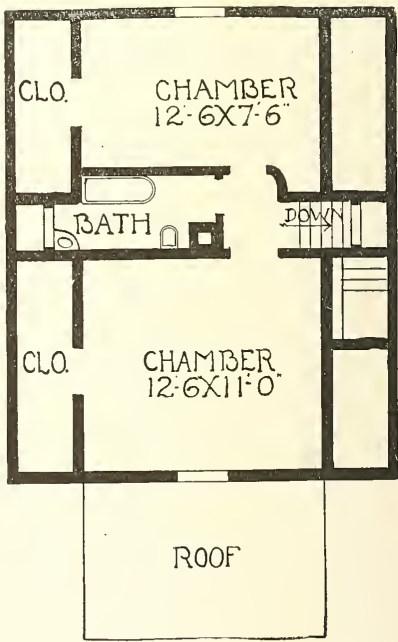

Complete plans and specifications for using Denison Load-Bearing Tile, licensed under Wilson-System Bearing Wa 11 Construction for $\$ 20$. 


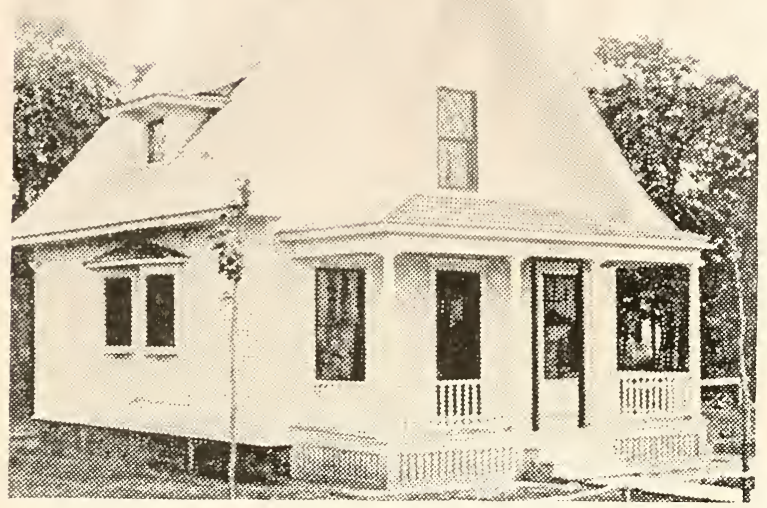

A Little White Cottage-No. 88

This cottage is $20 \mathrm{ft}$. 6 in. wide and $24 \mathrm{ft} .6 \mathrm{in}$. deep. Hardwood floors and pine to paint are used for finish throughout. The first story is $8 \mathrm{ft}$. $6 \mathrm{in}$. and the second $8 \mathrm{ft}$. in the clear. Cost to build, $\$ 1,375$. Complete plans and specifications for this cottage for $\$ 10$.
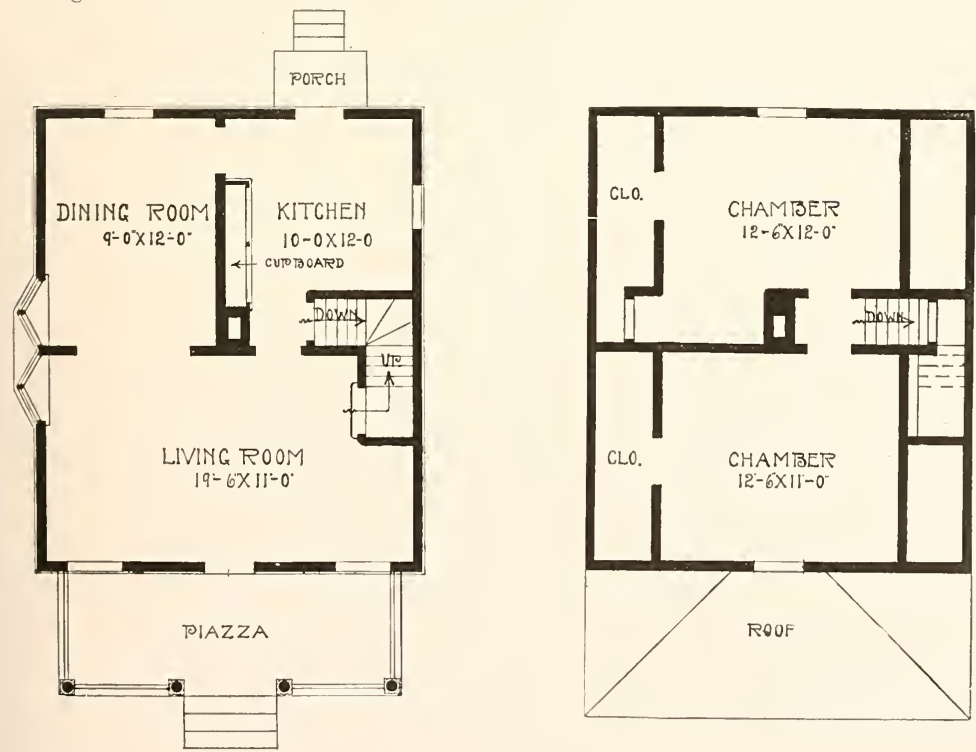

Complete plans and specifications for using Denison Load-Bearing Tile, licensed under Wilson-System Bearing W a 11 Construction for $\$ 20$. 


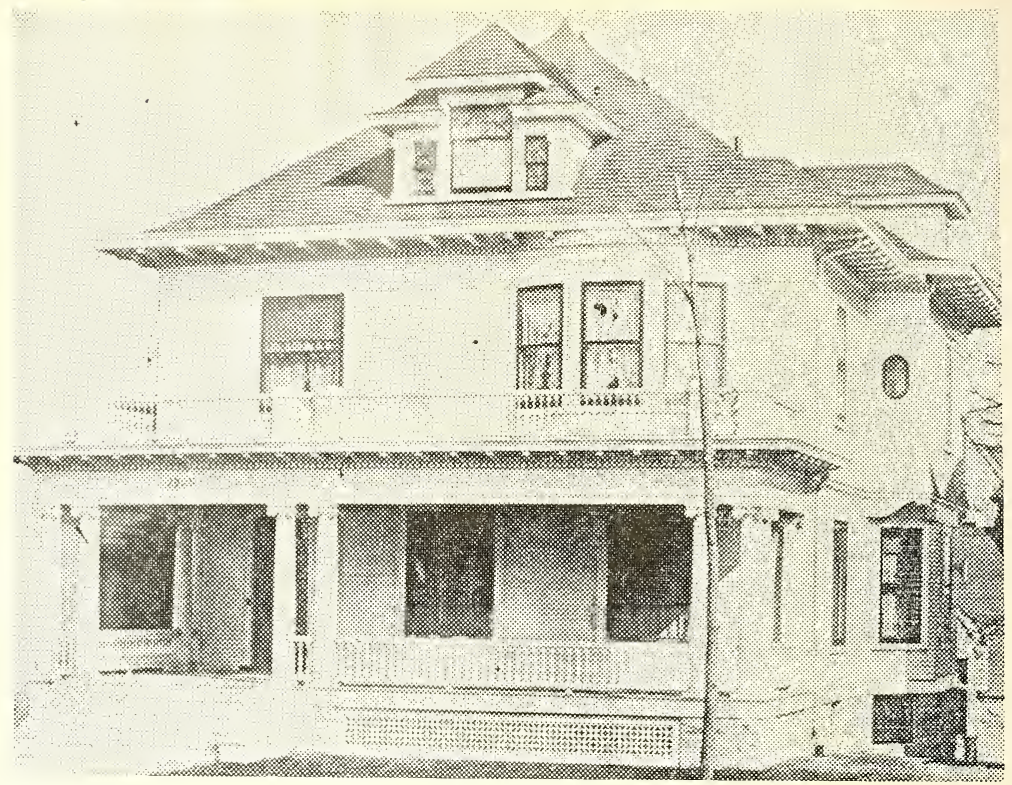

Very Good Colonial Design-No. 104

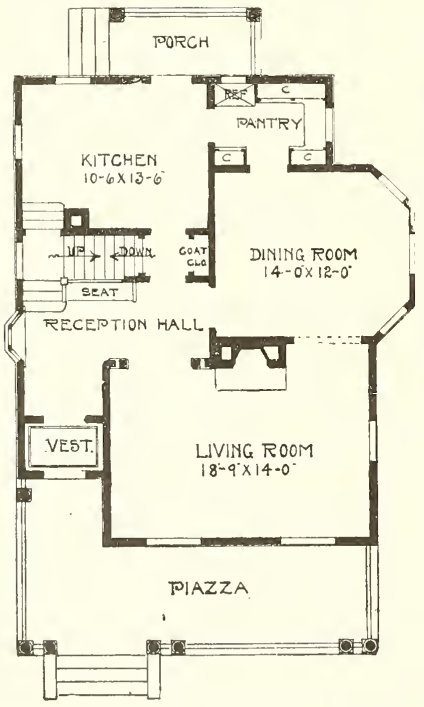

First story $9 \mathrm{ft}$., second story 8 ft. 6 n. $\mathrm{Size}$ $26 \times 34$ feet. First story finished in birch or gum a $n$ d second story in pine to paint. Cost to build $\$ 3,300$. Complete plans and specifieations for $\$ 25$.

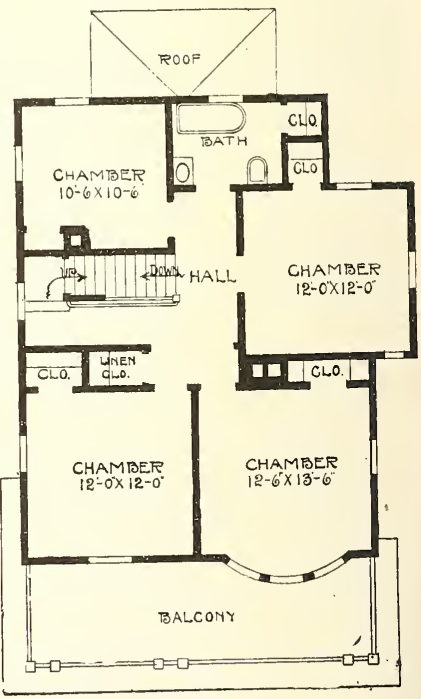

Complete plans and specifications for using Denison Load-Bearing Tile, licensed under Wilson-System Bearing W a 11 Construction for $\$ 50$. 


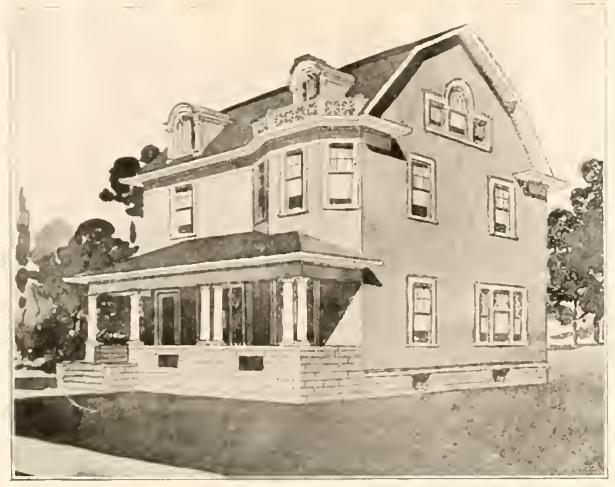

Something Quite Elegant About This House-No. 320

Here is a design that is very popular. Rooms large, well lighted and all connected with the reception hall. Front and rear stairs, beautiful open stairway in reception room. Four large chambers, unusually large closet space, bath room and closet for soiled linen opening out of same. Basement 7 feet, first story 9 feet, second story 8 feet 6 inches, space in attic to finish two or three rooms if desired. Built for a banker in Morris, Minn. Cost to build $\$ 3,600$. Complete set of plans and specifications for $\$ 25$.
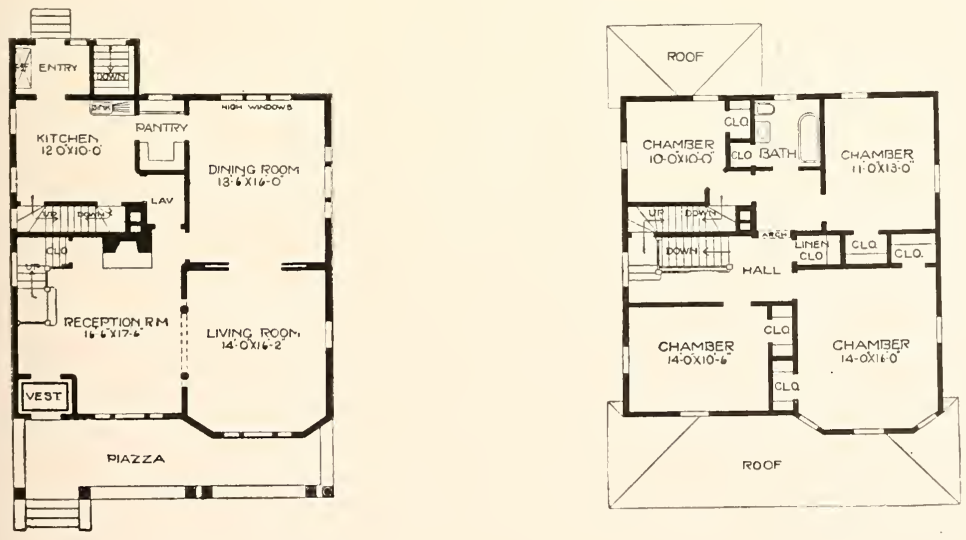

Complete plans and specifications for using Denison Load-Bearing Tile, licensed under Wilson-System Bearing $W$ a 11 Construction for $\$ 50$. 


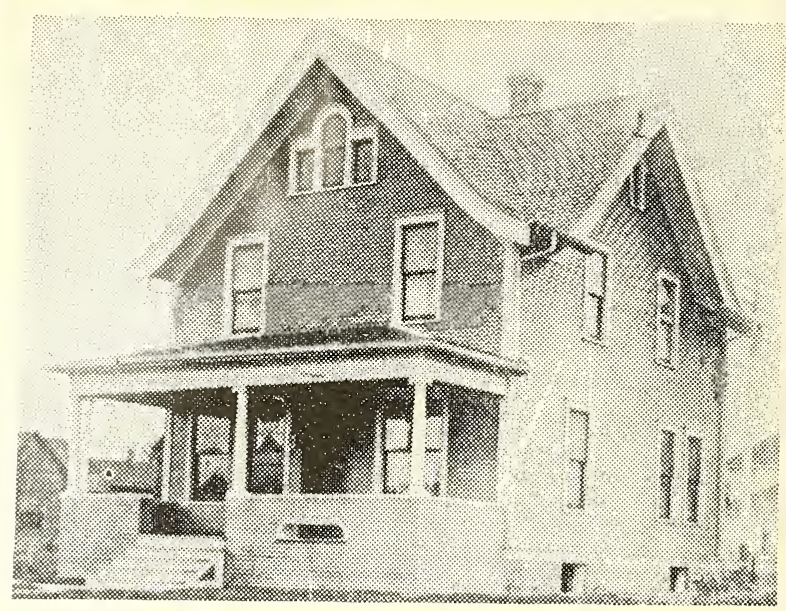

Built in Twelve Differcnt States-No. 92

Size $24 \mathrm{ft}$. wide and $26 \mathrm{ft}$. deep. There is a full basement $7 \mathrm{ft}$. high; first story 9 $\mathrm{ft}$., second story $8 \mathrm{ft}$. Also have this plan size $26 \times 28 \mathrm{ft}$. Cost to build, $\$ 2,200$. Complete set of plans and specifications for $\$ 15$. Plans for $26 \times 28 \mathrm{ft}$. $\$ 20$.
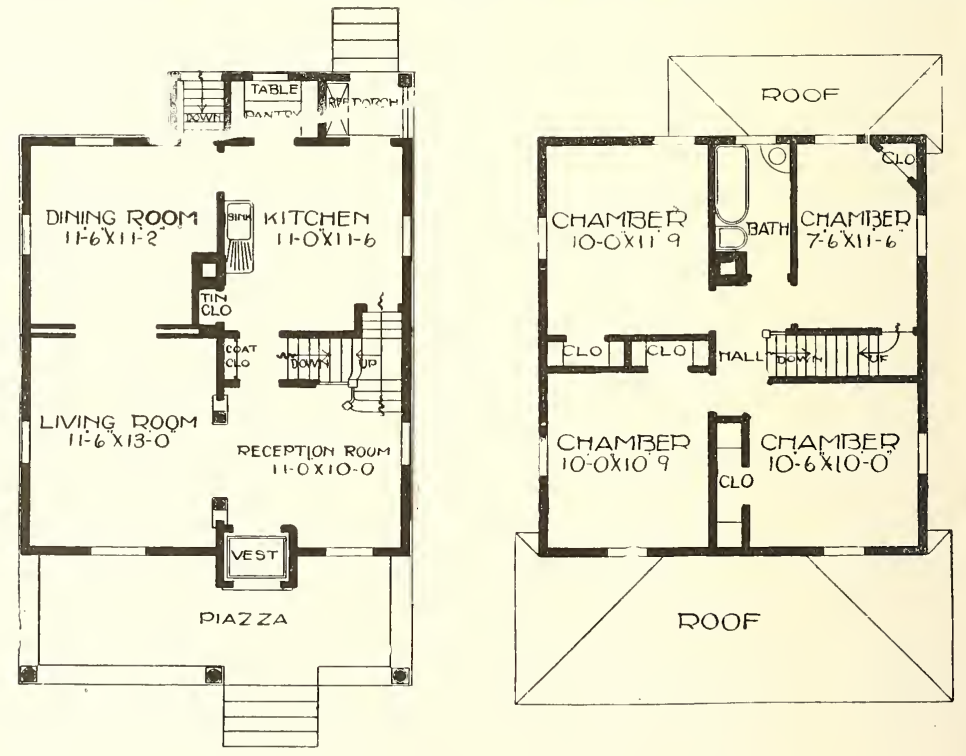

Complete plans and specifications for using Denison Load-Bearing Tile, licensed under Wilson-System Bearing $W$ a 11 Construction for $\$ 40$. 


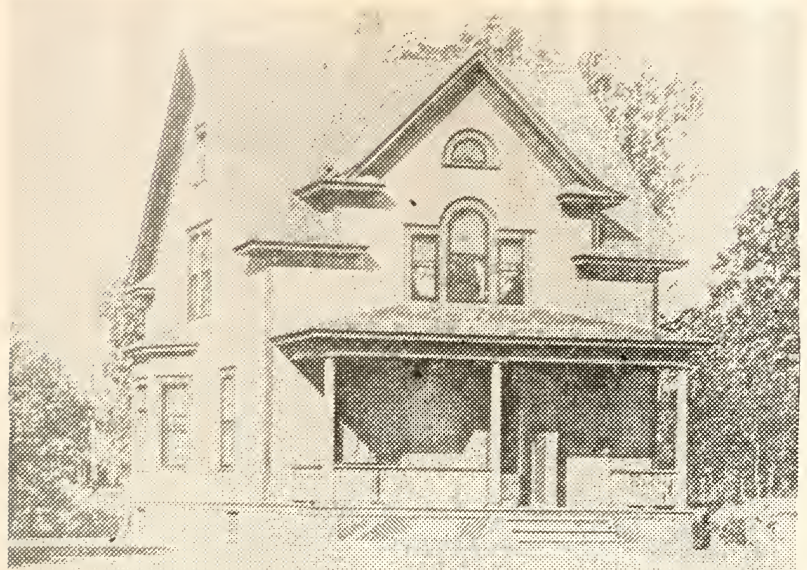

A Home-No. 946

Width $24 \frac{1}{2}$ feet, depth 32 feet. A most desirable cottage of seven rooms, a den and a large bath. It has all the appearances of a home and all the comforts, too. First story $9 \mathrm{ft}$., second story $\mathrm{S} \mathrm{ft}$. A full $\mathrm{t} \mathrm{ft}$. basement. Finish in first story birch, red oak, or gum, in second story pine to enamel. Birch floors in both stories. Cost to build, $\$ 2,200$. One set of plans and specifications for $\$ 15$.
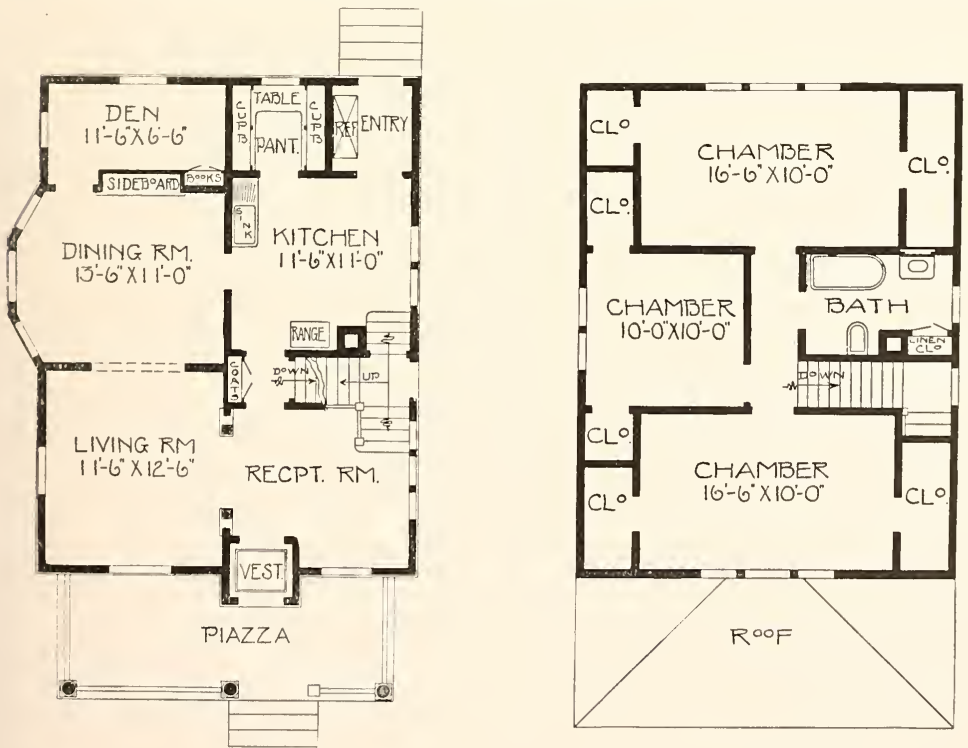

Complete plans and specifications for using Denison Load-Bearing Tile, licensed under Wilson-System Bearing W a 11 Construction for $\$ j 0$. 


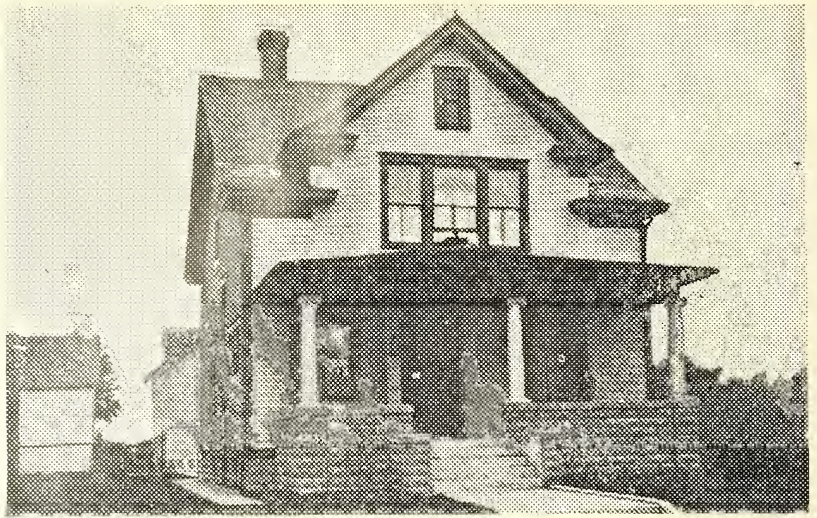

A Home of Comforts-No. 945

Width $241 / 2 \mathrm{ft}$, depth $32 \mathrm{ft}$. For economy of space and conveniences offered, this arrangement of rooms cannot be excelled. Although the living room and reception room are only of moderate size, thrown together as they are by a columned archway, they make one splendid big living room. The den is a feature worthy of comment. It can be used as a library or a sewing room, the latter always appealing to housewives. The first story is finished in a choice of red oak, birch, or gum and the second story in pine to enamel. Birch floors throughout. Cost to build, $\$ 2,300$. One set of plans and specifications for $\$ 15$.
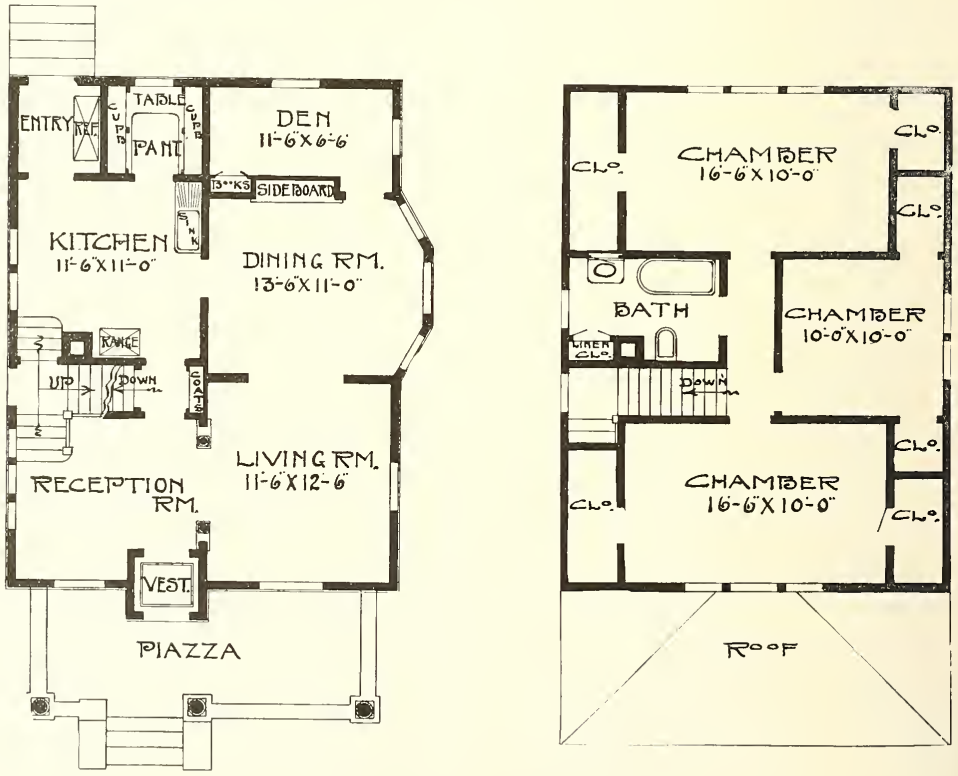

Complete plans and specifications for using Denison Load-Bearing Tile, licensed under Wilson-System Bearing Wa 11 Construction for $\$ 30$. 


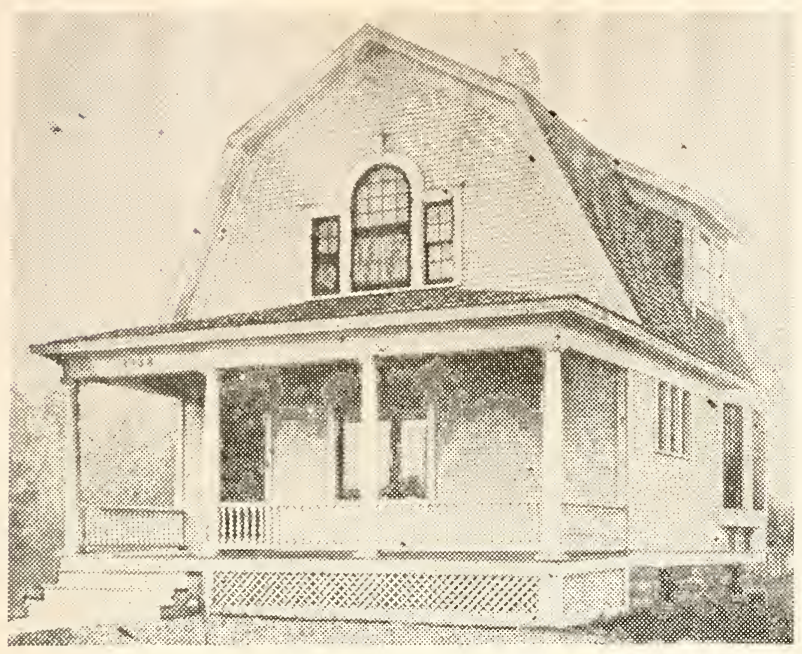

A Good Investment-No. 881

Width 22 feet, depth 24 feet. For economy and convenience in arrangement of rooms and attractiveness of exterior this plan cannot be excelled. First story 9 feet, second story $S$ feet. A full basement 7 feet deep. Birch or gum finish in first story, pine to paint in second and birch floors throughout. Cost to build, $\$ 1,750$. Complete set of plans and specifications for $\$ 13$.
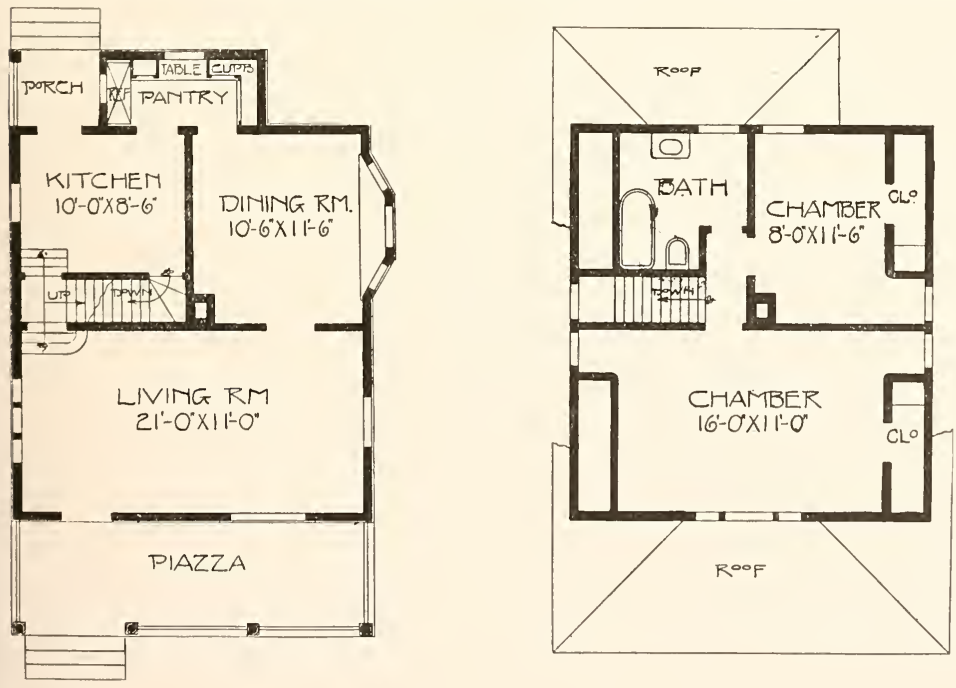

Complete plans and specifications for using Denison Load-Bearing Tile, licensed under Wilson-System Bearing IV a 11 Construction for $\$ 26$. 


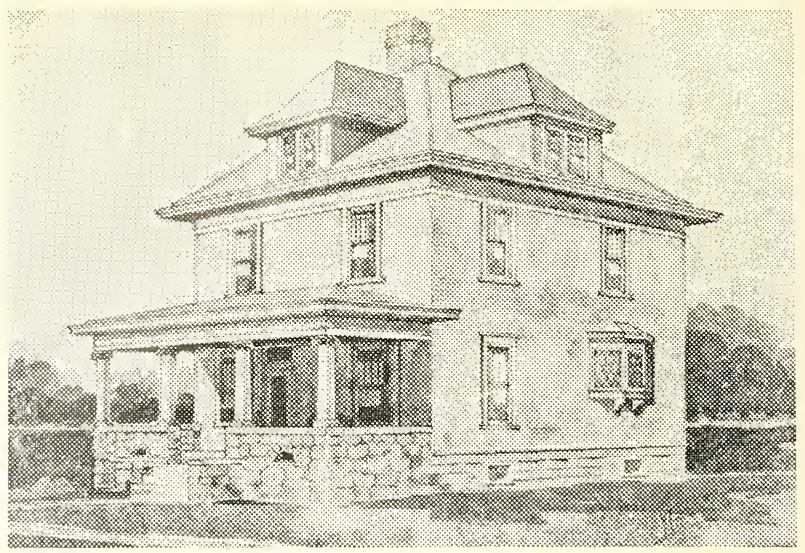

A Colonial Home-151

Cost to build, $\$ 3,000$. This price includes finishing the house throughout first story with white oak, birch or gum, beamed ceiling in dining room. Pine to paint in second story. Birch or maple floors throughout. Size 26x28; first story 9 feet, second story 8 feet, basement 7 feet in clear under the entire house. Complete plans and specifications for $\$ 25$.
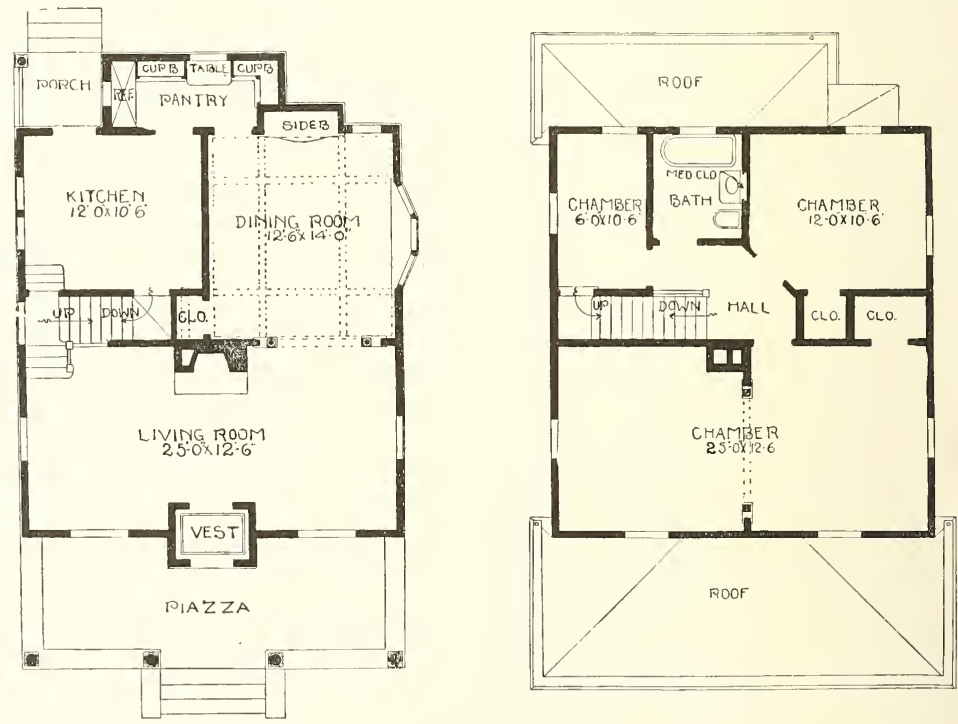

Complete plans and specifications for using Denison Load-Bearing Tile, licensed under Wilson-System Bearing W a 11 Construction for $\$ 50$. 


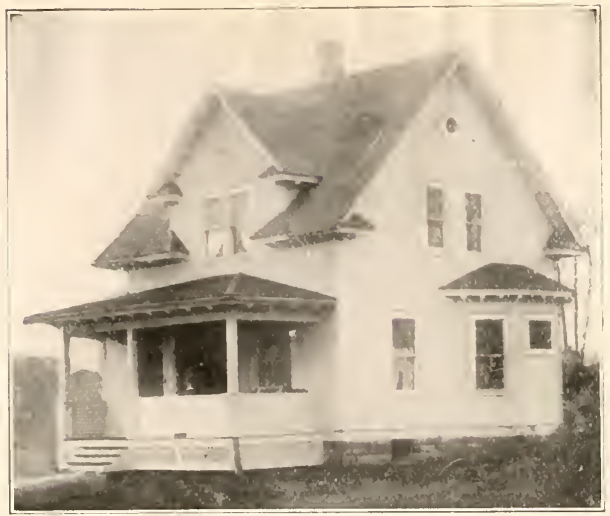

Cottage Home-No. 77

A splendid home for a small family. Sizes 26 feet wide, 26 feet deep, over the main part. First story 9 feet, second story 8 feet. Basement under whole house. All the rooms in the second story finish in the clear, the closets cutting off the low portion roof. First story finished with gum or birch, second story pine to paint. Birch or maple floors throughout. Cost to build, $\$ 2.075$. Complete set of plans and specifications for the mall sum of $\$ 15$.
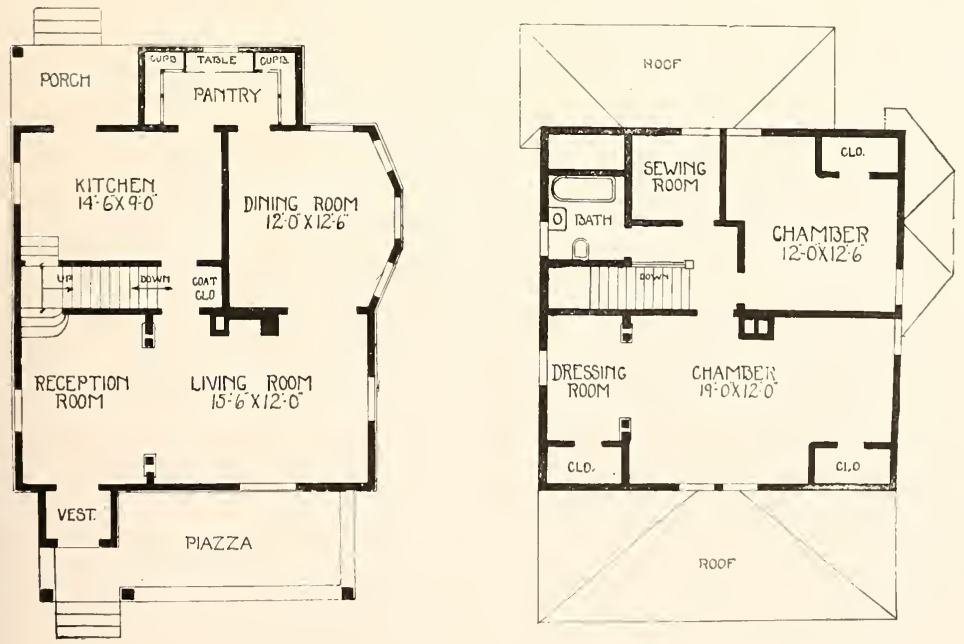

Complete plans and specifications for using Denison Load-Bearing Tile, licensed under WVilson-System Bearing $\mathrm{V}$ a 11 Construction for $\$ 30$. 


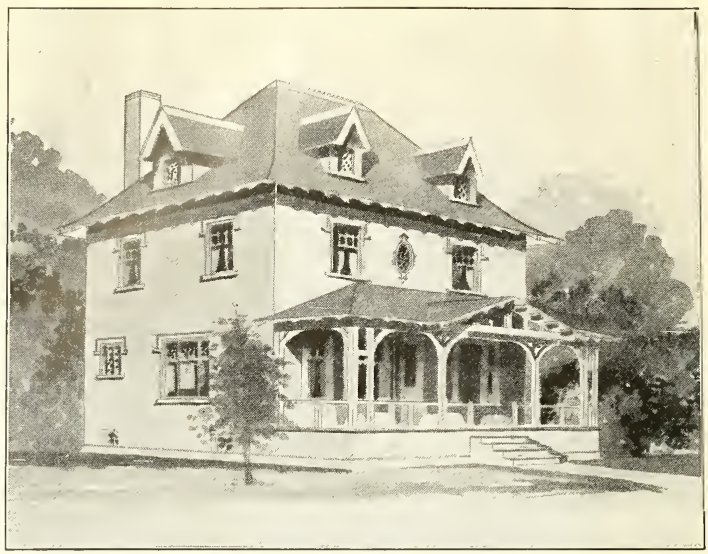

A Cement House-No. 317

Here is a beautiful cement house, built in the city of Minneapolis. Stories 9 feet in first story, second story 8 feet 6 inches, basement 7 feet. Basement under the whole house. Finish in first story gum or birch, second story pine to paint. Birch or maple floors throughout. This house was constructed for $\$ 3,250$. Complete plans and specifications for $\$ 25$.
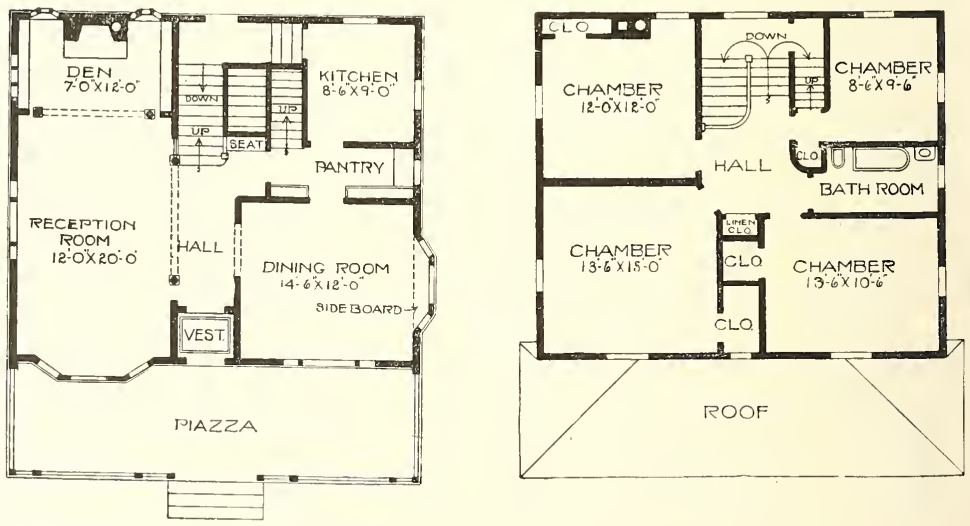

Complete plans and specifications for using Denison Load-Bearing Tile, licensed under Wilson-System Bearing $\mathrm{W}$ a 11 Construction for $\$ 50$. 


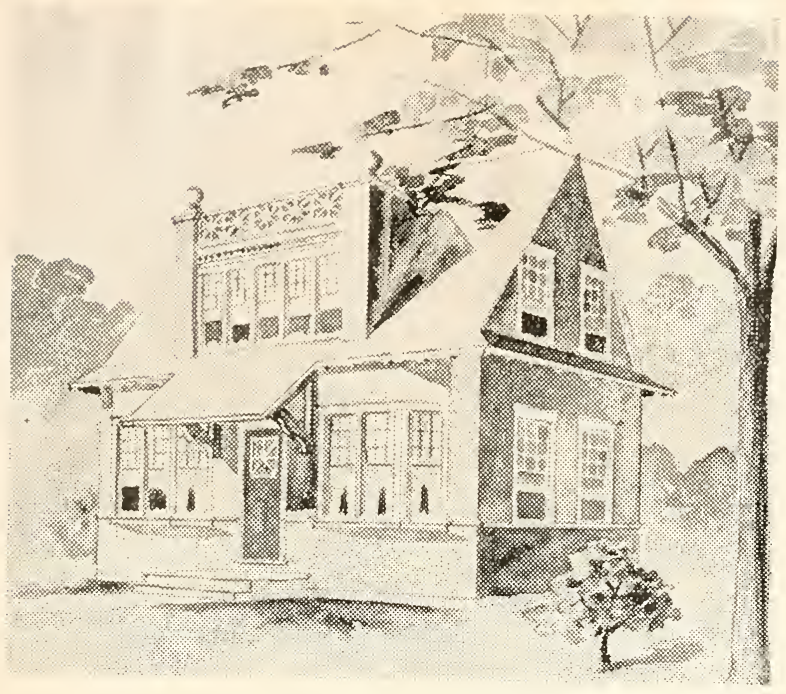

A Majestic Front-No. 367

This small design has been erected a number of times. The estimated cost is $\$ 1,100$. The main part is 28 feet wide and 17 feet deep, the kitchen portion 13 feet wide and 15 feet deep. The finish of this cottage is gum or birch in first story, pine to paint in second. Complete plans and specifications for $\$ 8$.
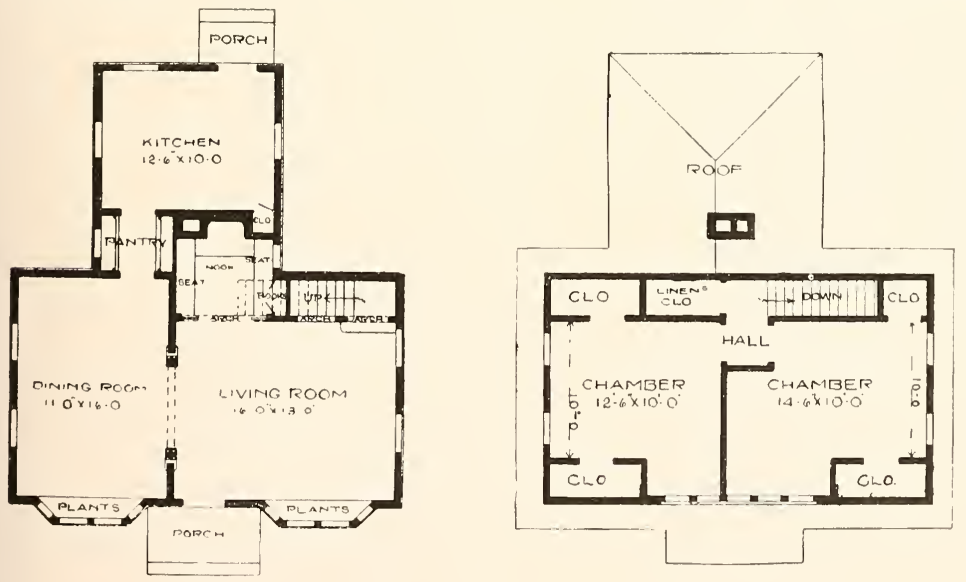

Complete plans and specifications for using Denison Load-Bearing Tile, licensed under Wilson-System Bearing $W$ a 11 Construction for $\$ 16$. 


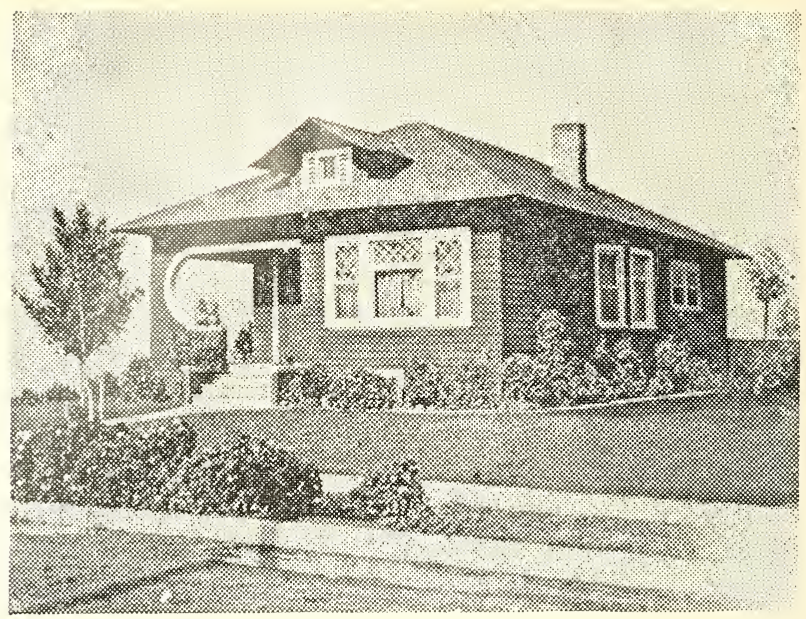

An Artistic Bungalow-No. 841

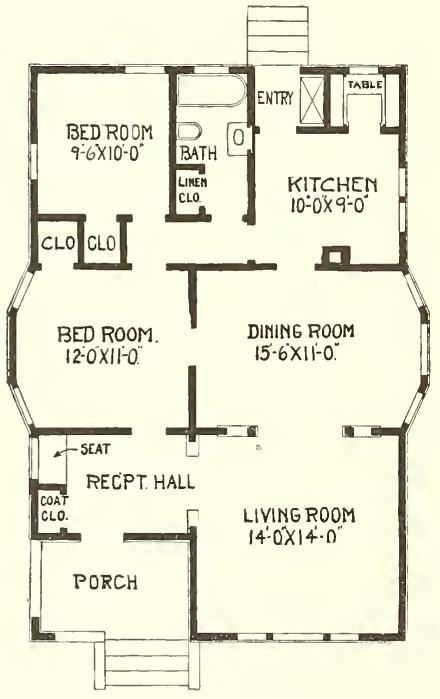

People who have been accustomed to living in flats will find themselves perfectly at home in a bungalow built after this plan. There are two fine bedrooms, besides a large living room, dining room, kitchen, also a small well arranged reception hall with coat closet and built-in seat.

There is, in my estimation, everything incorporated in this plan to make one's home complete.

Size, 26 feet wide and 40 feet deep over all. Cost to build, $\$ 1,900$. Complete plans and specifications for $\$ 15$.

Complete plans and specifications for using Denison Load-Bearing Tile, licensed under Wilson-System Bearing W a 11 Construction for $\$ 30$. 


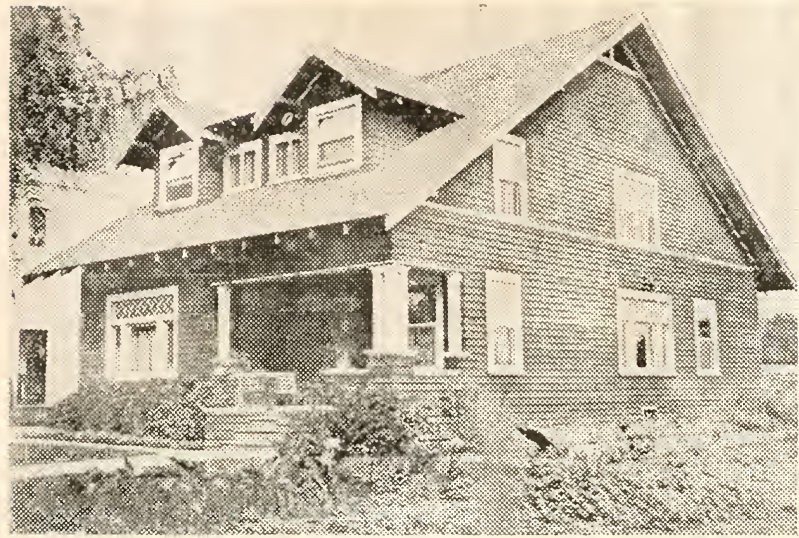

A Model Cottage Home-No. 844

Here is a very popular house to build, it has all the requirements to make a home complete in every respect. A special feature which I wish to call your attention to is the arrangement of the stairs. There is a combination stairs going up to the second story from the kitchen and living room. There is also a combination for going down to the basement and entrance to the kitchen. A full basement 7 feet deep. First story is 9 feet high, second 8 feet in the clear. Size of house 28 feet wide and 32 feet deep. Birch or gum finish and birch or maple floors. This is over a11. A house built after this design makes a splendid city or suburban home. Cost to build, $\$ 2,400$. Complete plans and specifications for $\$ 16$.
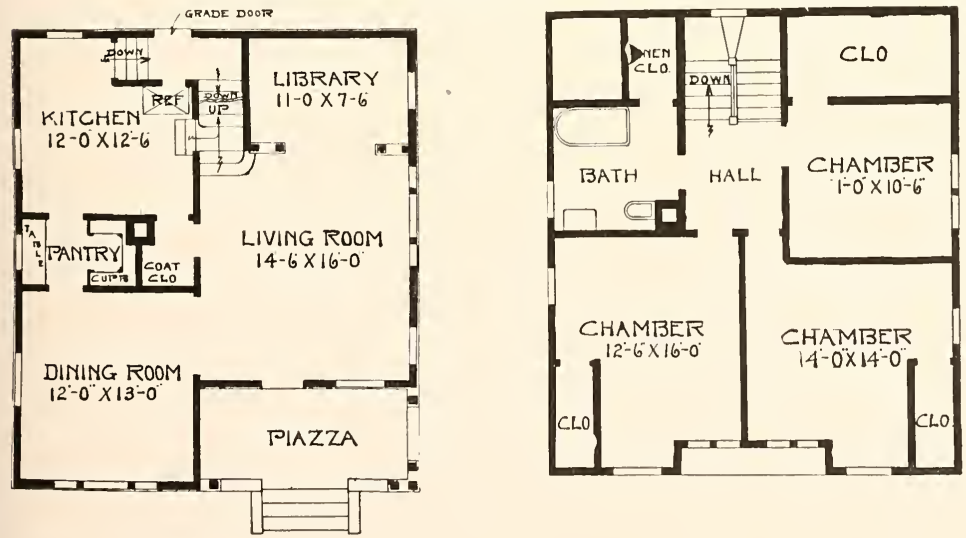

Complete plans and specifications for using Denison Load-Bearing Tile, licensed under Wilson-System Bearing $\mathbb{W}$ a 11 Construction for $\$ 32$. 


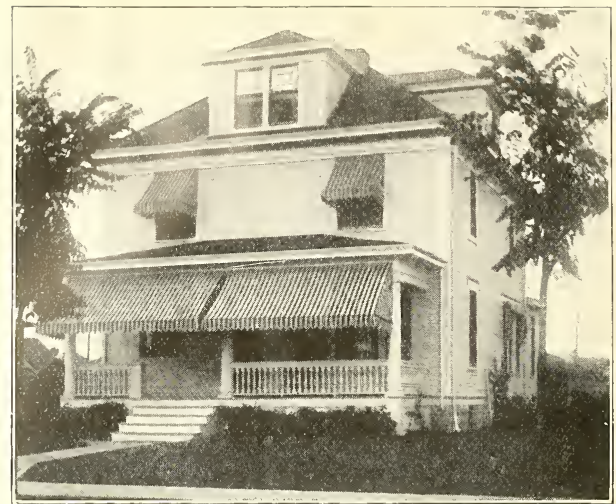

This is a Convenient Home-No. 232

The size of the house is 26 feet $\times 28$ feet. First story 9 feet, second story 8 feet 6 inches. Finish first story gum or birch, pine to paint in second. Birch or maple floors throughout. This house can be built in Minneapolis for $\$ 2,975$. Complete plans and specifications for this house for the sum of $\$ 25$.
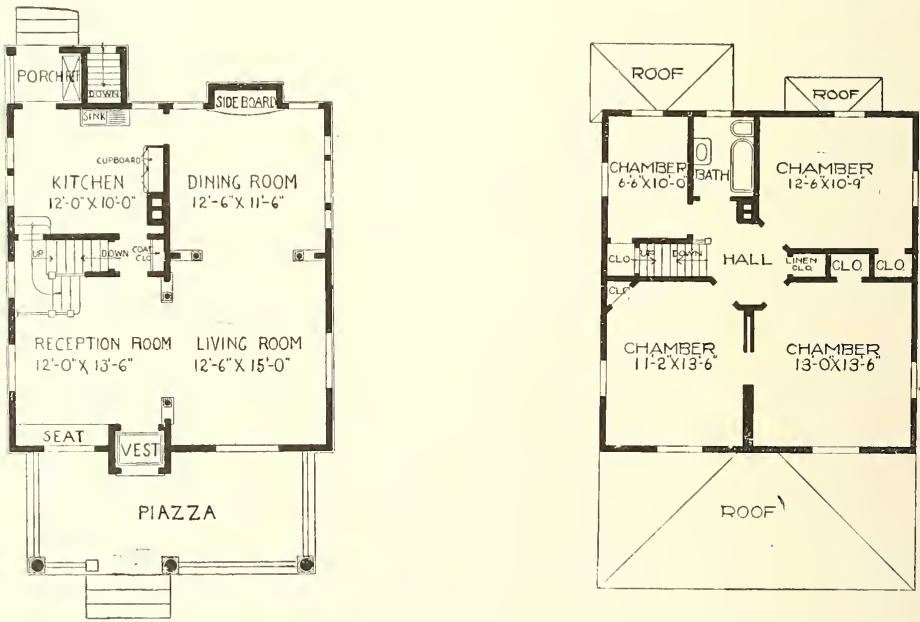

Complete plans and specifications for using Denison Load-Bearing Tile, licensed under Wilson-System Bearing $\mathrm{W}$ a 11 Construction for $\$ 50$. 


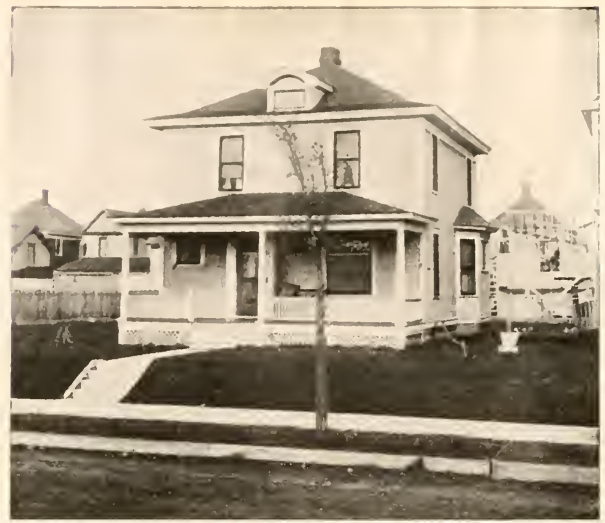

A Satisfactory Little Home-No. 307

Here is a house 24 feet $\times 26$ feet. First story 8 feet 6 inches, second story, 8 feet, basement 7 feet. These heights all in the clear. This is an unusually comfortable, economical house to build. Has been duplicated many times? Contains 8 nice rooms well arranged and lighted. Finish in first story to be birch or gum. Finish in pine throughout second story. Everyone who has built this house has been perfectly satisfied and say that there is no change that they would wish to make if they built again. Cost to build, $\$ 2,400$. Complete plans and specifications for the sum of $\$ 15$.

I also have this plan $26 \mathrm{ft} . \times 28 \mathrm{ft}$. First story $9 \mathrm{ft}$., second story $8 \mathrm{ft}$. Cost to build $\$ 2,700$. Complete plans and specifications, $\$ 20$.
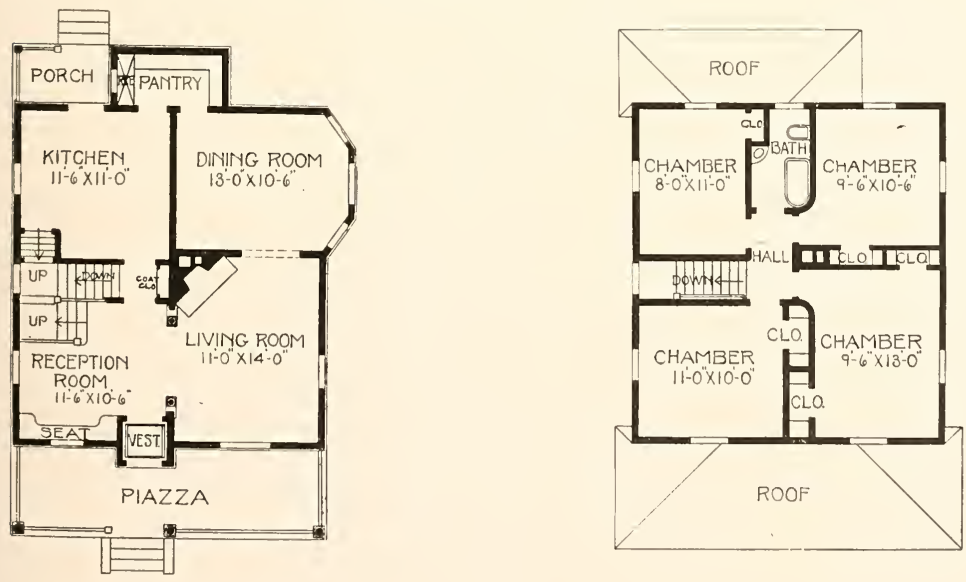

Complete plans and specifications for using Denison Load-Bearing Tile, licensed under Wilson-System Bearing II a 11 Construction for \$.t0. 


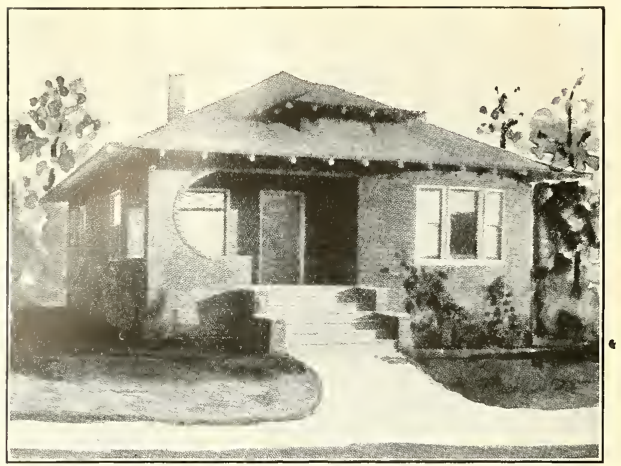

A Charming Bungalow-No. 5

Here is a beautiful example of a bungalow type, size 26 feet wide and 32 feet deep, basement under rear portion, ceiling 9 feet throughout, birch floors, hardwood finish. To be birch or gum. A cottage just for two. Cost to build with a bungalow finish, $\$ 800$. Cost to build as a winter residence, plastered and back plastered, finish complete, $\$ 1,200$. Complete plans and specifications for the same for $\$ 10$.

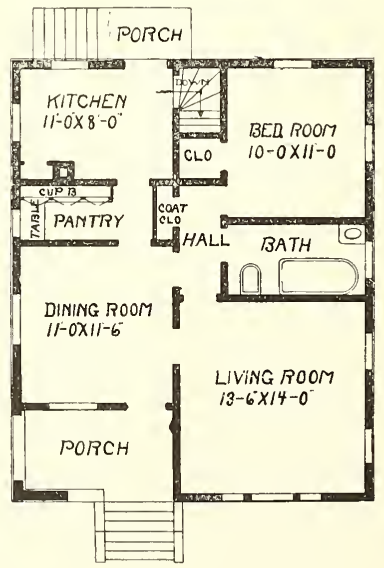

Complete plans and specifications for using Denison Load-Bearing Tile, licensed under Wilson-System Bearing Wa 11 Construction for $\$ 20$. 


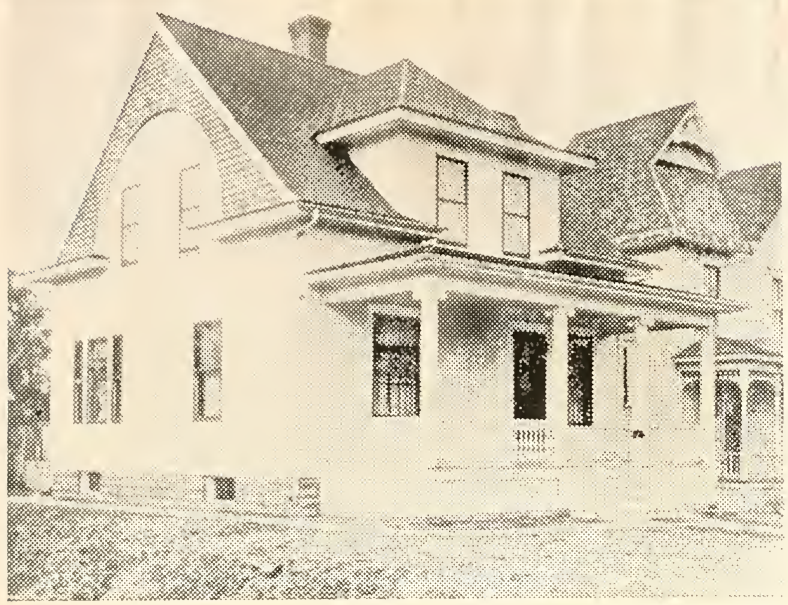

A Very Good Looking Cottage-No. 93

First story 9 feet, second story 8 feet. Basement 7 feet under the entire house. Hardwood floors throughout, hardwood finish in first story, to be gum or birch, pine to paint in second story. Size, 26 feet $\mathrm{x} 28$ feet long. Cost to build, $\$ 2,300$. Complete plan and specifications for $\$ 15$.

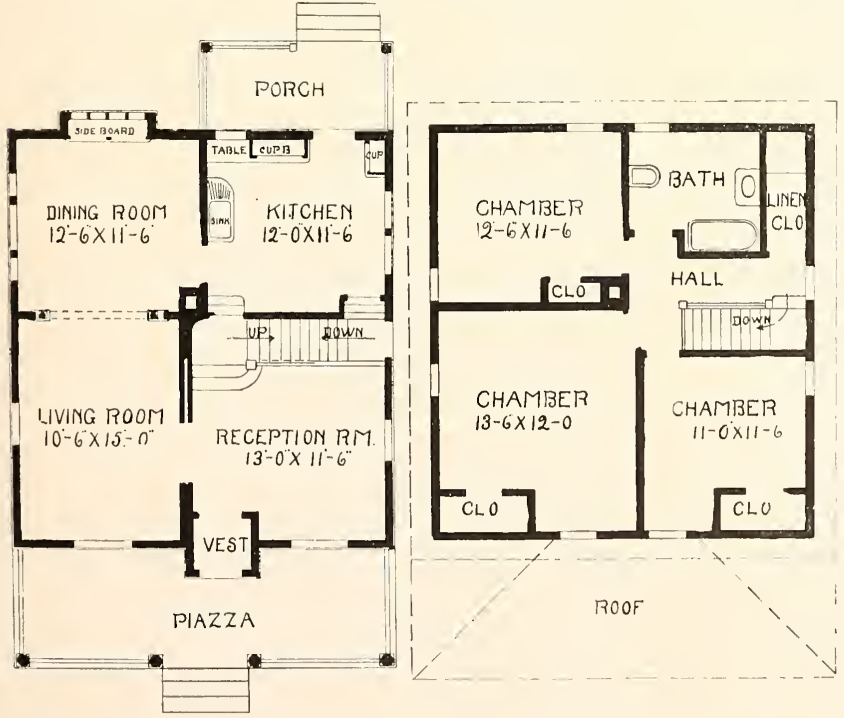

Complete plans and specifications for using Denison Load-Bearing Tile, licensed under Wilson-System Bearing $\mathrm{W}$ a 11 Construction for $\$ 30$. 


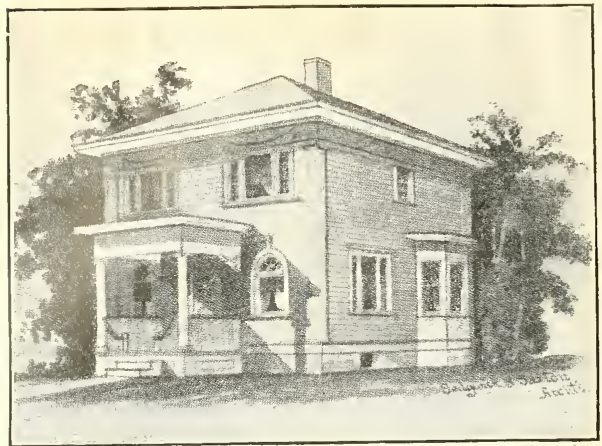

An Imposing Small House-No. 395

Width 22 feet, depth 26 feet. A full two-story house containing eight rooms, both stories being eight feet high. The exterior is treated excellently in "Colonial" style and the house has the appearance of being very much larger than it really is. Adjoining the living rooms is a room that can be used as either a library or bed room. The second story comprises four chambers each with a good closet and a bath room. The finish is birch or gum in the first story and pine to paint in the second story. A pleasing color effect could be obtained by painting the body of the house a cream color and the cornices, pilasters, porch, etc., white. Cost to build, $\$ 2,000$. Complete set of plans and specifications, $\$ 10$.
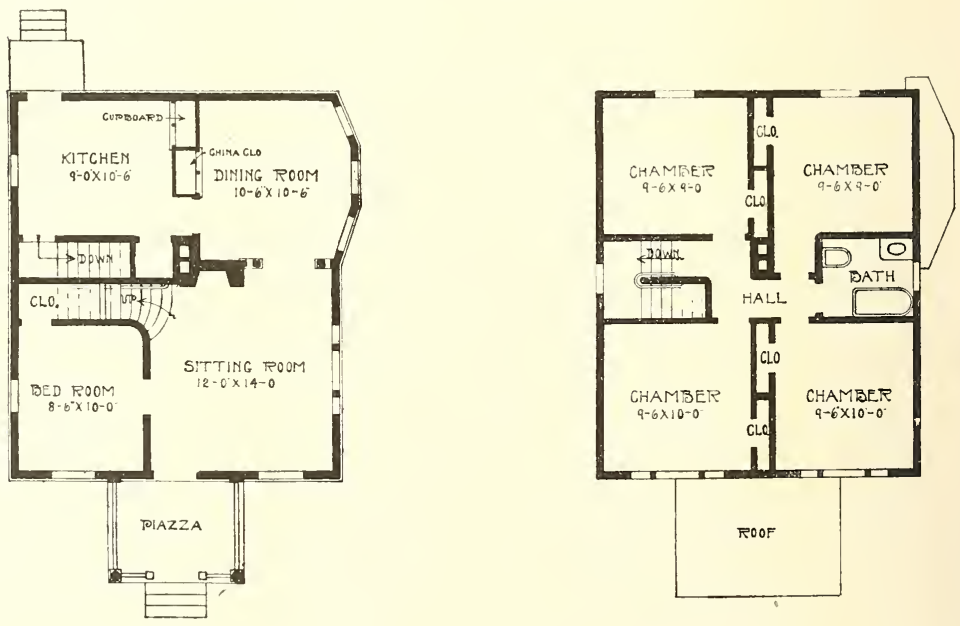

Complete plans and specifications for using Denison Load-Bearing Tile, licensed under Wilson-System Bearing IV a 11 Construction for $\$ 20$. 


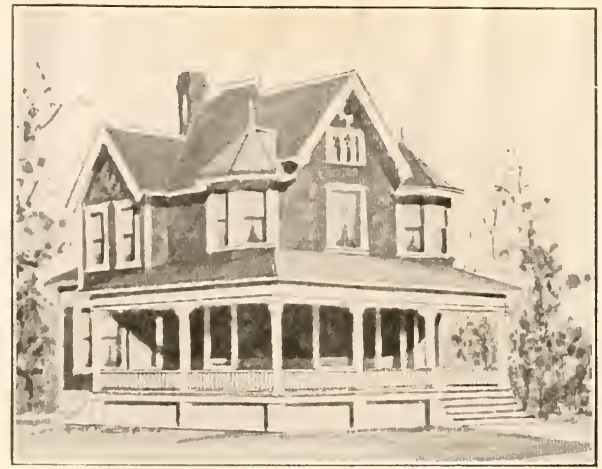

\section{A Good Design For Corner Lot-No. 341}

Width 30 feet, depth 47 feet. Height of stories, 9 feet and $81 / 2$ feet. An attractive design for an eight room house, plain, practical and economical. There is a spacious piazza, a vestibule, front and rear stairways. One large chimney provides flues for both the fire-place and kitchen range. First story finished in plain oak or gum and the second in pine to paint. Cost to build, $\$ 4,200$. Complete set of plans and specifications for $\$ 25$.
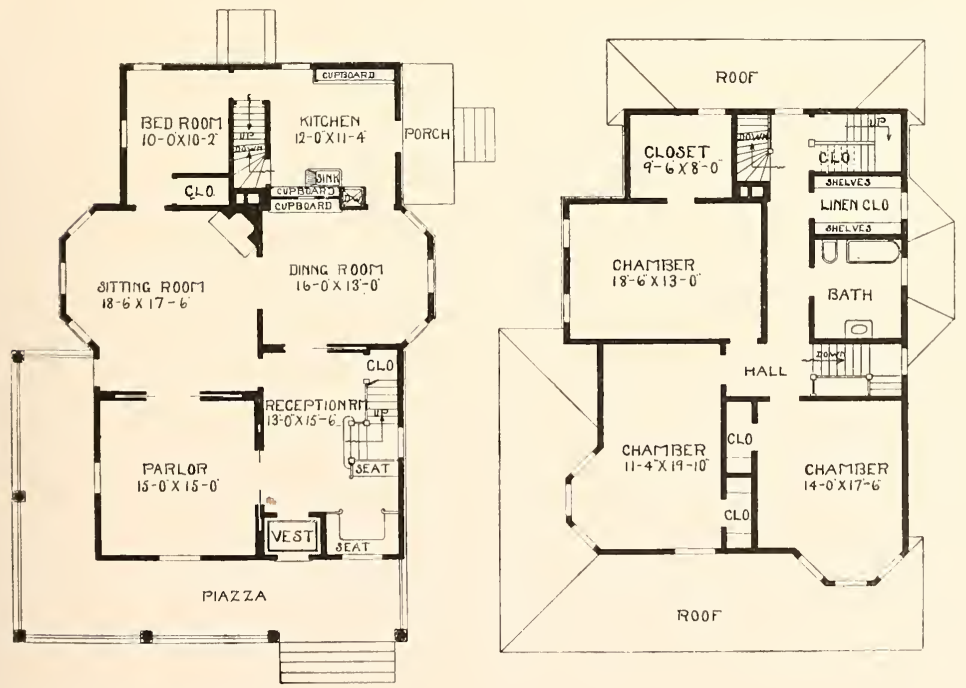

Complete plans and specifications for using Denison Load-Bearing Tile, licensed under WVilson-System Bearing IV a 11 Construction for $\$ 50$. 


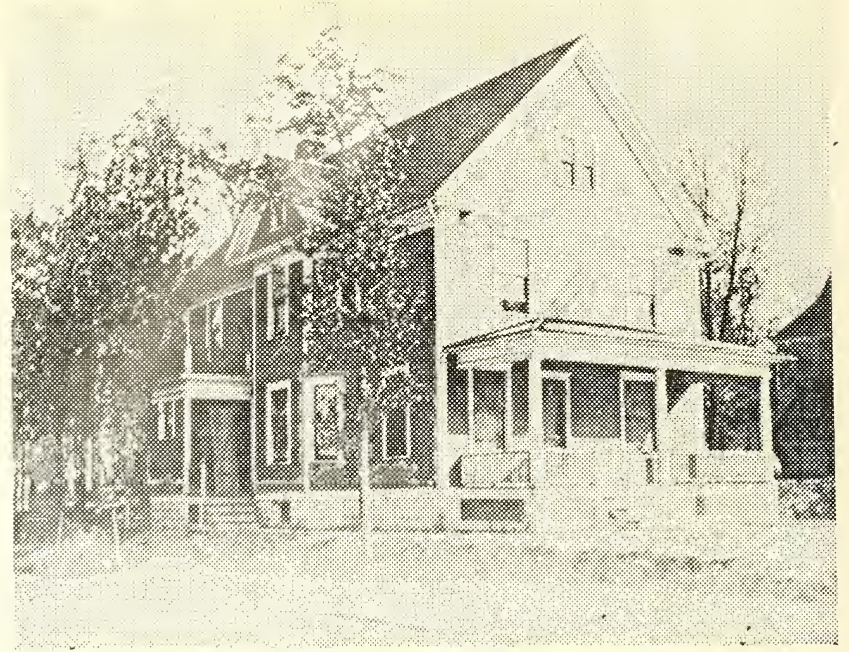

Very Commodious For Its Size-No. 6

Size 25 feet by 38 feet 6 inches over the main part; first story 9 feet, second story 8 feet 6 inches, and there is ample space for four nice rooms in attic if desired. Full basement under the entire house. Birch floors and birch or gum finish throughout first story, pine to paint in second story. Cost to build, $\$ 3,500$. Complete plans and specifications for $\$ 25.00$.

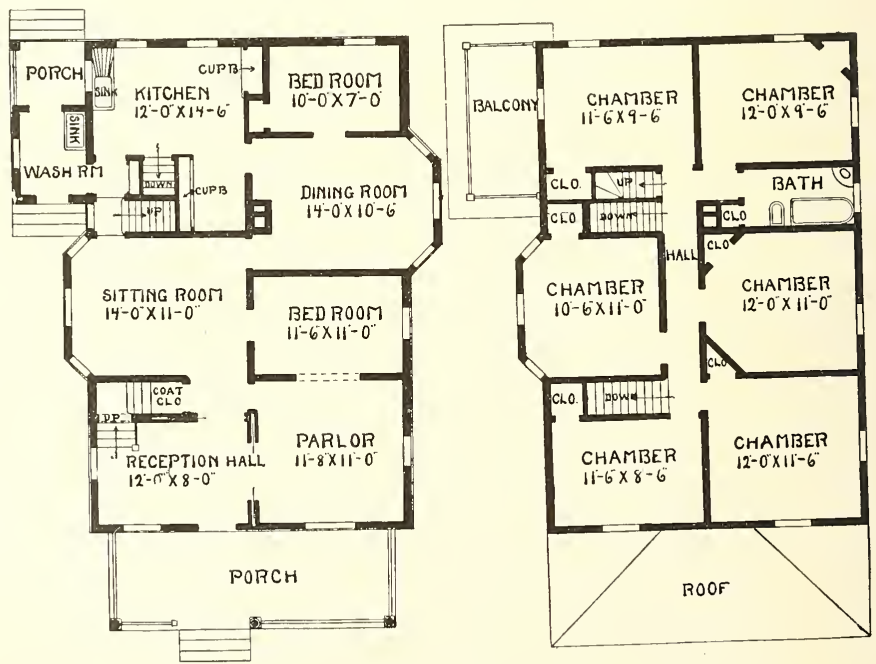

Complete plans and specifications for using Denison Load-Bearing Tile, licensed under Wilson-System Bearing Wa 11 Construction for $\$ 50$. 


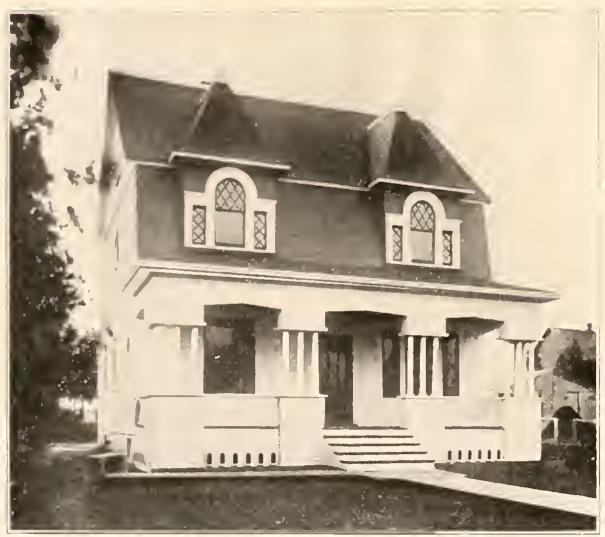

An Attractive Colonial-No. 230

Here is a very successful colonial design, which can be built for $\$ 3,100$. The size is $28 \times 26$ feet. First story 9 feet, second story 8 feet. Finish in first story to be gum or birch, second story pine to paint. Birch or maple floors throughout. Complete plans and specifications for this house for $\$ 20$.
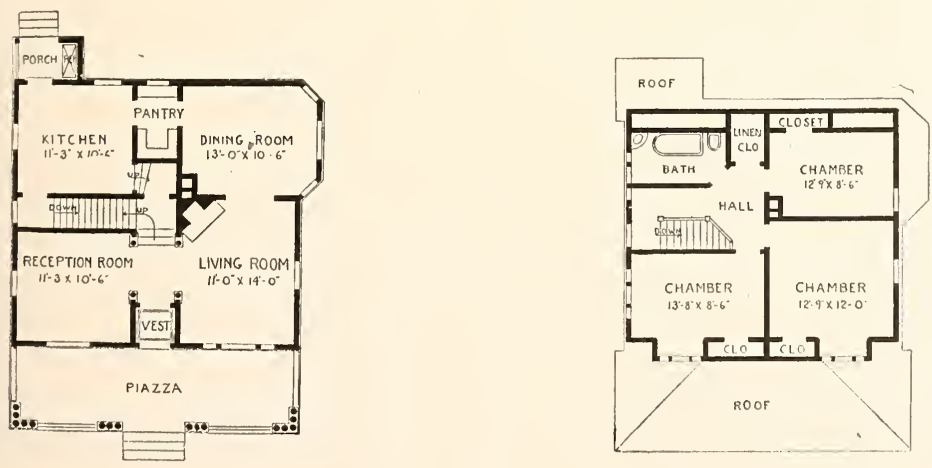

Complete plans and specifications for using Denison Load-Bearing Tile, licensed under Wilson-System Bearing $\mathrm{IV}$ all Construction for $\$ 40$. 


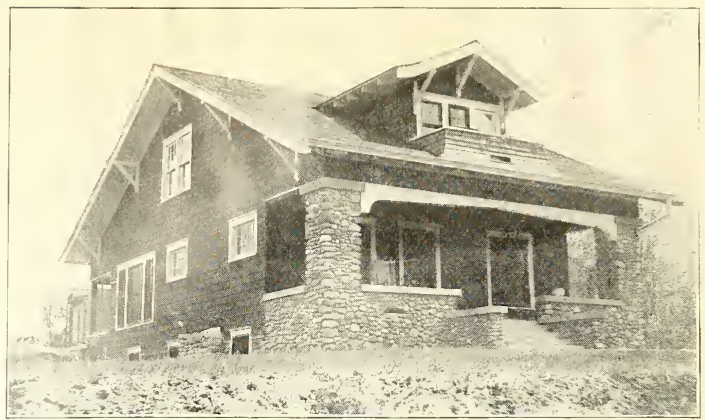

The Cobble Stone Bungalow-No. 979

For a bungalow here is a very practical and well arranged plan. There is a large piazza across the entire front with cobble stone piers in each corner which give a refinement to this home that is emphasized by the cobble stone masonry.

There is a very pretty stairway leading to the second story from the living room with seat built in across the end. Dining room is directly in back of living room with a large piazza across rear. This can be used in the summer as a dining room porch. There is a large entry and a very good sized kitchen with built-in cupboards. There is a bath room, large closet and a good sized bed room in the first story.

In the second story we have three good chambers and abundance of eloset space besides very pretty balconies both in front and rear. Size over main part exclusive of piazza is 28 feet wide and 32 feet deep. There is a full basement under entire building. First story 9 feet, second story 8 feet. Red gum finish throughout first story, pine to paint second story finish. Cost to build $\$ 3,200$. Complete plans and specifications $\$ 25$.
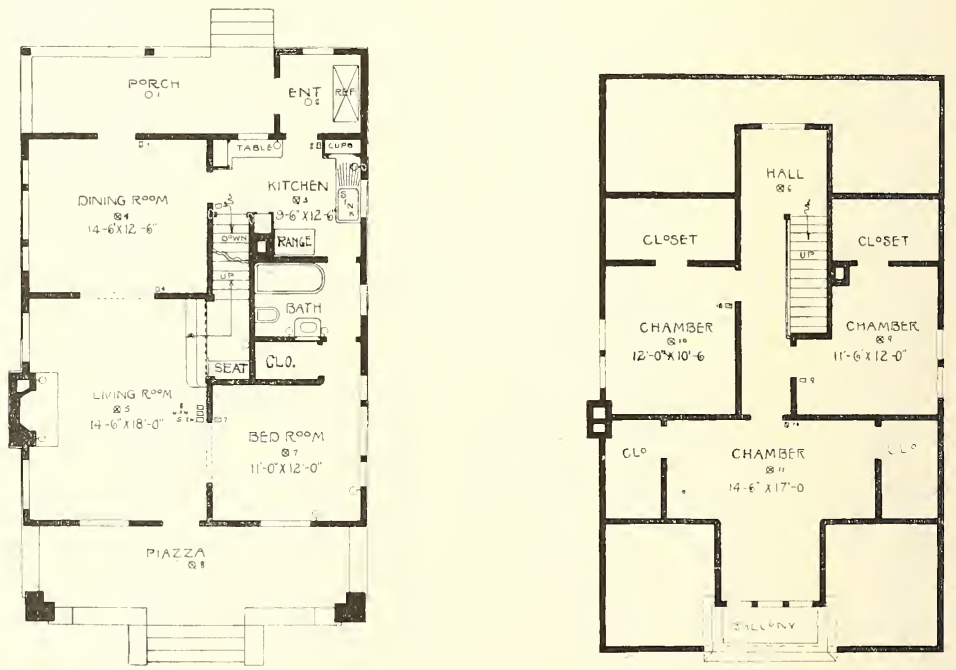

Complete plans and specifications for using Denison Load-Bearing Tile, licensed under Wilson-System Bearing $W$ a 11 Construction for $\$ 50$. 


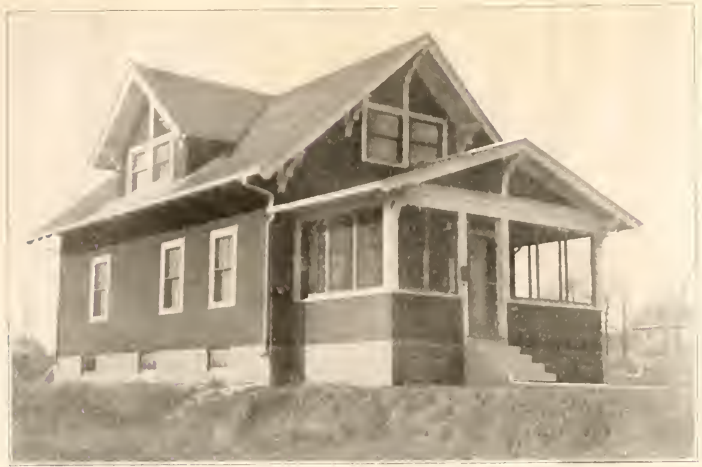

A Story And A Half Rough Cast Cottage-No. 727

This is rather a unique little design planned purposely for the home builder who wants as many rooms as possible for a morlerate amount of money.

This design has a large piazza aeross entire front and a large living room. There is also a den in the first story which can be used as a bedroom if desired. A good sized dining room with built in sideboard and a very conveniently arranged kitchen with built in euphoards, splendid entry with place for a refrigerator and mop and broom closet built in. There is also a grade door in the rear and the stairway leading to second story is semi-enclosed, making it very convenient and accessible from the kitchen.

Second story contains three chambers, large closet space and a good sized bath. There is a balcony that can be reached from the bathroom, making a place on which to put out bedding, rugs, etc. Full basement under entire house. First story 9 feet, second story 8 feet. Finish red gum or birch in first story, pine to paint in second story. Floors throughout white maple or birch.

size of house 26 feet by 30 feet. Cost to build, $\$ 2,350$. Complete plans and speeifications \$15.
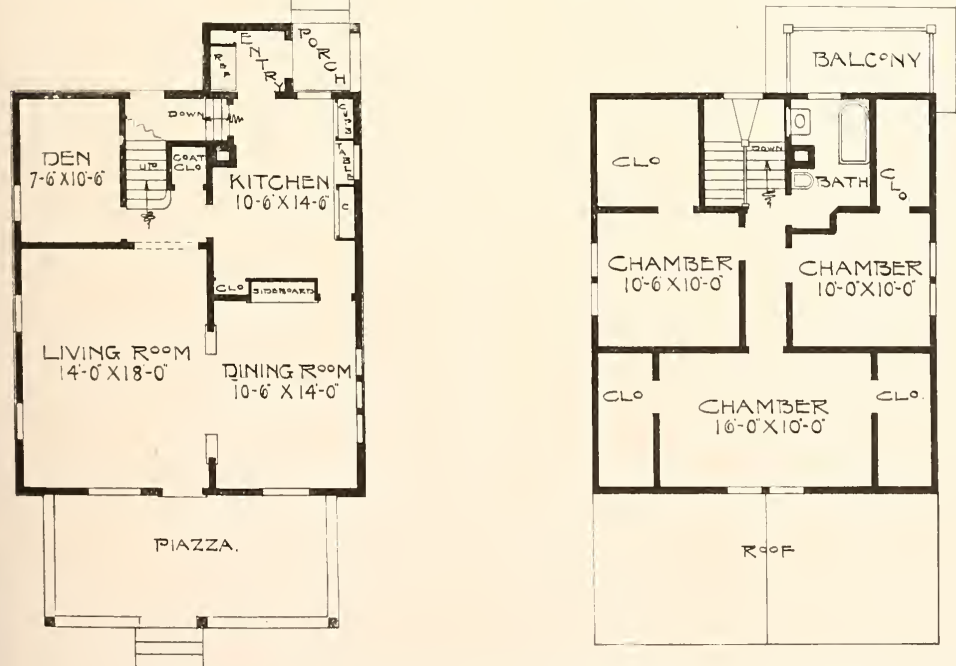

Complete plans and specifications for using Denison Load-Bearing Tile, licensed under Wilson-System Bearing IV a 11 Construction for $\$ 30$. 


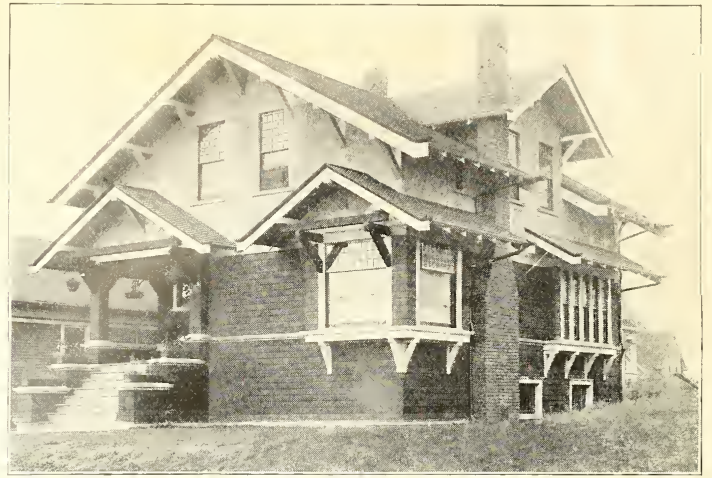

An Artistic Clapboard and Rough Cast Design-No. 764

The exterior of this house is made very attractive by projecting bows and roofing same over with wide open eornices. The house is clapboarded from the base course at grade to a belt line between the first and second stores. Above this the house is covered with rough cast and half timber. The main cornice is supported by heavy sawed brackets giving a very substantial appearance to the exterior of this home.

The first store is nicely arranged, having a beautiful large living room, open fire place and a wide landing for the stairs leading to the second story, having ample place to place the piano if one desires. Pretty dining room with projecting bow window, and small sun room in rear, also a built in sideboard. Dining room has splendid cupboards and all of the kitchen fixtures are nicely arranged to make the work convenient and easy.

There are three chambers in the second story, roomy elosets, good sized bath room and two linen elosets, and a splendid sleeping porch.

The size of this house is 28 feet wide and 30 feet deep. Full basement first story 9 feet, second story 8 feet. These heights all finish in the elear. Birch, red gum or red oak finish throughout the first story, pine to paint in second story, birch or maple floors throughout. Cost to build, $\$ 3,000$. Complete plans and specifications $\$ 25$.
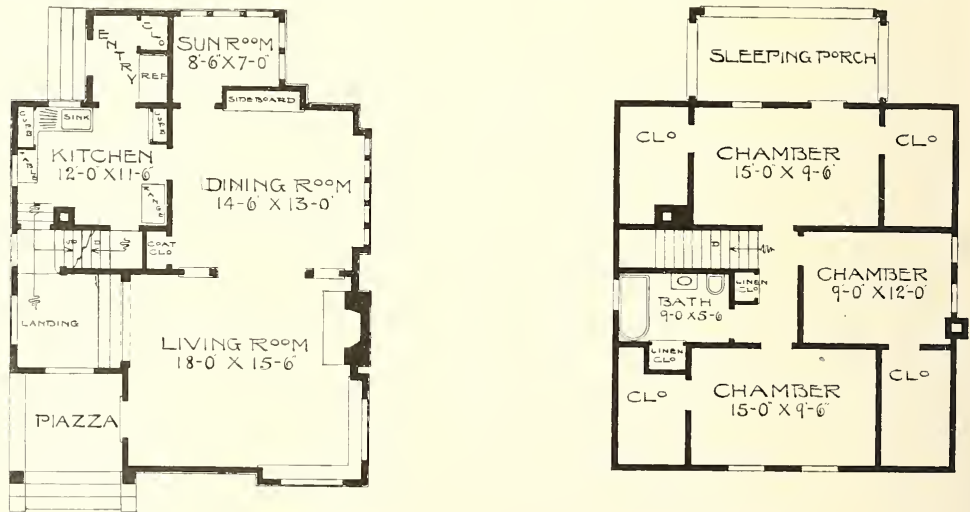

Complete plans and specifications for using Denison Load-Bearing Tile, licensed under Wilson-System Bearing $W$ a 11 Construction for $\$ 50$. 


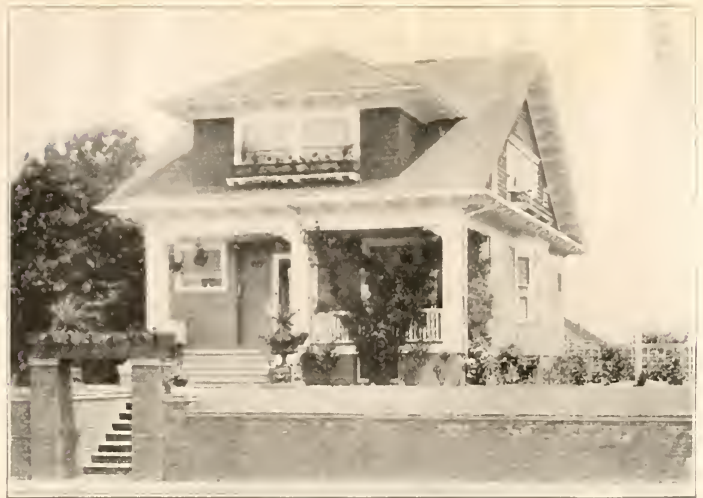

A Home-Like Cottage-No. 763

This is a very attractive cottage home at low cost. The large living room has a den opening off, which can be used as a bed room if desired. There are French doors between the two rooms so that it can be separate at any time. Dining room is connecterl with the living room by wide pedestal columned opening. The pedestals are 4 feet 6 inches high, making space for book-cases in same on the living room side. A very pretty built-in sideboard in dining room helps to make this room very attractive. Built in cupboards in kitelen with good sized entry in rear with space for refrigerator.

Three chambers and bath room in second story. Abundance of closet space. There is every feature in this house to make it complete in every respect. Size 24 feet wide and 30 feet deep under the main part. Full basement, first story 9 feet, seeond story 8 feet. Finished in first story with birch, red gum or red oak, in second story, pine to paint, birch or maple floors throughout. Cost to build, $\$ 2,600$. Complete plans and specifications $\$ 15$.
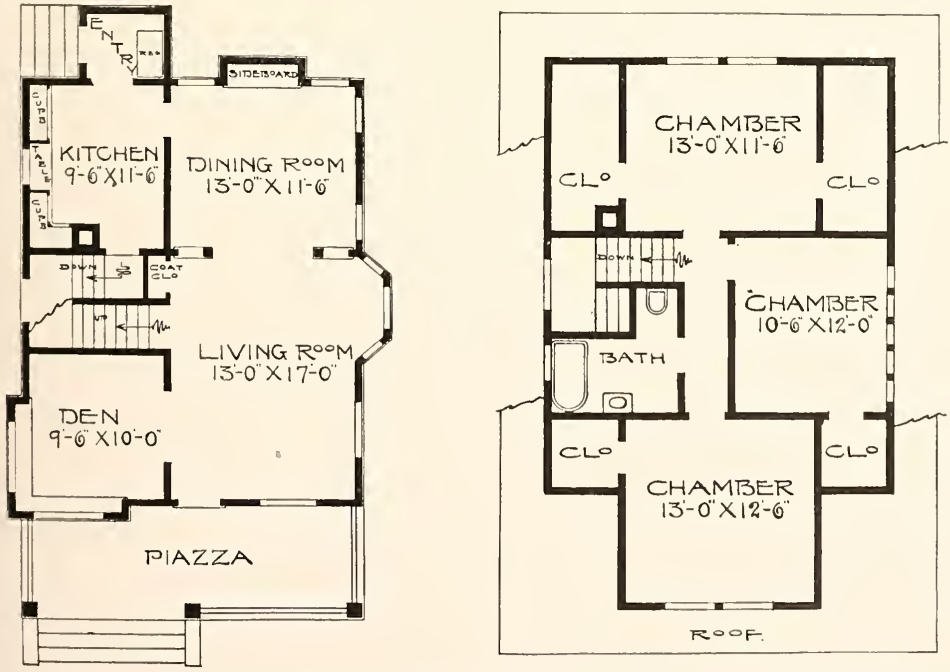

Complete plans and specifications for using Denison Load-Bearing Tile, licensed under Wilson-System Bearing IV a 11 Construction for $\$ 30$. 


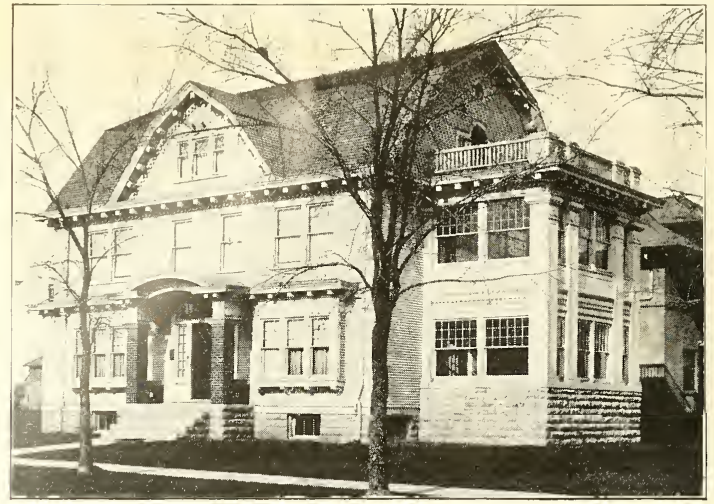

A Pure Georgian Colonial-No. 786

This home was carefully studied and worked out in the most minute detail. The general idea is typical of the old genuine Colonial home with central hall through the entire house with living rooms placed each side, and is sure to interest the man who is interested in Colonial architecture.

The second story has four splendid chambers and closet space that will make any housewife's heart bound with joy. Full basement under entire house, 7 feet 6 inches high, first story 9 feet 2 inches, second of feet 4 inches and third story 8 feet. First story finished in red gum with Circassian walnut reneered doors, second story white enamel on red gum wood with birch doors stained mahogany. Birch or maple floors throughout. Size 40 feet wide over main part and 32 feet deep. Cost to build, $\$ 8,500$. Complete plans and specifications $\$ 50$.
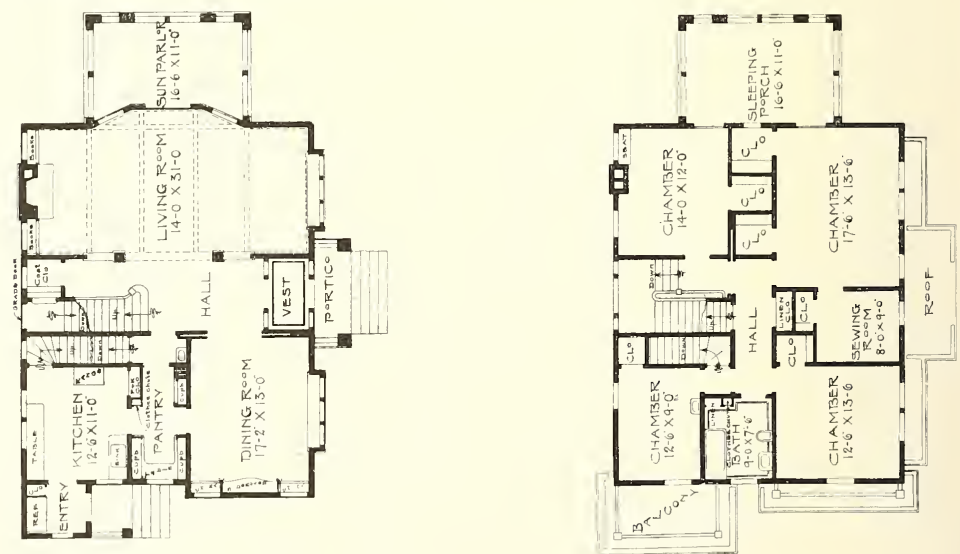

Complete plans and specifications for using Denison Load-Bearing Tile, licensed under Wilson-System Bearing W a 11 Construction for $\$ 100$. 


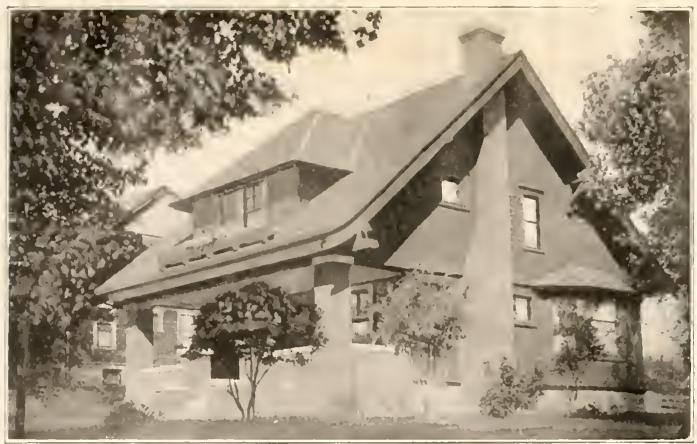

Typical California or Florida Bungalow-No. 969

This beautiful bungalow was recently built in the north for a person who wanted a truly "southern home," and contains many built-in conveniences such as book cases, a writing desk that is quite concealed and out of the way when closed. An imposing fireplace at one end of living room, built-in side board and china closets, large butler's pantry abundantly equipped with shelves, drawers and food compartments.

There is a piazza across the entire front. The entrance hall is separated from liring room by a pedestal oblong column arch way.

Off the rear entry is a commodious porch which can be used in winter when sashed in.

In the second story are three beautiful chambers and an unusually large bath room with built in eabinets and drawers for linen, etc., high sash light on either side of bath cabinet.

First story is clapboarded, above which the gables and dormers are all shingles. Clapboards are painted chocolate brown. Shingles on side are stained brown and the roof is finished in a moss green. A strikingly beautiful combination.

Inside finish first floor red gum, second story red gum or birch enameled white with mahogany doors. Oak floors throughout.

Size 26 feet wide 30 feet deep. Full basement. First floor 9 feet, second floor 8 feet. Cost approximately $\$ 4,000$. Complete plans and specifications $\$ 35$.
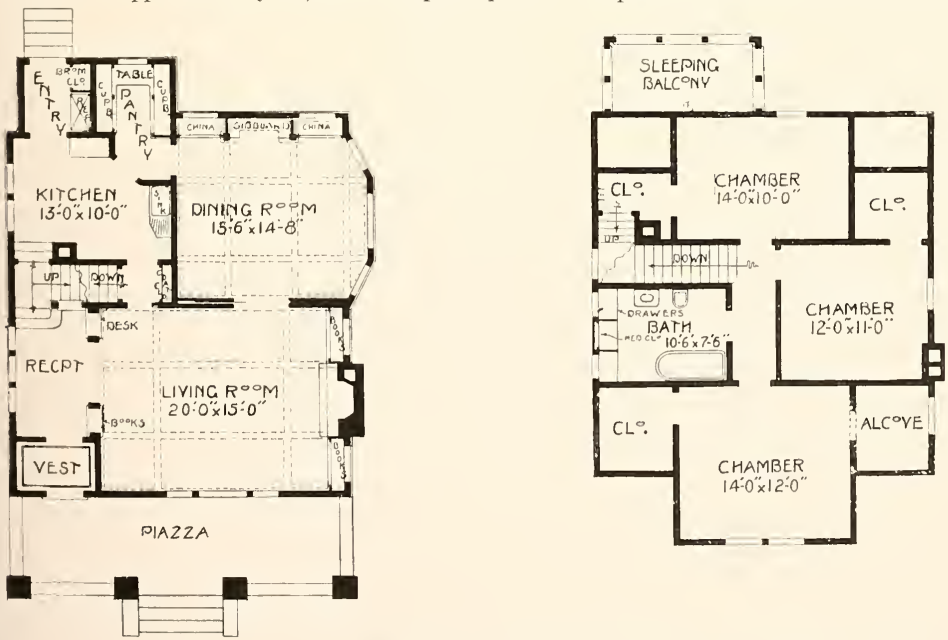

Complete plans and specifications for using Denison Load-Bearing Tile, bicensed under Wilson-System Bearing II a 11 Construction for $\$ 70$. 


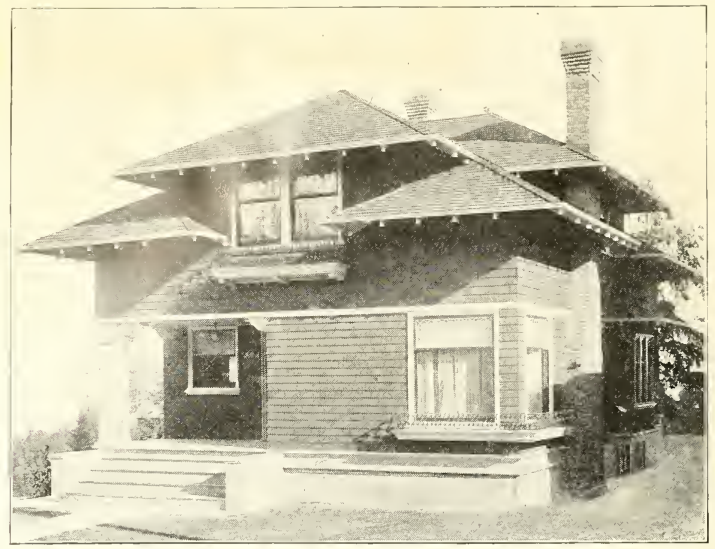

A Pretty Cottage Home-No. 748

This plan makes a very practical and economical home to build. The piazza is good sized and built under the main roof of house; can be sashed in the winter time and screened in the summer time. There is a pretty reception hall, and large living room. The living room opens joins dining room with French doors. A good sized kitchen with built in cupboards.

Second story has three good chambers, large closets and a very good bath. Full basement under entire building. Size 26 feet $x 36$ feet. First story 9 feet, second story 8 feet. Birch or maple floors throughout. Red gum finish in first story, pine to paint in second story. Cost to build, $\$ 2,800.00$. Complete plans and specifications $\$ 20$.
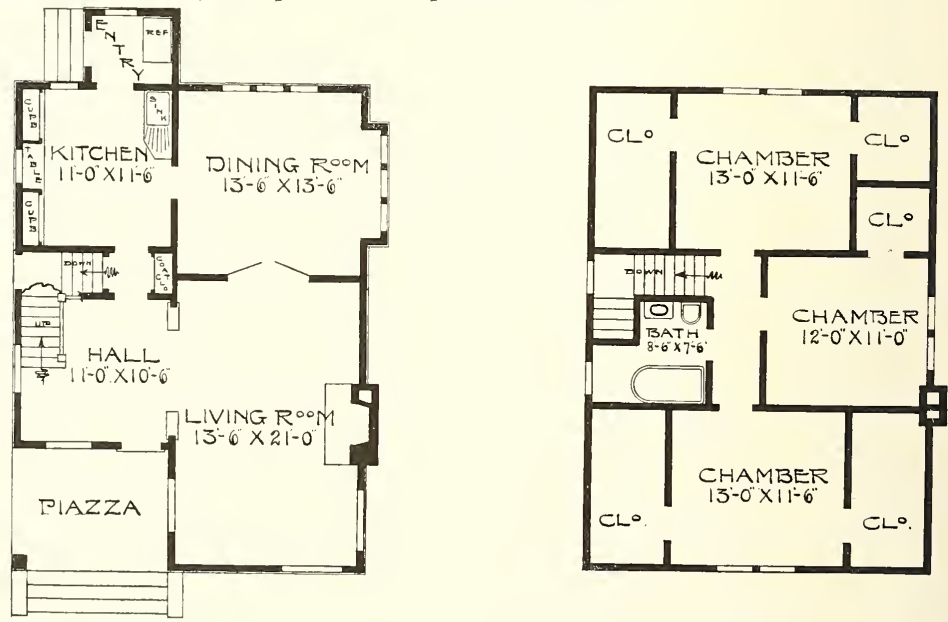

Complete plans and specifications for using Denison Load-Bearing Tile, licensed under Wilson-System Bearing W a 11 Construction for $\$ 40$. 


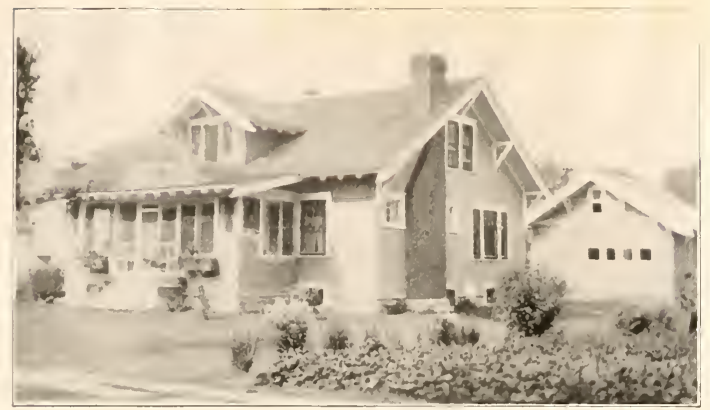

A Physician's Bungalow in New Hampshire-No. 782

This is especially well adapted to a wide lot or for a suburban home where there is ample space to give an attractive setting to the beauties of this dwelling.

The arrangement of the rooms is complete in every respect. In the second story there is a sewing room, chamber and den. If one desires, the large store room at the side can be made in one large chamber or two medium sized chambers, thus giving an unlimited amount of sleeping room space.

Size of house is 42 feet wide and 30 feet deep exclusive of piazza. Finish throughout the first story is red gum wood, red oak or birch and in second story finished part, red gum. Birch or maple floors throughout. Cost to build, $\$ 3,500$. Complete plans and specifications $\$ 25$.

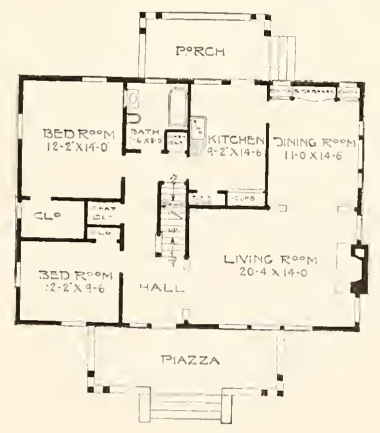

Complete plans and specifications for using Denison Load-Bearing Tile, licensed under Wilson-System Bearing IV a 11 Construction for $\$ 50$. 


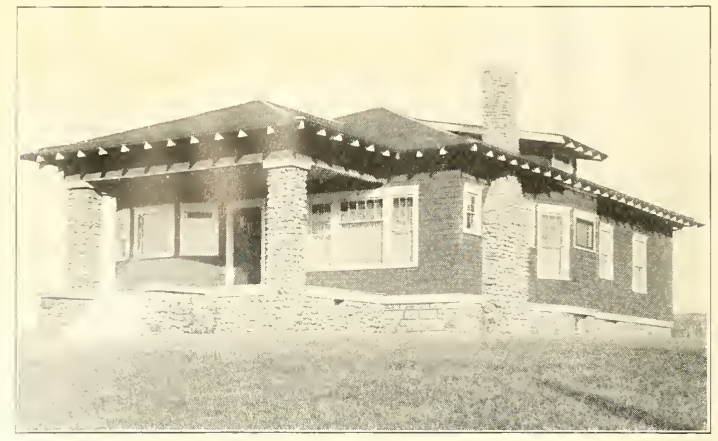

A Cobblestone Bungalow-No. 783

Your attention is called to the beautiful big piazza which is screened in during the summer time and sashed in during the winter, making a livable porch the year round. The piazza is 20 wide and 12 feet deep.

The main part of the house is 32 feet wide and 36 feet deep, finished throughout in red gum wood or birch, with birch or maple floors throughout entire house. Full basement 7 feet 6 inches in the clear, first story 9 feet. Cost to build, $\$ 2,200$. Complete plans and specifications $\$ 20$.

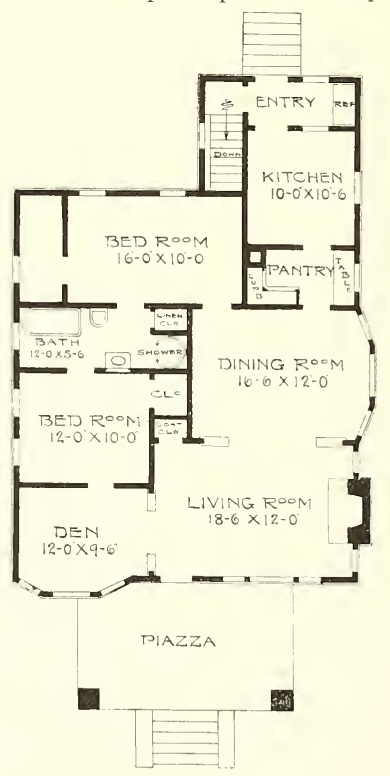

Complete plans and specifications for using Denison Load-Bearing Tile, licensed under Wilson-System Bearing $W$ a 11 Construction for $\$ 40$. 


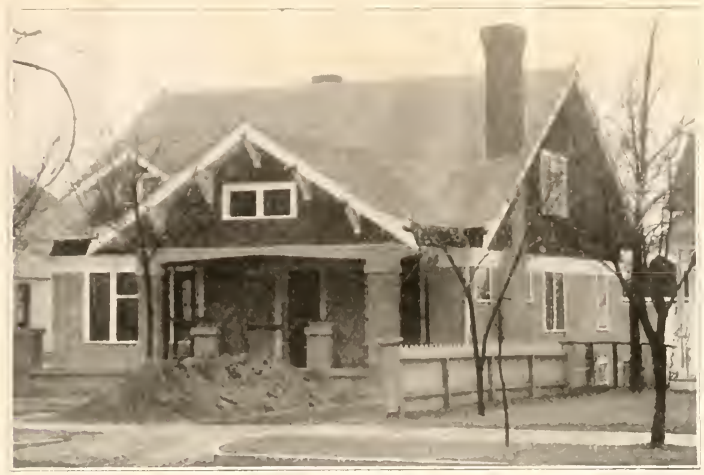

A California Bungalow Adapted to a Northern Climate-No. 784

As for arrangement of floor plan, this is one of the most comfy, cozy bungalows that we have ever designed. There is a full basement under this house 7 feet 6 inches in the clear. First story 9 feet 4 inches, second story chambers will finish 8 feet in the clear. Size of house 36 feet wide and 44 feet deep over the main part. Finish throughout first story red gum or red oak, birch or white maple floors throughout, gum finish in second story. Cost to build, $\$ 4,800$. Complete plans and specifications $\$ 35$.

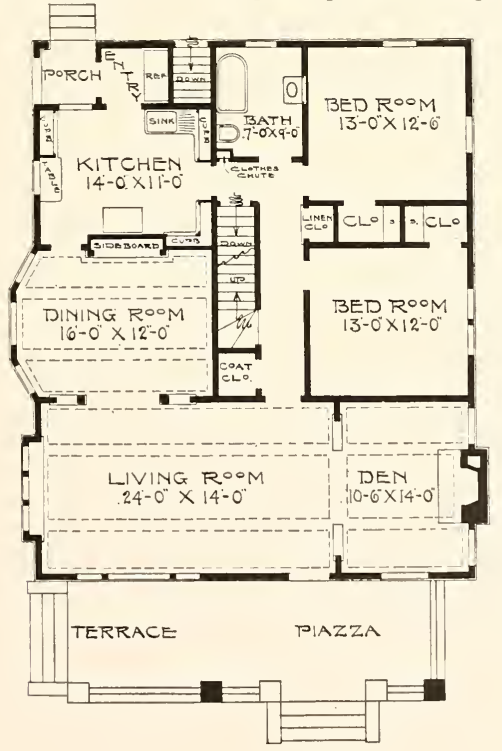

Complete plans and specifications for using Denison Load-Bearing Tile, licensed under WVilson-System Bearing II a 11 Construction for s70. 


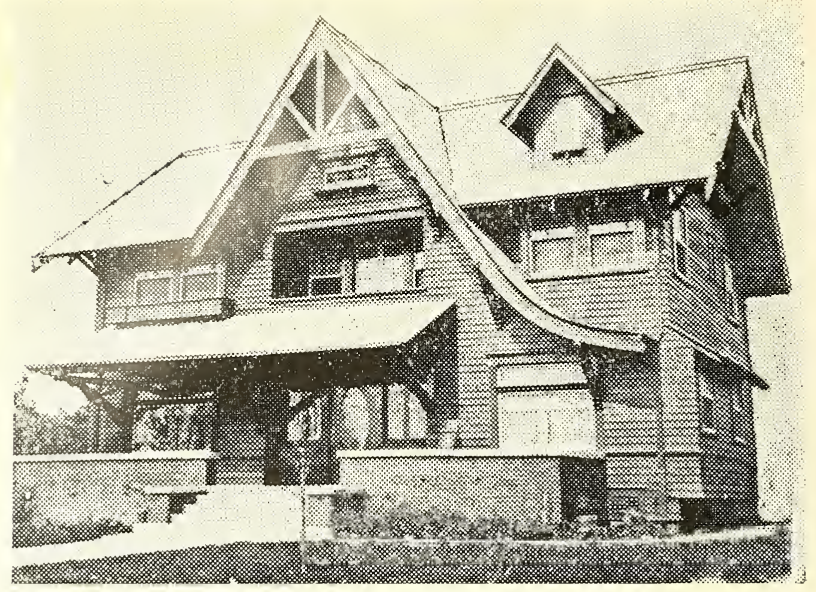

An Attractive Residence Home-No. 849

Size of house, 33 feet wide and 27 feet deep over the main part. First story finished in gum or birch; second story pine to paint; birch floors throughout; full basement under entire house; first story 9 feet, second story 8 feet. Cost to build, $\$ 4,150$. One complete set of plans and specifications, $\$ 25$.

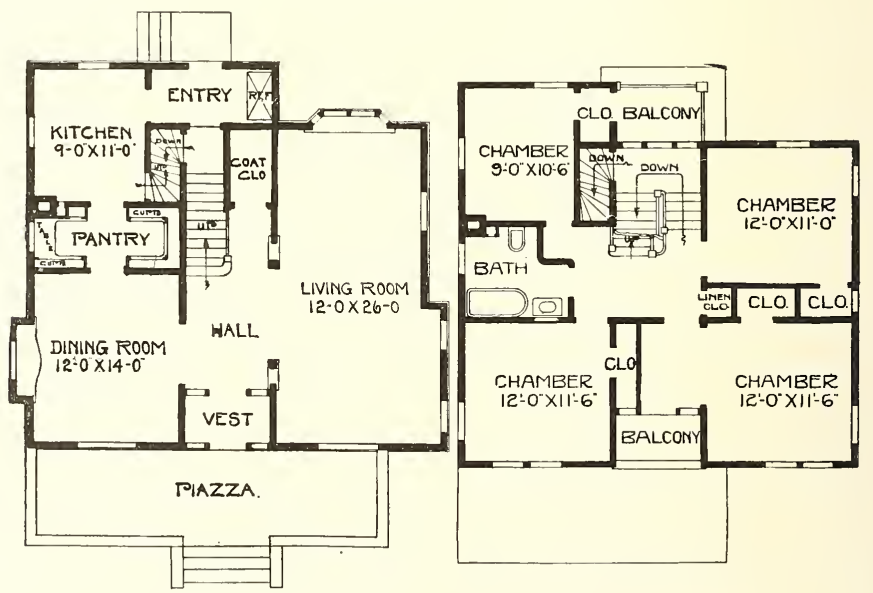

Complete plans and specifications for using Denison Load-Bearing Tile, licensed under Wilson-System Bearing W a 11 Construction for $\$ 50$. 


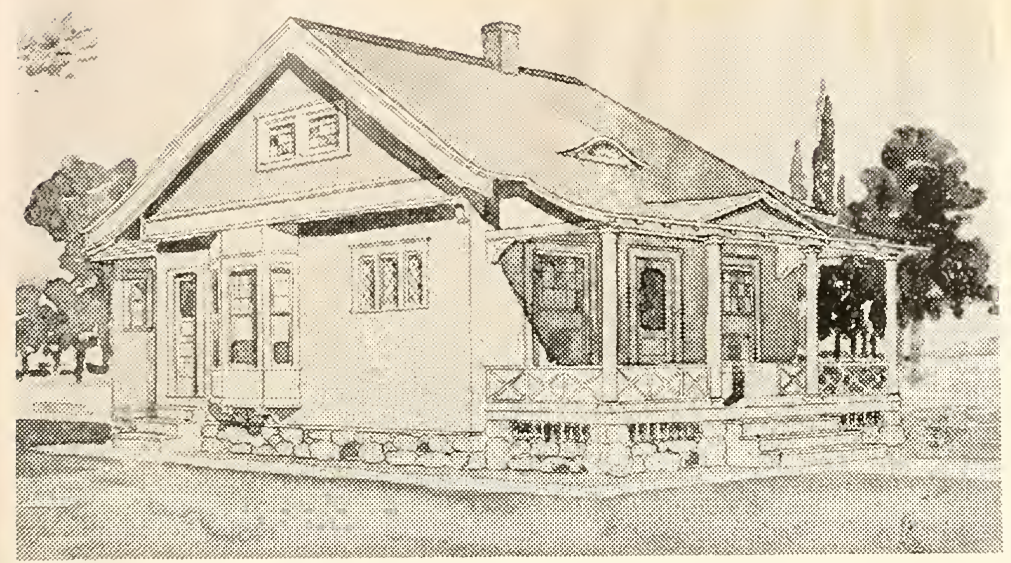

A One Story Cottage-No. 403

A design for a small one-story cottage. The size of main part is $25 \times 26$ feet, the kitchen portion $10 \times 15$. Finish in first story gum or birch, pine to paint in second. Birch or maple floors throughout. We estimate that this cottage can be built for $\$ 1,500$. Complete working plans and specifications for this house for $\$ 10$.

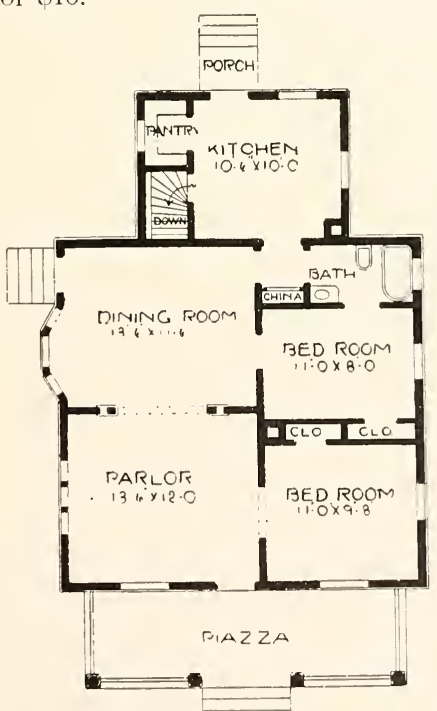

Complete plans and specifications for using Denison Load-Bearing Tile, licensed under Wilson-System Bearing Wa 11 Construction for $\$ 20$. 


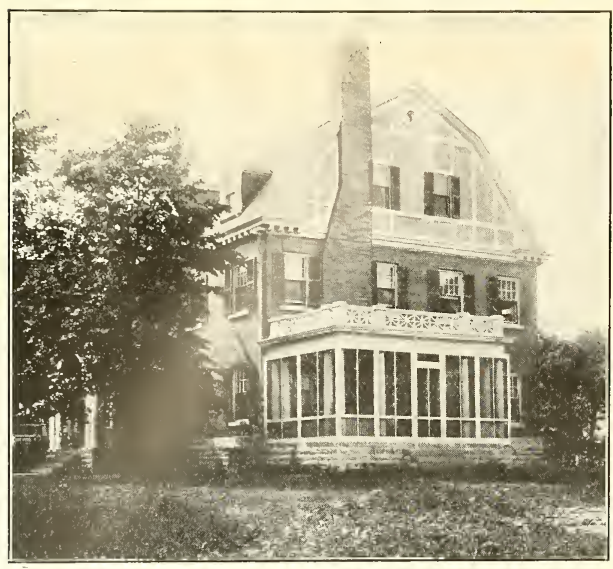

A Banker's Home-No. 33
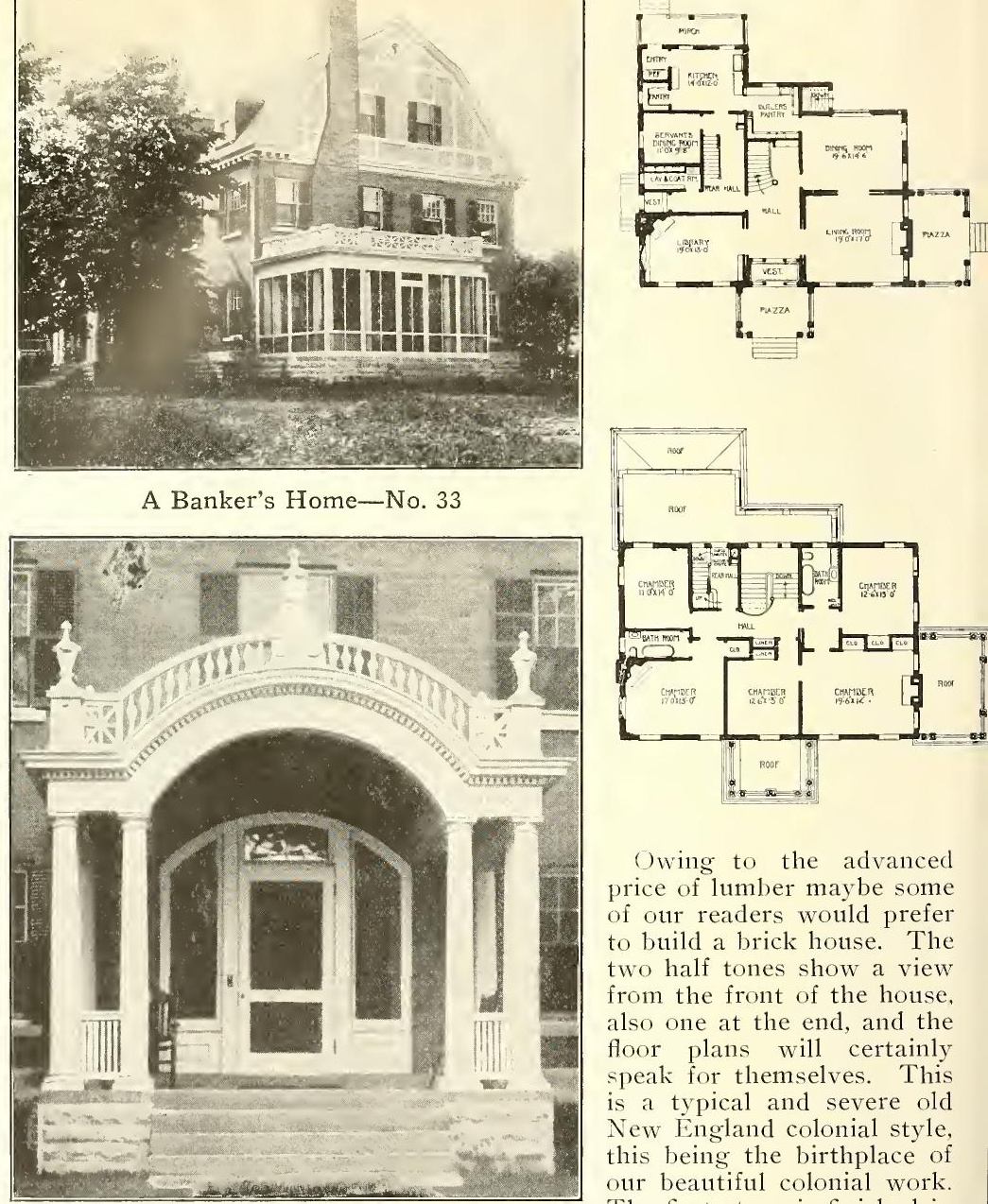

Owing to the advanced price of lumber maybe some of our readers would prefer to build a brick house. The two half tones show a view from the front of the house, also one at the end, and the floor plans will certainly speak for themselves. This is a typical and severe old New England colonial style, this being the birthplace of our beautiful colonial work. The first story is finished in white oak and gum; the second story of white enamel, full basement under the entire house. First story is 9 feet 6 inches, second story 8 feet 6 inches. The size of the house on the ground is $51 \mathrm{ft} .10 \mathrm{in} . \mathrm{x} 34 \mathrm{ft} .4 \mathrm{in}$. Write for information. Cost to build, $\$ 10,000$. Complete set of plans and specifications for $\$ 75$. 


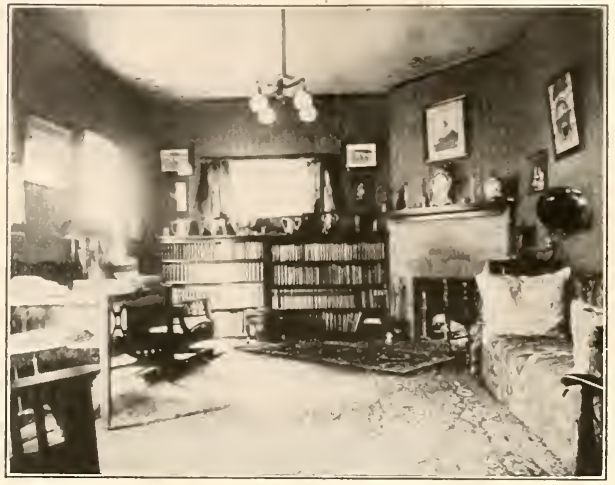

No. 33

Interior of the book room that is always so interesting and restful.

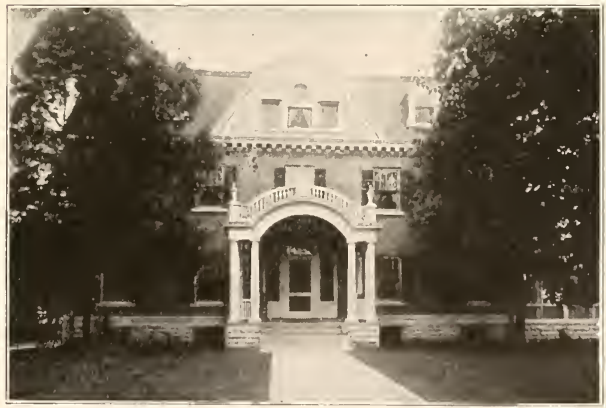

No. 33

A small view of entrance which is a very attractive feature to this residence.

Complete plans and specifications for using Denison Load-Bearing Tile, licensed under Vilson-System Bearing IV a 11 Construction for $\$ 150$. 


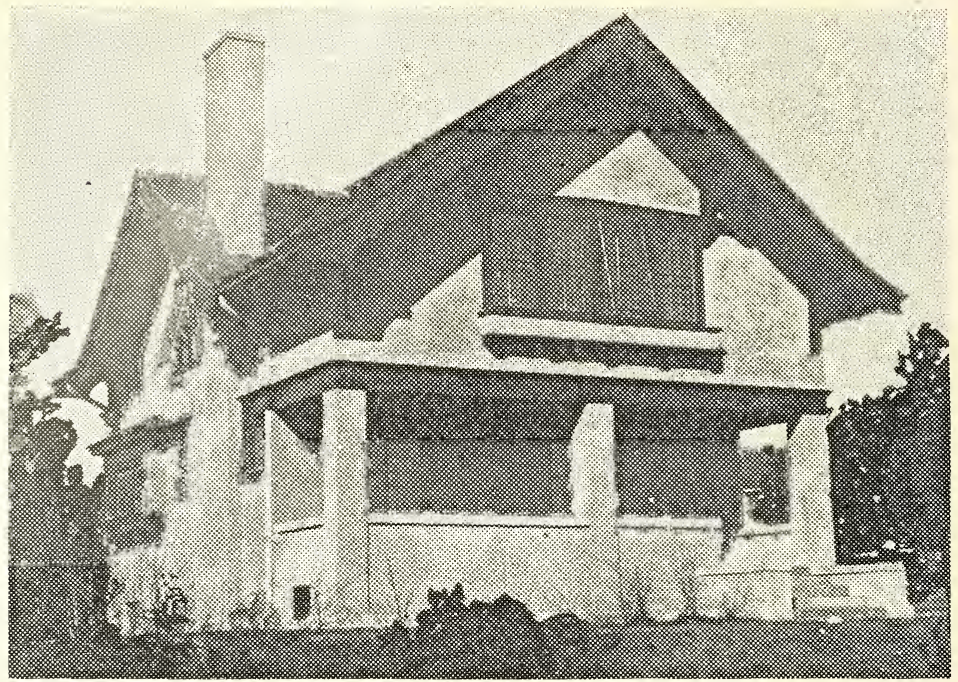

A Study in Cement-No. 943

Width 26 feet, depth 28 feet, over the main part. A decided departure from the ordinary cottage design is shown in this home. The house is singularly free from expensive detail work, its simplicity being its greatest charm. It is of frame construction with on exterior coat of rough-cast plaster. The low roof treatment gives the building a novel appearance and impresses one with the idea of a cozy, comfortable home. A fire-place, faced with large dull-glazed tile, the plain substantial pedestals and craftsman sideboard mark the bungalow style of interior treatment. The first story is finished in red oak, which can be beautifully treated with dark stains, and the second story is finished in Washington fir, gum or red oak. There are birch floors throughout. Cost to build, $\$ 2,600$. Price of plans and specifications $\$ 20$. 

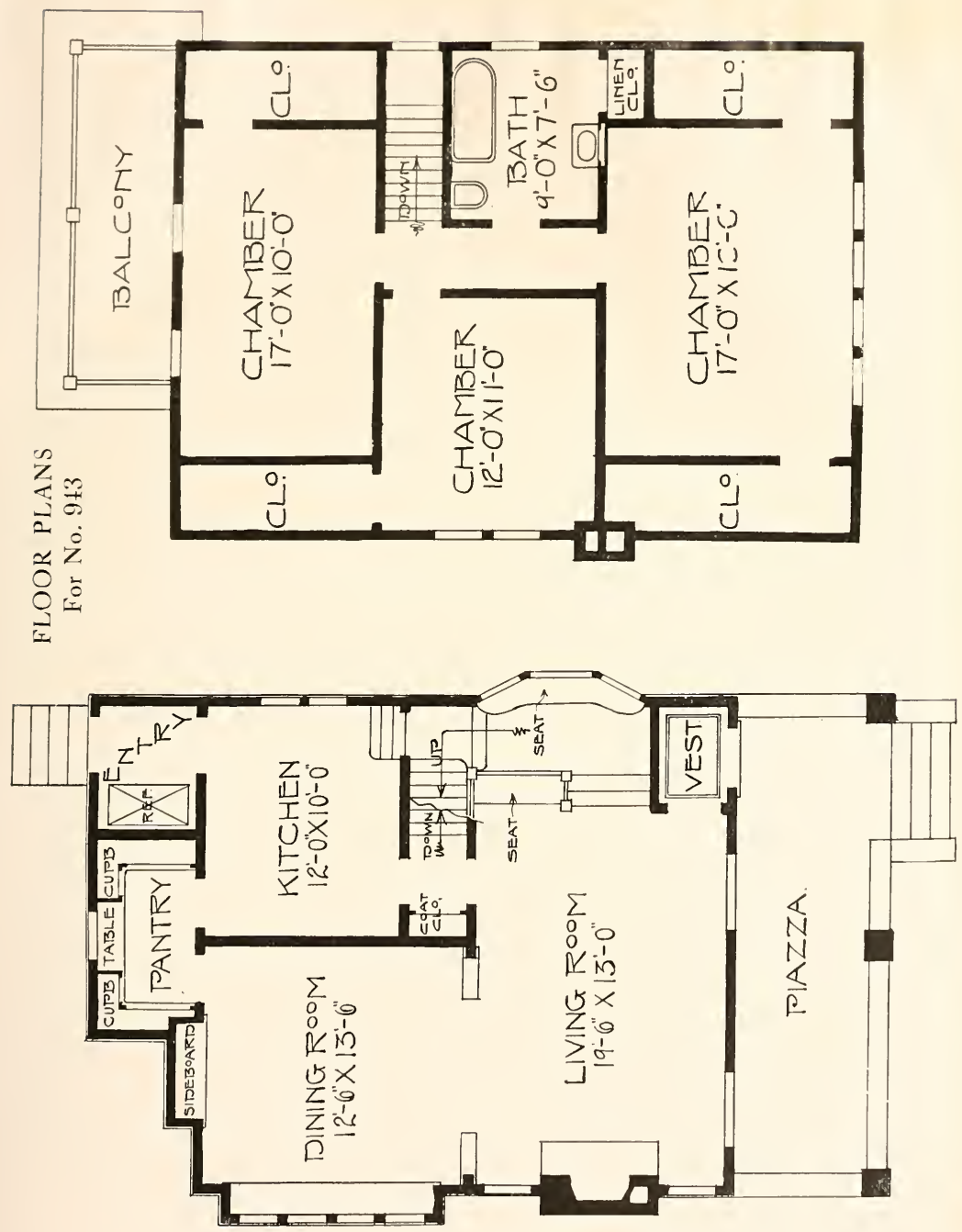

Complete plans and specifications for using Denison Load-Bearing Tile, licensed under Wilson-System Bearing $\mathrm{W}$ a 11 Construction for $\$ 40$. 


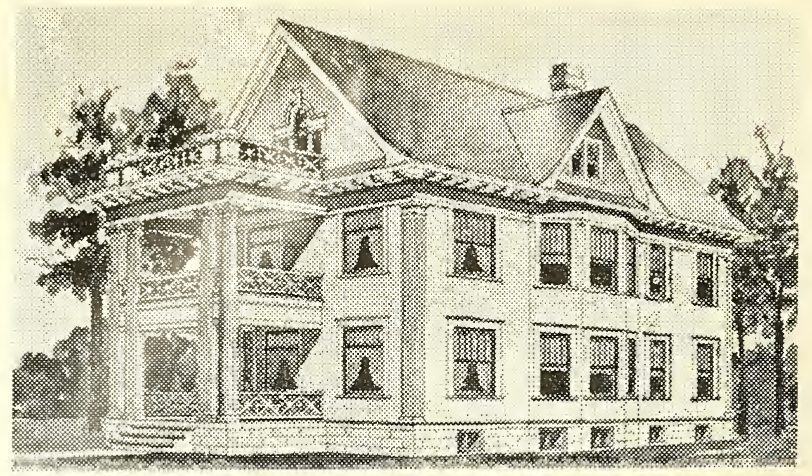

A Colonial Duplex House--No, 880

Size of house is 28 feet wide and 55 feet deep. First and second story 9 feet, basement, 7 feet 6 inches in the clear. Bireh floors throughout. Finish to be gum or birch. Piazza floors and ceiling are of No, 1 Washington fir. Cost to build, $\$ 5,800$. Complete set of plans and spec. ifications, $\$ 35$.

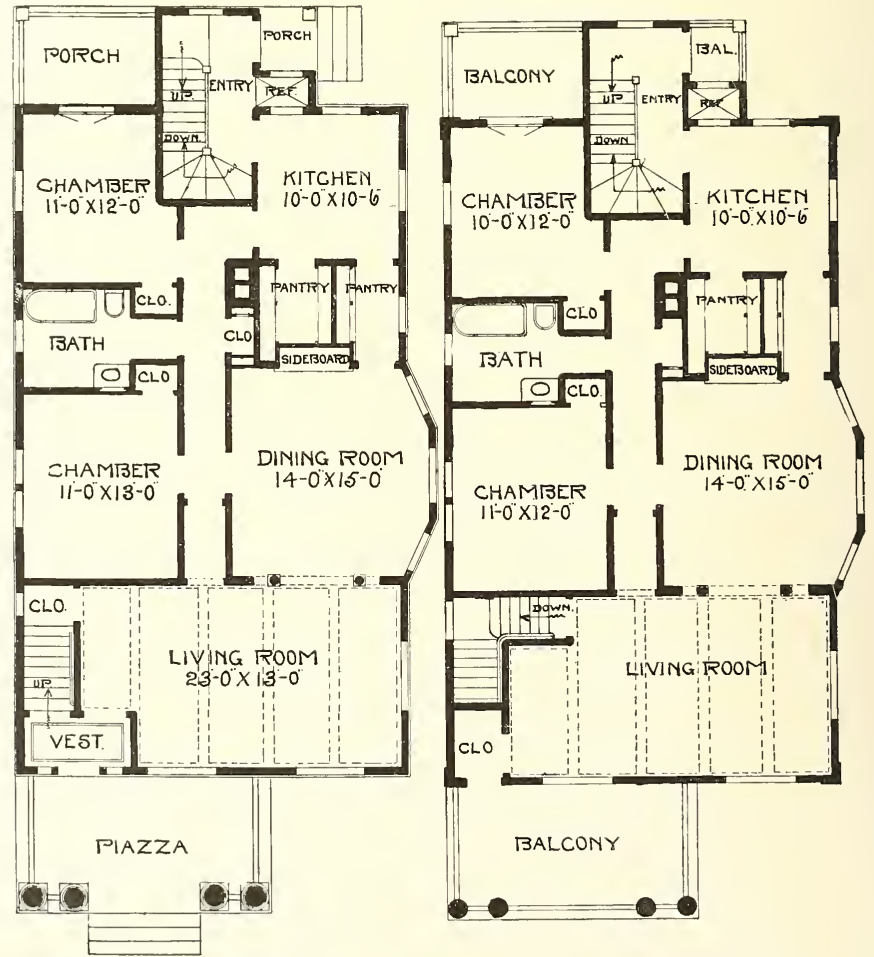

Complete plans and specifications for using Denison Load-Bearing Tile, licensed under Wilson-System Bearing IV a 11 Construction for $\$ 70$. 


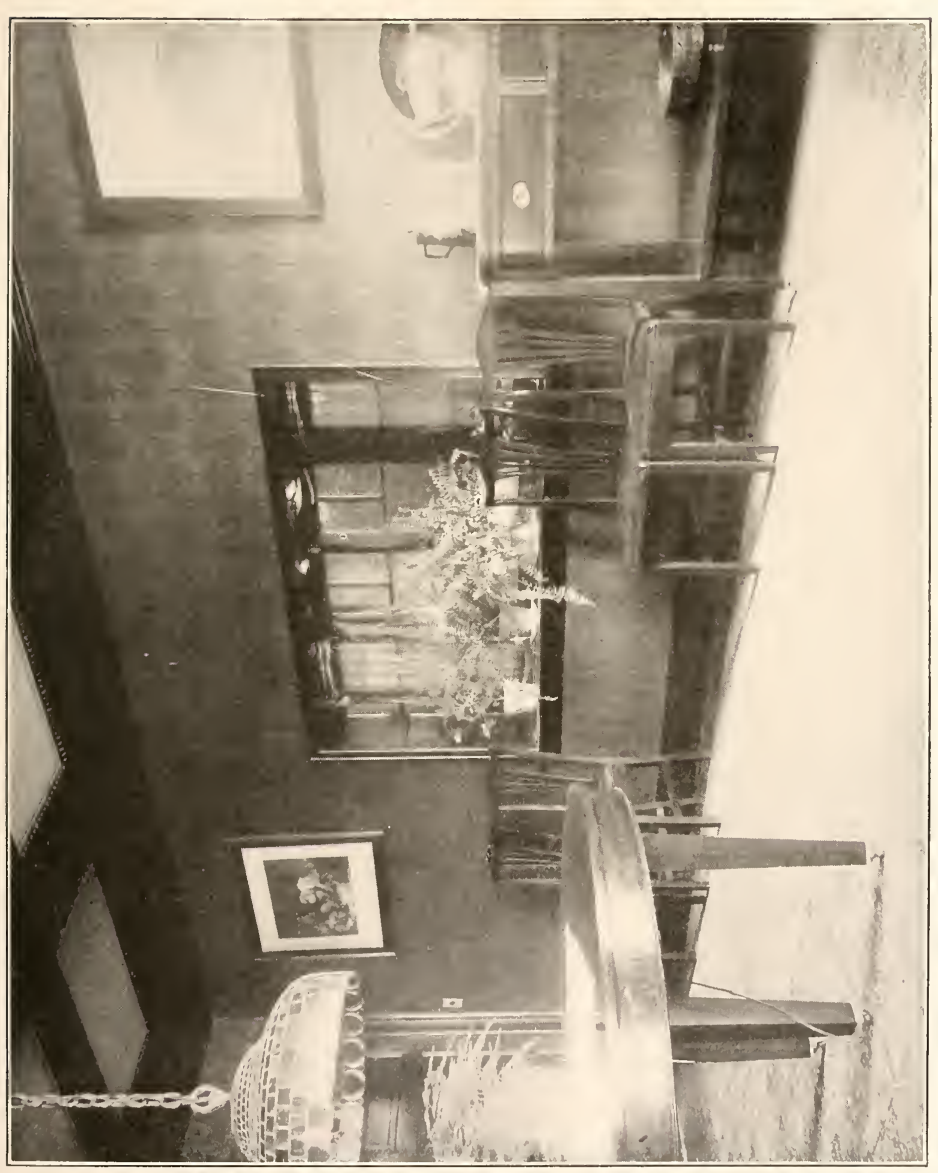

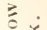

$=\frac{1}{3}$

我

吾密

$\Xi \stackrel{0}{=}$

ते

壾

。

(

总.

충

象

ธ。

는

$\stackrel{0}{0}$

.

든

일

$\equiv$

을

놀.

농

沓

Er

政

ㅎํ

$\exists \cong$

茓

产능

के

.

菏

on

.$\Xi$

I

छ.

苞 


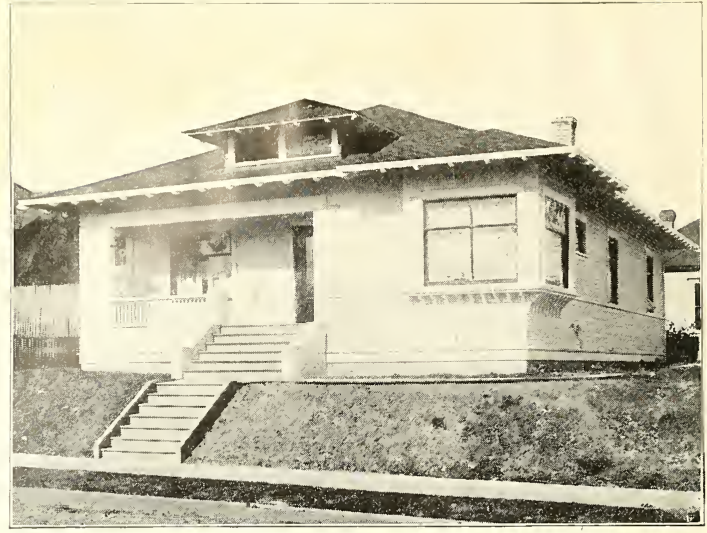

A Bungalow Study in Clapboard-No. 759

This little bungalow has a capacity of 3 nice chambers; the den in front can be used as a chamber if any one desires. It has a good piazza, large living room and a good sized dining room with built in side board. The kitchen is very complete and conveniently arranged.

There is a full basement under the entire house. First story 9 feet. Red gum or birch finish in entire first story with birch or white maple floors throughout. Size 28 feet wide and 42 feet deep.

Cost to build, $\$ 2,000$. Complete plans and specifications $\$ 20$.

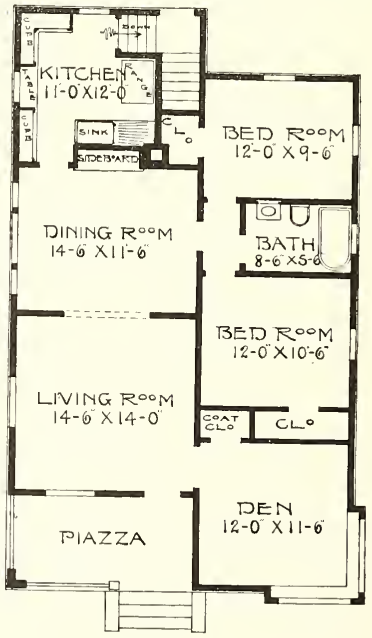

Complete plans and specifications for using Denison Load-Bearing Tile, licensed under Wilson-System Bearing $W$ a 11 Construction for $\$ 40$. 


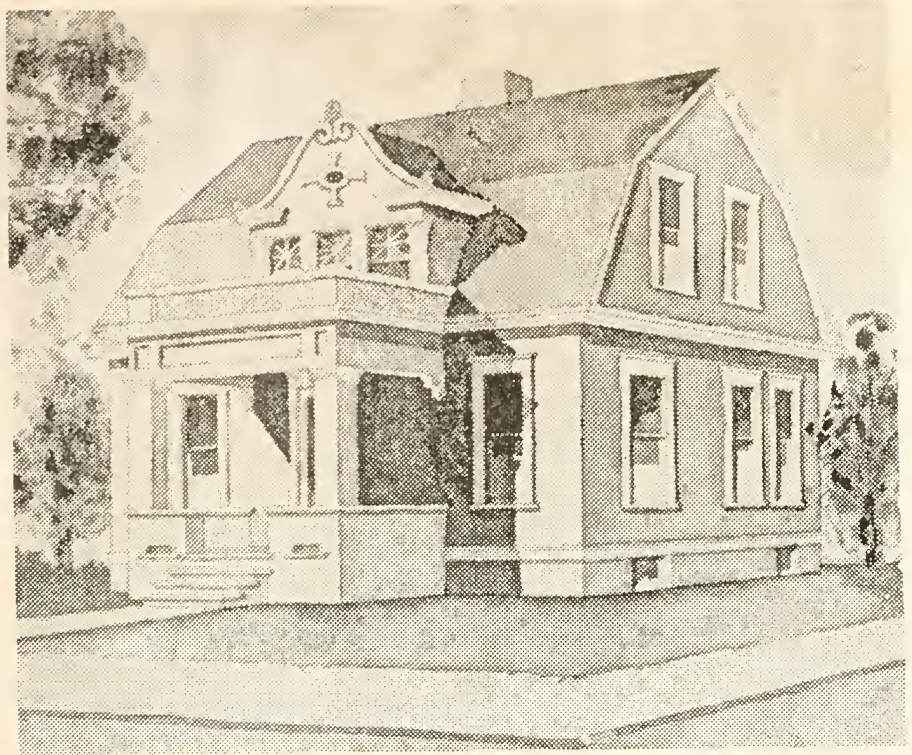

Just Right For A Small Family-No. 334

Is a pretty, compact and neat home of six rooms. Central entrance through roomy porch and vestibule into a large spacious reception hall, the same connecting with sitting room by columned archway.

Two nice chambers and bath in second story finished in pine to paint with ample closet room.

Gum or birch finish and birch or maple floors in first story. Cellar under the whole house. Size $25 \times 25$ feet. Total cost, $\$ 1,850$. Complete set of plans for $\$ 10$.
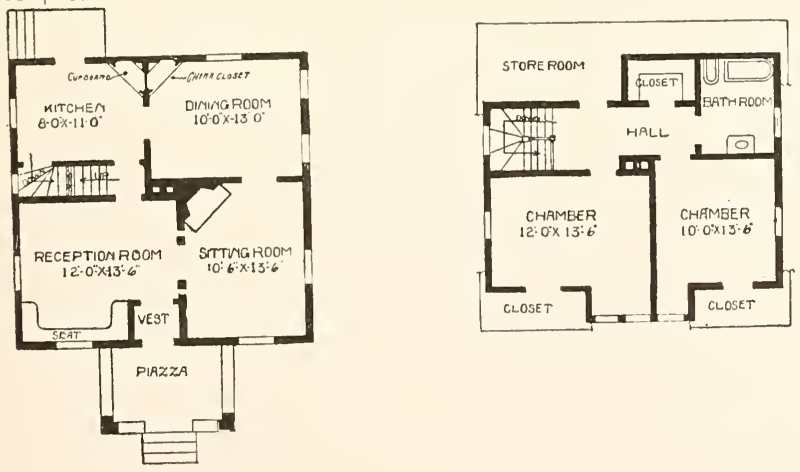

Complete plans and specifications for using Denison Load-Bearing Tile licensed under Wilson-System Bearing W a 11 Construction for $\$ 20$. 


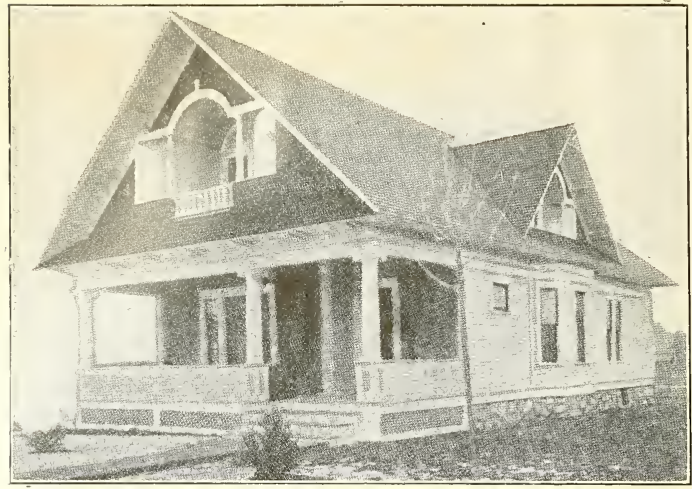

Design-No. 108

A beautiful story and a half residence with bungalow effect. This plan contains ten rooms, besides an abundance of closet space and bath room. On first floor besides living room, there are two nice chambers. You will notice that the bath is entered from a private hall which is quite an essential feature. Broad piazza across the entire front. On the second floor there are four large, light good shaped chambers, three of which have a small balcony. There is a full basement under rear part of house, 7 feet in the clear. First story is 9 feet, second story 8 feet. Birch floors throughout first story and gum or red oak finish. Second story in pine to paint. Size, $26 x 38$ feet deep. Cost to build, $\$ 2,450$. Complete set of plans and specifications for $\$ 20$.
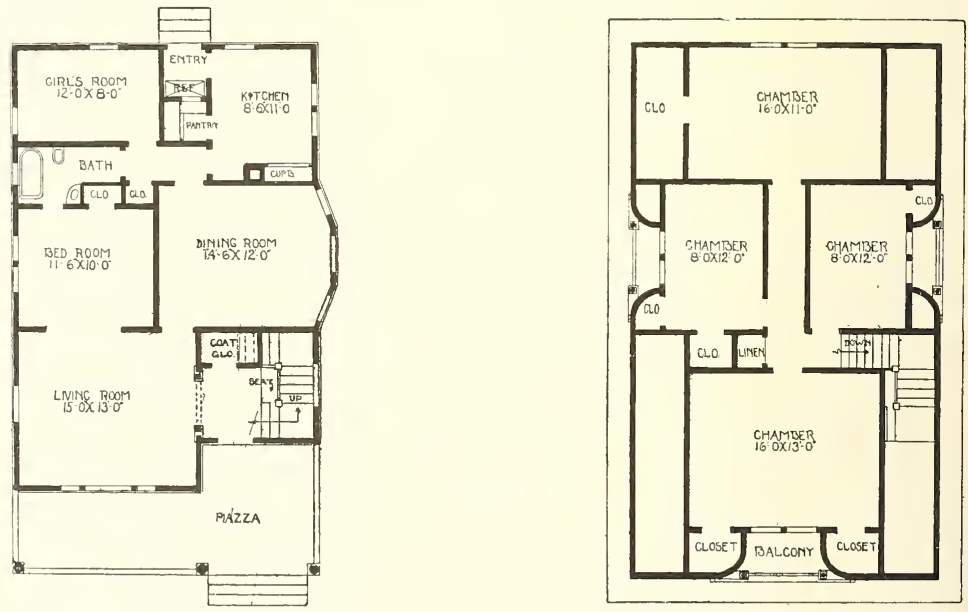

Complete plans and specifications for using Denison Load-Bearing Tile, licensed under Wilson-System Bearing $\mathrm{W}$ a 11 Construction for $\$ 40$. 


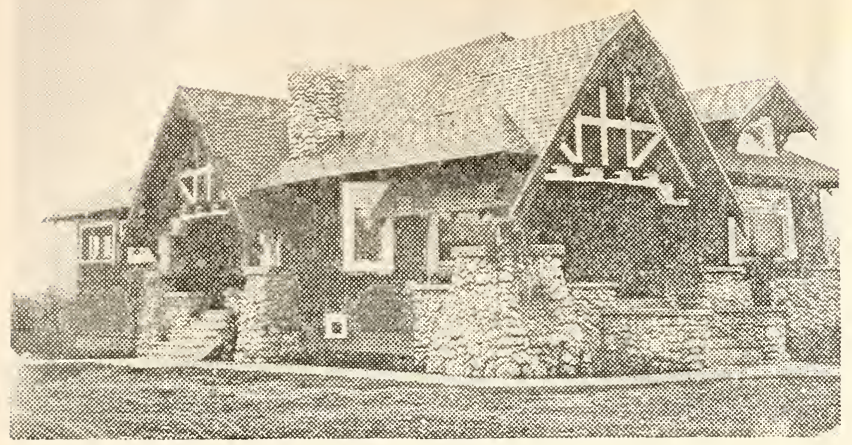

An Artistic Bungalow-No. 934

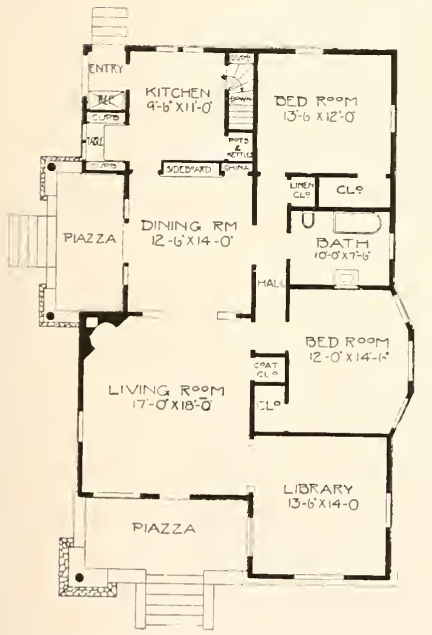

Width 32 feet, depth $5+$ feet. The cobblestone piazzas and massive piers are the most prominent details of this exterior. The entire house is covered with a hip roof, with a single dormer on the front. Over each piazza is a double-pitched gable, supported on octagon posts, the fronts ornamented with half-timbers and panels of colored plaster. There are seven rooms, all square and all on the one floor. The living room and library can be prettily finished in birch, which is the least expensive of hardwoods, but one of the prettiest. The dining room might be finished in red oak or gum. The kitchen and sleeping room portion of the house should be finished in pine, enameled white, with birch doors like those in living room. Cost to build, $\$ 4,500$. Complete set of plans and specifications for $\$ 30$.

Complete plans and specifications for using Denison Load-Bearing Tile, licensed under Wilson-System Bearing $W$ a 11 Construction for $\$ 60$. 

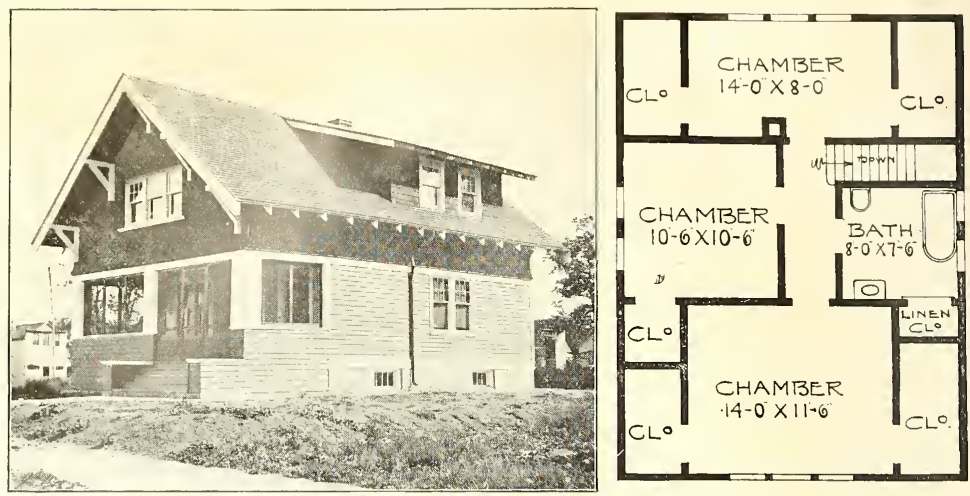

A Cottage or Bungalow, Just As You Like-No. 964

We gain almost one third more floor space than cau possibly bo accomplished in most any other cottages that are of this size on the ground floor, and there is no danger from the floors in the second story being cold where it projects, as the greatest care is taken in the construction of the same. Has a beautiful living-room across the front,

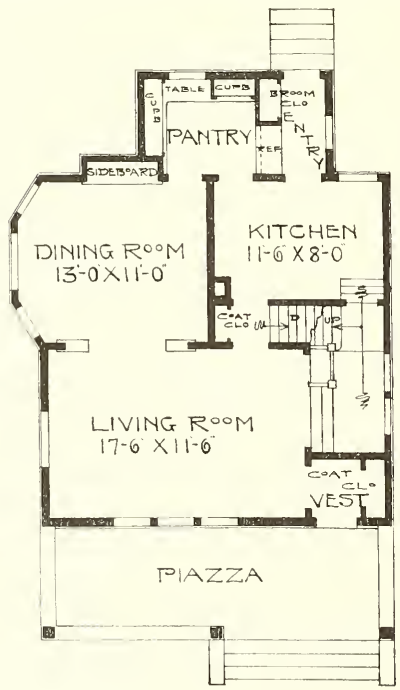
vestibule, coat closet, and a very attractive stairway with built-in seat. We have a nice entry and the refrigerator is iced from this space. There is also a large closet built-in for brooms, mops, tables leaves, etc. There are three fine sleeping rooms in the second story and if one desires a sleeping porch can be built over the rear one-story part, splendid closets and a liberal bath. Size 24 feet wide and 24 feet deep over the main part; full basement; first story 9 feet, second story 8 feet. First story finished in gum or birch; second story, pine, to paint; hardwood floors throughout

Cost to build, $\$ 2,150$. Complete set of plans and specifications of this bungalow for $\$ 18$.

Complete plans and specifications for using Denison Load-Bearing Tile, licensed under Wilson-System Bearing IV a 11 Construction for $\$ 36$. 


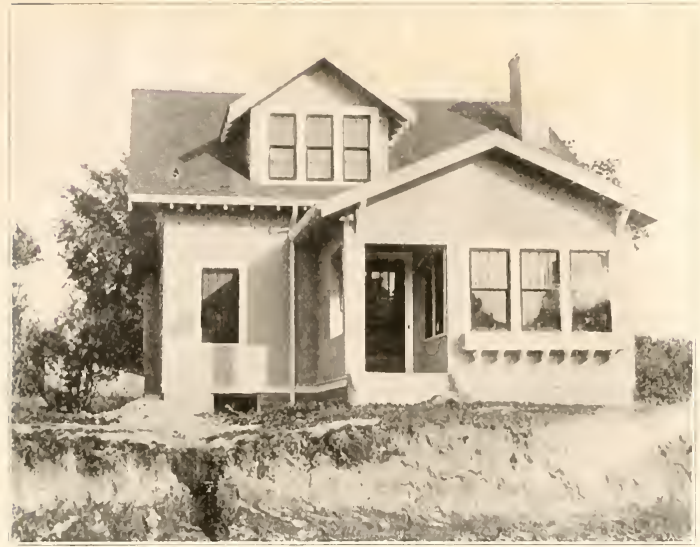

A Bungalow Study in Rough-Cast-No. 776

This bungalow plan has a living room that is ideal in all of its appointments. Beautiful fireplace at the end with sun parlor in front, opening into this room with two French doors. There is one bedroom in the first story which can be used as den or library or music room if one desires. Large dining room with pretty bay windows in same. Good sized pantry. Second story contains two large chambers and closet space, very large bathroom. Basement under entire house. First story 9 feet, second story 8 feet. Size 30 feet wide and 28 feet deep. Birch or maple floors throughout. Red gum or birch finish in first story and pine to paint in second story. Cost to build, $\$ 2,300$. Complete plans and specifications $\$ 15$.
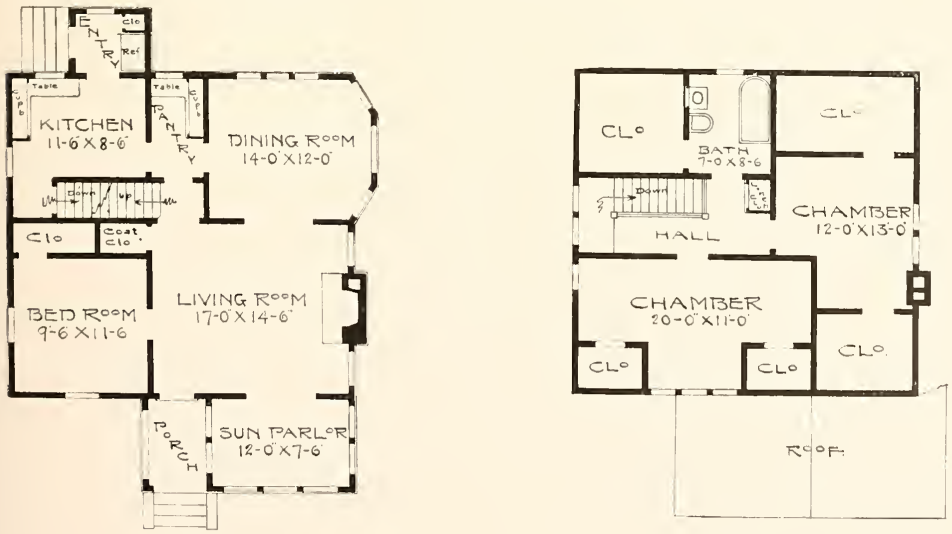

Complete plans and specifications for using Denison Load-Bearing Tile, licensed under Wilson-System Bearing $\mathrm{IV}$ all Construction for $\$ 30$. 


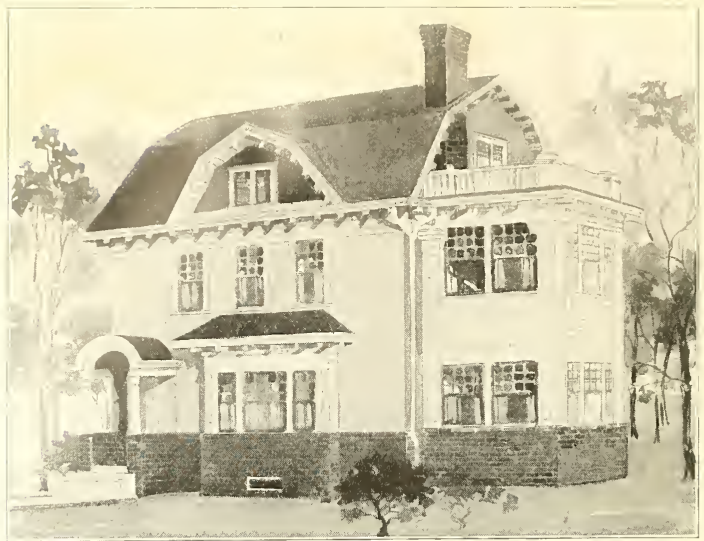

Georgian Colonial Design-No. 966

Evolution in Architecture in this Practical Home

Cost to build, $\$ 3,800$.

This is from actual tigures after this house has been duplicated in one of the largest cities in the United States four times. This plan is unique as it is the only plan designed up to the present time that can be adapted to five distinct styles of archiecture without changing the doors or windows, or materially affecting the general plan in any way. We have this house made up as an old New England Colonial, Craftsman style, and Fnglish half-timber. The size of the house is 26 feet wide and 28 feet deep over the main part. There is a sun room on the side which is 10 feet 6 inches wide, thus making a frontage of 36 feet 6 inches. Necessarily this calls for at least a 40 or 50 foot lot, or one wider still is even more appropriate for this home. The floor plans show a home that is complete. There is not one wisl that a thousand different home lovers have ever expressed but what are all included in this litile home. The sun room and the sleeping porch in ten years time are going to be the only kind of piazzas that will be put in homes, as in a cold climate a

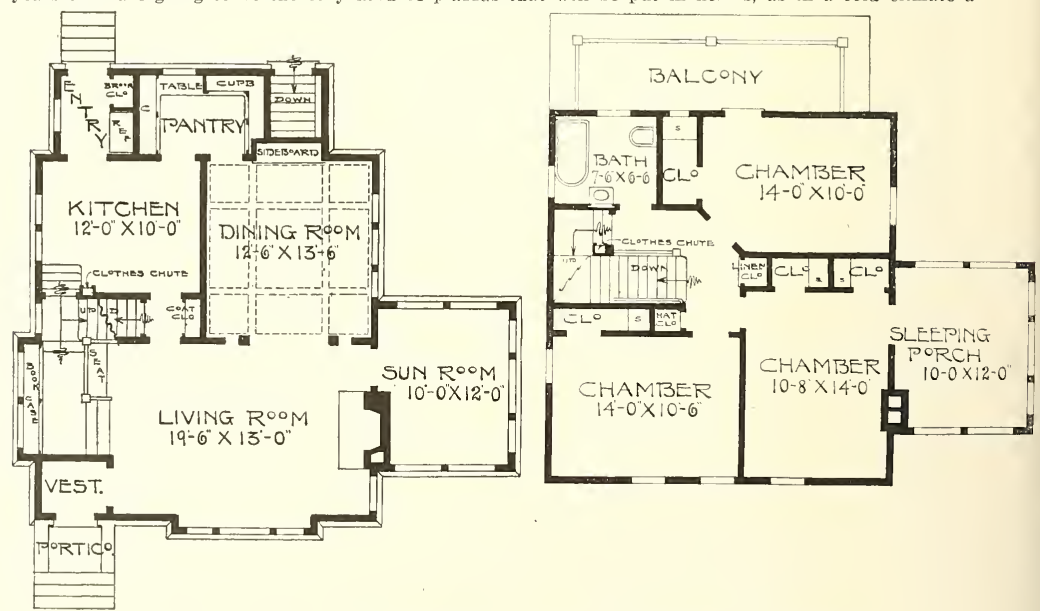

These floor plans can be reversed to fit the two exteriors on opposite page.

Complete plans and specifications for using Denison Load-Bearing Tile, licensed under Wilson-System Bearing Wall Construction for $\$ 70$. 


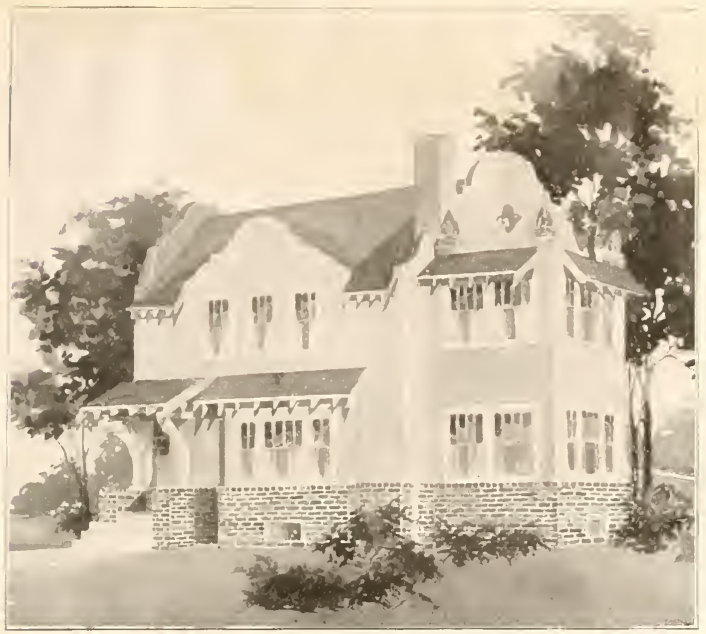

Spanish Mission Design-No, 966

See the floor plans on opposite page that go with these two beautiful exteriors.

piazza around the front and sometimes around the entire sides keeps out the sunshine from all the rooms and is only livable three months out of the twelve at the most. Now with sun room and a sleeping porch which are all sashed in, in case it gets too cool or starts to rain, you can put the windows down and raise the bottom one up and you can still sit on the piazza just the same, either in sunshine or rain, or snow. In your sun room we put in a radiator so that they are livable for 365 days in the year.

There is a full basement under this entire house. First story 9 feet, second story 8 feet. These heights are in the clear. First story is finished throughout in birch with birch floors throughout both first and second stories. Gum-wood or Georgian pine could be used if one desired. The second story is finished in pine to paint, with birch doors to stain mahogany color to give the old Colonial interior finish for the chambers. Complete set of plans and specifications for $\$ 35$ of any one of these designs. Will blue print the plan either side up so as to fit the lot that you have.

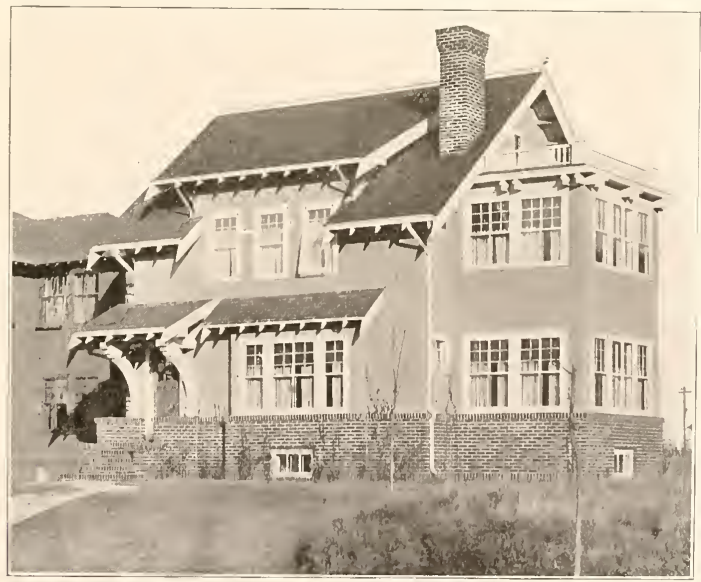

Craftsman Design With Brick Veneer to First Story Windows-No. 966 


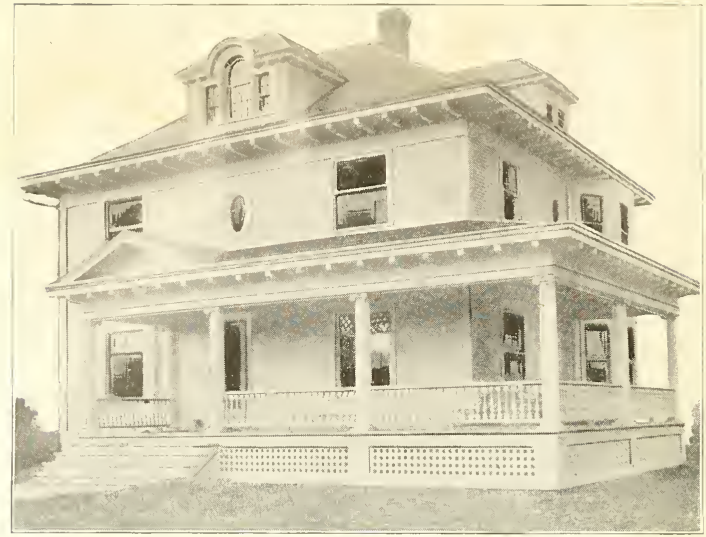

No. 397

This house has been erected a number of times, in various localities, is a commodious, conviently arranged and a comfortable house to live in. The size is 34 feet 6 inches wide and 30 feet 6 inches deep. The finish is birch or gum in first story and pine in the second story.

This house has a central entrance, and hall feature, and is a simple colonial design. The main stairs lead up from the centre of the house. There is a fine library $12 \times 12$ on the left of the hall, a sitting room on the right $13 \times 17$, a dining room back $16 \times 12$, a conveniently arranged pantry, with rear porch and a refrigerator space. There is a passage leading from the main hall to the kitchen and dining room, with lavatory.

There are two fireplaces in the first story, one in the sitting room and one in the library. The floors in both stories are of birch or maple.

The second story has four nice chambers and a bath, liberal stairs leading to the third story which can be finished in one large room for play room or storage purposes. It is well lighted with dormer windows. Cost of this house is estimated at $\$ 4,200$. Complete plans and specifications for this house for $\$ 25$.
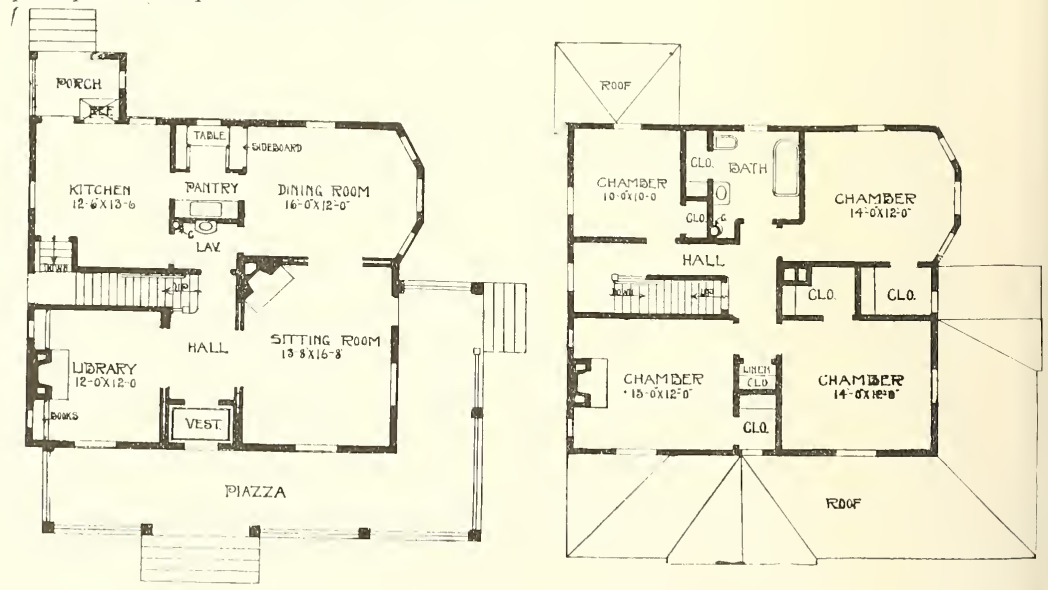

Complete plans and specifications for using Denison Load-Bearing Tile, licensed under Wilson-System Bearing $\mathrm{W}$ a 11 Construction for $\$ 50$. 


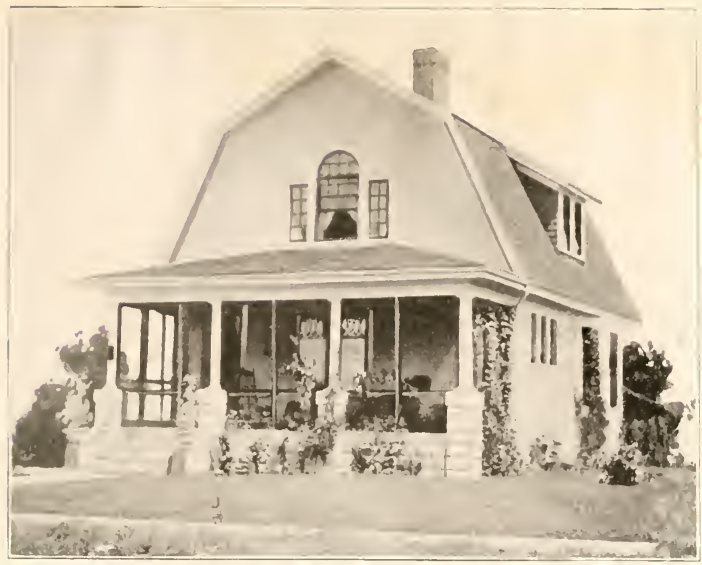

A Pretty Gable Roof-No. 112

$A$ beautiful colonial cottage. size 22 feet $\times 24$ feet, can be built for $\$ 1,600$ finisher complete. This cottage has a broad piazza across the entire front, and your attention is called to the beautiful living room, 21 feet $x 11$ feet, has a combination stairway and plant leige in dining room. Pantry in rear connecting kitchen and dining room. Has a rear porch with refrigerator in pantry and door opening from porch. There are two nice chambers in the second story, besides bath. There is a cellar under the kitchen and dining room. First story is 9 feet, second story $S$ feet. Finish in first story birch or gum, pine to paint in second. Birch or maple floors throughout. This house could be built as a bungalow for the sum of $\$ \$ 00$. Complete set of plans and specifications for $\$ 10$.
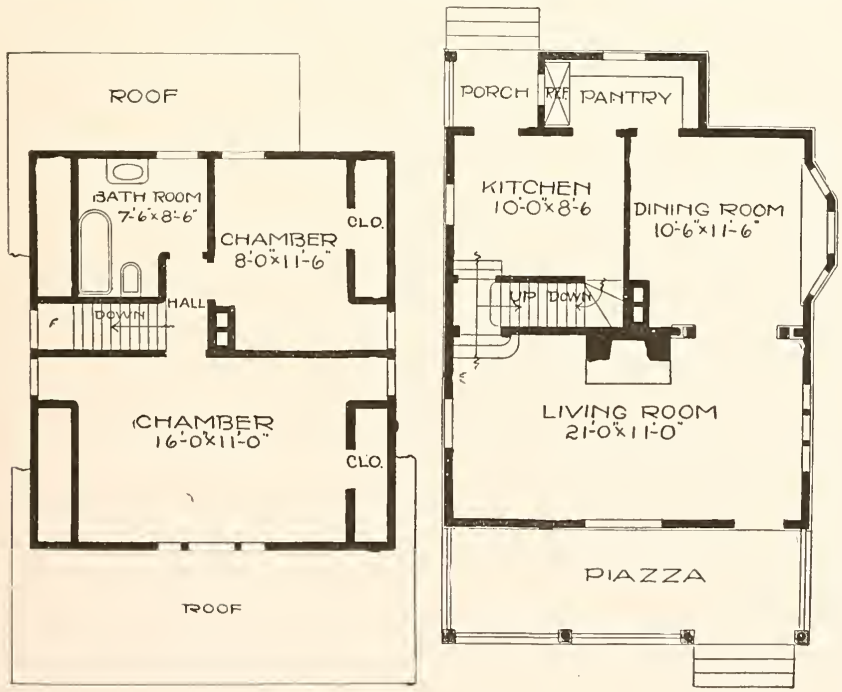

Complete plans and specifications for using Denison Load-Bearing Tile. licensed under Wilson-System Bearing IV a 11 Construction for $\$ 20$. 


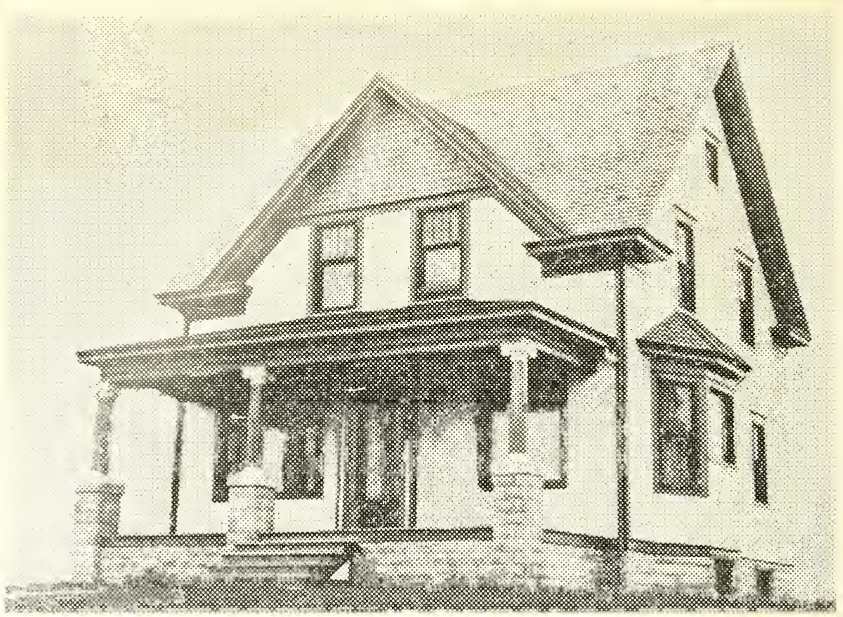

An Ideal Cottage-No. 890

Width 24 feet, depth 26 feet over the main part. A compact and economical sevenroom cottage, combination stairway and grade door, coat closet and large pantry. Birch or gum finish in first story and pine to paint in second, with birch floors throughout. Cost to build, $\$ 2,200$. Price of plans and specifications, complete, $\$ 15$.

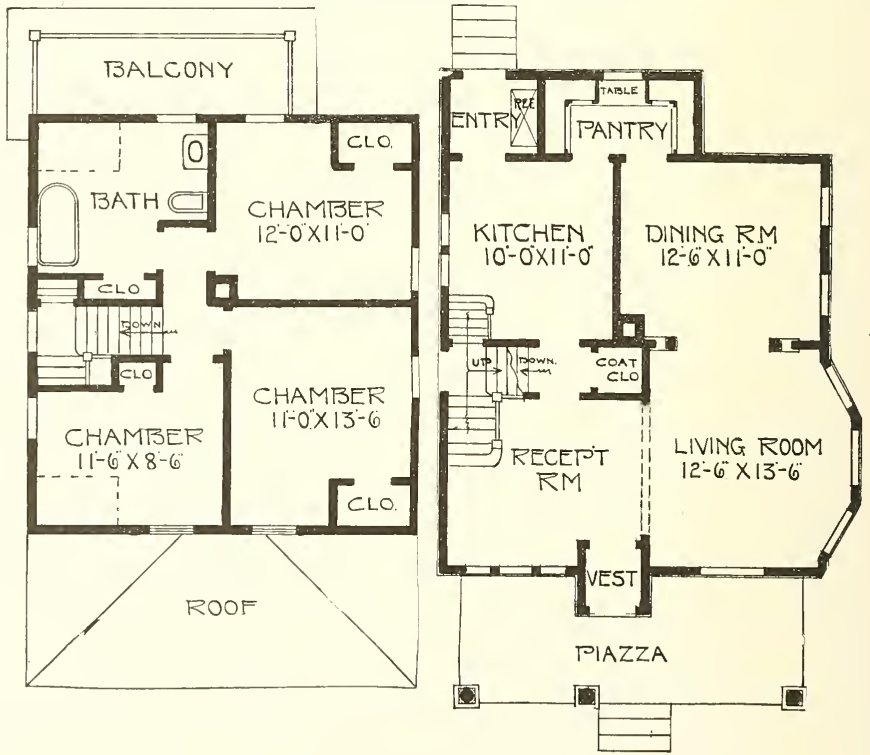

Complete-plans and specifications for using Denison Load-Bearing Tile, licensed under Wilson-System Bearing $W$ a 11 Construction for $\$ 30$. 


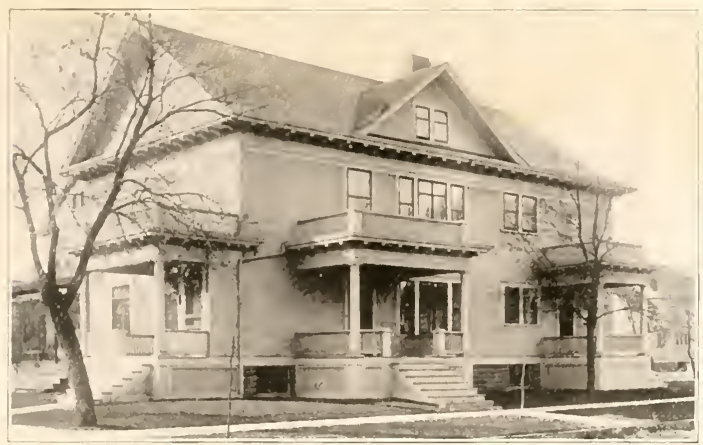

An Imposing Duplex-No. 785

An ideal building for a corner lot. Two indiridual front porches, no chance for an argument between tenants. The plan can be rerersed to fit any corner. Both front and rear stairways entirely separate. No comnection in any way with each other.

This kind of building makes a splendid investment and pays one owner $17 \%$ on his money invested in this building and lot. Size 28 feet wide, 48 feet deep orer the main part. Finished throughout in red gum or birch, birch or maple floors in both stories. Full basement, each story 9 feet. Cost to build, $\$ 5,200$. Complete plans and specifications $\$ 30$.

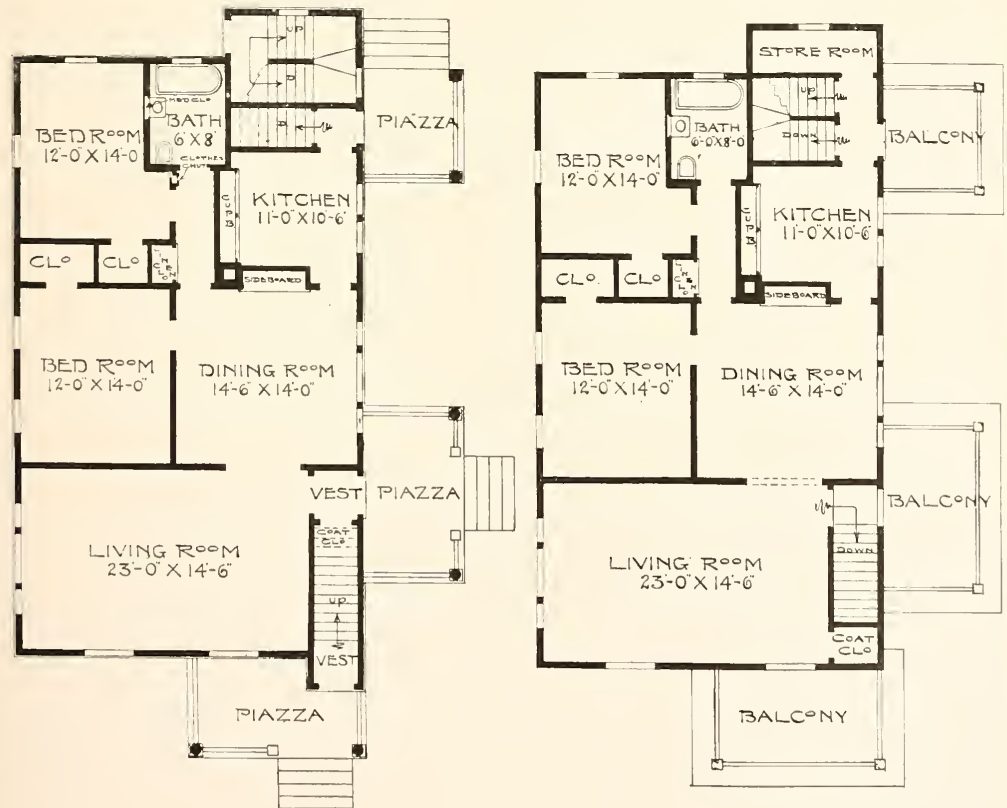

Complete plans and specifications for using Denison Load-Bearing Tile, licensed under Wilson-System Bearing IV a 11 Construction for $\$ 60$. 
A Good Money Proposition-No. 924

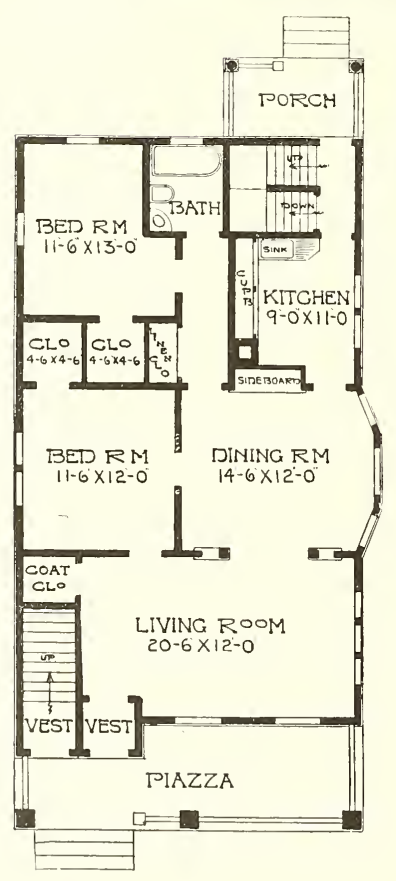

Width 26 feet depth 44 feet. A duplex built in a good location will bring in a rent of from $\$ 30$ to $\$ 50$ a month for each fiat. A flat dweller will appreciate the good features of these homes. A housewife will notice the size of the elosets first. A living room across the front of the house is a popular feature at the present time. There is a large piazza for each family, Birch finish and floors are used throughout each flat. The basement is 7 feet high, first feet high, first are 8 feet 9 inch es high. Cost to b uild $\$ 4,500$ Price of one com plete set of plans and specifications, $\$ 30$.

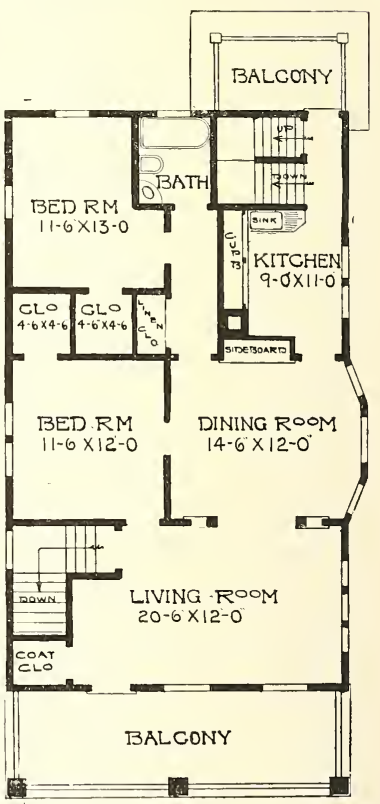

Complete plans and specifications for using Denison Load-Bearing Tile, licensed under Wilson-System Bearing $\mathrm{W}$ a 11 Construction for $\$ 60$. 


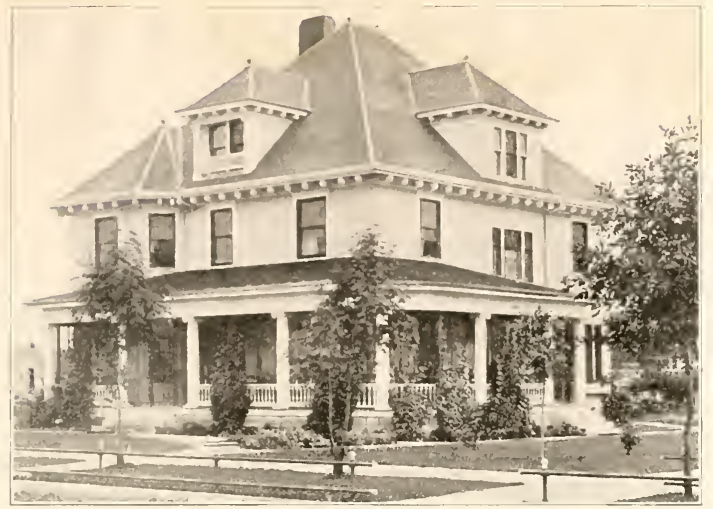

A Country Residence-No. 922

Width 36 feet, depth 40 feet. This house has been built as a country home. The large circular porch is an interesting feature, seldom incorporated in sinaller houses. Two large bays give the living room a beautiful symmetry and afford a view in all directions. The large reception hall may be entereil through either of two vestibules. The parlor is made a part of the reception room by columned arehways. There are four chambers. The hall is large enough to accommodate several chairs or a table. A very complete plan. Cost to build, $\$ 8,000$. Price, plans and specifications, $\$ 30$.

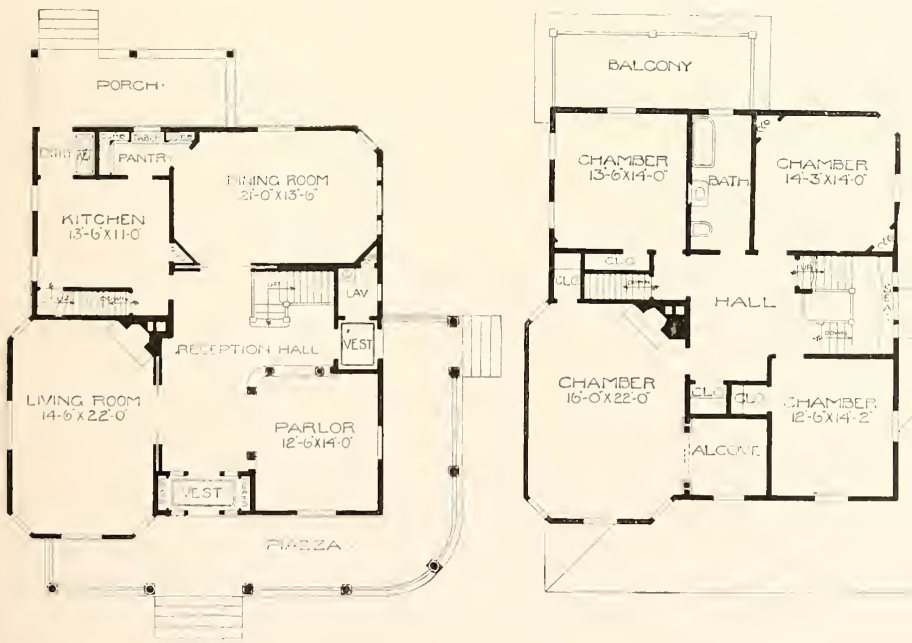

Complete plans and specifications for using Denison Load-Bearing Tile, licensed under Wilson-System Bearing IV a 11 Construction for $\$ 60$. 


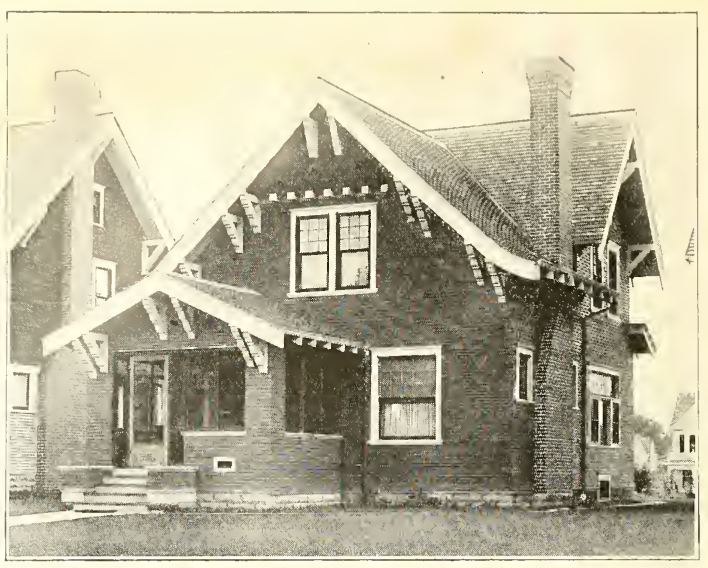

The Little Brown House-No. 940

Width 26 feet, depth 28 feet, over the main part. A splendid example of the modern type of story-and-a-half bungalows, the illustration speaks for itself. The first story is nine feet high and the second story eight feet high at all points. Cost to build, $\$ 3,200$. Plans and specifications for $\$ 25$.
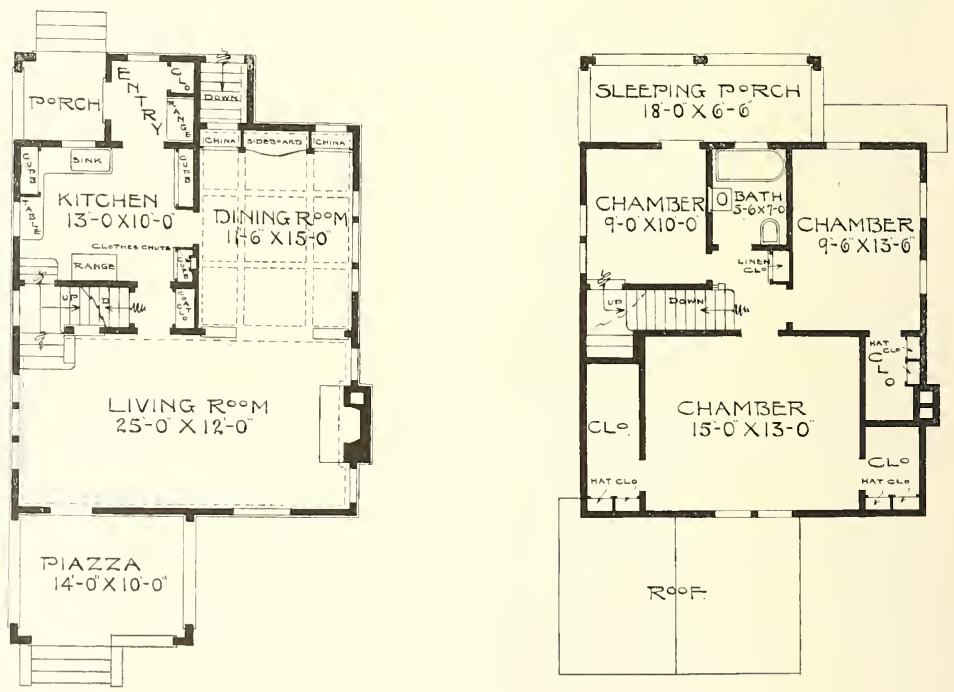

Complete plans and specifications for using Denison Load-Bearing Tile, licensed under Wilson-System Bearing $W$ a 11 Construction for $\$ 50$. 

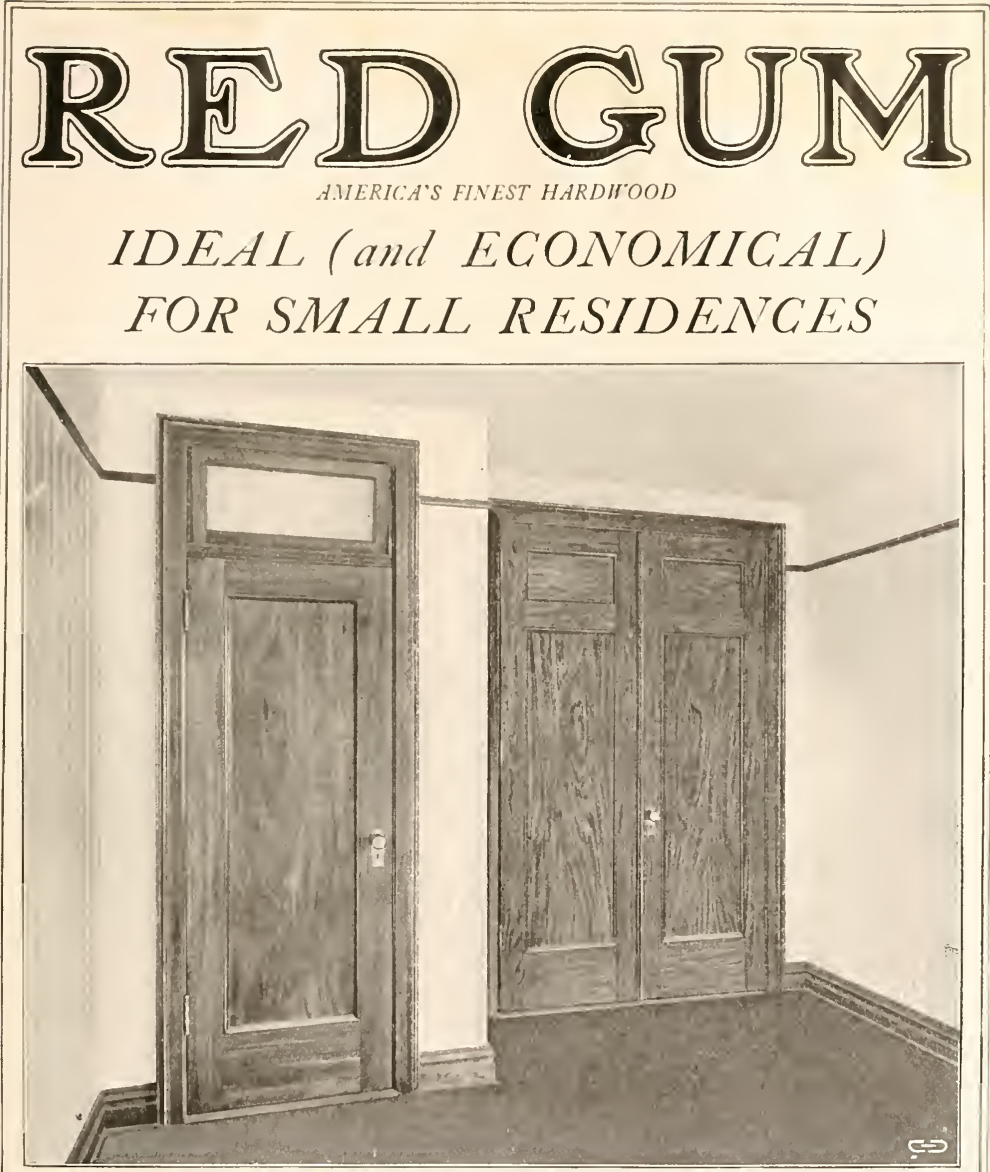

WHEN RED GUM IS USED IN COSTLY PUBLIC BUILDINGS (for interior finish and doors) it must be acknowledged to be the finest hardwood grown in America "for more modest uses." In beauty it stands on a par with Circassian Walnut and Mahogany. It is used throughout the United States not only in large and small residences and for fine furniture, but for the most elaborate woodwork of many of the great hotels, office and public buildings in the big cities.

YOU CAN AFFORD RED GUM FOR YOUR OWN HOME, for, you will be surprised to learn, it costs only a fraction of the price of the expensive hardwoods which are its only competitors. No matter what other wood you may have thought of using for Interior Trim, you will find that you can do beller by using RED GUM.

Write us about Red Gum. We will tell you how you can easily get it for your home. We will answer all your questions, and will send you pictures and general information of the highest value. Jusi try it. Wrile us fully. GUM LUMBER MFRS. ASSN., 901 Bank of Commerce Bldg., Memphis, Tenn. 


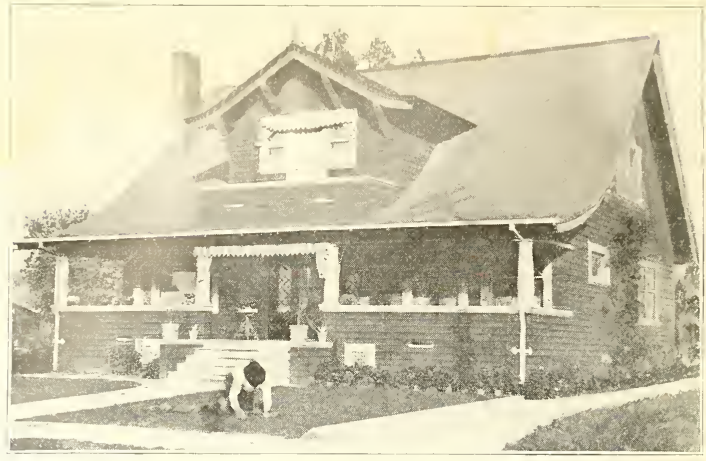

Sunshine-No. 921

Width 34 feet, depth 26 feet. The arrangement of the first floor is the prevailing idea in the present making of a complete home. This arrangement is compact, every inch of space being utilized to the best advantage. There are four rooms in the first story, all large and well lighted. The dining room has a beautiful built-in sideboard and china closets, which can be had for about $\$ 100$, complete with leaded glass doors and beveled plate mirrors. One can pass into the pantry for about three feet and open a door to the basement, thus combining an outside basement entrance with inside basement stairway. This is not only a practical home but an artistic one as well, being built at a cost less than that of a box of a home. Cost to build, $\$ 3,600$. Complete plans and specifications for $\$ 30$.
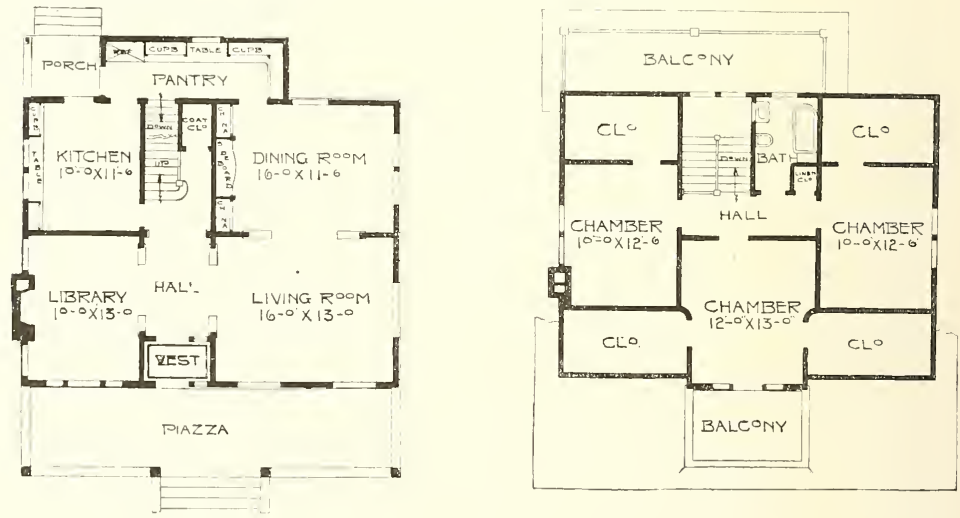

Complete plans and specifications for using Denison Load-Bearing Tile, licensed under Wilson-System Bearing $W$ a 11 Construction for $\$ 60$. 


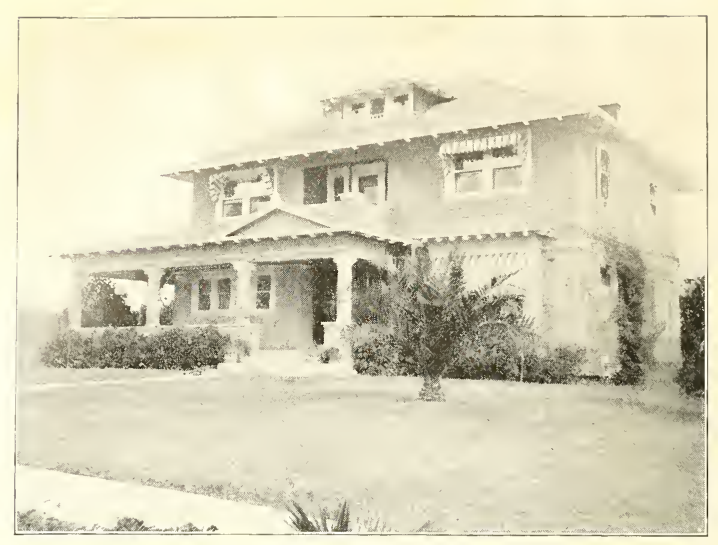

A Beautiful City or Suburban Home-No. 942

Width 36 feet, depth 32 feet. Simplicity is the key-note in the treatment of both the exterior and interior of this plan. The first story is covered with a coat of rough-cast cement and the second is shingled. Clapboards can be substituted for the cement if desired. The dining room is made beautiful by a beamed ceiling and paneled wainscoting. Another feature is the central hall with its broad stairway. In the library is a nook with a fire-place. There is a full basement $7 \mathrm{I} / 2$ feet deep. The first story is 9 feet high and the second $81 / 2$ feet high. The second story is finished in pine, enameled white, with birch doors, stained to represent mahogany. The dining room, hall, living room and library are finished in red oak, treated with the most improved stains, prepared especially to bring out the beautiful grain of the wood, with soft tones of brown. Cost to build, $\$ 4,800$. Price of plans and specifications, $\$ 35$. 


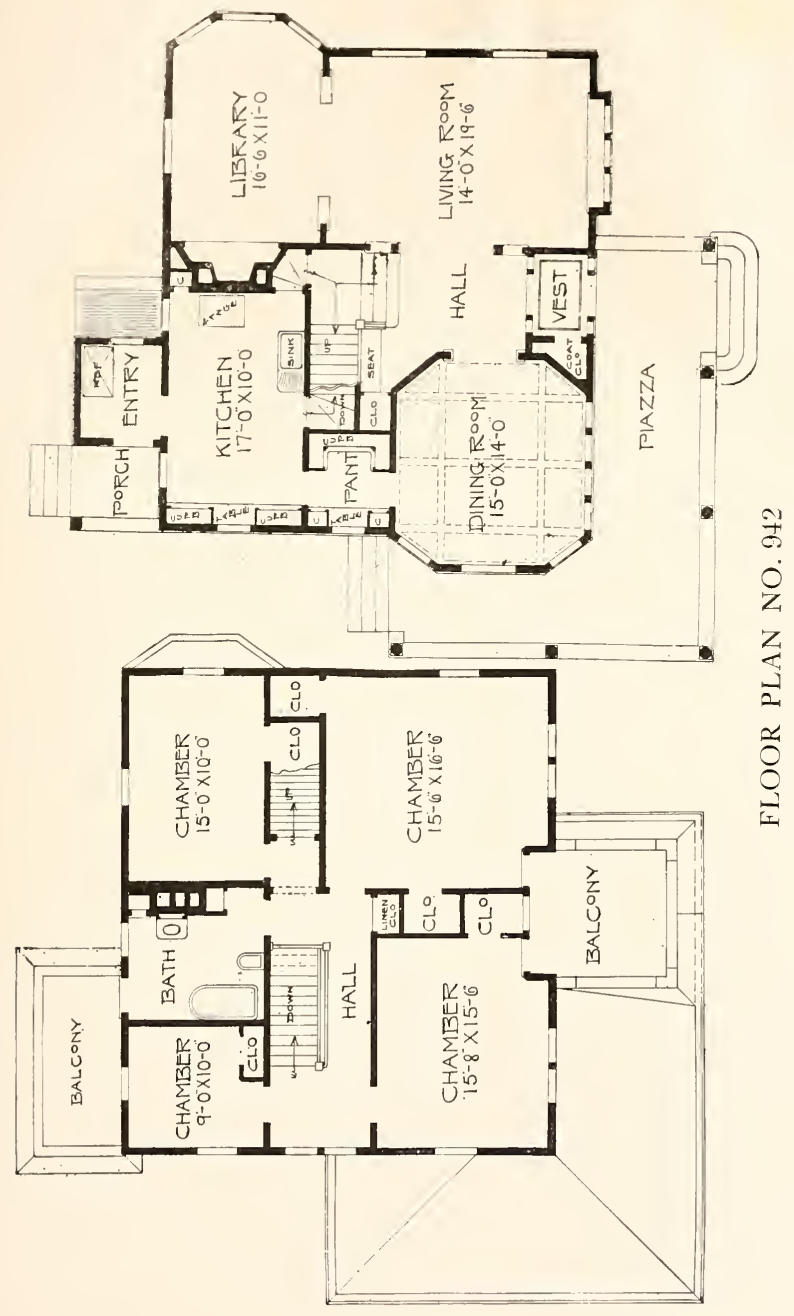




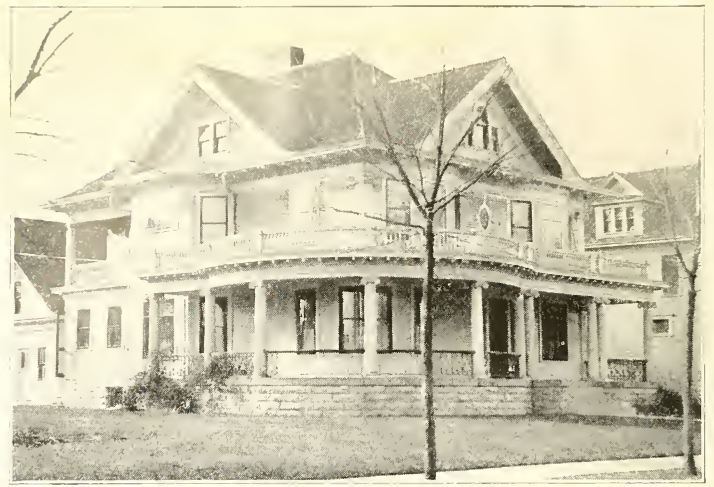

Colonial Design-No. 97

Here is the house for that good lot that you have been saving so long. This magnificent colonial residence, in my judgment, is an excellent example for you to study. You will notice how harmoniously the lines of the entire building are carried out. The house is 34 feet wide and 45 feet deep. Of course this is exclusive of piazzas. Full basement under entire house. First story 9 feet 6 inches, second story 9 feet. These heights in the clear when finished. If you are interested in this, or any of my other designs, would be pleased to have you call or write. Cost to build, $\$ 8,000$. Complete set of plans and specifications for $\$ 50$.
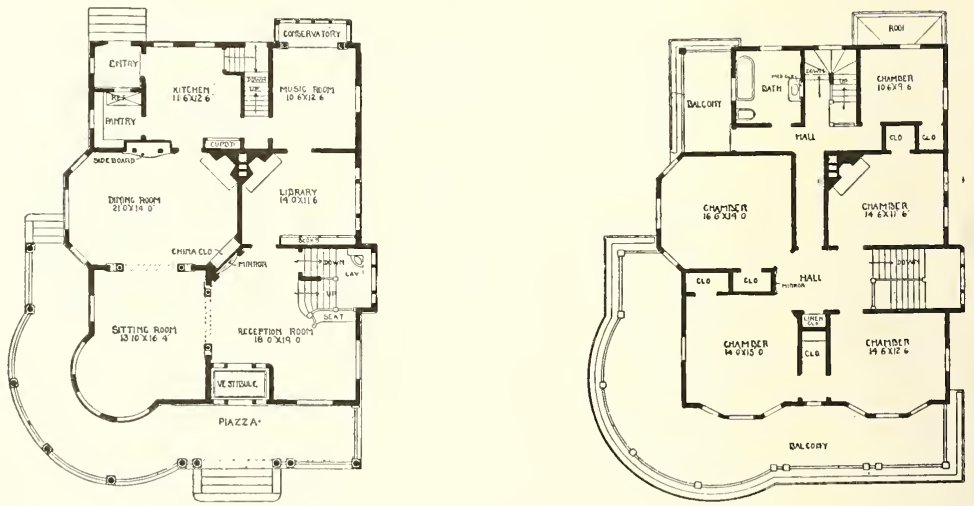

Complete plans and specifications for using Denison Load-Bearing Tile, licensed under Wilson-System Bearing IV a 11 Construction for $\$ 100$. 


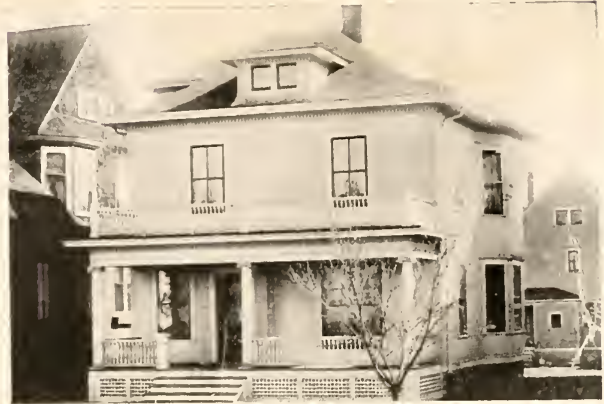

One Of Our Prize Designs-No. 111

Built 25 times

The arrangement of the floor of this house is the same as No. 86, except the house is reversed and the exterior is treated with the hip roof instead of a gable roof. Birch or maple floors throughout. The size of this house is $24 \times 26$ feet, first story 9 feet, second story 8 feet, with full basement. First story finished in gum or birch, second story pine to paint. This house cost to build, $\$ 2,500$. I will furnish one complete set of plans and specifications for $\$ 20$.
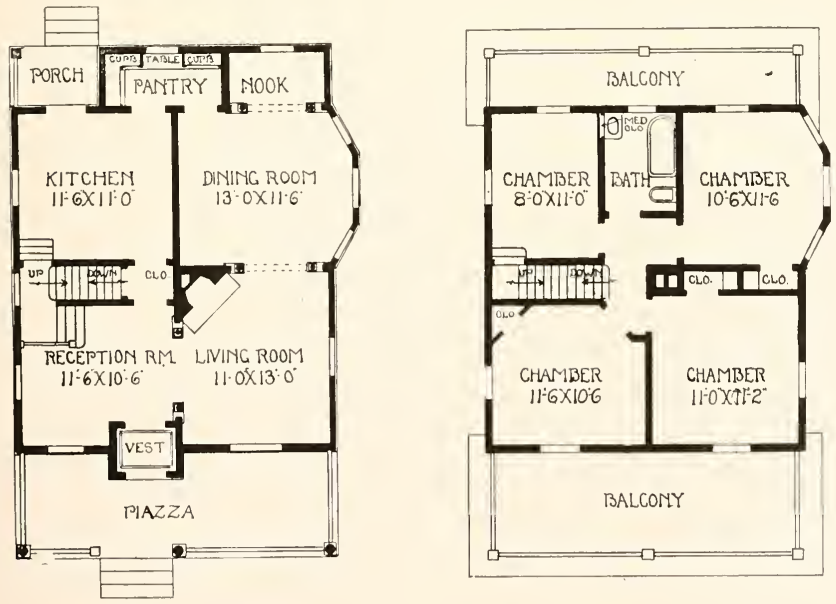

Complete plans and specifications for using Denison Load-Bearing Tile, licensed under Wilson-System Bearing $\mathbf{~}$ a 11 Construction for $\$ 40$. 


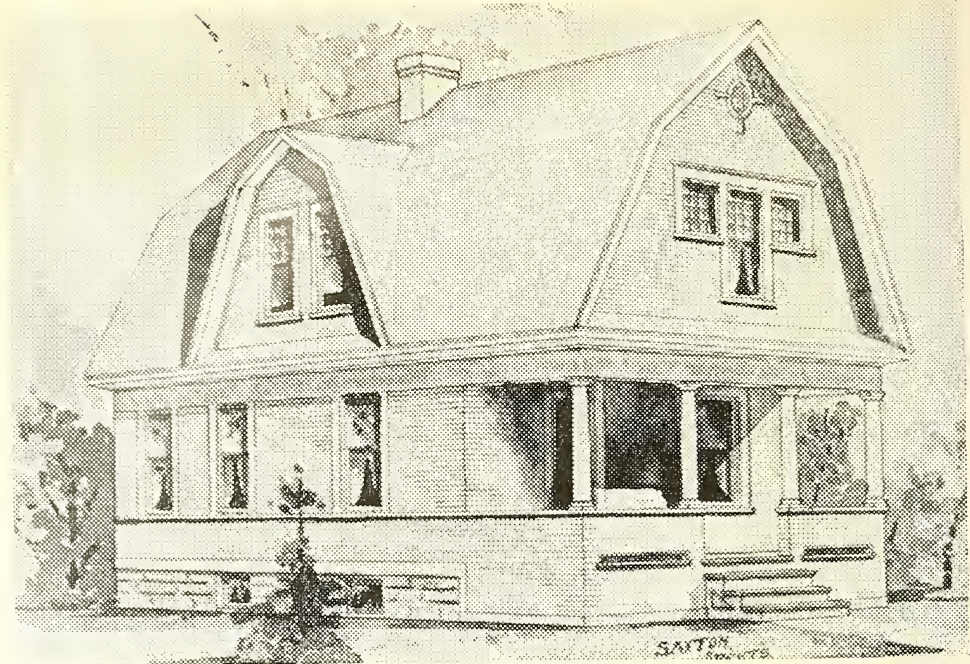

A Low Priced Colonial-No. 244

One of the most modern low priced colonial houses in the city of Minneapolis, built on Brown Brothers' new addition. Size of the house is 26 feet $\times 25$ feet. First story $\&$ feet 6 inches, second story 8 feet. Rooms all full height in second story, low parts cut off by large closets. This little cottage speaks for itself. Finish in first story gum or birch, second story pine to paint. Birch or maple floors throughout. Cost to build, $\$ 1,800$ Complete plans and specifications for $\$ 10$.
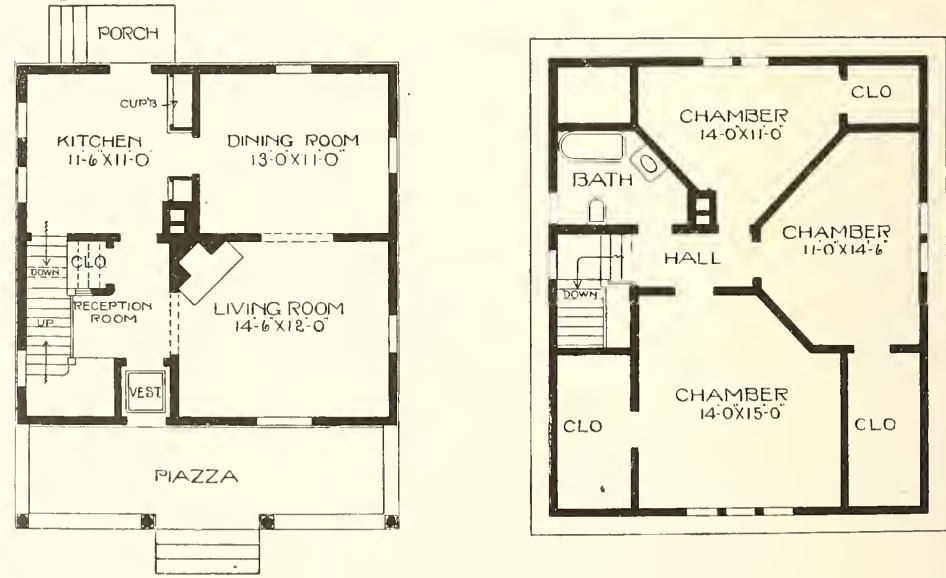

Complete plans and specifications for using Denison Load-Bearing Tile, licensed under Wilson-System Bearing W a 11 Construction for $\$ 20$. 


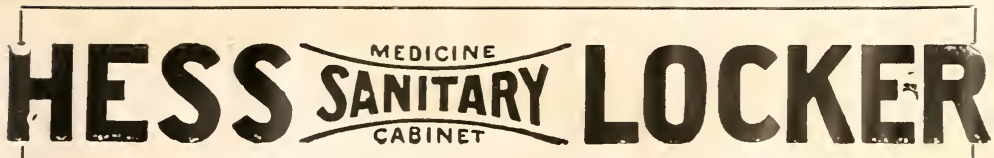

\section{THE BEST THING for the BATHROOM}

Dust, germ and vermin proof. Made of solid, smooth steel, beautifully enameled inside and out with best white baked enamel, as clean and smooth as a china

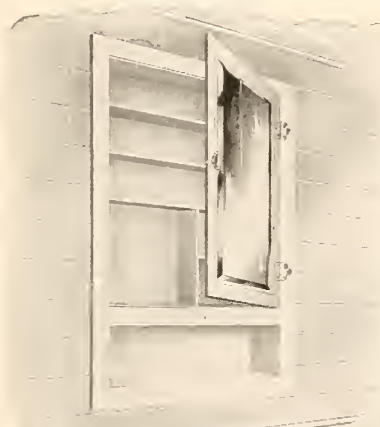

The Recessed Cabinet plate. Bronze handle and hinges, polished and nickel plated; shelves of enameled steel or polished plate glass, adjustable; plate glass mirror with beveled or plain edges.

They are suitable for the finest bathrooms, yet less expensive than wood.

Made in four sizes and four styles - to recess or to hang on the face of the wall.

We sell subject to your satisfaction and guarantee arrival in perfect condition. A dainty illustrated booklet is yours, if you will ask for it.

\section{Hess Warming \&

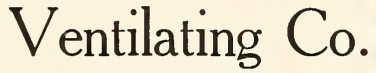

917-B Tacoma Building,

CHICAGO, ILL.

Makers, also, of Steel Hot Air Furnaces and Family Dish-Wasbing Machines The Outside Cabinet 


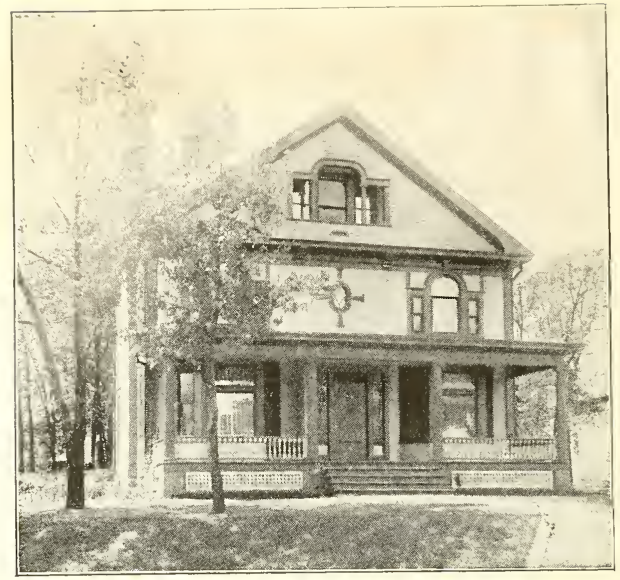

\section{A Colonial Design-No. 383}

Here is an ideal design for a colonial house, the arrangement is certainly a pleasing one. Finish is first story birch or gum, second story pine to paint. Birch or maple floors throughout. The house can be built for $\$ 4,000$. There is an elegant big attic, which can be left in one large room, or converted into servants' quarters. Complete plans and specifications for $\$ 25$.
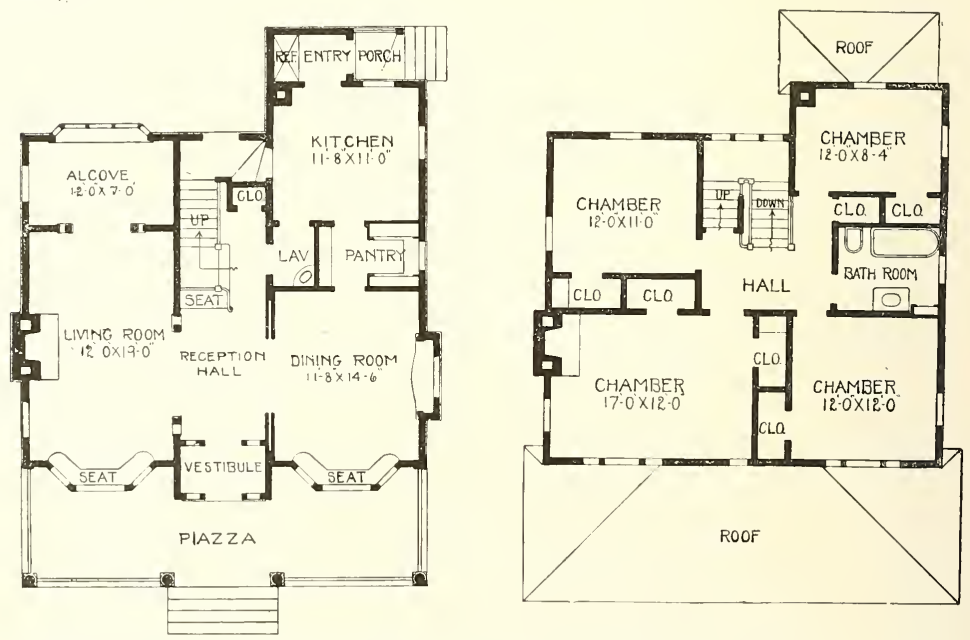

Complete plans and specifications for using Denison Load-Bearing Tile, licensed under Wilson-System Bearing $W$ a 11 Construction for $\$ 50$. 


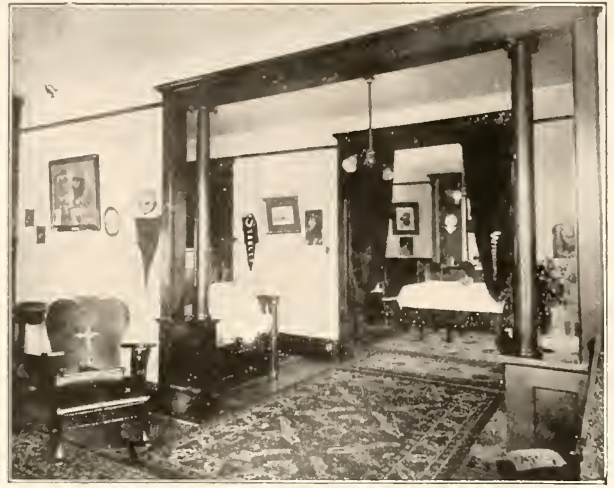

Interiors of No. 383

The two interiors are taken from 383 , one from the reception hall looking back through the living room into alcove, the other taken in the living room looking through the reception hall into the dining room. It is a pure colonial design.

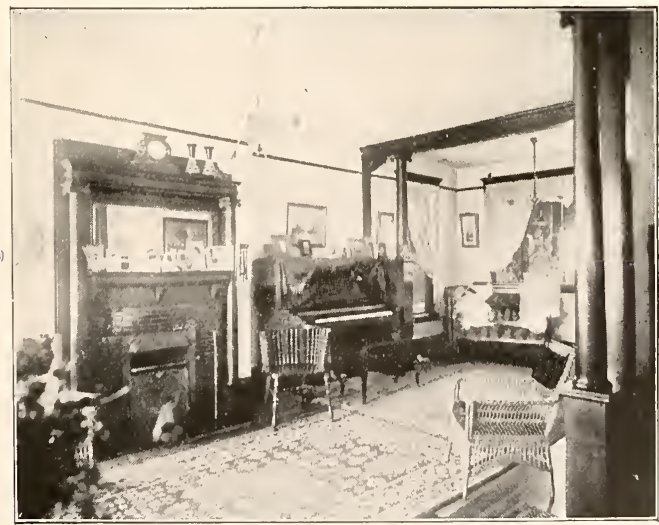




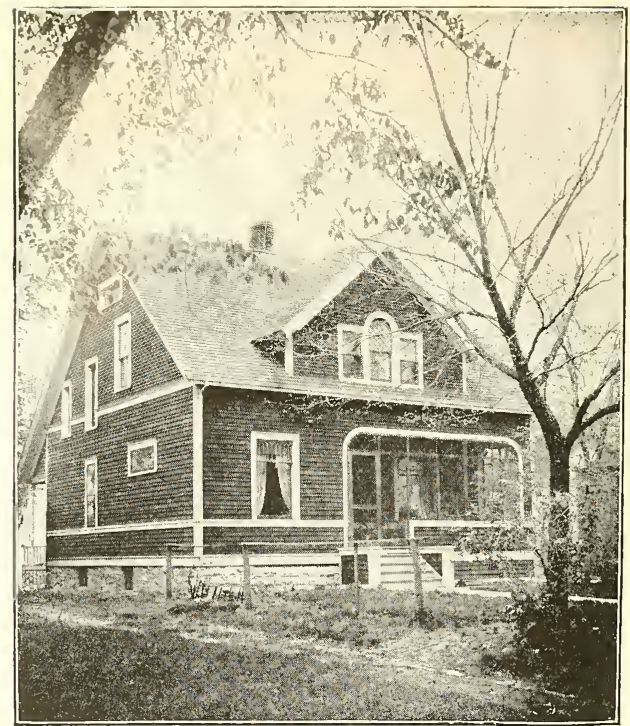

A Practical Cottage Home-No. 306

Built 300 times.

The first floor contains four splendid rooms and I believe the whole plan will speak for itself.

Second floor composed of three good sized chambers, bath room, and ample amount of closet room. Finish in first story gum or birch, second story pine to paint. Birch or maple floors throughout.

Dimensions-30 feet wide x 30 feet deep; ceiling or first story 9 feet 6 inches; ceiling of second story 9 feet. Cost $\$ 2,400$. Complete plans and specifications for $\$ 15$.
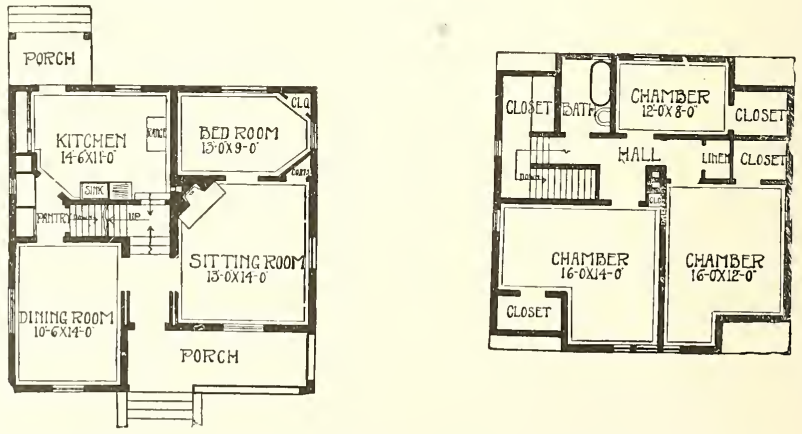

Complete plans and specifications for using Denison Load-Bearing Tile, licensed under Wilson-System Bearing Wal1 Construction for $\$ 30$. 


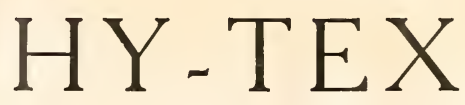

Stands for

\section{Quality}

Variety of shades and Textures

Service

Prices as low as consistent with highest Quality and Service

Call for HY-TEX Brick in your plans and specifications,

Insist on having HY-TEX Brick used in your building,

And you will have the best the Art and Science of Brickmaking can give you.

Hy-tex Brick are Manufactured by

\section{Hydraulic-Press Brick Company}

211 So. Fourth Street

Minneapolis - - Minnesota

AGENTS FOR

Denison Load-Bearing Tile Toch Brother's Dampproofing Paints American Terra Cotta \& Ceramic Co.

Mortar Colors Fireproofing \& Building Tile Wall Coping Metal Lath Cement Flue Lining 


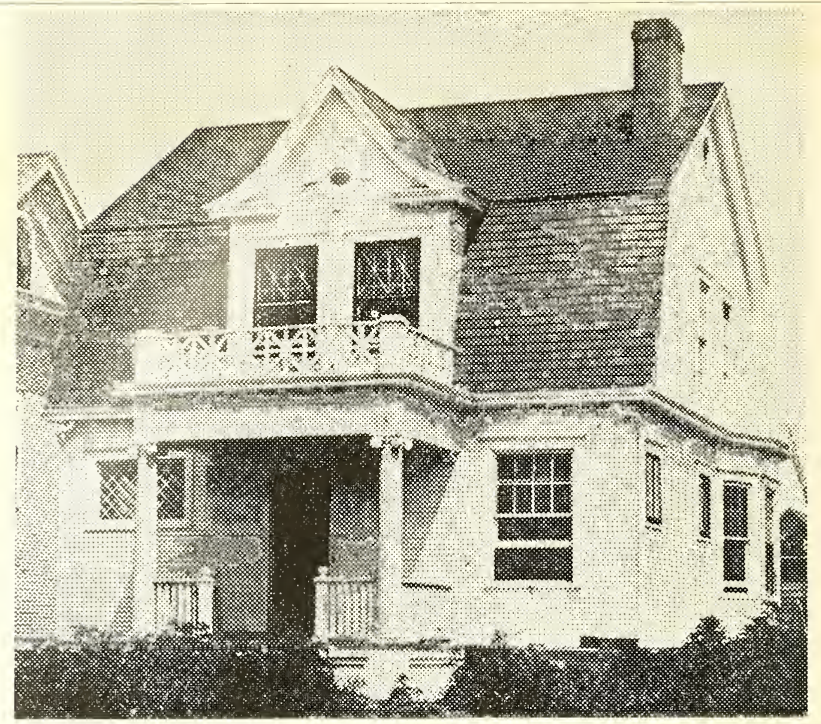

\section{A Cosy Little Home-No. 234}

Here is one of the most complete and modern little cottages that I ever produced and ean be built for $\$ 2,600$, ineluding hardwood floors, gum or birch finish down stairs in the three principal rooms. The balauce of the house is finished in pine to paint. There are three beautiful chambers in the second story. The size of the house is 26 $\mathrm{ft}$. x $28 \mathrm{ft}$. over all. Full basement, first story $9 \mathrm{ft}$., second $8 \mathrm{ft} .6 \mathrm{in}$. Complete plans for this beautiful house for $\$ 15$.
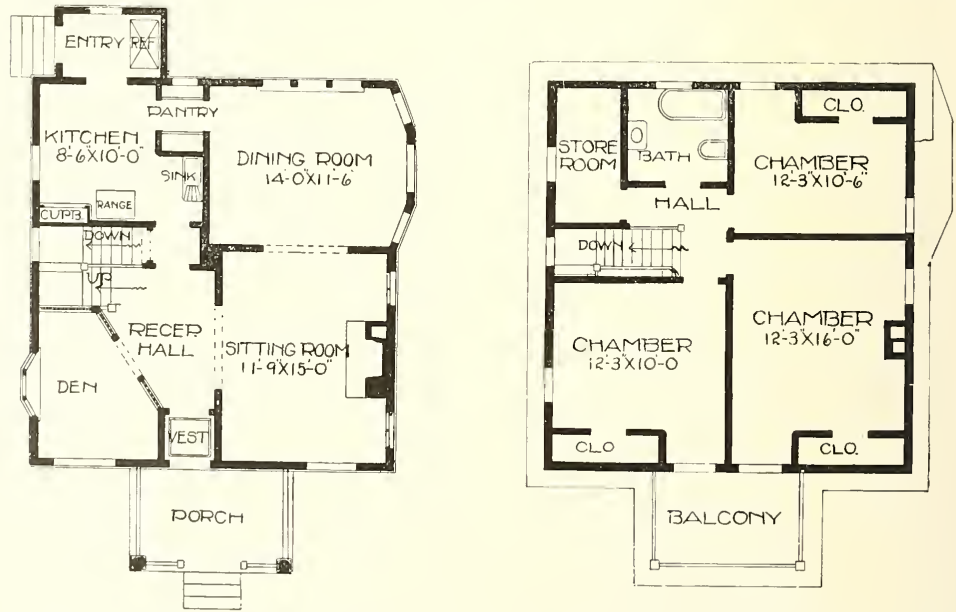

Complete plans and specifications for using Denison Load-Bearing Tile, licensed under Wilson-System Bearing $W$ a 11 Construction for $\$ 30$. 


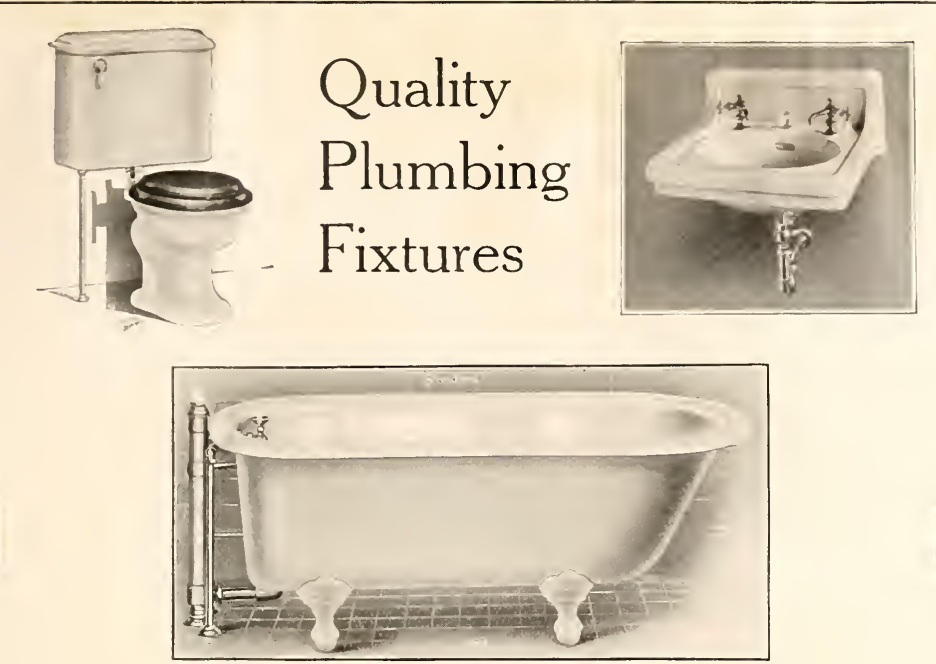

The above are exact illustrations of plumbing fixtures specified for houses in this catalog.

\section{Our Show Rooms Show Our Efficiency}

The specification of QUALITY PLUMBING FIXTURES in your building plans, is the same as making a positive paying investment.

It means that the first expense will dwindle to an early average that is negligible - while during the same time assured efficient service is given year after year.

When you are ready to decide on your plumbing fixtures visit our Display Rooms, where you can make your selection with the positive assurance that whatever style you select will be appropriate and distinctive in every detail.

We have a full line of the latest and most up-to-date designs in plumbing fixtures and house heating, hot water or steam boilers, on display at all times, and cordially invite you to visit and inspect our entire line.

\section{CENTRAL SUPPLY COMPANY}

"A House of Stability with a Force of Ability"

Manufacturers and Dealers

Plumbing, Heating Engineers, Gas, Water and Mill Supplies

312-314-316 Third St. So. Minneapolis Minn.

P. J. FREY, Pres. \& Gen. Mgr. A, L. POTTER, Mgr. of Sales A. C. ECKMAN, Asst. Treas. 


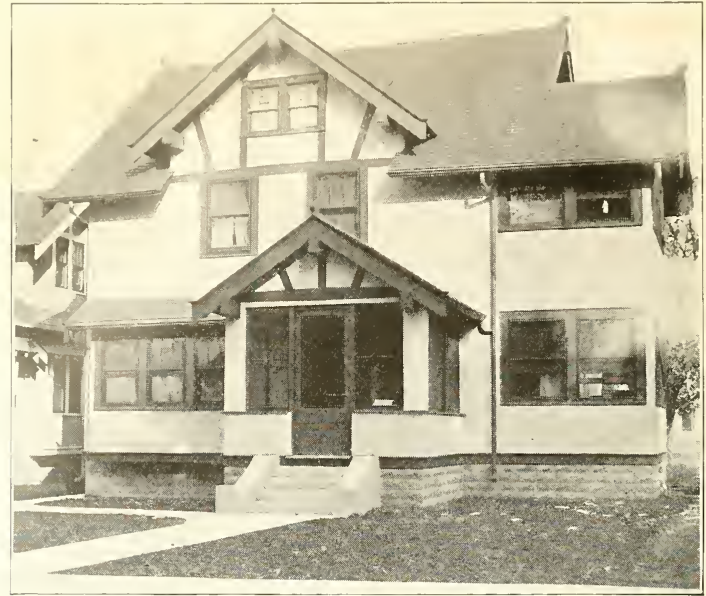

A Tired Man's Retreat-No. 778

This home is restful to look at and when you enter the interior is still more so. A beautiful living room, sun room opening off with French doors and an unusually well planned combination stairway. Second story contains three splendid chambers besides a large sleeping porch. Abundance of closet space. Birch or maple floors throughout. Red gum, birch or oak finish in first story, pine to paint in second story. Size 28 feet wide and 26 feet deep over the main part. Full basement. First story 9 feet, second story 8 feet. Cost to build, $\$ 3,400$. Complete plans and specifications $\$ 25$.
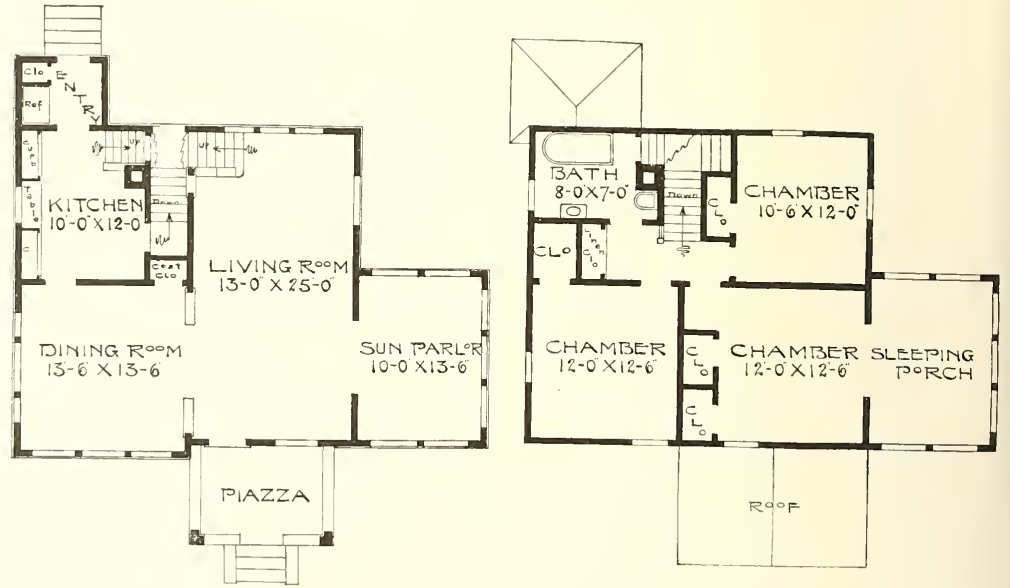

Complete plans and specifications for using Denison Load-Bearing Tile, licensed under Wilson-System Bearing $W$ all Construction for $\$ 50$. 


\section{Save the Dealer's Profit -- Buy as Dealers Buy AND WHERE THEY BUY}

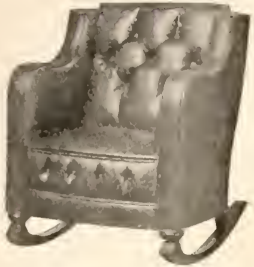

Shipped on approval

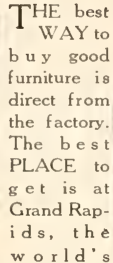

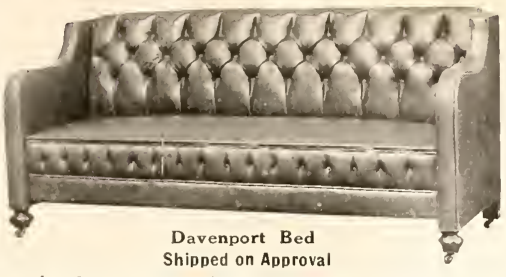

Quality Furniture at Factory Wholesale Prices

Offers you not merely a big economy, but insures you the latest and best from this great furniture market - the heart of the high-class furniture industry.

Quality Furniture - the Kind That Lasts a Life Time

Has satified thousands of discriminating people of taste-AND SAVED THEM MONEY BESIDES. Every piece is always sold on this policy-your money's worth or your money back. We will furnish your home or your office complete-no matter how simple or how elaborate your needs-and anything may be returned at our expense, IF NOT PERFECTLY SATISFACTORY,

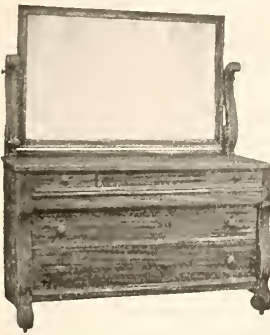

Shipped on Approval
Why not buy the $\mathrm{kind}$ of furniture that gives life-time Quality Furniture offers you the choice of the world's b e s t market and at wholesale factorydirect to you -prices.

You c a n buy our furniture in only on e waydirect from the factory at cost plus one

\section{FURNITURE TO LIVE WITH}

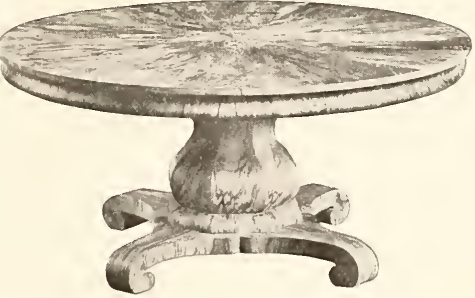

Shipped on Approval

small profit. You can keep it on only one condition-that you are perfectly satisfied with it. Our business success depends upon your re-orders. Hence upon your perfect satisfaction with the quality and economy of ourfurniture. Let us save you money-buy in the world's greatest furniture market, at wholesale factory prices.

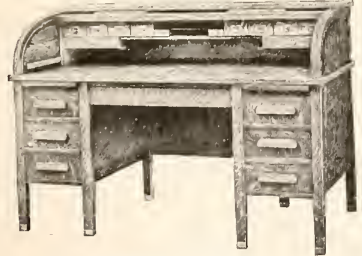

Shipped on Approval

From our large beautiful and richly illustrated furniture "DE LUXE" textbook you may make your selection from our entire line as $s$ at isfactorily as though you had everything in reality beforeyou. You have our promise that whatever you choose must satisfy you and please you or we send your

Shipped on Approval Shipped on Approval
This beautiful "Character in. Furniture De Lux."--book-will be sent you prepaid by Parcels Post

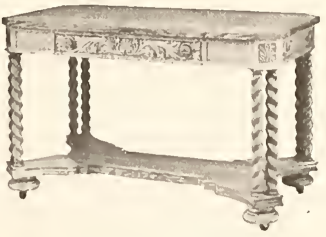

Shipped on Approval for 25 cents in stamps or silver-to pay for postage and packing-(we credit this on your first order or return your money if you wish to return the book).

Send for this guide to ECONOMY and QUALITY to-day.

SAVE THE DEALERS PROFIT $=$ BUY AS DEALERS BUY QUALITY FURNITURE CO.

No. 307-312 Quality Bldg. (Formerly Grand Rapids Furniture Mfg. Co.) GRAND RAPIDS, MICH. 


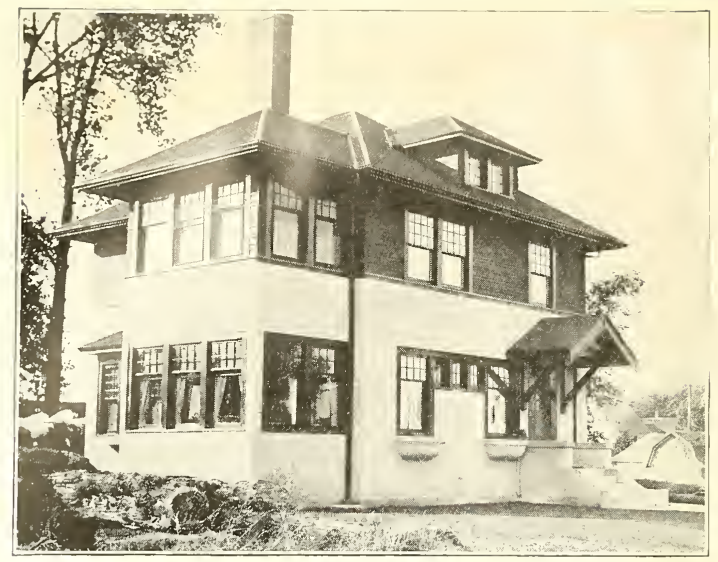

A Study in Shingle and Rough-Cast-No. 780

The sun room and sleeping porches are now a permanent part of the home and seem to be as essential as the chambers and bath. This plan has both of the above named features incorporated in it and the two floor plans are as complete as can possibly be made. They include every feature that a housewife has ever desired in the way of convenience. There is really no necessity for further description of this plan as everything is shown plainly on the two floor plans. The size of the house is 26 feet wide and 28 feet deep over the main part. Full basement, first story 9 feet, second story 8 feet. Birch or maple floors throughout. First story finish birch, red gum or red oak, second story pine to finish. Cost to build, $\$ 3,600$. Complete plans and specifications $\$ 25$.

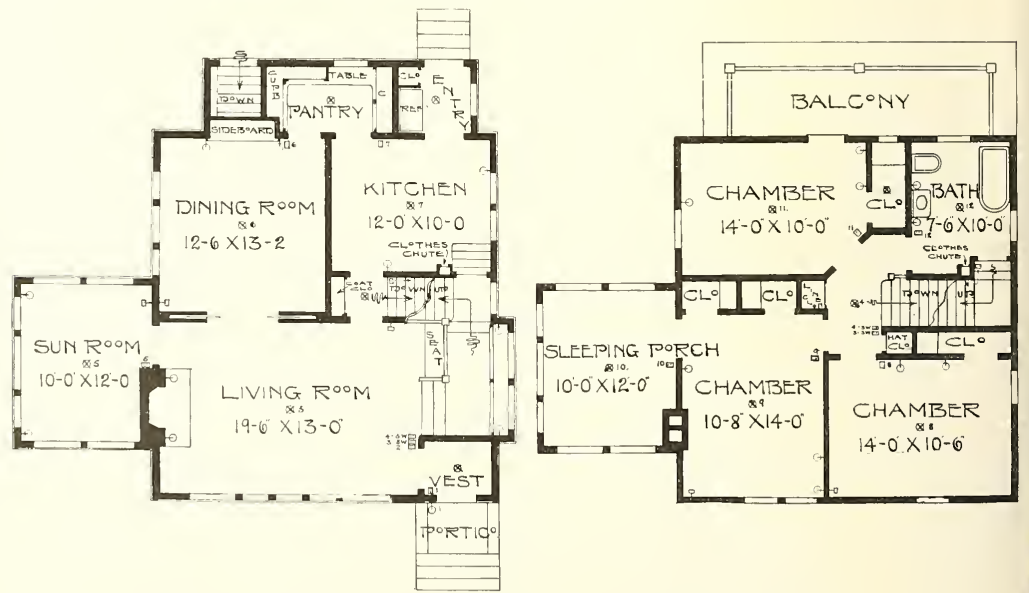

Complete plans and specifications for using Denison Load-Bearing Tile, licensed under Wilson-System Bearing $\mathrm{W}$ all Construction for $\$ 50$. 

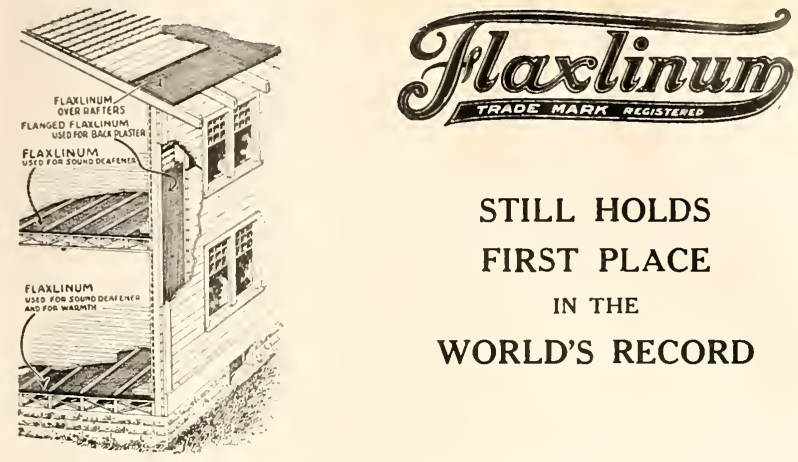

STILL HOLDS

FIRST PLACE

IN THE

WORLD'S RECORD

It is cheaper to build a warm house than to heat a cold one. Ask any user-they are all boosters. We do not try to cover up defects with paper-there are none. It is cheaper and better than back plaster.

It defies heat, cold and noise. Every user has found it indispensable. The cost is fully paid the first year in fuel saved. We will be pleased to get in close touch with you. Ask us questions.

We can save you 30 per cent on your coal bill. Write for sample of Flaxinum and booklet. It is free for the asking. Send a postal card today-right now.

\section{NOR'THERN INSULATING CO.,}

1400 University Avenue

St. Paul, Minnesota 
This bungalow has a very attractive first and second floor plan. As large liring rooms predominate in all the new plans, this one is supplied with a living room across the entire front, a dining room and kitchen in first story besides a good sized den, large pantry space and goor sized entry and combination stair way.

Second story has three large chambers and a sleeping porch in the rear.

Full basement under the entire house. First story 9 feet, second story 8 feet. Size 26 feet by 28 feet over main part. Finish to be red oak, birch or red gum

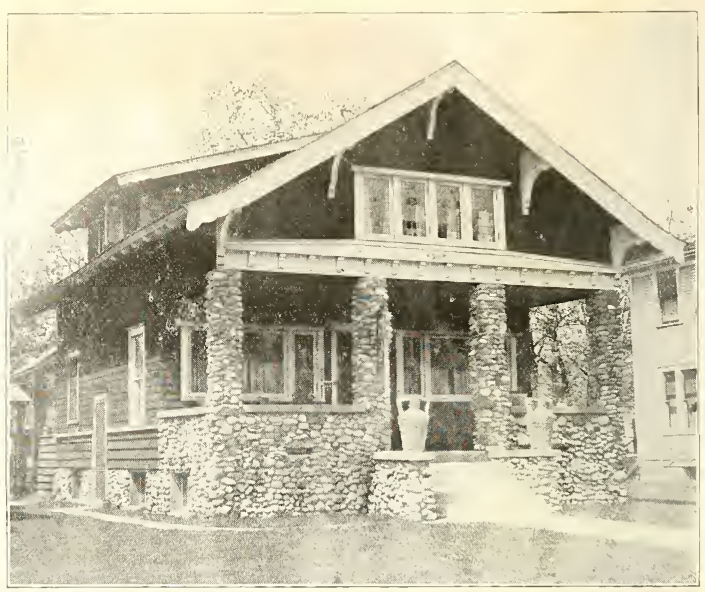

A Picturesque Cobble Stone Bungalow-No. 982 throughout first and pine to paint in second story. Birch or maple floors throughout. Cost to build, $\$ 2,700$. Complete plans and specifications $\$ 20$.
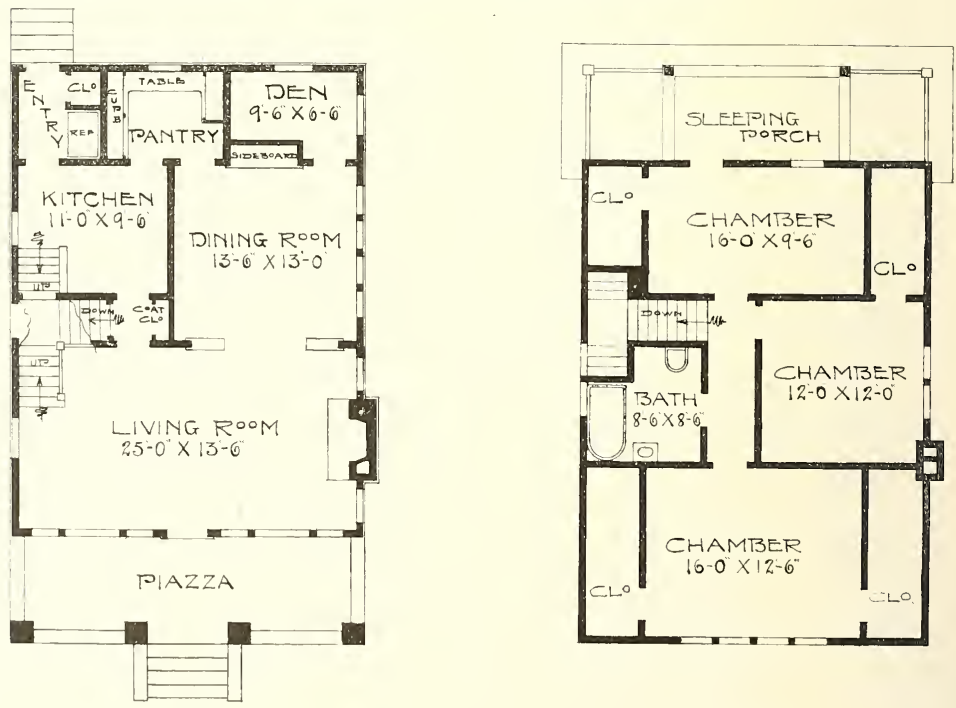

Complete plans and specifications for using Denison Load-Bearing Tile, licensed under Wilson-System Bearing W a 11 Construction for $\$ 40$. 


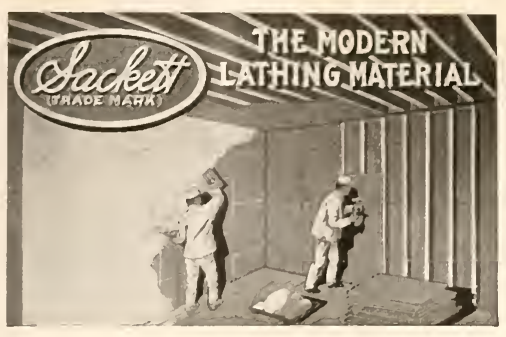

Build Wisely

Good builders everywhere use

\section{SACKETT PLASTER BOARD \\ "Instead of Lath"}

Because it is a permanent investment in Comfort, Protection and Economy. SACKETT is the "logical successor to wood lath." Nailed direct to wood studs and joists and plastered over, making a solid wall of Gypsum 3/4 inches thick. Protects the building from fire; keeps out winter's cold and summer's heat; makes the building more sanitary, more comfortable and a better investment. Investigate Sackett Plaster Board before you build.

Write today for Booklet 31

- mailed free

\section{United States Gypsum Co.}

New York Cleveland Chicago Minneapolis San Francisco

\section{The Bath Modern and a "Pittsburg"}

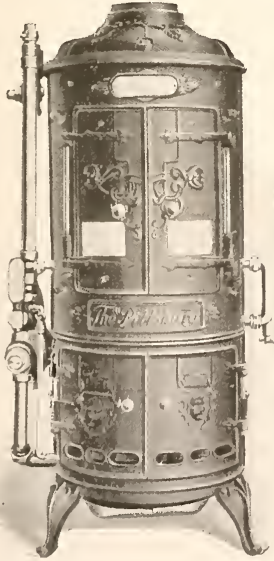

The most elaborate bath equipment would be merely ornamental without an unlimited supply of steaming hot water instantly available.

With a"Pittsburg" automatic Gas Water Heater connected to the hot water pipes, a turn of the faucet at any fixture- bath, shower, lavatory, Kitchen-provides hot water "Quick as a Wink."

Offices in Minneapolis, Pittsburg and all large cities

Loomis Specialty Company

Minneapolis 


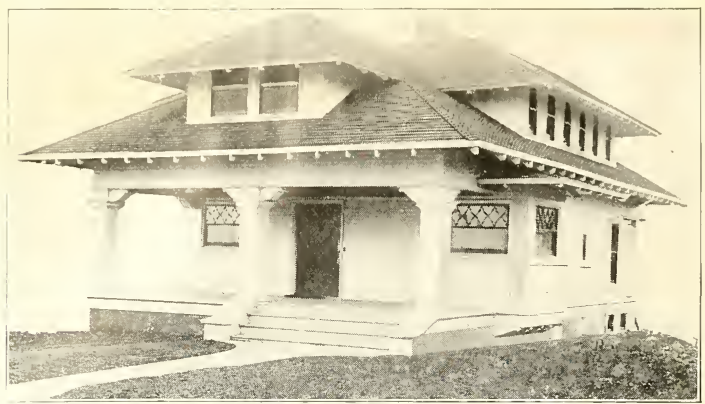

A Modest Cottage Plan-No. 762

For a story and a half bungalow this plan makes a very complete home. A beautiful living room across the entire front with seats built in a bow window at corner of room as shown by the floor plan. There is a nice dining room and kitchen, well arranged, also a bed room and bath room in the first story, this being quite an unusual feature in most homes.

There is also space in the second story for three more chambers if one desires. First story finished in birch, red gum or red oak with birch or maple floors throughout. Basement under the entire house, first story 9 feet, second story 8 feet. Size 26 feet wide and 38 feet deep. Cost to build. $\$ 2,100$. Complete plans and specifications $\$ 15$.

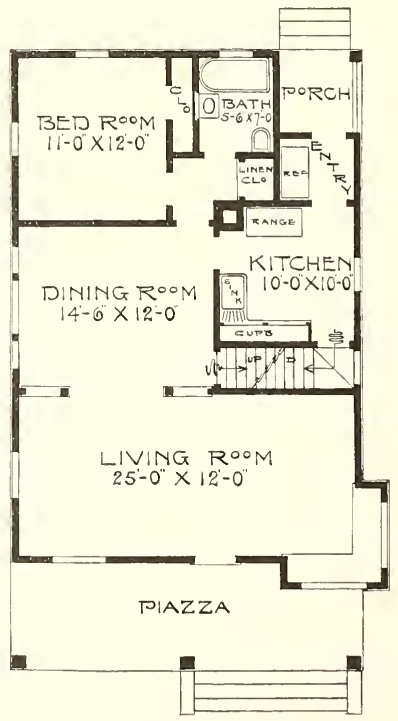

Complete plans and specifications for using Denison Load-Bearing Tile, licensed under Wilson-System Bearing $\mathrm{W}$ a 11 Construction for $\$ 30$. 


\section{Let $\underline{\text { Us Engineer }}$ Your Heating Plans}

No cost or obligation to you to find out before you buy, exactly what form of heating is most suitable and economical for your home, and the right size for efficient service and fuel economy. Our expert heat ing and ventilating engineers will engineer your problem.

\section{Stewart Furnaces}

The Stewart line embraces sizes and types to meet every heating requirement in warm air and combination furnaces for all kinds of fuel.

\section{WRITE FOR FOLDER B}

Find out why our engineering service will protect you in selecting a heating plant. Get our forms, draw your plans, and we will give you expert engineering absolutely free. Write for Folder B. today.

THE FULLER-WARREN CO. MILWAUKEE, WISCONSIN
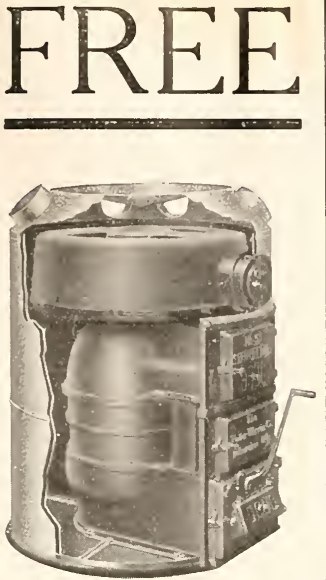

\section{The Only Real Stains}

If you have only seen the crude and tawdry colors of the thinned-painted imitations of

\section{Cabot's Shingle Stains}

You have no idea of the beautiful coloring effects of the true Stains. They are soft and deep, like velvet, but transparent, bringing out the beauty of the wood grain. Half as expensive as paint, twice as handsome, and the only Stains made of Creosote, "the best wood preservative known."

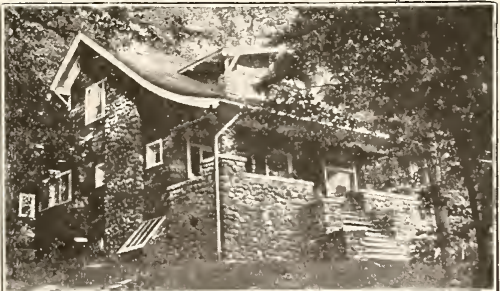

Stained with Cabot's Creosole Stains and lined with Cabot's Quilt. Designed and built by Tracy L. Freeman, Nyack, N. Y.

"Cabot's Stains are the only Stains I use when I get up the specifications, and if I build where other's specifications call for other stains I try to get them over to Cabot's, for the results are better for all concerned."

TRACY L. FREEMAN

CABOTS QUILTS

Cold-Proof, Heat-Proof, Sound-Proof, 28 Times Warmer than Common Paper

CABOT'S WATERPROOF CEMENT STAINS

For Rainproofing and Artistically coloring Stucco

SAMUEL CABOT, Inc., Mfg. Chemists, Boston, Mass.

24 W. Kinzie, Chicago

1133 Broadway, New York

JOHNSON, JACKSON \& CORNING, Agents, Minneapolis 
This makes a beautiful duplex home, giving two grand apartments under one roof, and would be a credit to any locality in any town or city. Size 35 feet wide and 60 feet deep, exclusive of sun-rooms and sleeping porches.

These beautiful floor plans are really self-explanatory, and it is not necessary to give a lengthy description of them. The arrangement of the rooms is as near perfect as can be obtained in a plan of this kind.

Full basement. First story 9 feet, second story 9 feet. Red gum or red oak finish in first story; pine to paint in second, birch or maple floors throughout. Cost to build, $\$ 11,000$. Complete plans and specifications $\$ 50$.

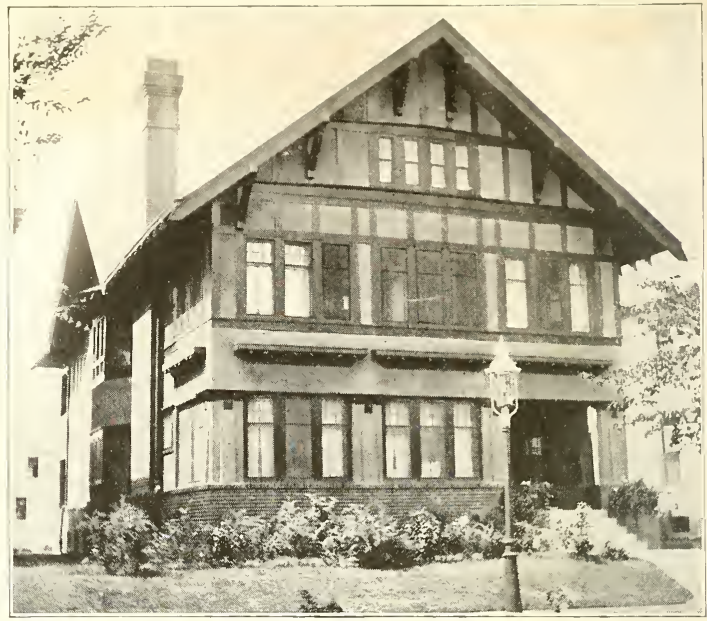

English Half Timber Duplex-No. 770
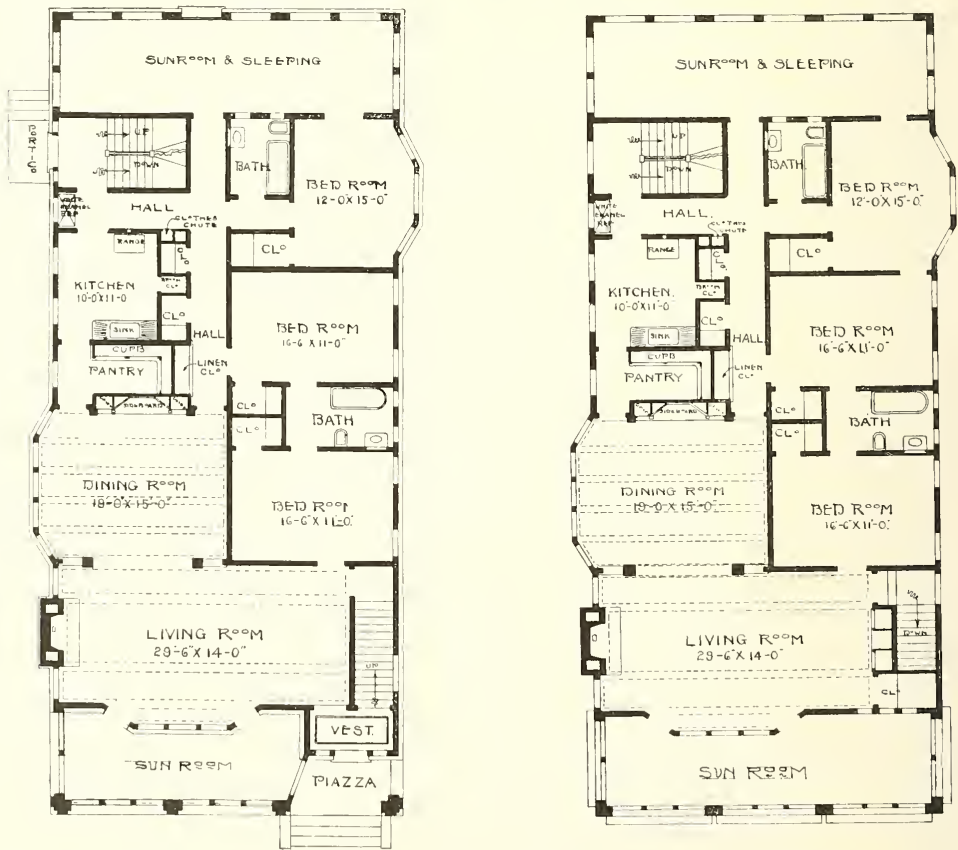

Complete plans and specifications for using Denison Load-Bearing Tile, licensed under Wilson-System Bearing W a 11 Construction for $\$ 100$. 


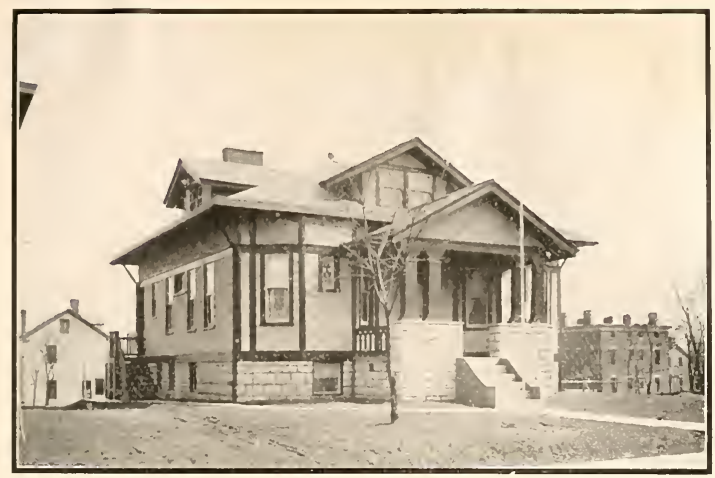

Residence of W. E. Crawford,

Wabash Ave., Cincinnati, Ohio

One does not often see a more attractive bungalow than the one illustrated above.

Much of it's beauty is attributable to the Asbestos "CENTURY"Shingles with which it is roofed and sided.

Asbestos "CENTURY" Shingles are fireproof and will endure all climatic conditions.

Let us tell you more about them.

Write for Booklet R.

\section{KEASBEY \& MATTISONCO.}

Factory

AMBLER, PENNSYLVANIA

OR

247-429 Washington Ave., N. Minneapolis, Minn. 


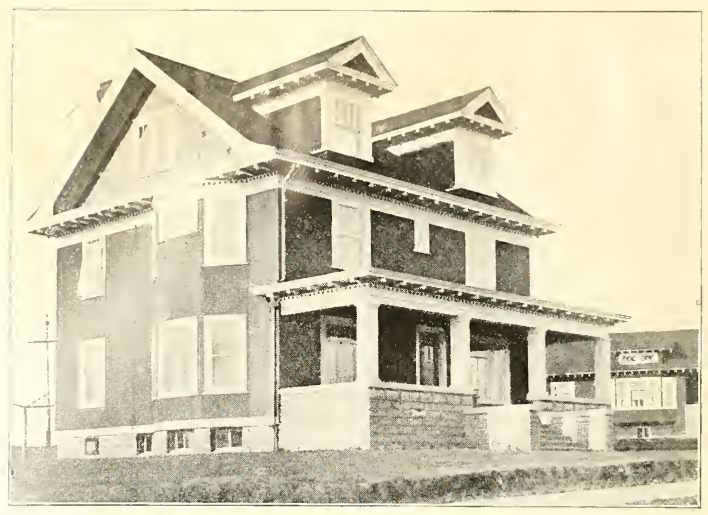

A Magnificent Colonial Home-No. 791

Built in Southern Minnesota. Here was one delighted owner. Entirely satisfied in every respect with his new home and I am almost ready to admit that it is a very good plan. There are four splendid rooms in first story, besides bath, closet and coat closet and every other small detail to make a home complete. Four beautiful chambers in second story, large closet and ideal bath. There is ample space in third story to finish up at least two or three rooms or large amusement room and maid's room. Full basement. First story 9 feet, second story 8 feet. These heights in the clear. Oak floors in first story, birch floors in second. Red Gum or white oak in first story finish, Red Gum stained to represent Circassian Walnut in second. Cost to build, $\$ 4,900$. One set complete plans and specifications $\$ 35$.
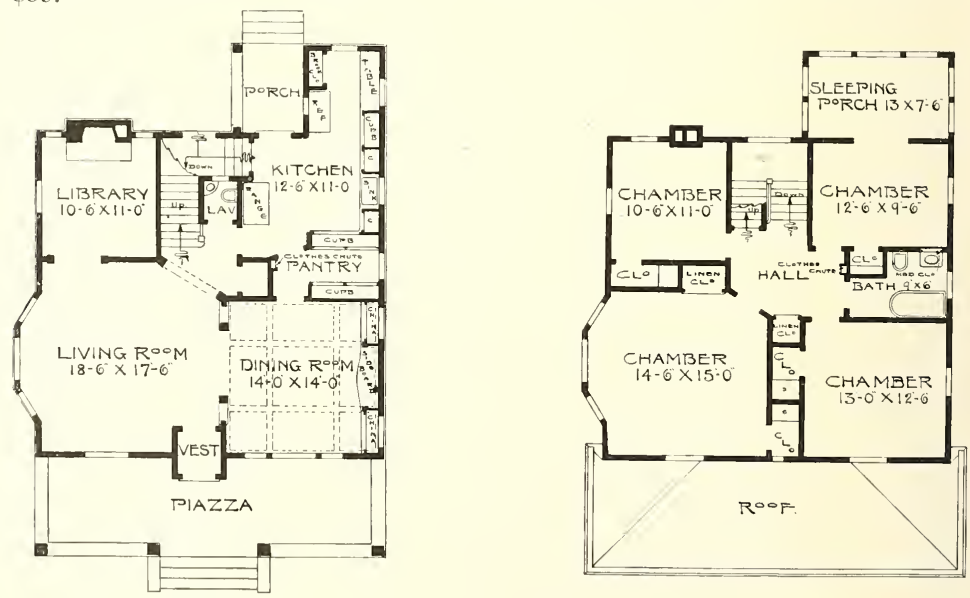

Complete plans and specifications for using Denison Load-Bearing Tile, licensed under Wilson-System Bearing W a 11 Construction for $\$ 70$. 


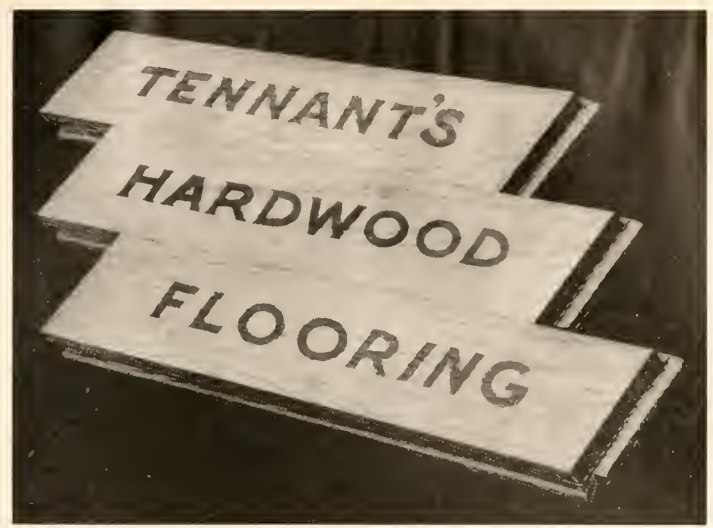

Manufactured by

\section{G. H. Tennant Company}

920 Sixth Avenue S. E. - - Minneapolis Minn.

G. H. Tennant Co. stands for

\section{QUALITY FLOORING}

We manufacture and sell all standard grades and sizes of

\section{Maple, Birch and Oak Flooring}

Thin Flooring to Lay over Old Floors

We carry a full line of $3-8 \times 11-2$ inches dressed and matched flooring, also 5-16 × $13-4$ inches square jointed parquet flooring strips.

\section{Send us your Inquiries}




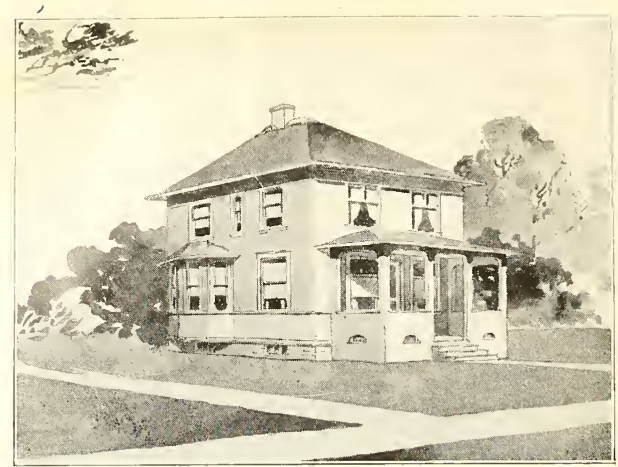

Two Story Colonial-No. 359

Here is a square economical home to build, containing 8 nice rooms, excellent closet space, bath and pantry. This is a very good colonial design and well liked by everybody. First story $9 \mathrm{ft}$., second story $8 \mathrm{ft}$. The size is $26 \mathrm{ft}$. x $28 \mathrm{ft}$. Finish first floor, oak or red gum wood, second floor, pine to paint. Cost to build, $\$ 2,000$. Complete plans and specifications, $\$ 25.00$.
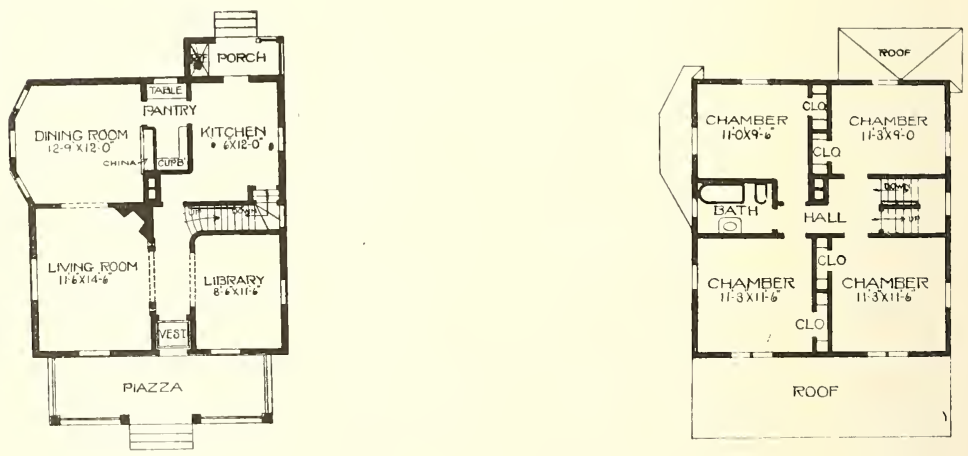

Complete plans and specifications for using Denison Load-Bearing Tile, licensed under Wilson-System Bearing Wa 11 Construction for $\$ 50$. 


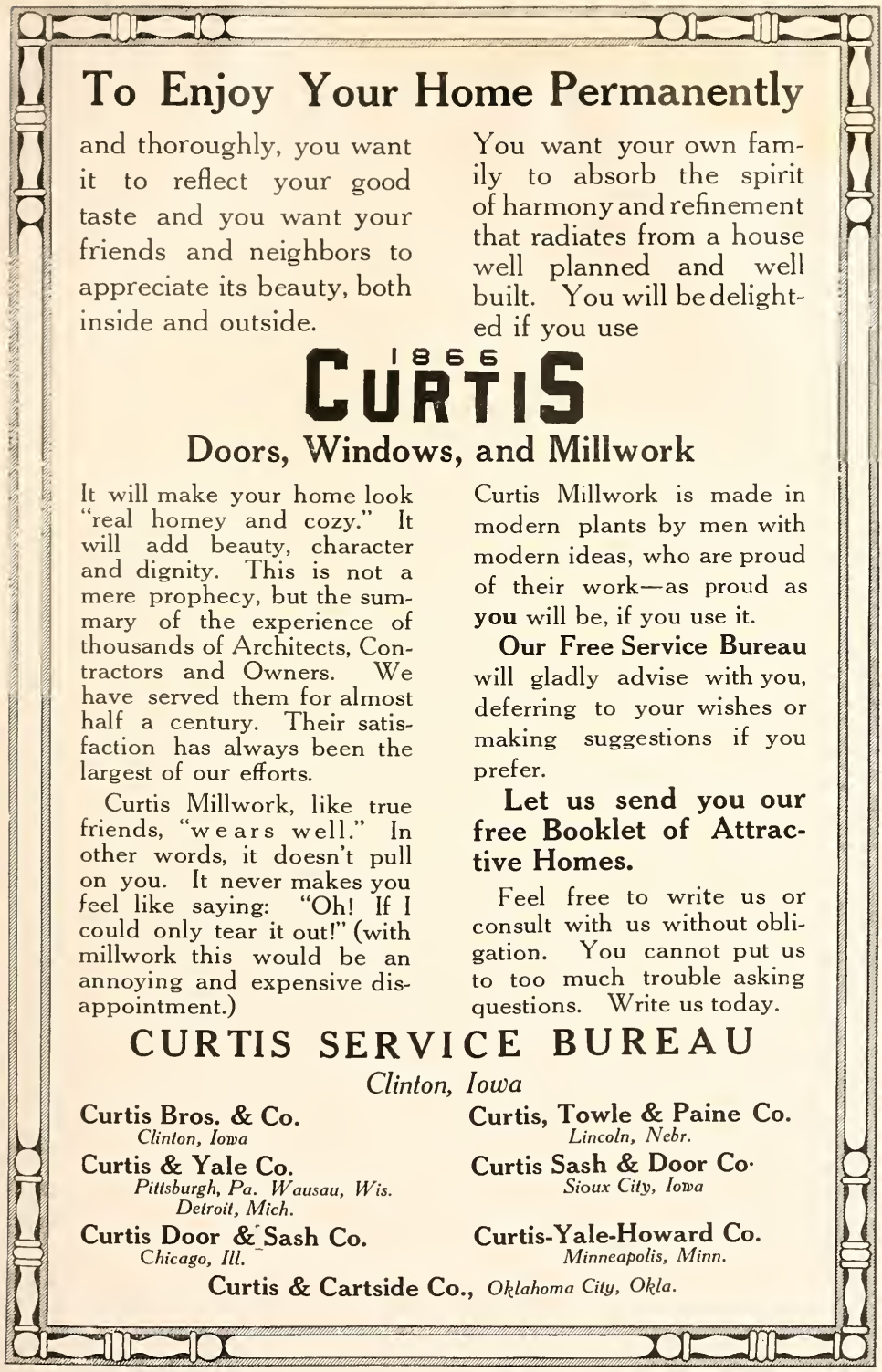




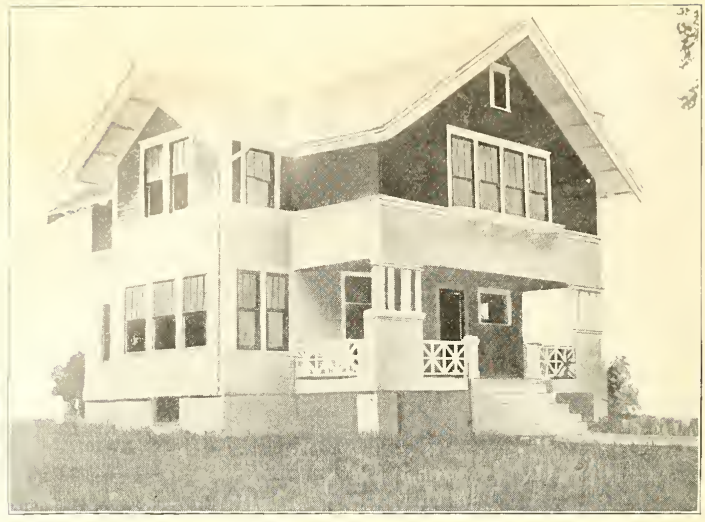

A Charming Combination Rough Cast and Clapboard-No. 774

Here is a very complete home and is one of the most complete lomes that can possibly be designed.

There is a wide piazza across the front. Large living room with end made into a semi suu-room, also a beautiful open fire-place across the corner. Pretty dining room with built in side-board and beamed ceiling. Large pantry and a very well arranged kitchen, and entry.

Second story contains 4 nice chambers, bath-room, abundance of closet space with a balcony in rear and large sleeping porch across the front. Full basement. Size 26 feet wide and 26 feet deep. First story 9 feet, second story 8 feet. Red gum, birch or red oak finish throughout first story, pine to paint in second story. Bireh or maple floors throughout. Cost to build, $\$ 2,800$. Complete plans and specifications $\$ 20$.
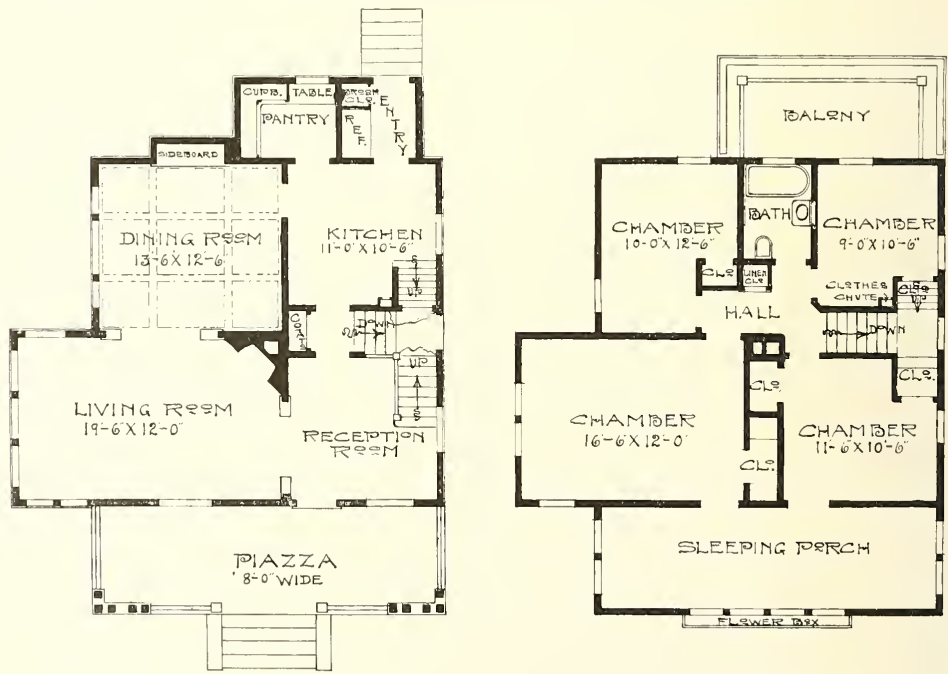

Complete plans and specifications for using Denison Load-Bearing Tile, licensed under Wilson-System Bearing IV a 11 Construction for $\$ 40$. 


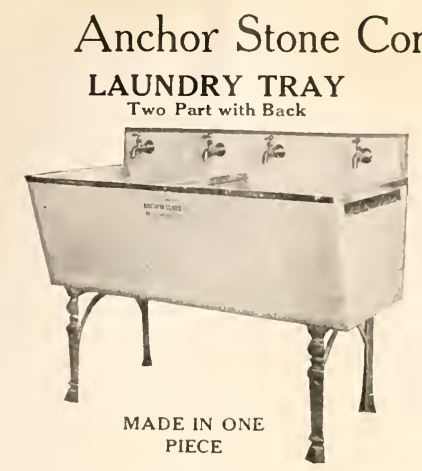

\section{Qualities}

Well made, amply strong to stand all strains and has been tested by years of constant use.

\section{Reasonable in Price}

Being manufactured in large quantities, this $\mathrm{Tub}$ can be sold very reasonably. How Obtained

If your dealer does not handle this tub, write us and we will see that a Tub is shipped promptly and in first class condition.

Anchor Stone Co.,

Recommendation City.

Minneapolis, Minn. May 22, 1908.

Regarding our opinion of the Anchor Stone Laundry Tub which we have sold for the past seven or eight years, desire to state that we have always found it to be a good article and fully worth the money it was sold for. We have had practically no complaints from our trade, and have always found it to be a ready seller for ordinary house jobs.

Wishing you continued success, we are

Yours very truly,

CENTRAL SUPPLY CO., Per P. J. Frey, President

\section{Anchor Stone Company's "J-K" Concrete Blocks}

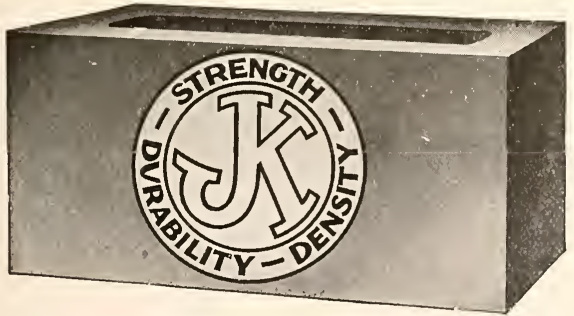

They keep the water out because they are made wet.

Call and see our Power Machine at work.

\section{THIS "J-K" \\ CONCRETE BLOCK \\ Made at Our Own \\ Factory}

We build cement foundations that satisfy the most exacting Owners and Architects.

\section{ANCHOR STONE COMPANY}

Telephones:

N. W. SOUTH 6185

T.S. CALHOUN 3122
2937 So. Lyndale Ave. MINNEAPOLIS, MINNESOTA U. S. A. 
A Bungalow with Artistic Cobble Stone

Treatment No. 771

This bungalow has a very attractive floor plan. Good sized screened in piazza, nice sun room and a beautiful living room with large open fire place built in. The dining room is male very attractive by built in sideboard and projecting bay window. Well arranged pantry and a cozy kitehen.

Three chambers in second story with large amount of closet space. Full basement. Width 26 feet deep, 28 feet over main part. First

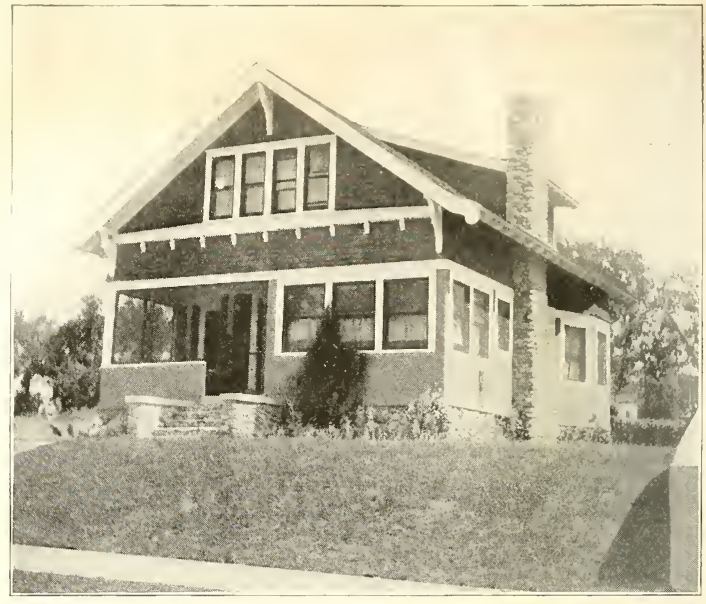
story 9 feet, second story 8 feet. These heights in the clear. Birch, red gum or red oak finish throughout the first story. Pine to paint in second story. Birch or maple throughout. floors Cost to build, $\$ 2,850$. Complete plans and specifications $\$ 20$.
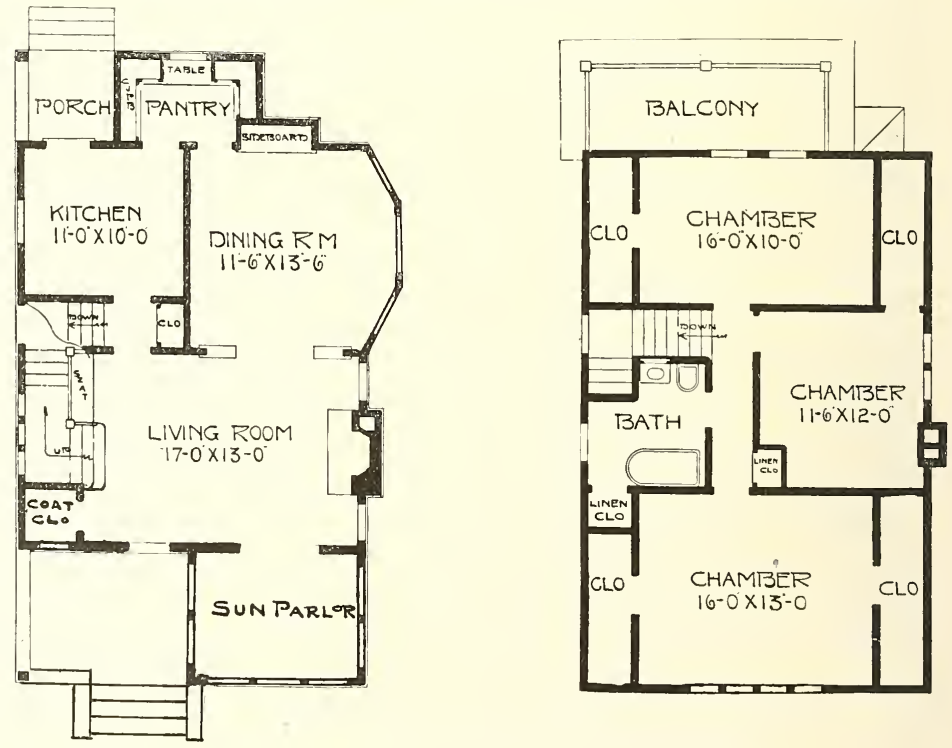

Complete plans and specifications for using Denison Load-Bearing Tile, licensed under Wilson-System Bearing IV a 11 Construction for $\$ 40$. 


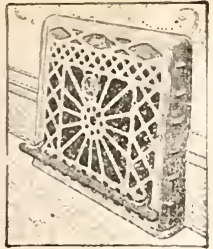

JNES REG1STER

\section{LET US ADVISE YOU ON THE HEATING} AND VENTILATION OF YOUR NEW HOME

Let us send you a booklet "The story of Home Sweet Home" FREE

\section{Address}

The United States Register Co.

Fonda Ave.

Battle Creek, Mich.
"Mid pleasures and palaces, Though we may roam,

Be it ever so humble, there's

No place like home."

The heating and ventilation of your residence goes a long ways towards making it HOME

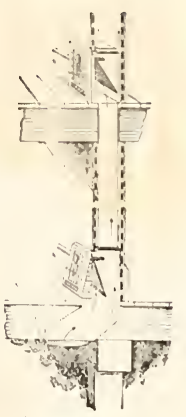

THE JONES SYSTEY

More than 350,000 homes built since 1900 are equipped with the

JONES Side-Wall REGISTERS Installed in accordance with

The JONES System of Warm Air Heating

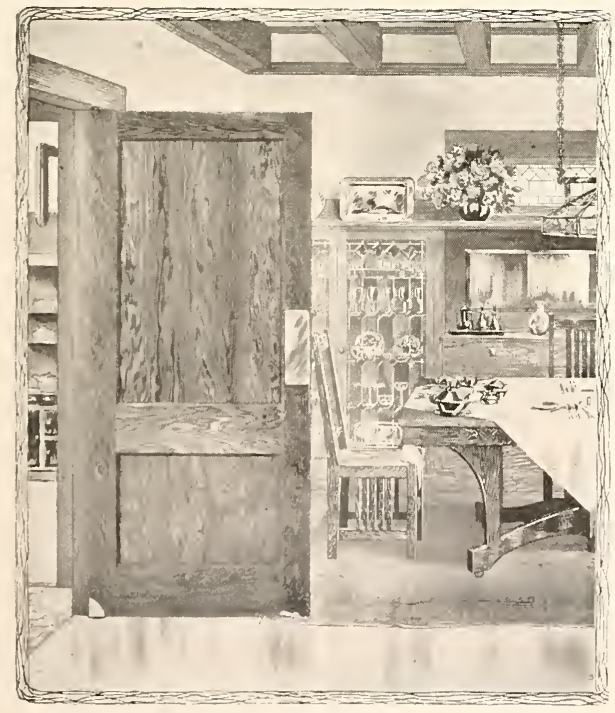

\section{MORGAN D O O R S}

Door architecture, refinements, durability are brought to their highest perfection in Morgan Doors. No other doors so completely satisfy or serve. No other doors add as much distinction to either the exterior or interior of a dwelling.

On the top rail of every genuine Morgan Door you can find the stamp of the maker. Every door so slamped is guaranteed.

Send your name for our book, "The Door Beautiful." Full of unique suggestiongs for your home.

\section{Morgan Company} OSHKOSH, WIS.

Distributed by MORGAN SASH \&DOOR CO. Chicago, lll.

MORGAN MILLWORK CO. Baltimore, Md. 


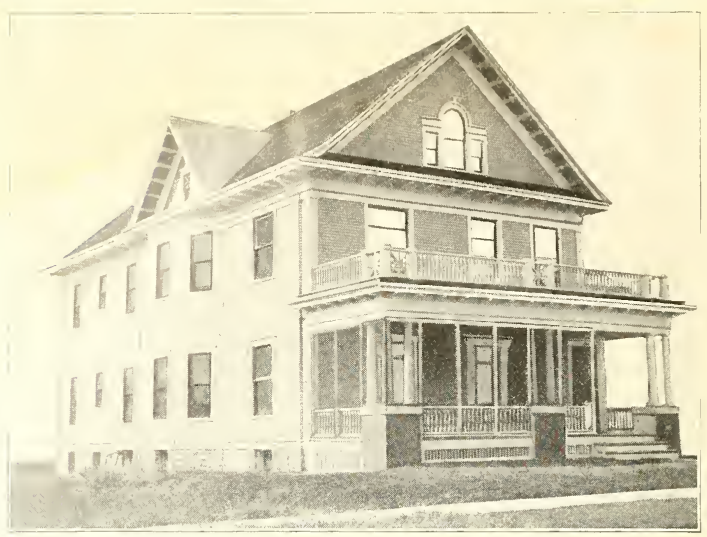

A Practical Duplex-No. 830

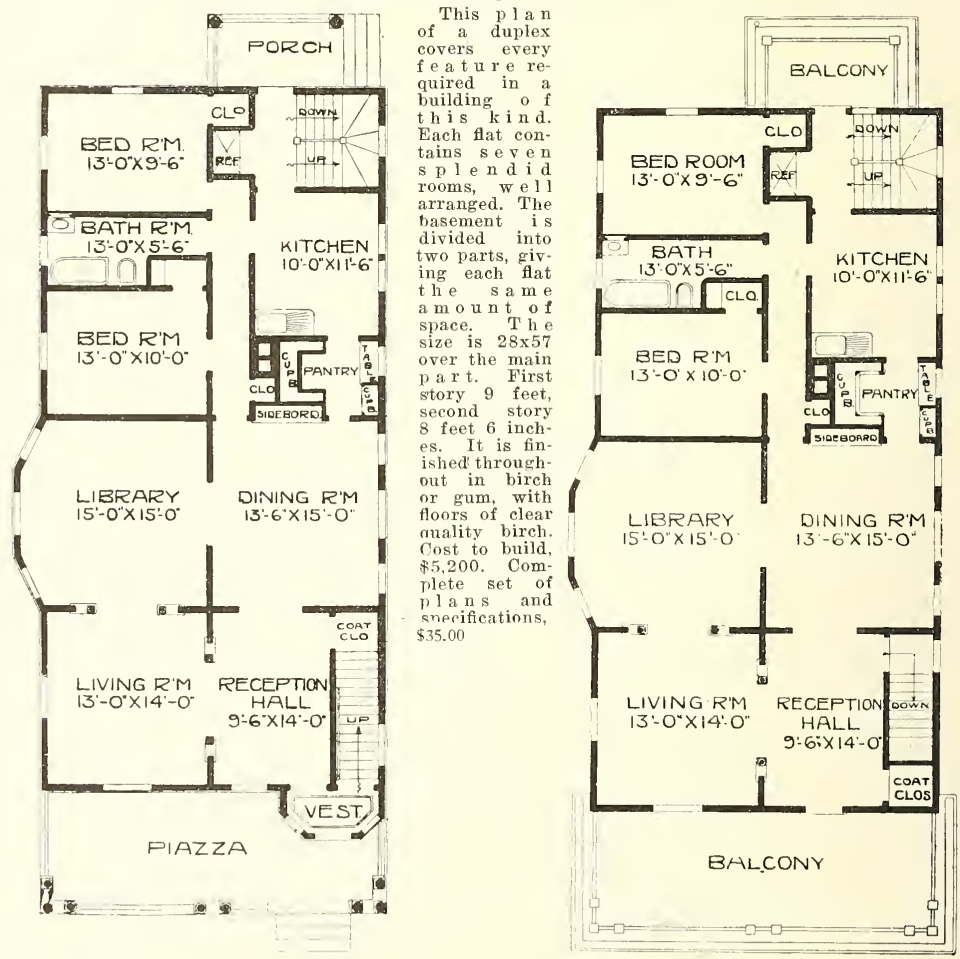

Complete plans and specifications for using Denison Load-Bearing Tile, licensed under Wilson-System Bearing IV a 11 Construction for $\$ 70$. 


\section{Standard Architectural Finishes}

that Appeal to the Particular and whose Excellence has been proved

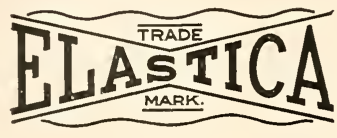

ELASTICA FLOOR FINISH For all floors, whether natural or painted.

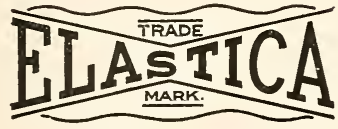

ELASTICA FINISH NO. 2

Highest quality varnish for inside work.

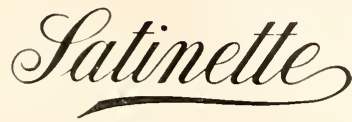

SATINETTE

The Perfect White Enamel, widely imitated, not equalled.

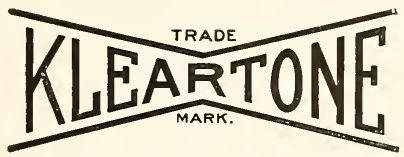

KLEARTONE STAINS

Up-to-date shades, easy to apply satisfactorily

Architect Glenn L. Saxton, specifies and recommends Elastica Floor Finish, Elastica No. 2, Satinette White Enamel and Kleartone Wood Stains, because he has found them reliable, uniform and enduring.

\section{Standard Varnish Works}

New York

Chicago

San Francisco

London

Berlin

Paris

Brussels

Melbourne

International Varnish Co., Ltd., Toronto, Canada 


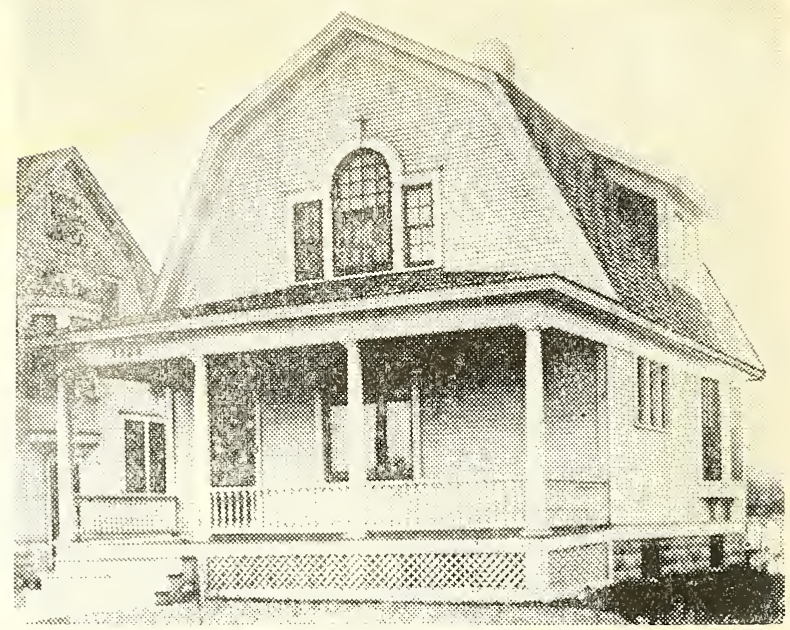

A Good Investment-No. 881

Width 22 feet, depth 24 feet. For economy and convenience in armangement of rooms and attractiveness of exterior this plan cannot be excelled. First story 9 feet, second story 8 feet. A full basement 7 feet deep. Birch or gumwood finish in first story, pine to paint in second and bireh floors throughout. Cost to build, $\$ 1,900$. One complete set of plans and specifications for $\$ 13$.

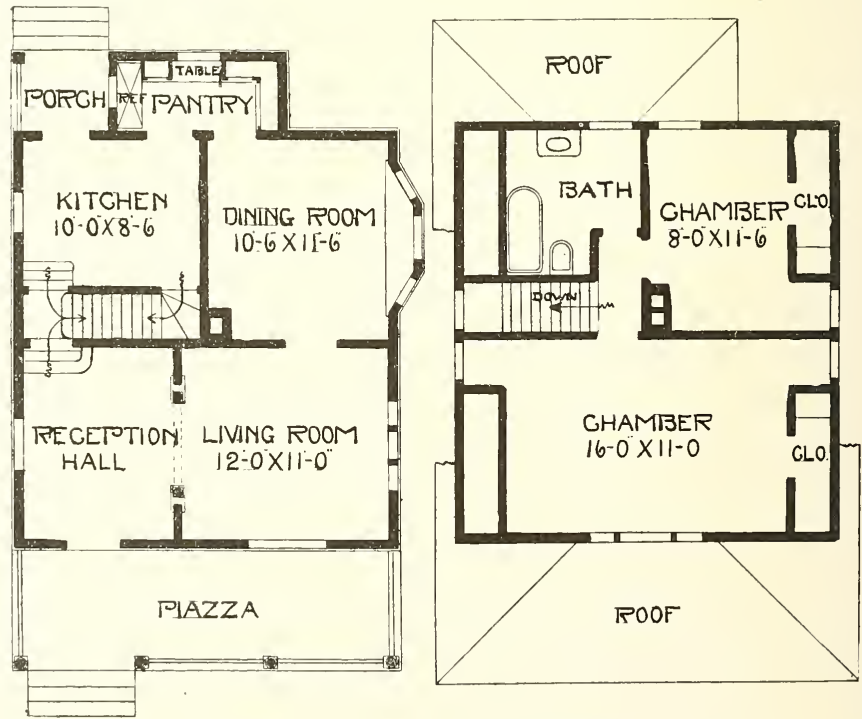

Complete plans and specifications for using Denison Load-Bearing Tile, licensed under Wilson-System Bearing $W$ a 11 Construction for $\$ 26$. 


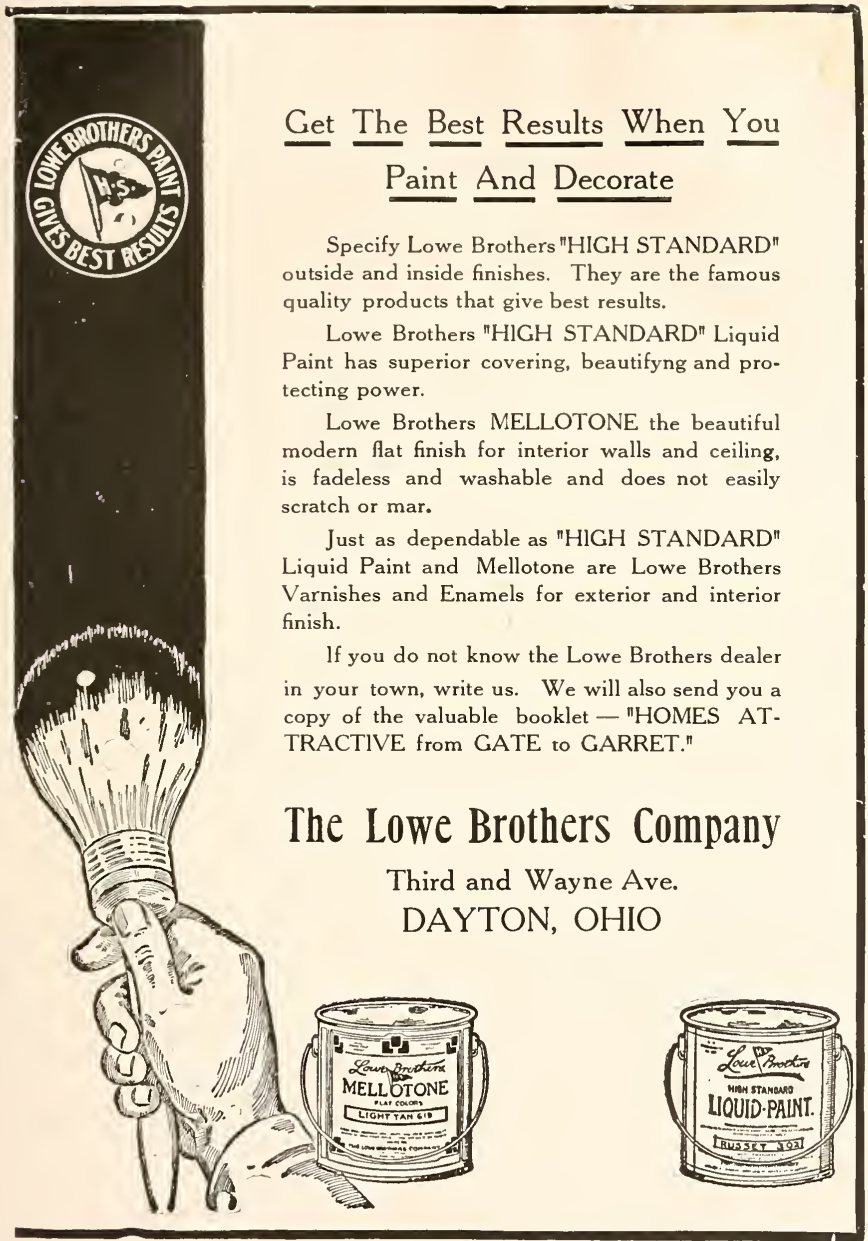




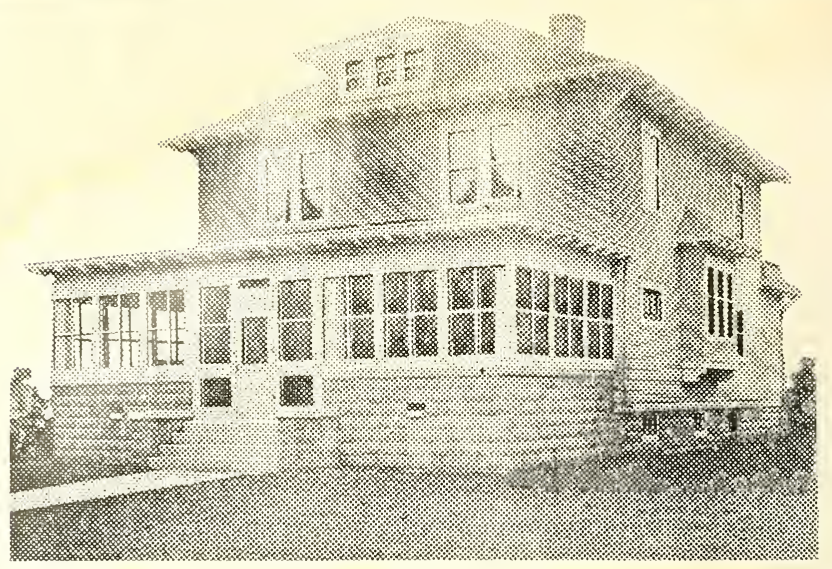

Spacious Yet Moderate in Cost-No. 736

People who are desirous of a very large piazza and living room can appreciate these merits in this design. The piazza is sashed in in winter and screened in summer. The living room extends across the entire front, thirty-one feet wide and seventeen feet deep. The dining room has built-in sideboard and china closets at each side. There is a balcony over rear one-story part. This can be made into a sleeping porch. Size thirty-two feet wide and thirty-six feet deep. Cost to build, $\$ 4,000$. Complete set of plans and specifications for $\$ 25$.
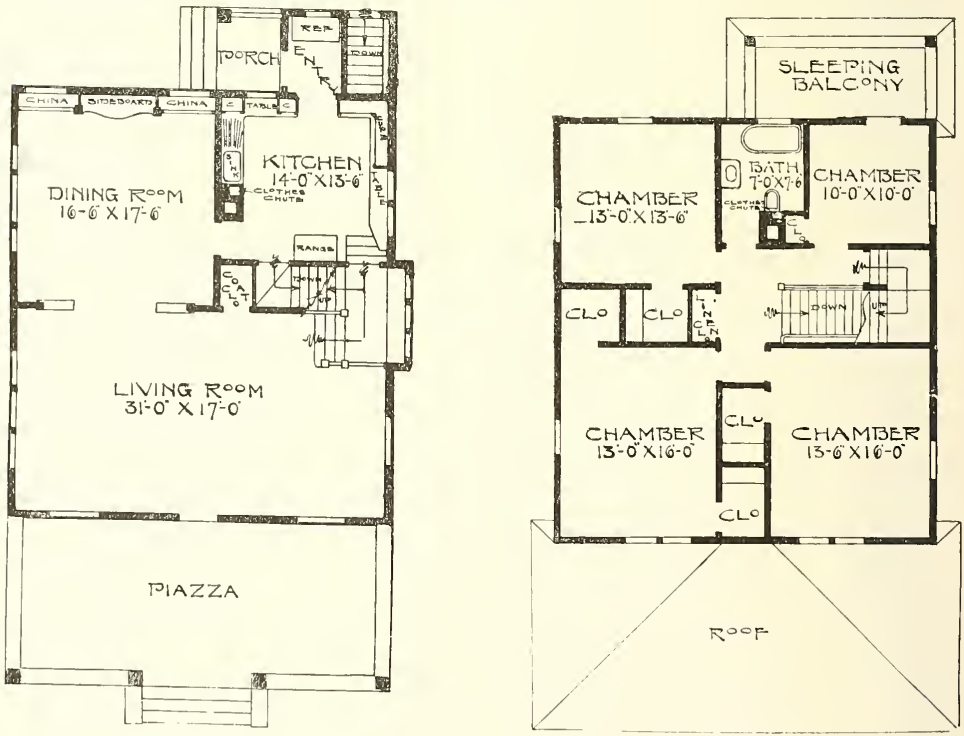

Complete plans and specifications for using Denison Load-Bearing Tile, licensed under Wilson-System Bearing Wa 11 Construction for $\$ 50$. 


\section{YES, THE WINTERS ARE COLD AND LONG}

but people living in homes heated by a "MUELLER" Boiler never have cause to complain of the cold because every portion of each room is thoroughly and uniformly heated in all kinds of weather. Many thousands in use.

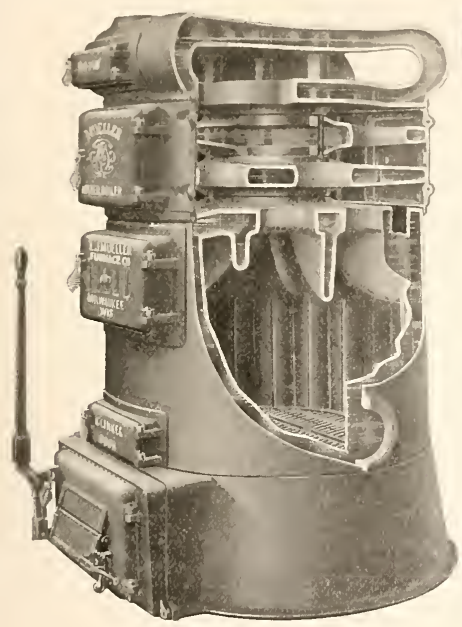

WATER BOILER

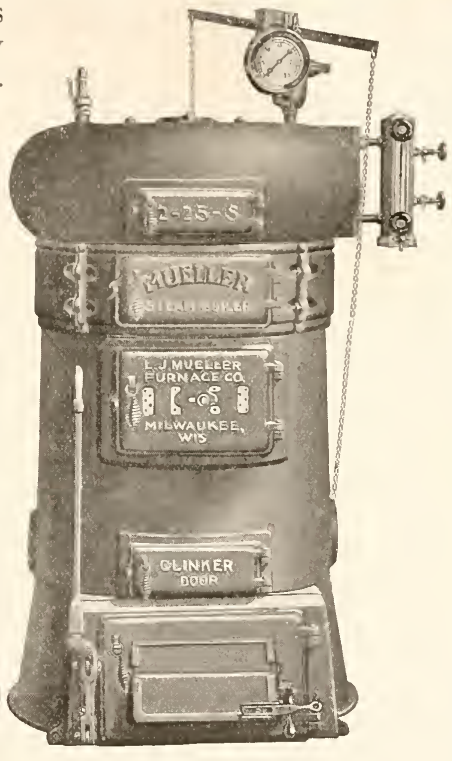

STEAM BOILER

The small amount of fuel these boilers require is surprising-The scientific and practical construction of the "MUELLER" Boiler is responsible. Its appetite for consuming fuel is very light.-Its power to deliver heat is great.

Investigate the "MUELLER." Some of your friends are using it. Ask them.

Made by

\section{J. MUELLER FURNACE CO.}

Makers of good heaters since 1857.

300 Florida Street

Milwaukee, Wisconsin

Branches

Minneapolis

631 3rd Ave. So.
St. Paul

158 E. 5th St.
Seattle

410 Occidental Ave.
Chicago

178 No. Deaborn St.
St. Louis 1322 Olive St. 


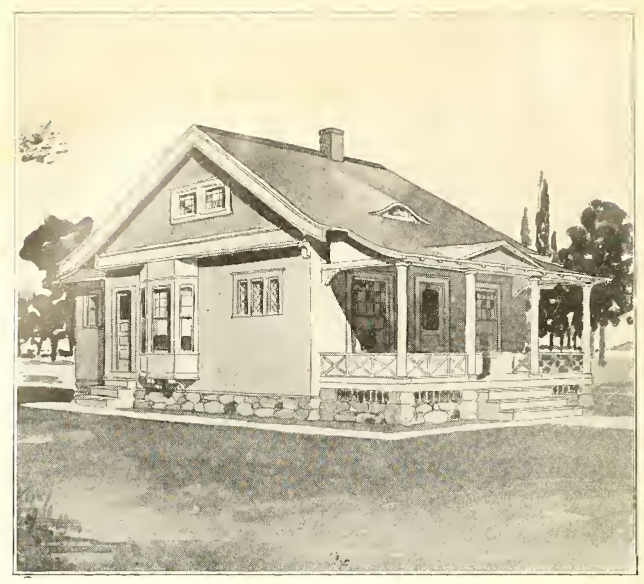

Suburban Bungalow--No. 242

You can build this cottage for the sum of $\$ 2,200$. That would finish the living-room and dining-room in gumwood, balance in pine to paint. First story $9 \mathrm{ft}$. in the clear. Complete plans and specifications for this house for $\$ 15.00$.

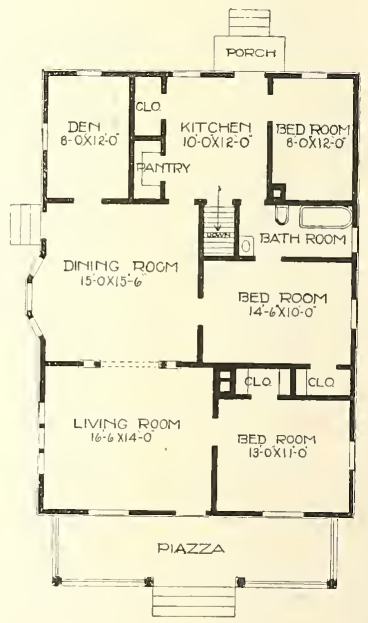

Complete plans and specifications for using Denison Load-Bearing Tile, licensed under Wilson-System Bearing Wa 11 Construction for $\$ 30$. 


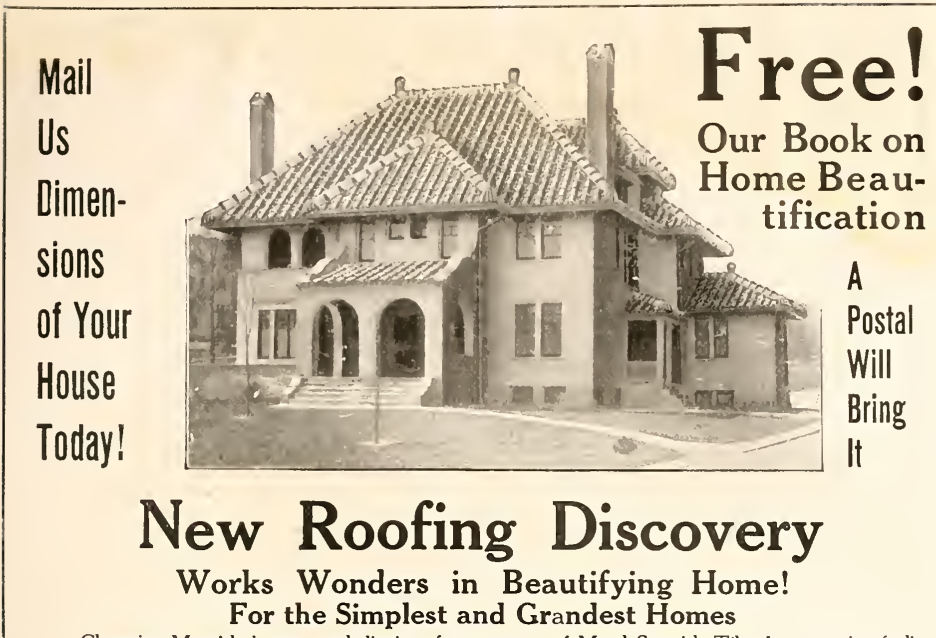

Charming Moorish beauty and dignity of appearance of Metal Spanish Tile gives an air of distinction to the home graced by this wonderful new and practically indestructible roofing.

It has taken home builders of America by storm, for it is the modernization of the wonderfully beautiul roofs of historic Spanish edifices.

The art of making this roofing, left behind by the fleeing Moors driven out of $S$ pain centuries ago, until 1910 could not be made practical for the modern home, despite its alluring beauties.

After years of experiment we have hit the solution. That is why today we are able to offer American homes the amazing attractiveness of

\section{Metal Spanish Tile Roofing}

lts scores of vital, practical advantages cost no more than common roofing, yet mean tremendous economy -it needs no repairs and outlasts several ordinary roofs because of its practically indestructible metal construction.

lt is absolutely wind, weather, storm, fire and lightning proof.

Easy to apply. No soldering, no special tools-any ordinary mechanic can apply it.

lnterlocking system by which tiles dovetail into each other makes the roof absolutely water tight and provides for expansion and contraction perfectly - summer and winter.

It is guaranteed non-breakable.

Home Builders-Simply send us today the dimensions of your building and we will tell you by return mail exact cost of all material.

Our new 1913 book on beautifying the modern American home by use of Metal Spanish Tile is yours for the asking. A postal will bring it.

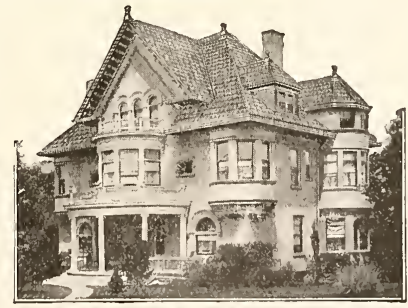

EDWARDS QUEEN ANNE METAL

Make a handsome long wearing roof. Made from best quality Worchester Grade Terne Plate furnished painted or galvanized size $10 \times 14$ inches. Easy to apply. We make 6 different styles of metal shingles all fully illustrated in our new 1913 booklet. Sent free on request.

\section{The Edwards Manufacturing Co.} "THE SHEET METAL FOLKS"

\section{5-585 Culvert St.}




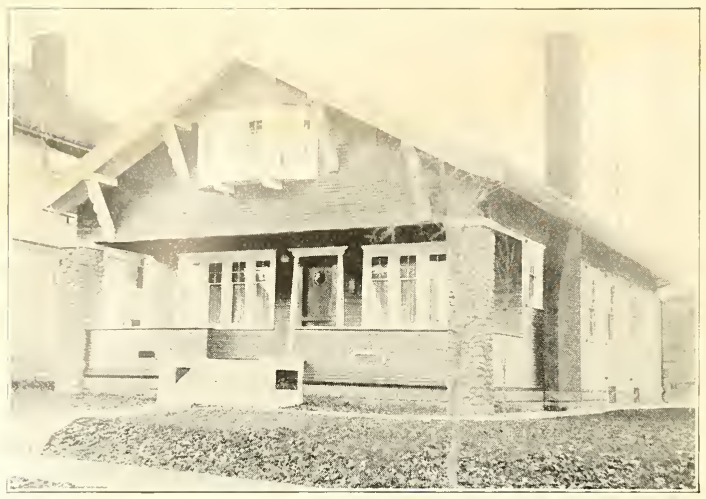

A Beautiful Bungalow Home-No. 829

Width 28 feet and depth 38 feet. This bungalow is very well suited to meet the requirements of a large family, having three large bedrooms on the first story, and space in the second story for two more, if they are desired. The exterior is exquisite, with its cobblestone piers, the dark brown body of the house with its ivory white trimmings. Cost to build, $\$ 2,200$. Price of plans and specifications, $\$ 16$.

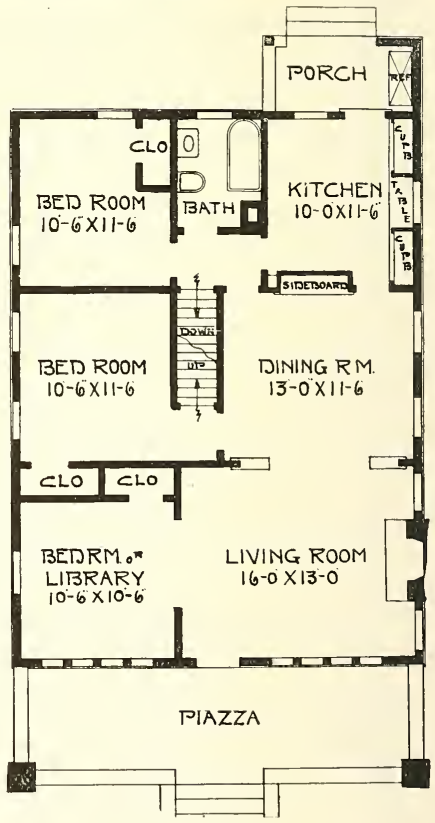

Complete plans and specifications for using Denison Load-Bearing Tile, licensed under Wilson-System Bearing $\mathrm{W}$ a 11 Construction for $\$ 32$. 


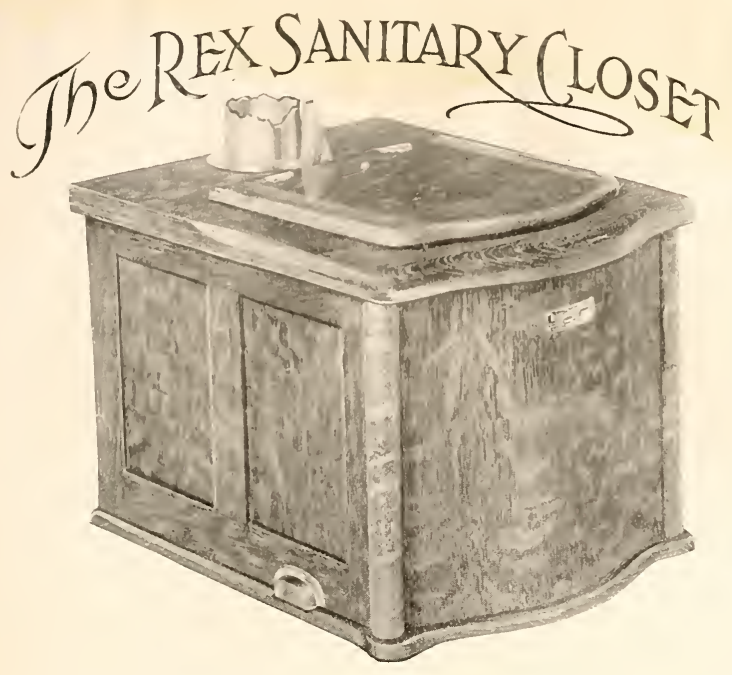

\section{Health and Happiness for the Home.}

IF YOU are about to build where sewer connection is not 1 available, or if where you now reside you do not have inside toilet closet conveniences, our Catalogue " $\mathrm{S}$ " will be a revelation to you.

Rex Sanitary Closets provide absolutely odorless and sanitary toilet closet facilities. without running water or sewerage. This system can be placed in almost any part of any home without difficulty.

In the new designs are embodied new and exclusive features (covered by patents), the most important of which are, the removal of every possibility of splash, the absolute absence of odors at all times, and the prompt and efficient sterilization of all waste material.

From the standpoint of health-protection, convenience and comfort, a Rex Sanitary and Odorless closet represents far greater value than any other article, regardless of price.

SEND US YOUR NAME AND ADDRESS TODAY. AND WE WILL

BE PLEASED TO SEND YOU COMPLETE INFORMATION.

\section{Rex Sanitary Closet Co.}

\section{NORTH SIXTH STREET}

MINNEAPOLIS, MINNESOTA 


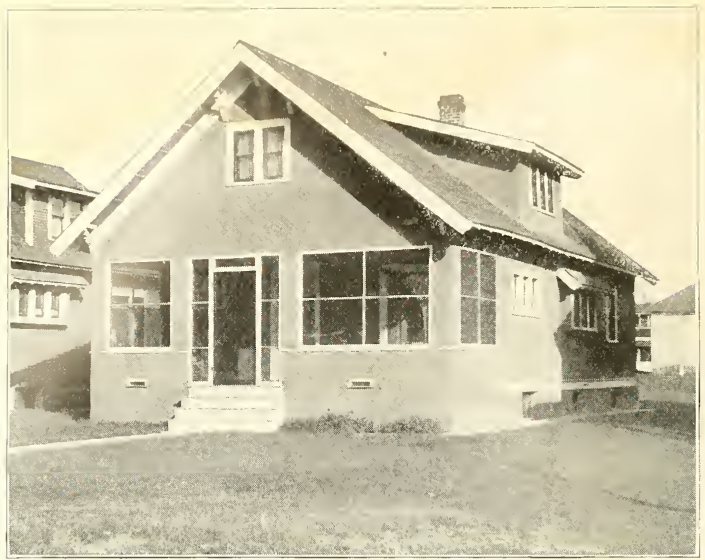

A Small Rough Cast Bungalow-No. 742

This makes a desirable floor plan, with large living room across the front, a dining room with bay window and a very conveniently arranged kitchen with built-in cupboards, table and everything complete and two bedrooms and a bathroom. There can also be finished two bedrooms in the attic if one desires. Size, 26 feet wide and 36 feet deep. There is a full basement. First story, 9 feet. Birch or maple floors throughout and birch, gum wood or red oak finish for the first story. Cost to build, $\$ 2,200$. Complete plans and specifications $\$ 18.00$.

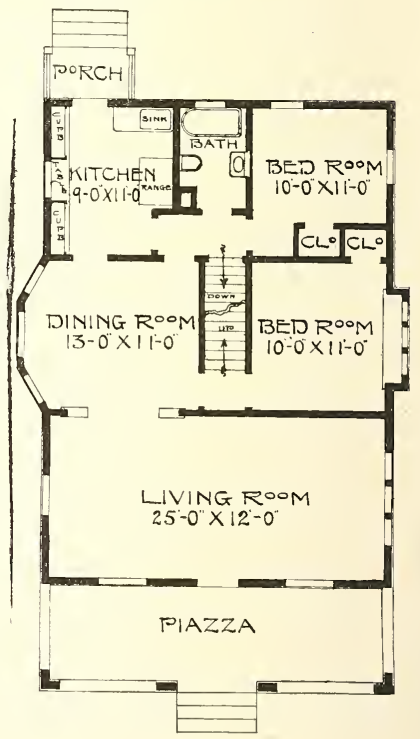

Complete plans and specifications for using Denison Load-Bearing Tile, licensed under Wilson-System Bearing Wall Construction for $\$ 36$. 


\section{THE VITAL PART}

of stucco, concrete or brick veneer buildings is the insulating or waterproof paper that is used for sheathing, also for laying under hardwood floors, where there is liability of dampness. a.r Gutrer

Be sure your building specifications call for

\section{BULL DOG}

\section{WATERPROOF} PAPER

and avoid the danger of dampness and its destructive tendencies.

Sold by leading lumber dealers. Insist that the name BULL DOG appears on every rollit is your protection against substitution.

Our brands of Deadening Felts, Tarred Felts, Red Rosins, Prepared Roofings, etc., are thoroughly dependable. It will pay you to insist on their use.

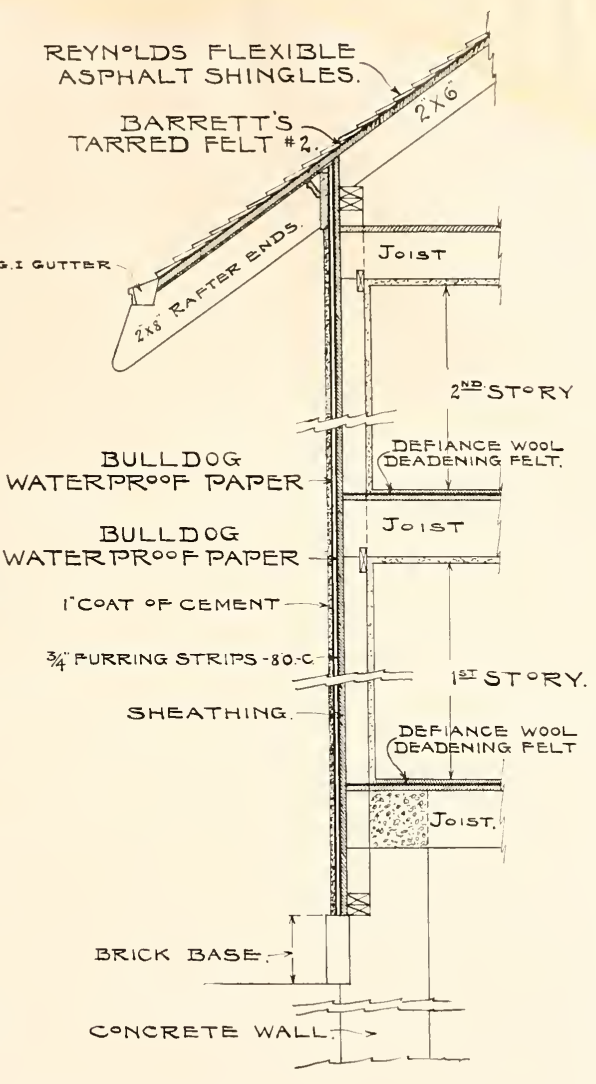

SEND FOR SAMPLE OF

REYNOLD'S FLEXIBLE ASPHALT SHINGLES

THE MODERN METHOD OF SHINGLING

GUARANTEED FOR TEN YEARS

MINNEAPOLIS PAPER CO.

MINNEAPOLIS, MINNESOTA 


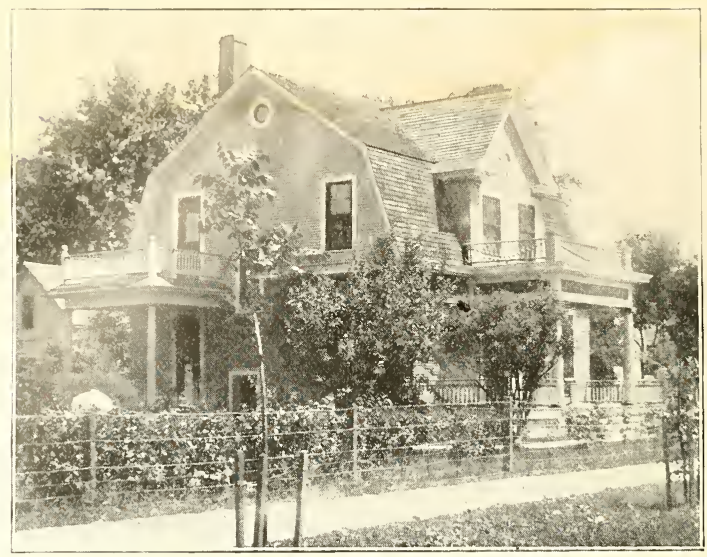

The Jordan Cottage-No. 399

This popular house is $26 \mathrm{ft}$. wide by $28 \mathrm{ft}$. deep. The stories are $9 \mathrm{ft}$. and $8 \mathrm{ft}$. 6 inches. The floors in the first story are of yellow pine, and the woodwork in the principal rooms Georgia pine stained. Finish in second story painted. Cost to build, $\$ 2,400$. Complete working drawings and specifications for this house for $\$ 21$.
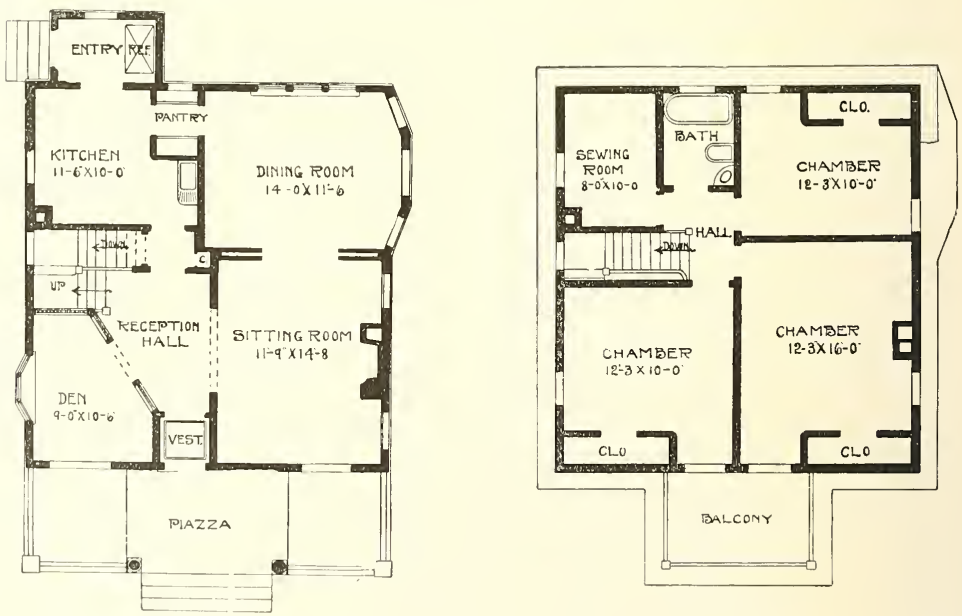

Complete plans and specifications for using Denison Load-Bearing Tile, licensed under Wilson-System Bearing $W$ a 11 Construction for $\$ 42$. 
For exterior Plaster use

Brown Hydraulic Lime with Cement, it will make a soft gray finish.

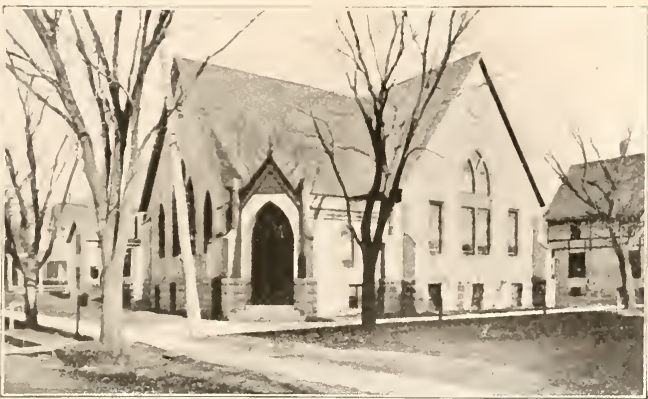

L èglise designed by Geo. Pass \& Son, Architects, Mankato, Minn.

\section{FOWLER E P A Y}

MANUFACTURERS

Lime, Austin Bricklayers Cement, Range and Cut Stone. MINNEAPOLIS MANKATO, MINN.

\section{THE MAJESTIC}

Foundation Coal Chute

Protects the building.

The door locks open automatically and protects the siding and foundation. When not in use the light of wire glass acts as a cellar window.

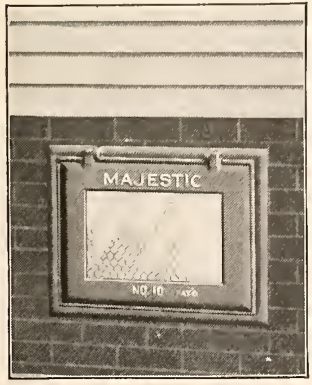

\section{Strong and \\ Durable Burgular Proof}

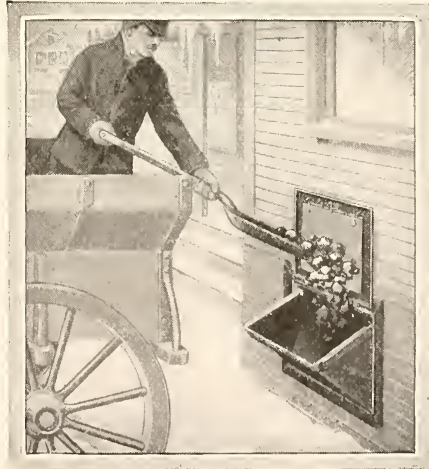

Write for catalogue.

THE MAJESTIC CO. Huntington Ind.

E. A. JACKSON \& BRO. F. LIEBRICH

ST. PAUL FOUNDRY CंO FOWLER \& PAY

CENTURY LUMBER CO.

SA VDERSON IRON CO.

QUEEN CITY WIRE \& IRON CO
50 Beckman Strect NEW YORK 1102 Monadnock Bldg. CHICAGO ST PAUL, MINN. MINNEAPOLIS, MINN. DES MOINES, IOWA OMAHA, NEBRASKA DENVER, COLORADO 


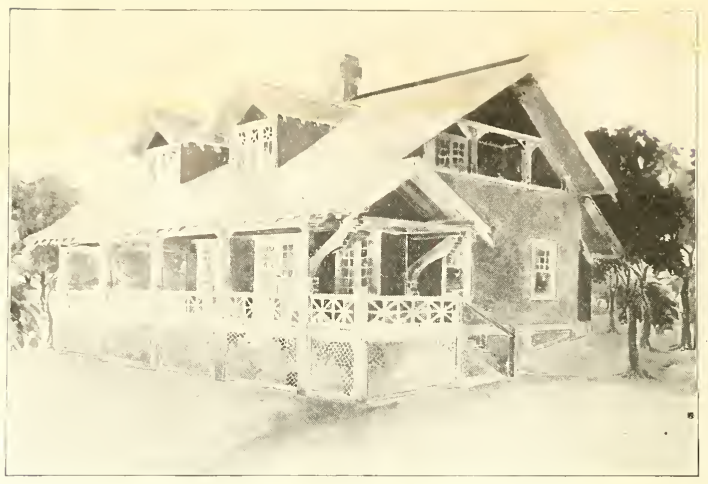

Florida Plantation Home-No. 794

Here is a typical Florida home, designed for an orange and grape fruit grower in Central Florida, but is well adapted to a summer home in any latitude. This is a plan which is well worth studying. The house is large on the ground, the rooms are conveniently arranged of good dimensions and airy.

Note the generous screened in piazza with the four rooms opening onto it with double French doors. Observe the two hospitable fire places. The broad stairway leads from the lower piazza to a sleeping porch above. There is another large sleeping porch at the opposite end of second floor with two very large chambers between.

This house was planned for a hill side overlooking a lake. The entrance to piazza could be in front, if desired.

The interior finish is patent wall board, put on with thin panels. Finish could be dull paint or stain as desired.

Cost to build as a summer home, $\$ 1,800$ to $\$ 2,400$. Complete plans and specifications, $\$ 25$.
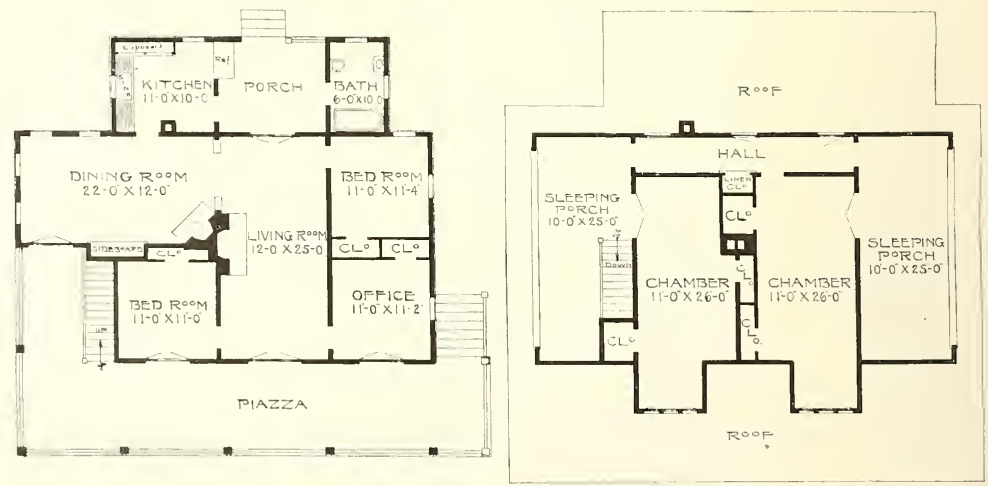

Complete plans and specifications for using Denison Load-Bearing Tile, licensed under WVilson-System Bearing $\mathrm{W}$ a 11 Construction for $\$ 50$. 


\section{$\underline{\text { Mechanical Housekeeping Devices }}$}

in the home are just as essential as labor saving machinery in the factory or office. A modern ELECTRIC HOME is the desire of every woman.

A complete equipment costs less than a fine rug or good piano.
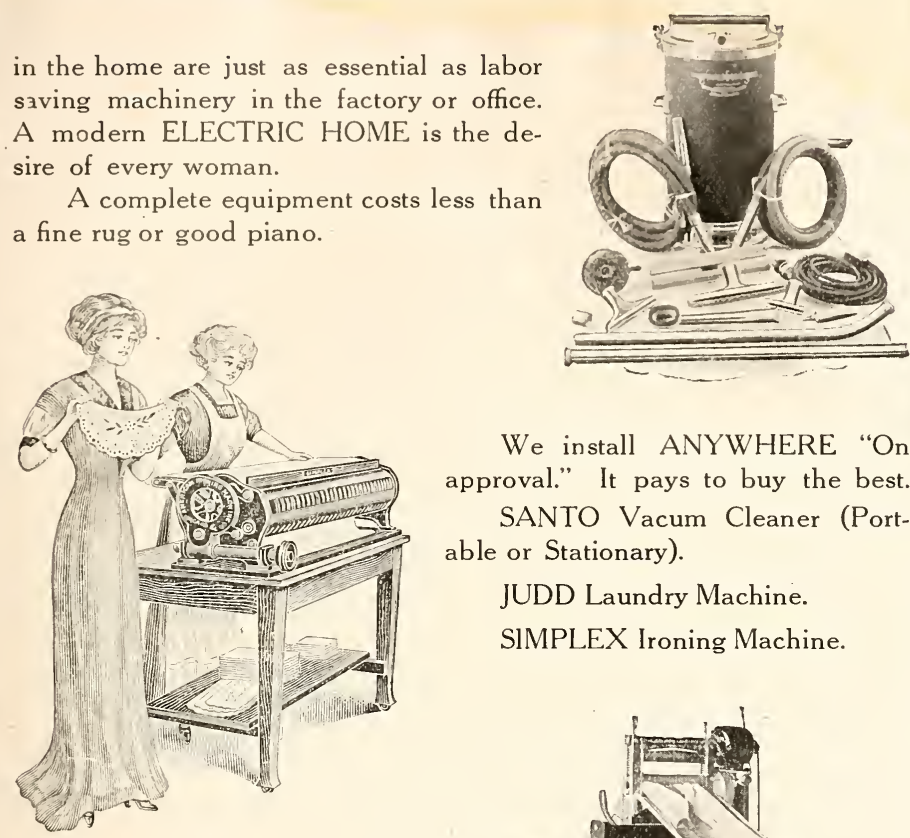

We install ANYWHERE "On approval." It pays to buy the best.

SANTO Vacum Cleaner (Portable or Stationary).

JUDD Laundry Machine.

SIMPLEX Ironing Machine.

The home supplied with these devices is free from the "SERVANT PROBLEM." They make it possible to do without poor servants, or help to keep the good ones satisfied.

FRIES-PATTERSON equipment will positively reduce the operating cost in your home.

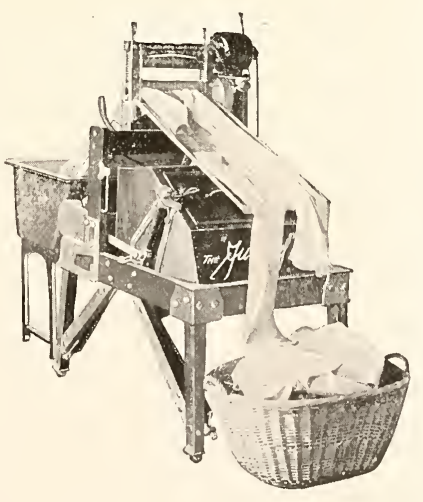

\section{Fries-Patterson Company.}

Garden Theatre Building 


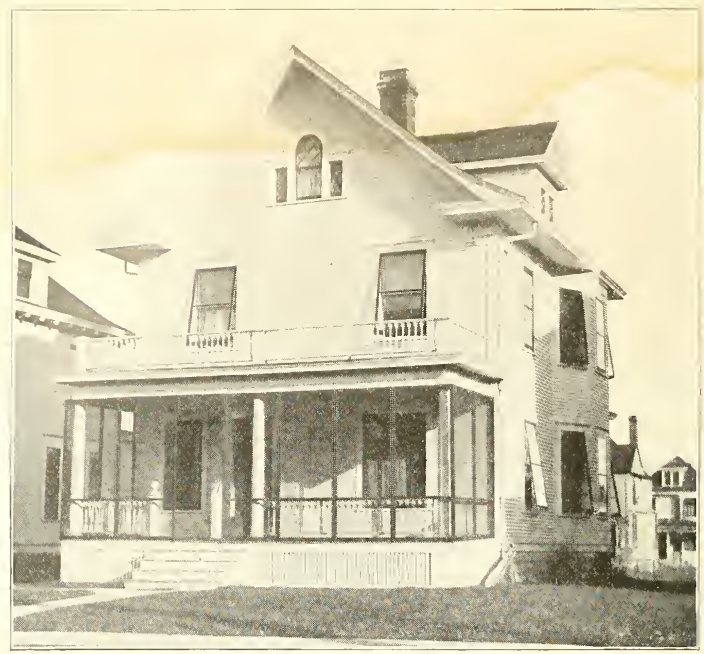

A Model Colonial Home-No. 925

The size of the house is $26 \times 28$ over the main part. Birch or red gumwood finish in first and pine to paint in second story. Cost to build, $\$ 3,000$. Complete plans and specifications $\$ 25$.

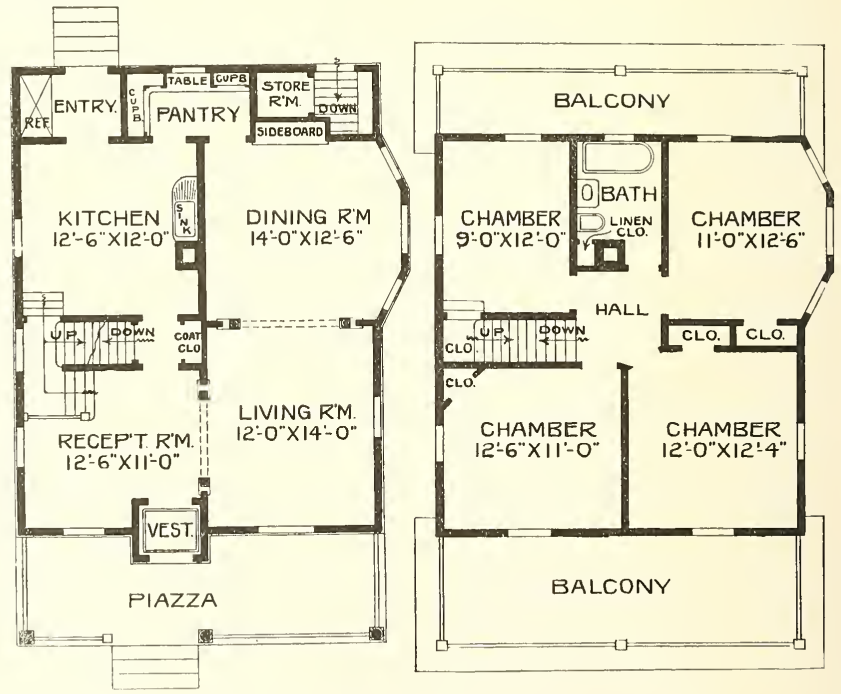

Complete plans and specifications for using Denison Load-Bearing Tile, licensed under Wilson-System Bearing IV a 11 Construction for $\$ 50$. 


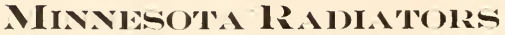

N1:

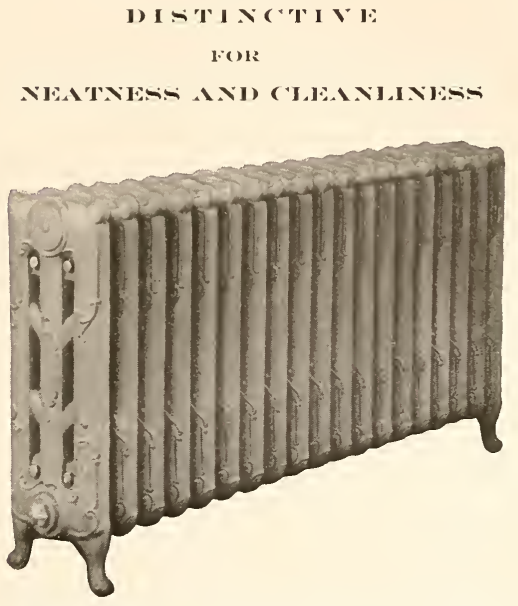

THES WIII. ADI BEAT'TY AND CONFOIST 'TO YOUR HONE

\section{ASIT YOCR ARCIIITIEC'T}

\author{
MINNESO'TA RADIATOR \\ COMPANY \\ DII.TH \\ MINN. \\ MINNIEAPQIAT \\ 1:3:3 ME'T, IIN IE IBIDOG.
}




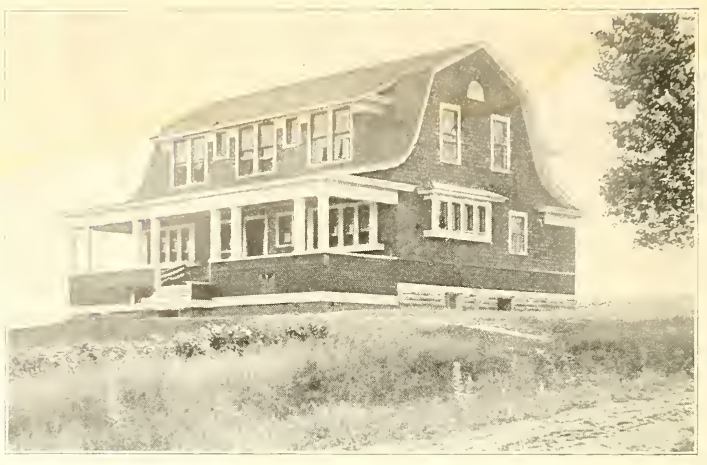

A Study in Shingles and Clapboards-No. 923

Width 39 feet, depth 24 feet over the main part. The living room covers one end of the house. Adjoining is a nook and fire-place, with seats at the sides. The dining room has a beamed ceiling. Entrance to the kitchen is gained through the pantry, which is well fitted up with cupboards, tables and flour-bins. There are three chambers and a nursery. The front and rear closets are provided with windows, the light and ventilation making the closet moth-proof. Cost to build, $\$ 4,000$. Price of plans, $\$ 25$.
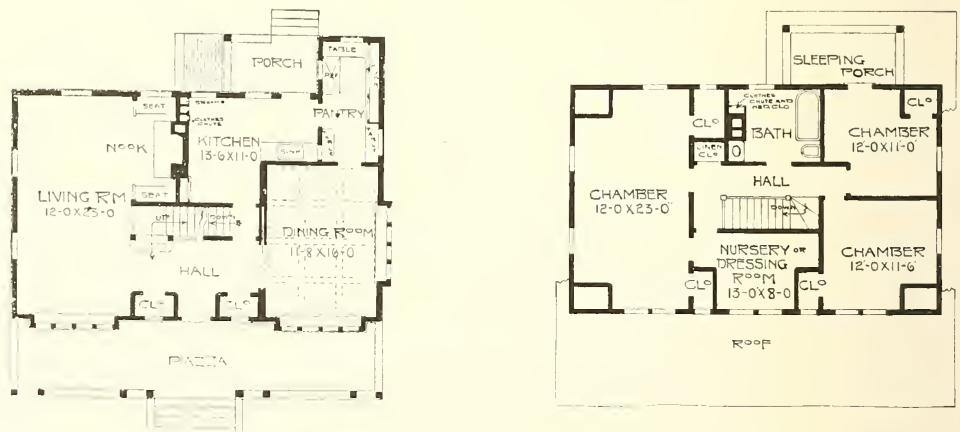

Complete plans and specifications for using Denison Load-Bearing Tilc, licensed under Wilson-System Bearing i a 11 Construction for $\$ 50$. 


\section{6

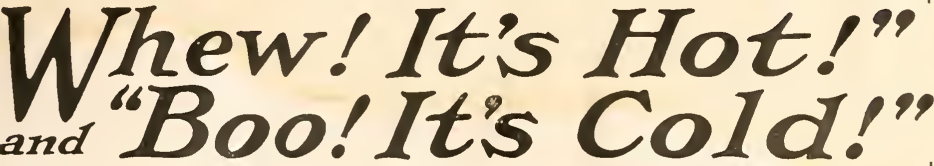

Are Expressions Never Heard In Homes Equipped With

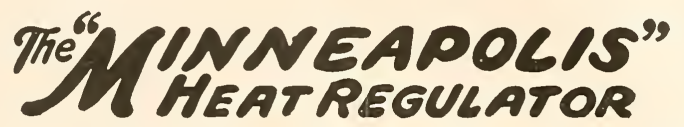

Enables one to determine exactly the degree of warmth desired during the day, indicate at bed time the temperature for the night, and secure automatically a return to warmer temperature at the time of arising. The time attachment when set will change the indicator at any pre-determined hour. For instance on retiring you set the indicator at 60 degrees for the night hours with the alarm set for a change to 70 at $7 \mathrm{~A}$. M. This change takes place silently and without further attention on your part.

\section{Two Styles of Time Attachment}

Model No. 47

Round Design 1 Day Clock
Model No. 60

Square Design 8 Day Clock

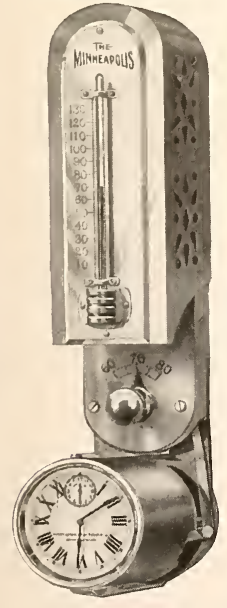

With Model No. 60, which is decidedly the "de luxe" device of all makes and models, both time and change run 8 days with one winding. The "Minneapolis" has been the standard for over 30 years. Insures comfort and health, saves fuel and ends the former round of continual attention.

Used with any heating plant, hot water, hot air, steam or natural gas. Sold and installed by the heating trade everywhere under a positive guarantee of satisfaction.

\section{The" MNN NEADOL1S" HEAT REGULATOR}

Executive Office and Factory 28th St. and Fourth Ave. Minneapolis, - Minn.

ST. PAUL, 140 Endicott Arcade BOSTON, 176 Federal Street

SYRACUSE, 217 East Washington Street CLEVELAND, 402 Garfield Building ST. LOUIS, 417 Title Guaranty Building CHICAGO, 1302 Chamber of Commerce Building

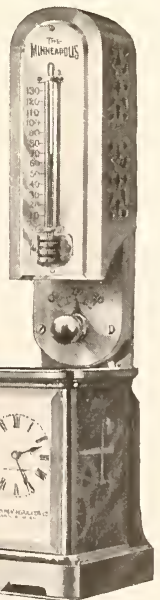




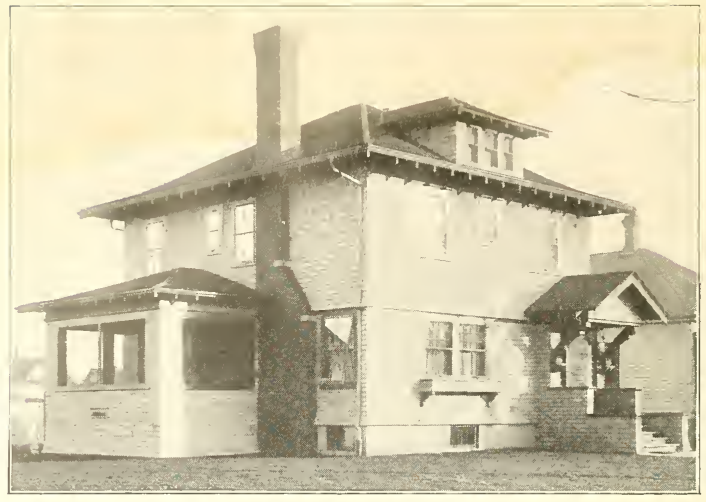

A Pretty Study in Brown Shingles-No. 787

A careful examination of the two floor plans will demonstrate that this is a mighty comfortable home.

The rooms in the first story are all conveniently arranged. Especial attention is called to the arrangement of the garage, avoiding the necessity of going into the coid on a winter's night. In the second story are four splendid chambers, fine large, closets and a small room in front that can be used for a child's sleeping room or dressing room. The sun room can be carried up two stories to make a sleeping porch for second story if desired.

Size 28 feet wide over main part, 30 feet deep. Full basement, 7 feet 6 inches high, first story 9 feet, second story 8 feet. Birch or white maple floors throughout, red gum wood or red oak for first story, gum wood in second story with birch doors, the gum wood enameled white and the doors stained a rich brown mahogany to give that splendid combination of white enamel and mahogany for sleeping rooms.

Cost to build, $\$ 3,500$. Complete plans and specifications $\$ 25$.

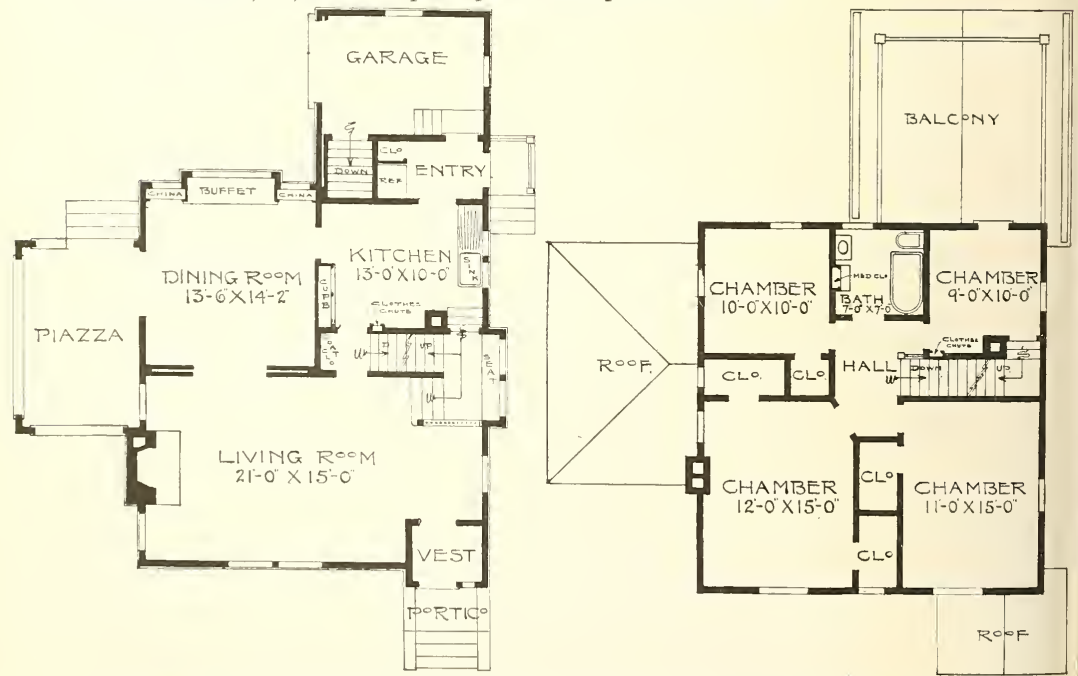

Complete plans and specifications for using Denison Load-Bearing Tile, licensed under Wilson-System Bearing $W$ al1 Construction for $\$ 50$. 


\section{Single Comb White Leghorns}

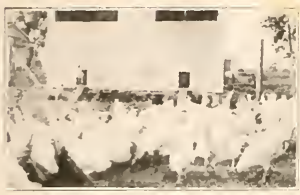

Feeding time at one of the colony houses
(EXCLUSIVELY)

\section{Full Blooded \\ Range Raised BIRDS}

HATCHING EGGS A SPECIALTY

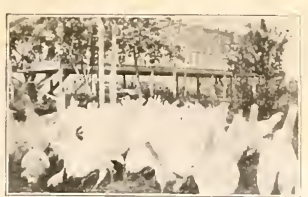

One of the laying houses under construction. Capacity 500 birds

\section{PRICES}

First Pen, per Setting of 15, \$6.00; Second Pen, $\$ 4.00$; Third Pen, $\$ 2.00$ Order now for spring deliveries

Eggs in large quantities and day old chicks. Prices on application.

Sale of day old chicks limited to Minneapolis and vicinity.

You are invited to visit our 10-acre plant and inspect the stock. Our eggs bring premium prices. at the leading clubs and hotels of Minneapolis.

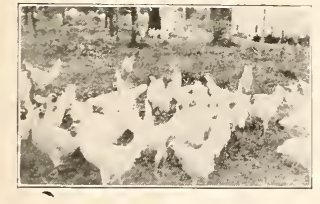

A bunch of beauties
The Richfield Poultry Products Co. ESTABLISHED 1911

THOS. H. ADAMS, Mgr.

N. W. Phone Colfax 5255801 Lyndale Ave. So.

Minneapolis, Minn.
For Service

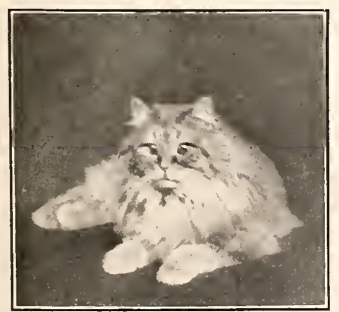

A. C. A. NUMBER 2004
Prince Amber

IMPERIAL POTENTATE

OF ORANGE PERSIANS

Solid Orange, fine coat, deep orange eyes, very cobby, fine bone and muscle. Exhibited only once and won first in all classes, winners' and special. Fee $\$ 10$.

At home to pedigreed queens at 3120 Stevens Ave., Minneapolis, Minn.

$$
\text { M. R. McGUIRE }
$$




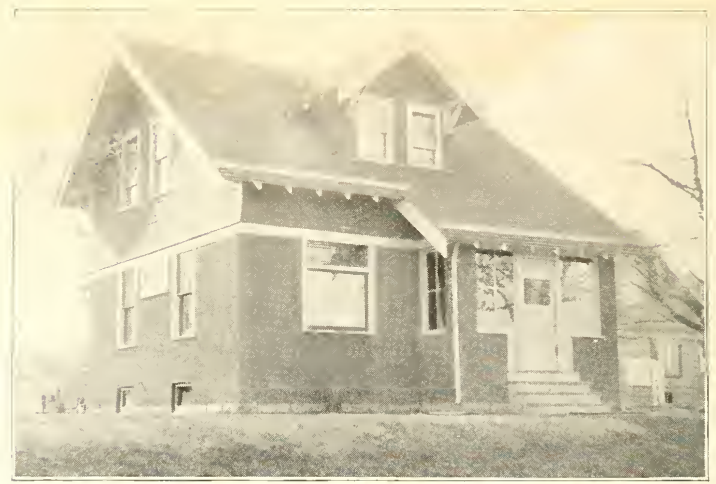

Rough Cast Cement Cottage-No. 731

This cottage is finished with rough cast cement plaster up to the belt course of the second story. The piazza is inclosed with sash which can be replaced by sereens in the summer. Size 24 by 26 feet. The living room is 11 feet 6 inches wide and 21 feet 6 inches long, with open fireplace and stairway across rear. The dining room connects with the living room by a pedestaled opening. There is a sideboard in the end of dining room. Kitchen has built-in cupboard. Each bedroom has two windows on opposite sides to give perfect ventilation. There is a full basement under entire house. First story, nine feet; second story, eight feet. Birch or gumwood finish in first story and pine to paint in second story and either birch or maple floors throughout. Cost to build, $\$ 2,150$. Complete plans and specifications, $\$ 20.00$
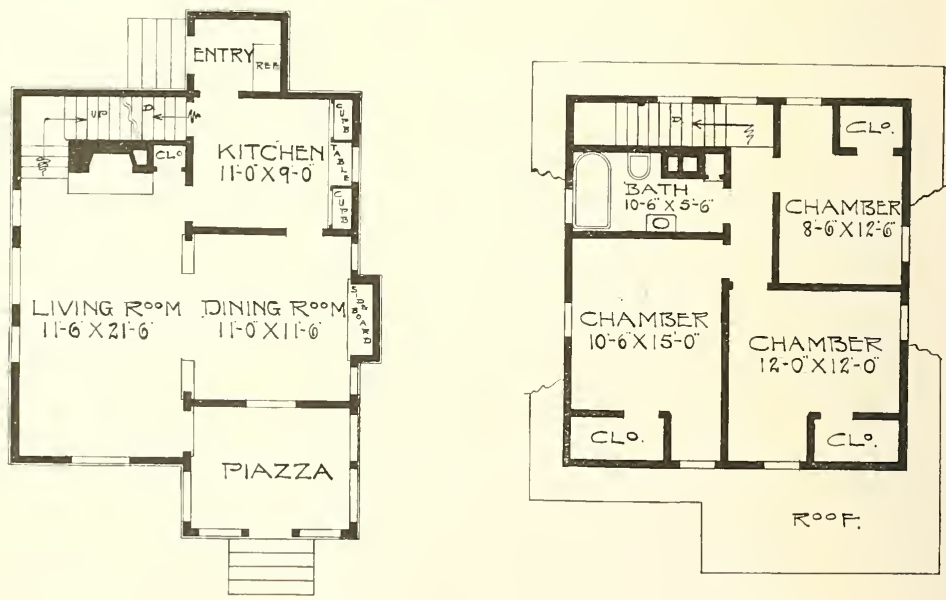

Complete plans and specifications for using Denison Load-Bearing Tile, licensed under Wilson-System Bearing W a 11 Construction for $\$ 40$. 
There is nothing better for lighting houses, barns, churches, stores, lodge-rooms and it is especially adapted for Domestic Science Departments in schools.

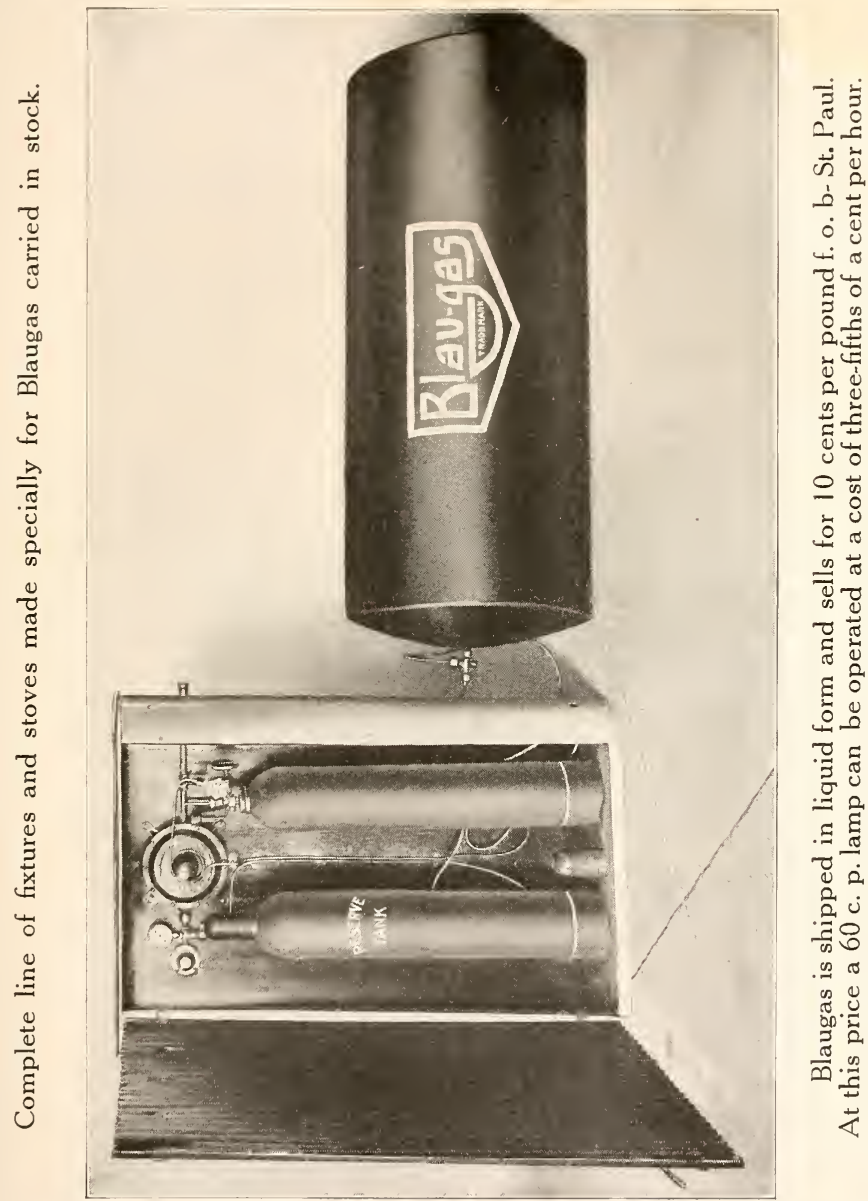

The ideal system for isolated lighting and cooking. Safe, clean, efficient and always ready for use. Price of standard size house plant $\$ 150.00$.

NORTHWESTERN BLAUGAS COMPANY ST. PAUL, MINNESOTA 


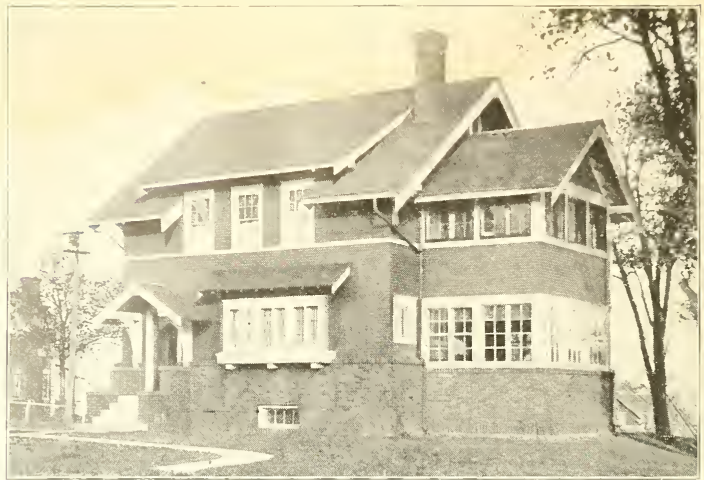

The Wonder House-No. 793

We have this plan made up as an old New England colonial, English half timber, Spanish mission and Georgia colonial, besides Craftsman, as shown above. The size of the house is twenty-six feet wide and twenty-eight feet deep under the main part. There is a sun room on the side which is ten feet six inches wide, thus making a frontage of thirty-six feet six inches. Necessarily this calls for at least a forty-five or fifty foot lot, or one wider still is even more appropriate for this home. Cost to build, $\$ 3,900$.

There is a full basement under this entire house. First story nine feet, second story eight feet in the clear. First story is finished throughout in birch or red gum and birch floors in first and second stories. The second story is finished in pine to paint, with bireh to stain mahogany color to give the old colonial interior finish for the chambers.

Complete plans and specifications, $\$ 35.00$.
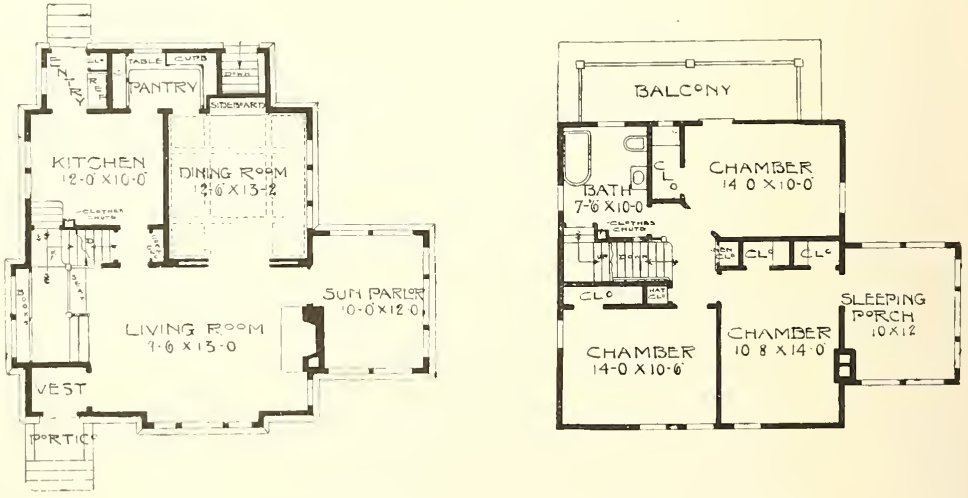

Complete plans and specifications for using Denison Load-Bearing Tile, licensed under Wilson-System Bearing IV a 11 Construction for $\$ 70$. 


\section{The Simplest Home \\ The Tiniest Cottage \\ Can Now Afford Electric Lights}

Comfortable evenings demand good illumination. For reading or working at night you require a steady brilliant light, and particularly where there are children, a light that is SAFE.

Mazda electric lighting is soft - white - the nearest approach to daylight. - Mazda electric lamps give nearly three times as much light for the same current consumption as carbon incandescent lamps. Mazda electric lighting is safe, clean and steady - always ready at the touch of a button.

Unwired homes can be "modernized" with electric light at small cost.

Telephone $\left\{\begin{array}{l}\text { N. W. Main } 189 \\ \text { T. S. Center } 1320\end{array}\right.$

for a cost estimate of wiring your home

\section{The Minneapolis}

General Electric Company 15 South Fifth Street 


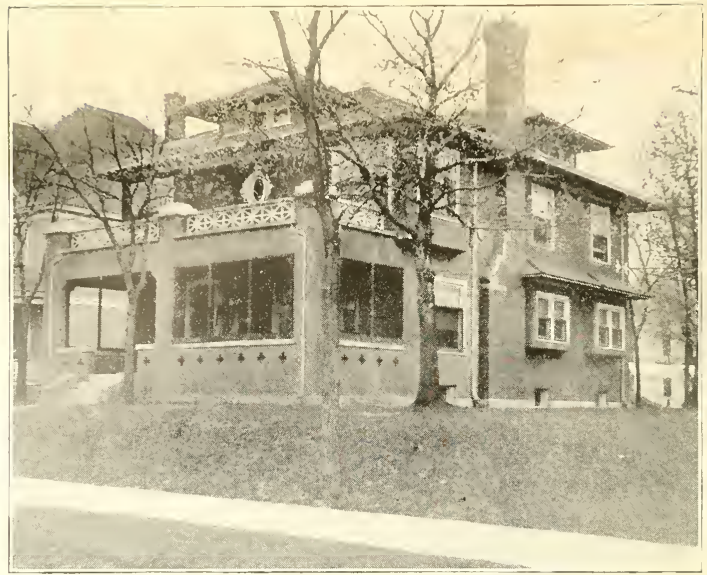

Spanish Rough Cast Mansion-No. 761

Here is a plan which has an arrangement of the living rooms entirely out of the ordinary. Size 30 feet wide and 40 feet deep over the main part. Full basement. First story, 9 feet; second story, 8 feet. Finish in birch. red oak or gumwood throughout the first story, with birch finish in second story. Cost to build, $\$ 5,200$. Complete plans, $\$ 35.00$.
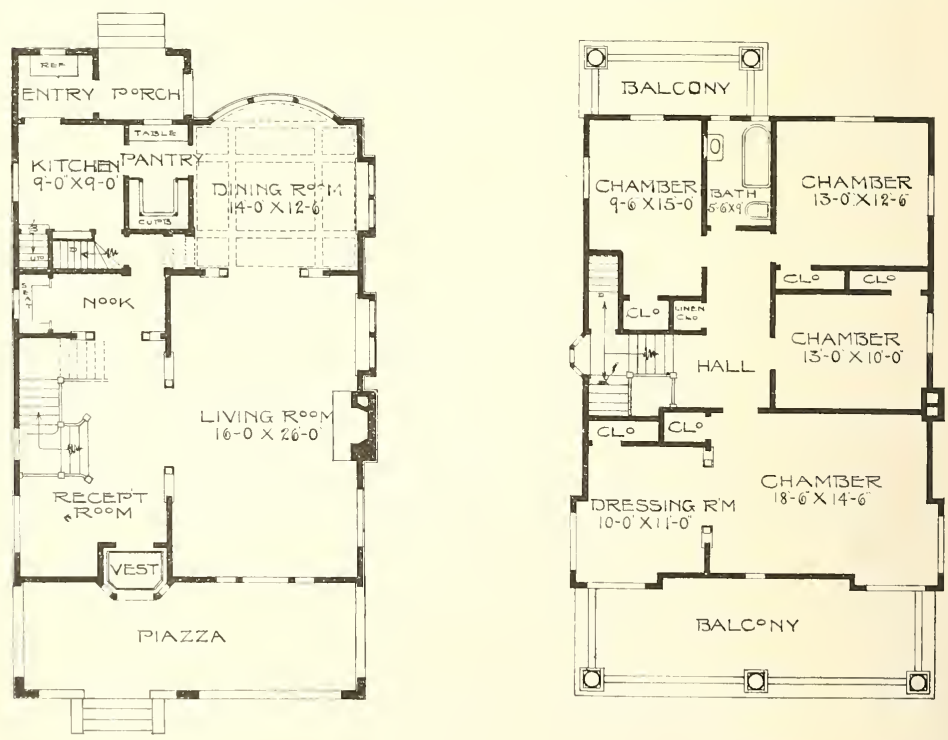

Complete plans and specifications for using Denison Load-Bearing Tile, licensed under Wilson-System Bearing Wa 11 Construction for $\$ 70$. 


\section{"HAVF A MILLION"}

SAXTON'S PATENT WALL PILUG is a simple device, used in plaster-joints of pyro-bar, Denison Load Bearing Tile, or any other tile, in joints of common brick and in slush

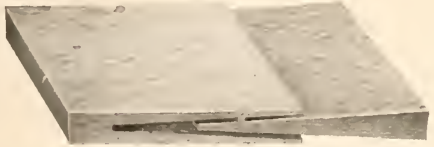
concrete and every place where you wish to fasten wood, metal, marble or granite work of any description.

Much cheaper for setting marble or granite than the brass wires in plaster paris.

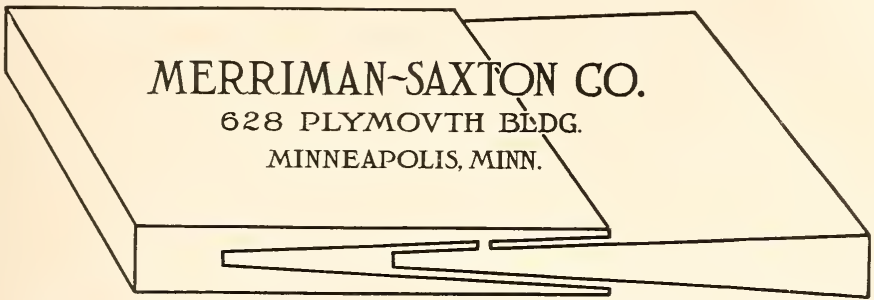

\$10 PER THOUSAND

F. O. B. Minneapolis

Endorsed by Building Inspectors and Best Reliable Contractors
Patented in the United States

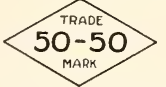

Patents Pending in Every Country

Except Greece and Russia

SAXTON'S PATENT WALL PLUG saves $\$ 15$ in U. S. currency for the builder on every 1000 plugs used, or its equivalent in grounds, sub-jambs, time and nails. This is a demonstrable scientific statement and can be proven so to any practical building contractor.

\section{$\$ 10$ Per 1000 PLUGS Save $\$ 15$}

\section{TO AI corracerons ARCHITECTS BUILDERS}

Send at once for full size samples, literature and detail information, and we will prove beyond doubt the simplicity and practicability of this simple device.

\section{Merriman-Saxton Company}

MANUFACTURERS OF

"SAXTON PATENT WALL PLUG"

628 Plymouth Building

Minneapolis, Minnesota 


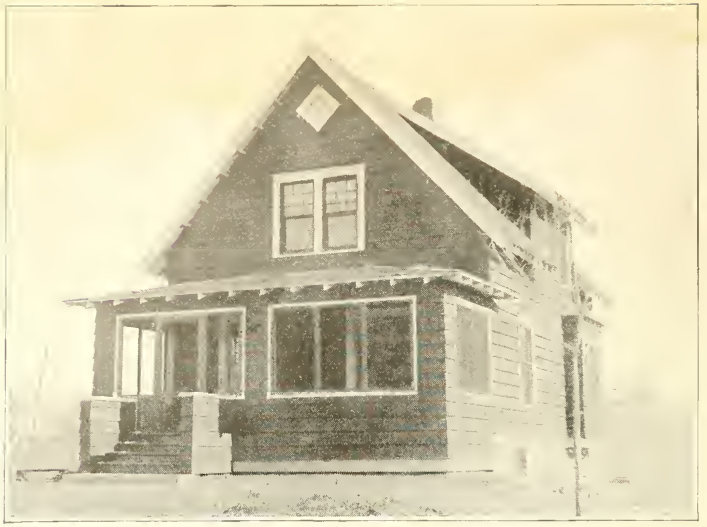

The McGuire Brown Cottage-No. 790

A real good Irishman's home. This little home is very practical and was designed by one of the best heating engineers in the United States. It is his own idea of a small cottage home. Very complete and compact.

Size 22 feet wide and 28 feet deep. First story 8 feet 6 inches, second story 7 feet 6 inches. Full basement, these heights all in the clear. Birch floors throughout. Red Gum finish in first story, Washington Fir or Southern Cypress in second story. Cost to build, $\$ 2,000$.

Mr. Saxton will furnish one complete set of plans and specifications for $\$ 17$.
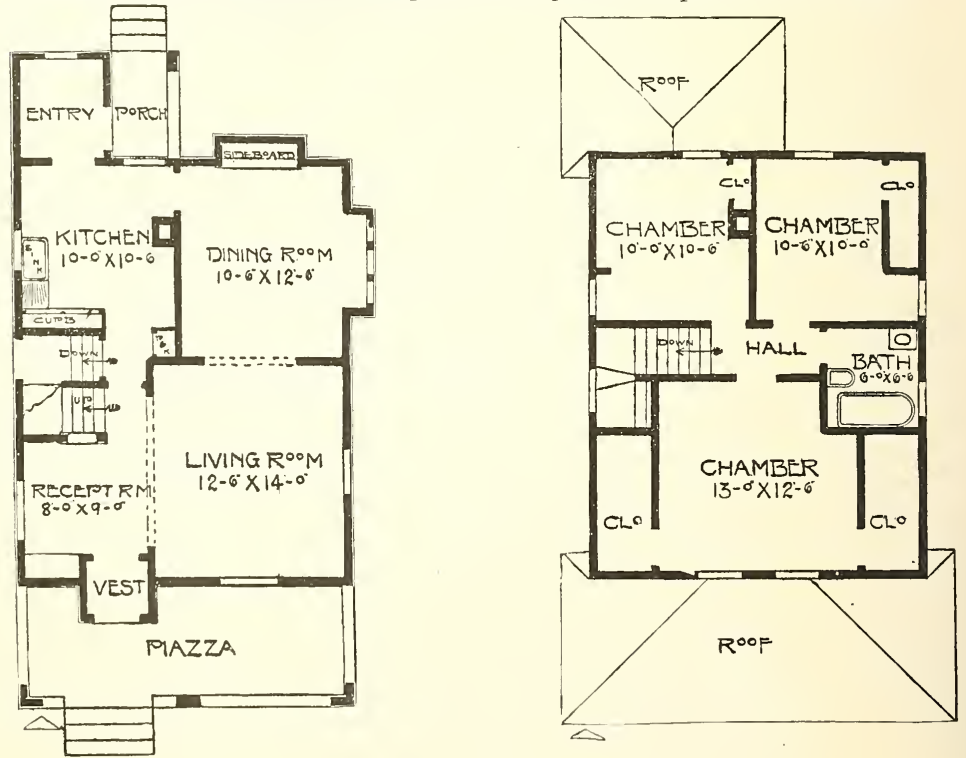

Complete plans and specifications for using Denison Load-Bearing Tile, licensed under Wilson-System Bearing IV a 11 Construction for $\$ 34$. 


\title{
Vapor-Vacuum Heating Kriebel $\mathbb{W}$ System
}

\author{
PHILADELPHIA, PA.
}

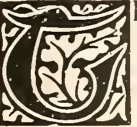
radiators.

\section{ADVANTAGES}

OVER

OTHER HEATING

PLANTS

HIS heating system is filled with vapor, and transmits the heat from the radiator to the room, as heat is transmitted the vapor condenses, creating the vacuum and exerting a constant suction on the boiler, pulling the heat up into the

I A guaranteed saving of over twenty-five per cent in fuel.

I Absolutely noiseless in operation. Less radiation than used for hot water or steam heating plants.

I Radiation can be closed off instantly, and the heat stopped, nothing to freeze.

I Risers are quarter the size and not full of water at any time.

I Exact amount of heat you want when you want it in each individual radiator.

I Is more flexible and simple to operate than any other heating plant, giving absolute satisfaction.

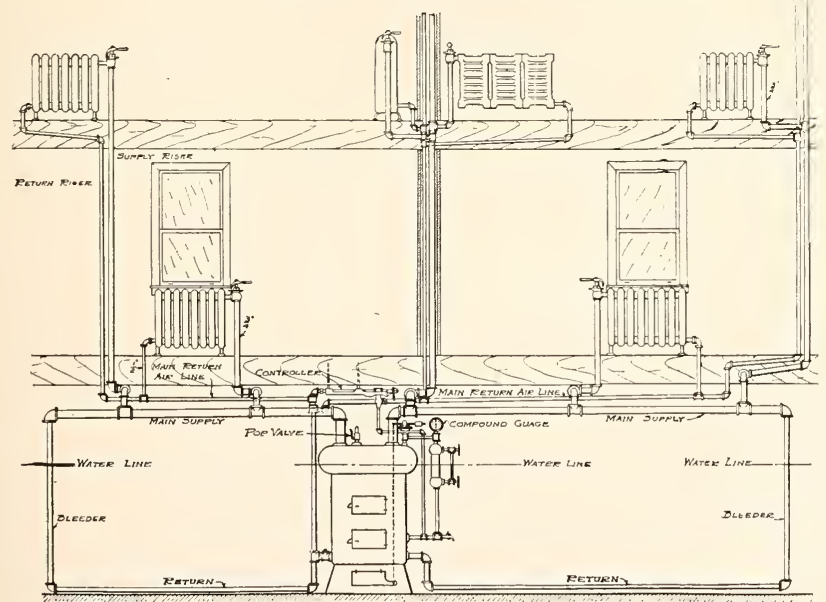

(DETAIL VAPOR-VACUUM HEATING, KRIEBEL SYSTEM)

The above stated facts make the "Vapor Vacuum" system the best and most complete and economical system for heating all classes of buildings. Further detailed information, blue prints and references given on application.

OFFICES: New York, Philadelphia, Minneapolis, St. Paul, Kansas City, Mo.

\section{NORTHWESTERN AGENCY HERMAN J. KLERISMANN




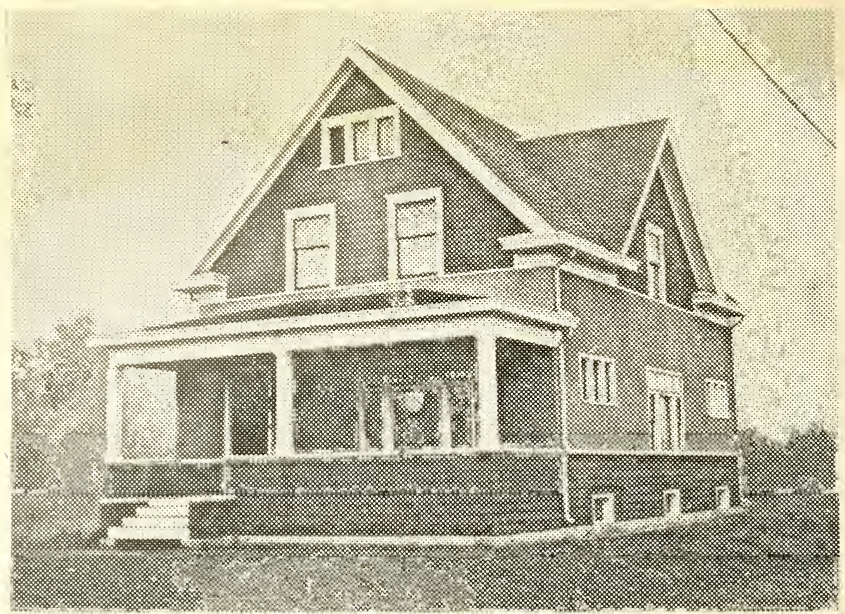

Cement and Shingles-No. 944

Width $24 \mathrm{ft}$, depth $36 \mathrm{ft}$. A substantial story-and-a-half cottage whose exterior comprises a combination of siding, rough-cast plaster and stained shingles. An effective

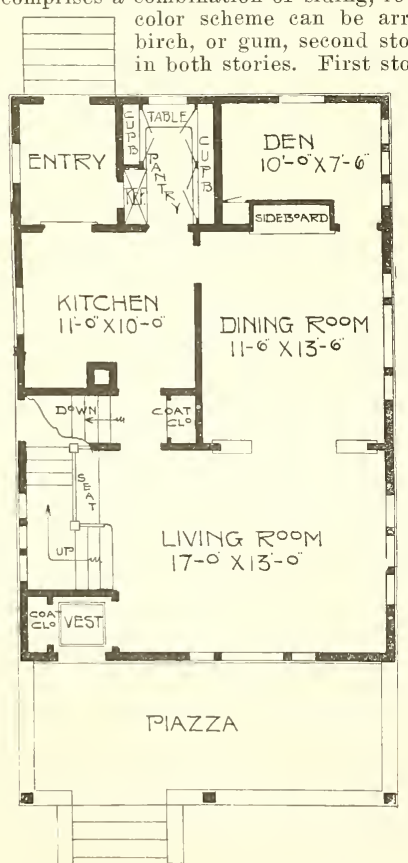

$9 \mathrm{ft}$. high and second story $8 \mathrm{ft}$. Cost to build, $\$ 3,000$. One set of plans and specifications for $\$ 20$.

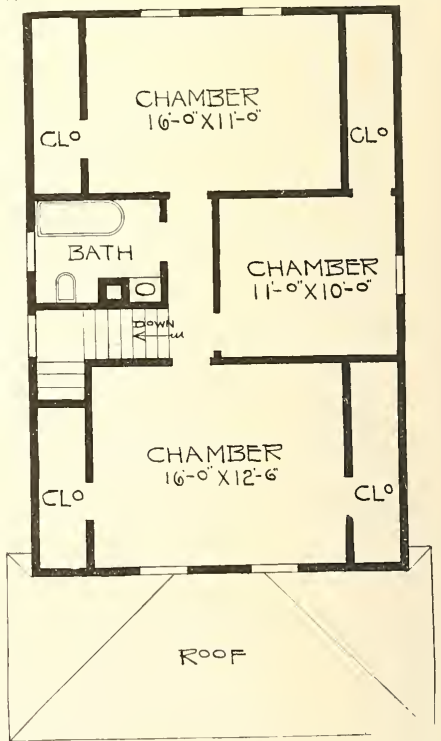

Complete plans and specifications for using Denison Load-Bearing Tile, licensed under Wilson-System Bearing Wall Construction for $\$ 40$. 


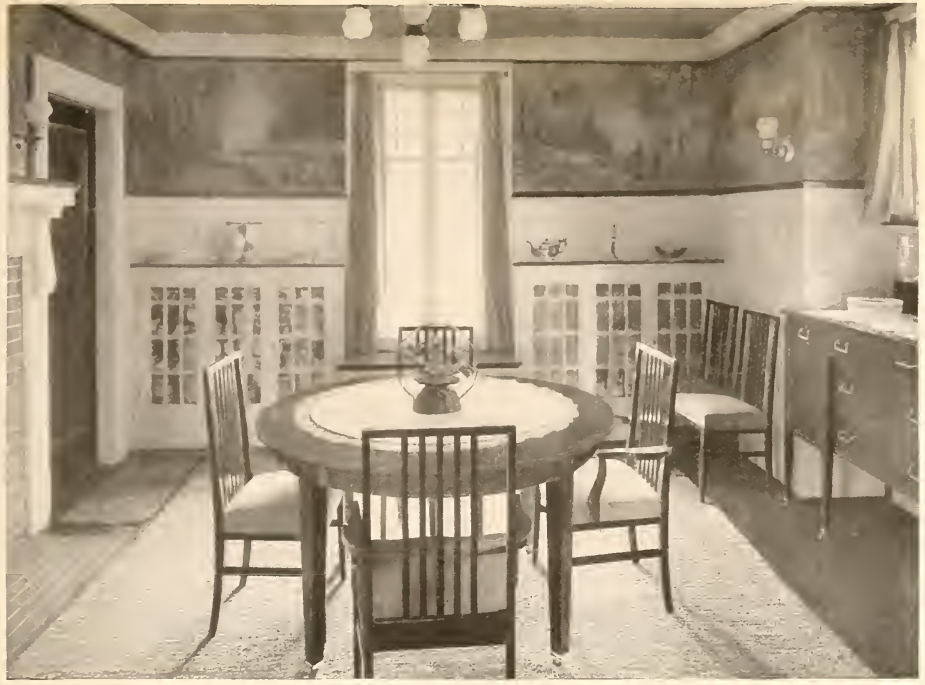

Dining Room Executed by our Decorators

\section{Interior Home Decorations}

That Express the

\section{Personality of the Owner}

The personal note in home decorations is a new one. lts importance becomes the more pronounced as one observes how deftly the decorative artist has combined the personal tastes of his client, together with his own technical knowledge, executing a harmonious and well balanced decorative scheme that is pleasing, artistic and refined. lt is in such personal service that our corps of decorative experts excel, also in that they can save you much expense by the mere avoidance of error. Our artists work in conjunction with your architect where they exercise general supervision.

We devote great space to the display of

Oriental and Hand Tufted Rugs, Special Handmade Furniture, Interior Woodwork Draperies and Nonfadable Wall Fabrics and Furniture Coverings

Wall Papers, Mural Decorations, Lighting Fixtures

We offer you our services in whole or in part. Upon request we will furnish original sketches or send one of our representatives to consult with you.

Write or telephone us today concerning your decorative problems.

N. W. Phone

Main 4530

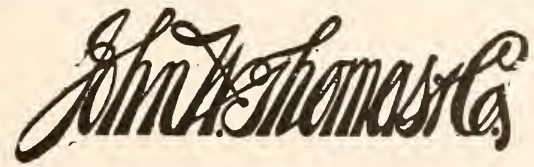

T. S. Phone Center 256

Minneapolis, Minnesota 


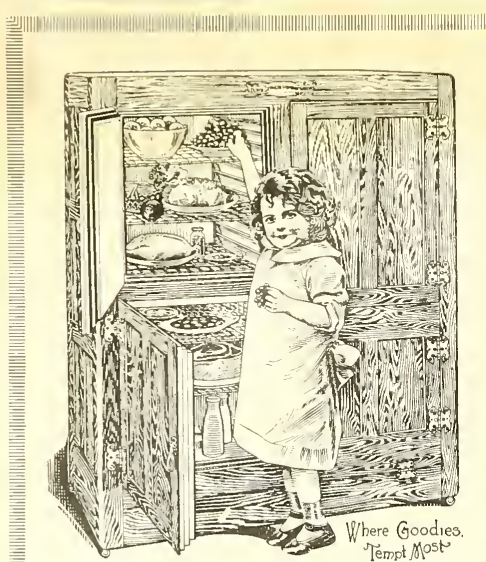

\section{Microbes and \\ Heat Spoil \\ the Meat}

\section{Bohn Syphon Refrigerators}

Where Goodies Tempt Most

\section{BUY A BOHN}

The Sanitary Safegaurd

\section{White Enamel Refrigerator Company}

59 W. 42nd Street, NEW YORK

30 E. Jackson Boulevard, CHICAGO

803 South Hill Street, LOS ANGELES

MAIN OFFICE AND WORKS: ST. PAUL, MINN.

"Bohn Syphon Refrigerators" are recommended by Glenn L. Saxton, Architect 


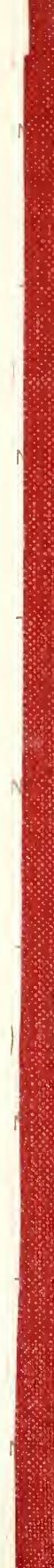




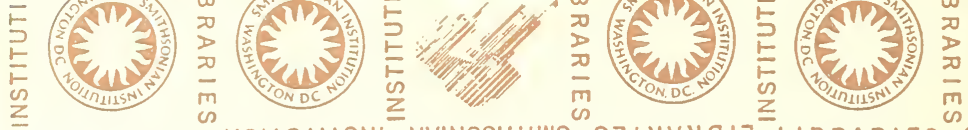

IAN INSTITUTION NOILIIILSNI NHINOSHLIWS SJIYHY8I7 LIBRARIES

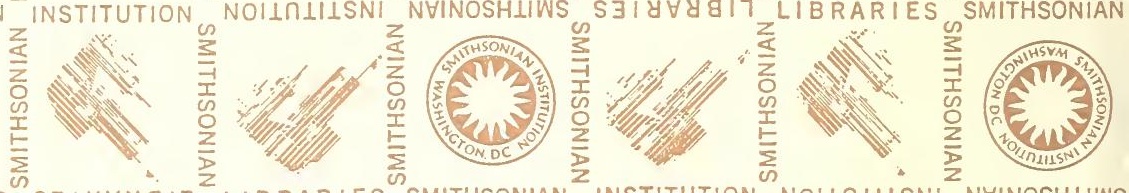

WS S
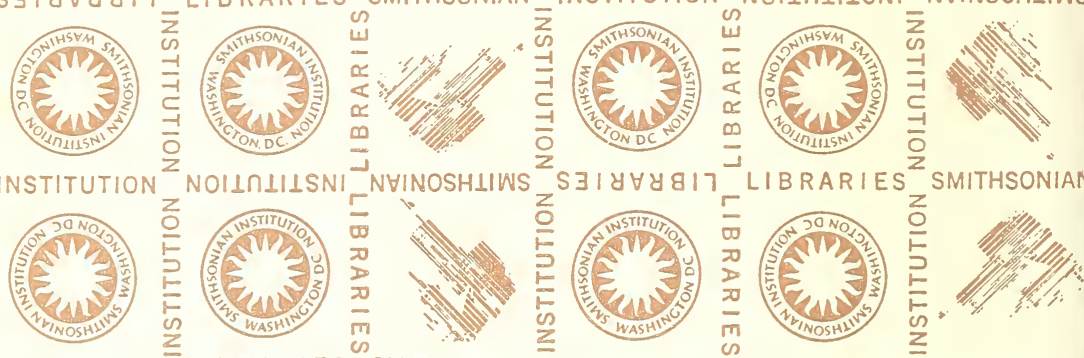

S 31 YYY817 LIBRARIES SMITHSONIAN

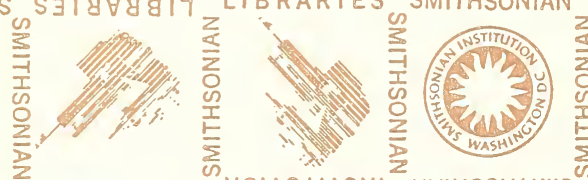

NSTITUTION

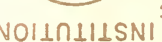

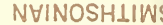

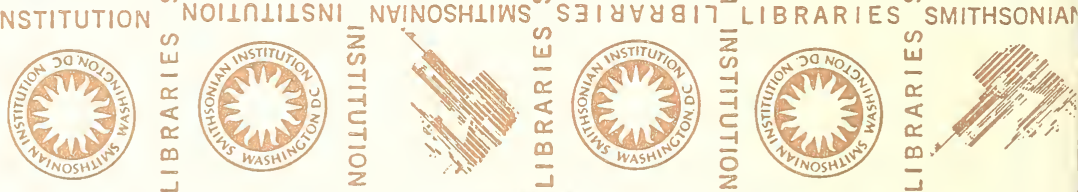

WS S 1 IYHYG17 LIBRARIES
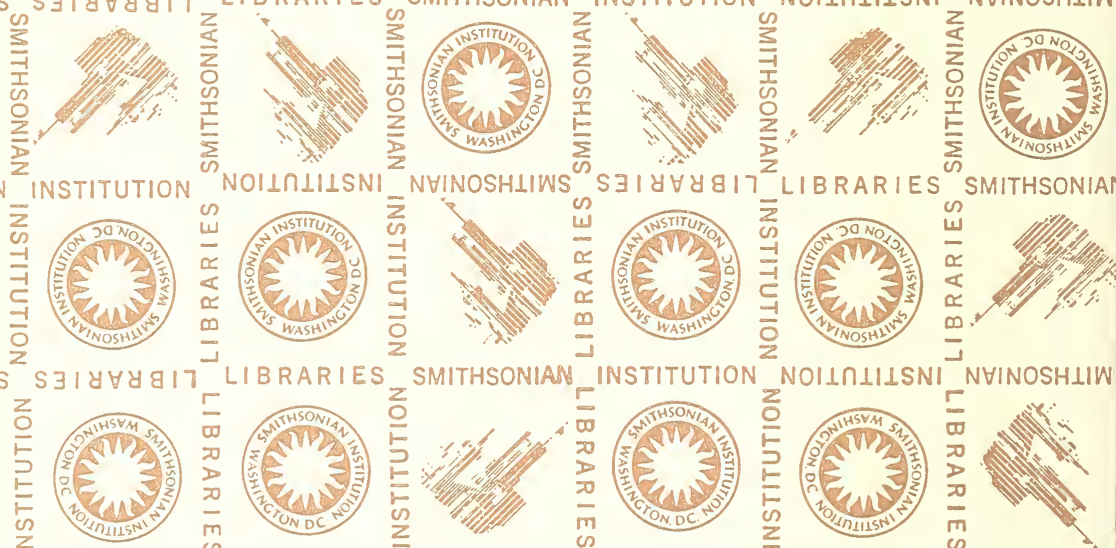

LIAN INSTITUTION
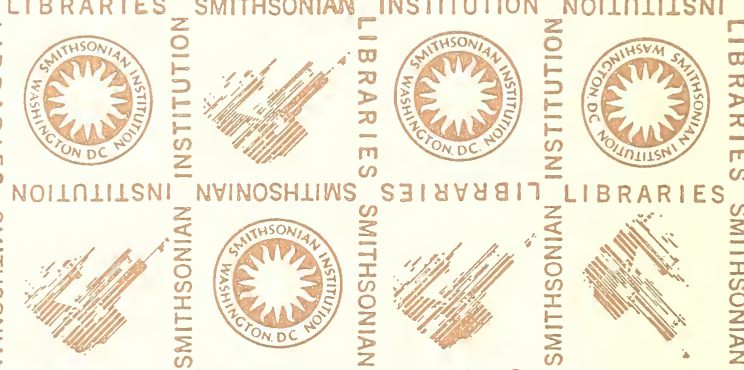

NHINOSHLWW

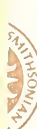
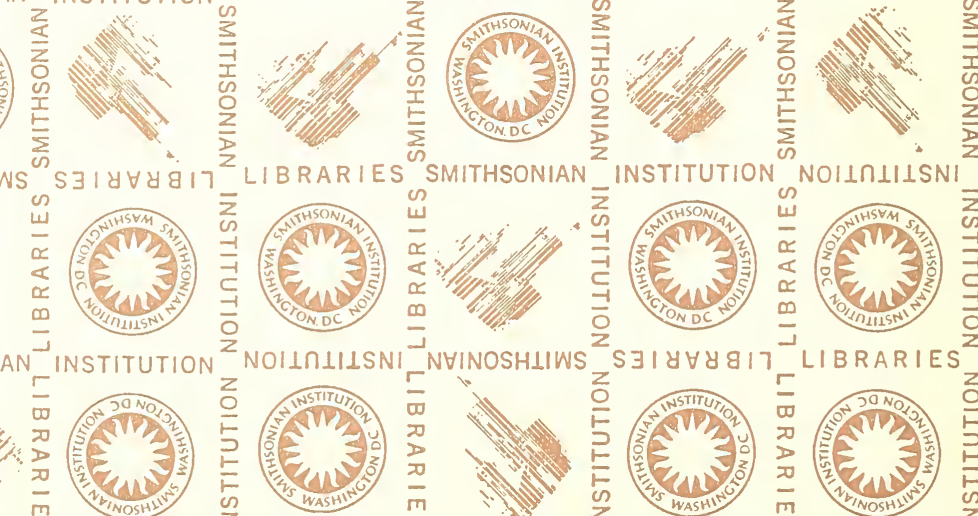

SMITHSONIAN
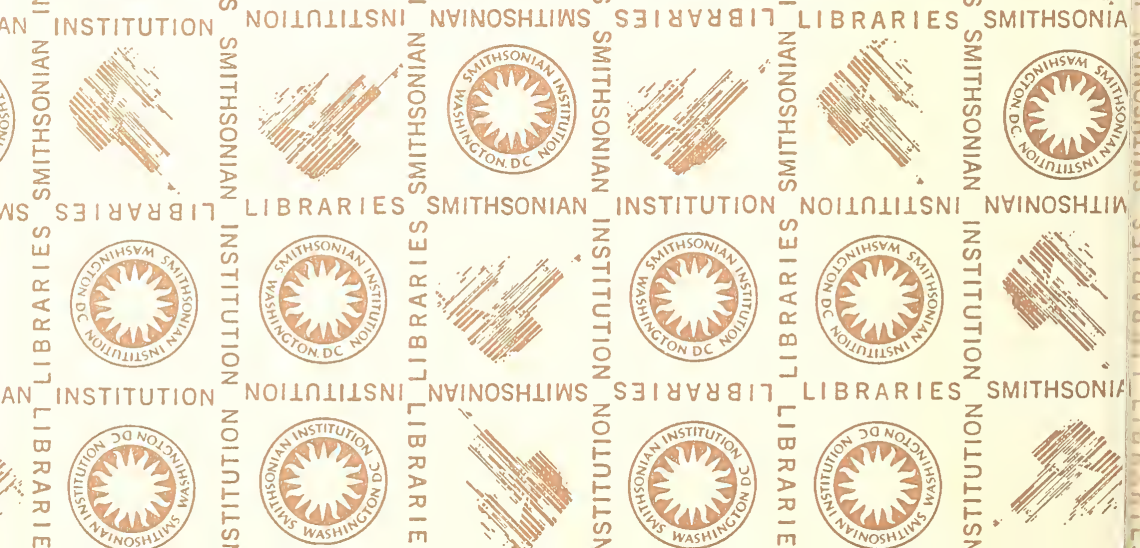

SMITHSONIF 
㮍

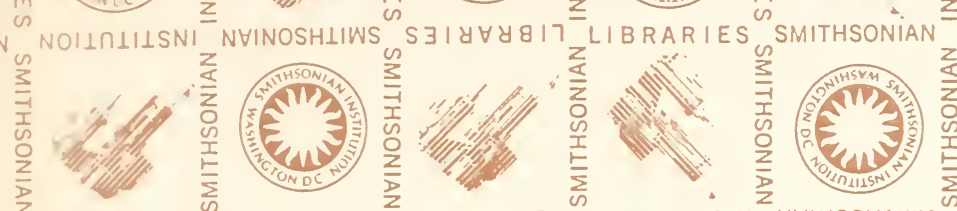

Y 817 LIBRARIES SMITHSONIAN
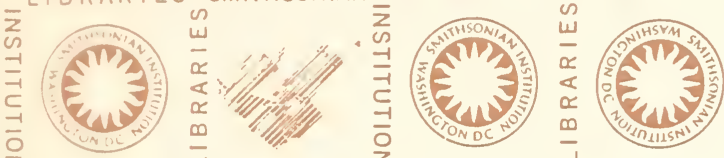

$\bar{z}$
c
-1
$\overline{1}$
$c$
-1
$\overline{0}$
2
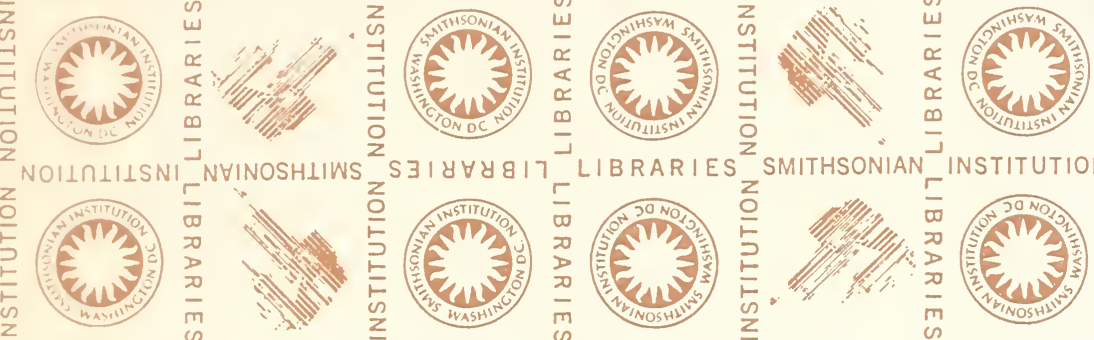

LIBRAR IES
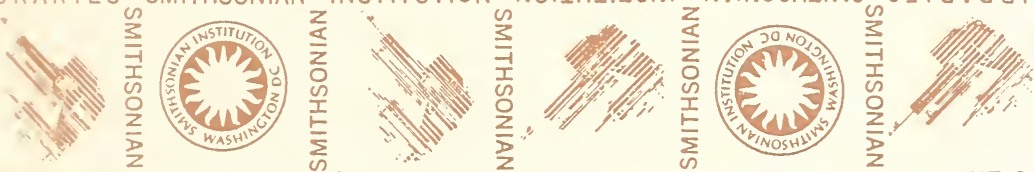

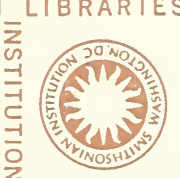

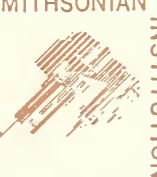

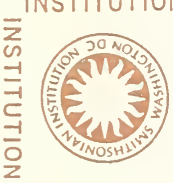

LIBRARIES

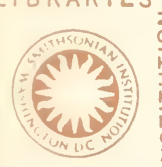

SMITHSONIAN
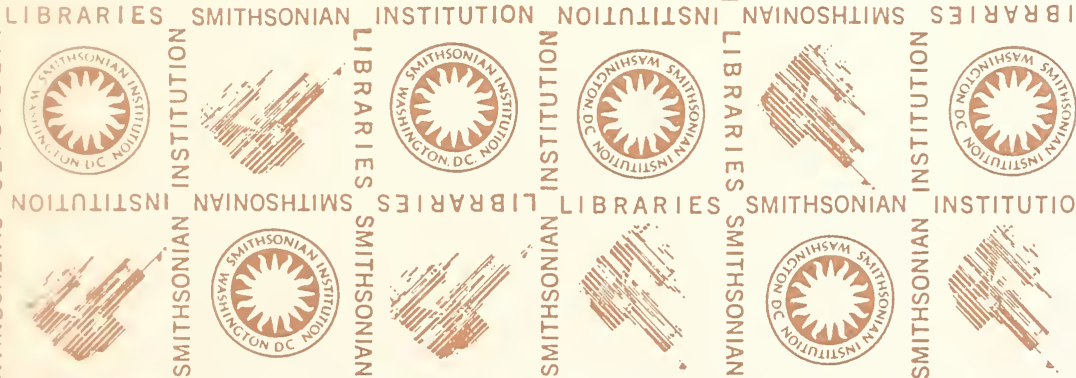

SMITHSONIAN

INSTITUTIOI
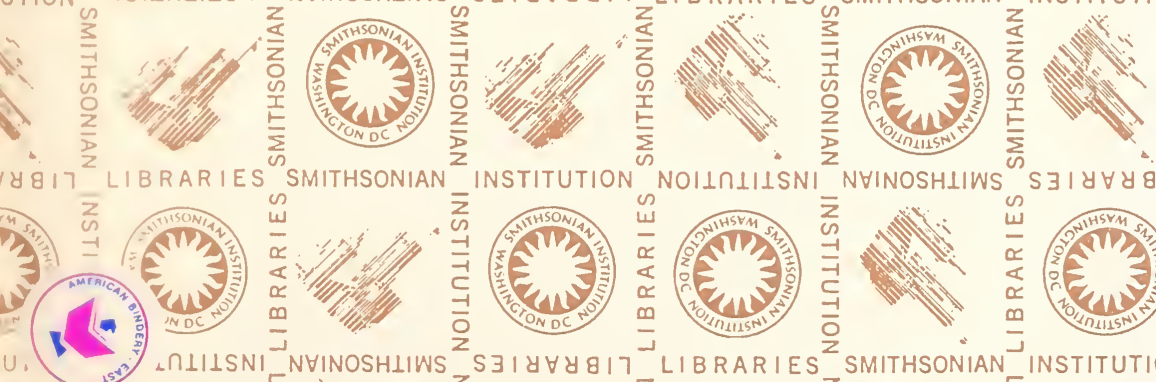
LIBRARIES
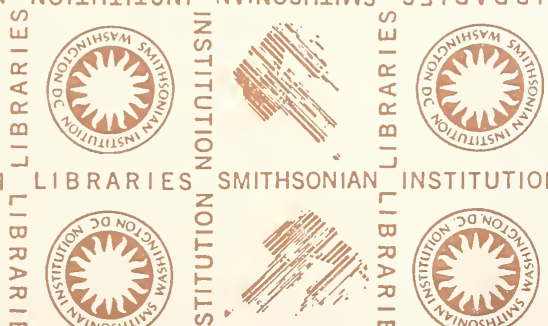
SMITHSONIAN INSTITUTION LIBRARIES

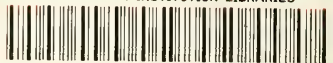

$\begin{array}{llll}3 & 9088 & 00566 & 3141\end{array}$ 